\title{
Die Gesellschaft mit beschränkter Haftung in Europa : eine rechtsvergleichende Studie zum Recht der GmbH in Deutschland, den Niederlanden und Frankreich
}

Citation for published version (APA):

Glozbach, P. (2008). Die Gesellschaft mit beschränkter Haftung in Europa : eine rechtsvergleichende Studie zum Recht der GmbH in Deutschland, den Niederlanden und Frankreich. [Doctoral Thesis, Maastricht University]. Maastricht University. https://doi.org/10.26481/dis.20081015pg

Document status and date:

Published: 01/01/2008

DOI:

$10.26481 /$ dis.20081015pg

Document Version:

Publisher's PDF, also known as Version of record

Please check the document version of this publication:

- A submitted manuscript is the version of the article upon submission and before peer-review. There can be important differences between the submitted version and the official published version of record.

People interested in the research are advised to contact the author for the final version of the publication, or visit the DOI to the publisher's website.

- The final author version and the galley proof are versions of the publication after peer review.

- The final published version features the final layout of the paper including the volume, issue and page numbers.

Link to publication

\footnotetext{
General rights rights.

- You may freely distribute the URL identifying the publication in the public portal. please follow below link for the End User Agreement:

www.umlib.nl/taverne-license

Take down policy

If you believe that this document breaches copyright please contact us at:

repository@maastrichtuniversity.nl

providing details and we will investigate your claim.
}

Copyright and moral rights for the publications made accessible in the public portal are retained by the authors and/or other copyright owners and it is a condition of accessing publications that users recognise and abide by the legal requirements associated with these

- Users may download and print one copy of any publication from the public portal for the purpose of private study or research.

- You may not further distribute the material or use it for any profit-making activity or commercial gain

If the publication is distributed under the terms of Article 25fa of the Dutch Copyright Act, indicated by the "Taverne" license above, 


\section{DIE GESELLSCHAFT MIT BESCHRÄNKTER HAFTUNG IN EUROPA}

\section{Eine rechtsvergleichende Studie zum Recht der GmbH in Deutschland, den Niederlanden und Frankreich}

PROEFSCHRIFT

ter verkrijging van de graad van doctor aan de Universiteit Maastricht, op gezag van de Rector Magnificus prof. mr. G. P. M. F. Mols

volgens het besluit van het College van Decanen,

in het openbaar te verdedigen

op woensdag 15 oktober 2008 om 14.00 uur.

door

Pierre Philippe Manfred Glozbach 


\section{Promotor}

Prof. dr. C. A. Schwarz

\section{Copromotor}

Dr. J. J. A. Hamers

\section{Beoordelingscommissie:}

Prof. dr. G. R. de Groot (voorzitter)

Prof. dr. B. T. M. Steins Bisschop

Dr. M. Bormann 


\section{Inhaltsverzeichnis}

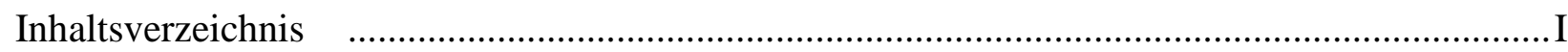

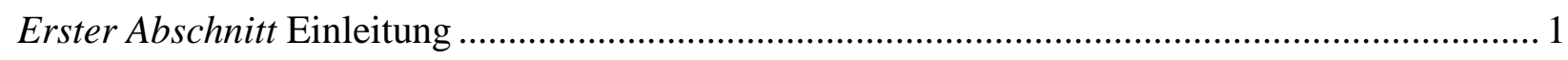

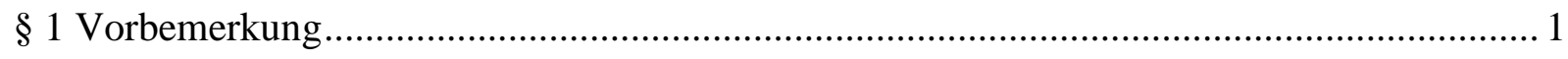

$\S 2$ Eröffnung des Wettbewerbs: Die Entwicklung des europäischen

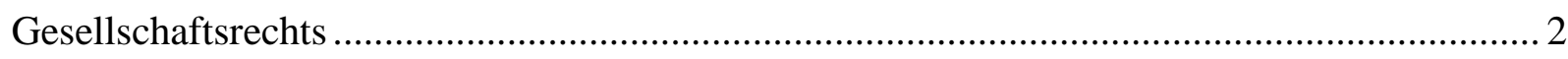

I. Niederlassungsfreiheit nach Art. 43 ff. EGV ........................................................... 2

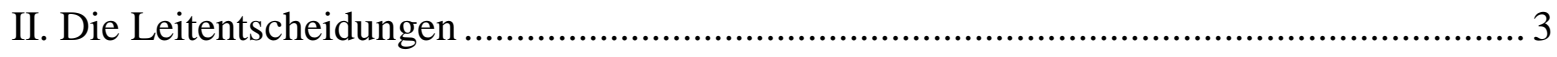

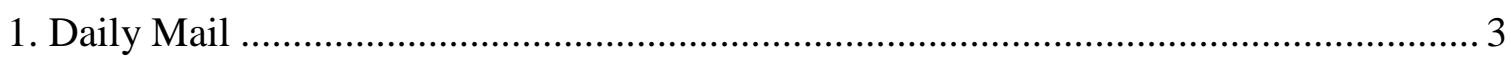

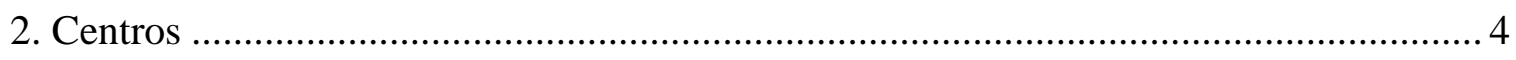

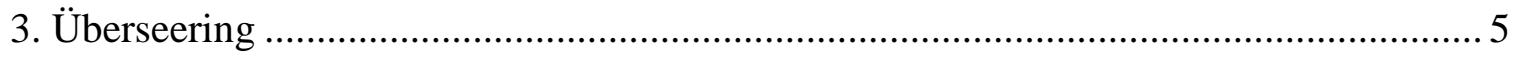

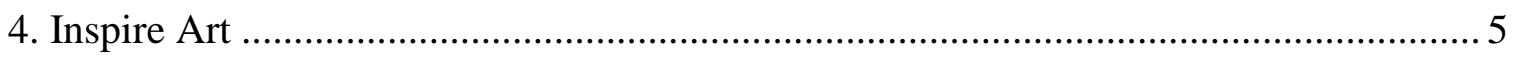

$\S 3$ Aufnahme des Wettbewerbs - Fokus der Untersuchung ............................................... 7

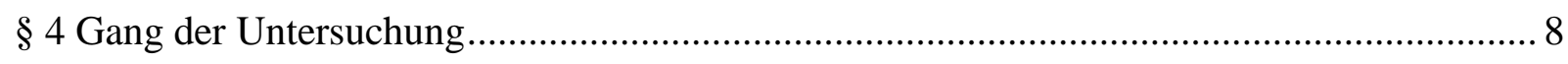

Zweiter Abschnitt Entwicklung und Reform des Rechts der Gesellschaften mit beschränkter Haftung in Deutschland, den Niederlanden und Frankreich sowie in Europa.......................................................... 9

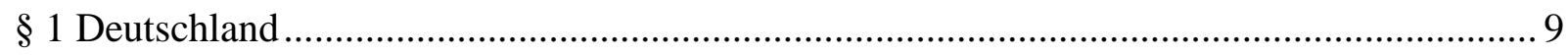

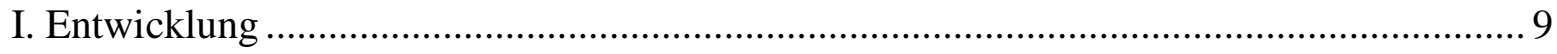

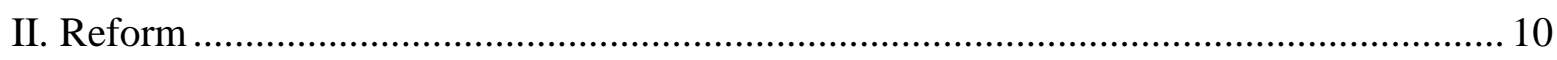

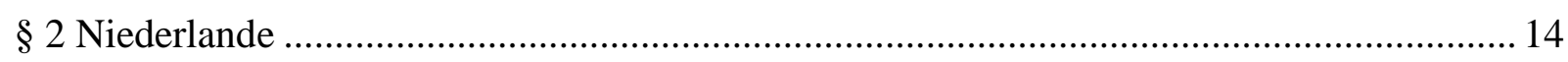

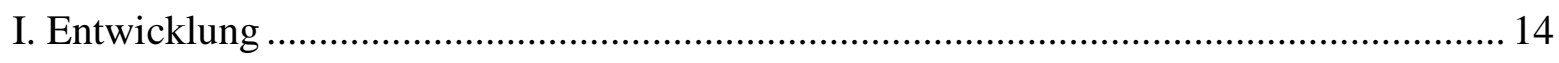

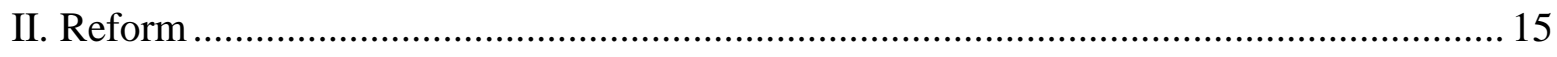

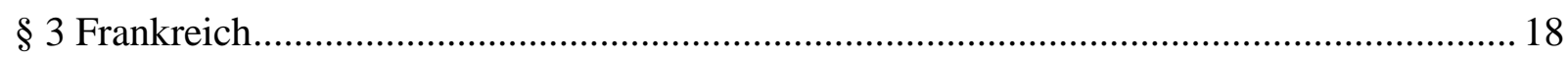

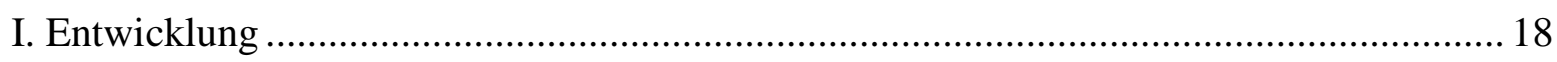

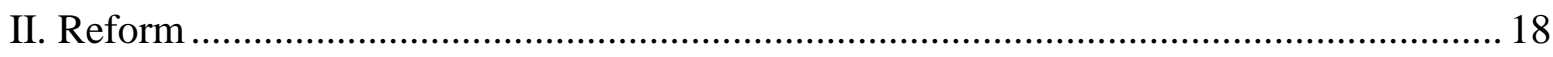

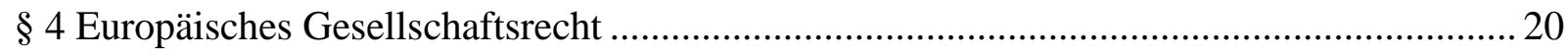

Dritter Abschnitt Schwerpunkte der Reformbestrebungen ..................................................... 21

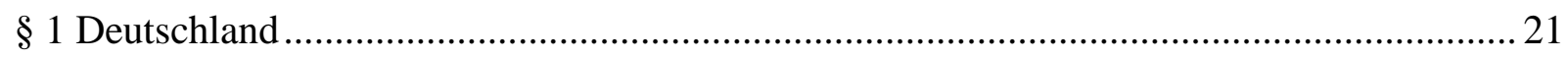

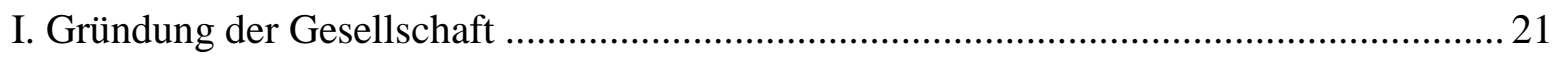

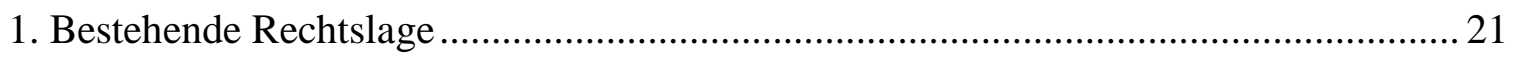

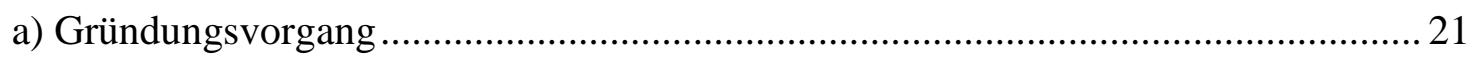

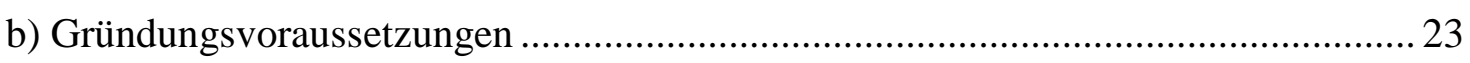

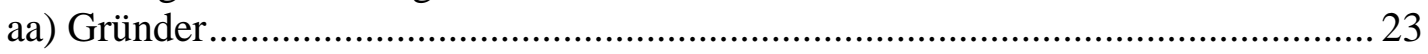

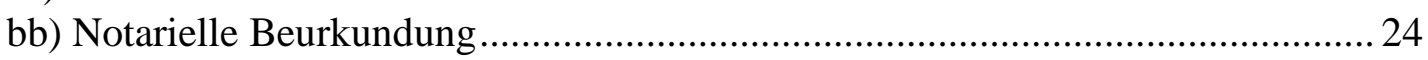

cc) (Teilweise) Erfüllung der Einlagepflichten ................................................... 25 


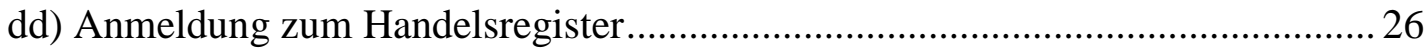

ee) Prüfung des Gründungsvorgangs durch das Registergericht ............................ 26

ff) Stellungnahme der Industrie- und Handelskammer .......................................... 27

gg) Rechtslage vor Eintragung im Handelsregister -

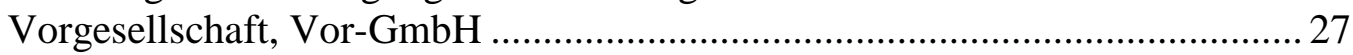

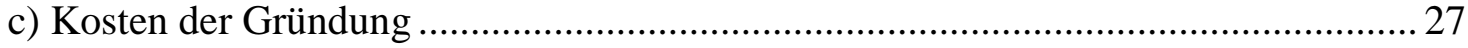

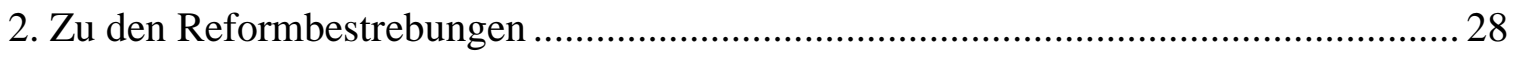

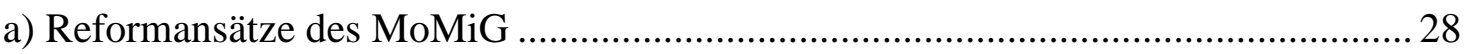

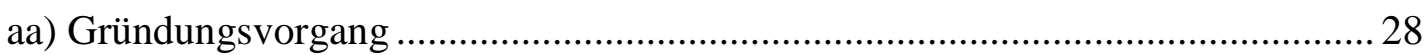

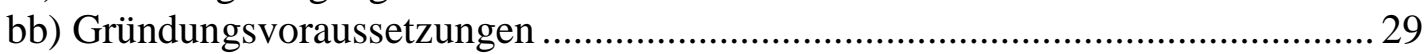

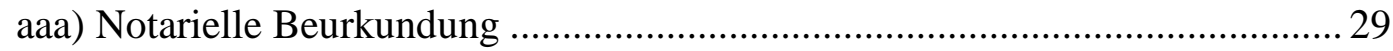

bbb) Verzicht auf Sicherheitsleitung bei Ein-Personen-GmbH .......................... 29

ccc) Verzicht auf Vorlage staatlicher Genehmigungen........................................229

ddd) Prüfung des Gründungsvorgangs durch das Registergericht ....................... 30

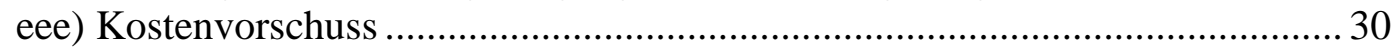

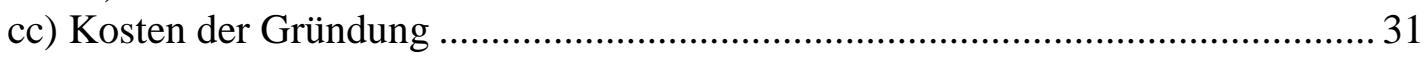

b) Reformüberlegungen in Praxis und Literatur ...................................................... 31

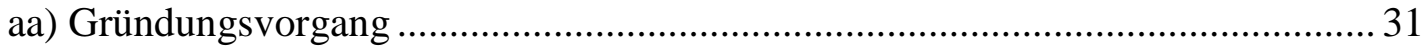

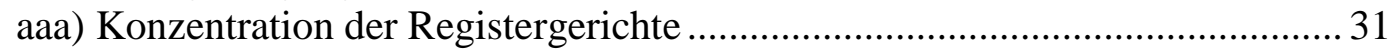

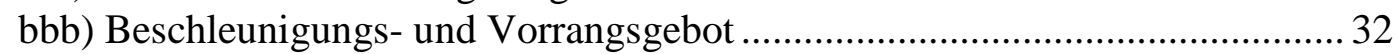

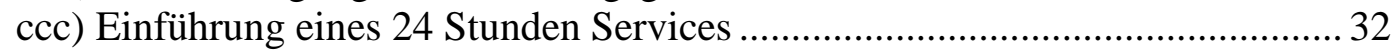

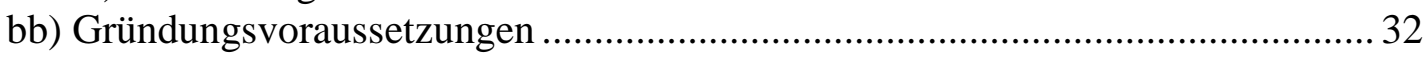

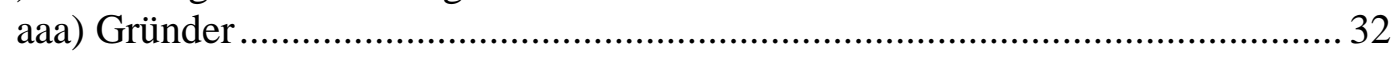

bbb) (Teilweise) Erfüllung der Einlagepflichten .............................................. 33

ccc) Prüfung des Gründungsvorgangs durch das Registergericht........................ 33

ddd) Stellungnahme der Industrie- und Handelskammer.................................. 34

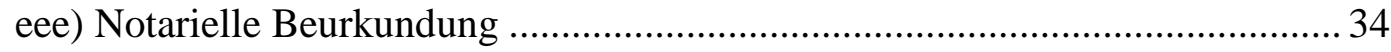

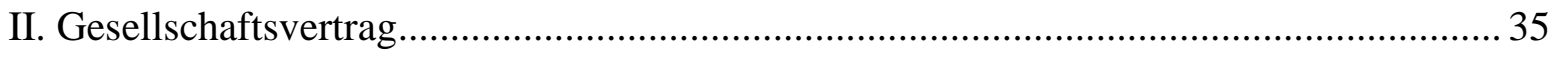

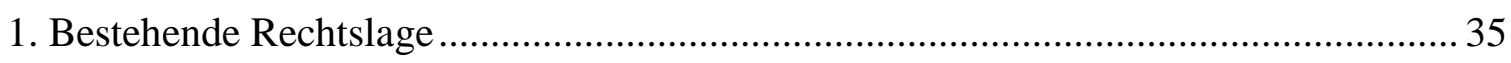

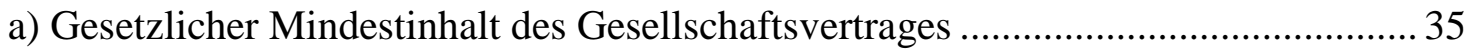

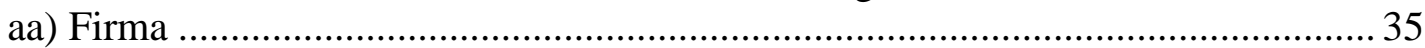

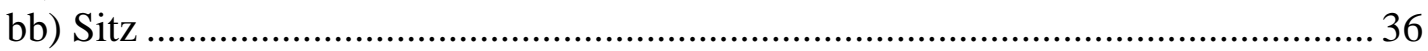

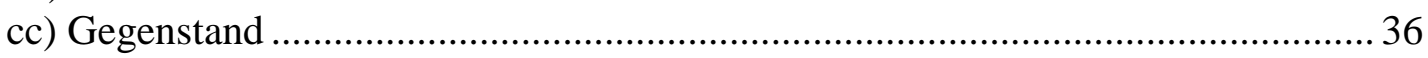

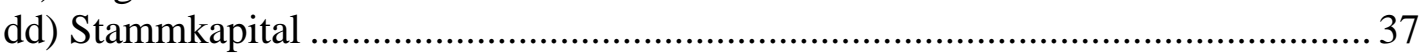

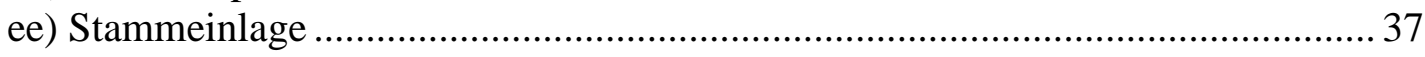

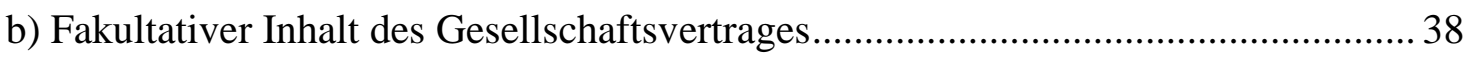

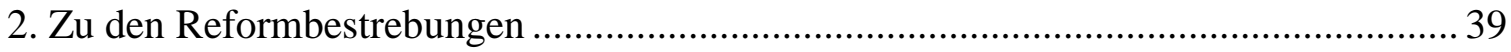

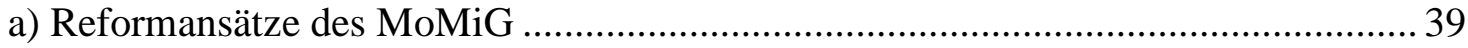

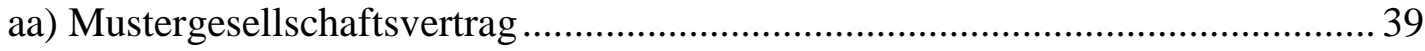

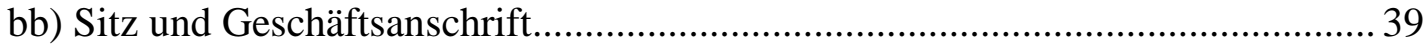

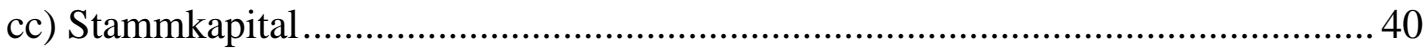

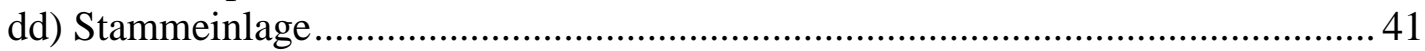

b) Reformüberlegungen in Praxis und Literatur .................................................... 42

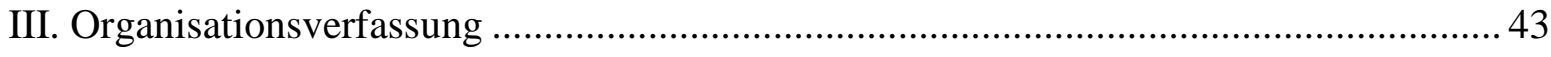

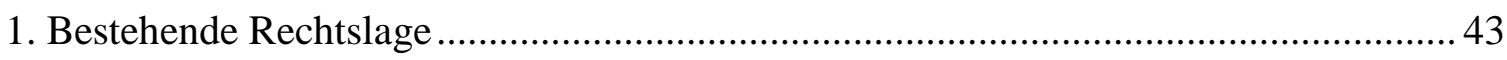

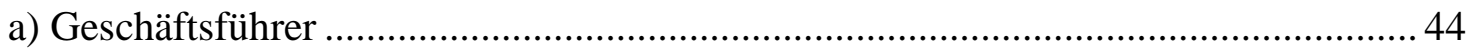




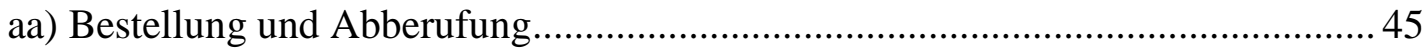

bb) Vertretung der Gesellschaft; Aufgaben und Befugnisse................................. 47

cc) Verantwortung und Haftungsregime ............................................................... 49

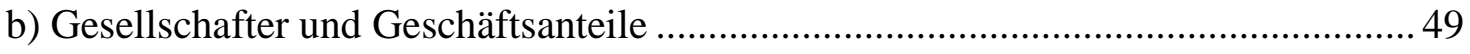

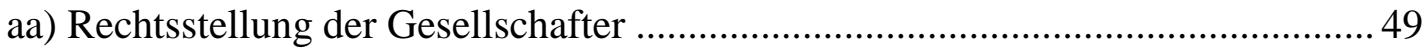

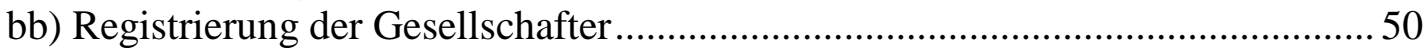

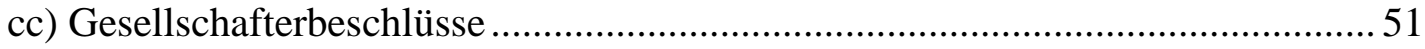

aaa) Formlose Beschlussfassung im allseitigen Einverständnis ........................51

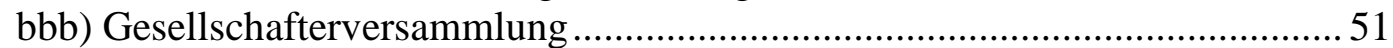

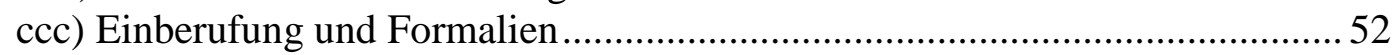

ddd) Stimmrecht und Vertretung............................................................... 53

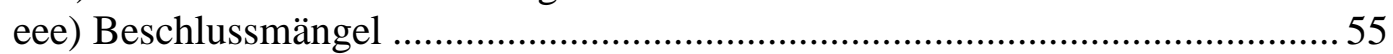

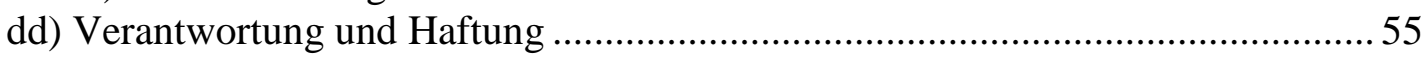

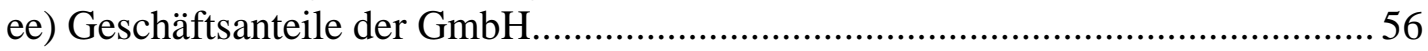

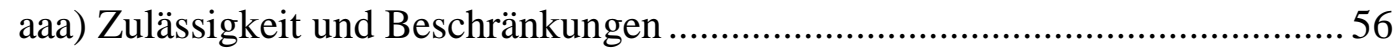

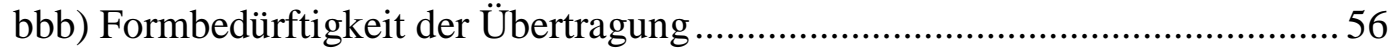

ccc) Nachweis Anteilsinhaberschaft ..................................................................5 57

ddd) Andienungspflichten und Vorkaufsrechte anderer

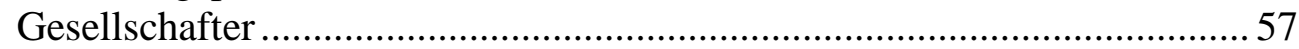

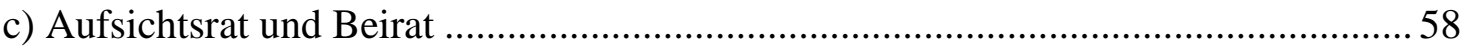

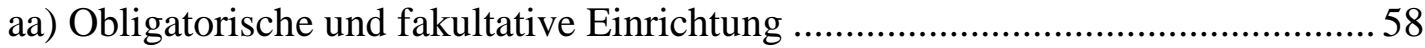

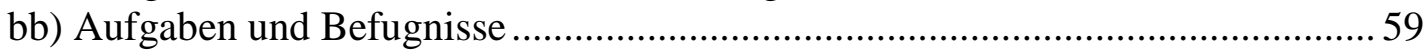

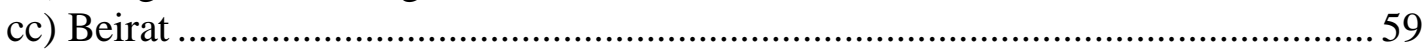

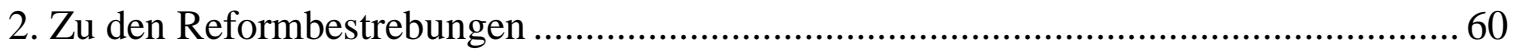

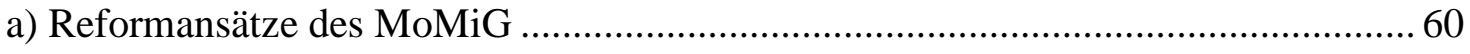

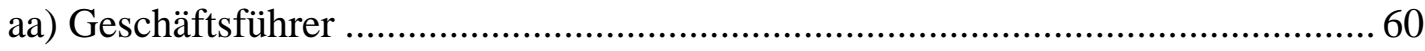

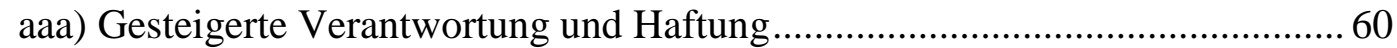

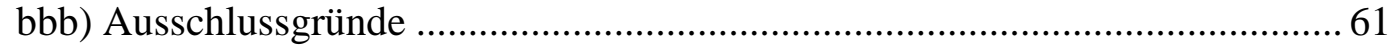

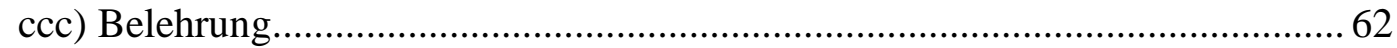

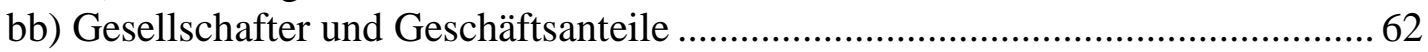

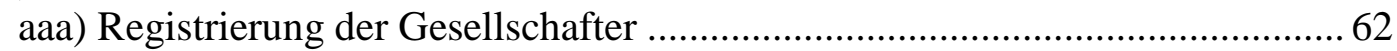

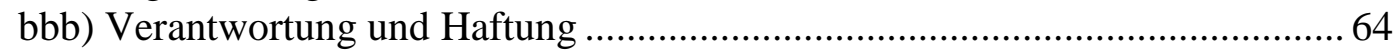

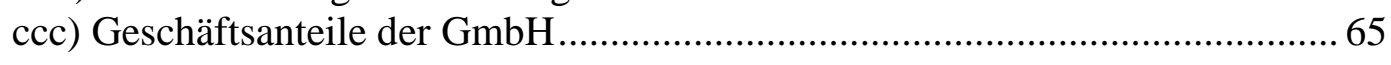

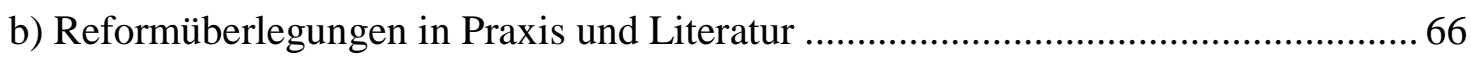

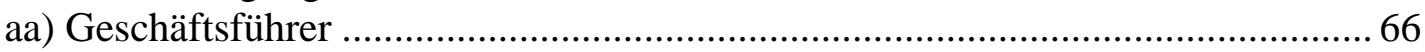

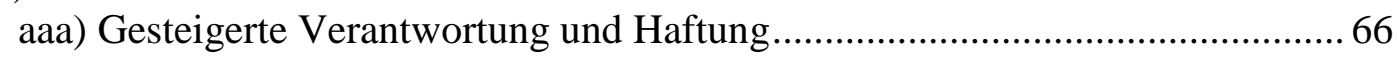

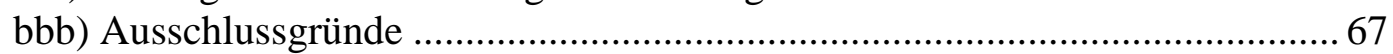

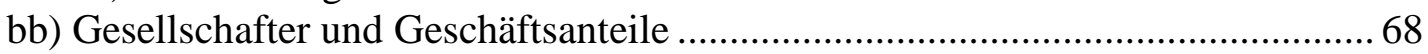

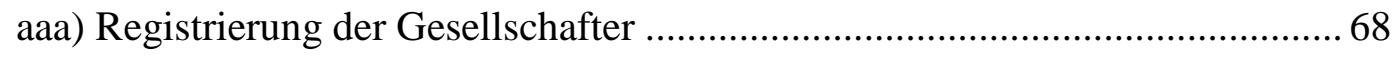

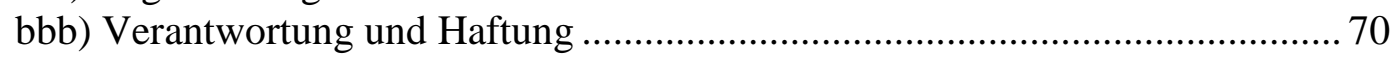

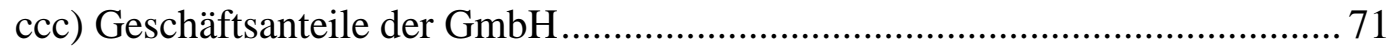

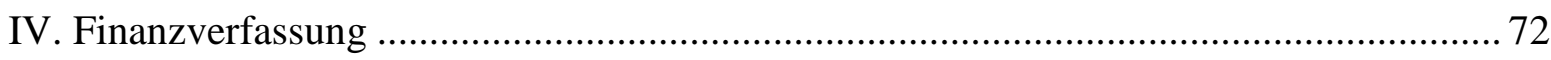

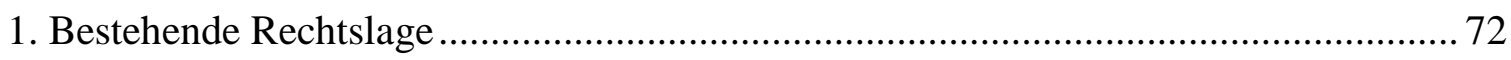

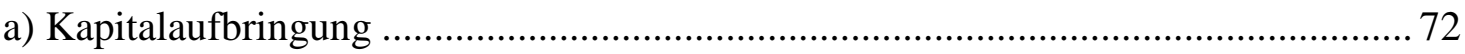

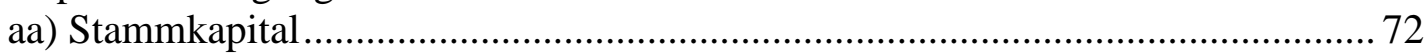

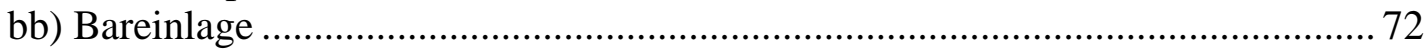

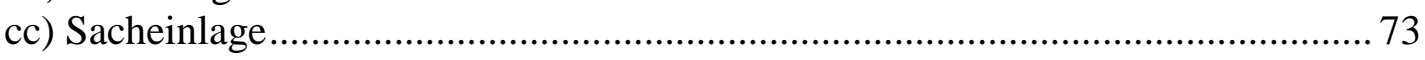




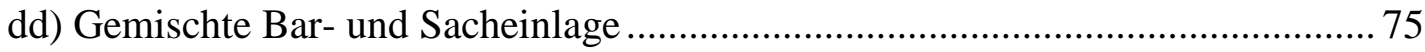

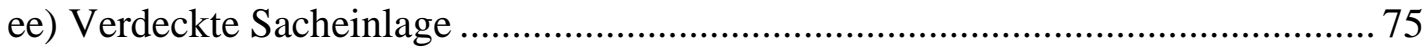

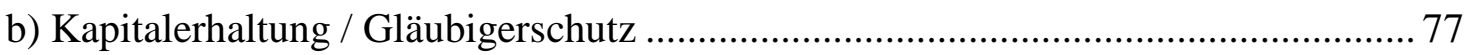

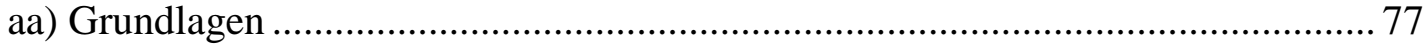

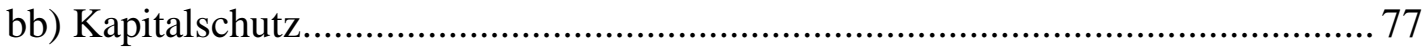

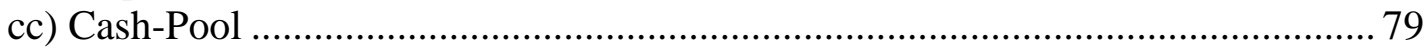

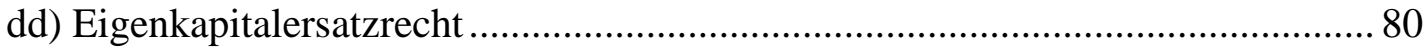

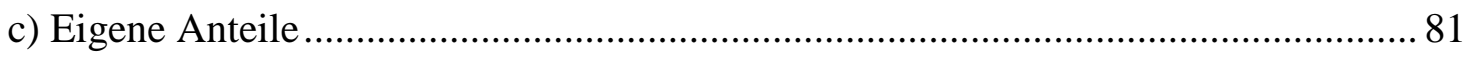

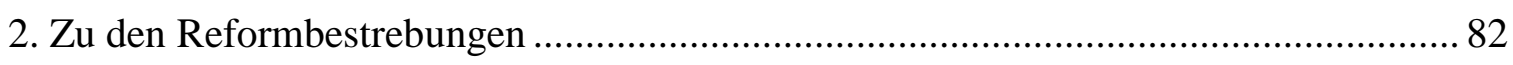

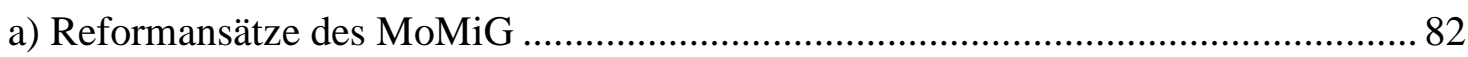

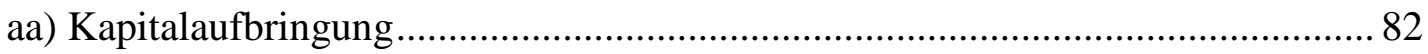

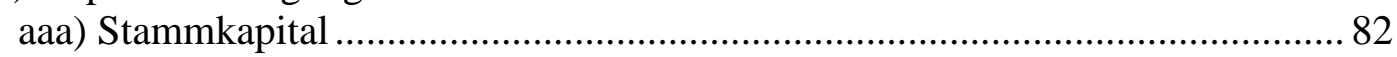

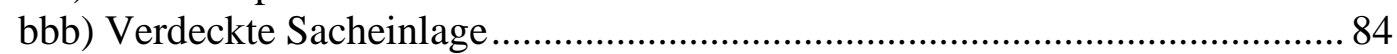

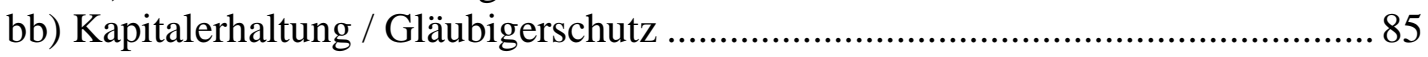

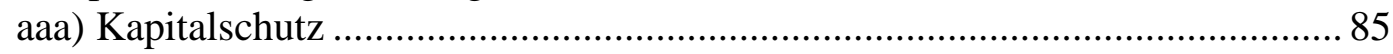

bbb) Deregulierung des Eigenkapitalersatzrechts ........................................... 86

cc) Haftungsbeschränkte Unternehmergesellschaft ............................................ 87

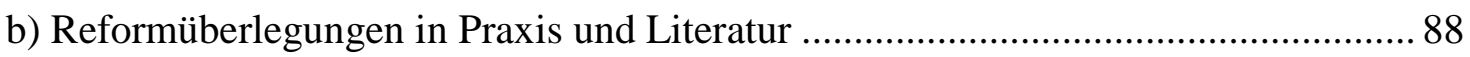

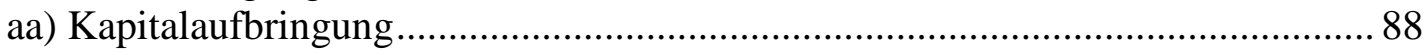

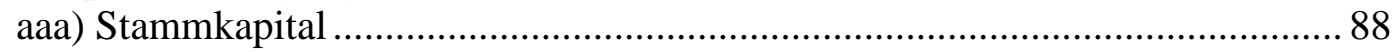

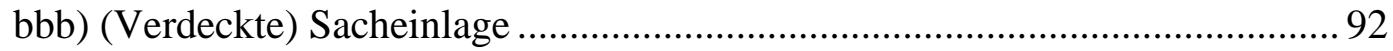

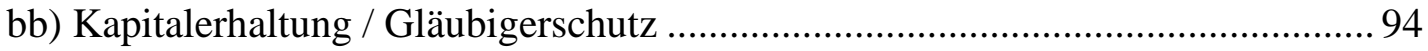

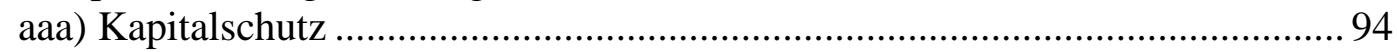

bbb) Deregulierung des Eigenkapitalsersatzrechts ......................................... 97

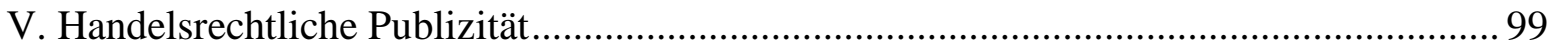

1. Handelsregister - Neuerungen durch das Gesetz über elektronische

Handelsregister und Genossenschaftsregister sowie das

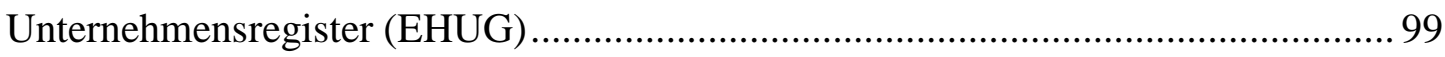

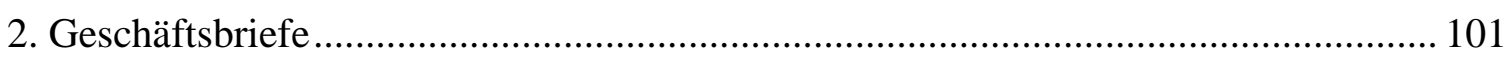

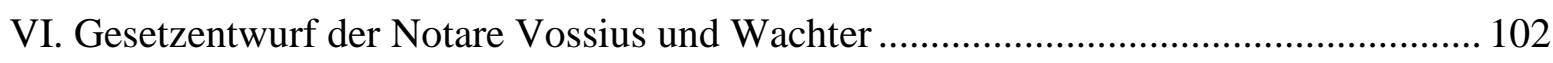

VII. Entwurf eines Gesetzes zur Vereinfachung der Gründung einer Gesellschaft mit beschränkter Haftung; GVGG........................................................ 102

VIII. Vorschläge alternativer Rechtsformen neben einer reformierten

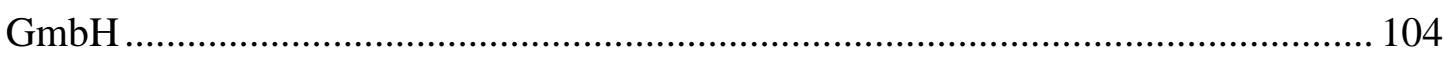

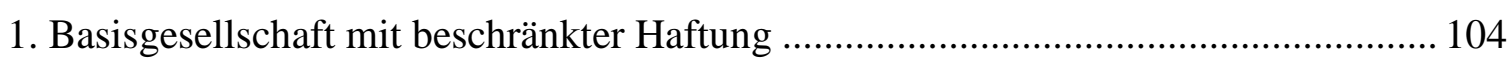

2. Die Unternehmensgründungsgesellschaft (auch „Unternehmergesellschaft“ oder „FlexCap“) ............................................................ 104

3. Kommanditgesellschaft mit beschränkter Haftung .................................................. 105

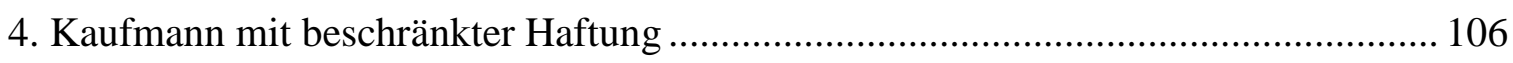

5. Personengesellschaft mit beschränkter Haftung ....................................................... 107

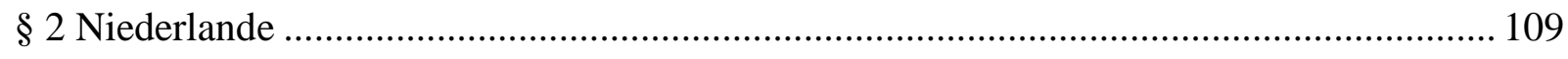

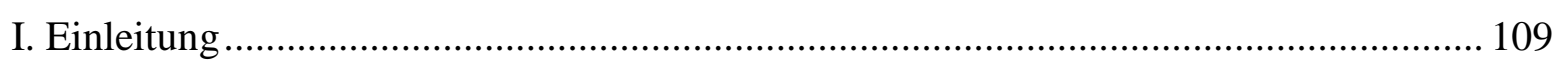

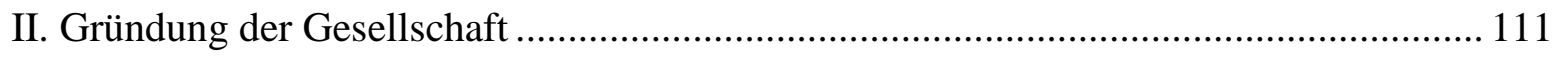




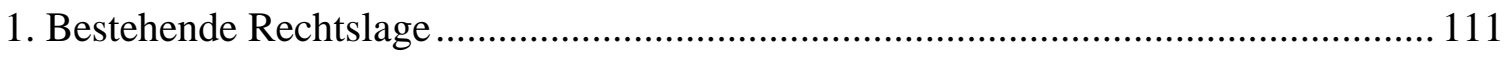

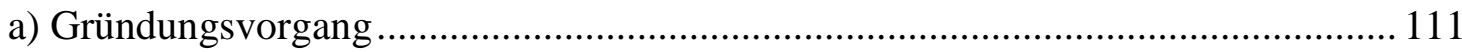

b) Gründungsvoraussetzungen (oprichtingsvereisten) ................................................ 111

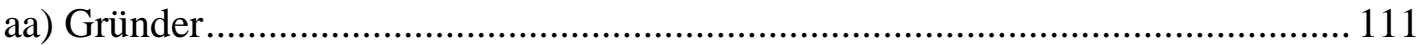

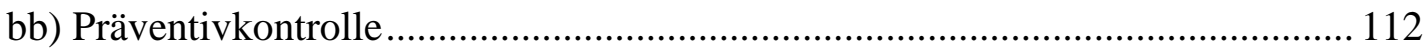

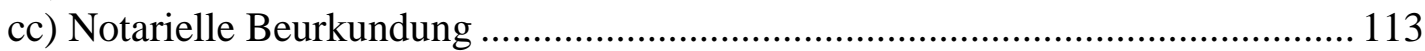

dd) (Teilweise) Erfüllung der Einlagepflichten ......................................................... 113

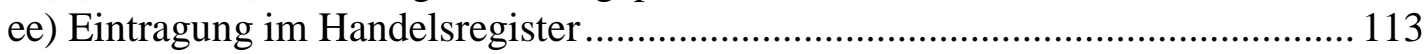

ff) Rechtslage vor Eintragung im Handelsregister - „B.V. i.o.“ ................................. 114

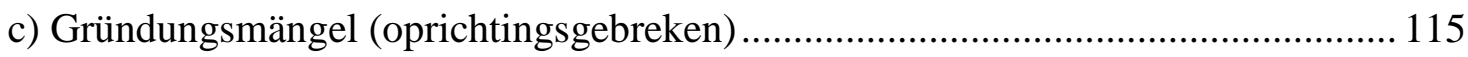

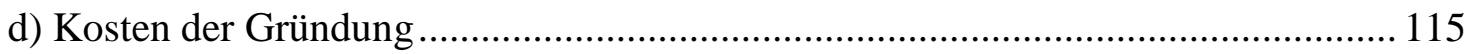

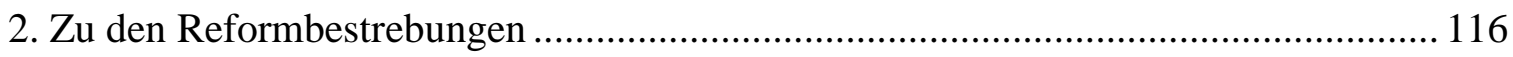

III. Satzung (,Statuten“); Stimmbindungsverträge

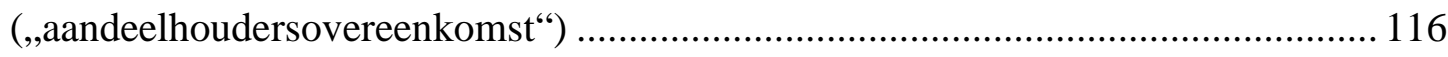

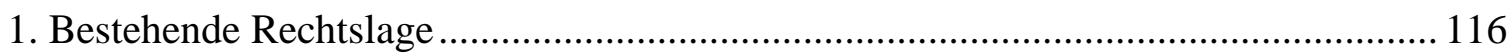

a) Gesetzlicher Mindestinhalt der Satzung (,Statuten“) ............................................. 116

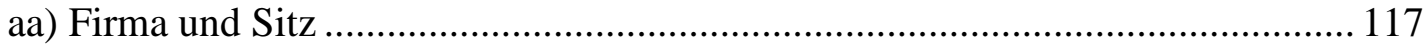

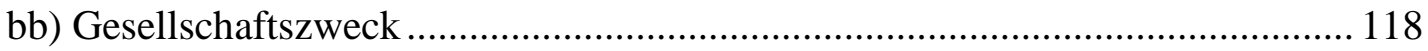

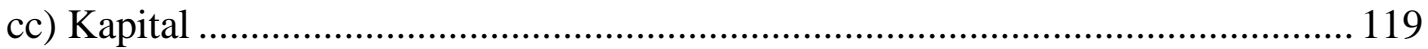

dd) Anzahl, Nennbetrag und Gattung der Anteile................................................... 119

ee) Dauer der Gesellschaft ................................................................................. 120

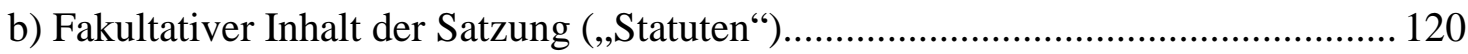

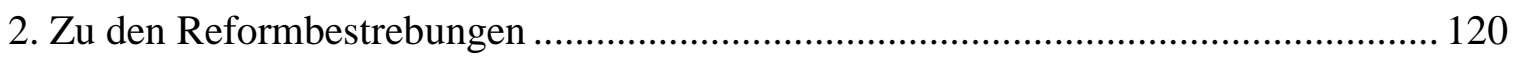

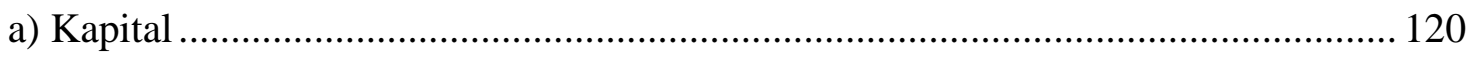

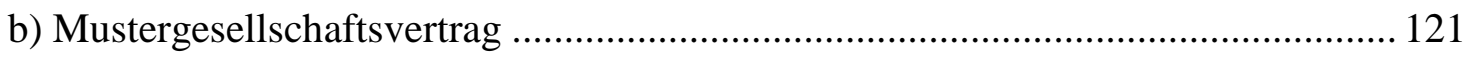

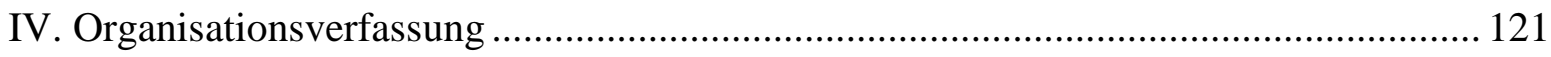

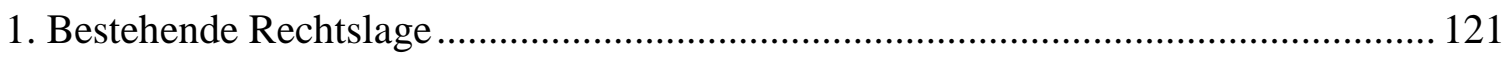

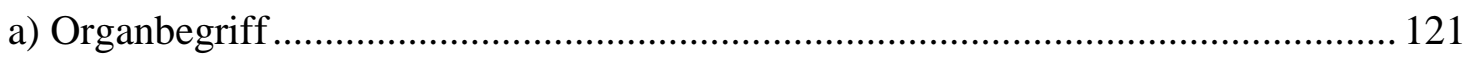

b) Geschäftsführung (,,bestuur“) und Vertretung........................................................ 122

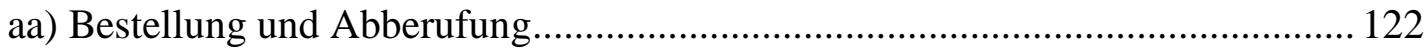

bb) Vertretung der Gesellschaft, Aufgaben und Befugnisse .................................... 123

cc) Verantwortung und Haftungsregime .............................................................. 124

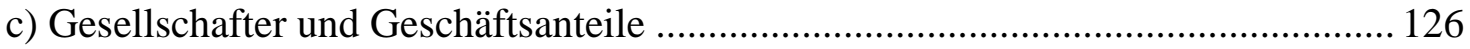

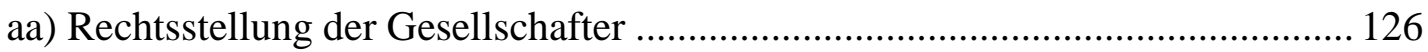

bb) Sonderrechte für einzelne Gesellschafter..................................................... 126 aaa) Prioritätsgeschäftsanteile .......................................................................... 127

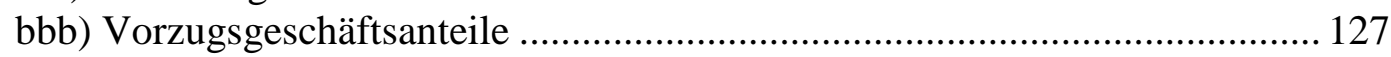

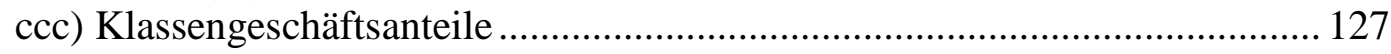

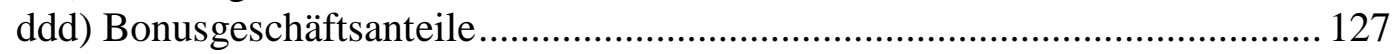

cc) Inhaber von Geschäftanteilszertifikaten („,Certificering“)............................... 128

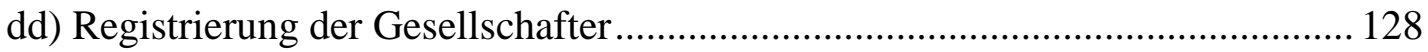

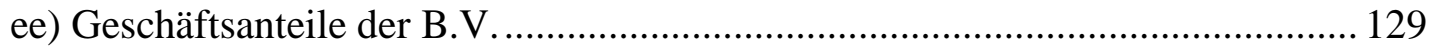

aaa) Zulässigkeit der Übertragung …………………………........................... 129

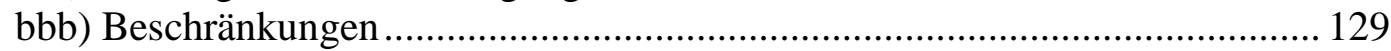




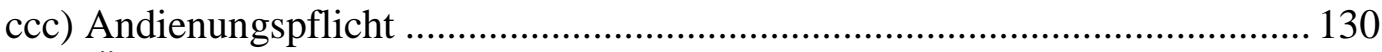

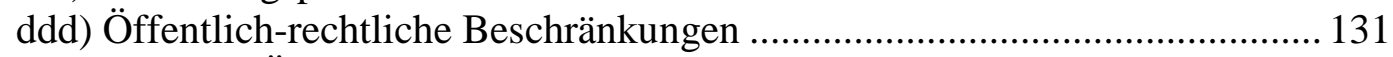

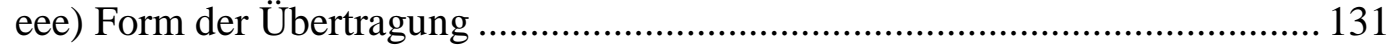

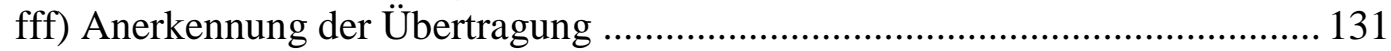

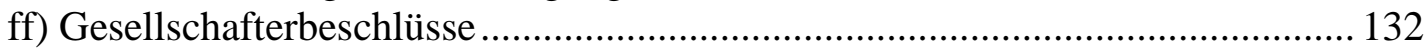

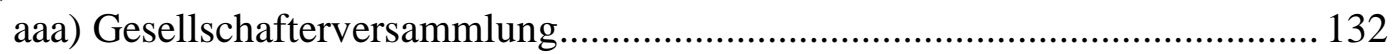

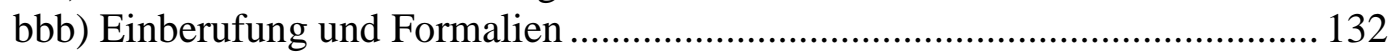

ccc) Stimmrecht und Vertretung ................................................................. 134

ddd) Stimmbindungsverträge (,,aandeelhoudersovereenkomst“)...................... 137

gg) Verantwortung und Haftung ................................................................... 137

d) Das Enquêterecht und die Gesellschafterklage im niederländischen

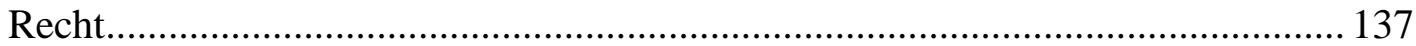

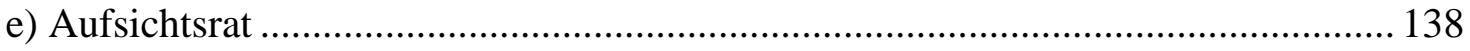

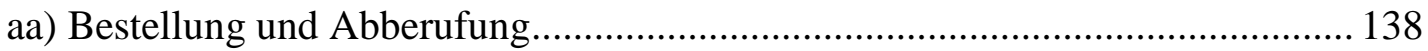

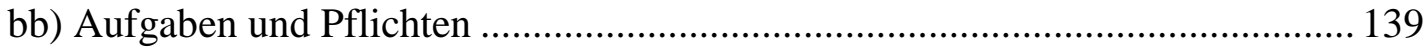

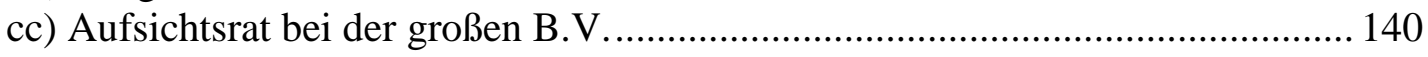

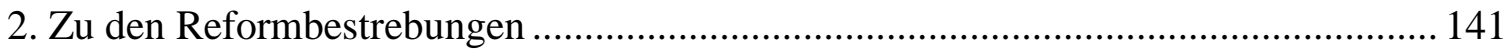

a) Reformansätze des Entwurfs eines Gesetzes zur Vereinfachung und

Flexibilisierung des B.V.-Rechts (,Wet vereenvoudiging en

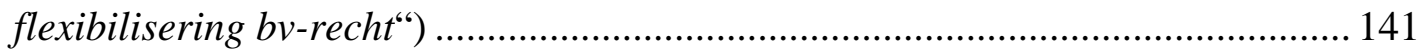

aa) Erweiterung des gesetzlichen Organbegriffs (Art. 2:189a NBG) .................... 141

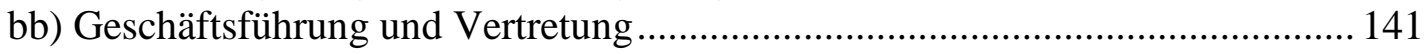

aaa) Bestellung und Abberufung (Artt. 2:242, 244, NBG) .............................. 141

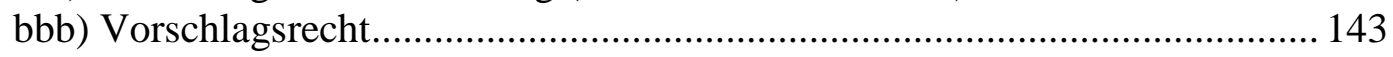

cc) Gesellschafter und Geschäftsanteile............................................................. 143

aaa) Jährliche Gesellschafterversammlung (Art. 2:218 NBG)......................... 143

bbb) Einberufung und Formalitäten ................................................................ 144

ccc) Teilnahmerechte anderer Personen als Gesellschafter (Art.

2:227 Abs. 2 und 4, Art. 197 Abs. 4 und Art. 198 Abs. 4

NBG)

ddd) Registrierung der Inhaber von Geschäftsanteilszertifikaten

mit Teilnahmerecht an der Hauptversammlung (Art. 2:194

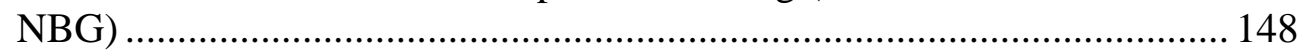

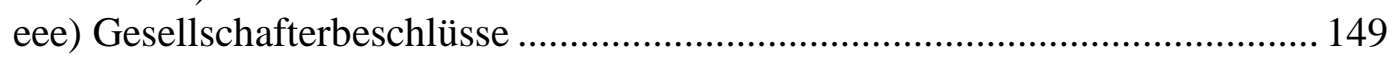

fff) Weisungsbefugnisse der Gesellschafterversammlung (Art.

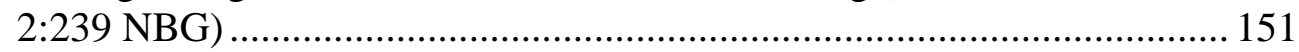

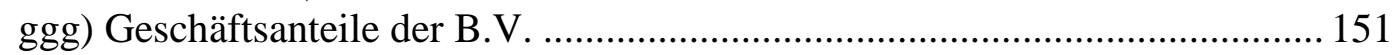

hhh) Stimmrechtslose Geschäftsanteile ....................................................... 155

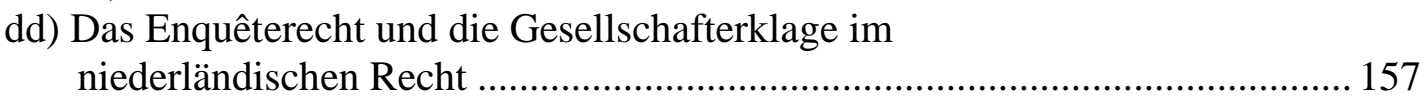

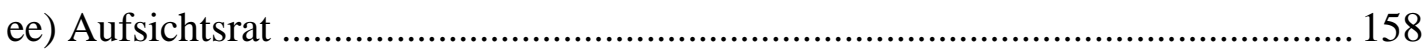

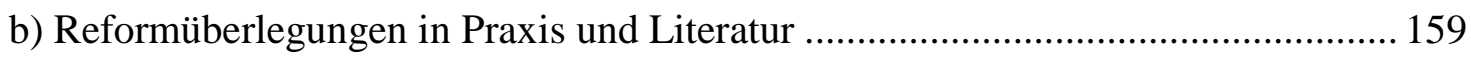

aa) Geschäftsführung und Vertretung ............................................................. 159

aaa) Vertretung der Gesellschaft, Aufgaben und Befugnisse ........................... 159

bbb) Verantwortung und Haftungsregime........................................................... 159

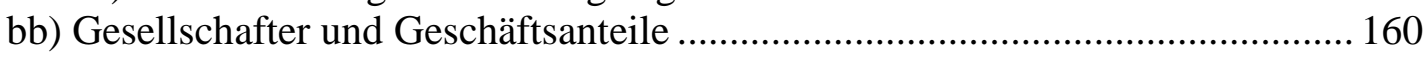

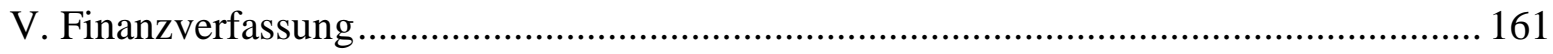




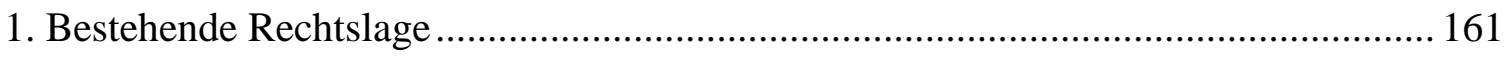

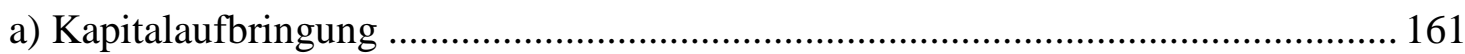

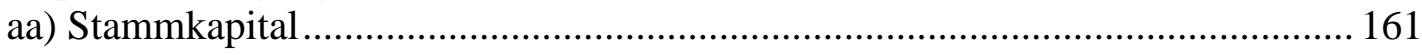

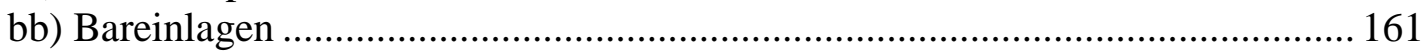

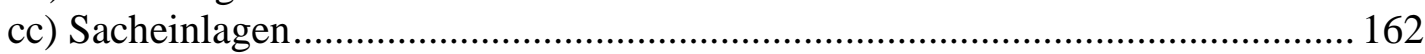

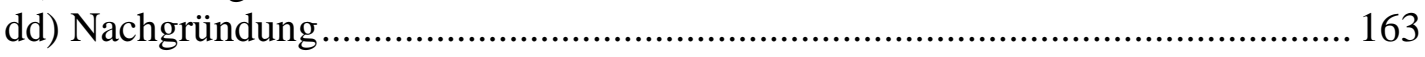

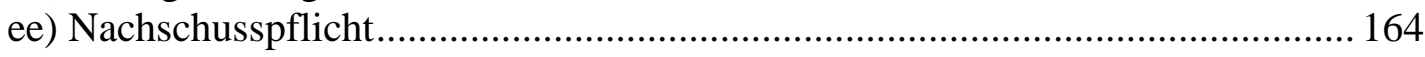

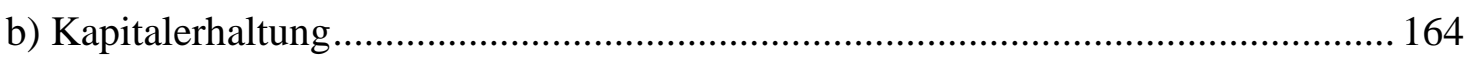

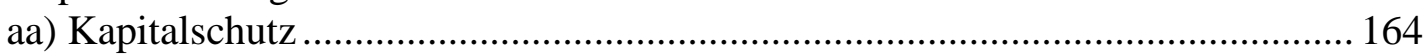

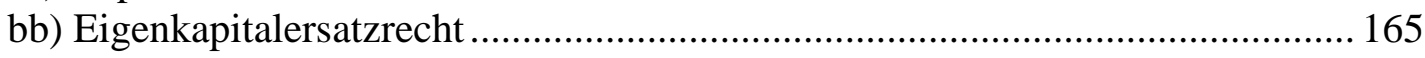

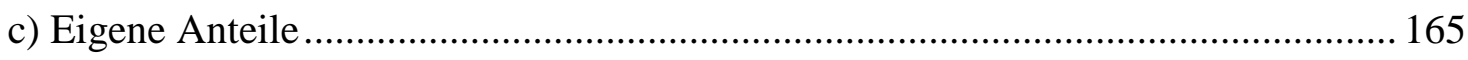

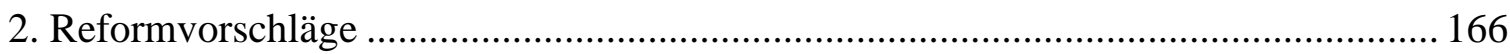

a) Reformansätze des Entwurfs eines Gesetzes zur Vereinfachung und

Flexibilisierung des B.V.-Rechts (,Wet vereenvoudiging en

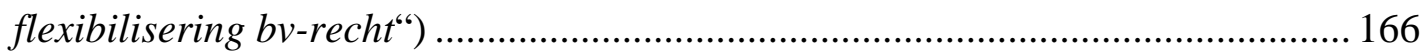

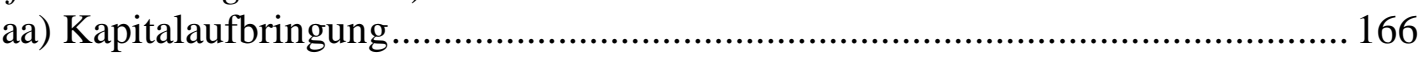

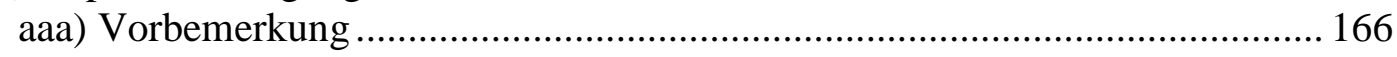

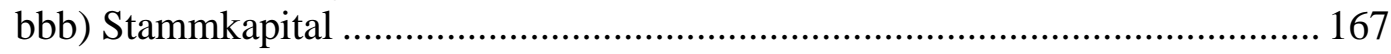

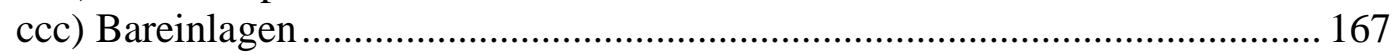

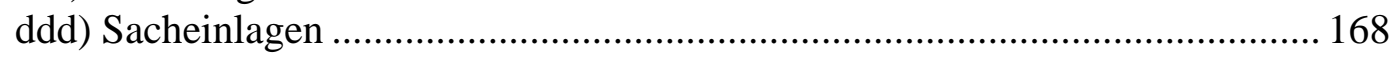

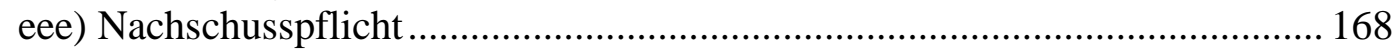

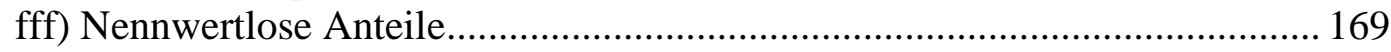

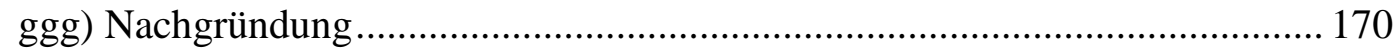

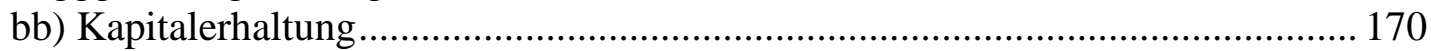

aaa) Ausschüttungstest ........................................................................ 170

bbb) Haftung der Geschäftsführer und Rückzahlungspflicht der

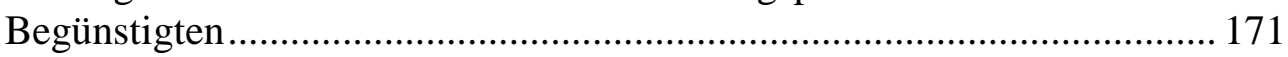

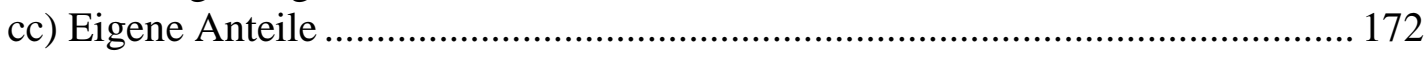

b) Reformüberlegungen in Praxis und Literatur ................................................ 173

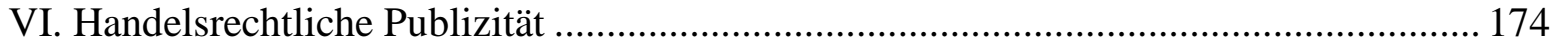

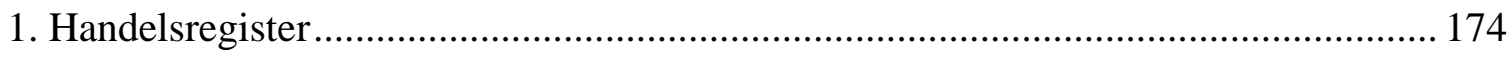

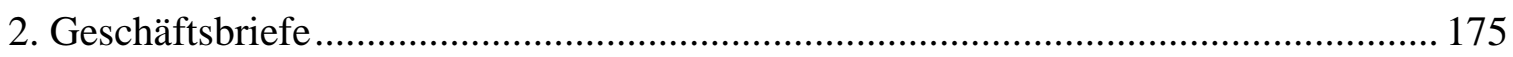

VII. Vorschläge alternativer Rechtsformen neben einer reformierten B.V. ..................... 175

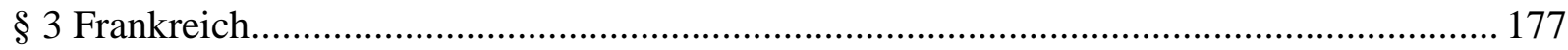

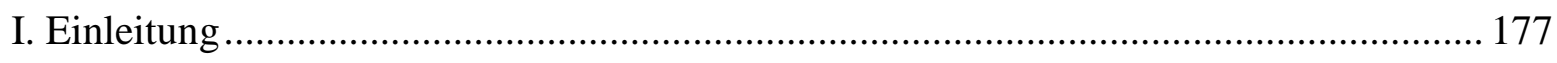

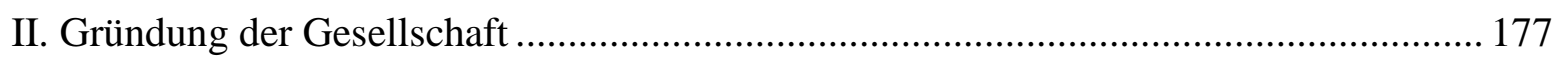

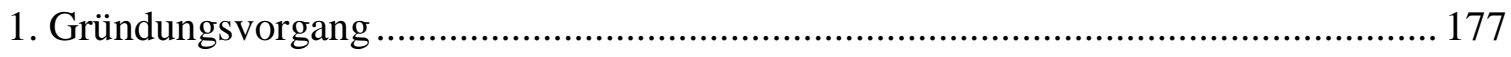

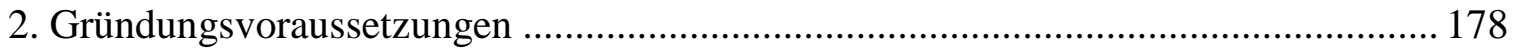

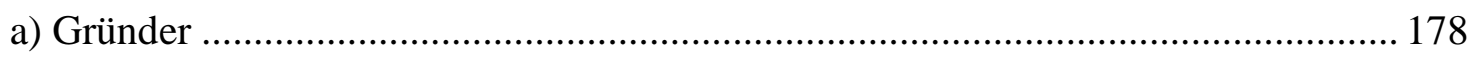

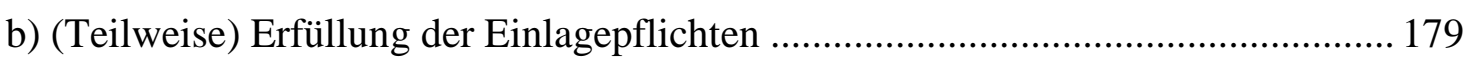

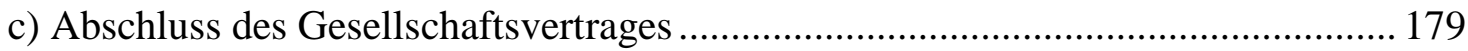

d) Formalitäten nach Unterzeichnung des Gesellschaftsvertrages.............................. 180

e) Veröffentlichung der Gründungsanzeige ........................................................ 181 


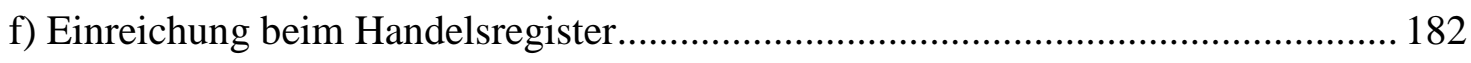

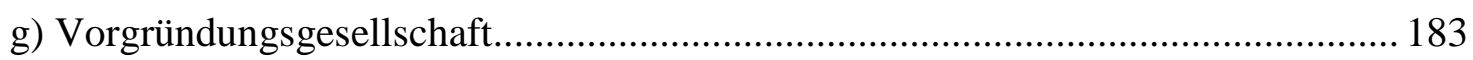

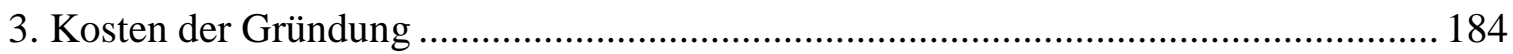

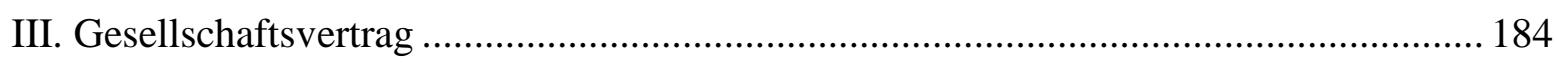

1. Gesetzlicher Mindestinhalt des Gesellschaftsvertrages ........................................ 184

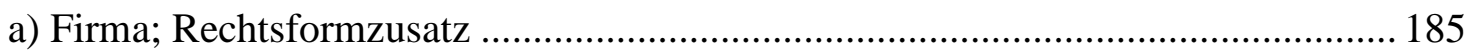

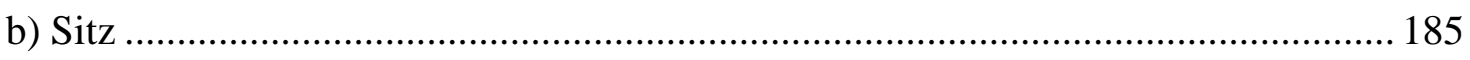

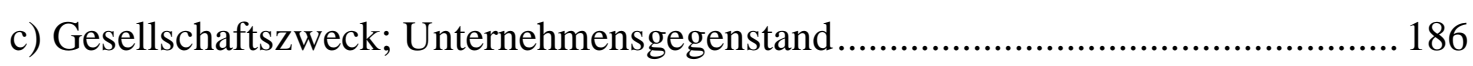

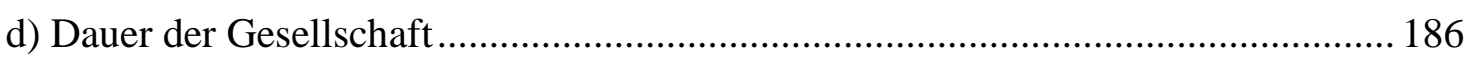

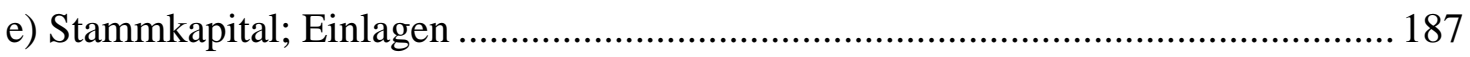

2. Fakultativer Inhalt des Gesellschaftsvertrages ..................................................... 188

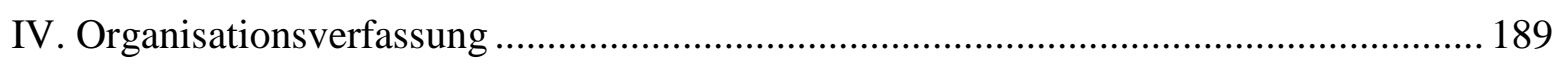

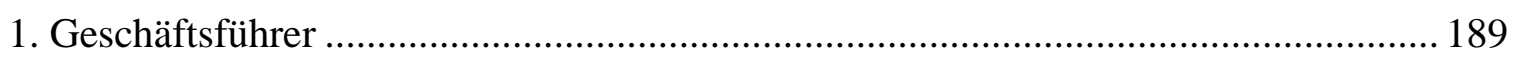

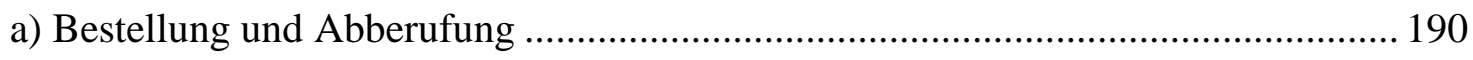

b) Vertretung der Gesellschaft; Aufgaben und Befugnisse....................................... 191

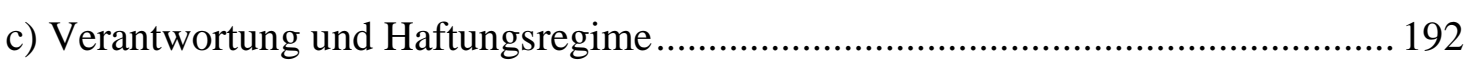

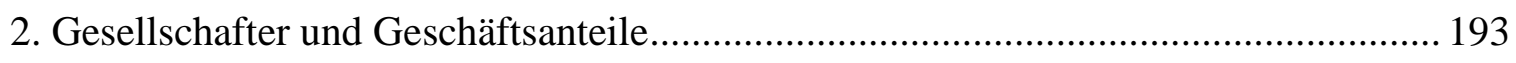

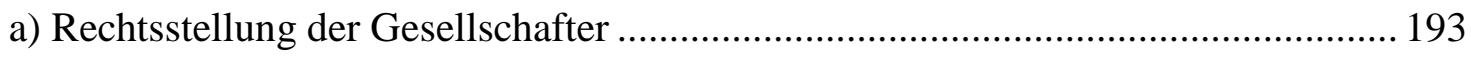

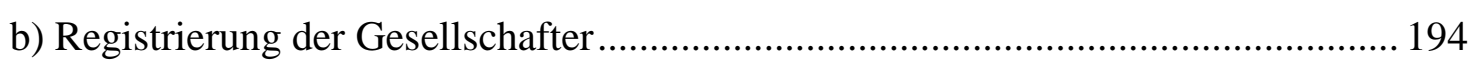

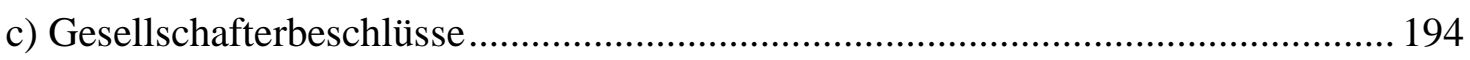

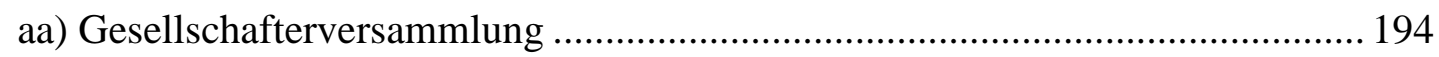

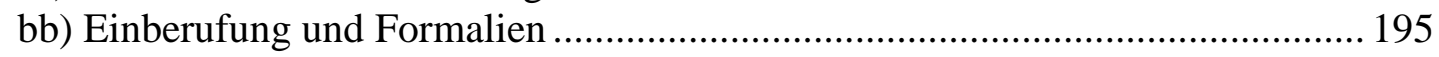

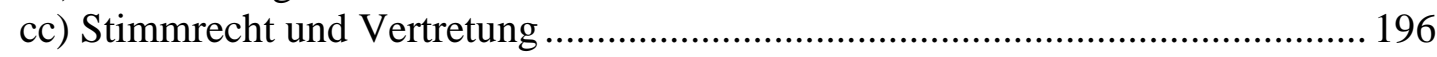

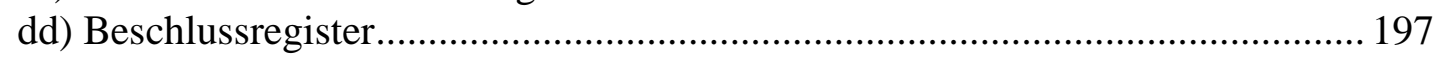

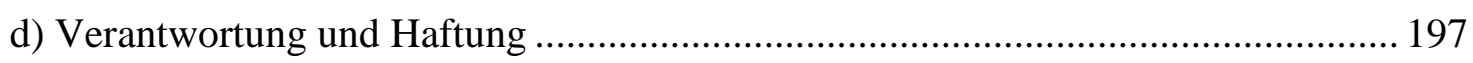

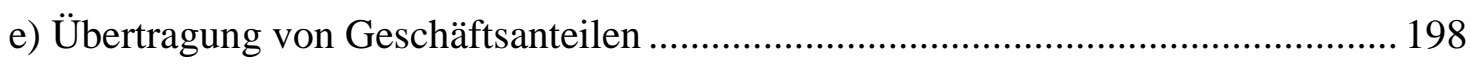

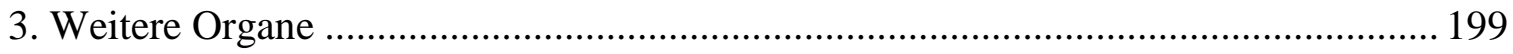

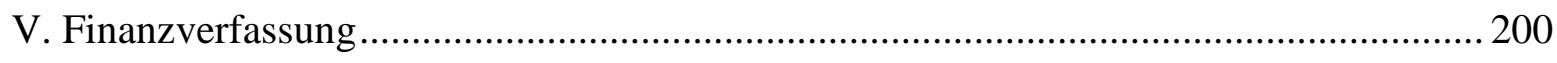

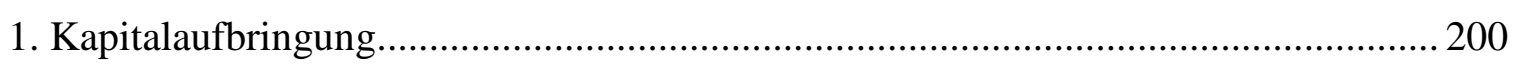

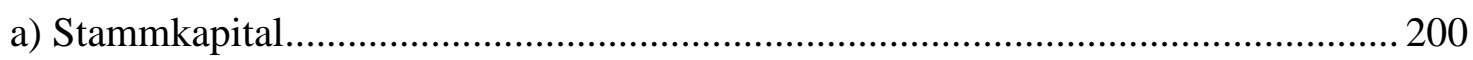

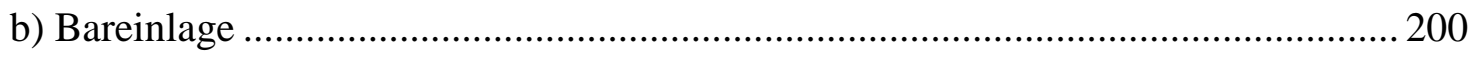

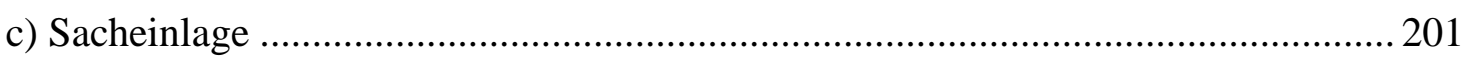

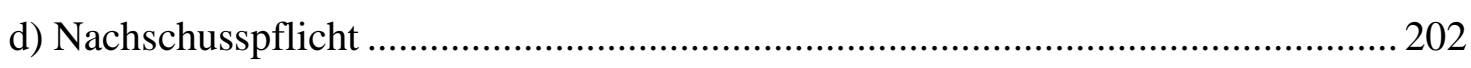

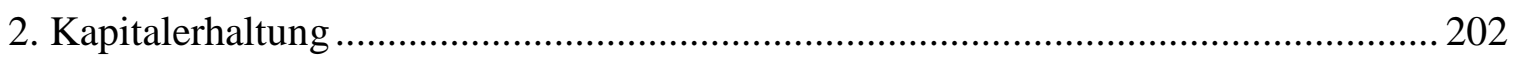

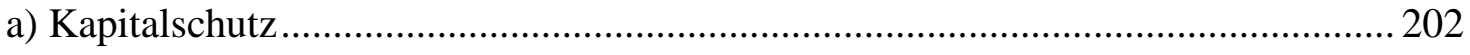

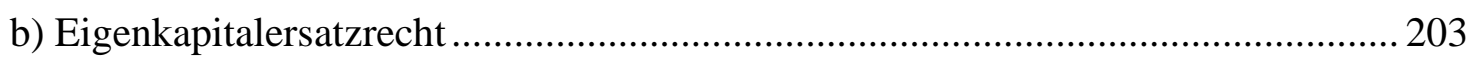

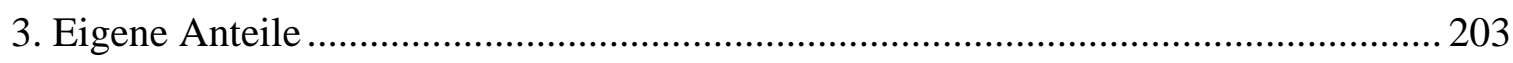

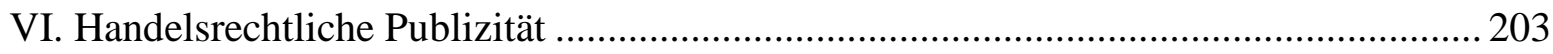

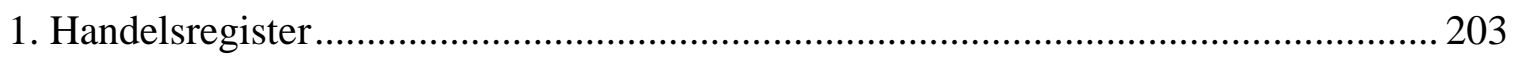


2. Geschäftsbriefe 204

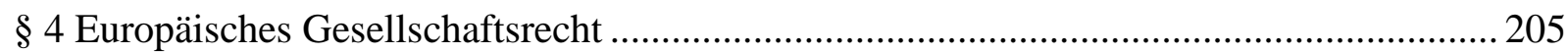

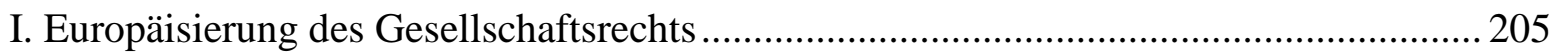

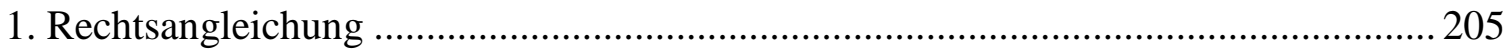

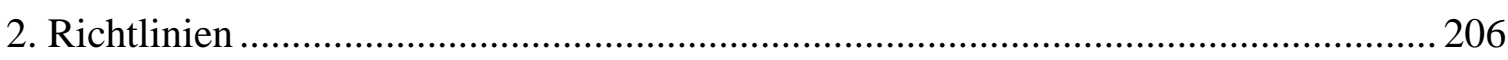

a) Erste gesellschaftsrechtliche Richtlinie 68/151/EWG Publizitätsrichtlinie 206

b) Zweite gesellschaftsrechtliche Richtlinie 77/91/EWG Kapitalrichtlinie

c) Dritte gesellschaftsrechtliche Richtlinie 78/855/EWG Fusionsrichtlinie

d) Vierte gesellschaftsrechtliche Richtlinie 78/660/EWG Jahresabschlussrichtlinie

e) Sechste gesellschaftsrechtliche Richtlinie 82/891/EWG Spaltungsrichtlinie 208

f) Siebte gesellschaftsrechtliche Richtlinie 83/349/EWG Konzernrechnungslegungsrichtlinie....

g) Achte gesellschaftsrechtliche Richtlinie 84/253/EWG -

Prüferbefähigungsrichtlinie

h) Elfte gesellschaftsrechtliche Richtlinie 89/666/EWG Publizitätsrichtlinie für Zweigniederlassungen

i) Zwölfte gesellschaftsrechtliche Richtlinie 89/667/EWG Einpersonengesellschaftsrichtlinie.

j) Richtlinie 2005/56/EG betreffend der Verschmelzung von Kapitalgesellschaften aus verschiedenen Mitgliedstaaten Verschmelzungsrichtlinie

k) Richtlinie 2003/58/EG zur Änderung der Richtlinie 68/151/EWG des Rates in Bezug auf die Offenlegungspflichten von Gesellschaften bestimmter Rechtsformen.

1) Richtlinie 2004/25/EG betreffend Übernahmeangebote

m) Richtlinie 2006/43/EG über Abschlussprüfungen von Jahresabschlüssen und konsolidierten Abschlüssen, zur Änderung der Richtlinien 78/660/EWG und 83/349/EWG des Rates und zur Aufhebung der Richtlinie 84/253/EWG des Rates

n) Richtlinie 2006/46/EG zur Abänderung der Richtlinien 78/660/EWG und 83/349/EWG hinsichtlich der Jahresabschlüsse bestimmter Arten von Unternehmen und konsolidierter Abschlüsse. 
o) Richtlinie 2006/68/EG des Europäischen Parlaments und des Rates vom 6. September 2006 zur Änderung der Richtlinie 77/91/EWG des Rates in Bezug auf die Gründung von Aktiengesellschaften und die Erhaltung und Änderung ihres Kapitals ................................................ 213

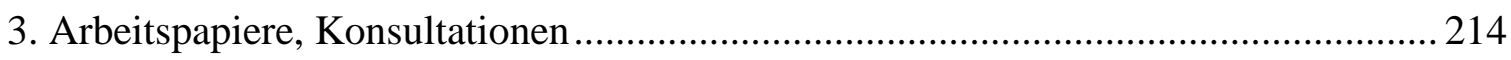

a) Bericht der Hochrangigen Gruppe von Experten auf dem Gebiet des Gesellschaftsrechts über moderne gesellschaftsrechtliche Rahmenbedingungen in Europa .................................................................... 214

b) Aktionsplan "Modernisierung des Gesellschaftsrechts und Verbesserung der Corporate Governance in der EU"

c) Aktionsplan "Vereinfachung des Unternehmensumfeldes für

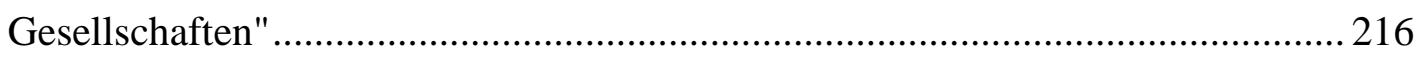

II. Die Europäische Privatgesellschaft oder Société Privée Européenne ............................ 217

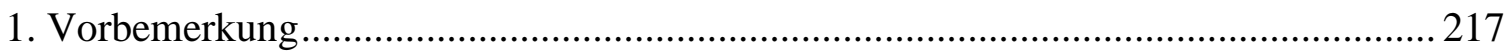

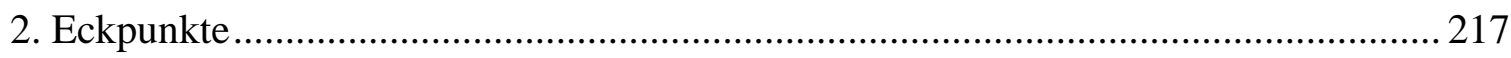

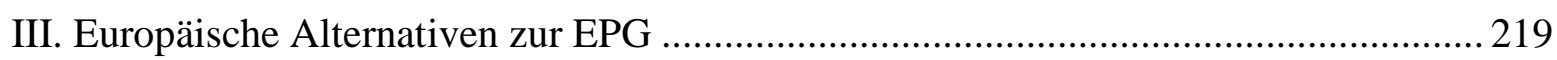

1. Die Europa AG - SE................................................................................. 219

2. Europäische Wirtschaftliche Interessensvereinigung (EWIV) ..................................2 219

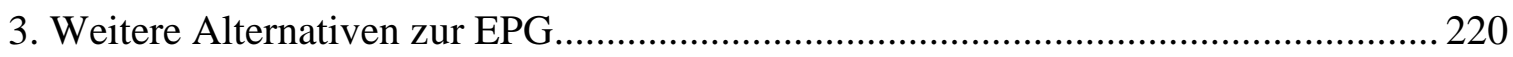

Vierter Abschnitt Rechtsvergleich und Schlussfolgerungen ................................................. 221

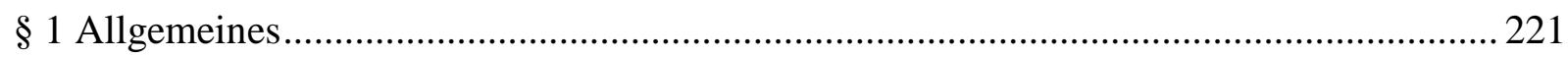

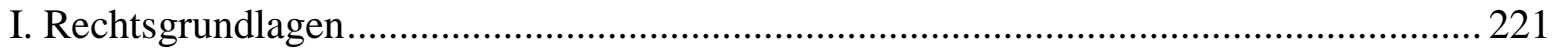

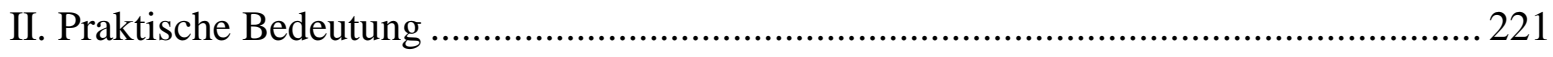

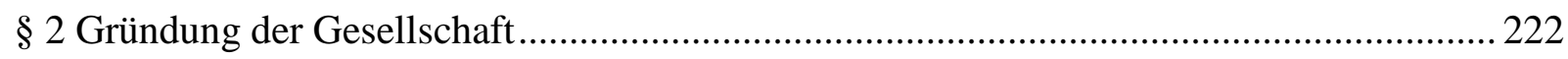

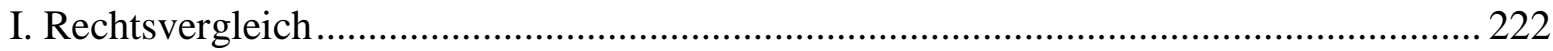

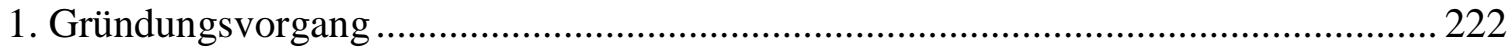

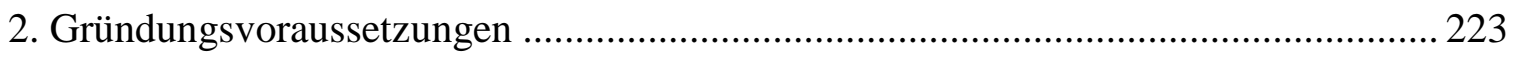

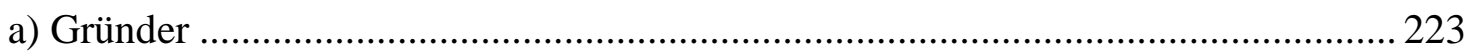

b) Abschluss des Gesellschaftsvertrages / Notarielle Beurkundung ...........................224

c) (Teilweise) Erfüllung der Einlagepflichten....................................................... 225

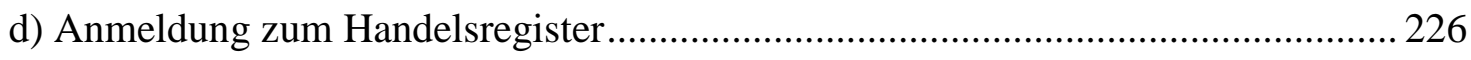

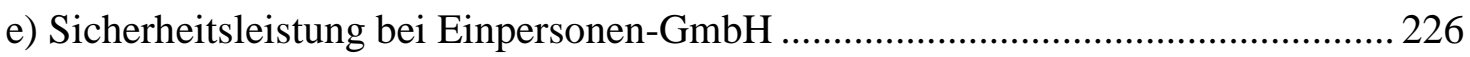

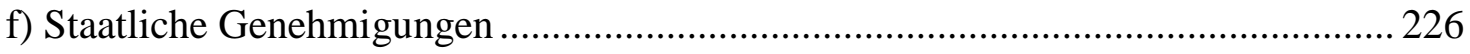

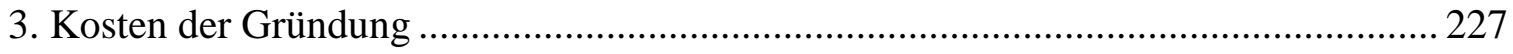

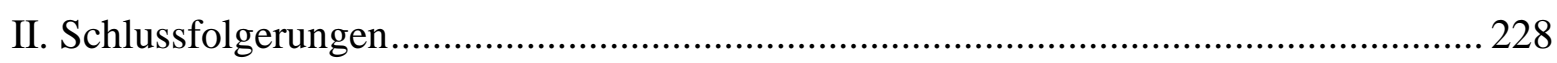

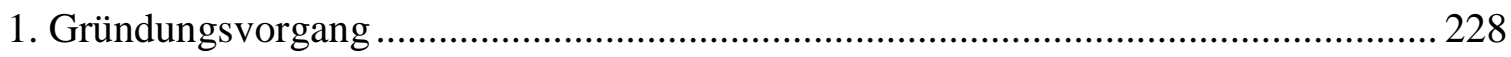

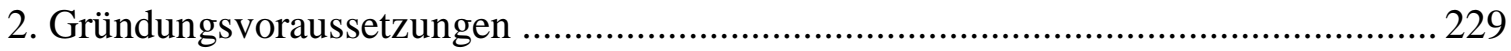

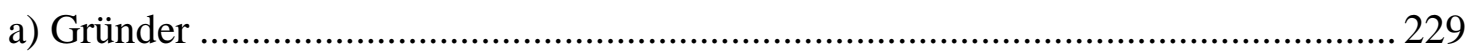




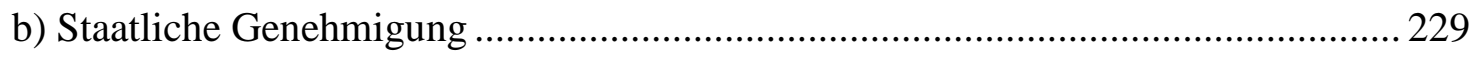

c) Abschluss des Gesellschaftsvertrages / Notarielle Beurkundung ...........................2 230

d) (Teilweise) Erfüllung der Einlagepflichten ........................................................ 231

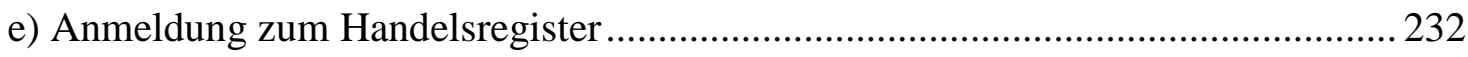

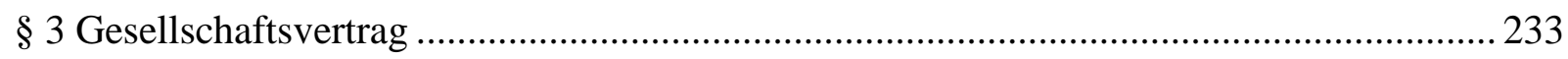

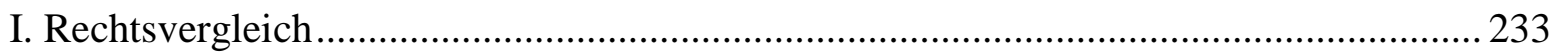

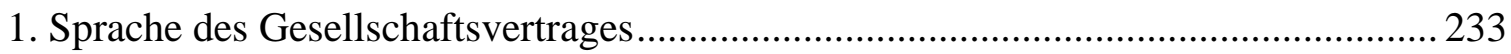

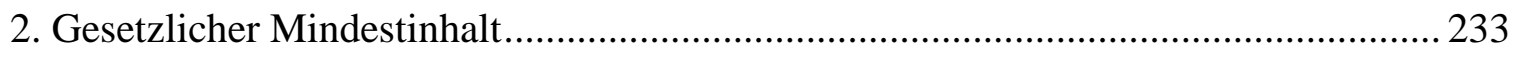

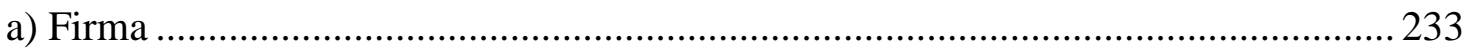

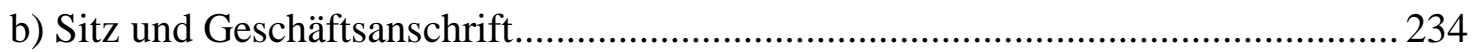

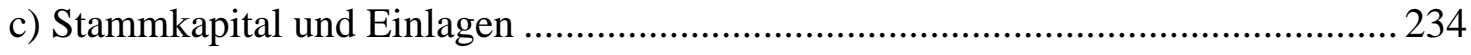

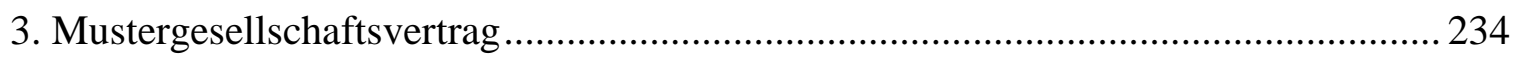

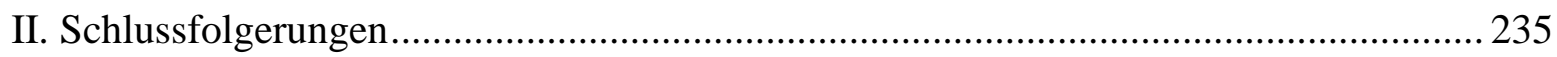

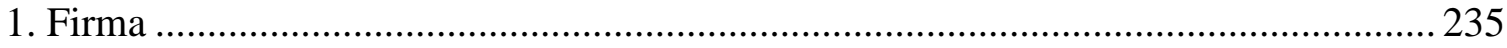

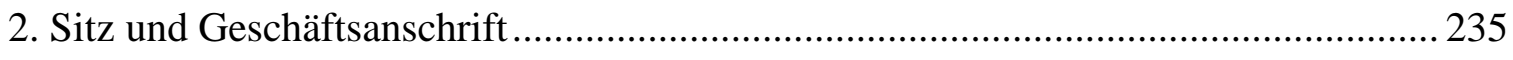

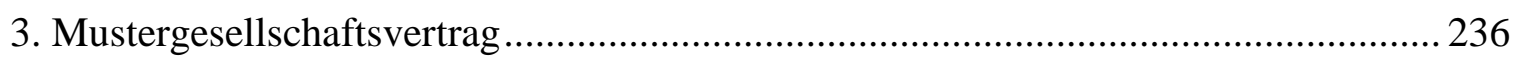

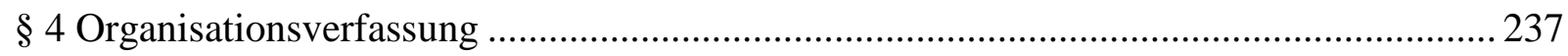

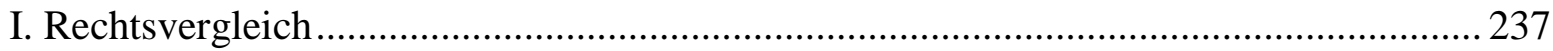

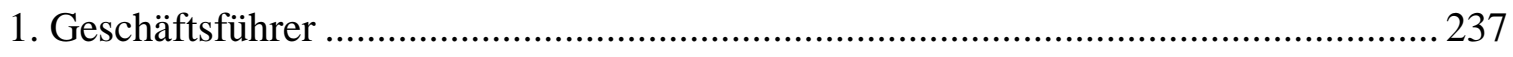

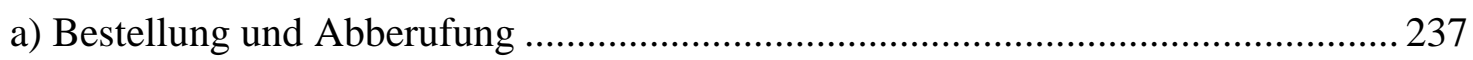

b) Vertretung der Gesellschaft; Aufgaben und Befugnisse.......................................2 238

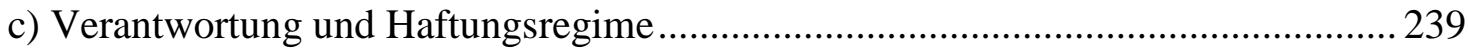

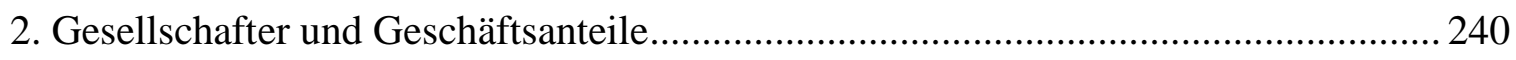

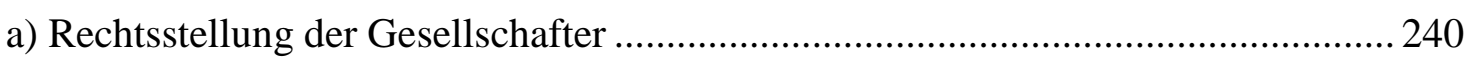

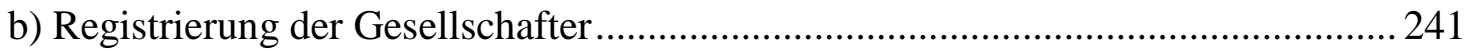

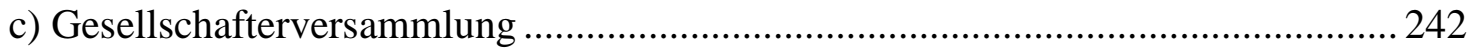

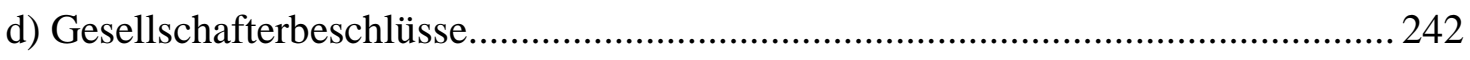

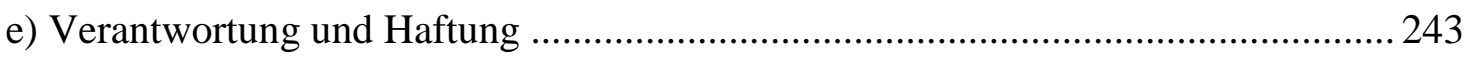

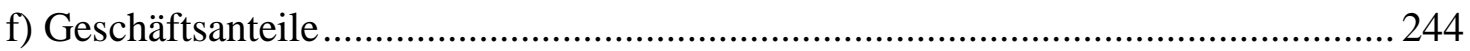

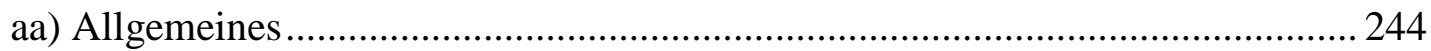

bb) Übertragungsmodalitäten / Beschränkungen ................................................... 244

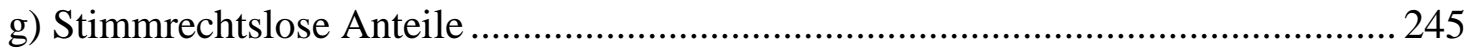

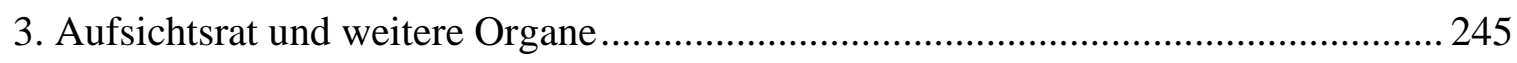

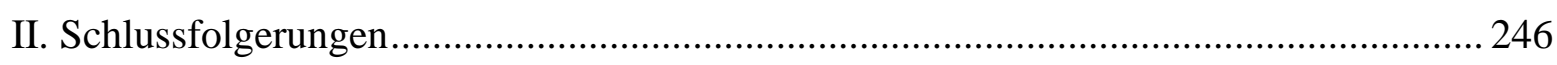

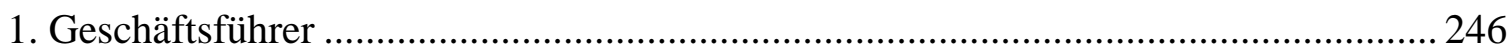

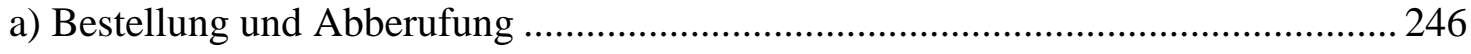

b) Publizität der Vertretungsverhältnisse ........................................................... 247

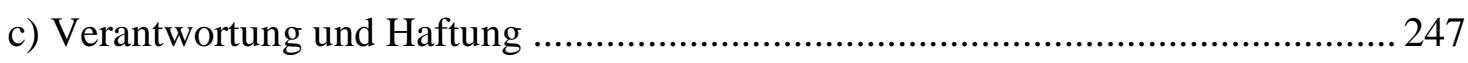

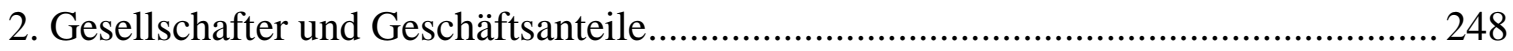




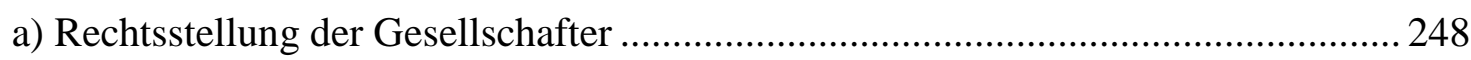

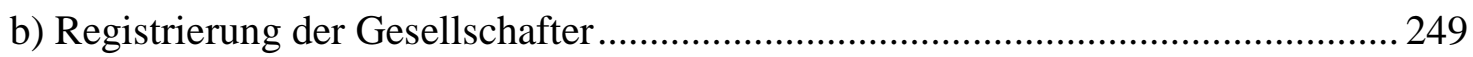

c) Gesellschafterversammlung / Gesellschafterbeschlüsse .......................................250

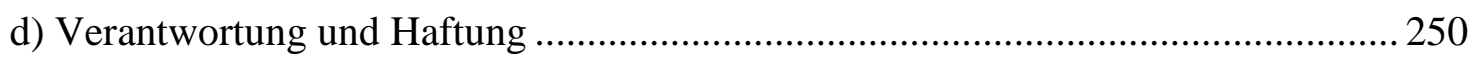

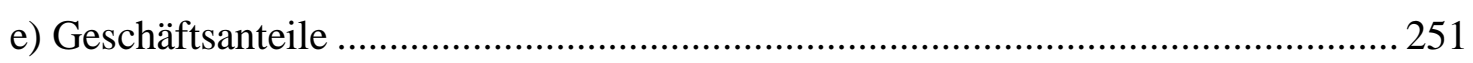

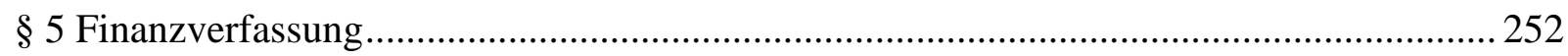

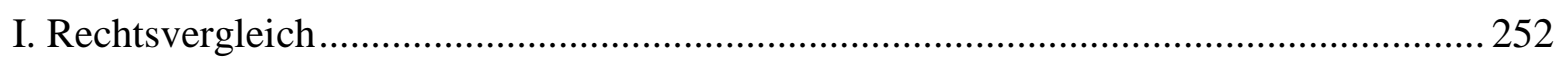

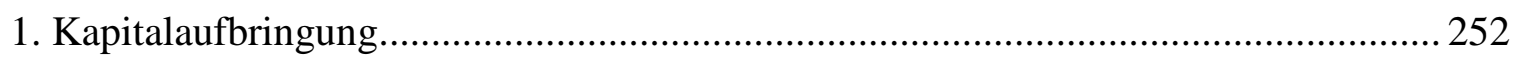

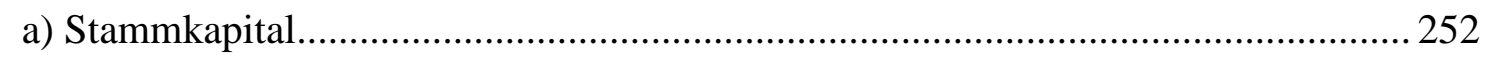

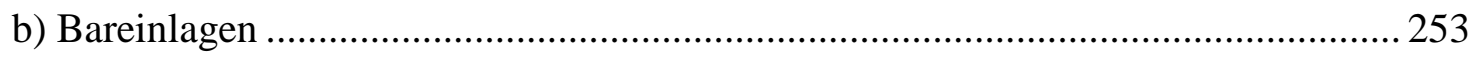

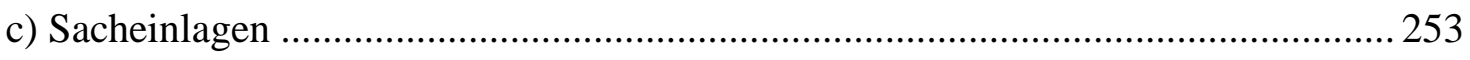

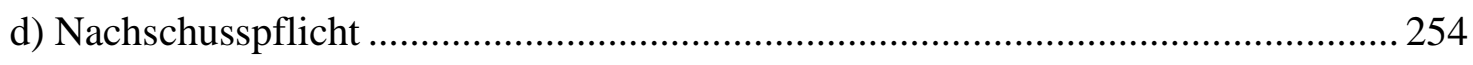

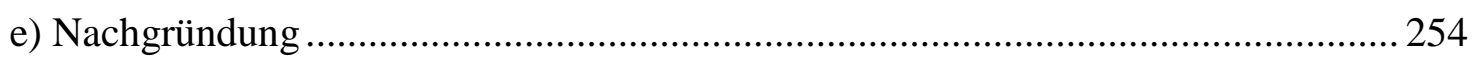

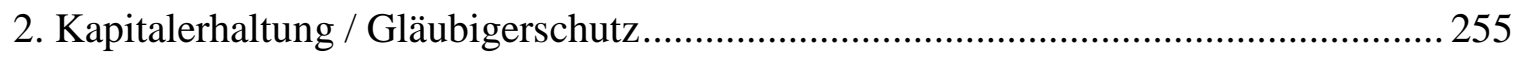

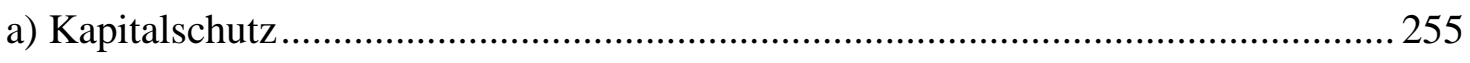

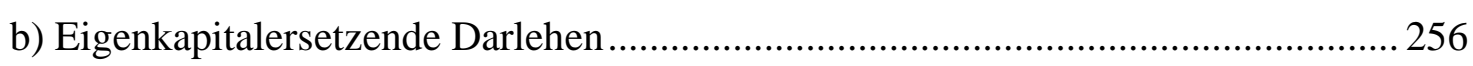

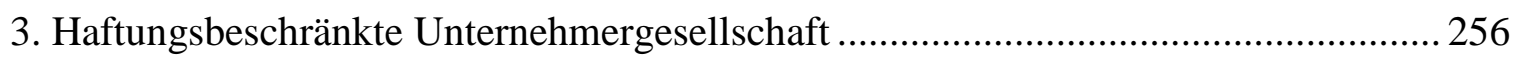

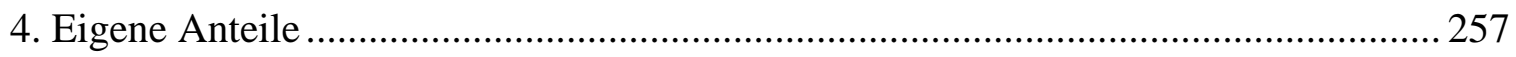

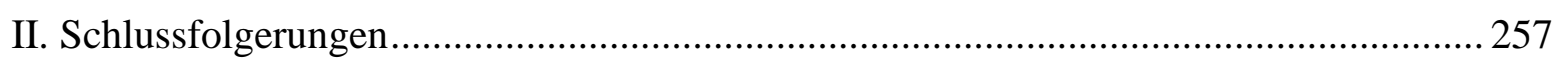

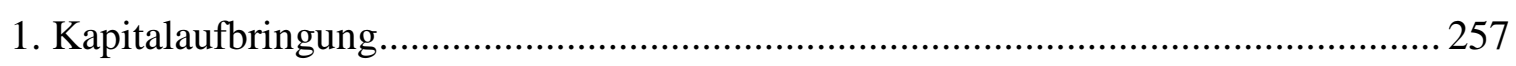

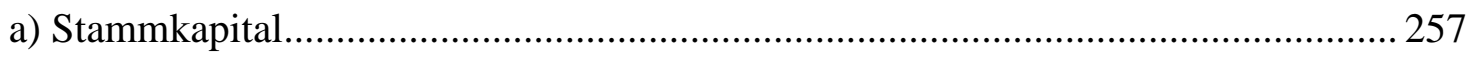

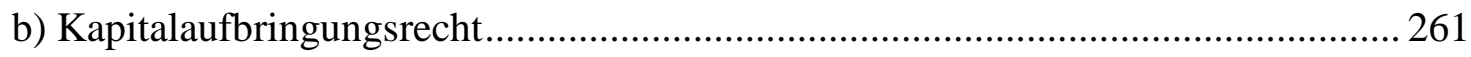

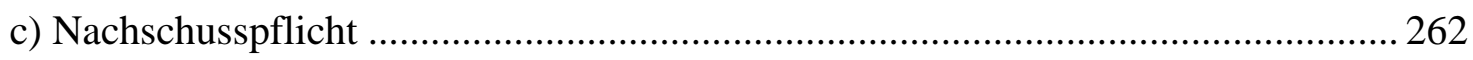

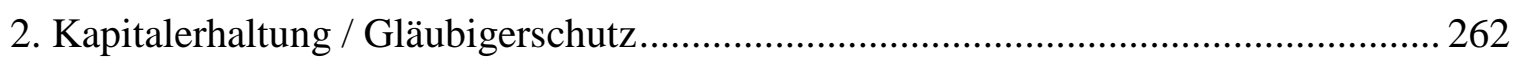

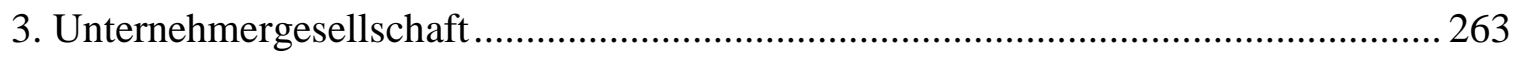

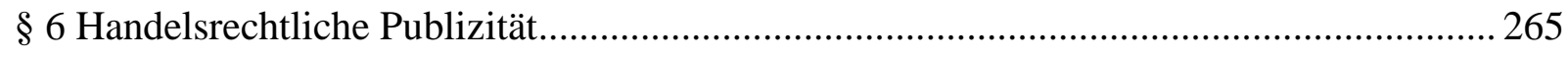

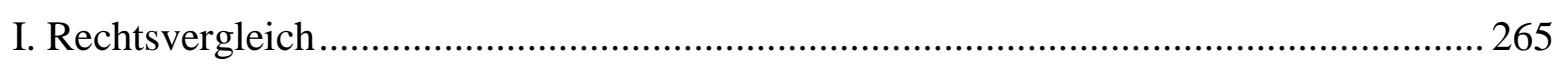

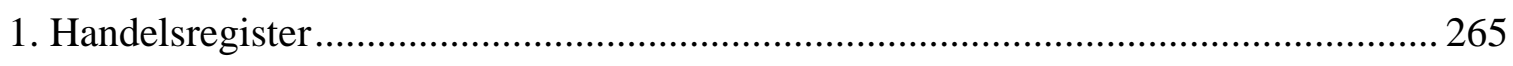

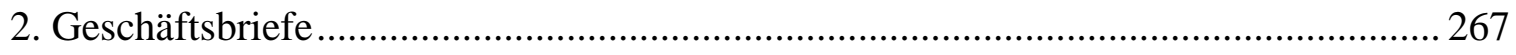

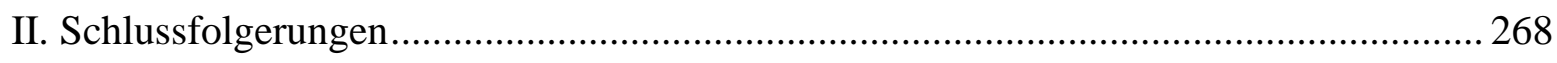

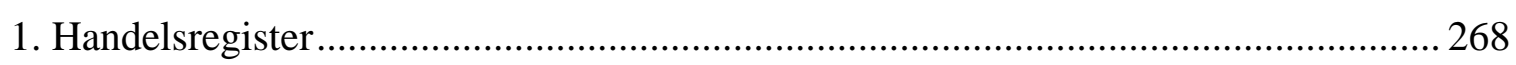

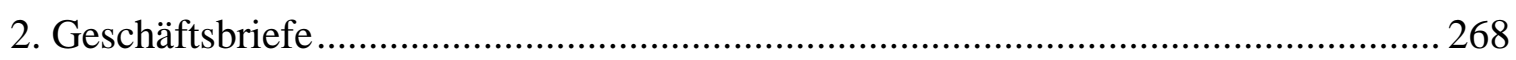

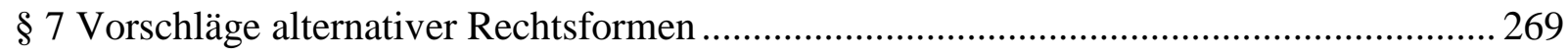

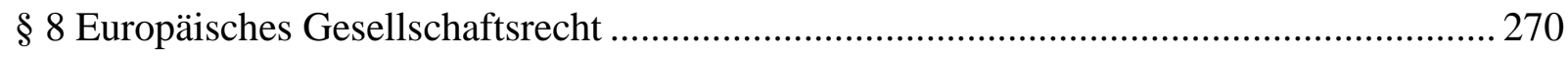

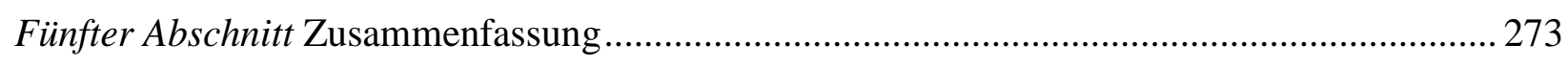

Sechster Abschnitt Anhänge .................................................................................................... 281

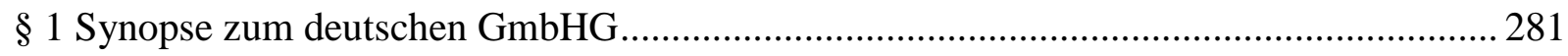

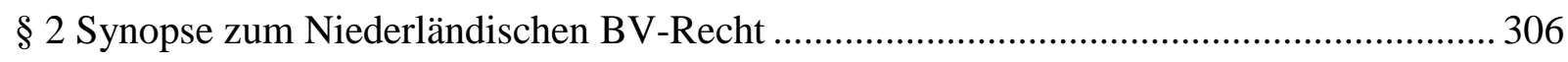


$\S 3$ Vorschriften des Code de Commerce betreffend die S.à.r.l............................................ 355

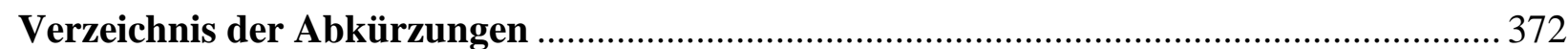

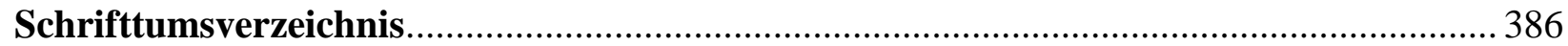





\section{Erster Abschnitt}

\section{Einleitung}

\section{$\S 1$ Vorbemerkung}

Bis in die späten neunziger Jahre definierte sich der Einfluss Europäischen Rechts auf die nationalen Rechtsordnungen nahezu ausschließlich über die Vorgaben, die sich aus den gesellschaftsrechtlichen EG-Richtlinien für das nationale Recht ergaben. Die nationalen Rechte anderer europäischer Rechtsordnungen waren für die Ausgestaltung der eigenen Rechtsordnung nahezu bedeutungslos. Dies änderte sich schlagartig, als der EuGH mit den grundlegenden Entscheidungen in Sachen Centros, Überseering und Inspire Art $^{1}$ eine europaweite Geltung nationaler Rechte etablierte und damit erstmals eine Auseinandersetzung der nationalen Gesetzgeber mit den (nunmehr konkurrierenden) Rechtsordnungen anderer Nationen erzwang $^{2}$. In der Folge kam es zu einem „Wettbewerb der Gesellschaftsrechte“ ${ }^{\text {“3 }}$, mit mehr oder minder umfangreichen Reformen des Gesellschaftsrechts in Frankreich, Spanien, teilweise auch Belgien, Luxemburg und Italien, und nahezu ausnahmslos entsprechenden Reformüberlegungen in den anderen Ländern ${ }^{4}$.

Die neuerliche Bewegung im Gesellschaftsrecht der Mitgliedstaaten - und dort insbesondere im Recht der Gesellschaften mit beschränkter Haftung (GmbH, S.à.r.l., B.V., Ltd. etc.) (nachfolgend unabhängig von der jeweiligen Bezeichnung im europäischen Mitgliedstaat auch „GmbH-Recht“ genannt) - gibt Anlass, die Gesellschaftsrechte der einzelnen Mitgliedsländer einander erneut gegenüber zu stellen. Untersucht werden im Folgenden die GmbH-Rechte in Deutschland und den Niederlanden - in beiden Ländern wurden unlängst Reformgesetze auf den Weg gebracht - sowie in Frankreich; dort wurde das Gesellschaftsrecht bereits im Jahre 2003 reformiert, so dass erste praktische Erfahrungen bereits zur Verfügung stehen. Ziel der Untersuchung ist es, den Modernisierungsbedarf eines europäischen, d.h. eines sich in Europa

1 Insbesondere die Entscheidungen des EuGH in den Angelegenheiten Centros - EuGH, 9. 3. 1999 - Rs. C 212/97; Überseering - EuGH, 5. 11. 2002 - Rs. C-208/00 sowie Inspire Art - EuGH v. 30. 9. 2003 - Rs. C 167/01 = GmbHR 2003, 1260 m. Anm. W. Meilicke.

2 So auch die Beobachtung bei Hirte/Bücker/Hirte S. $3 \mathrm{f}$.

3 Vgl. Bayer, BB 2003, 2357; Ebke JZ 2003, 927, 932 ff.; ders. EBLR 2005, 9 ff.; Eidenmüller ZIP 2002, 2233; ders., in: Eidenmüller (Hrsg.) Ausländische Kapitalgesellschaften im deutschen Recht (2004) § 1 Rdn. 17 ff.; ders./Rehm ZGR 2004, 159; Freitag EuZW 1999, 267; Geyrhalter/Gänßler NZG 2003, 409; Halbhuber ZEuP 2003, 418 (435 ff.); G. Roth RdW 1999, 381; Puszkajler IPRax 2000, 79; Sandrock/Wetzler (Hrsg.), Deutsches Gesellschaftsrecht im Wettbewerb der Rechtsordnungen (2004); Sedemund/Hausmann BB 1999, 809; Schanze/Jüttner AG 2003, 30; dies. AG 2003, 661; Spindler/Berner RIW 2003, 949; J. Thoma ERPL 2003, 545; de Wulf Ondernemingsrecht 1999, 318; Ebers ERPL 2003, 509.

$4 \quad$ Vgl. auch die Studie von BDI/Hengeler Müller. 
behauptenden GmbH-Rechts zu identifizieren und nach rechtsvergleichender Betrachtung, realisierbare nationale und/oder europäische Lösungen aufzuzeigen.

Die aktuelle Reform der Gesellschaftsrechte in Europa wurde - wie soeben ausgeführt durch das Europäische Gesellschaftsrecht, oder genauer, die Entscheidungen des Europäischen Gerichtshofs, angetrieben. Einleitend soll daher zunächst ein kurzer Blick auf die Entwicklung des Europäischen Gesellschaftsrechts unter besonderer Berücksichtigung der Europäischen Rechtsprechung geworfen werden, die für das Verständnis der nationalen Reformen von so grundlegender Bedeutung gewesen sind.

\section{§ 2 Eröffnung des Wettbewerbs: Die Entwicklung des europäischen Gesellschaftsrechts}

\section{Niederlassungsfreiheit nach Art. 43 ff. EGV}

Der Wettbewerb der Rechtsordnungen geht zurück auf die in Art. 43 EGV geregelte Niederlassungsfreiheit ${ }^{5}$. Die Niederlassungsfreiheit ist dem europäischem Primärrecht zuzuordnen, und entfaltet unmittelbare rechtliche Wirkung sowohl gegenüber dem geschützten Personenkreis als auch gegenüber den verpflichteten Mitgliedstaaten ${ }^{6}$.

Schutzzweck der Niederlassungsfreiheit nach Art. 43 EGV ist es, Unternehmern bei der Aufnahme und Ausübung selbständiger Erwerbstätigkeiten sowie bei der Gründung und Leitung von Unternehmen eine Inländerbehandlung im Aufnahmestaat zu garantieren ${ }^{7}$. In Bezug auf Gesellschaften gewährleistet die Niederlassungsfreiheit zum einen, eine identitätswahrende Verwaltungssitzverlegung in einem anderen Mitgliedstaat (so genannte primäre Niederlassungsfreiheit), zum anderen eine über Agenturen, Zweigniederlassungen oder Tochtergesellschaften mittelbare Entfaltung von Geschäftsaktivitäten in einem anderen Mitgliedstaat - ohne Notwendigkeit der Aufgabe des Hauptsitzes im Gründungsstaat (so genannte sekundäre Niederlassungsfreiheit ${ }^{8}$. Ob eine Gesellschaft sich auf die Niederlassungsfreiheit berufen kann, hängt nach Art. 48 EGV davon ab, ob sie nach den Rechtsvorschriften eines Mitglied-

Hofmeister WM 2007, 868, 869.

Hofmeister WM 2007, 868, 869. Zur Reichweite der Niederlassungfreiheit als Kollisionsnorm Eidenmüller/Rehm ZGR 2004, 159, 162.

$7 \quad$ Hofmeister WM 2007, 868, 869; Herdegen Rn. 317; Gebauer/Wiedemann/Weller Kap. 18 Rn. 3. Vgl. hierzu auch ausführlich Haratsch/Koenig/Pechstein Rn. 807 ff.

$8 \quad$ Hofmeister WM 2007, 868, 869. 
staates gegründet ist und in der Europäischen Union ihren Satzungssitz, ihre Hauptverwaltung oder ihre Hauptniederlassung hat ${ }^{9}$.

\section{Die Leitentscheidungen}

\section{Daily Mail}

Ausgangspunkt der durch die Niederlassungsfreiheit vermittelten, in den Wettbewerb der Rechtsordnungen mündenden Freizügigkeit der nationalen Gesellschaftsstatute war die berühmte Daily Mail-Entscheidung des EuGH aus dem Jahr $1988^{10}$. In dem der Entscheidung zugundeliegenden Fall wollte eine englische Investmentholdinggesellschaft aus Steuergründen, ihre Geschäftsleitung (central management and control), das nach damaligem englischen Recht einzige Anknüpfungsmerkmal zur Begründung der steuerlichen Ansässigkeit in Großbritannien, in die Niederlande verlegen. Das britische Rechte verlangte damals für eine derartige Transaktion eine Genehmigung des britischen Finanzministeriums (Treasury Departments $)^{11}$. Diese Genehmigung wurde vom britischen Finanzministerium verweigert, mit der Konsequenz, dass - hätte das Unternehmen seine Sitzverlegungsabsicht weiterverfolgt - es in den Niederlanden eine neue Gesellschaft hätte gründen müssen. Der EuGH entschied, dass die Niederlassungsfreiheit „,beim derzeitigen Stand des Gemeinschaftsrechts einer Gesellschaft, die nach dem Recht eines Mitgliedstaates gegründet ist und in diesem ihren satzungsmäßigen Sitz hat, nicht das Recht (gewährt), den Sitz ihrer Geschäftsleitung(im Widerspruch zu nationalen Wegzugsbeschränkungen) in einen anderen Mitgliedstaat zu verlegen“"12.

Auch wenn die Daily Mail-Entscheidung sich nur mit der europarechtlichen Verträglichkeit steuerlicher Wegzugsschranken befasste und nicht in einem gesellschaftsrechtlichen Zusammenhang erging, wurde hieraus geschlossen, dass der EuGH nationale Mobilitätsschranken im Allgemeinen als mit der Niederlassungsfreiheit vereinbar erachtete ${ }^{13}$.

9 Vgl. hierzu auch Hofmeister WM 2007, 868, 869.

10 EuGH Rs. 81/87, Slg. 1988, 5483 ff., 5512 Rn. 12 (“Daily Mail”).

11 So MünchKommBGB/Kindler Intern. WirtschaftsR Rn. 98 unter Verweis auf die damalige Regelung in Section 482 (1) (a) Income and Corporation Taxes Act 1970; aufgehoben durch Section 105 (6) des Finance Act 1988; siehe dazu auch Ebenroth/Eyles DB 1989, 363, 389 und 374.

12 EuGH Rs. 81/87, Slg. 1988, 5483 ff., 5512 Rn. 12 (“Daily Mail”); vgl dazu ausführlich MünchKommBGB/Kindler Intern. WirtschaftsR Rn. 98; Behrens IPRax 1989, 354; Ebenroth/Eyles DB 1989, 363 und 413; Sack JuS 1990, 352; Sandrock/Austmann RIW 1989, 249 sowie aus der neueren Literatur insbesondere Süß/Wachter/Hoffmann S. 210.

13 Süß/Wachter/Hoffmann S. 210; Behrens ZGR 1994, 1, 20 f.; Ebenroth/Eyles DB 1989, 363, 372; Staudinger/Großfeld IntGesR Rn. 123 m. zahlreichen weiteren Nachweisen. 


\section{Centros}

Eine Wende brachte die im Jahre 1999 ergangene Entscheidung in der Rechtssache Centros Ltd. ${ }^{14}$ Die Centros Ltd. war von einem dänischen Ehepaar anlässlich eines Englandbesuchs nach britischem Recht gegründet worden. Hierbei war von vorneherein beabsichtigt, dass die Gesellschaft ihre gesamte Geschäftstätigkeit über eine Zweigniederlassung ausschließlich in Dänemark abwickeln sollte. Im Gründungsstaat sollte lediglich eine Zustelladresse verbleiben. Als die Centros Ltd. im Jahre 1992 sodann die Eintragung einer Zweigniederlassung in Dänemark beantragte, verweigerte die zuständige Registerbehörde die Eintragung mit dem Argument, dass dies zu einer faktischen Umgehung der Kapitalaufbringungsvorschriften des dänischen Rechts führe. Der EuGH ließ dieses Argument indes nicht gelten und hat in der Verweigerung der Eintragung eine Beschränkung der sekundären Niederlassungsfreiheit gesehen, da es nicht rechtsmissbräuchlich sei, „,wenn ein Staatsangehöriger eines Mitgliedstaates, der eine Gesellschaft gründen möchte, diese in dem Mitgliedstaat errichtet, dessen gesellschaftsrechtlichen Vorschriften im die größte Freiheit lassen, und in anderen Mitgliedstaaten Zweigniederlassungen gründet ${ }^{\star * 15}$.

Ob die Centros-Entscheidung des EuGH zugleich eine Abkehr von den Aussagen der Daily Mail-Entscheidung bedeutete, wurde in der Folgezeit intensiv diskutiert. Insbesondere der Umstand, dass mit dem Vereinigten Königreich und Dänemark wiederum zwei Staaten, die der Gründungstheorie folgten (bei der Rechtssache Daily Mail war mit den Niederlanden ebenfalls ein Gründungstheoriestaat beteiligt), betroffen waren, gab Anlass über die Reichweite der Entscheidung und ihre Auswirkungen auf die Sitztheoriestaaten zu spekulieren ${ }^{16}$.

14 EuGH Rs. C -212/97, Slg. 1999, I-1459 ff. = IPRax 1999, 364 = NJW 1999, 2027 = NZG 1999, 297 m. Anm. Leible.

15 EuGH Rs. C -212/97, Slg. 1999, I-1459 ff. Rn. 27. Zur umfangreichen Literatur zu dieser Entscheidung vgl. die umfassenden Literaturangaben bei Süß/Wachter/Hoffmann S. 210 sowie Mellert/Verfürth S. $42 \mathrm{f}$.

16 Gegen eine Erstreckung der Entscheidung auf Sitztheoriestaaten: Ebke JZ 1999, 656, 658; Görk MittBayNot 1999, 300, 302; Kindler NJW 1999, 1993, 1997; Lange DNotZ 1999, 599, 606; Sonnenberger/Großerichter RIW 1999, 721, 726; Timme/Hülk JuS 1999, 1055, 1058; Hoffmann ZHR 164 (2000) 43, 48 f. Für eine Erstreckung der Entscheidung auf Sitztheoriestaaten sprachen sich aus: Behrens IPRax 1999, 323, 325 ff.; Bungert DB 1999, 1841, 1843; Dautzenberg FR 1999, 451, 452; Freitag EuZW 1999, 267, 269; Göttsche DStR 1999, 1403, 1406; Kieninger ZGR 1999, 724, 746; Sandrock BB 1999, 1337, 1341; Leible NZG 1999, 300, 301; Steindorff JZ 1999, 1140, 1141; Meilicke DB 1999, 627 f.; Risse MDR 1999, 752, 753; Sedemund/Hausmann BB 1999, 810. Eine überblicksartige Darstellung findet sich bei Süß/Wachter/Hoffmann S. 210 f., Hirte/Bücker/Hirte S. 4 ff. sowie Mellert/Verfürth S. 42 ff. 


\section{3. Überseering}

Drei Jahre später stellte der EuGH in der „Überseering-Entscheidung ${ }^{“ 17}$ klar, dass die Beachtung der Niederlassungsfreiheit eine Einschränkung der Sitztheorie verlangte ${ }^{18}$. Im den zu entscheidenden Fall hatten deutsche Instanzgerichte einer nach niederländischen Recht gegründeten Gesellschaft, der Überseering BV, nach der Verlegung ihrer Hauptverwaltung in die Bundesrepublik Deutschland, die Rechts- und Parteifähigkeit abgesprochen. Der EuGH hat darin eine Verletzung der primären Niederlassungsfreiheit gesehen, da die zugezogene Auslandsgesellschaft hierdurch zur Neugründung unter Beachtung der inländischen Regelungen gezwungen werde ${ }^{19}$. Zuziehende Gesellschaften seien als Gesellschaft ihres Gründungsrechts anzuerkennen, da sie ,jenseits der nationalen Rechtsordnung, die ihre Gründung und ihre Existenz regelt, keine Realität (hätten)“202. Art. 43, 48 EGV verlangten daher gerade, „die Rechtsfähigkeit [...] zu achten, die diese Gesellschaft nach dem Recht ihres Gründungsstaates (besitzten)“21. Der EuGH bekräftigte allerdings zugleich in konsequenter Fortführung seiner Rechtsprechung in der Rechtssache Daily Mail, dass es den Mitgliedstaaten unbenommen bleibe die ihrem Recht unterliegenden Gesellschaften Wegzugsbeschränkungen bis hin zur Auflösung bei Grenzübertritt zu unterwerfen ${ }^{22}$.

\section{Inspire Art}

In der bislang jüngsten Entscheidung des EuGH zur Niederlassungsfreiheit in der Rechtssache Inspire $\mathrm{Art}^{23}$ hatte der EuGH zu entscheiden, ob und inwieweit ein nationaler Gesetzgeber

17 EuGH Rs. C-208/00, Slg. 2002, I-9919 = IPRax 2003, 65 = NJW 2002, 3614 = EuZW 2002, 754 m. Anm. Wernicke.

18 Süß/Wachter/Hoffmann S. 211 f., Hirte/Bücker/Hirte S. 5 f. sowie Mellert/Verfürth S. 47 ff. Vgl. hierzu auch die Besprechungsaufsätze von Binz/Mayer GmbHR 2003, 249; Deininger IStR 2003, 214; Eidenmüller ZIP 2002, 2233; Forsthoff DB 2002, 2471; Großerichter DStR 2003, 159; von Halen WM 2003, 571; Heidenhain NZG 2002, 1141; Kallmeyer DB 2002, 2521; Kersting NZG 2003, 9; Kindler NJW 2003, 1073; Leible/Hoffmann RIW 2002, 925; Lutter BB 2003, 7; Paefgen DB 2003, 487; ders. WM 2003, 561; Roth IPRax 2003, 117; Schanze/Jüttner AG 2003, 30 sowie Zimmer BB 2003, 1.

19 EuGH Slg. 2002, I-9919 Rn. 59. Die Entscheidung des EuGH ging auf einen Vorlagebeschluss des BGH zurück (BGH IPRax 2000, $423=$ EuZW 2000, $412=$ NZG 2000, 926 m. Anm. Bous); dazu Süß/Wachter/Hoffmann S. 211 f., Hirte/Bücker/Hirte S. 5 f.; Mellert/Verfürth S. 47 ff.; .Altmeppen. DStR 2000, 1061; Bechtel NZG 2001, 21; Behrens EuZW 2000, 385; ders. IPRax 2000, 384; Forsthoff DB 2000, 1109; Jaeger NZG 2000, 918; Kindler RIW 2000, 649; Meilicke GmbHR 2000, 693; W.-H. Roth ZIP 2000, 1597; Zimmer BB 2000, 1361.

20 EuGH Slg. 2002, I-9919 Rn. 81

21 EuGH Slg. 2002, I-9919 Rn. 95.

22 EuGH Slg. 2002, I-9919 Rn. 70.

23 EuGH Rs. C - 167/01, IPRax 2004, 46 = NJW 2003, $3331=$ GmbHR 2003, 1260 m. Anm. W. Meilicke. Der Vollständigkeit halber sei noch auf die „SEVIC-Entscheidung“ des EuGH vom 13. Dezember 2005 hingewiesen, worin es allerdings um die Zulässigkeit grenzüberschreitender Verschmelzungen ging, insbesondere 
Sonderregelungen für „formal ausländische“ Gesellschaften („Fremdenrechte“) aufstellen $\operatorname{darf}^{24}$.

Im streitgegenständlichen Fall ging es um ein niederländisches Gesetz, durch das Gesellschaften ausländischen Rechts mit ausschließlichem Verwaltungssitz in den Niederlanden, besondere Pflichten (wie etwa die Führung des Zusatzes „formal ausländische Gesellschaft“" [formeel buitenlandse venootschap] im Registerblatt) und - damit im Zusammenhang stehend Haftungsrisiken auferlegt wurden ${ }^{25}$. Der EuGH hat die niederländische Regelung als nicht europarechtskonform angesehen: In dem Verlangen einen Zusatzvermerk im Hinblick auf die nur formal ausländische Gesellschaft offen zu legen, hat der EuGH einen Verstoß gegen die Elfte gesellschaftsrechtliche Richtlinie 89/666/EWG vom 21.12.1989 über die Publizität von Zweigniederlassungen ${ }^{26}$ gesehen ${ }^{27}$. Im Hinblick auf die Sanktionen, die für den Fall der Missachtung der Offenlegungspflichten vorgesehen waren, deutete der EuGH an, dass diese die erforderliche Vergleichbarkeit mit Sanktionen vermissen ließe, die für nach Art und Schwere gleiche Verstöße gegen nationales Recht vorgesehen $\operatorname{seien}^{28}$. Schließlich stelle das Mindestkapitalerfordernis und die hieran anknüpfende Geschäftsführerhaftung nach dem inländischen Recht eine unzulässige Beschränkung der Niederlassungsfreiheit ${ }^{29}$. Damit stellte der EuGH klar, dass allein die Anerkennung der Gesellschaft nicht geeignet sei, das Vorliegen eines Beschränkungstatbestandes zu verneinen ${ }^{30}$. Die Beschränkung der Niederlassungsfreiheit liege nicht in der Ablehnung der ausländischen Gesellschaft selbst sondern erfolge dadurch, dass das Gesellschaftsstatut durch zwingende Vorschriften des niederländischen Gesellschaftsrechts überlagert werde ${ }^{31}$.

die Vereinbarkeit von $§ 1$ UmwG mit den Art. 43, 48 EGV (diesen Hinweis gibt auch Hofmeister WM 2007, 868,Fn. 19); im Einzelnen siehe EuGH WM 2006, 92; Weiss/Wöhlert WM 2007, 580.

24 Vgl. zu der Entscheidung auch die Besprechungen bei Altmeppen NJW 2004, 97; Behrens IPRax 2004, 20; Bayer BB 2003, 2357; Eidenmüller/Rehm ZGR 2004, 159; Geyrhalter/Gänßler DStR 2003, 2167; Hirsch/Britain NZG 2003, 1100; Horn NJW 2004, 893; Kanzleiter DNotZ 2003, 885; Kersting/Schindler RdW 2003, 621; Kindler NZG 2003, 1086; Kleinert/Probst DB 2003, 2217; dies. MDR 2003, 1265; Leible/Hoffmann EuZW 2003, 677; Maul/Schmidt BB 2003, 2297; Müller-Bonanni GmbHR 2003, 1235; Schanze/Jüttner AG 2003, 661; Spindler/Berner RIW 2003, 949; Triebel/v. Hase BB 2003, 2409; Ulmer NJW 2004, 1201; Wachter GmbHR 2003, 1254; Weller DStR 2003, 1800; Ziemons ZIP 2003, 1913; Zimmer NJW 2003, 3585 sowie die Ausführungen bei Süß/Wachter/Hoffmann S. 212; Hirte/Bücker/Hirte S. 6 ff. und Mellert/Verführt S. 52 ff.

25 Näher dazu Leible/Hoffmann EuZW 2003, 677.

26 ABl. EG Nr. L 395, S. 36.

27 Rn. 26 der Entscheidung.

28 Rn. 59 ff. und 62 der Entscheidung.

29 Hofmeister WM 2007, 868, 870.

30 Rn. 99 ff. der Entscheidung; vgl. auch die Ausführungen bei Süß/Wachter/Hoffmann S. 212.

31 Süß/Wachter/Hoffmann S. 212; vgl. auch die ausführliche Darstellung in MünchKomm BGB Rn. 110 f. sowie Hirte/Bücker/Hirte S. 6 ff. und Mellert/Verführt S. $52 \mathrm{ff}$. 


\section{$\S 3$ Aufnahme des Wettbewerbs - Fokus der Untersuchung}

Um den Wettbewerb mit den anderen nationalen Gesellschaftsrechten aufnehmen zu können, hat eine Reform des GmbH-Rechts in Deutschland, den Niederlanden und Frankreich (dort im Hinblick auf bislang nicht realisierte oder umzukehrende Reformen) sich insbesondere auf die folgenden Punkte zu beziehen:

- Voraussetzungen der Gründung;

- Neuordnung des Kapitalrechts, insbesondere:

Erfordernis des Mindeststammkapitals und der damit verbundene

Schutz der Gläubiger,

Kapitalaufbringungs- und-erhaltungsgrundsätze;

- Fungibilität von GmbH-Anteilen;

- Insolvenzpraxis;

- Registerpublizität und Transparenz der Anteilseigner;

- Schutz gegen Missbrauchspraktiken unter beschränkter Haftung;

- Formerfordernisse bei Errichtung und Führung der Gesellschaft.

Die vorgenannten Bereiche sind regelmäßig eng miteinander verzahnt, weshalb etwaige Reformen der einzelnen Bereiche aufeinander abzustimmen $\operatorname{sind}^{32}$. Überlegungen zu einzelnen oder allen der vorbezeichneten Schwerpunktthemen finden sich in den meisten der bereits veröffentlichten Reformansätze in den Mitgliedsländern ${ }^{33}$.

So hat Frankreich 2003 mit der „Loi pour l'initiative économique“ (= „Gesetz betreffend die wirtschaftliche Initiative“) vor allem Erleichterungen bei der Gründung, Finanzierung und Übertragung von Unternehmen eingeführt (nachstehend im Dritten Abschnitt unter $\S 3$.). In Deutschland und den Niederlanden stehen ähnliche Reformen bevor, entsprechende Gesetzesentwürfe wurden bereits vorgelegt (nachstehend im Dritten Abschnitt unter $\S 1$ und $\S 2$ ). Schließlich werden die nationalen Bestrebungen flankiert durch eine immer progressivere europäische Gesetzgebung in dem Bereich des Gesellschaftsrechts (nachstehend im Dritten 
Abschnitt unter § 4). Eine Untersuchung zum Modernisierungsbedarf des GmbH-Rechts in Europa hat diese Entwicklungen zu berücksichtigen ${ }^{34}$.

\section{§ 4 Gang der Untersuchung}

Nach alledem ist die Grobgliederung der hier beabsichtigten rechtsvergleichenden Untersuchung vorgegeben: Im einem zweiten Abschnitt werden Entwicklung und Reform des GmbHRechts in Deutschland, den Niederlanden und Frankreich in einem groben Abriss nebeneinander gestellt. Im dritten Abschnitt werden die Schwerpunkte der Reformbestrebungen am Beispiel der einzelnen Länder untersucht und die Rechtsvorschriften de lege lata denen de lege ferenda gegenübergestellt. Die Reformbemühungen der nationalen Gesetzgeber werden sodann in den europäischen Kontext eingebunden. Schließlich werden die Rechtssysteme der einzelnen Länder in einem vierten Abschnitt zusammengeführt und sodann rechtsvergleichend untersucht. Die Arbeit schließt im fünften Abschnitt mit einem Gesamtergebnis, das in Thesen, das optimale Bildnis einer haftungsbeschränkten Gesellschaftsform zu zeichnen versucht und auf (europäische) Alternativen zu den nationalen Gesellschaftsrechten hinweist.

34 Vgl. auch die Studie von BDI/Hengeler Müller, dort insb. S. 8 ff. 


\section{Zweiter Abschnitt \\ Entwicklung und Reform des Rechts der Gesellschaften mit be- schränkter Haftung in Deutschland, den Niederlanden und Frankreich sowie in Europa}

\section{§ 1 Deutschland}

\section{Entwicklung}

Ohne gesetzliches Vorbild 1892 als nicht börsenfähige „kleine“ Kapitalgesellschaft konzipiert, die zwischen der börsenfähigen Aktiengesellschaft und den Personengesellschaften (,GbR, $O H G, K G$ “) steht, hat die Gesellschaft mit beschränkter Haftung (,GmbH“) sich schon bald als überaus erfolgreich erwiesen ${ }^{35}$. Die Anzahl der Gesellschaften mit beschränkter Haftung beträgt heute etwa eine Million ${ }^{36}$; damit existieren etwa fünfmal so viele Gesellschaften dieser Rechtsform wie es Aktiengesellschaften gibt ${ }^{37}$.

Trotz verschiedener legislatorischer Vorstöße ist das GmbH-Gesetz von 1892 - mit Ausnahme verschiedener sachlich wenig bedeutsamer gemeinschaftsrechtlich bedingter Änderungen, etwa aufgrund der ersten gesellschaftsrechtlichen Richtlinie („Publizitätsrichtlinie“) von 1968, - praktisch bis heute unverändert geblieben ${ }^{38}$. Eine in den 70iger Jahren angestrebte „große“ Reform des GmbH-Rechts scheiterte ${ }^{39}$. Die daraufhin 1980 lancierte „kleine“ Reform hat nur zu einigen wenigen Änderungen und Ergänzungen des GmbH-Gesetzes, etwa im Bereich des Eigenkapitalersatzrechts durch Einfügung der $\S 32 \mathrm{a}, \mathrm{b}$ GmbHG, geführt ${ }^{40}$.

BDI/Hengeler Müller S. 9; Altmeppen NJW 2004, 97.

36 Statistik von Kornblum GmbHR 2008, 19. Eine Überschreitung der Millionengrenze, die Kornblum bereits für das Jahr 2006 prognostiziert hatte (GmbHR 2005, 39) ist auch in 2007 nicht gelungen.

37 BDI/Hengeler Müller S. 9; Altmeppen NJW 2004, 97.

38 BDI/Hengeler Müller S. 9.

39 BDI/Hengeler Müller S. 9.

40 BDI/Hengeler Müller S. 9. 
Demgegenüber ist das GmbH-Recht richterrechtlich in den letzten Jahrzehnten - insbesondere in den Bereichen der Kapitalaufbringung und Kapitalerhaltung sowie in den Bereichen der Haftung der Geschäftsführer und Gesellschafter - wiederholt verändert worden ${ }^{41}$.

\section{Reform}

Bisherige Reformüberlegungen waren stets im Wesentlichen auf die Frage des notwendigen Mindeststammkapitals nach $\S 5$ GmbHG beschränkt. Hier existierte bereits ein Gesetzesentwurf der Bundesregierung ${ }^{42}$, dessen alleiniger Inhalt es war, das Mindeststammkapital von $25.000 €$ auf $10.000 €$ herabzusetzen. Ob mit einer derartigen Maßnahme die erhoffte Verbesserung der Wettbewerbsfähigkeit der deutschen $\mathrm{GmbH}$ hätte erreicht werden können, ist vielfach zu Recht bezweifelt worden ${ }^{43}$. So ist der Gesetzesentwurf auch gar nicht erst zur Beschlussfassung in den Bundestag gelangt.

In der Folge ${ }^{44}$ hat das Bundesjustizministerium mit dem Referentenentwurf eines „Gesetzes zur Modernisierung des GmbH-Rechts und zur Bekämpfung von Missbräuchen" (MoMiG) einen umfassenden Vorschlag zur Reform des deutschen GmbH-Rechts präsentiert ${ }^{45}$. Schwerpunkte des Referentenentwurfs waren zum einen die Beschleunigung von Unternehmensgründungen durch eine signifikante Absenkung des Mindeststammkapitals von $25.000 €$ auf $10.000 €$ sowie die Aufstellung geringerer Anforderungen an die Gründungsformalien $(A b$ kopplung des Eintragungsverfahrens von der verwaltungsrechtlichen Genehmigung; Zusammenspiel mit EHUG) und die Aufbringung des Mindeststammkapitals (Verzicht auf die Stellung besonderer Sicherheitsleistungen bei Gründung von Ein-Personen-GmbHs; Einteilung der Stammeinlagen; Übertragung von Geschäftsanteilen). Außerdem waren in dem Referentenentwurf erhebliche Erleichterungen bei der Kapitalerhaltung (Deregulierung des Eigenkapitalersatzrechts; Sicherung des Cash-Poolings) sowie Maßnahmen zur Erhöhung der Attraktivität der GmbH als internationaler Rechtsträger (Ermöglichung einer Sitzverlegung ins Ausland; gutgläubiger Erwerb von Geschäftsanteilen) angelegt. Schließlich sollte künftig Miss-

41 BDI/Hengeler Müller S. 9.

42 Entwurf eines Gesetzes zur Neuregelung des Mindestkapitals der GmbH (MindestkapG), im Volltext unter www.bmj.de abrufbar; vgl. dazu auch Melchior GmbHR 2005, R165.

43 Vgl. nur die Stellungnahmen von Altmeppen NJW 2004, 97; Mellert BB 2005, 1809, K. Schmidt DB 2005, 1095, Seibert BB 2005, 1061 sowie Flaßhoff/Krömker in Börsenzeitung v. 7.9.2005, S. 2.

44 Am 29. Mai 2006.

45 Entwurf eines Gesetzes zur Modernisierung des GmbH-Rechts und zur Bekämpfung von Missbräuchen, im Volltext unter www.bmj.de abrufbar. Hierzu wurden eine Vielzahl von Aufsätzen publiziert, die überwiegend deskriptiven Charakters sind. Vgl. etwa Leuering/Simon NJW-Spezial 2006, Heft 7, S. 315; Müller GmbHR 2006, 953; Gesmann-Nuissl WM 2006, 1756; Noack DB 2006, 1457; Römermann GmbHR 2006, 673; Seibert ZIP 2006, 1157 sowie ders. GmbHR 2006, R 241; Teichmann NJW 2006, 2444; Wachter GmbHR 2006, 793; Wulfetange BB 2006, 19. 
bräuchen der Rechtsform durch Gesellschafter begegnet werden, indem erleichterte Zustellungsmöglichkeiten sowie Regelungen für den Fall der Führungslosigkeit der Gesellschaft aufgenommen wurden. Der Referentenentwurf wurde den Bundesressorts, den Ländern und Verbänden zur Stellungnahme zugeleitet ${ }^{46}$.

Nach Auswertung der eingegangenen Stellungnahmen wurde vom Bundeskabinett am 23. Mai 2007 der Regierungsentwurf beschlossen ${ }^{47}$, der neben den nahezu unverändert übernommenen Ansätzen des Referentenentwurfs noch weiter gehende Reform- und Entbürokratisierungsansätze enthält: Vorgesehen ist ein Mustergesellschaftsvertrag für unkomplizierte GmbH-Standardgründungen. Wird er verwendet, soll nach dem Willen des Bundeskabinetts der Gesellschaftsvertrag nicht mehr notariell zu beurkunden sein. Der Regierungsentwurf sieht außerdem eine neue GmbH-Variante, die Unternehmergesellschaft (haftungsbeschränkt) vor, die ohne Mindeststammkapital auskommen soll. Um die Eintragung von GmbHs in das Handelsregister noch weiter zu beschleunigen, sieht der Regierungsentwurf eine noch konsequentere Abkopplung vom verwaltungsrechtlichen Verfahren vor, indem die Eintragung auch dann erfolgen können soll, wenn staatliche Genehmigungen für den geplanten Gewerbebetrieb (noch) nicht vorliegen. Ergänzt wurden Vorschläge zur Ausgestaltung des Rechts der Kapitalaufbringung und Kapitalerhaltung (Kodifizierung der verdeckten Sacheinlage, Einführung einer „Differenzhaftung“; Rückkehr zur „bilanziellen Betrachtungsweise“ bei Gesellschafterdarlehen und -sicherheiten). Schließlich wurden Regelungen aufgenommen, den Ausschluss ungeeigneter Personen für das Geschäftsführeramt noch leichter betreiben zu können $^{48}$.

Der Bundesrat hat unter dem 6. Juli 2007 eine Stellungnahme zu dem Gesetzesentwurf vorgelegt ${ }^{49}$. Die Stellungnahme befasst sich insbesondere mit der vereinfachten Gesellschaftsgründung, einem der Kernpunkte des Referenten- wie auch des Regierungsentwurfs. In diesem Zusammenhang spricht sich der Bundesrat insbesondere gegen die Verwendung der im Regierungsentwurf angelegten Mustergesellschaftsverträge aus: Eine merkliche Beschleunigung sei nicht erkennbar, die fehlende Flexibilität der Mustersatzung und die geringere Gründungsberatung führten hingegen $\mathrm{zu}$ erheblichen Nachteilen ${ }^{50}$. Auch für die Gründung der Unternehmergesellschaft (haftungsbeschränkt) schlagen die Länder die Fassung eines zu beurkun-

46 Aus der Pressemitteilung des Bundesministeriums der Justiz vom 29. Mai 2006, abrufbar unter www.bmj.de.

47 Regierungsentwurf eines Gesetzes zur Modernisierung des GmbH-Rechts und zur Bekämpfung von Missbräuchen, im Volltext unter http://www.bmj.bund.de/enid/5365569c5e5f928bbeb7584ee713b255 ,83aa5d305f7472636964092d09 323 63331/Gesellschaftsrecht/Die_GmbH-Reform_ts.html. Zur unfangreichen meist deskriptiven Literatur hierzu, siehe nur Breitenstein/Meyding BB 2007, 1457; 1458

48 Aus der Pressemitteilung des Bundesministeriums der Justiz vom 23. Mai 2007, abrufbar unter www.bmj.de.

49 Bundesrats-Drucksache Nr. 354/07 [Beschluss] vom 6. Juli 2007.

50 ebenda S. $1 \mathrm{f}$. 
denden Gründungsprotokolls vor ${ }^{51}$. Die Stellungnahme plädiert außerdem für eine Beibehaltung des derzeitigen Mindeststammkapitals sowie die Aufnahme gläubigerschützender Regelungen für die Unternehmergesellschaft (haftungsbeschränkt) ${ }^{52}$. Die Prüfung weitergehender Regelungen erbittet der Bundesrat für den Bereich der Kapitalerhaltung und -aufbringung ${ }^{53}$. Änderungswünsche formuliert die Stellungnahme schließlich auch im Hinblick auf die Person des Geschäftsführers ${ }^{54}$, den Ausschluss bestimmter Personen vom Geschäftsführeramt ${ }^{55}$ sowie die Regelung der gesetzlichen Vertretungsberechtigung ${ }^{56}$. Schließlich verlangt der Bundesrat Verschärfungen hinsichtlich der geplanten Zustellungserleichterungen und der Vorkehrungen gegen die Ausplünderung ${ }^{57}$.

$\mathrm{Zu}$ der Stellungnahme des Bundesrates hat sich die Bundesregierung im Juli 2007 geäußert $^{58}$. Danach sind von Seiten der Bundesregierung kaum Änderungen an dem Gesetzesentwurf vorgesehen. Allerdings sind einige Prüfungen angekündigt, die einige Neuerungen noch erwarten lassen. Zunächst befasst sich die Gegenäußerung mit dem Mustergesellschaftsvertrag, an dem voll und ganz festgehalten wird (,entspricht den Forderungen der Wirtschaft ${ }^{659}$ ). Sodann tritt die Bundesregierung der Forderung insbesondere der Notare entgegen, an dem Beurkundungserfordernis bei Gründung der GmbH bzw. Unternehmergesellschaft (haftungsbeschränkt) festzuhalten. Nach Auffassung der Bundesregierung bestehe bei der $\mathrm{GmbH}$ und Unternehmergesellschaft (haftungsbeschränkt), ,kein höherer Beratungsbedarf als bei der Gründung einer Personenhandelsgesellschaft oder einer private company limited by shares nach englischem Vorbild ${ }^{\star 60}$, wo ebenfalls keine Beurkundung vorgeschrieben sei. Vom Bundesrat verlangte Änderungen bei der vorgesehenen Reglung zur Unternehmergesellschaft (haftungsbeschränkt) werden abgelehnt ${ }^{61}$. Zugestimmt wird der Aufnahme ergänzender Regelungen für den Fall der Führungslosigkeit der $\mathrm{GmbH}^{62}$. Prüfen will die Bundesregierung, ob es eine Pflicht zur Bareinzahlung der Hälfte des (abgesenkten) Mindeststammkapitals geben soll $^{63}$. Angekündigt wird eine Anpassung der gesetzlichen Vertretungsregelung an die Usancen der Praxis (Einzelvertretung; Befreiung von $\$ 181$ BGB $)^{64}$. Aufgreifen will die Bundesregierung die Anregung des Bundesrates, § 41 GmbHG im Hinblick auf die Einführung einer

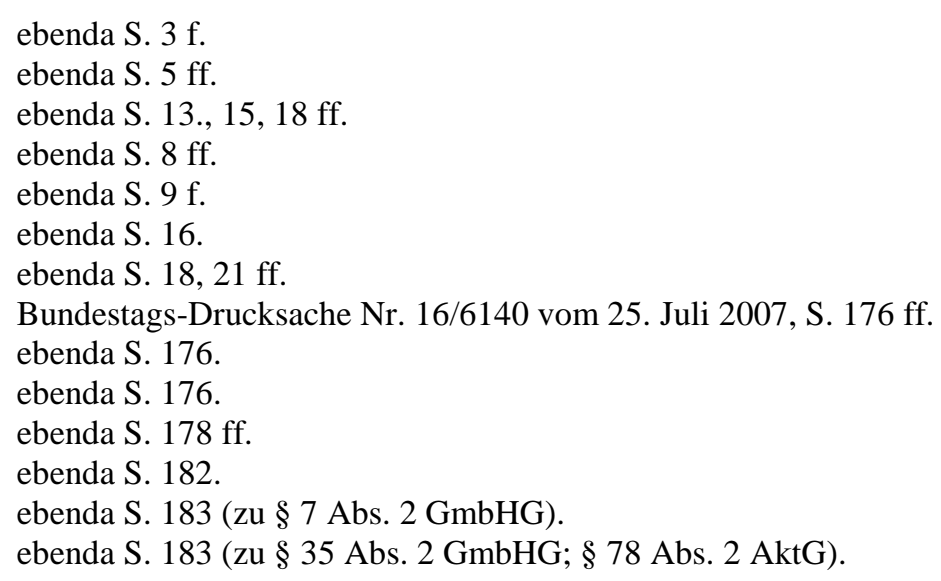


Intranparenzhaftung zu prüfen ${ }^{65}$. Geprüft wird ebenso, die Einführung des aktienrechtlichen Instituts des „genehmigten Kapitals“ bei $\S 55 \mathrm{GmbHG}^{66}$. Auch wird dem Anliegen des Bundesrates zugestimmt, dass weitere Sanktionen bei Missachtung der Eintragungspflicht bei Zweigniederlassungen ausländischer Gesellschaften geprüft werden sollten ${ }^{67}$. Schließlich wird nach dem übereinstimmenden Willen von Bundesrat und Bundesregierung, die Führungslosigkeit bei einem Gesellschafterantrag auf Insolvenzeröffnung glaubhaft zu machen sein ${ }^{68}$.

Der Deutsche Bundestag hat den Gesetzentwurf in der Sitzung vom 20. September 2007 in erster Lesung beraten und beschlossen, den Entwurf an den Rechtsausschuss (federführend) und an den Ausschuss für Wirtschaft und Technologie zu überweisen.

Der Rechtsausschuss des Deutschen Bundestages hat am 23. Januar 2008 eine öffentliche Sachverständigenanhörung zur GmbH-Reform durchgeführt ${ }^{69}$.

Weitere Schritte im Gesetzgebungsverfahren, vor der Verkündung und dem Inkrafttreten der GmbH-Reform, sind die abschließende Beratung in den Ausschüssen des Deutschen Bundestages, die zweite und dritte Lesung des Gesetzes im Deutschen Bundestag und der „Zweite Durchgang“ der Reform im Bundesrat. Wegen des späten Anhörungstermins ist ein Inkrafttreten zu Beginn des dritten Quartals 2008 wahrscheinlich ${ }^{70}$.

65 ebenda S. 186 (zu $\$ 41 \mathrm{GmbHG)}$.

66 ebenda S. 186 (zu $\$ 55 \mathrm{GmbHG})$.

67 ebenda S. 189 (zu $§ 13 d$ HGB).

68 ebenda $\mathrm{S} .191$ (zu $§ 15 \mathrm{InsO})$.

69 Weitere Informationen zu der Tagesordnung und zu eingeholten Stellungnahmen von Sachverständigen abrufbar unter http://www.bundestag.de/ausschuesse/a06/anhoerungen/28_MoMiG/index.html.

70 Aus der Pressemitteilung des Bundesministeriums der Justiz, abrufbar unter www.bmj.de. 


\section{§ 2 Niederlande}

\section{Entwicklung}

Die niederländische $\mathrm{GmbH}$ (besloten vennootschap - BV) wurde erst 1971 in Anpassung an die Erste gesellschaftsrechtliche Richtlinie der EG Nr. 68/151/EWG ${ }^{71}$ in die niederländische Rechtsordnung eingeführt. Bis zur Einführung der B.V. behalf sich der niederländische Mittelstand mit einer, aufgrund entsprechender Satzungsgestaltungen (,blokkeringsregeling“), „geschlossenen Variante“ der „Naamloze vennootschappen“ (im Folgenden „N.V.“), dem niederländischen Äquivalent der deutschen Aktiengesellschaft ${ }^{72}$. Faktisch entstanden so in den Niederlanden ohne gesetzliche Grundlage im Laufe der Zeit zwei Arten von Kapitalgesellschaften, nämlich die offene, unserer deutschen Aktiengesellschaft vergleichbare N.V. und die geschlossene, der deutschen $\mathrm{GmbH}$ nahe stehende N.V. ${ }^{73}$

Die 1971 eingeführte B.V. war denn auch nur eine formale Neuerung, trotz vielfacher Vorschläge $^{74}$, blieb sie in der Sache eine Sonderform der N.V.

Ende der 70er Jahre wurden die zwingenden Gesetzesbestimmungen zum Schutz des Gesellschaftskapitals und über die persönliche Haftung der Mitglieder und des Aufsichtsrats (insbesondere im Falle der Insolvenz) sowohl in der B.V. als auch in der N.V. verschärft ${ }^{75}$.

Weitere Gesetzesänderungen folgten in Anpassung europäischer Vorgaben und hatten beispielsweise die Verschmelzung, Spaltung und Bilanzierung von Kapitalgesellschaften zum Gegenstand $^{76}$.

Zum 1. Oktober 2004 wurden erstmals auch strukturelle Änderungen der B.V. und der N.V. vorgenommen. Mit dem Gesetz zur Änderung der Organisationsstruktur großer Kapitalgesellschaften (,structurvennootschappen“) wurden erstmals die Rechte der Gesellschafter in den

71 Vgl. hierzu im Einzelnen unten im Dritten Abschnitt $§ 4$ I. 2. a)

72 Vgl Hirte/Bücker/Rammeloo/de Kluiver S. 179 f.; Gotzen, in: Behrens, Die GmbH Rn. NL 1; Mehring, GmbH-Rechte S. 205, 206.

73 Gotzen, in: Behrens, Die GmbH Rn. NL 1.

74 Vgl. nur Bervoets/Lembeck, Die „GmbH Light“ - ein Trend in Europa, SWI 2004, 355 mit weiteren Nachweisen insb. auch zur niederländischen Literatur.

75 So genannte Gesetze zur Bekämpfung von Missbräuchen der N.V. und B.V. („Misbruikwetten“); vgl hierzu nur Hirte/Bücker/Rammeloo/de Kluiver S. 179 f.; Gotzen, in: Behrens, Die GmbH Rn. NL 1; Mehring, GmbH-Rechte S. 205, 206.

76 Vgl. hierzu im Einzelnen unten im Dritten Abschnitt unter § 4; dort insbesondere unter 2. o. 
Gesellschafterversammlungen gestärkt, zuvor waren die Gesellschafterrechte stets erweiteten Kompetenzen des Aufsichtsrats gewichen ${ }^{77}$.

\section{Reform}

Zuletzt ist im Rahmen eines Aktionsplans der niederländischen Regierung zur Förderung von Unternehmen vom Dezember 2003 eine Initiative zur Reform des Rechts der B.V. unter den Gesichtspunkten der Vereinfachung und Flexibilisierung des B.V.-Rechts auf den Weg gebracht worden ${ }^{78}$.

In diesem Zusammenhang wurde zum einen eine Expertengruppe unter dem Vorsitz des Professor Dr. H.J. de Kluiver eingerichtet, mit dem Auftrag, die von Literatur und Praxis identifizierten Problemkreise zu untersuchen und Vorschläge für eine Reform des B.V. Rechts in diesen Punkten vorzustellen. Das Expertengutachten wurde am 6. Mai 2004 vorgelegt (abzurufen unter www.justitie.nl/themas/wetgeving und www.flexbv.ez.nl). Das Gutachten enthält viele Empfehlungen, insbesondere zu den folgenden drei Hauptthemen: Organisationsverfassung und (Organ-)Befugnisse/Beschränkungen, Anteile und Zertifikate/Kapital und Gesellschaftsvermögen. Außerdem hat die Expertengruppe Vorschläge unterbreitet in Bezug auf die Regelung unvereinbarer Wertvorstellungen, das Überschreiten von Zielvorstellungen und die Formulierung des Gesellschaftsvertrages ${ }^{79}$.

Zum anderen wurde das Institut für Unternehmensrecht in Groningen vom Wirtschaftsministerium beauftragt, eine rechtsvergleichende Untersuchung durchzuführen, mit dem Ziel Alternativen zum existierenden Haftungsregime der B.V. aufzuzeigen (Der vollständige Abschlußbericht von M.L. Lennarts und J.N. Schutte-Veenstra von 31. März 2004 unter dem Titel „Versoepeling van het bv-kapitaalbeschermingsrecht“ ist abrufbar unter www.justitie.nl/themas/wetgeving sowie unter www.flexbv.ez.nl).

Die Empfehlungen der Expertengruppe sowie der Abschlußbericht der Universität Groningen dienten als Grundlage für einen Gesetzesentwurf (,Vorentwurf zur Vereinfachung und Flexibilisierung des B.V.-Rechts“, nachfolgend kurz „Vorentwurf“ genannt', der in drei Teilen, erstmals Anfang 2005 allen interessierten Kreisen zur Diskussion vorgestellt wurde ${ }^{80}$.

Süß/Wachter/Rademakers/de Vries S. 1132.

78 Vgl. zum Folgenden nur: Hirte/Bücker/Rammeloo/de Kluiver S. 178 ff., dort insbesondere S. 216 f.; siehe auch die Übersicht bei Timmermann NJB 2004, 1629 ff.

79 Hirte/Bücker/Rammeloolde Kluiver S. 216 f.; Timmermann NJB 2004, 1629 ff.

80 Hirte/Bücker/Rammeloo/de Kluiver S. 216 f.; Timmermann NJB 2004, 1629 ff. 
In dem ersten Teil werden Reformvorschläge zur internen körperschaftlichen Struktur der B.V. sowie hinsichtlich der Anteile und Bescheinigungen/Hinterlegungsscheine der B.V. zur Diskussion gestellt. Der zweite Teil, veröffentlicht am 20. Juli 2005, behandelt insbesondere die Beschränkung von Geschäftsanteilsübertragungen und enthält Regelungen zur Streitführung und -beilegung. Der dritte Teil wurde am 5. April 2006 zur Diskussion gestellt und enthält insbesondere Regelungen zum Gläubigerschutz und zu nennwertlosen Geschäftsanteilen.

Am 31. Mai 2007 wurde schließlich mit dem Entwurf eines Gesetzes zur Vereinfachung und Flexibilisierung des B.V.-Rechts (,Wet vereenvoudiging en flexibilisering bv-recht“) ein geschnürtes Gesetzespaket vorgelegt, das im Wesentlichen den Überlegungen des Vorentwurfs Rechnung trägt, dabei aber die in der öffentlich geführten Diskussion angesprochenen Aspekte berücksichtigt.

Bei der Vereinfachung und Flexibilisierung des B.V.-Rechts stand die Steigerung der Attraktivität der B.V. als Rechtsform für eine Vielzahl von Adressaten im Vordergrund. Insbesondere sollte die neue Rechtsform aber auch den in der Praxis identifizierten Notwendigkeiten an eine Gesellschaft mit beschränkter Haftung Rechnung tragen. Neben der erhöhten Attraktivität und Praktikabilität sollte die neue Rechtsform auch durch eine hohe Zuverlässigkeit gekennzeichnet sein. Das bedeutete insbesondere, dass in einem ausgeglichenen Entwurf der Gläubigerschutz Berücksichtigung finden musste. Desgleichen waren bei den Regelungen, die Beschlussfassung in Gesellschafterversammlungen betreffend die Interessen der Minderheitsaktionäre ausreichend zu berücksichtigen.

Im Einzelnen trägt der Entwurf den folgenden Gesichtspunkten Rechnung, die auch in den Empfehlungen der Expertengruppe wieder zu finden $\operatorname{sind}^{81}$ :

- weniger zwingendes und mehr regulierendes Recht;

- mehr Freiheit für die Gesellschafter das Unternehmen nach eigenen Gesichtspunkten auszugestalten unter Beachtung eines ausreichenden Schutzes der Interessen anderer Parteien;

- Regelungen, die unnötigerweise hinderlich oder ineffektiv sind, können erlöschen;

- Verminderung (administrativer) Lasten;

- $\quad$ ausgeglichener Gläubigerschutz;

- Beseitigung von Rechtsunsicherheiten;

81 Vgl. hierzu auch Hirte/Bücker/Rammeloo/de Kluiver S. 216 f. 
- Modernisierung und Angleichung des niederländischen Rechts unter Berücksichtigung der Vorgaben der nationalen und internationalen Praxis;

- Berücksichtigung der Entwicklungen in den umliegenden EU-Ländern;

- keine Schaffung einer neuen Rechtsform, aber Lösung der Schwierigkeiten und Hindernisse im gegenwärtigen B.V.-Recht.

Hauptaugenmerk der Reformüberlegungen liegt somit weniger auf der Gründungstechnik als vielmehr auf der Erarbeitung eines Alternativsystems für den Kapital-beziehungsweise Gläubigerschutz. Einzelne Erleichterungen wurden in diesem Bereich in der Vergangenheit bereits durch die Abschaffung der staatlichen Prüfung (durch das Justizministerium) der Gründungsverträge und etwaiger Satzungsänderungen erreicht. Die Unbedenklichkeitserklärung war für die Errichtung einer B.V. zwar weiterhin erforderlich (Art. 2:175 Abs. 2 i. V. m. Art. 2:179 NBG), die ministerielle Kontrolle nunmehr aber auf eine Untersuchung der Vergangenheit und des Vorhabens der Gesellschaftsgründer beschränkt. Die Kontrolle der gesetzlichen Regeln in der Satzung wurde in die Hände des Notars gelegt ${ }^{82}$.

Insbesondere wird vorgeschlagen, das Mindeststammkapital in Höhe von derzeit $18.000 €$ beziehungsweise das Erfordernis der Bank- und Wirtschaftsprüfererklärungen sowie die damit eng verbundenen Nachgründungsregelungen abzuschaffen. Demgegenüber wird erwogen, die Gläubiger stärker auf andere Weise zu schützen, beispielsweise durch Normierung strengerer Regeln zur Gewinnausschüttung. Insgesamt ist eine Akzentverschiebung von einer ,frontloaded control“ zu einer „backloaded control“ vorgesehen. Weitere Vorschläge des Gesetzesentwurfs beziehen sich auf den Dualismus zwischen der Geschäftsleitung und den Gesellschaftern ${ }^{83}$. 


\section{§ 3 Frankreich}

\section{Entwicklung}

Die französische $\mathrm{GmbH}$ (société à responsabilité limitée - S.à.r.l.) wurde 1925 nach dem Modell der deutschen $\mathrm{GmbH}$ geschaffen ${ }^{84}$. Mittlerweile bedienen sich etwa zwei Drittel der Unternehmensgründer dieser Gesellschaftsform ${ }^{85}$. Genau wie in den Niederlanden ist in Frankreich das Recht der S.à.r.l. nicht in einem eigenständigen Gesetz geregelt. Die einschlägigen Gesetzesbestimmungen sind vielmehr im Code de Commerce (C.com), dem französischen Handelsgesetzbuch, enthalten. Diese werden außerdem durch Regelungen in Rechtsverordnungen flankiert ${ }^{86}$.

\section{Reform}

Eine substantielle Reform des Code de Commerce wurde im Jahre 2000 durchgeführt. Im Zuge dieser Reform wurden insbesondere die Regelungen betreffend die Handelsgesellschaften, die mit dem Gesetz vom 24.7.1996 eingeführt worden waren, in den Code de Commerce integriert. ${ }^{87}$ Auch wurden die gesellschaftsrechtlichen Richtlinien der Europäischen Union von Frankreich sämtlich und ordnungsgemäß umgesetzt. Ein Wettbewerb der Rechtsformen, wie er in anderen Jurisdiktionen stattfand, blieb in Frankreich bislang aus, was daran liegen mag, dass die S.à.r.l. eine hohe Flexibilität für Gestaltungen im Tagesgeschäft bietet und gleichzeitig eine ähnlich günstige Haftungsverfassung besitzt, wie sie ansonsten nur der britischen Ltd. zu Eigen ist ${ }^{88}$.

84 Cozian/Viandier/Deboissy Rn. 997.

85 Cozian/Viandier/Deboissy Rn. 998.

86 Unter www.legifrance.gouv.fr können die wichtigsten Gesetzestexte online abgerufen werden. Vgl. hierzu auch Cozian/Viandier/Deboissy Rn. 997m.w.N. sowie Süß/Wachter/Karst S. 802.

87 Siehe Süß/Wachter/Karst S. 802; Seither spricht man auch vom nouveau Code de Commerce (dem neuen Code de Commerce); dieser nouveau Code de Commerce wurde später durch Verordnung vom 25. März 2004 und Gesetz vom 2. August 2005 zugunsten der kleinen und mittleren Gesellschaften nochmals geändert; siehe hierzu im Einzelnen Cozian/Viandier/Deboissy Rn. 997m.w.N. 
Am 1. August 2003 wurde die „loi pour l'initiative économique“689 (nachfolgend „LIE“ genannt) verabschiedet, welches bis auf wenige Bestimmungen am Tag nach seiner Veröffentlichung (am 5. 8. 2003) am 6. 8. 2003 in Kraft trat. Das Gesetz geht zurück auf den so genannten „Hurel-Bericht“ vom Juli 2002, in dem festgestellt wurde, dass Unternehmensneugründungen in der Rechtsform der S.à.r.l. in Frankreich eher rückläufig seien ${ }^{90}$.

Neben steuerrechtlichen und arbeitsrechtlichen Änderungen bringt dieses Gesetz vor allem Erleichterungen bei der Gründung, Finanzierung und Übertragung von Unternehmen. Zu diesem Zweck sieht es einige grundsätzliche Neuerungen im Bereich der S.à.r.1. vor ${ }^{91}$ :

89 Loi pour l'initiative économique, LIE (=Gesetz betreffend die wirtschaftliche Initiative), $\mathrm{n}^{\circ} 2003-721 \mathrm{v}$. 1.8.2003, Journal Officiel n ${ }^{\circ} 179$ v. 5.8.2003, S. 13449.

90 Vgl. Bervoets/Lembeck SWI 2004, 355 mit weiteren Nachweisen.

91 Vgl. zum Folgenden P. Becker GmbHR 2003, 706 und GmbHR 2003, 1120; Bervoets/Lembeck SWI 2004, 355; Kieninger, Aktuelle Entwicklungen des Wettbewerbs der Gesellschaftsrechte, Vortrag bei dem X. Travemünder Symposium zur ökonomischen Analyse des Rechts vom 29. März bis 1. April 2006 zu den „Entwicklungstendenzen des Zivilrechts in Europa“; Meyer/Ludwig, GmbHR 2005, 346; Mellert/Verfürth S. 120 ff. 


\section{§ 4 Europäisches Gesellschaftsrecht}

Auch das europäische Gesellschaftsrecht hat sich in den letzten Jahren rasch entwickelt. Es sind bis heute vierzehn gesellschaftsrechtliche Richtlinien von den Gemeinschaftsorganen vorgeschlagen und teilweise auch verabschiedet und von den Mitgliedstaaten bereits durchgeführt worden ${ }^{92}$. Das Europäische Einheitsrecht wurde 2001 um ein Statut der Europäischen Aktiengesellschaft, 2003 um ein Statut einer Europäischen Genossenschaft ergänzt ${ }^{93}$. Schließlich hat die Kommission in ihrem Aktionsplan von 2003 zahlreiche Vorschläge zur weiteren Modernisierung des Gesellschaftsrechts unterbreitet ${ }^{94}$. Einige dieser Vorschläge beziehen sich auf die Maßnahmen zur Kapitalaufbringung und Kapitalerhaltung, den Schutz der Gläubiger sowie auf die Erarbeitung des Statuts einer Europäischen Privatgesellschaft. Eine Reform der europäischen GmbH-Rechte hat vorgenannte Europäische Entwicklungen und Vorschläge für künftige Entwicklungen zu berücksichtigen ${ }^{95}$.

92 Vgl. hierzu unten Dritter Abschnitt $\S 42$.

93 Vgl. hierzu unten Dritter Abschnitt § 4 III 1.

94 Vgl. hierzu unten Dritter Abschnitt § 4 I. 3. b).

95 Vgl. hierzu den Überblick auf www.bdi-online.de sowie www.europa.eu.int. 


\section{Dritter Abschnitt \\ Schwerpunkte der Reformbestrebungen}

\section{$\S 1$ Deutschland}

\section{Gründung der Gesellschaft}

\section{Bestehende Rechtslage}

\section{a) Gründungsvorgang}

Die Gründung einer GmbH kann durch einen oder mehrere natürliche oder juristische Personen $(\S 1 \mathrm{GmbHG})$ vorgenommen werden und erfolgt durch Abschluss eines notariell beur-

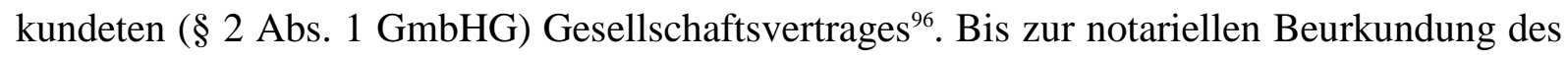
Gesellschaftsvertrages spricht man von der sog Vorgründungsgesellschaft ${ }^{97}$. Diese ist je nach Geschäftsbetrieb eine Gesellschaft bürgerlichen Rechts (GbR) oder eine Handelsgesellschaft (OHG). Mit der notariellen Beurkundung des Gesellschaftsvertrages entsteht die GmbH als so genannte Vor-GmbH ${ }^{98}$. Diese ist bereits uneingeschränkt rechts- und auch insolvenzfähig ist und folgt bereits dem Recht des GmbH-Gesetzes, mit Ausnahme der Regelungen die die Rechtsfähigkeit der Gesellschaft voraussetzen; dies sind insbesondere die Regelungen das

96 Grunewald 2. Teil F. Rn. 6; In der Praxis wird nicht selten vor Abschluss des notariell beurkundeten Gesellschaftsvertrages ein Vorvertrag geschlossen. Soll ein solcher Vorvertrag zur Gründung der Gesellschaft verpflichten, müssen die essentialia des Gesellschaftsvertrages (dies sind die in $\S 3 \mathrm{GmbHG}$ genannten Bestandteile, namentlich Stammkapital und zu übernehmende Stammeinlagen) bereits hinreichend bestimmbar festgelegt sein. Ausserdem bedarf auch der Vorvertrag in einem solchen Fall bereits der notariellen Form nach $\S 2$ GmbHG. Durch den Vorvertrag entsteht eine Vorgründungsgesellschaft in der Rechtsform einer GbR oder - falls ein kaufmännisches Gewerbe aufgenommen werden soll - in der Form einer OHG; vgl. im Einzelnen hierzu auch Raiser, S. 410.

97 Vgl. hierzu ausführlich Heckschen/Heidinger/Heidinger $§ 1$ Rn. 1 ff. Aus der umfassenden Rechtsprechung zur Vorgündungsgesellschaft und insbesondere der Haftungssituation in diesem Gründungstadium vgl. nur BGH DNotZ 1999, 224 = NJW 1998, 1645 (,Übergang der Rechte und Pflichten von der Vorgründungsgesellschaft auf die Vor-GmbH“); BGH GmbHR 2001, 293 (,persönliche Haftung der Gesellschafter"); BGH NJW 1999, 3483 = GmbHR 1999, 1134 (,Grundsätze zur GbRmbH“). 
Kapital der Gesellschaft betreffend ${ }^{99}$. Mit Eintragung im Handelsregister entsteht die GmbH schließlich als juristische Person $(\S 11 \text { Abs. } 1 \mathrm{GmbHG})^{100}$.

Bei der Gründung wird weiter unterschieden, ob die Gründung als Bar- oder Sachgründung erfolgt. Ist eine Bargründung vorgesehen, so erfordert diese neben der notariellen Beurkundung des Gesellschaftsvertrages nur die mindestens teilweise Einzahlung der Einlagen auf das festgelegte Stammkapital. Bei Anmeldung der Gesellschaft zum Handelsregister haben die Geschäftsführer zu versichern, dass ihnen die Einlagen endgültig zur freien Verfügung stehen. Nach Prüfung des Gründungsvorgangs durch das Registergericht, der Bezahlung der Gerichtsgebühren und der Kosten der Veröffentlichung, sowie einer Unbedenklichkeitsbescheinigung der Industrie- und Handelskammer im Hinblick auf die Firma kann die Eintragung der Gesellschaft im Register erfolgen ${ }^{101}$. Bei der Sachgründung bestehen zusätzliche Anforderungen, insbesondere die Verpflichtung zur Vorlage von Unterlagen über die Einbringung und den Wert der Sacheinlagen und eines Sachgründungsberichts ${ }^{102}$. Denkbar ist schließlich auch, die Einlageverpflichtung teilweise durch Geld und teilweise durch Sacheinlage zu erfüllen, so genannte Mischeinlage. In diesem Fall gelten im Hinblick auf den Teil der als Sacheinlage zu erbringen ist, die Regelungen für die Sachgründung entsprechend ${ }^{103}$.

Die Einzelheiten der Gründungsvorgänge sind komplex und aufgrund der erforderlichen Mitarbeit von Gründern, Rechtsanwälten, Notaren, Gerichten und Behörden sowie gegebenenfalls auch Wirtschaftprüfern bei der Bewertung einer Sacheinlage recht zeitintensiv ${ }^{104}$.

99 Vgl. hierzu ausführlich Heckschen/Heidinger/Heidinger $\S 1$ Rn. 6 ff. sowie Michalski/Michalski $\S 11 \mathrm{Rn}$. 58. Auch zur Vor-GmbH gibt es vielfältige Rechtsprechung vgl. nur BGHZ 51, 30, 32; BGHZ 117, 323, 326; BGHZ 134, 333, 336 (,,Rechtsnatur der Vor-GmbH“); BGHZ 120, 103 („,Namens- und firmenrechtsfähigkeit“); BGHZ 79, 239; 241; BGH ZIP 1998, 109 (,aktive und passive Parteifähigkeit“); BGHZ 80, 129, 130 („,Komplementärfähigkeit“, „Übergang der Rechte und Pflichten von der Vor-GmbH auf die GmbH“).

Umfassende Darstellung bei Büttner von Gieseking; Identität und Kontinuität bei der Gründung juristischer Personen 1967; überblicksartig Raiser, S. 436 ff.; Süß/Wachter/Terbrack S. 525. Zur Sonderthematik der Gründung einer GmbH unter Verwendung von Vorratsgesellschaften und Mantelgesellschaften vgl. umfassend Heckschen/Heidinger/Heidinger $\S 2$ Rn. 121 bis 240 sowie Heidinger ZGR 2005, 101. Der BGH hat sowohl die Verwendung von Vorratsgesellschaften als auch Mantelgesellschaften unter dem Begriff der wirtschaftlichen Neugründung zusammengefasst. Er fordert bei Verwendung von Vorratsgesellschaften und Mantelgesellschaften die Beachtung der Grundsätze der Kapitalaufbringung sowie der rechtlichen Neugründung. In beiden Fällen sind demnach die Anmeldung, Offenlegung und Versicherung entsprechend $\S 8 \mathrm{Ab}-$ satz 2 GmbHG durch alle Geschäftsführer erforderlich und es besteht weiterhin die Möglichkeit der Gründerhaftung in Form der Unterbilanzhaftung und Handelndenhaftung. Nach Auffassung von Heidinger ist die Rechtsprechungsansatz zu streng, seines Erachtens kommt auch eine eingeschränkte Anwendung des Gründungsrechts in Betracht, um die Ziele des Gläubigerschutzes und den Schutz vor Umgehung des Gründungsrechts zu erreichen.

Langenfeld S. 13 ff.; Süß/Wachter/Terbrack S. 538; MünchAnwHdbGmbHR/de Lousanoff § 3 Rn. 29 ff. Siehe auch Scholz/K.Schmidt $\S 9$ Rn. 4 sowie Rowedder/Schmidt- Leithoff $\S 3$ Rn. 25 ff. Langenfeld S. 13 ff.; Süß/Wachter/Terbrack S. 538; vgl. zur Abgrenzung von Bar- und Sacheinlage auch MünchAnwHdbGmbHR/de Lousanoff $§ 3 \mathrm{Rn} .29 \mathrm{ff}$.

104 BDI/Hengeler Müller S. 12; vgl. auch ausführlich zum Gründungsvorgang aus Sicht der Praxis Heckschen/Heidinger/Heidinger $\S \S 1$ bis 3 mit zahlreichen w. Nachw. 
Allerdings haben sich in der Praxis Erleichterungen herausgebildet ${ }^{105}$. So verlangen die Registergerichte etwa in der Regel keinen Nachweis der vollständigen oder teilweisen Einzahlung der Bareinlagen, sondern verlassen sich insoweit auf die in der Anmeldung abgegebenen Versicherungen der Geschäftsführer ${ }^{106}$. Auch wird die Stellungnahme der Industrie- und Handelskammer zur Firma der Gesellschaft nur noch ausnahmsweise eingeholt ${ }^{107}$. Schließlich wird die Eintragung der Gesellschaft in der Regel nicht von der Bezahlung der Gerichtsgebühren und der Kosten der Veröffentlichung abhängig gemacht ${ }^{108}$.

Weitere Erleichterungen des Gründungsvorgangs sieht das Gesetz über das elektronische Handels- und Unternehmensregister $(E H U G)$ vor, indem es beispielsweise kurze Fristen für die Eintragung von Bargründungen festschreibt ${ }^{109}$.

\section{b) Gründungsvoraussetzungen}

\section{aa) Gründer}

Gesellschafter einer GmbH können einer oder mehrere natürliche ${ }^{110}$ oder juristische Personen sein $^{111}$. Auch eine ausländische natürliche oder juristische Person kann an einer GmbH als Allein- oder Mitgesellschafter beteiligt sein ${ }^{112}$. Ist der Wohnsitz oder dauernde Aufenthaltsort der natürlichen Person außerhalb eines EU-Mitgliedstaats, so wird zum Teil von der Nichtigkeit der Gründung ausgegangen, wenn eine Aufenthaltserlaubnis nicht vorliegt oder sie mit einem Gewerbesperrvermerk versehen ist ${ }^{113}$.

Bei ausländischen juristischen Personen richtet sich deren Rechtsfähigkeit und Vertretungsverhältnisse nach dem Gesellschaftsstatut, d.h. dem betreffenden ausländischen Recht. Wenn

105 BDI/Hengeler Müller, S. 12.

106 BDI/Hengeler Müller, S. 12.

107 BDI/Hengeler Müller, S. 12.

108 BDI/Hengeler Müller, S. 12 sowie MünchAnwHdbGmbHR/de Lousanoff $§ 3$ Rn. 72 ff. m. w. N.

109 Vgl. hierzu unten in diesem Abschnitt $§ 1$, V. 1

110 Aufzählung der möglichen Gesellschafter bei Baumbach/Hueck/Hueck/Fastrich § 1 Rn. $24 \mathrm{ff}$.

111 Heckschen/Heidinger/Heckschen $\S 2$ Rn. 22; Baumbach/Hueck/Hueck/Fastrich § 1 Rn. 30; allg. dazu auch Scholz/Emmerich $\S 1$ Rn. 25 ff. Zu den Besonderheiten bei jur. Personen des öffentl. Rechts vgl. BGHZ 20, 124; Hachenburg/Ulmer $\$ 2$ Rn. 76; Rowedder/Schmidt-Leithoff § 2 Rn. 19 ff.

112 Hachenburg/Ulmer $\S 1$ Rn. 31 f., § 2 Rn. 70; Scholz/Emmerich $\$ 2$ Rn. 41 a; Lutter/Hommelhoff/Bayer $\S 2$ Rn. 3 f.; Roth/Altmeppen $\S 1$ Rn. 17, 22; Heckschen/Heidinger/Heckschen $\S 2$ Rn. 22; Langenfeld S. 10 f.; Süß/Wachter/Terbrack S. $527 \mathrm{f}$.

113 OLG Stuttgart GmbHR 1984, 156; KG GmbHR 1997, 413; vgl. hierzu wiederrum Süß/Wachter/Terbrack S. 527 sowie die übrigen in Fn. 103 Gennanten. 
dort - wie etwa im angloamerikanischen Rechtskreis - kein dem deutschen Handelsregister vergleichbares Register besteht, ist die Existenz der Gesellschaft und die Vertretungsberechtigung der für diese zeichnenden Personen auf andere Weise, zum Beispiel durch Beibringung eines Company's Secretary Certificate nachzuweisen ${ }^{114}$

\section{bb) Notarielle Beurkundung}

Der Gesellschaftsvertrag bedarf zwingend der notariellen Beurkundung (§ 2 Abs. 1 Satz 1 GmbHG), ansonsten ist er nichtig. Allerdings wird ein insoweit existierender Formmangel durch Eintragung der $\mathrm{GmbH}$ in das Handelsregister geheilt ${ }^{115}$.

Die Beurkundung hat grundsätzlich vor einem deutschen Notar in Deutschland zu erfolgen ( $\S$ $20 \mathrm{BNotO})^{116}$. Hierbei hat der Notar die Urkunde den Beteiligten vorzulesen. Die Urkunde ist von den Beteiligten zu genehmigen und sodann von ihnen und dem Notar zu unterzeichnen (vgl. $\S 8$ ff. BeurkG). In der Praxis wird dazu regelmäßig der Gesellschaftsvertrag als Anlage zu der der Gründungsurkunde mit beurkundet ${ }^{117}$.

Unklar ist, ob die Beurkundung des Gründungsprotokolls auch vor einem ausländischen Notar erfolgen kann. Entscheidend ist, ob die Beurkundung im Ausland der nach deutschem Recht vorgeschriebenen Geschäftsform entspricht ${ }^{118}$. Der $B G H^{119}$ hat hierzu festgestellt, dass eine Beurkundung vor einem ausländischen Notar dann wirksam ist, wenn dieser dem deutschen Notar nach Ausbildung, Stellung und Funktion gleichwertig ist und ein deutschen Grundsätzen entsprechendes Beurkundungsrecht anwendet (so etwa in Österreich, Belgien, Frankreich, Italien, Spanien, den Niederlanden und in Teilen der Schweiz) ${ }^{120}$. Diese Rechtsprechung des BGH ist bei den Instanzgerichten und in weiten Teilen der Literatur nicht unumstritten, weswegen bei statusrelevanten Vorgängen, wie etwa der Gründung einer $\mathrm{GmbH}$, regelmäßig eine Beurkundung in Deutschland vorgenommen werden sollte ${ }^{121}$.

114 Süß/Wachter/Terbrack S. 527 f.; Wachter DB 2004, 2795.

115 Vgl. BGHZ 21, 378, 381

116 Heckschen/Heidinger/Heckschen $\$ 2$ Rn.1; Michalski/Michalski § 2 Rn. 21; Scholz/Emmerich § 2 Rn. 17.

117 MünchenerHdbGesR S. 135 ff.; Süß/Wachter/Terbrack S. 534; zu der notariellen Form im Einzelnen vgl. Heckschen/Heidinger/Heidinger $\S 2$ Rn. 3 ff.

118 Süß/Wachter/Terbrack S. 534; Heckschen/Heidinger/Heidinger $\S 2$ Rn. 3 ff.; vgl. auch Baumbach/Hueck/Hueck/Fastrich § 2 Rn. 9; ausführlich hierzu auch Scholz/Westermann Einl. Rn. 94 f.; Hachenburg/Behrens Einl. Rn. 160 ff., 165; Staudinger/Großfeld IntGEsR 1998 Rn. 452 ff., 471 ff. alle m.w. N. BGHZ 80, 76 (,für die Beurkundung einer Satzungsänderung“).

120 Vgl. zu den Niederlanden OLG Düsseldorf GmbHR 1990, 169; zu Baseler Notaren LG Nürnberg-Fürth WM 1992, 950; OLG München GmbH-StB 1998, 12; kritisch zum Züricher Notariat Bredthauer BB 1986, 1864.

121 Bedenken im Hinblick darauf, ob die mit dem Beurkundungserfordernis verfolgte materielle Richtigkeitsgewähr bei einer Auslandsbeurkundung von Gesellschaftsverträgen und Satzungsänderungen gewahrt werden könne, äußert etwa Goette, MittRhNotK 1997, 1; ferner Großkomm-AktG/Röhricht § 23 Rn. 54. Vgl. 


\section{cc) (Teilweise) Erfüllung der Einlagepflichten}

Bei der Bargründung einer mehrgliedrigen $\mathrm{GmbH}$, einer $\mathrm{GmbH}$ also an der mehrere Gesellschafter beteiligt sind, hat jeder Gesellschafter auf seine Stammeinlage mindestens ein Viertel einzuzahlen; insgesamt ist der Gesellschaft dabei mindestens die Hälfte des gesetzlichen Mindeststammkapitals nach $\S 5$ Abs. $1 \mathrm{GmbHG}$, derzeit also 12.500,00 Euro zuzuführen (vgl. $\S 7$ Abs. 2 GmbHG) $)^{122}$.

Bei einer Ein-Personen-GmbH hat der Alleingesellschafter ebenfalls nur ein Viertel der Stammeinlage, jedenfalls aber die Hälfte des gesetzlichen Mindeststammkapitals einzuzahlen. Für den noch nicht eingezahlten Teil der Stammeinlage hat er allerdings Sicherheiten in Form des $§ 232$ BGB oder eines gleichwertigen Sicherungsmittels zu bestellen, $§ 7$ Abs. 2 S. 3 $\mathrm{GmbHG}^{123}$.

Sacheinlagen sind hingegen, unabhängig davon, ob die Gesellschaft mehrgliedrig oder als Ein-Personen-GmbH gegründet wird, stets in voller Höhe vor Anmeldung der Gesellschaft zum Handelsregister zu erbringen, und zwar so, dass sie zur endgültig freien Verfügung der Geschäftsführer stehen ( $\$ 7$ Abs. 3 GmbHG) $)^{124}$.

auch Kröll ZGR 2000, 111, 129 ff., der sich zu einer möglichen Änderung der Rechtsprechung zur Beurkundung von Satzungsänderungen sowie S. 150 f. zur Beurkundung von Gesellschaftsgründungen, Umwandlun und Geschäftsanteilsübertragungen auslässt. Zusammenfassende Darstellung bei Süß/Wachter/Terbrack S. 534; viele Hinweise auf die hierzu ergangene Literatur auch bei Heckschen/Heidinger/Heidinger $\S 2$ Rn. 2 Fn. 2. Vgl. auch Scholz/Priester $\S 53$ Rn. 74 m. w. N.

In Betracht kommt neben der Barzahlung und ist in der Praxis auch üblich, die (vorbehaltlose) Überweisung und Gutschrift des Betrages auf ein Konto der Vorgesellschaft. Vgl. zur Kontofähigkeit der Vorgesellschaft BGHZ 45, 338, 347; BGH GmbHR 1962, 233. Zur Zahlung auf das eigene Konto eines Gesellschafters vgl. BGH ZIP 2001, 513. Allgemein zu der Einlageverplfichtung, Raiser S. 417 f.; Süß/Wachter/Terbrack S. 536.

123 In teleologischer Auslegung des $§ 7$ GmbHG wird man auch andere wirtschaftliche gleichwertige Absicherungen zulassen müssen. Zu denken ist etwa an die Hinterlegung nicht börsengängiger Wertpapiere oder die Sicherungsübereignung beweglicher Sachen. Einzelheiten bei John Die Gründung der Einmann-GmbH; Kleberger S. 41 ff.; Zusammenfassende Überblicke geben Raiser, S. 432 ff. und Süß/Wachter/Terbrack S. 536.

124 John BB 1985, 626; Raiser, S. 432; Süß/Wachter/Terbrack S. 537. 


\section{dd) Anmeldung zum Handelsregister}

Die Anmeldung zum Handelregister erfolgt bei der Erstanmeldung durch sämtliche Geschäftsführer ${ }^{125}$ in notariell beglaubigter Form, § 78 GmbHG, § 12 Abs. 1 HGB. Außerdem sind die in $\S 8$ Abs. $1 \mathrm{GmbH}$ bezeichnete Schriftstücke als Anlage der Handelsregisteranmeldung beizufügen ${ }^{126}$.

\section{ee) Prüfung des Gründungsvorgangs durch das Registergericht}

Zuständig für die Eintragung der $\mathrm{GmbH}$ in das Handelsregister ist das für den angemeldeten Sitz der Gesellschaft zuständige Amtsgericht, vorausgesetzt dort wird ein Handelsregister geführt. Dieses hat aufgrund der vorgelegten Unterlagen zu prüfen, ob die Gesellschaft ordnungsgemäß errichtet und angemeldet worden ist ( $\$ 9 \mathrm{c}$ Abs. $1 \mathrm{GmbHG})^{127}$. Regelmäßig schaltet es im Rahmen der Gründungsprüfung die Industrie- und Handelskammer und gegebenenfalls weitere Stellen ein ${ }^{128}$.

Bedarf die von der Gesellschaft beabsichtigte Tätigkeit einer staatlichen Genehmigung, so ist diese der Handelsregisteranmeldung beizufügen ( 88 Abs. 1 Nr. 6 GmbHG). Genehmigungspflichtig im vorgenannten Sinne sind regelmäßig handwerkliche Tätigkeiten, Maklertätigkeiten nach $\S 34$ GewO, die Erbringung von Finanzdienstleistungen sowie der Betrieb eines Gaststättengewerbes ${ }^{129}$.

125 Einschließlich der Stellvertreter: Baumbach/Hueck/Hueck/Fastrich § 7 Rn. 2 unter Hinweis auf RG LZ 1914, 398; BayObLG DB 1987, 216.

126 Süß/Wachter/Terbrack S. 549; vgl. zu den Anlagen im Einzelnen Baumbach/Hueck/Hueck/Fastrich § 8 Rn. 3 ff.; Scholz/Winter $\S 8$ Rn. 3 ff.; Roth/Altmeppen $\S 8$ Rn. 2 ff.; Michalski/Heyder Rn. 2 ff.; MünchenerHdbGesR/Heinrich $\S 8$ Rn. 18.

127 Zum Prüfungsverfahren allgemein vgl. MünchAnwHdbGmbHR/de Lousanoff $\S 3$ Rn. 86 ff.; Süß/Wachter/Terbrack S. 547.

128 Dem Registerrichter ist es hingegen nicht gestattet, die Zweckmäßigkeit einzelner Vorschriften des Vertrages oder die Erfolgsaussichten der neu gegründeten Gesellschaft zu prüfen. Auch die Frage, ob das vereinbarte Stammkapital für den beabsichtigten Geschäftsumfang ausreicht, ist eigentlich seiner Prüfungskompetenz entzogen. Doch wird in der Praxis eine Eintragung abgelehnt werden, wenn die Unterkapitalisierung der Gesellschaft so stark und eindeutig ist, dass von einem Rechtsmissbrauch gesprochen werden muss. $\mathrm{Ha}$ chenburg/Ulmer $\S 9$ c Rn. 9, 31; Koch ZHR 146 (1982), 118, 136. Baumbach/Hueck/Hueck/Fastrich $§ 9$ c Rn. 4; Rowedder/Rittner/Schmidt-Leithoff $\$ 9$ c $\quad$ Rn. 19. Zusammenfassend Raiser S. 420 f.; Süß/Wachter/Terbrack S. 547.

129 Ein (- wie es dort heißt - keinen Anspruch auf Vollständigkeit erhebender) Katalog genehmigungspflichtiger Tätigkeiten findet sich bei Süß/Wachter/Terbrack S. 525. 


\section{ff) Stellungnahme der Industrie- und Handelskammer}

Wenn das Registergericht Zweifel an der Rechtmäßigkeit einer Eintragung hat, so hat es sich durch Einholung einer Stellungnahme der Industrie- und Handelskammer und gegebenenfalls weiterer Stellen, etwa der Handelskammer bei handwerklichen Unternehmen rückzuversichern ( $\$ 23 \mathrm{HRV}$ ). Da diese Anhörung bei GmbH-Gründungen praktisch die Regel ist, wird in der Praxis regelmäßig schon im Vorfeld der notariellen Beurkundung des Gesellschaftsvertrages die Zulässigkeit der Firma und des Gegenstandes der Gesellschaft mit der zuständigen Industrie- und Handelskammer abgeklärt und die entsprechende Stellungnahme dem Registergericht gleich mit eingereicht ${ }^{130}$.

\section{gg) Rechtslage vor Eintragung im Handelsregister - Vorgesellschaft, Vor-GmbH}

Wie bereits oben unter a) in diesem Abschnitt dargestellt, werden bei Gründung drei Phasen unterschieden, die der Vorgründungsgesellschaft, der Vorgesellschaft oder Vor-GmbH und der GmbH als solcher. In der Zeit zwischen dem notariellen Abschluss des Gesellschaftsvertrages und der Entstehung der GmbH als juristischer Person durch Eintragung im Handelsregister besteht eine Vorgesellschaft oder auch Vor-GmbH ${ }^{131}$. Über die Rechtsnatur der Vorgesellschaft besteht heute weitgehende Einigkeit: Sie ist Vorstufe und notwendige Durchgangsstation auf dem Wege zur GmbH, wandelt sich mit der Erlangung der Rechtsfähigkeit ipso iure und mit allen ihren Aktiva und Passiva in die GmbH um, ist mit dieser identisch ${ }^{132}$.

\section{c) Kosten der Gründung}

Da die Einschaltung eines rechtlichen Beraters, gerade bei Standardgründungen nicht unbedingt erforderlich ist, sind die einzig zwingenden Kosten bei Errichtung einer GmbH die No-

130 Süß/Wachter/Terbrack S. 526.

131 Büttner von Gieseking; Identität und Kontinuität bei der Gründung juristischer Personen 1967. Aus der neueren Literatur vgl. nur die ausführliche Darstellung bei Heckschen/Heidinger/Heidinger $\S 1 \mathrm{Rn} .1 \mathrm{ff} . \mathrm{m}$. zahlreichen w. N.

132 BGHZ 80, 129, 138 f.; Hachenburg/Ulmer $\S 11$ Rn. 73; Scholz/K.Schmidt $\S 11$ Rn. 25; Baumbach/Hueck/Hueck $\$ 11$ Rn. 6; Lutter/Hommelhoff $\S 11$ Rn. 3; Einzelheiten bei Büttner von Gieseking; Identität und Kontinuität bei der Gründung juristischer Personen 1967. Vorstehender Grundsatz gilt allerdings nur, wenn und solange die Gesellschafter an der Eintragungsabsicht der Gesellschaft festhalten. Haben sie hingegen von vorneherein keine Eintragung beabsichtigt oder aber streben sie nicht mehr an, liegt nach den allgemeinen Grundsätzen des Gesellschaftsrechts eine OHG oder Gesellschaft bürgerlichen Rechts vor (so genannte unechte Vorgesellschaft). Bei der unechten Einpersonengründung treffen die Rechtfolgen einer bereits entfalteten Geschäftstätigkeit im Zweifel den Gründer persönlich; anders OLG Bremen ZIP 2000, 2201, das auch in einem solchen Fall für eine Innenhaftung plädieren; Siehe dazu auch Raiser, S. 439. 
targebühren, die im Zusammenhang mit der Beurkundung des Gesellschaftsvertrages anfallen. Bei einer Gesellschaft, die mit dem gesetzlichen Mindestkapital in Höhe von $25.000 €$ ausgestattet wird, sind dies durchschnittlich ca. $300 €$. Die genaue Höhe der Kosten hängt von einer Vielzahl weiterer Faktoren ab, wie etwa, ob es sich um eine Einpersonen- oder eine Mehrpersonen-GmbH handelt und ob der beurkundende Notar auch den (nicht beurkundungspflichtigen) Beschluss über die Geschäftsführerbestellung und die Gesellschafterliste erstellt. Die Gebühren können sich je nachdem auf $126 €$ bis $399 €$ jeweils zuzüglich Auslagen und Umsatzsteuer belaufen ${ }^{133}$.

\section{Zu den Reformbestrebungen}

\section{a) Reformansätze des MoMiG}

\section{aa) Gründungsvorgang}

Wegen der - insbesondere im Vergleich zu den europäischen Brüdern und Schwestern der deutschen $\mathrm{GmbH}$-schwerfälligen, langwierigen und kostspieligen Gründung einer deutschen $\mathrm{GmbH}$, war es ein erklärtes Ziel der GmbH-Reform, den Gründungsvorgang zu erleichtern und zu beschleunigen. In diesem Zusammenhang ist auch das Gesetz über elektronische Handelsregister und Genossenschaftsregister sowie das Unternehmensregister („EHUG“) zu sehen, dass der deutsche Gesetzgeber in Anpassung europäischer Vorgaben bereits Anfang 2007 verabschiedet hat ${ }^{134}$. Mit dem Regierungsentwurf zum MoMiG wird dieses gesetzgeberische Ziel fortgeführt, indem weitere Erleichterungen und Beschleunigungen vorgesehen sind, die in dieser Untersuchung an den entsprechenden thematischen Stellen behandelt werden sollen $^{135}$.

133 Wachter GmbHR 2005, 717, 723, vgl. dort auch die Fn. 62; Süß/Wachter/Terbrack S. 530. Hierzu auch Rowedder/Schmidt-Leithoff $\$ 2$ Rn. 78 f.

134 Siehe hierzu unten in diesem Abschnitt $§ 1$, V. 1

135 BDI/Hengeler Müller S. 11; Breitenstein/Meyding BB 2007, 1457. 


\section{bb) Gründungsvoraussetzungen}

\section{aaa) Notarielle Beurkundung}

Für unkomplizierte Standardgründungen (die Regierungsbegründung nennt insoweit u. a. die Bargründung oder Gesellschaften mit höchstens drei Gesellschafter) stellt der Gesetzgeber als Anlage zum GmbHG eine Gründungsdokumentation (so genanntes „Gründungs-Set“), bestehend aus Mustergesellschaftsvertrag, Handelsregisteranmeldung, Niederschrift der Gesellschafterversammlung und Gesellschafterliste zur Verfügung. Wird dieses Muster ohne Veränderungen verwendet, so ist keine notarielle Beurkundung des Gesellschaftsvertrages erforderlich und es soll nur eine öffentliche Beglaubigung der Unterschriften erforderlich sein ${ }^{136}$. Der Preis für die Privilegierung ist die Aufgabe jeglicher Individualität bei der Gestaltung der Satzung; sobald die Gründer eine der in den Mustern vorgeschlagenen Varianten ändern oder ergänzen wollen oder aber einen andren Unternehmensgegenstand wählen wollen, lebt die Beurkundungsbedürftigkeit der Satzung wieder auf ${ }^{137}$.

\section{bbb) Verzicht auf Sicherheitsleitung bei Ein-Personen-GmbH}

Der Entwurf sieht einen Verzicht auf die vom Gründer einer Ein-Personen-GmbH bislang abverlangte Sicherheitsleistung für den noch nicht eingezahlten Teil der Stammeinlage vor ( 7 Abs. 2 S. 3, § 19 Abs. 4 GmbHG), so dass künftig auch der Einzelne die GmbH-Gründung nur durch das Einzahlen der Hälfte des gesetzlichen Mindeststammkapitals auf das Gesellschaftskonto bewirken kann $^{138}$.

\section{ccc) Verzicht auf Vorlage staatlicher Genehmigungen}

Die Eintragungsverfahren sollen beschleunigt werden, indem sie vom Verfahren um die verwaltungsrechtliche Genehmigung vollständig abgekoppelt werden. Während der Referentenentwurf ${ }^{139}$ noch vorsah, dass verwaltungsrechtliche Genehmigungen zwar nicht zur Eintra-

136 Begründung des Regierungsentwurfs, Allgemeiner Teil S. 57.

137 Begründung des Regierungsentwurfs, Allgemeiner Teil S. 57; Gerade den letzten Umstand, nämlich die eingeschränkte Wahl eines Unternehmensgegenstandes, lassen Breitenstein/Meyding BB 2007, 1457, 1458 an dem Erfolg des Gründungs-Sets zweifeln. Die Mustersatzung sehe als wählbare Geschäftszwecke drei Alternativen (Handel mit Waren, die Produktion von Waren, Dienstleistungen) vor, die nach bisheriger Rechtslage wegen mangelnder Individualisierung nicht als ausreichend betrachtet würden.

139 Referentenentwurf vom 29.5.2006. 
gung vorliegen - hier sollte stattdessen genügen, dass die Gesellschafter versichern, dass sie die Genehmigung bei der zuständigen Stelle beantragt haben - aber innerhalb von drei Monaten oder innerhalb einer vom Gericht gesetzten anderen Frist in Handelsregister nachgewiesen werden musste, sieht der Regierungsentwurf ${ }^{140}$ nunmehr einen völligen Verzicht auf die Einreichung der Genehmigungsurkunde vor ${ }^{141}$

\section{ddd) Prüfung des Gründungsvorgangs durch das Registergericht}

Der Regierungsentwurf stellt ausdrücklich klar, dass das Gericht bei der Gründungsprüfung nur dann die Vorlage von Einzahlungsbelegen oder sonstigen Nachweise verlangen kann, wenn es erhebliche Zweifel hat, ob das Kapital ordnungsgemäß aufgebracht wurde. Bei Sacheinlagen wird die Werthaltigkeitskontrolle durch das Registergericht auf die Frage beschränkt, ob eine „,nicht unwesentliche“ Überbewertung vorliegt. Dies entspricht der Rechtslage bei der Aktiengesellschaft. Nur bei entsprechenden Hinweisen kann damit künftig nach Vorstellung des Gesetzgebers im Rahmen der Gründungsprüfung eine externe Begutachtung veranlasst werden $^{142}$.

$\mathrm{Ob}$ die Vorstellungen des Gesetzgebers auch in der Praxis zu einer Erleichterung führen, darf indes bezweifelt werden, denn aus Gründen der Vorsicht sollte auch in Zukunft Belege über die Aufbringung des Kapitals bereitgehalten werden, für den Fall, dass das Gericht - aus welchen Gründen auch immer - Zweifel an der Aufbringung anmeldet ${ }^{143}$

\section{eee) Kostenvorschuss}

Die Einforderung des Kostenvorschusses führte bislang stets zu einer Verzögerung der Eintragung. Daher ist vorgeschlagen worden, die Kostenordnung dahingehend zu ändern, dass bei der Neugründung einer $\mathrm{GmbH}$ kein Kostenvorschuss angefordert werden soll ${ }^{144}$. Der Gesetzgeber hat das Problem bereits mit dem Gesetz über die elektronischen Handelsregister $(\text { EHUG })^{145}$ durch eine Änderung des $\S 8$ Abs. 2 KostO gelöst. $\S 8$ Abs. 2 KostO regelt nunmehr, dass Satz 1, wonach das Gericht die Durchführung eines Antragsverfahrens davon abhängig machen soll, dass der Vorschuss gezahlt oder sichergestellt wird, nicht gelten soll,

140 Begründung des Regierungsentwurfs, Allgemeiner Teil S. 57.

141 Gesmann-Nuissl WM 2006, 1756, 1757 Breitenstein/Meyding BB 2007, 1457; 1458.

142 Begründung des Regierungsentwurfs, Besonderer Teil S. 79.

143 Breitenstein/Meyding BB 2007, 1457; 1458.

144 Wachter, Die GmbH-Reform in der Diskussion, S. 55, 88.

145 Siehe hierzu unten in diesem Abschnitt $§ 1$, V. 1 
wenn der (deutsche) Notar erklärt hat, dass er für die Kostenschuld des Antragstellers die persönliche Haftung übernimmt ${ }^{146}$.

\section{cc) Kosten der Gründung}

Mit Schaffung der Möglichkeit der Gründung einer GmbH unter Verwendung einer Mustersatzung $^{147}$ ist das zwingende Erfordernis der Beurkundung des Gesellschaftsvertrages durch einen in Deutschland ansässigen Notar weggefallen. Dementsprechend fallen bestenfalls keine Kosten für die Gründung einer Gesellschaft an. Entscheiden sich die Gründer dennoch zur Heranziehung eines rechtlichen Beraters, sei es eines Notars oder aber eines Rechtsanwalts, so sind die Kosten auf der Grundlage der gesetzlichen Gebühren oder einer zwischen den Beteiligten geschlossenen Mandatsvereinbarung zu ermitteln.

\section{b) Reformüberlegungen in Praxis und Literatur}

Die Vorschläge in Praxis und Literatur zielen in erster Linie auf eine Beschleunigung und Vereinfachung des Gründungsverfahrens, da aufgrund des Festhaltens des deutschen Gesetzgebers an der Mindestkapitalisierungspflicht nur in beschränktem Maße Möglichkeiten bestehen, die Gründungsformalitäten zu vereinfachen ${ }^{148}$.

\section{aa) Gründungsvorgang}

\section{aaa) Konzentration der Registergerichte}

Zum Teil wird vorgeschlagen die dezentrale Registerführung in Deutschland weiter aufzulockern und die Kompetenz zur Registerführung auf ausgewählte Amtsgerichte zu konzentrieren. Zugleich sei eine fachliche Spezialisierung bei den Registerrichtern und Rechtspflegern anzustreben. In diesem Zusammenhang gelte es vor allem, die personelle und sachliche Ausstattung deutlich zu verbessern ${ }^{149}$.

146 Gesetz über elektronische Handelsregister und Genossenschaftsregister sowie das Unternehmensregister v. 10.11.2006 (EHUG), BGB1. I 2006, S. 2553 v. 15.11.2006.

147 Vgl. hierzu im Einzelnen in diesem Abschnitt unten II. 2. a) aa).

148 BDI/Hengeler Müller S. 13.

149 Schon 2003 hatten Keidel/Krafka/Willer, aaO. die Registerführung in Deutschland kritisiert; zuletzt hat Wachter, Die GmbH-Reform in der Diskussion, S. 55, 71 den Vorschlag einer zentralisierten Registerführung nochmals unterbreitet. 


\section{bbb) Beschleunigungs- und Vorrangsgebot}

Vorgeschlagen wird außerdem, im FGG oder GmbHG einen allgemeinen Grundsatz aufzunehmen, wonach über die Gründung neuer GmbHs stets vorrangig und unverzüglich zu entscheiden sei. Die Gründung neuer GmbHs gelte damit kraft Gesetzes stets als eilbedürftig ${ }^{150}$.

\section{ccc) Einführung eines 24 Stunden Services}

Schließlich haben sich in der Literatur gewichtige Stimmen für die Einführung eines „express service" in Deutschland nach dem Vorbild des englischen Companies House ausgesprochen. Der Gedanke ist, dass Unternehmensgründer künftig gegen Zahlung eines gewissen Gebührenzuschlags verlangen können, dass über ihren Antrag auf Eintragung einer $\mathrm{GmbH}$ noch am selben Tag entschieden wird ${ }^{151}$.

\section{bb) Gründungsvoraussetzungen}

\section{aaa) Gründer}

Unter Bezugnahme auf die in der Praxis immer wieder auftretenden Beanstandungen der Beteiligung ausländischer Personen an der Gründung einer deutschen GmbH trotz Fehlens entsprechender einschränkender Bestimmungen im GmbH-Gesetz ${ }^{152}$, plädiert Wachter ${ }^{153}$ für die ausdrückliche Zulassung ausländischer Personen als Geschäftsführer oder Gesellschafter einer

150 Dieser Vorschlag von Wachter, Die GmbH-Reform in der Diskussion, S. 55, 85 ist nicht neu. Er entwickelt letztlich lediglich einen Gedanken fort, dem der Gesetzgeber bereits 2004 im Rahmen des Handelsregistergebühren-Neuordnungsgesetzes vom 3. Juli 2004 - BT-Drucks. 15/2251 v. 17. Dezember 2003 - durch Einführung einer Bescheidungsfrist Rechnung getragen hatt. Neu ist der Vorschlag hingegen insoweit, als dass er eine Aufnahme der Beschleunigungsanordnung in ein formelles Bundesgesetz anregt. Der Gedanke dahinter ist, die Verpflichtung des Handelsregisters transparent zu machen, insbesondere auch für ausländische Unternehmensgründer und deren Berater, denen die Existenz der Handelsregisterverordnung unter Umständen gar nicht bekannt ist.

151 Vgl. nur Spahlinger/Wegen, S. 277 mit vielen weiteren Nachweisen sowie zuletzt Wachter, Die GmbHReform in der Diskussion, S. 55, 86.

152 Ausführlich zum Streitstand Böttcher/Ries S. 206 f. mit zahlreichen w. N.

153 Wachter, Die GmbH-Reform in der Diskussion, S. 55, 107 f., eine differenzierte Analyse des vorgenannten Problems findet sich bei Bohlscheid RNotZ 2005, 505. 
deutschen GmbH. Dies würde - so Wachter - nicht nur das Gründungsverfahren beschleunigen, sondern wäre zugleich ein Beleg für die Weltoffenheit des deutschen GmbH-Rechts.

\section{bbb) (Teilweise) Erfüllung der Einlagepflichten}

BDI und Hengeler ${ }^{154}$ schlagen vor, bei Gesellschaften, deren Stammkapital den Mindestbetrag (§ 5 Abs. $1 \mathrm{GmbHG)}$ nicht übersteigt, künftig auf die Voraussetzung der teilweisen Einzahlung der Bareinlagen vor Anmeldung ( $\$ 7$ Abs. 2 GmbHG) und Eintragung ( $\$ 9 \mathrm{c}$ Abs. 1 GmbHG) zu verzichten. Die teilweise Einzahlung der Bareinlagen könne auch abgesichert indem man Geschäftsführer und Gesellschafter verpflichte, die Einzahlung der erforderlichen Beträge innerhalb kurzer Frist (etwa fünf Banktagen) nach Eintragung der Gesellschaft dem Registergericht nachzuweisen. Kämen die Geschäftsführer und Gesellschafter dieser Verpflichtung nicht nach, würde die Gesellschaft von Amts wegen gelöscht. Im Register würde bis zur vollständigen Einzahlung des Mindeststammkapitals bei der Angabe des Stammkapitals der Vermerk „Mindestbetrag nicht einbezahlt“ angebracht werden. Eine Täuschung des Rechtsverkehrs wäre nicht zu befürchten, da die Zeitspanne zwischen Eintragung und Nachweis der Einzahlung kurz und das Register jederzeit (über das Internet) eingesehen werden kann. Die zusätzliche Belastung des Registers wäre gering und würde durch die verschiedenen Entlastungen (keine Überprüfung der Gesellschaftsverträge, keine Nachprüfung der Einzahlungen u.a.) aufgewogen ${ }^{155}$. Die nachträgliche Einzahlung der erforderlichen Bareinlagen könnte weiter abgesichert werden, indem die (dann insoweit wohl nicht mehr einschlägige) Sanktion des $\S 81$ Abs. 1 Nr. 1 GmbHG (Strafbarkeit falscher Angaben über die Leistung der Einlagen) durch eine entsprechende Sanktion für die Verletzung der Verpflichtung zur nachträglichen Einzahlung ergänzt werde. Ein weitere Nebeneffekt wäre, dass bei einem Verzicht auf die teilweise Einzahlung der Bareinlagen künftig auf die entsprechenden Versicherungen der Geschäftsführer ( 8 Abs. 2 GmbHG) verzichtet werden könne.

\section{ccc) Prüfung des Gründungsvorgangs durch das Registergericht}

Wachter $^{156}$ schlägt vor, nicht gänzlich auf die Kontrolle der ordnungsgemäßen Kapitalaufbringung bei Anmeldung zu verzichten sondern die Verantwortlichkeit hierfür schlichtweg auf

154 BDI/Hengeler Müller S. 13.

155 BDI/Hengeler Müller S. 13.

156 Vgl. im Einzelnen nur Wachter, Die GmbH-Reform in der Diskussion, S. 55, 104. 
den beurkundenden Notar zu übertragen; dieser soll dafür die unbeschränkte und unbeschränkbare persönliche Haftung übernehmen. Eine solche Kompetenzverteilung sei nicht nur im Interesse der Entlastung der staatlichen Justiz, sondern führe zwangsläufig zu einer erheblichen Beschleunigung des Gründungsverfahrens. Das Registergericht brauche demnach nur noch eine formale Kontrolle des Gründungsvorgangs vorzunehmen. § 9c Abs. 2 GmbHG sei dahingehend zu ändern, dass das Gericht die Eintragung einer $\mathrm{GmbH}$ wegen einer mangelhaften, fehlenden oder nichtigen Satzungsbestimmung nur dann ablehnen darf, wenn der Notar Zweifel an der Wirksamkeit der Satzung in der Urkunde ausdrücklich vermerkt ${ }^{157}$.

In diesem Zusammenhang sei auch das bestehende Firmenrecht zu diskutieren. Es soll nach Auffassung von Wachter ${ }^{158}$ unverändert bleiben. Allerdings soll die Einhaltung des Firmenrechts, insbesondere im Hinblick auf den Rechtsformzusatz und andere offensichtliche Rechtsverstöße nicht mehr durch das Registergericht oder durch die Industrie- und Handelskammern überprüft werden, sondern durch den beurkundenden Notar. Verbleibende Verstöße gegen das Firmenrecht sind sodann von Wettbewerbern und Marktteilnehmern im Rahmen firmen- und wettbewerbsrechtlicher Rechtsstreitigkeiten geltend zu machen ${ }^{159}$.

\section{ddd) Stellungnahme der Industrie- und Handelskammer}

Auch eine Mitwirkung der Industrie- und Handelskammer soll nach dem Willen einiger gewichtiger Stimmen in der Literatur namentlich Wachters künftig entfallen. Sie sei nicht erforderlich, da das Registergericht über die Gründung einer neuen $\mathrm{GmbH}$ eigenverantwortlich und abschließend entscheide. § 23 HRV sei demnach dahingehend zu ergänzen, dass bei Unternehmensneugründungen eine Stellungnahme der Industrie- und Handelskammer (Auch in zweifelhaften Fällen) nicht eingeholt werden $\operatorname{soll}^{160}$.

\section{eee) Notarielle Beurkundung}

Anders als von zahlreichen Stimmen in der Literatur ${ }^{161}$ verlangt, hält der Regierungsentwurf an der grundsätzlichen Beurkundungsbedürftigkeit des Gründungsvorgangs einer $\mathrm{GmbH}$ fest; einen Verzicht auf eine notarielle Beurkundung des Gesellschaftsvertrages sieht der Regie-

Wachter, Die GmbH-Reform in der Diskussion, S. 55, 96.

58 Wachter, Die GmbH-Reform in der Diskussion, S. 55, 107.

159 Wachter, Die GmbH-Reform in der Diskussion, S. 55, 107.

160 Vgl. zum Ganzen Keidel/Krafka/Willer, S. 53; Scholz/Winter $§ 9$ c Rn. 12 sowie konkret im Hinblick auf den unterbreiteten Vorschlag Wachter, Die GmbH-Reform in der Diskussion, S. 55, 81.

161 Vgl. Koegel GmbHR 2003, 1225 sowie auch Hadding ZIP 2003, 2133; Walz/Fembacher NZG $2003,1134$. 
rungsentwurfs nur bei unveränderter Verwendung der Mustersatzung vor. Nach Auffassung des Gesetzgebers überwiegt der Schutzzweck einer notariellen Beurkundung das sicherlich zutreffende Argument der Literatur, dass die Gründung einer Gesellschaft durch den Verzicht auf das Erfordernis der notariellen Beurkundung des Gesellschaftsvertrages ( $§ 2$ Abs. 1 $\mathrm{GmbHG}$ ), nochmals erheblich vereinfacht und beschleunigt würde. Fiele das Beurkunderfordernis fort, könnten die Gründer den Gesellschaftsvertrag, ebenso wie den Gesellschaftsvertrag einer Personengesellschaft, privatschriftlich abschließen ${ }^{162}$.

Unberücksichtigt lässt der Regierungsentwurf auch die in vielen Stellungnahmen geforderten weiteren Erleichterungen der Beurkundungspflicht, insbesondere die Abschaffung des zu langen Verlesen begleitender Dokumente führende Vollständigkeitsgrundsatzes wird nicht vorgesehen. Allerdings weist der Entwurf im Allgemeinen Teil seiner Begründung darauf hin, dass solche Änderungen möglicherweise Gegenstand einer Reform des Beurkundungsgesetzes ein könnten ${ }^{163}$

\section{Gesellschaftsvertrag}

\section{Bestehende Rechtslage}

\section{a) Gesetzlicher Mindestinhalt des Gesellschaftsvertrages}

Der Gesellschaftsvertrag hat einen obligatorischen Inhalt nach $\S 3$ Abs. 1 GmbHG, der durch einen fakultativen ergänzt werden kann ${ }^{164}$. Obligatorische Angaben nach $\S 3$ Abs. $1 \mathrm{GmbHG}$ sind:

\section{aa) Firma}

Die Firma ist der Name der Gesellschaft, unter dem sie im Handelsverkehr allein auftreten kann (vgl. $\S ~ 4,13$ Abs.3 in Verbindung mit $\S 6$ und 17 HGB).

Mit der Maßgabe, dass die gewählte Firma über eine bestimmte Kennzeichnungs- und Unterscheidungskraft verfügt sowie das Verbot der Irreführung und Täuschung beachtet wird, sind

162 Vgl. zum Streitstand nur Scholz/Emmerich § 2 mit zahlreichen Nachweisen; BDI/Hengeler Müller S. 13.

163 Begründung des Regierungsentwurfs, Allgemeiner Teil S. 57.

164 Baumbach/Hueck/Hueck/Fastrich $§ 3$ Rn. 5 ff.; Roth/Altmeppen $\S 3$ Rn. 6 ff. Michalski/Michalski 33 Rn. 6 ff. 
die Gesellschafter in der Firmenbildung unbeschränkt. Dabei haben Sie gemäß $§ 4$ Abs. 1 GmbHG die Möglichkeit, zwischen einer Personenfirma, die den Namen eines, mehrerer oder aller Gesellschafter enthält, einer Sachfirma, die den Gegenstand des Unternehmens in der Firma verwendet, einer Mischvariante oder einer reinen Phantasiefirma zu wählen ${ }^{165}$. In jedem Fall aber muss die Firma nach $\S 4$ Abs. 2 GmbHG die Bezeichnung „Gesellschaft mit beschränkter Haftung“ oder eine entsprechende, allgemein verständliche Abkürzung, wie z.B. „GmbH“, Gesellschaft mbH“" enthalten ${ }^{166}$.

\section{bb) Sitz}

Der Sitz der Gesellschaft ist der Ort, den der Gesellschaftsvertrag bestimmt ( $\S 4 \mathrm{a}$ Abs. 1 $\mathrm{GmbHG).} \mathrm{Als} \mathrm{Ort} \mathrm{im} \mathrm{vorgenannten} \mathrm{Sinne} \mathrm{ist} \mathrm{stets} \mathrm{eine} \mathrm{im} \mathrm{Inland} \mathrm{gelegene} \mathrm{politische} \mathrm{Ge-}$ meinde zu bestimmen ${ }^{167}$. Hierbei können die Gesellschafter nach Maßgabe des $\S$ 4a Abs. 2 GmbHG als Sitz entweder den Ort wählen, an dem sich der Betrieb oder die Geschäftsleitung befindet oder die Verwaltung geführt wird. Grundsätzlich kann für die Gesellschaft nur ein Sitz gewählt werden, auch wenn sie mehrere Betriebs- oder Verwaltungsstätten hat ${ }^{168}$.

\section{cc) Gegenstand}

Unter dem Unternehmensgegenstand versteht man im Gegensatz zum Zweck der Gesellschaft den Bereich und die Art der Tätigkeit, die von der Gesellschaft ausgeübt werden soll. Die Festlegung der von der GmbH satzungsmäßig zu entfaltenden Tätigkeit ist in den Grenzen des gesetzlich Zulässigen beliebig. Daher können auch soziale oder ideelle Aktivitäten Gegenstand der Gesellschaft $\operatorname{sein}^{169}$.

165 Ausführlich zum Ganzen Scholz/Emmerich $§ 4$ Rn. 7 ff; Baumbach/Hueck/Hueck/Fastrich $\$ 4$ Rn. 5 ff.; Lutter/Hommelhoff/Lutter/Bayer $\S 4$ Rn. 6 ff.; Roth/Altmeppen $\S 4$ Rn. 2 ff. Rowedder/SchmidtLeithoff/Schmidt-Leithoff $\S 4$ Rn. 7 ff.; Zusammenfassend Süß/Wachter/Terbrack S. 531; vgl. auch Heckschen/Heidinger/Heckschen $\S 3$ Rn. 1 ff. m. zahlreichen N. aus der Praxis und Rechtsprechung. Scholz/Emmerich $\$ \quad 4 \quad$ Rn. 7 ff; Baumbach/Hueck/Hueck/Fastrich $\$ \quad 4 \quad$ Rn. 5 ff.; Lutter/Hommelhoff/Lutter/Bayer $\S 4$ Rn. 6 ff.; Roth/Altmeppen $\S 4$ Rn. 2 ff. Rowedder/SchmidtLeithoff/Schmidt-Leithoff $\S 4$ Rn. 7 ff.; Süß/Wachter/Terbrack S. 532. Der Sitz der Gesellschaft muss sich in Deutschland befinden, weil in Deutschland bis vor kurzem jedenfalls noch die Sitztheorie galt; vgl. dazu Heckschen/Heidinger/Heckschen $\S 3 \mathrm{Rn} .33$ sowie $\S 12 \mathrm{Rn} .1 \mathrm{ff}$.

168 Zur Problematik des Doppelsitzes einer Kapitalgesellschaft vgl. nur Scholz/Emmerich $\S 3$ Rn. 4 ff., $\S 4 \mathrm{a} \mathrm{Rn.}$ 16; Michalski/Michalski § 4a Rn. 16; Lutter/Hommelhoff $\S 4 \mathrm{a}$ Rn. 4 ff. jeweils m. w. N. sowie Süß/Wachter/Terbrack S. 532 und Heckschen/Heidinger/Heckschen $§ 3$ Rn. 34.

169 Ausführlich zum Ganzen Heckschen/Heidinger/Heckschen $§ 3$ Rn. 19 ff. sowie MünchHdbGesR/Heinrich $\S$ 19, Rn. 43 m. w. N. 
Mit dem Erfordernis den so umschriebenen Unternehmensgegenstand im Gesellschaftsvertrag anzugeben, verfolgt das Gesetz einen dreifachen Zweck: Zunächst soll den beteiligten Verkehrskreisen durch Einsichtnahme in das Handelsregister ermöglicht werden, sich über den Tätigkeitsbereich der Gesellschaft zu informieren. Außerdem wird dem Registergericht durch die Pflichtangabe die Prüfung möglicher Genehmigungspflichten erleichtert. Schließlich dient der Unternehmensgegenstand im Innenverhältnis dazu, die Geschäftsführungsbefugnis der Geschäftsführer statutarisch zu beschränken und die Gesellschafter so vor sachfremden Geschäften der Geschäftsführer zu schützen (vgl. § 37 Abs. 1 GmbHG) ${ }^{170}$.

\section{dd) Stammkapital}

Nach $\S 3$ Abs. 1 Nr. 3 GmbHG muss die Höhe des Stammkapitals der Gesellschaft mit einem festen Betrag in der Satzung angegeben sein, und zwar bei Neugründungen in Euro. Die Mindesthöhe des anzugebenden Stammkapitals ergibt sich aus $\S 5$ Abs. 1 GmbHG und beträgt derzeit $25.000 €^{171}$.

\section{ee) Stammeinlage}

Schließlich sind im Gesellschaftsvertrag zwingend die Stammeinlagen anzugeben. Das sind diejenigen in Euro anzugebenden Beträge die jeweils auf einen übernommenen Geschäftsanteil zu leisten sind ${ }^{172}$. Die Summe aller Stammeinlagen entspricht dem Betrag des Stammkapitals. Bislang kann jeder Gesellschafter bei der Gründung nur eine Stammeinlage übernehmen, die mindestens $100 €$ betragen und in Euro durch 50 teilbar sein muss ( $\$ 5$ Abs. 3 GmbHG). Nach dieser Stammeinlage richtet sich der jeweilige Geschäftsanteil (§ 14 GmbHG). Daraus folgt zugleich, dass die Stammeinlagen im Gesellschaftsvertrag für jeden Gesellschafter gesondert ausgewiesen werden müssen, wobei außerdem die auf die Stammeinlage bereits erbrachte Einlage sowie der Zeitpunkt der Einzahlung angegeben werden soll. Bei Sacheinlagen

170 Scholz/Emmerich $\S 3$ Rn. 11 ff.; Lutter/Hommelhoff $§ 3$ Rn. 6; vgl. auch Süß/Wachter/Terbrack S. 532.

171 Raiser, S. 394; Süß/Wachter/Terbrack S. 532; Scholz/Emmerich § 3 Rn. 11 ff.; Lutter/Hommelhoff $§ 3$ Rn. 6; Die durch die Euro-Umstellung in der Übergangszeit sowie aufgrund der Besitzstandswahrung vor der Umstellung errichteter Gesellschaften vielfältigen Mäglichkeiten der Mindetsbeträge und Nennbetragstückelungen die bis heute weiter zulässig existieren zeigt Heckschen/Heidinger/Heckschen $\S 3$ Rn. 43 auf.

172 Neben dem Begriff der Stammeinlage verwendet das Gesetz zur Bezeichnung der Mitgliedschaft in der $\mathrm{GmbH}$ auch den Begriff des Geschäftsanteils ( $\$ 114 \mathrm{ff}$. GmbHG). Der Geschäftsanteil wird abgebildet durch den Betrag der Stammeinlage ( $§ 14 \mathrm{GmbHG})$. In der Praxis werden die Begriffe häufig synonym verwandt. Im Entwurf des MoMiG soll künftig auch auf eine Unterscheidung verzichtet werden; dort wird nur noch von Geschäftsanteilen die Rede sein, vgl. nachfolgend in diesem Abschnitt unter II. 2. dd). Siehe hierzu auch Raiser, S. 396. 
sind entsprechend Gegenstand und Betrag der Stammeinlage aufzuführen ( $\$ 5$ Abs. 4 $\mathrm{GmbHG})^{173}$.

\section{b) Fakultativer Inhalt des Gesellschaftsvertrages}

Ergänzungen des Gesellschaftsvertrages sind zulässig, soweit sie nach Maßgabe allgemeiner Grundsätze (etwa $\S 138$ BGB) oder des GmbHG nicht verboten sind (z.B. $\S 51$ Abs. 3 $\mathrm{GmbHG}$ ). In diesen Grenzen besteht ein weit reichender Gestaltungsspielraum, der lediglich dort endet, wo in den unverzichtbaren Kernbereich von Gesellschafterrechten eingegriffen wird (so etwa bei rigiden Regelungen zum Einberufungs-, Teilnahme- und Stimmrecht in der Gesellschafterversammlung) ${ }^{174}$.

Manche ergänzenden Bestimmungen müssen, um wirksam zu sein, im Gesellschaftsvertrag selbst enthalten sein, § 3 Abs. 2 GmbHG; andere können im Gesellschaftsvertrag getroffen werden, genauso aber auch lediglich Bestandteil einer schuldrechtlichen Nebenvereinbarung sein. Solche außerhalb des Gesellschaftsvertrages getroffenen Vereinbarungen sind in der Praxis weit verbreitet, denn sie haben den Vorteil nach allgemeinen zivilrechtlichen Grundsätzen frei veränderbar zu sein, andererseits entfalten sie aber auch keine absolute Wirkung gegen neu eintretende Gesellschafter ${ }^{175}$.

Häufig wird eine personalistischere Ausgestaltung der Rechte und Pflichten der Gesellschafter vorgesehen, indem beispielsweise Abtretungs- und Einziehungsklauseln sowie Vorkaufsrechte betreffend die Geschäftsanteile, Mehrfachstimmrechte, Abfindungsbeschränkungen und Regelungen zur Einberufung und Beschlussfähigkeit der Gesellschafterversammlung in die Satzung aufgenommen werden oder Gegenstand einer schuldrechtlichen Nebenvereinbarung sind ${ }^{176}$.

173 Raiser, S. 395 f.; Süß/Wachter/Terbrack S. 532; Scholz/Emmerich $§ 3$ Rn. 27 ff.; Lutter/Hommelhoff $§ 3$ Rn. 10.

174 Scholz/Emmerich $\S 3$ Rn. 61; Hachenburg/Ulmer § 2 Rn. 64; Süß/Wachter/Terbrack S. 533. Ausführlich zur Satzungsgestaltung Heckschen/Heidinger/Heckschen § 3, dort insbesondere bei Rn. 56 bis 274.

$175 \mathrm{Vgl}$ zu den zahlreichen Erscheinungsformen schuldrechtlicher Gesellschaftsvereinbarungen Noack, S. 40 mit w. Nachweisen. In der neueren Literatur Scholz/Emmerich § 3 Rn. 42 ff.; Lutter/Hommelhoff $§ 3$ Rn. 15 Süß/Wachter/Terbrack S. 533; Raiser, S. 412 ff.

176 Häufig werden schuldrechtliche Nebenabreden zur Vermeidung der mit einer Handelsregistereintragung verbundenen Publizität außerhalb des Gesellschaftsvertrages geschlossen. Insbesondere in Familien geführten Unternehmen werden typischerweise Abreden die den Einfluss der Familie sichern sollen geschlossen (Stimmbindungsverträge oder Stimmpoolvereinbarungen, und zwar naturgemäß außerhalb des Gesellschaftsvertrages denn die Einflussnahmemöglichkeiten sollen gerade nicht öffentlich sein. Scholz/Emmerich $\S 3$ Rn. 42 ff.; Lutter/Hommelhoff $§ 3$ Rn. 15; Süß/Wachter/Terbrack S. 533. 


\section{Zu den Reformbestrebungen}

\section{a) Reformansätze des MoMiG}

\section{aa) Mustergesellschaftsvertrag}

Wie oben bereits ausgeführt wird für unkomplizierte Standardgründungen ein Mustergesellschaftsvertrag als Anlage zum GmbHG zur Verfügung gestellt. Entscheiden sich die Gründer für die Verwendung dieses Muster, so ist keine notarielle Beurkundung des Gesellschaftsvertrages, sondern nur eine öffentliche Beglaubigung der Unterschriften erforderlich. Der Mustervertrag wird durch Muster für die Handelsregisteranmeldung flankiert (so genanntes „Gründungs-Set“). So können in den genannten Fällen sämtliche Schritte bis zur Eintragung in das Handelsregister ohne zwingende rechtliche Beratung bewältigt werden ${ }^{177}$.

\section{bb) Sitz und Geschäftsanschrift}

Aufgrund der Rechtsprechung des EuGH zur Niederlassungsfreiheit ${ }^{178}$ ist es EUAuslandsgesellschaften nunmehr möglich, ihren Verwaltungssitz - abweichend vom statutarischen Sitz - in einem anderen Staat - also auch in Deutschland - zu wählen. Diese Auslandsgesellschaften sind in Deutschland als solche, d.h. in ihrer ausländischen Rechtsform (z.B. als S.à.r.l. oder B.V.), anzuerkennen. Umgekehrt steht deutschen Gesellschaften diese Möglichkeit schon aufgrund der Regelung in $\S 4 \mathrm{a}$ Abs. 2 GmbHG nicht zur Verfügung. Durch Streichung des $\S 4 \mathrm{a}$ Abs. 2 GmbHG soll es deutschen Gesellschaften künftig ermöglicht werden, einen Verwaltungssitz zu wählen, der nicht notwendig mit dem Satzungssitz übereinstimmt. Dieser Verwaltungssitz kann auch im Ausland liegen. Damit soll der Spielraum deutscher Gesellschaften erhöht werden, ihre Geschäftstätigkeit auch außerhalb des deutschen Hoheits-

177 Begründung des Regierungsentwurfs, Allgemeiner Teil S. 56 und 60 sowie im Besonderen Teil S. 61. Vgl. hierzu auch Karsten GmbHR 2007, 958, 962 ff; Heckschen DStR 2007, 1442 sowie jüngst Ulmer ZIP 2008, 45, 46. Schröder/Cannivé NZG 2008, 1 sehen die bisherigen Regeln für den Unternehmensgegenstand durch die Einführung der „Katalogunternehmensgegenstände“ gar in Frage gestellt.

178 Centros - EuGH, 9. 3. 1999 - Rs. C -212/97; Überseering - EuGH, 5. 11. 2002 - Rs. C-208/00; Inspire Art EuGH v. 30. 9. 2003 - Rs. C - 167/01; vgl. hierzu ausführlichst oben Erster Abschnitt § 2 II mit entsprechenden Nachweisen zu Literatur und Rechtsprechung. Zur Rechtssache Überseering und ihre Folgen vgl. nur Lutter BB 2003, 7; explizit zu den Auswirkungen von Inspire Art auf die GmbH Priester DB 2005, 1315 sowie K. Schmidt ZHR 168 (2004), 493; zu allen drei vorgenannten Entscheidungen Paefgen ZIP 2004, 2253 sowie Riegger ZGR 2004, 510. 
gebiets zu entfalten. Selbstverständlich bleibt es dabei, dass die GmbH mit Verwaltungssitz im Ausland bei einem deutschen Registergericht registriert sein muss ${ }^{179}$.

Andererseits bleibt es auch nach dem Entwurf dabei, dass beim Registergericht zur Beschleunigung der Rechtsverfolgung gegenüber Gesellschaften auch eine inländische Geschäftsanschrift zwingend anzugeben ist. Dies gilt für $\mathrm{GmbH}$, aber auch für Aktiengesellschaften, Einzelkaufleute, Personenhandelsgesellschaften sowie Zweigniederlassungen (auch von Auslandsgesellschaften). Wenn unter dieser eingetragenen Anschrift eine Zustellung (auch durch Niederlegung) faktisch unmöglich ist, wird die Möglichkeit verbessert, gegenüber juristischen Personen (also insbesondere der $\mathrm{GmbH}$ ) eine öffentliche Zustellung im Inland zu bewirken. Dies bringt eine ganz erhebliche Deregulierung für die Gläubiger der GmbHs, die bisher, insbesondere in den so genannten Bestattungsfällen ${ }^{180}$, mit den Kosten und Problemen der Zustellung (insbesondere auch Auslandszustellungen) zu kämpfen hatten ${ }^{181}$.

\section{cc) Stammkapital}

Der deutsche Gesetzgeber hat sich für eine bloße Herabsetzung und gegen eine vollständige Abschaffung des Stammkapitals, wie es in anderen europäischen Ländern bereits vorgemacht worden ist, entschieden ${ }^{182}$. Durch die Beibehaltung eines immer noch nennenswerten Mindeststammkapitals bei Gründung von immerhin $10.000 €$ soll nach dem Willen des Gesetzge-

179 Begründung des Regierungsentwurfs, Besonderer Teil S. 65; vgl. hierzu auch die Ausführungen bei Flesner NZG 2006, 641 und Wachter GmbHR 2006, 793 sowie jüngst Preuß GmbHR 2007, 57. Nach dem Willen des BMJ soll es allerdings künftig möglich sein, die Gesellschaft unter Wahrung ihrer Identität dem Recht eines anderen Staates zu unterstellen, wenn die betroffenen Rechtsordnungen dies zulassen (grenzüberschreitender Rechtsformwechsel); in diesem Fall würde die Gesellschaft im ausländischen Register eingetragen und im deutschen gelöscht werden; vgl. Referentenentwurf für ein Gesetz zum Internationalen Privatrecht der Gesellschaften, Vereine und juristischen Personen; abrufbar unter http://www.bmj.de/enid/29822660d3b7c055bca2e36f8b868768,0/ Internationa-

les_Privatrecht/Internationales_Gesellschaftsrecht_1fh.html.

180 Bei Hirte ZinsO 2003, 833 findet sich eine umfassende Erörterung der Problematik, die Hirte als organisierte „Bestattung“ von Kapitalgesellschaften bezeichnet. Der oder die Gesellschafter einer bereits insolventen inländischen Kapitalgesellschaft verkaufen dabei ihre Anteile an einen oder mehrere „neue“ Gesellschafter, die durch einen „Bestattungsunternehmer“ vermittelt werden. Bei den neuen Gesellschaftern handele es sich regelmäßig um vermögenslose Personen, die bereit sind, gegen ein geringes Entgelt in die formale Stellung eines Gesellschafters der Kapitalgesellschaft einzutreten. Sodann wird der Sitz der Gesellschaft verlegt, typischerweise an einen kleineren Ort, häufig in den neuen Bundesländern. Dieser Vorgang wiederholt sich in der Folge ein oder mehrere weitere Male. Im Ergebnis dieser Transaktionen gehen die Geschäftsunterlagen und die Vermögenswerte der Gesellschaft regelmäßig ,verloren“. Eine weitere Spielart der „Unternehmensbestattung“ ist die Anteilsübertragung auf Ausländer, auf Inländer mit Wohnsitz im Ausland oder auf ausländische Gesellschaften. 
bers eine gewisse Seriositätsschwelle erhalten werden ${ }^{183}$. Andererseits wird mit der Absenkung gerade Kleinunternehmen und Existenzgründern, insbesondere aus dem Dienstleistungssektor, ermöglicht, bei geringem Kapitalbedarf leichter eine Gesellschaft zu gründen als bis$\operatorname{her}^{184}$.

\section{dd) Stammeinlage}

Künftig ist statt der übernommenen Stammeinlagen die Zahl der von jedem Gesellschafter übernommenen Geschäftsanteile in dem Gesellschaftsvertrag zu bezeichnen ${ }^{185}$. Diese Änderung trägt dem Umstand Rechnung, dass ein Gesellschafter nach § 5 Abs. 2 GmbHGE künftig auch bei der Gründung mehrere Geschäftsanteile übernehmen kann ${ }^{186}$. Darüber hinaus ist eine inhaltliche Änderung mit der hier vorgeschlagenen Regelung nicht verbunden. Durch die vorgeschlagene Neufassung werden aber die von den Gesellschaftern zu übernehmenden Geschäftsanteile und somit ihre Beteiligung beziehungsweise ihre Mitgliedschaft gegenüber ihrer Einlageverpflichtung in den Vordergrund gerückt ${ }^{187}$. Die Erklärung des Gesellschafters, sich an der Gesellschaft beteiligen zu wollen, war schon bisher notwendiger Inhalt des Gesellschaftsvertrags ${ }^{188}$. Die Neufassung der Vorschrift bringt die Notwendigkeit einer solchen Beitrittserklärung durch das Erfordernis der Angabe der Nennbeträge der übernommenen Geschäftsanteile besser zum Ausdruck. Zudem stimmt dies mit der Vorstellung des Gesellschafters überein, dass er einen Geschäftsanteil an der Gesellschaft übernimmt und anschließend hält ${ }^{189}$.

Darüber hinaus wird hierdurch geregelt, dass die Gesellschafter die Geschäftsanteile jeweils gegen eine Einlage auf das Stammkapital zu übernehmen haben. Die Einlageverpflichtung entsteht nunmehr nicht mehr mit der Aufnahme der Stammeinlage, sondern mit der Aufnahme des Nennbetrags des jeweiligen Geschäftsanteils in den Gesellschaftsvertrag. Die Regelung ist an $\S 2$ AktG angelehnt. Es soll deutlich werden, dass die Gründer sämtliche Geschäftsanteile sofort übernehmen müssen, was dem Prinzip der Einheitsgründung entspricht. Gleichzeitig kommt die logische Unterscheidung zwischen der Beteiligung des Gesellschafters beziehungsweise einer Mitgliedschaft und seiner Einlageverpflichtung bei Gründung der

183 Kritisch dazu Haas DStR 2006, 993, Roth, in: FS Doralt, 2004, S. 479, S. 479, 482; Blaurock, in: FS Raiser, 2005, S. 3, 13 f.; s. auch Eidenmüller GmbHR 2005, 433, 436; Krüger, Mindestkapital und Gläubigerschutz, 2005, S. $223 \mathrm{ff}$.

184 Vgl. hierzu im Einzelnen auch unten in diesem Abschnitt unter IV. 1. a) und 2. a) aa) aaa) (i).

185 Begründung des Regierungsentwurfs, Besonderer Teil S. 63.

186 Vgl. hierzu unten in diesem Abschnitt unter IV. 1. a) und 2. a) aa) aaa) (ii) und (iii).

187 Begründung des Regierungsentwurfs, Besonderer Teil S. 63.

188 Vgl. insoweit oben in diesem Abschnitt II. 1. a) ee).

189 Begründung des Regierungsentwurfs, Besonderer Teil S. 63 f. 
Gesellschaft zum Ausdruck ${ }^{190}$. Der Begriff „Stammeinlage“ hat diese Differenzierung nach Auffassung des Gesetzgebers verwischt ${ }^{191}$. Die Höhe der Einlageverpflichtung beziehungsweise das Verhältnis von Nennbetrag des Geschäftsanteils und Stammeinlage ergibt sich aus der vorgeschlagenen Änderung des $\S 14 \mathrm{GmbHG}^{192}$.

\section{b) Reformüberlegungen in Praxis und Literatur}

Gegen die Einführung einer Mustersatzung wird eingewandt ${ }^{193}$, ein Mustergesellschaftsvertrag biete weder für den Unternehmensgründer noch für das Registergericht einen echten Mehrwert. Zum einen dürfte eine fakultative Standardsatzung beim Registergericht keine spürbare Entlastung bewirken. Denn in jedem Fall müsse das Registergericht zumindest prüfen, ob die vorgelegte Satzung der Mustersatzung in vollem Umfang entspricht oder ob nicht doch gewisse Abweichungen erfolgt sind ${ }^{194}$.

Zum anderen halte jeder Notar ohnehin bereits heute eine oder mehrere „Mustersatzungen“ für Unternehmensgründer bereit, die sich in der Praxis bewährt hätten und vom Handelsregister problemlos eingetragen würden. Einem Unternehmensgründer, der von der Möglichkeit der individuellen Satzungsgestaltung keinen Gebrauch machen wolle, stehe es bereits heute frei, auf eine solche Satzung zurückzugreifen. Bei einer solchen Satzung, die sich mehr oder weniger auf die gesetzlichen Mindestangaben beschränke und deren Umfang unter Umständen nur ein oder zwei Seiten umfasse, sei der Prüfungsaufwand des Registergerichts bereits heute sehr gering, so dass auch die Eintragung regelmäßig schnell und unkompliziert erfolge. „Mustersatzungen“ gebe es bereits heute in ausreichender Zahl, so dass ein Bedürfnis dafür, diese im Wege der Rechtsverordnung er zu schaffen nicht erkennbar sei ${ }^{195}$.

Schließlich könnte die Vorgabe staatlicher Mustersatzungen dazu führen, dass es faktisch zu einer gewissen Beeinträchtigung der Satzungsautonomie komme ${ }^{196}$. So werde sich ein Unternehmensgründer unter Umständen auch dann eher für die Verwendung einer Mustersatzung statt einer individuell ausgestalteten Satzung entscheiden, auch wenn diese im Einzelfall

190 Begründung des Regierungsentwurfs, Besonderer Teil S. 64.

191 Begründung des Regierungsentwurfs S. $64 \mathrm{f}$.

192 Vgl. hierzu unten in diesem Abschnitt unter IV. 1. a) und 2. a) aa) aaa) (ii) und (iii).

193 K. Schmidt DB 2006, 1096; Wachter, Die GmbH-Reform in der Diskussion, S. 55, 91 ff.; vgl. auch Priester ZIP 2006, 161 sowie Schall/Westhoff GmbHR 2005, R 357. 
überhaupt nicht passend ist, nur weil die Eintragung dann sofort erfolge und nicht eine unbestimmbar lange Zeit in Anspruch nimmt ${ }^{197}$.

\section{Organisationsverfassung}

\section{Bestehende Rechtslage}

Die GmbH hat zwei notwendige Handlungsorgane, nämlich die Gesellschafter in ihrer Gesamtheit, auch Gesellschafterversammlung genannt (hierzu sogleich unter b), und die Geschäftsführer (vgl. für die Einzelheiten hiernach unter a). Die Gesellschafterversammlung ist das oberste Willensbildungsorgan der Gesellschaft; ihr obliegen die Grundlagenentscheidungen ( $§ 46 \mathrm{GmbHG})$. Darüber hinaus steht es den Gesellschaftern frei, Geschäftsführungsangelegenheiten sowohl generell, beispielsweise im Gesellschaftsvertrag oder in einer Geschäftsordnung als auch im Einzelfall durch Weisungen und Gesellschafterbeschlüsse an sich zu ziehen $^{198}$. Die durch die Gesellschafterversammlung in der vorgenannten Art und Weise gesetzten Regeln und Bedingungen bilden den Rahmen für die Geschäftsführungsbefugnis des oder der Geschäftsführer im Innenverhältnis, die Vertretungsberechtigung, die nach Außen wirkt, bleibt hiervon unberührt, sie ist gegenüber Dritten gemäß $§ 35$ Abs. 1 GmbHG unbeschränkt ${ }^{199}$.

Die klare Unterscheidung zwischen Gesellschafterversammlung und Geschäftführern gilt unabhängig davon, ob alle oder einige der Geschäftsführer zugleich auch Gesellschafter sind. Hintergrund ist das im GmbH-Recht geltende Prinzip der Drittorganschaft (auch Fremdorganschaft genannt), nach welchem es unerheblich ist, ob die Geschäftsführer zugleich auch Gesellschafter sind oder nicht ${ }^{200}$.

197 K. Schmidt DB 2006, 1096 f.; Wachter, Die GmbH-Reform in der Diskussion, S. 55, 91 ff. Anders ist offensichtlich die Erfahrung von Karsten GmbHR 2006, 57 im Hinblick auf die Beeinträchtigung der Satzungsautonomie bei Einführung einer Mustersatzung. Er spricht sich nach der Auswertung von $250 \mathrm{GmbH} \mathrm{Ge}-$ sellschaftsverträgen aus dem Bereich des mittelständischen Handwerks, für eine vereinfachte Gründung unter Verwendung einer standardisierten Satzung bei gleichzeitigem Verzicht auf die Beurkundung aus. Zu einen diametral entgegengesetzten Ergebnis gelangen Bayer/Hoffmann/Schmidt GmbHR 2007, 953, die aus Gründen der in der Praxis überwiegend vorzufindenden Komplexität von GmbH-Satzungen die Einführung einer Mustersatzung ablehnen und allenfalls für Einpersonen-GmbH einen begrenzten Anwendungsbereich gestatten wollen.

198 In der Rechtswirklichkeit ist die im Gesetz angelegte Balance zwischen den Organen regelmäßig aufgehoben bzw. zu Ungunsten des Geschäftsführers durch umfangreiche Zustimmungskataloge in der Geschäftsordnung oder Satzung verschoben; vgl. hierzu Raiser S. 537 ff., dort insbesondere S. 538.

199 Raiser S. 537 ff.; Süß/Wachter/Terbrack S. 551 ff.; Grunewald, S. 339 f.; Scholz/Schneider § 6 Rn. 2.

200 Vgl. Baumbach/Hueck/Hueck/Fastrich Einl. Rn. 23, § 6 Rn. 8; Hachenburg/Ulmer $§ 6$ Rn. 15; Hachenburg/Mertens $§ 35$ Rn. 38 f.; Scholz/Schneider Rn. 24 f. sowie Süß/Wachter/Terbrack S. 551 ff. 


\section{a) Geschäftsführer}

Die GmbH muss mindestens einen ${ }^{201}$ Geschäftsführer haben, § 6 Abs. 1 GmbHG; nach oben ist die Zahl indes nicht begrenzt ${ }^{202}$. Eine höhere Mindestanzahl, aber auch eine Höchstanzahl oder konkret bestimmte Anzahl notwendiger Geschäftsführer kann daher durch den Gesellschaftsvertrag bestimmt werden; enthält dieser keine Regelungen, entscheidet die nach $§ 46$ Nr. 5 GmbHG für die Bestellung der Geschäftsführer zuständige Gesellschafterversammlung mit einfacher Mehrheit auch darüber, wie viele ernannt werden sollen ${ }^{203}$.

Auch die Dauer der Geschäftsführertätigkeit kann durch die Satzung geregelt werden. Eine Mindest- oder Höchstgrenze gibt das Gesetz hier nicht vor, so dass bei Fehlen einer ausdrücklichen Regelung in der Satzung die Bestellung als Geschäftsführer bis auf Widerruf auf Lebenszeit erfolgt ${ }^{204}$.

Anders als in den Niederlanden können nur natürliche Personen zu Geschäftsführern bestellt werden; juristische Personen können nicht die Geschäftsführung einer $\mathrm{GmbH}$ übernehmen (§ 6 Abs. 2 Satz $1 \mathrm{GmbHG})^{205}$. Als Eignungsvoraussetzung verlangt $§ 6$ Abs. 2 GmbHG außerdem, dass es sich bei dem Geschäftsführer um eine unbeschränkt geschäftsfähige Person handelt, die nicht wegen Konkursdelikten nach den $§ \S 283-283 d$ StGB vorbestraft ist (absolute Ausschlussgründe). Keinen Ausschlussgrund im Sinne des § 6 Abs. 2 Satz 2 GmbHG stellt die Verurteilung wegen einer anderen Straftat (insbesondere Untreue oder Steuerhinterziehung) oder wegen einer Insolvenzstraftat nach ausländischem Recht dar ${ }^{206}$. Relative Ausschlussgründe vom Geschäftsführeramt sind Untersagungen der Ausübung eines Berufs, Berufszweigs, Gewerbes oder Gewerbezweigs durch gerichtliches Urteil oder durch vollziehbare Entscheidung einer Verwaltungsbehörde ( $\$ 6$ Abs. 2 Satz 3 GmbHG). Der Gesellschaftsvertrag kann auch hier beliebige weitere persönliche Merkmale vorschreiben, die ein Geschäfts-

201 Zur Unzulässigkeit der Übertragung der Geschäftsführerbefugnisse auf einen Dritten, beispielsweise einen Prokuristen: BGHZ 13, 61, 65; 34, 27, 31; 64, 72, 76. Im Geltungsbereich des MitbestG bzw. des MontanMitbestG sogar zwei, da als weitere Geschäftsführer ein Arbeitsdirektor zu bestellen ist ( 33 MitbestG, $\S$ 13 MontanMitbestG, § 13 MitbestErgG); vgl. hierzu nur Baumbach/Hueck/Hueck/Fastrich $\S 6$ Rn. 5 m. w. $\mathrm{N}$.

202 Ohne Geschäftsführer würde eine $\mathrm{GmbH}$ nicht eingetragen. Etwas anderes ist, wenn die Geschäftsführer nach der Eintragung wegfallen oder an der Geschäftsführung gehindert sind; dann ist in dringenden Fällen allerdings nur für die Zeit bis zur Behebung des Mangels (im Zweifel also der Bestellung eines neuen Geschäftsführers durch die Gesellschafterversammlung) durch das Gericht ein Notgeschäftsführer zu bestellen (§ 29 BGB). Wird der Mangel auf Dauer nicht behoben und auch kein neuer Geschäftsführer bestellt, so liegt ein wichtiger Auflösungsgrund vor ( $\$ 61 \mathrm{GmbHG})$. Siehe dazu Raiser S. $540 \mathrm{f}$.

Baumbach/Hueck/Hueck/Fastrich $\S 6$ Rn. 5; Hachenburg/Ulmer $\S 6$ Rn. 6; Scholz/Schneider $\S 6$ Rn. 8; Raiser, S. 538 ff.; Grunewald S. 339 ff.; Süß/Wachter/Terbrack S. 559. Scholz/Schneider $\$ 6$ Rn. 7 f.; Süß/Wachter/Terbrack S. $551 \mathrm{ff}$. Süß/Wachter/Terbrack S. 551 ff.; Heckschen/Heidinger/Heidinger $§ 4$ Rn. 21 ff.

206 Scholz/Schneider $\S 6$ Rn. 7 f.; LG Köln GmbHR 1995, 656 = MittRhNotK 1995, 237; Wachter NotBZ 2001, 233, 234; Süß/Wachter/Terbrack S. 559 f. 
führer mitbringen soll, wie etwa ein Mindestalter oder die Zugehörigkeit zu einer Familie oder Gesellschaftergruppe ${ }^{207}$.

Nicht erforderlich ist, dass ein Geschäftsführer die deutsche Staatsangehörigkeit besitzt, auBerdem nicht dass er seinen Wohnsitz oder aber seinen gewöhnlichen Aufenthaltsort im Inland hat; er muss auch nicht der deutschen Sprache mächtig sein ${ }^{208}$. Streitig ist allerdings, inwieweit ein Ausländer zumindest jederzeit die Möglichkeit haben muss, in die Bundesrepublik Deutschland einzureisen. Teilweise wird vertreten, ein Ausländer könne seinen gesetzlichen Pflichten als Geschäftsführer nicht jederzeit nachkommen, wenn er diese Möglichkeit nicht hätte ${ }^{209}$. Unproblematisch sind danach die Fälle, in denen der ausländische Geschäftsführer über die Staatsangehörigkeit eines EU-Mitgliedstaats verfügt, da er als solcher schon aufgrund des Gemeinschaftsrechts jederzeit nach Deutschland einreisen kann ${ }^{210}$. Nicht zu beanstanden ist die Bestellung eines Ausländers zum Geschäftsführer danach außerdem, wenn der ausländische Geschäftsführer für eine Dauer von bis zu drei Monaten auch ohne Visum in die Bundesrepublik Deutschland einreisen kann ${ }^{211}$. Nach anderer Auffassung bestehen keine praktischen Erfordernisse für eine solche jederzeitige Einreisemöglichkeit, da die realen Möglichkeiten moderner Kommunikationsmittel eine Erfüllung der Geschäftsführerpflichten auch ohne jederzeitige Einreisemöglichkeit erlauben ${ }^{212}$.

\section{aa) Bestellung und Abberufung}

Die Bestellung der Geschäftsführer ist regelmäßig Aufgabe der Gesellschafterversammlung ( $\S 6$ Abs. 3 Satz 2, 46 Nr. 5 GmbHG). Im Gesellschaftsvertrag kann allerdings von dieser Regel abgewichen werden ${ }^{213}$. Verbleibt es mangels entsprechender Satzungsregelung bei der

207 Raiser S. 542. Zu den Schwierigkeiten die solche Festlegungen im Rahmen des Allgemeinen Gleichbehandlungsgesetzes bringen (AGG) vgl. nur Krause AG 2007, 392. Nach § 44 GmbHG können auch stellvertretende Geschäftsführer berufen werden. Sie sind regelmäßig im Innenverhältnis in ihrer Geschäftsführung beschränkt; im Aussenverhältnis, also hinsichtlich der Vertretungsmacht und der Haftung sind sie hingegen den (ordentlichen) Geschäftsführern gleichgestellt und werden auch ohne Stellvertreter-Zusatz als Geschäftsführer in das Handelsregister eingetragen.

208 Raiser S. 541 f.; OLG Frankfurt NZG 2001, 757; OLG Zweibrücken NZG 2001, 857 m.Anm. Wachter; Roth/Altmeppen/Altmeppen $\S 6$ Rn. 14; allgemein dazu Heckschen/Heidinger/Heidinger $\S 4$ Rn. 25 ff..

209 So etwa OLG Zweibrücken GmbHR 2001, 435 sowie OLG Hamm MittBayNot 1999, 579; weitere Nachweise bei Wachter NotBZ 2001, 233, 235.

210 EuGH NZG 1998, 809, 811.

211 OLG Frankfurt NZG 2001, 757.

212 OLG Dresden GmbHR 2003, 537 m. zust. Anm. Wachter ZIP 1999, 1577; vgl. allgemein zu Vorstehendem auch Süß/Wachter/Terbrack S. 560; Heckschen/Heidinger/Heidinger $§ 4$ Rn. 25 ff., letzterer m. zahlreichen N. aus der Praxis, Literatur und Rechtsprechung.

213 In der Praxis finden sich in den Gesellschaftsverträgen häufig Bestellungssonderrechte eines Gesellschafters oder einer Gesellschafterfamilie. Nicht selten ist auch die Übertragung der Bestellungskompetenz auf einen Aufsichtsrat oder Beirat vorgesehen. Unzulässig wäre hingegen eine Regelung, wonach die Bestellungskompetenz den vorhanden Geschäftsführern übertragen wird, denn hierdurch würde die zweigliedrige Orga- 
Bestellungskompetenz der Gesellschafterversammlung, so bedarf es zur Bestellung der Geschäftsführer eines Beschlusses der Gesellschafter mit einfacher Mehrheit der abgegebenen Stimmen (§ 47 Abs. 1 GmbHG). Auch hier kann der Gesellschaftsvertrag abweichende Regelungen bezüglich der Mehrheitserfordernisse festlegen ${ }^{214}$.

Bei einer Regelung der Bestellung des Geschäftsführers in der Satzung kann diese entweder als unechter oder als echter Satzungsbestandteil ausgestaltet sein. Bildet die Satzungsbestimmung einen unechten Bestandteil, so ist - mangels anders lautender Bestimmungen - davon auszugehen, dass die Bestellung nur bei Abschluss und Beurkundung des Gesellschaftsvertrages erfolgen soll. Die Dauer der Bestellung, die Abberufung, die Amtsniederlegung und die Neubestellung von Geschäftführern richten sich hingegen nach allgemeinen Regeln. Häufiger ist die Bestellungskompetenz zugunsten einzelner Gesellschafter als echter Satzungsbestandteil geregelt. Hierbei wird einem oder mehreren Gesellschaftern das Recht eingeräumt, entweder den oder die Geschäftführer zu bestimmen, so dass die Gesellschafter bei der Bestellung an die getroffene Wahl gebunden sind oder die Bestellung selbst vorzunehmen oder aber selbst die Geschäftsführung zu übernehmen ${ }^{215}$.

Das Amt des Geschäftsführers endet automatisch, wenn bei ihm die Voraussetzungen des $\S 6$ Abs. 2 GmbHG entfallen, er verstirbt oder seine Bestellung auf andere Weise endet, wie etwa durch Zeitablauf oder wenn die Gesellschaft, in der er als Organ bestellt ist durch eine aufnehmende Verschmelzung erlischt. Auch ist der Geschäftsführer berechtigt sein Amt jederzeit - außer zur Unzeit, die dann vorliegt, wenn die Amtsniederlegung rechtsmissbräuchlich wäre, etwa weil der Geschäftsführer durch die Amtsniederlegung seiner Verpflichtung zur Stellung des Insolvenzantrags entgehen will - niederzulegen. Die Niederlegungserklärung ist gegenüber dem Organ abzugeben, das für die Bestellung zuständig gewesen ist, d.h. soweit keine anderweitige Regelung in der Satzung getroffen worden ist gegenüber der Gesellschafterversammlung ${ }^{216}$.

Schließlich kann die Bestellung eines Geschäftsführers grundsätzlich jederzeit durch die Gesellschafter widerrufen werden (§38 Abs. 1 GmbHG). Auch der Widerruf der Bestellung (die Abberufung) erfolgt - in Ermangelung anderer Satzungsregelungen - durch Beschlussfassung

nisationstruktur der GmbH aufgehoben. Zulässigkeit und Unzulässigkeit der zahlreich vorkommenden Bestellungsregelungen sind bereits diverse Male höchstrichterlich durchgeprüft worden; vgl. insoweit nur RGZ 165, 68; 170, 358; BGH BB 1962, 196; GmbHR 1982, 129; WM 1989, 250. Vgl. hierzu auch Raiser S. 553. Scholz/Schneider $\$ 6$ Rn. 27 ff.; Süß/Wachter/Terbrack S. 560 f.; Grunewald, S. 241 f.

215 Vgl. nur Raiser S. 409f und S. 460. Zur Bedeutung von Vorschlagsrechten in der Satzung siehe auch OLG Hamm ZIP 1986, 1188 und OLG Düsseldorf WM 1990, 265.

216 Vgl. allgemein zu den Beendigungsgründen für die Organstellung Scholz/Schneider $§ 6$ Rn. 27 ff. und $\S 38$ Rn. 4; Baumbach/Hueck/Zöllner/Noack § 38 Rn. 77 ff.; Süß/Wachter/Terbrack S. 560 f.; Grunewald, S. 241 f. Speziell die Amtsniederlegung mit ihren materiell-rechtlichen Anforderungen und praktischen Konsequenzen beschreibt Heckschen/Heidinger/Heidinger $\S 4$ Rn. 41 ff. 
in der Gesellschafterversammlung mit einfacher Mehrheit der abgegebenen Stimmen $(\S \S 47 \mathrm{f}$. $\mathrm{GmbHG})^{217}$.

Jede Änderung in der Person der Geschäftsführer ist zur Eintragung in das Handelsregister anzumelden und durch entsprechenden Abberufungsbeschluss, Niederlegungserklärung oder Sterbeurkunde nachzuweisen. Anmeldepflichtig sind damit insbesondere Neubestellung, Ausscheiden und Amtsniederlegung (vgl. § 39 Abs. 1 GmbHG) $)^{218}$.

Die Eintragung der angemeldeten Änderungen hat, außer wenn sie eine Änderung der gesellschaftsvertraglich geregelten Vertretungsmacht zum Inhalt hat, lediglich einen deklaratorischen Effekt. Der Geschäftsführer ist somit bereits in dem Zeitpunkt in dem nach dem Inhalt des Beschlusses seine Bestellung wirksam werden soll, für die $\mathrm{GmbH}$ handlungsbefugt und berechtigt, allerdings kann er ohne Handelsregistereintragung den Nachweis seiner Vertretungsberechtigung nur schwerlich führen ${ }^{219}$.

Die Bestellung als körperschaftlicher Akt ist von dem zugrunde liegenden Anstellungs- oder Gesellschaftsverhältnis zu unterscheiden. Es handelt sich insoweit um verschiedene Rechtsverhältnisse mit jeweils eigenem rechtlichem Schicksal, das heißt, die Beendigung des einen Rechtsverhältnisses hat nicht zwangsläufig auch das Ende des anderen Rechtsverhältnisses zur Folge. In der Praxis sind allerdings so genannte Kopplungsklauseln üblich und auch zulässig, mit deren Hilfe ein Gleichlauf beider Rechtsverhältnisse bewirkt werden kann, indem für den Fall, dass das Organverhältnis durch Abberufung endet auch die automatische Beendigung des Anstellungsverhältnisses geregelt wird ${ }^{220}$.

\section{bb) Vertretung der Gesellschaft; Aufgaben und Befugnisse}

Die Geschäftsführer vertreten die Gesellschaft gerichtlich und außergerichtlich ( $\$ 35$ Abs. 1 GmbHG). Diese auch als organschaftliche Vertretungsbefugnis der Geschäftsführer bezeichnete Vertretungsmacht ist unbeschränkt und im Interesse des Verkehrsschutzes auch nicht

217 Ein einzelner Minderheitsgesellschafter kann einen Geschäftsführer selbst bei Gefahr im Verzug nicht gegen den mehrheitlichen Willen der übrigen Gesellschafter abberufen. Ihm steht allerdings das Verfahren des einstweiligen Rechtschutzes offen, soweit es ihm gelingt ein Anspruchsinteresse zu begründen, $\S \S 916,940$ ZPO. Vgl. hierzu nur Raiser, S. 557 sowie allgemein dazu Süß/Wachter/Terbrack S. 561 und Heckschen/Heidinger/Heidinger $\S 4$ Rn. 53 ff., letzterer mit w. N. zu Rechtsprechung und Literatur.

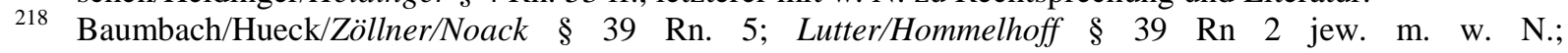
Süß/Wachter/Terbrack S. 561.

219 BGH GmbHR 1996, 50; OLG Hamburg NZG 2000, 698; Baumbach/Hueck/Zöllner/Noack § 39 Rn. 24 ff.; Lutter/Hommelhoff § 39 Rn 1; Michalski/Terlau/Schäfers § 39 Rn. 22; Süß/Wachter/Terbrack S. 561.

220 Vgl. nur in jüngster Zeit Grobys/Glanz NJW-Spezial 2007, 129 mit zahlreichen Nachweisen zu Rechtsprechung und Literatur. 
einschränkbar (§ 37 Abs. 2 Satz 1 GmbHG). Der Grundsatz der Unbeschränkbarkeit wird im Innenverhältnis freilich durch die Möglichkeit der Gesellschafter in der Satzung Bindungen an die Zustimmung der Gesellschafterversammlung oder eines Aufsichtsrats vorzusehen sowie umfassend Weisungen in der Gesellschafterversammlung zu erteilen relativiert ${ }^{221}$. Auch wird die Gesellschaft in offensichtlichen Fällen des Überschreitens der intern festgelegten Geschäftsführungsbefugnis durch die Regeln über den Missbrauch der Vertretungsmacht geschützt ${ }^{222}$.

Wenn der Gesellschaftsvertrag nichts anderes regelt, sind bei mehreren Geschäftsführern nur alle Geschäftsführer gemeinsam zur Vertretung ermächtigt (§ 35 Abs. 2 Satz 2 GmbHG). Sie müssen jedoch nicht gleichzeitig handeln ${ }^{223}$. Die Form der Vertretung kann von den Gesellschaftern abweichend von der gesetzlichen Gestaltung geregelt werden, § 35 Abs. 2 Satz 2 GmbHG. Hierbei haben die Gesellschafter zum einen die Möglichkeit in der Satzung die stets gewünschte Vertretungsform festzulegen; zum anderen kann in der Satzung lediglich die Ermächtigung der Gesellschafterversammlung oder eines Aufsichtsrats geregelt sein, die Vertretungsform im Einzelfall zu bestimmen ${ }^{224}$. Ist in der Satzung eine solche Ermächtigung enthalten, so kann die Gesellschafterversammlung durch Beschluss allen oder einzelnen Geschäftsführern Einzelgeschäftsführungsberechtigung erteilen und/oder sie von den Beschränkungen des Selbstkontrahierungsverbots und des Verbots der Mehrfachvertretung gemäß § 181 BGB befreien $^{225}$. Mit Wirkung im Innenverhältnis ist auch eine Verteilung der Geschäftsführung nach Bereichen, z.B. nach kaufmännischen und technischen Bereichen, möglich ${ }^{226}$.

221 Baumbach/Hueck/Zöllner/Noack $§ 35$ Rn. 78 ff.; Scholz/Schneider $§ 35$ Rn. 21 ff.; Süß/Wachter/Terbrack S. 561 f.; Heckschen/Heidinger/Heidinger $\S 4$ Rn. 2 ff.

222 BGH WM 1984, 305, 306 sowie schon BGH WM 1972, 1380 und RGZ 134, 67, 71; vgl. auch BGH WM 1983, 83, 85 und BGH WM 1975, 658 in denen engere Maßstäbe für die Feststellung eines Missbrauchstatbestands gesetzt werden. Allgemein dazu Baumbach/Hueck/Zöllner/Noack § 35 Rn. 159 ff. m. vielen w. N. BGH WM 1986, 315.

224 Umstritten ist, ob die Regelung der Vertretungsverhältnisse auch den Geschäftsführeren selbst überlassen werden kann, Raiser S. 547 f. Dagegen wird zutreffend eingewandt, dass mit der Gesamtvertretungsanordnung den Gesellschafter ein Kontrollinstrument zur Verfügung steht, was nicht durch die zu kontrollierenden Personen beseitigt können werden sollte. Vgl. zum Streitstand nur Hachenburg/Mertens § 35 Rn. 78; Scholz/Schneider $\S 35$ Rn. 67 einerseits und Baumbach/Hueck/Zöllner $§ 35$ Rn. 54 und Lutter/Hommelhoff $\S 35 \mathrm{Rn} .33$ andererseits.

225 Eine von dem gesetzlichen Grundsatz der Gesamtvertretung abweichende Regelung der Vertretungsmacht ohne entsprechende Ermächtigung im Gesellschaftsvertrag ist unwirksam; siehe nur Hachenburg/Mertens § 35 Rn. 78; Scholz/Schneider § 35 Rn. 64 ff.; Baumbach/Hueck/Zöllner/Noack $§ 35$ Rn. 106; Roth/Altmeppen $\S 35$ Rn. 36; Michalski/Lenz § 35 Rn. 49; Rowedder/Schmidt-Leithoff/Koppensteiner $§ 35$ Rn. 53.

226 Allgemein zum Umfang der Vertretungsmacht Heckschen/Heidinger/Heidinger $§ 4$ Rn. 2 ff. m. w. N. 


\section{cc) Verantwortung und Haftungsregime}

Die Geschäftführer haben in den Angelegenheiten der Gesellschaft die Sorgfalt eines ordentlichen Geschäftsmannes anzuwenden ( $\$ 43$ Abs. $1 \mathrm{GmbHG}$ ). Sie haben danach für diejenigen Kenntnisse und Fähigkeiten einzustehen, die für den Geschäftszweck der Gesellschaft üblicherweise erforderlich sind ${ }^{227}$ $\S 43 \mathrm{GmbHG}$ handelt allerdings nur von den Pflichten, der Verantwortung und Haftung des Geschäftsführer gegenüber der Gesellschaft Verletzen die Geschäftsführer ihre Pflichten nach Maßgabe des $§ 43 \mathrm{GmbHG}$, so steht der Anspruch allein der Gesellschaft zu. Er kann allerdings unter bestimmten Voraussetzungen auch von den Gesellschaftern geltend gemacht werden. Auch mögen sich Gläubiger der Gesellschaft einen solchen Anspruch der Gesellschaft pfänden und überweisen lassen. Aus der Geschäftsführung heraus können sich allerdings auch unmittelbare Haftungsansprüche gegenüber den Geschäftsführern zugunsten der Gesellschafter (z.B. bei verbotener Einlagenrückgewähr) sowie zugunsten Dritter (besonders praxisrelevant sind hier Haftungsfälle wegen Maßnahmen beziehungsweise unterlassenen Maßnahmen des Geschäftsführers im Vorfeld einer Krise der Gesellschaft beispielsweise nach Maßgabe des $\S 64 \mathrm{GmbHG})$ ergeben. Sowohl im GmbHG (vgl. nur $\S \S 30,31$ und $64 \mathrm{GmbHG)}$ als auch außerhalb hiervon (vgl. nur $\S 823$ BGB) finden sich hierzu eine ganze Reihe von Haftungstatbeständen ${ }^{228}$.

\section{b) Gesellschafter und Geschäftsanteile}

\section{aa) Rechtsstellung der Gesellschafter}

Die Rechte des einzelnen Gesellschafters sind von denen der Gesellschaftergesamtheit zu unterscheiden. Die Rechte einzelner Gesellschafter sind echte Rechte und Pflichten, die in erster Linie im zweiten Abschnitt des GmbH-Gesetzes ( $§ 13$ ff. GmbHG) ihren Niederschlag gefunden haben. Wenn hingegen die Gesellschaftergesamtheit angesprochen wird ( $\S 45$ bis $51 \mathrm{GmbHG})$, so geht es nicht um einzelne Rechte und Pflichten, sondern um die Rechte der Gesamtheit der Gesellschafter als oberstes Willensbildungsorgan der Gesellschaft ${ }^{229}$. Die Gesellschafter können ihre Befugnisse als Gesellschaftergesamtheit im Gesellschaftsvertrag be-

227 Baumbach/Hueck/Zöllner, § 43 Rn. 9 Rowedder/Koppensteiner $§ 43$ Rn. 5; Scholz/Schneider $§ 43$ Rn. $1 \mathrm{ff}$.

228 Nicht vorgeschrieben im GmbH-Gesetz ist die Einrichtung eines Kontrollsystems wie es in der Aktiengesellschaft nach Maßgabe von $\S 91$ Abs. 2 AktG existiert. Allerdings ist in der Beratungspraxis in den Gesellschaften auf die Einrichtung eines solchen Systems auch in der GmbH hinzuwirken, damit sich insbesondere auch Mitgeschäftsführer bei einer mehrgliedrigen Geschäftsführung nicht für Fehlverhalten anderer Mitgeschäftsführer verantworten müssen. Allgemein zu dem Thema Haftung und Verantwortlichkeit Raiser, S. 564 ff.; Süß/Wachter/Terbrack S. 562; Scholz/Schneider $§ 43$ Rn. 2 f. letzterer mi zahlreichen w. N. Die Gesellschafter- und Geschäftsleiterhaftung bei europäischen Auslandsgesellschaften mit tatsächlichem Inlandssitz in Deutschland diskutiert Eidenmüller NJW 2005, 1618. 
liebig festlegen. Unentziehbar und unübertragbar sind Entscheidungen zu grundlegenden Fragen sowie zu Änderungen der Satzung; ansonsten können die Gesellschafter die ihnen zustehenden Befugnisse beliebig auf andere Organe (z.B. Geschäftsführer, Beirat) durch Satzungsangelegenheit übertragen ${ }^{230}$. Des Weiteren können die Gesellschafter über ihr umfassendes Weisungsrecht jederzeit - auch gegen den Willen des Geschäftsführers - in das operative Geschehen der Gesellschaft eingreifen (vgl. § 37 Abs. 1 GmbHG) ${ }^{231}$.

Eine den Befugnissen der Gesellschafter entsprechende Pflicht zur Wahrnehmung ihrer Rechte besteht grundsätzlich nicht. Nur in Ausnahmefällen wird man etwas Derartiges kraft Treuepflicht annehmen können ${ }^{232}$.

\section{bb) Registrierung der Gesellschafter}

Die Gesellschafter werden nicht im Handelsregister eingetragen. Allerdings ist bei der Erstanmeldung der Gesellschaft nach $\S 8$ Abs. 1 Nr. 3 GmbHG eine von den Geschäftsführern zu erstellende Liste der Gesellschafter mit zum Handelsregister einzureichen, aus der sich Name, Vorname, Geburtsdatum, Wohnort und Stammeinlage jedes Gesellschafters ergeben muss. Diese wird vom Handelsregister verwahrt und kann dort von jedermann eingesehen werden. Bei Veränderungen in den Personen der Gesellschafter oder dem Umfangs ihrer Beteiligung ist die Liste von den Geschäftsführern gemäß $§ 40 \mathrm{GmbHG}$ zu aktualisieren und zur Aufbewahrung zum Handelsregister einzureichen ${ }^{233}$.

Damit die Geschäftsführer ihrer Verpflichtung zur Einreichung einer aktualisierten Liste der Gesellschafter nachkommen können und damit die Gesellschaft Kenntnis über ihre aktuellen Gesellschafter erhält, gilt im Falle einer Veräußerung von Geschäftsanteilen nur derjenige als Gesellschafter, dessen Erwerb unter Nachweis des Übergangs bei der Gesellschaft angemeldet worden ist (vgl. § 16 Abs. $1 \mathrm{GmbHG})^{234}$.

229 Vgl. nur Scholz/K. Schmidt § 45 Rn. 1 ff. und Baumbach/Hueck/Zöllner $§ 45$ Rn. 2 f. jeweils m. w. N.

230 Hachenburg/Ulmer $\S 53$ Rn. 2; Scholz/Priester $\S 53$ Rn. 19; Scholz/K. Schmidt § 45 Rn. 1; Raiser, S. 579 ff.; Süß/Wachter/Terbrack S. 551 f.; allgemein dazu Heckschen/Heidinger/Heckschen $§ 5$ Rn. 38 ff. m. w.N. Scholz/K. Schmidt § 45 Rn. 1; Raiser, S. 579 ff.; Süß/Wachter/Terbrack S. 551 f.

232 Scholz/Schneider $\S 40$ Rn. 3 mit zahlreichen Nachweisen zu Literatur und Rechtsprechung; Süß/Wachter/Terbrack S. 551 f. Umfassend zu den Mitgliedspflichten Raiser S. 469 ff.

233 Scholz/Schneider $\S 40$ Rn. 1 m. w. N.; Süß/Wachter/Terbrack S. 552.

234 Allerdings ist die Verpflichtung des $\S 16$ GmbHG auch ohne Einreichung einer Gesellschafterliste zu erfüllen. Die Anmeldung nach $\S 16 \mathrm{GmbHG}$ ist formlos möglich und kann vom Veräußerer wie auch vom Erwerber vorgenommen werden. Regelmäßig wird sie im Auftrag beider Parteien durch den Notar vorgenommen. Handelt es sich bei der Geschäftsanteilsübertragung um eine Umhängung im Konzern, so kann es vorteilhaft - da zeitsparend - sein dem in Vollmacht handelnden Rechtsanwalt zugleich eine Vollmacht der Gesellschaft zur Annahme einer solchen Anmeldung nach $\S 16$ GmbHG zu erteilen. Vgl. zu dem Ganzen Raiser, S. 508 f.; Süß/Wachter/Terbrack S. 552. 


\section{cc) Gesellschafterbeschlüsse}

Die von den Gesellschaftern in den Angelegenheiten der Gesellschaft zu treffenden Bestimmungen können in dreifacher Weise erfolgen, zum einen durch Fassung entsprechender Beschlüsse außerhalb einer Versammlung beispielsweise im schriftlichen Verfahren, zum anderen, falls die Zustimmung der Gesellschafter zu einer Maßnahme erforderlich ist, durch schriftliche oder mündliche Abgabe derselben oder drittens - wie es regelmäßig passiert durch Beschlussfassung in einer Gesellschafterversammlung ( $\S 47$ Abs. 1, 48 Abs. 1 $\mathrm{GmbHG})^{235}$.

\section{aaa) Formlose Beschlussfassung im allseitigen Einverständnis}

Stimmen alle Gesellschafter einer Beschlussfassung unter Verzicht auf die durch Gesetz und/oder Gesellschaftsvertrag vorgeschriebenen Form- und Fristerfordernisse zu, so ist eine Beschlussfassung auch außerhalb physischer Versammlungen gestattet, beispielsweise durch schriftliche Beschlussfassung im Umlaufverfahren oder gar telefonischen Rundruf, soweit nicht im Einzelfall zwingende Formvorschriften einer solchen Beschlussfassung entgegenstehen $^{236}$.

\section{bbb) Gesellschafterversammlung}

In der GmbH gilt nach ganz überwiegender Ansicht der Grundsatz der sachlichen Allzuständigkeit der Gesellschafter(Versammlung). Das bedeutet, dass die Gesellschafter über den Zuständigkeitskatalog des $\S 46 \mathrm{GmbHG}$ hinaus berechtigt sind, Kompetenzen an sich zu ziehen und Beschlüsse auch im Zuständigkeitsbereich der Geschäftsführung zu fassen ${ }^{237}$. Andererseits kann die Gesellschafterversammlung ihr nach Maßgabe des § 46 GmbHG zustehende Kompetenzen auch auf andere Organe verlagern oder ergänzend zu § $46 \mathrm{GmbHG}$ eigene weitere Kompetenzen schaffen. Die Grenze der Disponibilität der Gesellschafterzuständigkeiten

Süß/Wachter/Terbrack S. 556; Raiser, S. 583 ff.; Ausführlich zu dem Ganzen Heckschen/Heidinger/Heckschen $§ 5 \mathrm{Rn} .17 \mathrm{ff}$.

236 Vgl. zu dieser Problematik BGH ZIP 1999, 1352 und BGH ZIP 1998, 22; Scholz/K.Schmidt § 48 Rn. 71 ; Grunewald S. 354.

237 Baumbach/Hueck/Zöllner § 46 Rn. 89; Baumbach/Hueck/Zöllner/Noack § 37 Rn. 15 ff.; Hachenburg/Mertens $\S 37$ Rn. 15 ff; Michalski/Lenz § 37 Rn. 10. 
bildet das dem GmbH-Recht immanente Prinzip der Trennung von Gesellschafterversammlung als oberstes Willensbildungsorgan und Geschäftsführung als Leitungsorgan ${ }^{238}$.

\section{ccc) Einberufung und Formalien}

Das GmbH-Recht regelt das Verfahren zur Einberufung und Durchführung der Gesellschafterversammlung nur sehr lückenhaft ${ }^{239}$. Im Hinblick auf die Einberufungszuständigkeit bestimmt $\S 49$ GmbHG, dass die Geschäftsführer zur Einberufung der Gesellschafterversammlungen berechtigt (Abs. 1) und nach Maßgabe der Absätze 2 und 3 sogar verpflichtet sind, wenn das Gesetz oder der Gesellschaftsvertrag dies ausdrücklich bestimmen oder es im Interesse der Gesellschaft erforderlich erscheint. Sind mehrere Geschäftsführer bestellt, so ist jeder einzelne von ihnen zur Einberufung befugt und zwar auch dann, wenn die Geschäftsführer ansonsten nur gemeinsam zur Vertretung der Gesellschaft berechtigt sind ${ }^{240}$.

Darüber hinaus ist auch ein Aufsichtsrat (und gegebenenfalls bei Vorliegen weiterer Voraussetzungen auch ein Beirat) zur Einberufung der Gesellschafterversammlung berechtigt, falls ein solches Gremium in der Gesellschaft existiert. Schließlich sind nach Maßgabe des $§ 50$ GmbHG auch Gesellschafter zur Einberufung einer Gesellschafterversammlung berechtigt, wenn diese mindestens $10 \%$ des Gesellschaftskapitals auf sich vereinen und zuvor eine erfolglos gebliebene Aufforderung an die Geschäftsführung zur Einberufung einer Gesellschafterversammlung gerichtet haben ${ }^{241}$.

Die Einberufung erfolgt nach $\S 51$ Abs. 1 GmbHG durch eingeschriebenen Brief, und zwar mindestens eine Woche vor dem Versammlungstermin ${ }^{242}$. Aus dem Inhalt der Einladung haben sich neben der Ankündigung dass eine Gesellschafterversammlung abgehalten werden soll, insbesondere Identität der Gesellschaft sowie des Einberufungsorgans, wie auch Ort und Zeit der Versammlung zu ergeben ${ }^{243}$. Des Weiteren ist bei der Berufung, also grundsätzlich ebenfalls innerhalb der Ein-Wochen-Frist des $§ 51$ Abs. 1 GmbHG, die Tagesordnung mitzuteilen ( $\$ 51$ Abs. 2 GmbHG). Eine Nachreichung von Tagesordnungspunkten ist allerdings,

238 Baumbach/Hueck/Zöllner $§ 46$ Rn. 5 f. und Rn. 92 ff.; Scholz/K.Schmidt $\S 45$ Rn. 9 sowie $§ 46$ Rn. 2; Hachenburg/Hüffer $\S 45$ Rn. 19; Rowedder/Schmidt-Leithoff/Koppensteiner $\S 45$ Rn. 7 ff. jew. m. w. N.; Süß/Wachter/Terbrack S. 556. Siehe auch die unter Fn. 228 Genannten.

239 Scholz/K.Schmidt § 49 Rn. 1 ff.; Grunewald S. 354; Süß/Wachter/Terbrack S. 556 f.

240 BayObLG NJW-RR 2000, 181 = ZIP 1999, 1597, 1599. Vgl. dazu allgemein Heckschen/Heidinger/Heckschen $§ 5$ Rn. 1 ff.; Raiser, S. 584; Süß/Wachter/Terbrack S. 556; Grunewald S. 354.

241 Zu diesem Minderheitenrecht vgl. BGH ZIP 1998, 1269 m. Anm. Riegger; Heckschen/Heidinger/Heckschen $\S 5$ Rn. 1 ff..

242 Statt aller Scholz/K.Schmidt § 51 Rn. 13 ff. m. zahlreichen w. N.; vgl. auch Süß/Wachter/Terbrack S. 556 und Grunewald S. 354; Zur Fristberechnung BGHZ 100, 264.

243 Baumbach/Hueck/Zöllner § 51 Rn. 11 ff.; Süß/Wachter/Terbrack S. 556; Grunewald S. 354. 
ohne dass dies eine Fehlerhaftigkeit der hierüber gefassten Beschlüsse nach sich zieht, noch drei Tage vor der Versammlung möglich (§ 51 Abs. $4 \mathrm{GmbHG}^{244}$.

Ist im Gesellschaftsvertrag kein besonderer Ort für die Abhaltung der Gesellschafterversammlungen vorgesehen, so findet diese im Zweifel am statutarischen Sitz der Gesellschaft statt ${ }^{245}$. Mit der Zustimmung sämtlicher Gesellschafter ${ }^{246}$ ist allerdings auch die die Festlegung eines anderen, auch im Ausland ${ }^{247}$ befindlichen Ortes zulässig ${ }^{248}$.

Das GmbHG enthält keine Regelungen im Hinblick auf die Durchführung der Gesellschafterversammlung. In der Praxis finden sich daher zwecks Vermeidung diesbezüglicher Unklarheiten und Streitereien regelmäßig entsprechende Bestimmungen im Gesellschaftsvertrag; oftmals betreffend den Vorsitz und die Beschlussfähigkeit der Gesellschafterversammlung ${ }^{249}$.

Auch eine allgemeine Vorschrift über Niederschriften über die Gesellschafterversammlungen sind dem GmbHG - mit Ausnahme der Protokollierungspflicht in $\S 48$ Abs. 3 GmbHG für Ein-Personen-Gesellschaften - unbekannt. Daher ist eine generelle Protokollierungspflicht nach Maßgabe des $\S 48$ Abs. 3 GmbHG regelmäßig in den Gesellschaftsverträgen vorgese$\operatorname{hen}^{250}$.

\section{ddd) Stimmrecht und Vertretung}

Zur Teilnahme an der Gesellschafterversammlung ist jeder Gesellschafter berechtigt; darauf, ob er auch mit abstimmen kann, kommt es nicht $\mathrm{an}^{251}$. Ein Recht auf Teilnahme an der Gesellschafterversammlung haben auch Bevollmächtigte von Gesellschaftern, sofern nicht in ihrer Person ein wichtiger Grund liegt, der gegen ihre Teilnahme spricht ${ }^{252}$. Die Teilnahme sonstiger Dritter, wie auch eines Beistands oder Beraters, kann durch den Gesellschaftsvertrag oder

\footnotetext{
244 Statt aller Baumbach/Hueck/Zöllner $§ 51$ Rn. 11 ff. m. w. N.

245 Analog $§ 121$ Abs. 4 S. 1 AktG, vgl. BGH WM 1985, $568=$ GmbHR 1985, 256.

246 BGH GmbHR 1985, 256, 257.

247 OLG Düsseldorf GmbHR 1990, 169, 171.

248 Baumbach/Hueck/Zöllner $§ 51$ Rn. 15; zum Ganzen Süß/Wachter/Terbrack S. 556.

249 Allgeimen zu den Formalitäten einer Gesellschafterversammlung mit Empfehlungen zur praktischen Durchführung Heckschen/Heidinger/Heckschen $§ 5$ Rn. 17 ff. sowie Raiser S. 579 ff.; vgl. auch den Überblick bei Süß/Wachter/Terbrack S. 556

250 Vgl. dazu nur Baumbach/Hueck/Zöllner § 47 Rn. 28 sowie § 48 Rn. 22 ff. m. w. N.; Süß/Wachter/Terbrack S. 556.

251 BGH NJW 1972, 2225; BGH DB 1985, 1837 = WM 1985, 568.

252 Süß/Wachter/Terbrack S. 558; Scholz/K. Schmidt § 48 Rn. 20; Grunewald S. 354 f.; a. A. Lutter/Hommelhoff $\S 48$ Rn. 4 unter Hinweis auf die typisch personalistische Struktur der GmbH. Zu den an die Vollmacht zu stellenden Wirksamkeitsvoraussetzungen: $§ 47$ Abs. 3 GmbHG sowie $\S \S 164$ ff. BGB.
} 
durch einen mit einfacher Mehrheit gefassten Gesellschafterbeschluss gestattet werden ${ }^{253}$. Nach vereinzelter Auffassung sollen die Gesellschafter im Einzelfall aufgrund ihrer Treuepflicht untereinander sogar verpflichtet sein, die Anwesenheit eines Beistands zu gestatten ${ }^{254}$.

Wenn das Gesetz oder der Gesellschaftsvertrag nichts anderes bestimmt, werden Gesellschafterbeschlüsse mit einfacher Mehrheit der abgegebenen Stimmen gefasst ( $§ 47$ Abs. 1 GmbHG) $)^{255}$. Nach $\S 47$ Abs. 2 GmbHG gewähren je $50 €$ eines Geschäftsanteils eine Stim$\mathrm{me}^{256}$. Zur Stimmabgabe ist im Grundsatz jeder Gesellschafter berechtigt. Auch bei Verpfändung; Pfändung oder Nießbrauch bleibt grundsätzlich der Gesellschafter stimmberechtigt und nicht etwa der aus dem Geschäftsanteil wirtschaftliche Berechtigte ${ }^{257}$. Geschäftsunfähige und beschränkt geschäftsfähige Gesellschafter werden durch ihren gesetzlichen Vertreter vertreten $^{258}$. Das Stimmrecht ist dem Gesellschafter nur in den Fällen genommen, in denen er durch die Beschlussfassung entlastet beziehungsweise von einer Verbindlichkeit befreit werden soll $^{259}$. Gleiches gilt, wenn über die Vornahme eines Rechtsgeschäfts oder die Einleitung oder Erledigung eines Rechtsstreits mit dem Gesellschafter zu beschließen ist oder sonstige den jeweiligen Gesellschafter betreffende gesellschaftsvertragliche Regelungen betroffen sind ${ }^{260}$.

Qualifizierte Mehrheiten sind gesetzlich zur Änderung des Gesellschaftsvertrages sowie zur Zustimmung zu strukturändernden Maßnahmen (wie etwa Verschmelzungen oder den Abschluss von Unternehmensverträgen als verpflichtete Gesellschaft) vorgesehen. Auch bedarf es regelmäßig zur Vornahme eines solchen Beschlusses der notariellen Beurkundung (vgl. für Satzungsänderungen $§ 53$ Abs. 2 GmbHG). Die vorgenannten Beschlüsse entfalten darüber hinaus erst dann rechtliche Wirkung, wenn sie in das Handelsregister eingetragen sind ( $\$ 54$ Abs. 3 GmbHG für die Satzungsänderung) $)^{261}$

253 Vgl. dazu ausführlich Baumbach/Hueck/Zöllner § 48 Rn. 6; Süß/Wachter/Terbrack S. 556; Grunewald S. 354.

254 Scholz/K. Schmidt § 48 Rn. 22; Grunewald S. 355.

255 Baumbach/Hueck/Zöllner $\$ 47$ Rn. 23; aus der Rechtsprechung dazu OLG Celle GmbHR 1998, 140.

256 Vgl. hierzu nur Baumbach/Hueck/Zöllner $\$ 47$ Rn. 66 ff. der sich auch zur Euro-Umstellung und abweichenden Gestaltungsmöglichkeiten äußert.

257 Raiser, S. 591 f. Ausführlich zum Stimmrecht Baumbach/Hueck/Zöllner $§ 47$ Rn. 32 ff.

258 Es ist in der Praxis nicht unüblich, meist aus steuerlichen Erwägungen, Geschäftsanteile auf die minderjährigen Kinder eines Gesellschafters zu übertragen. Die hierbei entstehende Problematik, dass der Gesellschafter zugleich im eigenen Namen und im Namen der Kinder abstimmen muss ist unter dem Gesichtspunkt eines Verstoßes gegen $\S 1629$ Abs. 2 Satz 1, 1795 Abs. 2 in Verbindung mit § 181 BGB kontrovers diskutiert worden. Zuletzt hat der BGH in einem Urteil das eine KG betraf (BGHZ 65, 93) entschieden, das § 181 BGB auf Vertragsänderungen anwendbar sei, auf Beschlüsse zur Geschäftsführung hingegen nicht. Dem ist zu folgen. Vgl. hierzu Raiser, S. 591 f.

259 Zum Ruhen des Stimmrechts bei Gesellschaftseigenen Anteilen Baumbach/Hueck/Zöllner § 47 Rn. 57.

260 Baumbach/Hueck/Zöllner $\$ 47$ Rn. 60 ff.; Süß/Wachter/Terbrack S. 557.

261 Umfassend zur Satzungsänderung Heckschen/Heidinger/Heckschen § 5 Rn. 27 ff. m. zahlreichen w. N. zu Rechtsprechung und Literatur und Hinweisen zur Praxis. Aus der Kommentarliteratur vgl. statt aller Scholz/Priester § 53 Rn. 59 ff., § 54 Rn. 62; überblicksartig wird die Satzungsänderung beschrieben bei Süß/Wachter/Terbrack S. 558; Grunewald S. 356 f. 


\section{eee) Beschlussmängel}

Das GmbHG enthält keine Regelungen darüber, wie bei Beschlussmängeln verfahren werden soll. Nach der noch überwiegenden Ansicht in Judikatur und Literatur ist diese gesetzliche Lücke durch entsprechende Anwendung der aktienrechtlichen Bestimmungen ( $\S \S 241 \mathrm{ff}$. AktG) zu schließen; den Besonderheiten des $\mathrm{GmbH}$-Rechts wird durch Modifikationen der aktienrechtlichen Regelungen Rechnung getragen ${ }^{262}$. Danach ist ein mangelhafter Beschluss regelmäßig anfechtbar, ausnahmsweise nichtig (nach Maßgabe des Katalogs des $\S 241$ $\mathrm{AktG})^{263}$.

\section{dd) Verantwortung und Haftung}

Grundsätzlich sind die Gesellschafter allein zur Erbringung der auf das Stammkapital übernommenen Stammeinlage verpflichtet (vgl. §§ 19 und $24 \mathrm{GmbHG).} \mathrm{Daneben} \mathrm{besteht} \mathrm{keine}$ den Befugnissen entsprechende Pflicht der Gesellschafter zur Ausübung ihrer Teilnahme- und Kontrollrechte, es sei denn eine entsprechende Pflicht zur Geschäftsführung ist im Gesellschaftsvertrag für einzelne Gesellschafter vorgesehen. Fehlt eine solche Regelung im Gesellschaftsvertrag, so ist nur in Ausnahmefällen als Ausfluss der gesellschaftsrechtlichen Treupflicht eine Verpflichtung der Gesellschafter zur Wahrnehmung ihrer Rechte anzunehmen ${ }^{264}$.

Fehlt es an einer Handlung oder vorwerfbaren Unterlassung einer Maßnahme durch die Gesellschafter, so ist auch eine Haftung gegenüber der Gesellschaft oder Dritten über die Einlage hinaus nur schwerlich begründen. Greift der Gesellschafter beziehungsweise die Gesamtheit der Gesellschafter als Organ hingegen durch Weisungen oder faktische Einflussnahme in die Geschäftsführung ein, so ist eine entsprechende Verantwortung zu bejahen ${ }^{265}$.

262 Zur Entwicklung Baumbach/Hueck/Zöllner § 47 Rn. 20 m. w. N.; vgl. auch Süß/Wachter/Terbrack S. 557; Zöllner/Noack ZGR 1989, 525, 532 ff.; Grunewald S. 358 f.

263 Scholz/Priester $§ 53$ Rn. 59 ff., § 54 Rn. 62; Süß/Wachter/Terbrack S. 558; Grunewald S. 356 f.; Ausführlich zur Beschlussanfechtung der Beschlussfeststellungsklage und nichtigen Beschlüssen Heckschen/Heidinger/Heckschen $§ 5$ Rn. 46 ff.

264 Ausführlich zu Umfang und Reichweite der Mitgliedspflichten Raiser S. 469 ff. sowie zur Haftung ders. S. 489 ff.; vgl. auch Süß/Wachter/Terbrack S. 551 sowie umfassend hierzu Vetter ZGR 2005, 788.

265 Andere Fälle, in denen eine Durchgriffshaftung in der Vergangenheit bejaht worden sind, sind Fälle der materiellen Unterkapitalisierung der GmbH, Bestandsvernichtende Eingriffe und Fälle der Vermögensvermischung. Hierzu überblicksartig Grunewald S. 382; Süß/Wachter/Terbrack S. 551 ff. sowie Raiser, S. 490 und Vetter ZGR 2005, 788 mit jeweils zahlreichen Beispielen zur einschlägigen Rechtsprechung. Die Gesellschafter- und Geschäftsleiterhaftung bei europäischen Auslandsgesellschaften mit tatsächlichem Inlandssitz in Deutschland diskutiert Eidenmüller NJW 2005, 1618. 
ee) Geschäftsanteile der GmbH

\section{aaa) Zulässigkeit und Beschränkungen}

Obwohl die Geschäftsanteile an einer GmbH gemäß $§ 15$ GmbHG grundsätzlich frei veräuBerlich und vererblich sind, hat der Gesetzgeber an verschiedenen Stellen im Gesetz eine Übertragbarkeit beschränkt beziehungsweise die Erschwerbarkeit der Übertragung durch die Gesellschafter vorgesehen. So verbietet das Gesetz beispielsweise die Übernahme mehrerer Geschäftsanteile bei der Gründung ( $\$ 5$ Abs. 2 GmbHG), ermöglicht die Bildung unterschiedlich großer Geschäftsanteile, erschwert deren spätere Teilung ( $17 \mathrm{GmbHG}$ ), lässt die Verkörperung des Anteilsrechts in einem Wertpapier nicht zu und unterwirft die Veräußerung und Übertragung der notariellen Form ( $§ 15$ Abs. 3, 4 GmbHG $)^{266}$. Außerdem wird den Gesellschaftern die Möglichkeit gegeben, eine Übertragung durch Schaffung zusätzlicher Voraussetzungen in der Satzung, insbesondere der Anknüpfung der Übertragung an Genehmigungserfordernisse durch Gesellschaft und/oder Gesellschafterversammlung, zu erschweren $(\S 15 \text { Abs. } 5 \mathrm{GmbH})^{267}$. Die Zulassung derartiger Beschränkungen beziehungsweise Beschränkungsmöglichkeiten soll insbesondere den spekulativen Handel mit GmbHGeschäftsanteilen verhindern und den Nachweis der Mitgliedschaftsrechte erleichtern ${ }^{268}$. Auch soll den Gesellschaftern ermöglicht werden, durch geeignete Satzungsbestimmungen ein stärker personenbezogenes Gesellschaftsverhältnis herzustellen und sich so vor einer Überfremdung oder der Eingliederung in einen Konzern zu schützen ${ }^{269}$.

\section{bbb) Formbedürftigkeit der Übertragung}

Wie soeben dargestellt, bedarf die Abtretung von GmbH-Geschäftsanteilen der notariellen Beurkundung ( $\$ 15$ Abs. 1, $3 \mathrm{GmbHG)}$ ). Ebenfalls der notariellen Beurkundung bedarf das schuldrechtliche Verpflichtungsgeschäfts zur Abtretung des GmbH-Geschäftsanteils, wenngleich ein etwaiger Formmangel durch die ordnungsgemäß beurkundete Abtretung geheilt

266 Statt aller Raiser S. 503 ff. w. vielen w. N.

267 Ein vollständiger Ausschluss der Veräußerlichkeit im Gesellschaftsvertrag ist ebenfalls möglich. Allerdings steht dem betroffenen Gesellschafter dann aber ein Recht zum Austritt zu, wenn die weitere Bindung an die Gesellschaft für ihn unzumutbar geworden ist. RGZ 80, 175, 179; BayObLG WM 1989, 142; Raiser S. 503. Beispiele für entsprechende Satzungsregelungen finden sich bei Heckschen/Heidinger/Heckschen $\S 3$ Rn. $129 \mathrm{ff}$. 
wird (§ 15 Abs. 4 GmbHG). Der Zwang zur notariellen Beurkundung umfasst sämtliche Nebenabreden ${ }^{270}$.

\section{ccc) Nachweis Anteilsinhaberschaft}

Die Geschäftsanteilsübertragung ist im Verhältnis zwischen Abtretendem und Abtretungsempfänger sowie im Verhältnis zu Dritten mit deren notarieller Beurkundung wirksam, sofern nicht im Geschäftsanteilskauf- und/oder Übertragungsvertrag etwas Abweichendes geregelt ist. Im Verhältnis gegenüber der Gesellschaft gilt hingegen nur derjenige als Erwerber, dessen Erwerb unter Nachweis des Übergangs bei der Gesellschaft angemeldet worden ist $(\S 16$ GmbHG). Dies bedeutet zugleich, dass der abtretende Gesellschafter bis zu der Anmeldung alle seine Mitgliedschaftsrechte behält und auch weiterhin etwa zum Bezug des Gewinnanspruchs sowie zur Ausübung des Stimmrechts berechtigt ist ${ }^{271}$. Zur Pflicht der Geschäftsführer in Übertragungsfällen eine berichtigte Liste der Gesellschafter zu erstellen, wurde oben bereits das Notwendige gesagt ( $\$ 40 \mathrm{GmbHG}$, vgl. oben in diesem Abschnitt unter III. 1. b) bb)).

\section{ddd) Andienungspflichten und Vorkaufsrechte anderer Gesellschafter}

Gesetzliche Andienungspflichten oder Vorkaufsrechte bei Geschäftsanteilsabtretungen existieren in Deutschland nicht. Doch mögen derartige Regelungen durch die Gesellschafter in der Satzung vorgesehen werden ${ }^{272}$.

270 Zulässig ist auch die Abtretung künftiger Geschäftsanteile, die mit dessen Entstehung durch Eintragung in das Handelsregister wirksam wird. Auch eine derartige Abtretung bedarf allerdings der notariellen Beurkundung. Vgl. BGHZ 21, 245 und 383; 29, 303; BGH ZIP 1999, 925; in der Literatur vgl. nur Raiser, S. 504 sowie Süß/Wachter/Terbrack S. 553.

271 In der Praxis spielt die treuhänderische Übertragung des Geschäftsanteils zum Beispiel in der Form der Sicherungsabtretung eine nicht unbeträchtliche Rolle. Im Außenverhältnis wird der Treuhänder Gesellschafter mit allen Rechten und Pflichten. Inwieweit er im Innenverhältnis gegenüber dem Treugeber verpflichtet ist, richtet sich nach dem Treuhandvertrag, der grundsätzlich als solcher formfrei ist, es sei denn er enthält bereits in der Urkunde die Verpflichtung zur Rückübertragung (str., vgl. nur BGH ZIP 2006, 1343 sowie ZIP 2006, 1295). Zum Ganzen Raiser, S. 504 f. und Süß/Wachter/Terbrack S. 554.

272 Süß/Wachter/Terbrack S. 554; Beispiele für entsprechende Satzungsregelungen finden sich wiederum bei Heckschen/Heidinger/Heckschen $§ 3$ Rn. 146 ff. 


\section{c) Aufsichtsrat und Beirat}

\section{aa) Obligatorische und fakultative Einrichtung}

Das GmbHG kennt grundsätzlich keinen zwingend einzurichtenden Aufsichtsrat. Es erlaubt in $\S 52 \mathrm{GmbHG}$ allerdings ausdrücklich seine Bildung durch die Satzung und verweist hinsichtlich seiner Ordnung und Aufgaben ergänzend auf Vorschriften des Aktienrechts ${ }^{273}$.

Ausnahmsweise ist auch bei der $\mathrm{GmbH}$ zwingend ein Aufsichtsrat zu bilden. Anwendung findet in diesen $d r e i$ durch die Mitbestimmung veranlassten Fällen dann nicht $\S 52 \mathrm{GmbHG}$, sondern die jeweilige nach dem anordnenden Gesetz geltende Bestimmung:

- Die erste Ausnahme für die der Gesetzgeber die Bildung eines Aufsichtrats vorsieht, betrifft GmbHs, die ein Unternehmen im Sinne des § 1 MontanmitbestG betreiben und deren Arbeitnehmerzahl unmittelbar oder mittelbar unter Hinzurechnung der Arbeitnehmer von ihr beherrschter Konzernunternehmen in der Regel 1000 übersteigt (so genannter montanmitbestimmter Aufsichtsrat). Die praktische Relevanz dieser Form der Mitbestimmung ist indes gering ${ }^{274}$.

- Zweitens ist in einer GmbH zwingend ein Aufsichtsrat vorzusehen, wenn die Gesellschaft zwar die vorgenannten Voraussetzungen nicht erfüllt, allerdings regelmäßig mehr als 2000 Arbeitnehmer bei der $\mathrm{GmbH}$ selbst oder bei der $\mathrm{GmbH}$ und ihr zuzurechnender Konzernunternehmen beschäftigt sind (so genannte paritätische Mitbestimmung nach dem MitbestG 1976).

- Schließlich ist, wiederum unabhängig vom Unternehmensgegenstand, nach § 1 DrittelbG (vormals $§ 77$ BetrVG 1952) dann ein Aufsichtsrat in der Gesellschaft bilden, wenn der Gesellschaft mehr als 500 Arbeitnehmer unmittelbar oder mittelbar zuzurechnen sind (so genannte drittelparitätische Mitbestimmung nach DrittelbG).

Obligatorisch ist der Aufsichtsrat außerdem gemäß $§ 3$ KAGG (seit 1. Januar 2004 im Investmentgesetz - InvG geregelt) für Kapitalanlagen-GmbH's ${ }^{275}$.

Lutter/Hommelhoff, $\S 52$ Rn. 1.

Scholz/Schneider $\$ 52$ Rn. 9.

Lutter/Hommelhoff, § 52 Rn. 1; Scholz/Schneider $§ 52$ Rn. 52 ff. 


\section{bb) Aufgaben und Befugnisse}

Trotz gleichen Namens und mancher Verweisung in das Aktienrecht bestehen erhebliche Unterschiede in der Ausgestaltung, der Stellung und Zusammensetzung des Aufsichtsrats sowie der ihm obliegenden Aufgaben und Befugnisse je nach dem welche, gesetzliche Regelung der Errichtung zugrunde lag.

Sofern die Errichtung nach den genannten Regeln des MitbestimmungsG erfolgte, hat der Aufsichtsrat die weitgehenden Kompetenzen des Aufsichtsrats einer Aktiengesellschaft ( $\$ 25$ Abs. 1 MitbestG). Insbesondere steht ihm - und zwar zwingend - das Recht zur Bestellung und Anstellung der Geschäftsführer zu. Auch kann und soll der Aufsichtsrat sich einen Katalog solcher Geschäfte aufstellen, zu deren Abschluss seine vorherige Zustimmung erforderlich sein soll ( $\$ 111$ Abs. 4 AktG).

Kommt das DrittelbG zur Anwendung, hat der Aufsichtsrat nicht das Recht zur Bestellung und Anstellung der Geschäftsführer, da $\S 1$ Abs. 1 Nr. 3 DrittelbG anders als $\S 25$ Abs. 1 des Mitbestimmungsgesetzes nicht auf $\S 84 \mathrm{AktG}$ verweist.

Der fakultative (nach Maßgabe des $\S 52 \mathrm{GmbHG)} \mathrm{aufgrund} \mathrm{entsprechender} \mathrm{Satzungsbestim-}$ mung eingerichtete Aufsichtsrat hat lediglich die Aufgaben und Befugnisse, die ihm die Satzung einräumt oder die $\S 52 \mathrm{GmbHG}$ in Verbindung mit dem AktG zuweist; mindestens aber obliegt ihm systemimmanent die Überwachung der Geschäftsführung ${ }^{276}$.

\section{cc) Beirat}

Ein Beirat ist im GmbHG zwar nicht vorgesehen, kann jedoch aufgrund der Satzungsautonomie der Gesellschafter statt oder neben einem Aufsichtsrat qua entsprechender Satzungsregelung eingerichtet werden. Nicht selten ist beispielsweise ein Beirat in Familiengesellschaften zur Repräsentation einzelner Familienstämme in der Gesellschaft vorgesehen. Die Aufgaben und Befugnisse richten sich mangels gesetzlicher Grundlage ausschließlich nach den Bestimmungen des Gesellschaftsvertrages. Dabei gilt, dass sämtliche Befugnisse, die der Gesellschafterversammlung zustehen und die übertragbar sind, auch dem Beirat zugewiesen werden können. Ist dem Beirat allerdings aufgrund der Satzung die Überwachung der Geschäftsführung anvertraut, so liegt tatsächlich kein Beirat sondern ein Aufsichtsrats vor, auf den die Regelung des $\S 52 \mathrm{GmbHG}$ mit den Verweisungen ins Aktienrecht anzuwenden ist ${ }^{277}$.

276 Lutter/Hommelhoff, § 52 Rn. 1; Scholz/Schneider $§ 52$ Rn. 9; Grunewald, S. 352.

277 Umfassend hierzu Raiser, S. 611 ff. vgl. auch zusammenfassend Süß/Wachter/Terbrack S. 563 f. 


\title{
2. Zu den Reformbestrebungen
}

\section{a) Reformansätze des MoMiG}

\author{
aa) Geschäftsführer
}

\section{aaa) Gesteigerte Verantwortung und Haftung}

Der Regierungsentwurf verschärft die Haftung des Geschäftsführers im Rahmen des $§ 64$ Abs. 2 GmbHG. Nach bisheriger Rechtslage sind die Geschäftsführer einer GmbH der Gesellschaft gegenüber zum Ersatz von Zahlungen verpflichtet, die nach Insolvenzreife der Gesellschaft (Zahlungsunfähigkeit oder Überschuldung) geleistet werden und somit zur Schmälerung des Massevermögens beiträgt ( $\$ 64$ Abs. 1 Satz 1 GmbHG). In der Praxis hat man die bestehende Unsicherheit im Hinblick auf den Zeitpunkt der unter den Voraussetzungen der Zahlungsunfähigkeit oder Überschuldung entstehenden Insolvenzantragspflicht zunehmend zur Umgehung einer ordnungsgemäßen Abwicklung genutzt, indem man das Vermögen der Gesellschaft vor Insolvenzreife an die Gesellschafter verteilte und danach der Geschäftsführer verschwand, so genannte Ausplünderungsfälle ${ }^{278}$. Dies soll künftig durch eine vorgelagerte Verantwortlichkeit der Geschäftsführer vermieden werden:

Künftig soll den Geschäftsführer eine Ersatzpflicht auch dann treffen, wenn er durch Zahlungen an die Gesellschafter die Zahlungsunfähigkeit der Gesellschaft herbeiführt ( 64 Abs. 2

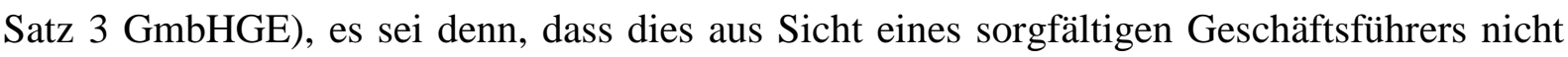
erkennbar war. Da auch Gesellschafterweisungen den Geschäftsführer nicht von seiner Haftung entbinden können ( $\S 64$ Abs. 2 Satz 2, 43 Abs. 2 Satz 3 GmbHG), lassen sich damit die genannten Schutzlücken schließen ${ }^{279}$.

278 Begründung des Regierungsentwurfs, Besonderer Teil, S. 105 f.; Gesmann-Nuissl WM 2006, 1756, 1763; Ehinger BB Special 2006 Nr. 7, S. 25.

279 Begründung des Regierungsentwurfs, Besonderer Teil, S. 105 f.; Gesmann-Nuissl WM 2006, 1756, 1763. Borges ZIP 2004, 733 sowie Poertzgen NZI 2007, 8, 15, ders. GmbHR 2007, 1258 sowie jüngst ders. NZI 2008, 9 geht das nicht weit genug. Vgl. hierzu auch umfassend zum Referentenentwurf, allerdings ohne eigenen Vorschlag Greulich/Bunnemann NZG 2006, 681. Nach Ansicht Borges' ist die schadensersatzbewehrte Insolvenzantragspflicht (§ 64 Abs 1 GmbHG) traditionell (aber unreflektiert) im Gesellschaftsrecht geregelt. Unter Heranziehung der Entstehungsgeschichte des § 64 Abs. 1 GmbHG und zur Rechtslage in anderen Rechts spricht er sich für eine insolvenzrechtliche Qualifikation der Antragspflicht aus. Für eine Rückkehr zur Regelung des $\S 64$ Satz 3 GmbHG n.F. aus dem Referentenentwurf plädieren Böcker/Poertzgen WM 2007, 1203. 


\section{bbb) Ausschlussgründe}

Während bislang nur derjenige von der Übernahme des Geschäftsführeramtes ausgeschlossen war, der wegen einer der Straftaten der $\S \S 283$ bis 283 d StGB (Bankrott, Verletzung der Buchführungspflichten, Gläubigerbegünstigung und Schuldnerbegünstigung) verurteilt ist, erstreckt der Regierungsentwurf die so genannten Ausschlusstatbestände des $§ 6$ Abs. 2 Satz 3 (Tätigkeitsverbote für Geschäftsführer) auf zentrale Bestimmungen des Wirtschaftsstrafrechts, namentlich auf Verurteilungen wegen Insolvenzverschleppung sowie die Erklärung falscher Angaben bei der Gesellschaftsgründung ( $\S 399-401$ AktG und $\S ~ 82,84 \mathrm{GmbHG}$ ). Darüber hinaus führt zukünftig eine Verurteilung zu einer Freiheitsstrafe von mindestens einem Jahr wegen einer oder mehrere vorsätzlich begangener Straftaten nach $\S 265 \mathrm{~b}$ (Kreditbetrug), § 266 (Untreue) oder $\S 266$ a StGB (Vorenthalten und Veruntreuen von Arbeitsentgelt) zur Annahme der generellen Ungeeignetheit als Geschäftsführer ${ }^{280}$.

Verzichtet wurde darauf, weitere Tatbestände des allgemeinen Strafrechts, wie etwa $\S 263$ und 263a StGB (Betrug und Computerbetrug), §§ 264 und 264a StGB (Subventions- und Kapitalanlagebetrug als Ausschlusstatbestände aufzunehmen. Zur Begründung heißt es im Regierungsentwurf, Verurteilungen nach diesen Vorschriften stünden nicht regelmäßig im Zusammenhang mit der Tätigkeit eines Geschäftsführers oder einer sonstigen wirtschaftlichen Tätigkeit; eine Aufnahme in den Ausschlusskatalog würde daher einen zu starken Eingriff in die durch Artikel 12 GG gewährte Berufsfreiheit bedeuten ${ }^{281}$.

Aus demselben Grund sollen nach dem Willen des Gesetzgebers auch nur Verurteilungen wegen vorsätzlich begangener Straftaten zur Amtsunfähigkeit führen, was bedeutet, dass das fahrlässige oder grob fahrlässige Begehen dieser Straftaten (z.B. die grob fahrlässige Gläubiger- oder Schuldnerbegünstigung) künftig für die Qualifizierung zum Geschäftsführer irrelevant sein soll ${ }^{282}$.

280 Die absoluten Tätigkeitsverbote des deutschen Rechts blieben bislang deutlich hinter den in Nachbarrechtsordnungen üblichen zurück; Haas WM 2006, 1369 und 1417. Allgemein zu den Auschlussgründen Weyand ZInsO 207, 754; Zu Recht kritisch zu dem Katalog in $\$ 6$ Abs. 2 GmbHG de lege lata daher Mülbert, JZ 2002, 826, 835: „,keine innere Logik“; Stein, AG 1987, 165, 168 ff.; Hirte/Lanzius/Mock, in: Lutter, Arbeitskreis Kapital in Europa, 2006, C VI 1 und E II.; siehe teilweise auch Fleischer, WM 2004, 157, 164 f.; Drygala, ZIP 2005, 423, 425; siehe auch den Entwurf für ein Forderungssicherungsgesetz (FoSiG), BTDrucks. 15/3594, S. 9. Noch weitergehend Eidenmüller/Rehberg NJW 2008, 28 ff., die eine Erstreckung des Bestellungsverbotes nach $\S 6$ Abs. 2 S. 3 und 4 GmbHG auch auf Geschäftsführer ausländischer Gesellschaften verlangen, wenn diese ihre Tätigkeit vornehmlich im Inland entfalten.

282 Begründung des Regierungsentwurfs, Besonderer Teil, S. 73 f.; Gesmann-Nuissl WM 2006, 1756, 1764; Breitenstein/Meyding BB 2007, 1457, 1462; Wachter GmbHR 2006, 793. 
Schließlich verzichtet der Entwurf auch auf eine deliktische Inanspruchnahme solcher Gesellschafter, die „sehenden Auges“ eine amtsunfähige Person bestellen und die Geschäfte von ihr führen lassen ${ }^{283}$. Zur Begründung heißt es in dem Regierungsentwurf, eine angeordnete Gesellschafterhaftung, würde - im Gegensatz zum Aktienrecht, wo eine solche Haftung durch den Aufsichtsrat vorgesehen ist - eine nicht vertretbare Systemdurchbrechung darstellen ${ }^{284}$.

\section{ccc) Belehrung}

Wegen des überschaubaren Belehrungsgehalts den $\S 8$ Abs. 3 Satz 2 GmbHG i. V. m. $§ 53$ Abs. 2 des Bundeszentralregistergesetzes vorsieht und der größeren Sachnähe bei Gesellschaften mit Verwaltungssitz im Ausland soll es nach dem Willen des Gesetzgebers, der sich insoweit im Einklang mit der bereits heute herrschenden Meinung befindet, künftig möglich sein, die Belehrung nach $\S 53$ Abs. 2 des Bundeszentralregistergesetzes auch durch einen Notar im Ausland, einen Vertreter eines vergleichbaren rechtsberatenden Berufes oder einem Konsularbeamten vornehmen zu lassen ( 88 Abs. 3 S.2 GmbHGE $)^{285}$.

\section{bb) Gesellschafter und Geschäftsanteile}

\section{aaa) Registrierung der Gesellschafter}

\section{(i) Vorbemerkung}

Gesellschafter und Geschäftsführer haben in den letzten Jahren offenbar wiederholt versucht, eine ordnungsgemäße Liquidation oder Insolvenz wirtschaftlich gefährdeter oder insolventer Gesellschaften zu verhindern, indem sie das noch vorhandene Gesellschaftsvermögen beiseite schafften und eine Inanspruchnahme durch Gläubiger der Gesellschaft durch wiederholte die Eigentümerschaft verschleiernder Verkäufe der Geschäftsanteile sowie Abberufung, sämtlicher Geschäftsführer erschwerten oder unmöglich machten ${ }^{286}$.

\footnotetext{
So eine Schadensersatzhaftung der Gesellschafter war bereits im Bunderatsentwurf über ein ForderungssicherungsG, BT-Drucks. 16/511 angelegt; dazu unter anderem Drygala ZIP 2005, 423.

284 Begründung des Regierungsentwurfs, Besonderer Teil, S. 74 f.; Gesmann-Nuissl WM 2006, 1756, 1764.

285 Begründung des Regierungsentwurfs, Besonderer Teil, S. 78, 80; Breitenstein/Meyding BB 2007, 1457 , 1458.

286 Begründung des Regierungsentwurfs, Allgemeiner Teil, S. 58; BDI/Hengeler Müller S. 40. 


\section{(ii) Aufwertung der Gesellschafterliste}

Zur Verbesserung der Transparenz und damit besseren Verfolgbarkeit und Durchsetzbarkeit von Ansprüchen gegen die Gesellschafter sind in der Gesellschafterliste künftig die Geschäftsanteile durchgehend zu nummerieren. Die Nummerierung vereinfacht auch die eindeutige Bezeichnung eines Geschäftsanteils und führt damit zu einer erheblichen praktischen Erleichterung insbesondere im Rahmen von Anteilsübertragungen; eine Verbesserung der Transparenz die nicht zuletzt auch deshalb zweckmäßig ist als der Entwurf künftig auf einen Mindestbetrag für Stammeinlagen verzichten will und die Möglichkeit schafft bei Errichtung der Gesellschaft mehrere Stammeinlagen zu übernehmen. Die Nummerierung erhält des Weiteren zusätzliche Bedeutung durch die Freigabe der Teilung von Geschäftsanteilen ${ }^{287}$.

Eine weitere Aufwertung erfährt die Gesellschafterliste durch die Änderung des $§ 16$ Abs. 1 GmbHG. Danach soll künftig im Verhältnis zur GmbH nur noch derjenige als Gesellschafter gelten - und damit zur Ausübung seiner Gesellschafterrechte berechtigt sein, der - über die auch weiterhin erforderliche Anmeldung bei der Gesellschaft hinaus ( $§ 16$ Abs. 1 Satz 2 GmbHG) - in der zum Handelsregister eingereichten Gesellschafterliste ausgewiesen ist ( $\$ 16$ Abs. $1 \mathrm{GmbHGE})^{288}$.

\section{(iii) Gutgläubiger Erwerb der Geschäftsanteile}

Die so in ihrer Bedeutung aufgewertete Gesellschafterliste soll künftig auch den gutgläubigen Erwerb von Geschäftsanteilen ermöglichen, ohne dass der Veräußerer - wie bislang - seine Anteilsinhaberschaft über eine ununterbrochene Kette von Abtretungsurkunden seit Gründung nachweisen, oder dieselbe garantieren muss ${ }^{289}$. Erforderlich ist nach dem neuen $\S 16$ Abs. 3

287 Begründung des Regierungsentwurfs, Besonderer Teil, S. 76.

288 Begründung des Regierungsentwurfs, Besonderer Teil, S. 84 f.; Gesmann-Nuissl WM 2006, 1756, 1758; Breitenstein/Meyding BB 2007, 1457, 1459. Hägele GmbHR 2007, 258 geht in diesem Zusammenhang der Frage nach inwieweit eine Anmeldung nach $\S 16$ GmbHG die Mitteilungspflicht der Erwerbergesellschaft nach $\S 21$ AktG entbehrlich macht. Er kommt zu dem Ergebnis, dass sowohl nach geltender Rechtslage als auch nach Inkrafttreten des MoMiG könne der Schutzbereich der beiden Norm nicht gleichgesetzt werden könne. Da der des $\S 21$ AktG weiter sei und die Mitteilung auch strengeren Formvorschriften unterliege, könne die Mitteilung nach $\S 16$ GmbHG nicht die aktienrechtliche Anmeldung ersetzen. Eine Ausnahme gelte lediglich beim Vollerwerb aller Anteile der GmbH. Dieser Befund bleibe auch nach der künftigen Rechtslage unverändert. Die Praxisfolgen für das M\&A-Geschäft untersuchen Götze/Bressler NZG 2007 , 894.

289 Begründung des Regierungsentwurfs, Besonderer Teil, S. 87 f.; Gesmann-Nuissl WM 2006, 1756, 1758 Breitenstein/Meyding BB 2007, 1457, 1459 f. Ausführlich zu den Hintergründen sowie mit zahlreichen Bei- 
GmbHGE lediglich, dass der Veräußerer drei Jahre lang unwidersprochen in die Gesellschafterliste eingetragen ist und der Erwerber keine Kenntnis beziehungsweise grob fahrlässige Unkenntnis von der Unrichtigkeit der Gesellschafterliste hat ${ }^{290}$.

Primär verantwortlich für die Einreichung bleibt auch in Zukunft der Geschäftsführer, dessen Prüfpflichten sich allerdings bemerkenswerter Weise trotz des enormen Bedeutungszuwachs der Gesellschafterliste nicht erhöhen sollen. Wirkt indes ein Notar bei der Veränderung im Gesellschafterkreis mit, etwa bei der Geschäftsanteilsveräußerung (vgl. § 15 GmbHG), soll dieser künftig selbst die Liste unverzüglich nach deren Wirksamwerden namens der Geschäftsführer zum Handelsregister einreichen (§ 40 Abs. 1 Satz 2 GmbHGE) ${ }^{291}$.

\section{bbb) Verantwortung und Haftung}

Der Entwurf sieht eine Erweiterung beziehungsweise Verschärfung der Gesellschafterpflichten vor, wenn sich die Gesellschaft im Zustand der „Führungslosigkeit befindet, der Geschäftsführer abberufen wurde, sein Amt niedergelegt hat oder sein Aufenthalt unbekannt ist.

In diesem Fall sollen die Gesellschafter - existiert ein Aufsichtsrat, dann dieser - den Platz des Geschäftsführers einnehmen - sie sollen dann jeder einzeln zur Entgegennahme von Willenserklärungen und Zustellung befugt ( $§ 35 \mathrm{Abs} .2$ Satz $2 \mathrm{GmbHGE}$ ), und zur Stellung des Insolvenzantrags verpflichtet sein ( $\$ 64$ Abs. 1 Satz 2, 3 GmbHGE; 15 Abs. 1 InsOE $^{292}$ ). Die Gesellschafter sollen auf diese Weise angehalten werden, die GmbH nicht zum Schaden des Rechtsverkehrs führungslos zu lassen; gerade das „Abtauchen des Geschäftsführers“ zur Umgehung der Insolvenzantragspflicht soll hierdurch vermieden werden ${ }^{293}$.

Die neu geschaffene Insolvenzantragspflicht trifft den Gesellschafter allerdings nicht, wenn dieser darlegen und beweisen kann, dass er entweder vom Insolvenzgrund (Zahlungsunfähigkeit beziehungsweise Überschuldung) oder aber der Führungslosigkeit keine Kenntnis hatte.

spielen für die praktische Bedeutung des gutgläubigen Erwerbs Vossius DB 2007, 2299 ff. sowie Bohrer DStR 2007, 995.

290 Begründung des Regierungsentwurfs, Besonderer Teil, S. 87 f.; vgl. hierzu Gesmann-Nuissl WM 2006, 1756, 1758 f.; Götze/Bressler NZG 2007, 894 sowie jüngst Harbarth ZIP 2008, 57. Vgl. zur - vom Gesetzgeber nach Auffassung der Verfasser übersehenen - Erstreckung des Gutglaubensschutzes auf die der Gesellschafterliste zu entnehmenden Stückelung Böttcher/Blasche NZG 2007, 565.

Begründung des Regierungsentwurfs, Besonderer Teil, S.100, Gesmann-Nuissl WM 2006, 1756, 1759.

292 Zur Verlagerung der Insolvenzantragspflicht in die InSO Poertzgen ZInsO 2007, 574; ders. NZI 2008, 9 sowie Knof/Mock GmbHR 2007, 852, die insb. die Auswirkungen der Verlagerung der Insolvenzantragspflicht in die InSO auf Auslandsinsolvenzen beleuchten. Siehe auch Schmahl NZI 2008, 6 zum subsidiören Insolvenzantragsrecht bei Führungslosigkeit.

293 Begründung des Regierungsentwurfs, Besonderer Teil, S. 62 f. 
Anders als noch im Referentenentwurf vorgesehen, soll nach der Begründung des Regierungsentwurfs die Antragspflicht also bereits dann entfallen, wenn der Gesellschafter nur eines der beiden Entlastungskriterien nicht kennt. Mit Kenntnis im vorgenannten Sinne ist positive Kenntnis gemeint; Kennen müssen genügt grundsätzlich nicht. Allerdings soll ein bewusstes Verschließen vor der Kenntnis in Bezug auf die Insolvenzantragspflicht der Gesellschafter der positiven Kenntnis gleichstehen. Ein solches bewusstes Verschließen wird man nach der Intention des Gesetzgebers wohl bereits dann annehmen müssen, wenn der Gesellschafter das Vorliegen auch nur eines der Kriterien für seine Ersatzzuständigkeit - Insolvenzgrund oder Führungslosigkeit - nicht zum Anlass nimmt, auch das Vorliegen des zweiten Antragsgrundes zu erforschen ${ }^{294}$

\section{ccc) Geschäftsanteile der GmbH}

Vereinfacht und entformalisiert wird des Weiteren die Übernahme sowie der Umgang mit den Kapitalanteilen einer GmbH. So sollen die Gesellschafter künftig individueller über die jeweilige Höhe ihrer Stammeinlagen bestimmen und sie dadurch besser nach ihren Bedürfnissen und finanziellen Möglichkeiten ausrichten können. Bislang muss die Stammeinlage mindestens $100 €$ betragen und darf nur in Einheiten von mindestens $50 €$ aufgeteilt werden. Der Entwurf sieht vor, dass jeder Geschäftsanteil nur noch auf einen Betrag von mindestens einem Euro lauten muss ${ }^{295}$. Vorhandene Geschäftsanteile können künftig leichter gestückelt wer$\operatorname{den}^{296}$.

Die Flexibilisierung setzt sich bei der Übertragung von Geschäftsanteilen fort. Sie soll erleichtert werden. So soll das Verbot, bei der Errichtung der Gesellschaft mehrere Geschäftsanteile zu übernehmen ( $\$ 5$ Abs. 2 GmbHG), aufgehoben werden. Auch das Verbot, mehrere Teile von Geschäftsanteilen gleichzeitig an denselben Erwerber $\mathrm{zu}$ übertragen (§ $17 \mathrm{GmbHG})$, soll fallen ${ }^{297}$.

294 Begründung des Regierungsentwurfs, Besonderer Teil, S. 63 f.; Gesmann-Nuissl WM 2006, 1756, 1762; K. Schmidt, Die GmbH-Reform in der Diskussion, S. 143, 149.

295 Begründung des Regierungsentwurfs, Besonderer Teil, S. 65 f.

296 Vgl. hierzu sogleich unten in diesem Abschnitt IV. 2. a) aa) aaa) (ii) und (iii).

297 Begründung des Regierungsentwurfs, Besonderer Teil, S. 89 f. 


\title{
b) Reformüberlegungen in Praxis und Literatur
}

\author{
aa) Geschäftsführer
}

\section{aaa) Gesteigerte Verantwortung und Haftung}

Auch in der Literatur gilt das Hauptaugenmerk einer Verbesserung des Gläubigerschutzes in der Insolvenz der Gesellschaft durch Erweiterung beziehungsweise Verschärfung der Verantwortlichkeit des Geschäftsführers respektive der Gesellschafter im Rahmen des $\S 64$ $\mathrm{GmbHG}^{298}$.

\section{(i) Überlegungen $K$. Schmidts}

K. Schmidt ${ }^{299}$ sieht keine Notwendigkeit für eine Änderung des bestehenden Insolvenzverschleppungshaftungssystems, da bei richtiger Deutung des $§ 64 \mathrm{GmbHG}$ bereits de lege lata der Haftungsschutz vor der Insolvenz beginne. Die ex-ante Wirkung des deutschen Haftungsschutzssystems erkennt $K$. Schmidt in der „bisher kaum bemerkte(n)“ Verwandtschaft der deutschen Insolvenzverschleppungshaftung mit dem Konzept des Wrongful Trading“. Der gemeinsame Ansatz liege insbesondere darin, dass nicht eigentlich die Versäumung eines Insolvenzantrags, sondern die Fortführung des Unternehmens auf Gläubigerrisiko untersagt sei. Auch $§ 64$ Abs. 1 GmbHG sei richtigerweise als ein Verbotstatbestand zu verstehen (unerlaubte Unternehmensfortführung), nicht als ein Gebotstatbestand (unerlaubte Versäumung des Insolvenzantrags $)^{300}$.

Auf der Rechtsfolgenseite sei ein Ersatz des Gesamtgläubigerschadens in Anwendung des $\S 92$ InsO sicherzustellen. Für eine daneben stehende Haftungsnorm des $\S 64$ Abs. 2 GmbHG bestünde dann keine Notwendigkeit mehr ${ }^{301}$.

298 Umfassend zu dem Nachstehenden auch Haas, Reform des gesellschaftsrechtlichen Gläubigerschutzes, Gutachten E zum 66. Deutschen Juristentag sowie auch Knof DStR 2007, 1536 und 1580.

299 K. Schmidt, Die GmbH-Reform in der Diskussion, S. 143, 151 ff.; ders. GmbHR 2007, 1 ff.; ders. GmbHR 2007, 1072.

300 K. Schmidt, Die GmbH-Reform in der Diskussion, S. 143, 151 ff., 166; ders. GmbHR 2007, 1 ff.; ders. GmbHR 2007, 1072.

301 K. Schmidt, Die GmbH-Reform in der Diskussion, S. 143, 151 ff., 167; ders. GmbHR 2007, 1 ff.; ders. GmbHR 2007, 1072. 


\section{(ii) Überlegungen von BDI und Hengeler}

Eine Vorverlagerung des Gläubigerschutzes versuchen auch BDI und Hengeler Müller zu erreichen, indem sie eine Erstreckung der Insolvenzantragspflicht des $§ 64$ Abs. $1 \mathrm{GmbHG}$ auf den Tatbestand der drohenden Zahlungsunfähigkeit ( $\$ 18$ InsO) anregen ${ }^{302}$.

\section{bbb) Ausschlussgründe}

Die Erweiterungen der Ausschlussgründe durch das MoMiG-Reformgesetz wird in der Literatur durchweg begrüß $\mathrm{t}^{303}$. Auch wird die Beibehaltung der Berufsverbotsregelung in $\S 6 \mathrm{Abs} .2$ Satz 4 GmbHG nicht in Frage gestellt, wohl aber deren Ausdehnung.

So haben etwa Vossius und Wachter in ihrem privaten Reformentwurf eines GmbHG vorgeschlagen, auch im Ausland ausgesprochene Tätigkeitsverbote einzubeziehen ${ }^{304}$. Zusätzlich hat K. Schmidt empfohlen, als weiteren neuen Ausschließungsgrund die Masselosigkeit einer GmbH-Insolvenz in den Katalog des $§ 6$ GmbHG aufzunehmen ${ }^{305}$.

Steffek $k^{306}$ schlägt gar die Einführung einer Disqualifizierungsregelung nach englischem Vorbild vor.

302 BDI/Hengeler Müller S. $30 \mathrm{f}$.

303 Vgl. nur Haas WM 2006, 1369 und 1417; Mülbert, JZ 2002, 826, 835: „,keine innere Logik“; Stein, AG 1987, 165, 168 ff.; Hirte/Lanzius/Mock in: Lutter, Arbeitskreis Kapital in Europa, 2006, C VI 1 und E II.; siehe teilweise auch Fleischer, WM 2004, 157, 164 f.; Drygala, ZIP 2005, 423, 425. Siehe aber auch Stein AG 1987, 165, die die Verfassungswidrigkeit der „Berufsverbote“ rügt.

304 Vgl. § 8 Abs. 4 des Entwurfs von Vossius und Wachter, online abrufbar unter www.gmbhr.de, in Auszügen abgedruckt in BB 2005, 2539: „Geschäftsführer kann weiter nicht sein, wer nach einer im Inland anzuerkennenden Entscheidung eines Gerichts oder einer Verwaltungsbehörde eines anderen Staates die Übernahme einer dem Geschäftsführer vergleichbaren Stellung untersagt ist.“ Der Vorschlag hat eine breite Zustimmung in der Literatur gefunden. K. Schmidt, Die GmbH-Reform in der Diskussion, S. 143, 146, regt allerdings an, den Vorschlag Vossius und Wachters um einen ordre-public Vorbehalt zu ergänzen, für solche Verbote, die außerhalb der EU angesprochen werden. In dieselbe Richtung geht die Überlegung von Eidenmüller/Rehberg NJW 2008, 28 ff., die eine Erstreckung der deutsche Gewerbeverbote auf Geschäftsführer ausländischer Gesellschaften mit Tätigkeitsschwerpunkt in Deutschland verlangen.

306 Steffek ZRP 2007, 228 ff.; dies ist auch eine der Forderungen des Bundesrates BR. Drs. 354/07 (B), S. 8 ff.; vgl. hierzu auch Thole ZIP 2007, 1590 und Heckschen DStR 2007, 1442, 1459. 


\section{bb) Gesellschafter und Geschäftsanteile}

\section{aaa) Registrierung der Gesellschafter}

\section{(i) Aufwertung der Gesellschafterliste}

Der Aufwertung der Gesellschafterliste in der vom Referentenentwurf und auch noch vom Regierungsentwurf zum MoMiG beschriebenen Form, nämlich durch gesetzliche Festlegung, dass künftig im Verhältnis zur GmbH nur noch derjenige als Gesellschafter gelten soll, der in der zum Handelsregister eingereichten Gesellschafterliste ausgewiesen ist ( $\$ 16$ Abs. 1 GmbHGE), ist entgegengesetzt worden, dass die Verlässlichkeit der Aktualität der Gesellschafterliste nicht - auch nicht durch Inanspruchnahme der die Geschäftsanteilsveräußeung beurkundenden Notare - gewährleistet werden könne ${ }^{307}$. Gefolgt ist man dem Gesetzgeber allerdings insoweit, als auch in der Literatur die Notwendigkeit der Etablierung eines gutgläubigen Erwerbs gesehen wird und entsprechende alternative Vorschläge unterbreitet worden $\operatorname{sind}^{308}$.

\section{(ii) Gutgläubiger Erwerb der Geschäftsanteile}

\section{(1) Überlegungen Grunewalds}

Grunewald ${ }^{309}$ unterstützt den Vorschlag des Referentenwurfs/Regierungsentwurfs, als Rechtsscheinsbasis für den gutgläubigen Erwerb von Geschäftsanteilen, den „Registerbestand“ gemeint ist ganz offensichtlich die beim Handelsregister befindliche Gesellschafterliste - heranzuziehen.

307 Vgl. nur Zöllner Die GmbH-Reform in der Diskussion, S. 175, 190 mit zahlreichen weiteren Nachweisen insbesondere mit Hinweis auf den Gesetzentwurf von Vossius/Wachter, online abrufbar unter www.gmbhr.de.

308 Vgl. sogleich hiernach unter ii. sowie die Ausführungen bei Zöllner Die GmbH-Reform in der Diskussion, S. 175, 190; Vossius/Wachter www.gmbhr.de; Gehling ZIP 2006, 689; Grunewald ZIP 2006, 685.

309 Grunewald ZIP 2006, 685, 686; dies. Der Konzern 2007, 13. Im Ergebnis will auch Müller GmbHR 2006, 953 die Gesellschafterliste als Rechtsscheinsträger akzeptieren. Allerdings plädiert er für ein Anknüpfen der Dreijahresfrist des $\S 16$ GmbHGE an den Eintragungszeitpunkt und nicht den Zeitpunkt der Unrichtigkeit der Gesellschafterliste. 


\section{(2) Überlegungen Zöllners}

Demgegenüber hält Zöllner ${ }^{310}$ die Gesellschafterliste aus den oben unter (i) genannten Erwägungen als Rechtscheinsbasis für nicht ausreichend belastbar. Er schlägt vor, einen Gutglaubenserwerb auf der Grundlage einer ununterbrochenen Kette notariell beurkundeter Abtretungserklärungen, die auf den ersten Inhaber des Geschäftsanteils zurückzuführen ist, zu gestatten. Der Gefahr von Doppelabtretungen bei verschiedenen Notaren möchte er begegnen, indem er einen Rechtsschein nur für Abtretungsketten in derselben Urkunde, eventuell mit Allonge, gewährt.

\section{(3) Überlegungen Gehlings}

In dieselbe Richtung geht der Vorschlag Gehlings ${ }^{311}$, der für eine Verbriefung von GmbHAnteilen einsteht und die Verfügung darüber ausschließlich durch Indossament in notarieller Form zulassen will.

\section{(4) Überlegungen Vossius und Wachters}

Vossius und Wachter ${ }^{312}$ schlagen die Schaffung eines vom Gründungsnotar zu führenden Anteilsregisters vor. An das Anteilsregister selbst wollen die Autoren indes keinen Verkehrsschutz knüpfen, sondern sehen dafür wiederum die von dem registerführenden Notar dem Handelsregister aufgrund des Anteilsregisters übermittelte Gesellschafterliste vor.

\section{(5) Ansicht des BDI und Hengelers}

BDI und Hengeler ${ }^{313}$ sind der Auffassung, dass erst die Eintragung der Gesellschafter im Handelsregister zu einer vollen Transparenz des jeweiligen Gesellschafterbestandes führe. Nach Einführung des elektronischen Handelsregisters ${ }^{314}$ könnte der jeweilige Gesellschafter-

310 Zöllner Die GmbH-Reform in der Diskussion, S. 175, 191.

311 Gehling ZIP 2006, 685, 689.

$312 \S 24$ des zitierten Gesetzentwurfs von Vossius/Wachter, online abrufbar unter www.gmbhr.de. So wohl auch der Gedanke von Hamann NZG 2007, 492. In diese Richtung geht auch die Überlegung von Harbarth ZIP 2008, 57; er möchte den Gutglaubensschutz zudem auf Rechte an Geschäftsanteilen erstrecken und plädiert daher für deren Eintragungsfähigkeit im Register.

314 Vgl. hierzu auch unten Vierter Abschnitt $\$ 4$ II 2 e) 
bestand über das Internet abgerufen werden. Die Eintragung der Gesellschafter im Handelsregister würde ebenso wie bei Personengesellschaften weder zur Überfrachtung noch zur Unübersichtlichkeit des Registers führen. Folge der Eintragung der Gesellschafter im Handelsregister wäre die Geltung der negativen Publizität des Handelsregisters (§ 15 HGB).

\section{bbb) Verantwortung und Haftung}

In der Literatur wird die vom $M o M i G$ angedachte Ersatzzuständigkeit der Gesellschafter im Fall der Führungslosigkeit der Gesellschaft durchweg begrüßt ${ }^{315}$. Der Vorstoß des Gesetzgebers sei allerdings nicht neu, basierte er doch auf Überlegungen, die bereits im Jahr 2005 im Zusammenhang mit dem (Geheim-)Entwurf eines MiKaTraG (Entwurf eines Gesetzes zur Bekämpfung von Missbräuchen, zur Neuregelung der Kapitalaufbringung und zur Förderung der Transparenz im GmbH-Recht) angestellt worden seien ${ }^{316}$.

Ebenfalls bereits im MiKaTraG angelegt und konkretisiert im Entwurf eines Forderungssicherungsgesetzes ${ }^{317}$ ist die Überlegung, die vorgenannte Anwachsung von Geschäftsführerpflichten um eine akzessorische Gesellschafterhaftung im Fall des Handelns von gesetzlich disqualifizierten Geschäftsführern zu ergänzen. Nach Artikel 11 des Entwurfs eines Forderungssicherungsgesetzes ${ }^{318}$ sollen „Gesellschafter, die vorsätzlich oder grob fahrlässig eine Person, die nicht Geschäftsführer sein kann, zum Geschäftsführer bestellen oder nicht abberufen oder ihr tatsächlich die Führung der Geschäfte überlassen, [...] der Gesellschaft solidarisch für den Schaden (haften), der dadurch entsteht, dass diese Person die ihr gegenüber der Gesellschaft bestehenden Obliegenheiten verletzt.“

K. Schmidt geht der vorgenannte Vorschlag allerdings nicht weit genug; er wünscht sich eine Verschuldensvermutung mit Entlastungsbeweis für den Fall, dass ein Gesellschafter mit mehr als $10 \%$ am Kapital der Gesellschaft beteiligt ist ${ }^{319}$. Darüber hinaus wäre nach Ansicht des Haas $^{320}$ zu erwägen, ob die Geschäftsführerlosigkeit ein Verfolgungsrecht nach Vorbild von $\S 93$ Absatz 5 AktG begründen könnte.

Vgl. nur Kleindiek ZGR 2007, 276.

K. Schmidt, Die GmbH-Reform in der Diskussion, S. 143, 149; vgl. zuletzt auch Kleindiek ZGR 2007, 276.

317 Gesetzentwurf des Bundesrates v. 2.2.2006, BT-Drucks. 16/511.

318 Gesetzentwurf des Bundesrates v. 2.2.2006, BT-Drucks. 16/511.

319 K. Schmidt, Die GmbH-Reform in der Diskussion, S. 143, 149

320 Haas GmbHR 2006, 729 


\section{ccc) Geschäftsanteile der GmbH}

Dem Ruf nach einer Entformalisierung und Vereinfachung des Umgangs und der Übertragung von Geschäftsanteilen ist der Gesetzgeber - wie gesehen - in weiten Teilen bereits gefolgt.

Festgehalten hat der Gesetzgeber hingegen an dem Erfordernis notarieller Beurkundung der Geschäftsanteilsübertragung, einem Formerfordernis, das nach der Begründung des Hoffmannschen GmbHG-Entwurfs der Reichsregierung von $1891^{321}$ die Gesellschafter stärker mit der Gesellschaft verbinden und dazu neben anderem den Geschäftsanteil vom Markt- und Börsenverkehr fernhalten sollte. Auch in der Folgezeit hat die höchstrichterliche Rechtsprechung und teilweise auch die Oberlandesgerichte die Fernhaltung vom Handel als wesentlichen Zweck des Beurkundungserfordernisses bezeichnet ${ }^{322}$.

In der Literatur ist nicht nur der Zweck des Beurkundungszwangs umstritten, sondern vor allem auch seine Eignung, diese Zwecke tatsächlich zu erfüllen. Die unterschiedlichen Auffassungen lassen sich grob in die Gegner eines notariellen Beurkundungserfordernisses und die Befürworter einer solchen Regelung unterteilen ${ }^{323}$.

\section{(i) Befürworter des Beurkundungszwangs}

Namentlich Zöllner ${ }^{324}$ hält eine notarielle Beurkundung als Warnform für den Anteilserwerb jedenfalls solange für unverzichtbar, wie eine Haftung der Gesellschafter für die Aufbringung und Erhaltung des Stammkapitals vorgesehen ist. Darüber hinaus sei ein Festhalten am Beurkundungszwang auch im Interesse der Gesellschafter und der Gesellschaft, denn nur so lasse sich ein ordnungsgemäßer Erwerb des Geschäftsanteils sicherstellen. Schließlich bilde die Beurkundung eine wichtige Grundlage dafür, dass die Gläubiger bei nicht voll eingezahlten oder bei teilrückgezahlten Anteilen die materiell richtigen Personen in Anspruch nehmen könnten ${ }^{325}$.

Entwurf I, S. 23 ff. vgl. auch Zöllner, Die GmbH-Reform in der Diskussion, S. 175, 177 m.w.N.

322 RGZ 68, 394, 396; 135, 70, 71; 164, 162, 170; BGHZ 13, 49, 51 ff.; 19, 69, 71; 75, 352, 353; 127, 129,135 f; 130, 71, 74; 141, 207; BGH NJW 1996, 3338; vgl. auch OLG München BB 1995, 427 und 1996, 1296. Zur Bedeutung der notariellen Beurkundung allgemein Wicke ZIP 2006, 977.

324 Zöllner, Die GmbH-Reform in der Diskussion, S. 175 ff.; vgl. aber auch Kanzleiter ZIP 2001, 2105.

325 Zöllner, Die GmbH-Reform in der Diskussion, S. 175, 182. 


\section{(ii) Gegner des Beurkundungszwangs}

Die Gegner des Beurkundungszwangs meinen, die Formzwecke durch alternative, im Ausland erprobte Regelungsinstrumente genauso abbilden zu können ${ }^{326}$. Genannt wird in diesem $\mathrm{Zu}-$ sammenhang insbesondere das Regelungsinstrument der gesetzlichen Vinkulierung.

\section{Finanzverfassung}

\section{Bestehende Rechtslage}

\section{a) Kapitalaufbringung}

\section{aa) Stammkapital}

Das Stammkapital einer GmbH muss wenigstens $25.000 €$ betragen ( $\$ 5$ Abs. $1 \mathrm{GmbHG})^{327}$; es ist entweder in Geld (so genannte Bareinlage), durch Einbringung vermögenswerter Gegenstände (so genannte Sacheinlage) oder durch eine Kombination von Geld- und Sachleistung (so genannte gemischte Einlage) aufzubringen. Das Stammkapital gliedert sich in Stammeinlagen, deren Betrag für jeden Gesellschafter unterschiedlich bestimmt sein mag, allerdings nicht unter $100 €$ liegen darf und durch $50 €$ teilbar sein muss. In der Summe muss der Wert der Stammeinlagen der Stammkapitalziffer entsprechen. Jeder Gesellschafter kann bei der Gründung nur eine Stammeinlage übernehmen. ( $\$ 5$ Abs. 1 und $3 \mathrm{GmbHG})^{328}$.

\section{bb) Bareinlage}

Bei Gründung muss der Gesellschaft im Zeitpunkt der Anmeldung ein unbelastetes Vermögen von mindestens $12.500 €$ zur Verfügung stehen; hierbei muss bei einer vereinbarten Leistung von Bareinlagen auf jede Stammeinlage mindestens ein Viertel eingezahlt worden sein $(\S 7$ Abs. 2 GmbHG).

326 Vgl. etwa Heidenhain ZIP 2001, 721; ders. ZIP 2001, 2113, differenzierend nach rechtsvergleichender Betrachtung Behrens Die GmbH-Reform in der Diskussion, S. 195 ff.

327 Darüber hinaus besteht keine gesetzliche Pflicht zur Ausstattung der Gesellschaft mit dem für den Gesellschaftszweck erforderlichen Eigenkapital, BGHZ 31, 268; 68, 312; BGH NJW 1979, 2104, st. Rechtsprechung, vgl. auch BGHZ 127, 33. 
In der Satzung kann der Fälligkeitszeitpunkt für die Leistung der (Rest-)Einlage beliebig festgelegt werden; wegen der Differenzhaftung der anderen Mitgesellschafter ( $\$ 24 \mathrm{GmbHG}$ ) ist allerdings regelmäßig eine sofortige Einzahlungsverpflichtung in voller Höhe in der Satzung bestimmt. Fehlt es an einer derartigen statutarischen Bestimmung, so liegt es regelmäßig in der Zuständigkeit der Gesellschafterversammlung über die Einforderung der restlichen Einlagen zu beschließen ( $\$ 46$ Nr. 2 GmbHG). In diesem Fall, wird die Einlageforderung spätestens im Zeitpunkt der Mitteilung der beschlossenen Zahlungsaufforderung durch die Geschäftsführung fällig. Genauso wie ein Fälligkeitszeitpunkt bereits in der Satzung bestimmt sein mag, kann auch die Kompetenz zur Beschlussfassung über die Einforderung von der Gesellschafterversammlung durch Satzungsregelung auf die Geschäftsführung übertragen wer$\operatorname{den}^{329}$.

Besondere Reglungen gelten bei der Errichtung einer Einpersonen-Gesellschaft; da hier ein Ausfallsschutz durch die Möglichkeit der Inanspruchnahme weiterer Mitgesellschafter gemäß $\S 24 \mathrm{GmbHG}$ fehlt, verlangt das Gesetz neben der Mindesteinzahlung von $12.500 €$ eine Sicherheit im Sinne der $\S \S 232$ ff. BGB ${ }^{330}$ für den übrigen Teil der Geldeinlage, es sei denn, das Stammkapital ist voll einzuzahlen ( $§ 7$ Abs. 2 Satz $3 \mathrm{GmbHG}){ }^{331}$. Die Sicherungen werden wieder frei mit der Volleinzahlung der Bareinlage, aber auch bei Beitritt mindestens eines weiteren Gesellschafters. Entsprechend entsteht auch nach Gründung der Gesellschaft eine Besicherungspflicht für ausstehende Einlagen, wenn die GmbH zwar durch mehrere Personen gegründet wird, innerhalb von drei Jahren seit Eintragung im Handelsregister aber nur noch einen Gesellschafter besitzt ( $\$ 19$ Abs. 4 GmbHG) ${ }^{332}$.

\section{cc) Sacheinlage}

Die Satzung kann statt der Bareinlageverpflichtung auch eine Verpflichtung zur Einlage eines Gegenstandes vorsehen (Sacheinlage). In diesem Fall ist der Gegenstand als auch der Betrag der Stammeinlage, auf den sich die Sacheinlage bezieht, sowie der Name des zur Leistung

\footnotetext{
Süß/Wachter/Terbrack S. 536; Goette, S. 40; Raiser, S. 417.

LG München I GmbHR 1985, 397.

331 In der Praxis wird die Sicherheit regelmäßig durch Bankbürgschaft oder aber vereinzelt auch durch Bürgschaften oder Garantien solventer Dritte erbracht. Vgl. hierzu auch Süß/Wachter/Terbrack S. 536; Raiser, S. 432 f. sowie oben in diesem Abschnitt unter $\S 1$ I 1 b) cc).

332 Allgemein dazu Baumbach/Hueck/Hueck/Fastrich § 7 Rn. 10 f.; Hachenburg/Ulmer $§ 7$ Rn. 61 sowie Michalski/Heyder $§ 7$ Rn. 27; vgl. auch Süß/Wachter/Terbrack S. 536; Raiser, S. 433.
} 
verpflichteten Gesellschafters ausdrücklich in der Satzung zu bestimmen ( $§ 5$ Abs. 4 $\mathrm{GmbHG})^{333}$.

Gegenstand einer Sacheinlage können alle Sachen, Rechte und sonstigen Vermögensgegenstände sein, welche in die Gesellschaft zu deren freier Verfügung eingebracht werden können und einen feststellbaren wirtschaftlichen Wert aufweisen ${ }^{334}$. Als Gegenstand der Sacheinlage kommen etwa Material und Werkzeuge ${ }^{335}$; Gebrauchsüberlassung ${ }^{336}$; Urheberrechte ${ }^{337}$; Lizenz-

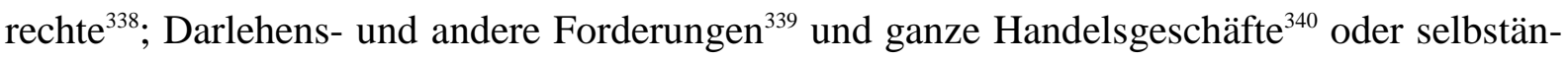
dige Betriebsteile ${ }^{341}$ in Betracht. Nicht geeignet sind hingegen etwa Dienstleistungen (Entsprechend $\S 27$ Abs. 2 AktG) und persönliche Werkleistungspflichten ${ }^{342}$.

Die Sacheinlage ist durch die Gesellschafter nach objektiven Kriterien zu bewerten; hierbei ist höchstens die Zugrundelegung des aktuellen Verkehrswertes des in die Gesellschaft einzubringenden Gegenstandes gestattet ${ }^{343}$. Die Gesellschafter haben einen schriftlichen Sachgründungsbericht zu erstellen, in dem dem Handelsregister gegenüber die wesentlichen Umstände darzulegen sind, aus denen sich die Bewertung der Sacheinlage ergibt. Bei einer Überbewertung der Sacheinlage hat der zur Einlage Verpflichtete die Differenz zwischen tatsächlichem Wert der Sacheinlage und der auf die übernommene Stammeinlage zu entrichtenden Einlage in bar auszugleichen (dies folgt bereits aus $§ 9$ Abs. $1 \mathrm{GmbHG}$, wird aber regelmäßig als Verpflichtung auch in die Gründungs- oder Kapitalerhöhungsvereinbarung aufgenommen) ${ }^{344}$. Ist der Wert des Gegenstandes zu niedrig angesetzt worden, so ist der Mehrbetrag, nach Wahl der Gesellschafter entweder an den Gesellschafter in bar auszuzahlen, der Betrag in die Kapitalrücklage einzustellen oder ein Gesellschafterdarlehen in entsprechender Höhe zu vereinba$\operatorname{ren}^{345}$.

333 Umstritten ist, ob diese Angaben auch in einer Anlage zum Gesellschaftsvertrag gemacht werden können:dafür Baumbach/Hueck/Hueck/Fastrich $§ 5$ Rn. 43; MünchHdbGesR/Heinrich $§ 9$ Rn. 22; dagegen Scholz/Winter $\S 5$ Rn. 86, Hachenburg/Ulmer $\S 5$ Rn. 112; wohl auch MünchAnwHdbGmbHR/Seibt $\S 2$ Rn. 63; vgl. auch Süß/Wachter/Terbrack S. 537; Raiser, S. 423; Goette, S. 48.

334 Baumbach/Hueck/Hueck/Fastrich $\S 5$ Rn. 23 ff. m. w. N.; Süß/Wachter/Terbrack S. 537; Raiser, S. 423; Goette, S. 48. BGH NJW 1979, 216. BGHZ 28, $314=$ NJW 1959, 383. BGHZ 15, 52, 60 = NJW 1954, 1842; BGHZ 113, 335, $341=$ DStR 1991, $915=$ NJW 1991, 1754; BGHZ $145,150=$ DStR 2000, $1963=$ NJW 2001, 67; BGH DStR 1995, 498 = NJW 1995, 460. BGHZ 45, 338, 342 = NJW 1966, 1311 BGHZ 145, $150=$ DStR 2000, $1963=$ NJW 2001, 67. Süß/Wachter/Terbrack S. 537; Raiser, S. 424 f.

343 Die Einzelheiten der Bewertungsansätze werden sehr kontrovers diskutiert, vgl. hierzu OLG München WM 1991, 1669; Baumbach/Hueck/Hueck/Fastrich $\$ 5 \quad 5 \quad$ Rn. 33 ff. $\quad$ m. w. N. zum Streitstand; Süß/Wachter/Terbrack S. 537; Raiser, S. 426; Goette, S. 50. Scholz/Winter § 9 Rn. 4 ff. m. w. N.; Baumbach/Hueck/Hueck/Fastrich § 9 Rn. 8; Süß/Wachter/Terbrack S. 537; Raiser, S. 425 f.; Goette, S. 50.

345 Süß/Wachter/Terbrack S. 537; Goette, S. 50. 
Die Bewertung der Sacheinlage hat auf den Zeitpunkt der Anmeldung der Gesellschaft zum Handelsregister zu erfolgen ${ }^{346}$.

Die Erbringung der Sacheinlageverpflichtung ist grundsätzlich formfrei möglich, sofern nicht das zwischen Gesellschaft und Gesellschafter zu vollziehende Verkehrsgeschäft die Einhaltung einer bestimmten Form verlangt (so etwa bei Grundstücken, § 311b BGB oder bei GmbH-Geschäftsanteilen, $\S 15$ Abs. 3 und 4 GmbHG) $)^{347}$.

Sacheinlagen sind stets bereits vor der Anmeldung der Gesellschaft zum Handelsregister in voller Höhe zu bewirken, und zwar so, dass sie zur endgültig freien Verfügung der Geschäftsführer stehen ( $\$ 7$ Abs. $3 \mathrm{GmbHG})^{348}$.

\section{dd) Gemischte Bar- und Sacheinlage}

Eine Gemischte Bar- und Sacheinlage liegt vor, wenn zur Aufbringung der Stammeinlage zum Teil die Leistung von Geld, zum Teil aber auch die Einbringung eines übertragbaren und vermögenswerten Gegenstandes vereinbart worden ist. Jeder Teil einer derartigen Einlage wird dann für sich nach den Regeln der Bar- beziehungsweise Sacheinlage nach den vorstehenden Grundsätzen behandelt ${ }^{349}$.

\section{ee) Verdeckte Sacheinlage}

Wird unter Umgehung der vorgenannten Sacheinlagevorschriften statt einer vereinbarten Bareinlage tatsächlich - gewollt oder ungewollt - eine Sachleistung eingebracht, so liegt eine so genannte verdeckte Sacheinlage vor ${ }^{350}$. Ein häufiges Beispiel für eine solche verdeckte Sacheinlage ist, wenn der Gesellschafter zunächst das Vereinbarte leistet, die Gesellschaft ihm den

346 OLG Köln GmbHR 1998, 43; OLG Köln GmbHR 1999, 293; dazu auch BGH NJW 2002, 824. Aus der Literatur siehe nur Baumbach/Hueck/Hueck/Fastrich $\S 9$ Rn. 8 und Lutter/Hommelhoff $\S 9$ Rn. 5 m. w. N.

347 Ist die Einhaltung einer bestimmten Form, regelmäßig ist dies die notarielle Beurkundung, vorgeschrieben, so wird die Erfüllung der Sacheinlageverpflichtung in der Praxis regelmäßig in der GmbHGründungsurkunde mit erklärt und beurkundet, da so keine zusätzlichen Notarkosten entstehen. Süß/Wachter/Terbrack S. 537.

348 Süß/Wachter/Terbrack S. 537; Raiser, S. 426; Goette, S. 50.

349 RGZ 159, 321, 326; OLG Stuttgart GmbHR 1982, 109; OLG Zweibrücken GmbHR 1981, 214; Süß/Wachter/Terbrack S. 538.

350 Süß/Wachter/Terbrack S. 538; Raiser, S. 427 ff.; vgl. zum Ganzen auch Heckschen/Heidinger/Heidinger $\S 2$ Rn. 35 ff. Brandner Festschrift für Karlheinz Boujong, S. 37 ff. 
empfangenen Betrag allerdings sofort als Darlehen oder aber als Kaufpreis für einen im Eigentum des Gesellschafters stehenden Gegenstands zurückgewährt (so genanntes Hin- und Herzahlen $)^{351}$. Für die betroffenen, teils gutgläubigen Gesellschafter hat die Aufdeckung einer verdeckten Sacheinlage katastrophale Folgen ${ }^{352}$, denn die Verpflichtung zur Bareinlage bleibt in voller Höhe bestehen; sowohl das schuldrechtliche Umsatzgeschäft ${ }^{353}$ als auch das dingliche Verfügungsgeschäft ${ }^{354}$ sind unwirksam.

In der Rechtsprechung ${ }^{355}$ und Literatur hat man, um den vorgenannten Konsequenzen zu begegnen, die unterschiedlichsten Modelle für eine Heilung verdeckter Sacheinlagen entwickelt $^{356}$ :

Nach Ansicht des $\mathrm{BGH}^{357}$ kann die bei der Gesellschaftsgründung vereinbarte Bareinlage, die faktisch als Sacheinlage erbracht wurde, durch einen Gesellschafterbeschluss, der in notariell beurkundeter Form mit satzungsändernder Mehrheit von drei Vierteln der abgegebenen Stimmen gefasst werden muss ( $§ 53$ Abs. 2 GmbHG), in eine Sacheinlage umqualifiziert werden. In dem Beschluss ist der Gesellschafter, der von der Änderung betroffen ist, namentlich ebenso zu bezeichnen wie die erbrachte Sacheinlage. Daneben ist - dem Sachgründungsbericht entsprechend - ein durch alle Geschäftsführer und den betroffenen Gesellschafter zu unterzeichnender, über die Änderung der Einlagedeckung von der Bar- zur Sacheinlage aufklärender Bericht zu erstellen. Zusätzlich ist ein Nachweis der Werthaltigkeit der Sacheinlage zu erbringen, und zwar des Wertes nicht im Zeitpunkt der ursprünglichen Leistung, sondern in dem Zeitpunkt der Heilung der verdeckten Sacheinlage. Schließlich haben die Geschäftsführer bei Anmeldung zu versichern, dass die Sacheinlage werthaltig und der Gesellschaft von den Gesellschaftern übertragen worden ist ${ }^{358}$. Die so durchgeführte Heilung der verdeck-

351 BGHZ 113, 335, 344 f. Rowedder/Schmidt-Leithoff/Pentz § 19 Rn 141; Hachenburg/Ulmer § 19 Rn. 101. Ausführlichst dazu mit Beispielen aus der Praxis Heckschen/Heidinger/Heidinger $\$ 2$ Rn. $47 \mathrm{ff}$.

352 So K. Schmidt, in Blaurock, Recht der Unternehmen in Europa, S. 105, 117; vgl. auch Brandner in FS Boujong, 1996, S. 37, 42 („,Rechtsfolgenkatastrophe“); sowie Heidenhain GmbHR 2006, 455; J. Vetter, Reform des gesellschaftsrechtlichen Gläubigerschutzes, in: Verhandlungen des 66. Deutschen Juristentages, Band II/1, 2006, P 75, P 85 f. und Grunewald, S. 328 (,drakonische Rechtsfolgen“"). Das folgt aus einer entsprechenden Anwendung des $\S 27$ Abs. 3 AktG.

354 BGH ZIP 2003, 1540; vgl. hierzu auch Hachenburg/Ulmer § 19 Rn. 113 ff.; Michalski/Ebbing § 19 Rn. 148 m. w. N. zur früher (d.h. vor der Entscheidung des BGH) herrschenden Auffassung nach der nur das Verplfichtungsgeschäfts unwirksam sein sollte.

355 Vgl. zur Zulässigkeit einer Heilung BGHZ 132, 141 = ZIP 1996, 668.

356 Vgl. etwa K. Schmidt, in Blaurock, Recht der Unternehmen in Europa, S. 105, 119; Grunewald in FS Rowedder, 1994, S. 111, 114 ff., dies. WM 2006, 2333, 2335 f.; Brandner in FS Boujong, 1996, S. 37, 45; Krieger ZGR 1996, 674, 691; Schöpflin GmbHR 2003, 57, 64; Heidenhain GmbHR 2006, 455 , 457 f.; Roth/Altmeppen $\S 19$ Rn. 61 sowie Trölitzsch, Differenzhaftung für Sacheinlagen in Kapitalgesellschaften 1998, S. $194 \mathrm{ff}$.

357 Grundlegend BGH NJW 1996, 1473 = GmbHR 1996, 351 = ZIP 1996, 668; jüngst BGH DB 2003, $1894=$ ZIP 2003, 1540.

358 Vgl. zum Ganzen insbesondere Heckschen/Heidinger/Heidinger $§ 2$ Rn. 77 ff.; Süß/Wachter/Terbrack S. 526 und 538 sowie die zahlreichen Nachweise bei Lutter/Hommelhoff/Lutter/Bayer $§ 5$ Rn. 5.6 und 36. 
ten Sacheinlage wird mit Eintragung der Satzungsänderung im Handelsregister ex nunc wirk$\operatorname{sam}^{359}$.

\section{b) Kapitalerhaltung / Gläubigerschutz}

\section{aa) Grundlagen}

Die Grundsätze der Kapitalaufbringung und Kapitalerhaltung sind nach dem deutschen Rechtsverständnis wesentliche Voraussetzung für das Privileg des beschränkten Haftungsfonds in der $\mathrm{GmbH}$. Die Kapitalaufbringung wird - wie bereits oben verschiedene Mal erwähnt - durch die Verpflichtung jedes Gesellschafters, nicht nur für die Leistung der von ihm selbst übernommenen Bar- oder Sacheinlagen, sondern auch für die von seinen Mitgesellschaftern übernommenen, aber nicht erbrachten Einlagen einzustehen, zu gewährleisten versucht ( $\S 24,16$ Abs. 2 GmbHG) ${ }^{360}$. Entsprechendes gilt für die Sicherung der Kapitalerhaltung; hier geraten neben den betroffenen Gesellschaftern auch die anderen Mitgesellschafter in die Haftung, wenn die Gesellschaft ihren Gesellschaftern gegenüber Leistungen erbringt, die eine Unterbilanz verursachen oder eine bestehende Unterbilanz erhöhen ( $§ 30$ Abs. 1, 31 Abs. $3 \mathrm{GmbHG})^{361}$.

\section{bb) Kapitalschutz}

Die $\S \S 30,31$ GmbHG schützen das Vermögen der Gesellschaft, das (rechnerisch) zur Erhaltung des Stammkapitals erforderlich ist. Auf eine konkrete Zusammensetzung des Vermögens kommt es nicht an; geschützt wird allein die wertmäßige Abbildung des Stammkapitals. Andererseits ist das Vermögen nur vor (Rück-)Zahlungen an die Gesellschafter geschützt; keinen Schutz gewähren die vorgenannten Kapitalerhaltungsregelungen vor einer anderweitigen Auszehrung des Stammkapitals ${ }^{362}$.

\footnotetext{
359 Sehr übersichtlich dargestellt bei Heckschen/Heidinger/Heidinger § 2 Rn. 79; Süß/Wachter/Terbrack S. 538.

360 BDI/Hengeler Müller S. $17 \mathrm{ff}$.

361 BDI/Hengeler Müller S. 17 ff.; Süß/Wachter/Terbrack S. 541.

362 Süß/Wachter/Terbrack S. 541; Grunewald, S. 367 f.; Ausführliche Darstellung bei Heckschen/Heidinger/Heidinger $\S 9 \mathrm{Rn} .1 \mathrm{ff}$.
} 
$\S 30$ Abs. $1 \mathrm{GmbHG}$ enthält das Verbot, das zur Erhaltung des Stammkapitals erforderliche Vermögen der Gesellschaft an die Gesellschafter auszuzahlen; in § $31 \mathrm{GmbHG}$ wird ein Verstoß durch Festlegung entsprechender Rückzahlungs- und Erstattungspflichten sanktioniert ${ }^{363}$.

Auszahlungen im Sinne des $\S 30 \mathrm{GmbHG}$ sind solche Verringerungen des Gesellschaftsvermögens - gleichgültig auf welche Art - die zu einer Unterbilanz führen, oder zu einem Zeitpunkt vorgenommen werden, zu dem eine solche Unterbilanz bereits besteht ${ }^{364}$.

Liegt eine Verletzung des $\S 30 \mathrm{GmbHG}$ im vorgenannten Sinne vor, so steht der Gesellschaft ein Erstattungsanspruch zunächst gegen den Leistungsempfänger nach $\S 31 \mathrm{GmbHG}$ beziehungsweise aufgrund eventueller weiterer Vorschriften (z.B. $\S 812$ ff. BGB) zu. Darüber hinaus kommt eine (beschränkte) ${ }^{365}$ Inanspruchnahme der übrigen Gesellschafter auf Grundlage des $\S 31$ Abs. 3 Satz 1 GmbHG und (hier allerdings unbeschränkt) der pflichtwidrig handelnden Geschäftsführer gemäß $\S 43$ Abs. 3 GmbHG in Betracht. Letztere sind zudem nach Maßgabe des $\S 31$ Abs. 6 den nach $\S 31$ Abs. 3 GmbHG in Anspruch genommenen Gesellschaftern ausgleichspflichtig ${ }^{366}$.

Der Rückzahlungsanspruch aus $\S 31$ Abs. 1 GmbHG richtet sich auf die wertmäßige Wiederherstellung des das Stammkapital deckenden Vermögens ${ }^{367}$. Somit muss die Rückzahlungsverpflichtung nicht stets den gesamten Auszahlungsbetrag erfassen, sondern kann im Einzelfall auch lediglich in dem Ausgleich einer bestehenden Wertdifferenz bestehen ${ }^{368}$. Andererseits gilt, dass der einmal entstandene Rückerstattungsanspruch gegen den betreffenden $\mathrm{Ge}-$ sellschafter nicht entfällt, sondern trotz wertmäßig abgebildetem Stammkapital in voller Höhe zu leisten ist, wenn nach einer verbotenen Rückzahlung das Gesellschaftsvermögen anderweitig bis zur Höhe des Stammkapitals wiederhergestellt ist ${ }^{369}$.

363 Vgl. dazu nur Scholz/Westermann § 31 Rn. 13 ff.; Michalski/Heidinger $§ 31$ Rn. 18 ff. jeweils m. w. N.; siehe auch die Zusammenfassungen bei Süß/Wachter/Terbrack S. 541; Grunewald, S. 367 f. BGH GmbHR 2004, 302; BGHZ 31, 258; BGH NJW 1987, 1194; Michalski/Heidinger $§ 30$ Rn. 34.

365 Beschränkt auf den Betrag der Stammeinlage BGH DNotZ 2002, 472 = GmbHR 2002, 549 ohne Abzug des eigenen Anteils am Stammkapital BGH ZIP 2003, 2068 = NJW 2003, 3629.

366 Süß/Wachter/Terbrack S. 541; Grunewald, S. 368.

367 BGHZ 31, 265.

368 Süß/Wachter/Terbrack S. 541; Grunewald, S. 369.

369 Dies geht auf zwei Entscheidungen des BGH aus dem Jahr 2000 zurück (BGH vom 20./29. Mai 2000 Balsam/Procedo I-III, BGHZ 144, 341, abgedruckt in NZG 2000, 883; ZIP 2000, 1256 und NZG 2000, $888=$ BB 2000, 1483, 1484) in denen dieser klargestellt hat, dass er den Rückzahlungsanspruch nach $\S 31$ Abs. 1 GmbHG als dem Einlageanspruch der Gesellschaft vergleichbar erachtet,so dass der einmal entstandene Anspruch auch bei späterer anderweitiger Wiederherstellung des Gesellschaftskapitals nicht entfällt.. 


\section{cc) Cash-Pool}

Verkürzt dargestellt handelt es sich bei den so genannten Cash-Pool- oder auch CashManagement-Systemen ${ }^{370}$ um Konzernfinanzierungsinstrumente, bei denen die Liquidität der einzelnen Konzernunternehmen bei einem der verbundenen Unternehmen gebündelt und sodann an andere Konzernunternehmen ausgeliehen wird ${ }^{371}$. In der Praxis werden das so genannte ,virtuelle“ oder auch „,notionale“ und das ,physische“ Cash Pool unterschieden.

Am häufigsten findet sich in der Praxis das physische Cash Pool: Hierbei werden die Liquiditätsüberschüsse auf den Bankkonten (Quellkonten) der angeschlossenen Konzernuntergesellschaften bankarbeitstäglich auf das bei der Konzernobergesellschaft oder einer von dieser dafür eingerichteten Finanzierungsgesellschaft bestehende Bankkonto (Zielkonto) transferiert. Die Quellkonten sind damit am Abend eines jeden Bankarbeitstages glattgestellt ${ }^{372}$.

Rechtlich sind die Geldab- und -zuflüsse nach mittlerweile wohl einhelliger Auffassung als wechselseitig begebene Darlehen zu qualifizieren ${ }^{373}$. In dem Moment, in dem ein Konzernunternehmen Liquidität an das Zielkonto abführt, gewährt es der Obergesellschaft ein Darlehen oder vermindert eine dieser gegenüber bestehende Verbindlichkeit. Wird umgekehrt dem Konzernunternehmen Liquidität vom Zielkonto zugeführt, so liegt entweder eine Darlehensgewährung an die Untergesellschaft oder die Verminderung von Darlehensansprüchen vor, die dieser gegen die Obergesellschaft zustehen ${ }^{374}$.

370 Näher dazu Jäger DStR 2000, 1653 ff.; Cahn ZHR 166 (2002), 278 ff.; Wehlen in Lutter/Scheffer/Schneider, Handbuch der Konzernfinanzierung, 1998, S. 805 ff.; Theisen, Der Konzern, 2. Aufl. 2000, S. 452 ff.; Ammelung/Kaeser DStR 2003, 655 ff.; Sieger/Wirtz ZIP 2005, 2277 f.

371 Joost, Die GmbH-Reform in der Diskussion, S. 31, 32 f. Zu den Problemen des Cash-Pooling nach bisheriger Rechtslage,insbesondere im Zusammenhang mit den Regelungen zur Kapitalerhaltung und Kapitalaufbringung Schäfer BB 2006 BB Special Nr. 7, 5 sowie ders. DStR 2006, 2085; vgl. insoweit auch Wessels ZIP 2006, 1701.

$372 \mathrm{Zu}$ den Technikalien insbes. Wehlen in Lutter/Scheffler/Schneider, Handbuch der Konzernfinanzierung, 1998, Rn. 23.1 ff.; ferner etwa Jäger DStR 2000, 1653 f.; Sieger/Hasselbach BB 1999, 645; Grothaus/Halberkamp GmbHR 2005, 1317 f., einen guten Überblick über die Thematik gibt Priester ZIP 2006, 1557.

373 Priester ZIP 2006, 1557; Bayer in FS Lutter, S. 1011, 1014 f.; Cahn ZHR 166 (2002), 278, 280; Grothaus/Halberkamp GmbHR 2005, 1317 f.; Hellwig in FS Peltzer, S. 163, 165; Jäger DStR 2000, 1653; Langner GmbHR 2005, 1017, 1022; Sieger/Hasselbach BB 1999, 645; abw. Ulmer ZHR 169 (2005), 1, 4 f.: unregelmäßige Verwahrung ( $\$ 700$ BGB).

374 Nach dem Abschied des BGH von der rein bilanziellen Betrachtungsweise bei Geschäften mit Gesellschaftern (grundlegend BGH v. 24. November 2003, abgedruckt in GmbHR 2004, $302 \mathrm{~m}$. Anm. Bähr/Hoos = DStR 2004, 427) wird in der Literatur kontrovers diskutiert, inwieweit der Cash-Pool ohne Haftungsrisiken weiter durchgeführt werden kann. Führt der Entzug von Liquidität bei der Tochtergesellschaft zu einer Unterbilanz, so ist nach neuer Rechtsprechung - ungeachtet eines ggfs. vollwertigen (und damit aktivierbaren) Rückzahlungsanspruchs - ein Verstoß der Kapitalerhaltungsvroschrift des $\S 30 \mathrm{GmbHG}$ gegebn, mit den daraus resultierenden Haftungsfolgen. Vgl. statt aller zu der uferlosen Literatur in Folge des „NovemberUrteils“ des BGH Michalski/Heidinger $§ 30$ Rn. 49 mit zahlreichen N. 
Das virtuelle Cash Pooling hat im Ergebnis denselben Effekt wie der physische Cash Pool ${ }^{375}:$ : Anders als beim physischen Cash-Pool wird die Liquidität nicht tatsächlich transferiert; es findet eine rein rechnerische Zusammenfassung der Salden aller teilnehmenden Konzerngesellschaften statt, so dass mangels effektiver Zahlungsflüsse keine tatsächliche Darlehensgewährung erfolgt ${ }^{376}$.

\section{dd) Eigenkapitalersatzrecht}

Das GmbH-Gesetz sieht in den $\S \S 32 \mathrm{a}, 32 \mathrm{~b}$ besondere Rechtsfolgen für den Fall vor, dass ein Gesellschafter der GmbH in einem Zeitpunkt, in ihr die Gesellschafter als ordentliche Kaufleute Eigenkapital zugeführt hätten, ein Darlehen gewährt. Hintergrund ist, dass es den Gesellschaftern aufgrund ihrer besonderen Finanzierungsfolgeverantwortung für die GmbH nicht freistehen soll, das unter diesen besonderen Bedingungen zur Verfügung gestellte Kapital in der Krise wieder abzuziehen. Wenn sich der Gesellschafter in der Krise gegen eine Liquidation und für die Fortführung der Gesellschaft entschließt, so hat er die Fortführung durch Zuführung von Eigenkapital und nicht von Fremdkapital zu unterstützen ${ }^{377}$. Wählt er dennoch eine Finanzierung der Gesellschaft mittels Fremd-, nämlich darlehensweise gewährtem Kapital, so bestimmt $\S 32$ a Abs. 1 GmbHG, dass er im Falle der Insolvenz der Gesellschaft mit seinem Rückzahlungsanspruch lediglich wie ein Eigenkapitalgeber, d.h. wie ein nachrangiger Insolvenzgläubiger ( $§ 39$ InsO) behandelt werden soll. Flankiert wird die Regelung des $\S 32$ a GmbHG durch einen Erstattungsanspruch der Gesellschaft aus $§ 32$ b GmbHG, der dann entsteht, wenn das Darlehen im letzten Jahr vor Beantragung der Eröffnung des Insolvenzverfahrens zurückgezahlt worden ist. Darüber hinaus bestimmt $\S 135$ InsO, dass Rechtshandlungen, die dem Gläubiger einer eigenkapitalersetzenden Forderung Befriedigung gewähren, anfechtbar sind, wenn sie im letzten Jahr vor Stellung des Antrags auf Verfahrenseröffnung erfolgt $\operatorname{sind}^{378}$.

Die gesetzlichen Regelungen werden allgemein als verunglückt angesehen; die Diskussionen darüber haben eine Vielzahl gerichtlicher Entscheidungen erzwungen und zu einer ausufern-

375 Dazu Morsch NZG 2003, 97, 98; Langner GmbHR 2005, 1017, 1022; Grothaus/Halberkamp GmbHR 2005, 1317, 1322 f.; Priester ZIP 2006, 1557.

376 Und somit auch keine Verletzung des $\S 30$ GmbHG zu befürchten ist; siehe Morsch NZG 2003, 97, 98; Langner GmbHR 2005, 1017, 1022; Grothaus/Halberkamp GmbHR 2005, 1317, 1322 f.; Priester ZIP 2006, 1557.

377 Süß/Wachter/Terbrack S. 542; K. Schmidt ZIP 2006, 1925 ff.

378 Vgl. zur Rechtsprechung Goette S. 87 ff.; zur Literatur vgl. die Nachweise bei Michalski/Heidinger §§ 32a, 32b Rn. 43 ff. sowie Heckschen/Heidinger/Heidinger $\S 9$ Rn. 28 ff.; Süß/Wachter/Terbrack S. 542; K. Schmidt ZIP 2006, 1925 ff. 
den Literatur geführt ${ }^{379}$. Stark verkürzt dargestellt, beschreibt die Rechtsprechung zum Eigenkapitalersatzrecht in ihrer gegenwärtigen Form eine Verhaltenshaftung des Gesellschafters wenn dieser trotz erkennbarer Krise die ihm nach Ansicht der Rechtsprechung obliegende Entscheidung zwischen Sanierung und Liquidierung der Gesellschaft nicht trifft und statt dessen die Krise der Gesellschaft durch darlehensweise Zwischenfinanzierung künstlich in die Länge zieht $^{380}$

\section{c) Eigene Anteile}

Nach Maßgabe des $\S 33$ GmbHG kann die Gesellschaft eigene Geschäftsanteile nur erwerben sofern die Einlage auf die Geschäftsanteile voll geleistet ist und der Erwerb aus dem über den Betrag des Stammkapitals hinaus vorhandenen Vermögen geschehen ist und die Gesellschaft die nach § 272 Abs. 4 HGB vorgeschrieben Rücklage für eigene Anteile bilden kann, ohne das Stammkapital oder eine nach dem Gesellschaftsvertrag zu bildende Rücklage zu mindern, die nicht zur Zahlung an die Gesellschafter verwandt werden darf (§ 33 Abs. 2 Satz 1 GmbHG). Daneben ist der Erwerb eigener Anteile zulässig zur Abfindung von Gesellschaftern im Rahmen von Umwandlungsfällen ( $§ 33$ Abs. 3 GmbHG $)^{381}$.

Erfolgt der Erwerb eigener Geschäftsanteile durch die GmbH ohne dass die nach Maßgabe der Sätze 1 und 2 des $\S 33$ Abs. 2 GmbHG vorausgesetzten Bedingungen gegeben sind, so ist, das schuldrechtliche Geschäft hierüber nichtig ( 33 Abs. 1 GmbHG, § 134 BGB). In der Folge ist das dingliche Verfügungsgeschäft nach Maßgabe der bereicherungsrechtlichen Vorschriften ( $\S 812$ ff. BGB) rückabzuwickeln ${ }^{382}$.

379 Goette S. 87 ff.; beispielhaft sei verwiesen auf: BGHZ 95, 192; BGH GmbHR 1996, 285; BGHZ 76, 326; BGHZ 81, 311; BGHZ 31, 258 sowie zum Schrifttum auf die umfassenden Nachweise bei Scholz/K. Schmidt $\S 32$ a, 32b GmbHG; vgl. auch jüngst Bork ZGR 2007, 250. Süß/Wachter/Terbrack S. 542; K. Schmidt ZIP 2006, 1925 ff.

381 Süß/Wachter/Terbrack S. 542, Raiser, S. $646 \mathrm{ff}$.

382 Süß/Wachter/Terbrack S. 542; Raiser, S. 646 f.; Grunewald, S. 371. 


\section{Zu den Reformbestrebungen}

\section{a) Reformansätze des MoMiG}

\section{aa) Kapitalaufbringung}

\section{aaa) Stammkapital}

\section{(i) Mindeststammkapital}

Der Regierungsentwurf sieht wie bereits der Referentenentwurf eine Herabsetzung des Mindeststammkapitals von bisher $25.000 €$ auf $10.000 €$ vor. $§ 5$ Abs. 1 GmbHG der die Höhe des Mindeststammkapitals regelt, wird entsprechend geändert. Ausweislich der Begründung soll damit einer zunehmenden Kritik von Praxis und Wissenschaft an Höhe und Sinnhaftigkeit des bisherigen Mindeststammkapitals Rechnung getragen werden. Durch die bloße Herabsetzung und nicht Abschaffung des Mindeststammkapitals werde berücksichtigt, dass diesem die Funktion einer Seriositätsschwelle beigemessen wird. Andererseits werde mit der Absenkung gerade Kleinunternehmen und Existenzgründern ermöglicht, bei geringem Kapitalbedarf leichter eine Gesellschaft zu gründen als bisher ${ }^{383}$.

\section{(ii) Höhe der Stammeinlage}

Weiter sollen die Gesellschafter die Größe der von ihnen zu übernehmenden Stammeinlagen individueller als bisher bestimmen können. Als einzige Begrenzung ist vorgesehen, dass jede Stammeinlage auf einen Betrag in vollen Euro (mindestens also einen Euro) lauten muss. Bislang muss die Stammeinlage jedes Gesellschafters mindestens $100 €$ betragen ( $§ 5$ Abs. 1 $\mathrm{GmbHG})^{384}$. Hierauf soll künftig verzichtet werden. Zum Schutz der Gesellschaftsgläubiger trägt der Mindestbetrag der einzelnen Stammeinlage nach zutreffender Auffassung des Gesetzgebers nichts bei ${ }^{385}$. Die Kapitalerhaltung nach den $\S 30$ Abs. 1, § 31 Abs. 1 GmbHG orientiert sich an dem zur Erhaltung des Stammkapitals als Ganzem erforderlichen Vermögen.

\footnotetext{
383 Begründung des Regierungsentwurfs, Besonderer Teil, S. 66; vgl. insoweit auch schon oben in diesem Abschnitt unter $\S 1$ II 2. a) cc).

384 Begründung des Regierungsentwurfs, Besonderer Teil, S. 66 a. E..; vgl. insoweit auch schon oben in diesem Abschnitt unter $\S 1$ II 2. a) dd).

385 Vgl. hierzu auch schon Flesner NZG 2006, 641, 642.
} 
Demgegenüber ist die Größe der jeweiligen Stammeinlage nur für die Ausfallhaftung der Mitgesellschafter gemäß den $\S \S 24,31$ Abs. 3 GmbHG von Belang. Auch hier dient sie nur dazu, die von den Mitgesellschaftern zu erstattenden Beträge nach dem Verhältnis ihrer Geschäftsanteile zu berechnen. An dieser Funktion als Rechengröße ändert sich auch dann nichts, wenn die Größe der Stammeinlagen individuell bestimmt werden kann. Dem Schutz der Gesellschaftsgläubiger dient als Ausschüttungssperre weiterhin das gezeichnete Kapital ${ }^{386}$.

\section{(iii) Teilbarkeit der Stammeinlagen}

Mit dem neu gefassten $§ 5$ Abs. 2 GmbHG braucht der Betrag der Stammeinlage jedes Gesellschafters nur noch auf volle Euro zu lauten ${ }^{387}$. Hierbei handelt es sich in erster Linie um eine Folgeänderung zur Neuregelung des $§ 5$ Abs. 1 GmbHG. Zudem wird eine Liberalisierung der Teilbarkeitsregel für Stammeinlagen gegenüber den bisherigen Vorgaben in $\S 5$ Abs. 3 Satz 2 GmbHG verfolgt. Das Verbot der Übernahme mehrerer Stammeinlagen bei Errichtung der Gesellschaft nach $§ 5$ Abs. 2 GmbHG wird aufgehoben.

Der Vorschlag des Regierungsentwurfs entspricht der bisher schon herrschenden Auffassung in der Literatur ${ }^{388}$, die den stets angeführten Zweck des Verbots der Übernahme mehrerer Stammeinlagen, nämlich dass für die Gründung die Einheit der Stammeinlage und des Geschäftsanteils sichergestellt sowie darüber hinaus die Personalisierung der Beteiligung an der Gesellschaft gestärkt und eine geringere Fungibilität erreicht werden soll, schon seit langem mit überzeugenden Gründen angezweifelt hatte. Ausdrücklich offen lässt der Gesetzgeber allerdings, ob im Recht der GmbH überhaupt noch ein schutzwürdiges Regelungsinteresse an einer Verringerung der Fungibilität der Geschäftsanteile besteht. Die freie Übertragbarkeit der Geschäftsanteile bei der GmbH werde anders als im Recht der AG nach wie vor durch das Erfordernis der notariellen Beurkundung nach $§ 15$ Abs. 3 erschwert. Daher könne die Entstehung eines Handels mit Geschäftsanteilen wie bei Aktien ausgeschlossen werden ${ }^{389}$. Daneben würde durch die Stärkung der Gesellschafterliste und die Schaffung der Möglichkeit eines gutgläubigen Erwerbs von Geschäftsanteilen einer Unübersichtlichkeit der Beteiligungsverhältnisse wirksam begegnet.

386 Begründung des Regierungsentwurfs, S. 67; Vgl. auch Ehinger BB Special 2006 Nr. 7, S. 24 mit Kommentaren allerdings noch zum Referententwurf.

387 Begründung des Regierungsentwurfs, Besonderer Teil, S. 67; vgl. insoweit auch schon oben in diesem Abschnitt unter $\S 1$ II 2. a) dd).

388 Vgl. nur Bormann GmbHR 2006, 1021, Flesner NZG 2006, 641, 642 f. sowie Happ ZHR 169 (2005), 6 mit vielen weiteren Nachweisen.

389 Nach Auffassung des Verfassers gibt es einen Markt für Geschäftsanteile bereits seit langem; die Verpflichtung zur notariellen Beurkundung von Geschäftsanteilsübertragungen hat den auch spekulativen Handel mit Geschäftsanteilen nicht verhindern können. 
Aufgrund der Neufassung des $\S 5$ Abs. $2 \mathrm{GmbH}$ ist schließlich sichergestellt, dass der Betrag der Stammeinlagen und folglich auch der Betrag der Geschäftsanteile künftig auf volle Euro lauten müssen. Verhindert wird demzufolge, dass bei Teilungen Beträge mit unübersichtlichen Nachkommastellen sowie dadurch bedingte Rundungsprobleme entstehen. Mit dieser gesetzlichen Änderung ist im Übrigen in keiner Weise die Einrichtung oder Förderung eines Kapitalmarktsegments zum Börsenhandel von GmbH-Anteilen geplant, was in der Vergangenheit häufig als Kritik gegen die Aufhebung des $§ 5$ Abs. 3 Satz 2 vorgebracht wurde ${ }^{390}$.

\section{bbb) Verdeckte Sacheinlage}

Die bestehenden Rechtsunsicherheiten im Bereich der Kapitalaufbringung ${ }^{391}$ werden dadurch beseitigt, dass das Rechtsinstitut der „,verdeckten Sacheinlage“ im Gesetz klar geregelt wird. Eine verdeckte Sacheinlage liegt danach vor, wenn zwar formell eine Bareinlage vereinbart und geleistet wird, die Gesellschaft bei wirtschaftlicher Betrachtung aber einen Sachwert erhalten soll. Der Entwurf sieht des Weiteren vor, dass die Gesellschafter künftig auch mit einer „,verdeckten Sacheinlage“ ihre Verpflichtung gegenüber der Gesellschaft erfüllen können sollen. Der Gesellschafter muss aber beweisen, dass der Wert der verdeckten Sacheinlage den Betrag der geschuldeten Bareinlage erreicht hat. Kann er das nicht, muss er die Differenz in bar erbringen ${ }^{392}$. Die für die Praxis schwer nachzuvollziehenden Vorgaben der Rechtsprechung zur verdeckten Sacheinlage sowie die einschneidenden Rechtsfolgen, die dazu führen, dass der Gesellschafter seine Einlage im Ergebnis häufig zweimal leisten muss, werden hierdurch beseitigt ${ }^{393}$.

\footnotetext{
390 Begründung des Regierungsentwurfs, Allgemeiner Teil, S. 39 ff.

391 Vgl. hierzu oben in diesem Abschnitt unter IV 1. a).

392 Begründung des Regierungsentwurfs, Allgemeiner Teil, S. 56.

393 Begründung des Regierungsentwurfs, Allgemeiner Teil, S. 56. Vgl. in der Literatur dazu etwa Kallmeyer DB 2007, 2755; eine Kodifizierung der verdeckten Sacheinlage ausdrücklich begrüßend Bormann GmbHR 2007, 897, 900 ff. Ausführlich zu den einzelnen denkbaren Fallkonstellationen einer verdeckten Sacheinlage Veil ZIP 2007, 1241; Kritisch bis ablehnend Büchel GmbHR 2007, 1065; differenzierter Drygala NZG 2007, 561, 563; siehe dazu auch Drygala/Kremer ZIP 2007, 1289. Nach Auffassung von Priester ZIP 2008, 55 fällt der Gesetzgeber mit der Neuregelung ins andere Extrem. War die bisherige Sanktion zu scharf, ist die Regelung nach seinem Dafürhalten jetzt zu milde. Vorgeschlagen wird ein Mittelweg, bei dem die Einlageschuld fortexistiert, mit dem nachgewiesenen Wert der Sache aber verrechnet wird. Vgl. auch jüngst Ulmer ZIP 2008, 45, 50 ff., der vorschlägt die Differenzierung von Bar- und Sacheinlage zugunsten einer „Innenlösung“ nach dem Vorbild des KG-Rechts.
} 


\section{bb) Kapitalerhaltung / Gläubigerschutz}

Die sehr komplex gewordene Materie des Eigenkapitalersatzrechts ( $\S 30 \mathrm{ff}$. GmbHG) wird erheblich vereinfacht und grundlegend dereguliert. Beim Eigenkapitalersatzrecht geht es um die Frage, ob Kredite, die Gesellschafter ihrer GmbH geben, als Darlehen oder als Eigenkapital behandelt werden. Das Eigenkapital steht in der Insolvenz hinter allen anderen Gläubigern zurück. Grundgedanke der Neuregelung ist, dass die Organe und Gesellschafter der gesunden $\mathrm{GmbH}$ einen einfachen und klaren Rechtsrahmen vorfinden sollen. Dazu werden die Rechtsprechungs- und Gesetzesregeln über die kapitalersetzenden Gesellschafterdarlehen (§§ 32a, 32b GmbHG) im Insolvenzrecht neu geordnet; die Rechtsprechungsregeln nach $\S 30$ GmbHG werden aufgehoben. Eine Unterscheidung zwischen „kapitalersetzenden“ und „,normalen“ Gesellschafterdarlehen wird es nicht mehr geben ${ }^{394}$.

\section{aaa) Kapitalschutz}

Der Regierungsentwurf ${ }^{395}$ sieht die Anfügung eines neuen Satzes 2 in $\S 30$ Abs. 1 GmbHG vor, der sich auf den unverändert gebliebenen Satz 1 bezieht und folgenden Wortlaut hat: „Satz 1 gilt nicht bei Leistungen, die zwischen den Vertragsteilen eines Beherrschungs- oder Gewinnabführungsvertrags ( $\$ 291$ des Aktiengesetzes) erfolgen oder durch einen vollwertigen Gegenleistungs- oder Rückgewähranspruch gegen den Gesellschafter gedeckt sind ${ }^{\star 396}$ Damit kehr der Entwurf zur bilanziellen Betrachtungsweise bei der Ermittlung des der Gesellschaft zur Verfügung stehenden Vermögens zurück ${ }^{397}$.

In der Begründung heißt es, der Vorschlag stelle eine Reaktion auf die Verunsicherungen dar, die durch die Entscheidung des BGH vom 24. November 2003 entstanden seien, wonach Kreditgewährungen an Gesellschafter zu Lasten des gebundenen Vermögens der GmbH auch dann als verbotene Auszahlungen im Sinne von $\S 30$ Abs. 1 GmbHG anzusehen seien, wenn der Rückzahlungsanspruch vollwertig sei ${ }^{398}$.

394 Begründung des Regierungsentwurfs, Allgemeiner Teil, S. 39 ff. Dazu insgesamt Freitag WM 2007, 1681; vgl. auch Hölzle GmbHR 2007, 729.

395 Begründung des Regierungsentwurfs, Besonderer Teil, S. 93 ff.

396 Begründung des Regierungsentwurfs, Besonderer Teil, S. 93 ff.; Priester ZIP 2006, 1557.

397 Gesmann-Nuissl WM 2006, 1756, 1761; vgl. dazu auch Winter DStR 2007, 1484.

398 Begründung des Regierungsentwurfs, Besonderer Teil, S.93; Priester ZIP 2006, 1557. Zu den Folgen für das Cash Pooling Schäfer BB 2006 BB Special Nr. 7, 5, der den Vorschlag des damals noch aktuell vorliegenden Referentenentwurfs ausdrücklich begrüsst. Differenzierte Betrachtung bei Drygala/Kremer ZIP 2007, 1289. 


\section{bbb) Deregulierung des Eigenkapitalersatzrechts}

Eine grundlegende Reformierung erfährt auch die sehr komplex gewordene Materie des Eigenkapitalersatzrechts ( $\S 32$ a und b GmbHG), indem die Rechtsprechungs- und Gesetzesregeln über die kapitalersetzenden Gesellschafterdarlehen ( $\S 32 \mathrm{a}, 32 \mathrm{~b} \mathrm{GmbHG})$ im Insolvenzrecht neu geordnet werden; die Rechtsprechungsregeln nach $\S 30 \mathrm{GmbHG}$ aufgehoben werden. Die bisherige Unterscheidung zwischen „kapitalersetzenden“ und „normalen“ Gesellschafterdarlehen wird es nach dem Willen des Gesetzgebers nicht mehr geben ${ }^{399}$.

\section{(i) Aufgabe der Rechtsprechungsregeln}

Die Rechtsprechungsregeln zu den eigenkapitalersetzenden Gesellschafterdarlehen sollen ausweislich des Regierungsentwurfs und in Folge der Umstrukturierung aufgegeben werden $^{400}$. § 30 Abs. 1 Satz 3 GmbHGE stellt künftig klar, dass Gesellschafterdarlehen und gleichgestellte Leistungen nicht wie haftendes Eigenkapital zu behandeln sind. Tilgungsleistungen auf solche Forderungen können folglich keine nach $§ 30$ Abs. 1 Satz 1 GmbHG verbotenen Auszahlungen des zur Erhaltung des Stammkapitals erforderlichen Vermögens sein $^{401}$.

\section{(ii) Verlagerung der Novellenregeln ins Insolvenzrecht: Nachrang und Anfechtung}

Die $\S \S 32 \mathrm{a}, \mathrm{b}$ GmbHG werden aufgehoben und deren Regelungsinhalte in das Insolvenzrecht verlagert, wo sie systematisch auch hingehören ${ }^{402}$. Durch die Verlagerung wird die Bedeutung der Eigenkapitalersatzregelungen zugleich ausgebaut, da sie dort nicht nur für die $\mathrm{GmbH}$, sondern auch für die KG sowie Personengesellschaften ohne natürliche Person als persönlich haftenden Gesellschafter Gültigkeit beanspruchen (§ 39 Abs. 4 InsOE).

Durch Streichung des Merkmals „kapitalersetzend“ sind künftig alle Gesellschafterdarlehen in der Insolvenz nachrangig ( $\$ 39$ Abs. 1 Nr. 5 InsOE). Ebenso sollen alle Gesellschafterdarlehen - nicht nur die kapitalersetzenden - die im Jahr vor Stellung des Insolvenzantrags von

399 Begründung des Regierungsentwurfs, Besonderer Teil, S. 58; vgl. auch Flitsch DZWiR 2006, 397 sowie Schiffer BB 2006, BB Special Nr. 7, 14. Ausführlich Darstellung bei Habersack ZIP 2007, 2145. Zu den Konsequnezen für die Konzernfinanzierung vgl. jüngst Burg/Westerheide BB 2008, 62.

400 Begründung des Regierungsentwurfs, Besonderer Teil, S. 93 ff.; Vgl. dazu Bormann, DB 2006, 2616 ff.; Haas ZInsO 207, 617; Gesmann-Nuissl WM 2006, 1756, 1761; Flitsch DZWiR 2006, 397, 398 ff.; Schiffer BB 2006, BB Special Nr. 7, $14 \mathrm{f}$.

401 Begründung des Regierungsentwurfs, Besonderer Teil, S. 95; Gesmann-Nuissl WM 2006, 1756, 1761; Flitsch DZWiR 2006, 397, 398 ff.; Schiffer BB 2006, BB Special Nr. 7, 14, 15.

402 Begründung des Regierungsentwurfs, Besonderer Teil, S. 96; vgl. auch Flitsch DZWiR 2006, 397, 400. 
der Gesellschaft zurückgezahlt worden sind, durch Anfechtung wieder zur Masse gezogen werden können $(\S 135 \text { InsOE })^{403}$.

\section{(iii) Kleinbeteiligungs- und Sanierungsprivileg}

Die Bestimmungen der $\S 32$ a Abs. 3 Satz 2 und 3 GmbHG zum Kleinbeteiligungs- und Sanierungsprivileg werden übernommen ${ }^{404}$. Danach sind kleinbeteiligte Gesellschafter und solche die zum Zwecke der Überwindung einer Krise ein Darlehen gewähren, von den Regeln über den Kapitalersatz befreit; ihre Darlehen sollen - wie bislang auch - keine insolvenzrechtliche Rückstufung erfahren; sie werden wie Fremdkredite behandelt ( $\$ 39$ Abs. 5 In$\mathrm{sOE})^{405}$.

Die Beteiligungsquote für die Inanspruchnahme des Kleinbeteiligtenprivileg soll für alle in $\S 39$ Abs. 4 Satz 1 InsOE genannten Gesellschaften einheitlich auf $10 \%$ lauten. Für eine von der Rechtsprechung ${ }^{406}$ vorgenommene Differenzierung zwischen $\mathrm{GmbH}$ und Aktiengesellschaft sei ein Grund nicht ersichtlich ${ }^{407}$.

Das Sanierungsprivileg erfährt keinerlei Änderungen. Infolge der durchgängigen Aufgabe des Merkmals der „Krise“ greift das Sanierungsprivileg allerdings künftig bereits ab dem Zeitpunkt der drohenden oder eingetretenen Zahlungsunfähigkeit beziehungsweise der Überschuldung der Gesellschaft und bleibt bis zur ,,nachhaltigen Sanierung“ bestehen ${ }^{408}$.

\section{cc) Haftungsbeschränkte Unternehmergesellschaft}

Der Regierungsentwurf führt eine neue Einstiegsvariante der $\mathrm{GmbH}$, die haftungsbeschränkte Unternehmergesellschaft ( $§ 5 \mathrm{a} \mathrm{GmbHG}$ ), ein, die den Bedürfnissen von Existenzgründern, die am Anfang nur sehr wenig Stammkapital haben und benötigen (z.B. im Dienstleistungsbereich), Rechnung tragen soll. Anders als vielfach gefordert, handelt es sich dabei nicht um

403 Begründung des Regierungsentwurfs, Besonderer Teil, S. 95; Bormann, DB 2006, 2616, 2617 und 2618 ; Haas ZInsO 207, 617, 620 f.; Gesmann-Nuissl WM 2006, 1756, 1759. Zu den Auswirkungen auf das Rechtsinstitut des Rangrücktritt sowie die handelsbilanziellen und steuerrechtlichen Konsequenzen vgl. Kammeter/Geißelmeier NZI 2007, 214.

404 Begründung des Regierungsentwurfs, Besonderer Teil, S. 131.

405 Dazu Freitag WM 2007, 1681, 1682 f.; Gesmann-Nuissl WM 2006, 1756, 1760; kritisch zum Ganzen allerdings vor dem Hintergrund der Änderungen im Zusammenhang mit dem KapAEG Peters ZNotP 2004, 418.

406 BGHZ 90, 381.

407 Begründung des Regierungsentwurfs, Besonderer Teil, S. 131.

408 Begründung des Regierungsentwurfs, Besonderer Teil, S. 131. 
eine neue Rechtsform unterhalb oder neben der $\mathrm{GmbH}$, sondern um eine (echte) $\mathrm{GmbH}$, die ohne bestimmtes Mindeststammkapital gegründet werden kann ${ }^{409}$. Diese $\mathrm{GmbH}$ darf ihre Gewinne aber nicht voll ausschütten. Sie soll auf diese Weise das Mindeststammkapital der normalen $\mathrm{GmbH}$ nach und nach ansparen ${ }^{410}$.

\section{b) Reformüberlegungen in Praxis und Literatur}

\section{aa) Kapitalaufbringung}

\section{aaa) Stammkapital}

Das rechtswissenschaftliche Schrifttum ist sich uneins. Nach wie vor wird das Erfordernis eines Mindeststammkapitals von vielen Autoren zum Schutz der Gläubiger und als Nachweis wirtschaftlicher Solidität und persönlicher Seriosität als unverzichtbar angesehen ${ }^{411}$. Der Europäische Gerichtshof ${ }^{412}$; die so genannte „Winter-Gruppe“ (= „High Level Group of Compa-

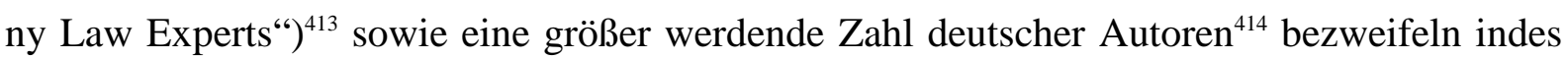
die Erforderlichkeit oder auch nur Nützlichkeit eines Mindestkapitals.

\section{(i) Überlegungen der Befürworter eines Mindeststammkapitals}

Ein wesentliches Argument der Befürworter eines Mindeststammkapitals ist stets der Schutz der Gläubiger gewesen ${ }^{415}$. „Die Gesellschafter, die für die Verbindlichkeiten der Gesellschaft persönlich nicht haften ( $\S 13$ Abs. 2 GmbHG), sollten den vertraglichen und gesetzlichen

409 Siehe in Abgrenzung hierzu den Gesetzentwurf zur Schaffung einer Unternehmergründungsgesellschaft UGG, unten in diesem Abschnitt unter VIII 2.

410 Begründung des Regierungsentwurfs, Besonderer Teil, S.70.; Siehe dazu auch die ausführliche Darstellung bei Freitag/Riemenschneider ZIP 2007, 1485, Seibert GmbHR 2007, 673 und Veil GmbHR 2007, 1080; siehe auch Wilhelm DB 2007, 1510 und Heckschen DStR 2007, 1442, 1445 f.. Kritisch wegen der Überschuldungsnähe einer UG ohne bzw. mit geringem Eigenkapital Drygala NZG 2007, 561. Aufgrund empirischer Daten ablehnend Niemeier ZIP 2007, 1794. Ablehend auch Bormann GmbHR 2007, 897, 898 f., der die UG für zu sehr an Gesellschafterinteressen ausgerichtet hält.

411 Siehe nur Schärtl GmbHR 2007, 344 m. w. N., der zur Rückbesinnung auf die „Doppelfunktion des Stammkapitals“ (,Realfunktion“ - „Bilanzfunktion“) mahnt.

412 EuGH, Entscheidung „Inspire Art“, v. 30.9.2003, DB 2003, 2219, 2222.

413 Siehe hierzu unten $\$ 4$ I 3. a).

414 Vgl. zum Ganzen Priester Die GmbH-Reform in der Diskussion, S. 1 ff.; siehe auch Blaurock FS Th. Raiser 2005, S. 3 ff.; Grunewald/Noack GmbHR 2005, 189 ff.; Eidenmüller/Engert GmbHR 2005, 433 ff.; Triebel/Otte ZIP 2006, 311, 312; dies. ZIP 2006, 1321; BDI/Hengeler Müller S. 18 f.

415 BDI/Hengeler Müller S. $18 \mathrm{f}$. 
Gläubigern der Gesellschaft einen „Haftungsfonds“ als „Mindeststammkapitalgarantie“ zur Verfügung stellen“416. Schließlich kennzeichne das Mindesthaftkapital zugleich den Mindestbetrag mit dem der Gesellschafter am Unternehmensrisiko beteiligt sei ${ }^{417}$. Das Mindeststammkapital sei gewissermaßen der „Preis“, die „Eintrittskarte“ oder der „Einsatz“ für die Vergünstigung der Haftungsbeschränkung ${ }^{418}$.

Zu Gunsten eines Mindestkapitals wird sodann der auch in der Begründung zum Regierungsentwurf angesprochene Gesichtspunkt der „Seriositätsschwelle“ bemüht ${ }^{419}$. Viele Gründer insbesondere kleinerer Unternehmen würden nach Auffassung des BDI und Hengeler zweifellos umsichtiger und verantwortungsvoller handeln, wenn sie ein nicht unerhebliches wirtschaftliches Risiko übernähmen und eine insoweit bestehende „Seriositätsschwelle“ überwinden müssten ${ }^{420}$.

Das Mindeststammkapital wird auch mit der Überlegung gerechtfertigt, die Existenz einer gewissen Haftungsmasse verstärke die wirtschaftliche Solidität gerade neu gegründeter Gesellschaften ${ }^{421}$. Diese Überlegung ist plausibel, zumal gerade in der Start-up Phase eines Unternehmens nahezu unvermeidbar (Anlauf-)Verluste entstehen, die durch ein gewisses Kapital aufgefangen werden könnten und so eine frühe Insolvenz verhindert werden könnte ${ }^{422}$.

Schließlich wird auf die Krisenfrüherkennungsvorschrift des $§ 49$ Abs. 3 GmbHG verwiesen, die an den Verlust des halben Stammkapitals anknüpft und eine Pflicht des Geschäftsführers zur Einberufung der Gesellschafterversammlung postuliert, in der über die Fortführung des Unternehmens oder eine frühe masseerhaltende Liquidation entschieden werden soll. Mit Aufgabe oder einer drastischen Herabsenkung des Mindeststammkapitals würde die Schutz-

416 BDI/Hengeler Müller S. 18 f. Zur Wirksamkeit des Gläubigerschutzes durch Nennkapital Engert GmbHR 2007, 337.

417 Bericht des Rechtsausschusses zum Entwurf der GmbH Novelle, BT-Drucks. 8/3908 v. 15.4.1980, S. 69; Heidinger DNotZ 2005, 97, 98.

418 Im Ergebnis so wie hier Goette DStR 2005, 197, 198; Kleindiek DStR 2005, 1366, 1369; BDI/Hengeler Müller S. 19. Auch Eidenmüller/Engert GmbHR 2005, 433, 437, räumen ein, das Mindestkapital sorge dafür, dass eine $\mathrm{GmbH}$ nur gründet, wer damit einigermaßen unternehmerische Absichten verfolgt. Mitunter wird auch auf die Notwendigkeit, ein angebliches Marktversagen zu korrigieren, verwiesen, s. Eidenmüller GmbHR 2005, 433, 434 ff. Diese Zusammenhänge sind jedoch vage und entziehen sich jeglicher Nachprüfung. Angesicht der Schaffung einer ohne Mindestkapital auskommenden UG resignierend Heckschen DStR 2007, 1442, 1445. In dieselbe Kerbe schlägt Bormann GmbHR 2007, 897, 899; nach dessen Ansicht die Einführung einer Unternehmensgesellschaft eine Herabsetzung des Mindeststammkapitals obsolet werden lasse.

419 Priester Die GmbH-Reform in der Diskussion, S. 1 ff. Kritisch dazu Haas DStR 2006, 993, Roth, in: FS Doralt, 2004, S. 479, S. 479, 482; Blaurock, in: FS Raiser, 2005, S. 3,13 f.; s. auch Eidenmüller GmbHR 2005, 433, 436; Krüger, Mindestkapital und Gläubigerschutz, 2005, S. 223 ff.

420 BDI/Hengeler Müller S. $19 \mathrm{f}$.

421 BDI/Hengeler Müller S. 19; siehe auch Engert GmbHR 2007, 337.

422 Vgl. nur MünchKomm.HGB/Priester, 2004, § 120 HGB Rn. 29 m.w.N. sowie Lutter AG 1998, 375 f.; Engert GmbHR 2007, 337. 
funktion des $\S 49$ Abs. $3 \mathrm{GmbHG}$, denn bei einem Mindeststammkapital von $1 €$ wäre es im Zeitpunkt der Einberufung für Sanierungsmaßnahmen zu spät ${ }^{423}$.

\section{(ii) Überlegungen der Gegner eines Mindeststammkapitals ${ }^{424}$}

Gegen die Überlegung, dass das Mindeststammkapital dem Schutz der Gläubiger diene, wird eingewandt, dass der Betrag des Mindeststammkapitals häufig in keinem wirtschaftlich angemessenen Verhältnis zu Umfang oder Inhalt der geschäftlichen Tätigkeit der Gesellschaft stehe und dementsprechend das Risiko der Gläubiger nicht abbilden könne ${ }^{425}$. Den Beweis lieferten die vielen masselosen Insolvenzen ${ }^{426}$. Hinzu komme, dass die Mindestkapitalisierungspflicht sich in der einmaligen anfänglichen Aufbringung der Stammeinlagen erschöp-

423 Bormann GmbHR 2006, 1021, 1022; Kallmeyer DB 2007, 2755, 2757; Priester Die GmbH-Reform in der Diskussion, S. 1 ff. In der Praxis kommt dem $§ 49$ Abs. 3 GmbHG freilich nur marginale Bedeutung zu. Die Gründe hierfür sind vielfältig (S. hierzu Haas, in Gutachten zum 66. DJT 2006 E 104 ff.). Einer der Gründe ist jedenfalls, dass dem Verlust der Hälfte des Stammkapitals keine taugliche Signalwirkung zukommt, sich die Gesellschaft mithin oftmals schon tief in der Krise befindet, ohne dass der zeitliche Anwendungsbereich des $§ 49$ Abs. 3 GmbHG überhaupt eröffnet ist (A. A. Lutter, AG 1998, 375, 376). Andererseits gilt dies naturgemäß insbesondere dann, wenn die Gesellschaft ein vergleichsweise niedriges Mindestkapital aufweist. Hier wird das von $\S 49$ Abs. 3 GmbHG ausgehende Signal regelmäßig zu spät kommen; vgl. hierzu auch Haas DStR 2006, 993, 997.

424 Zur hier zusammenfassend referierten Kritik am Mindestkapital ausführlicher etwa Bachmann, ZGR 2001, 351, 365 ff.; Bauer, S. 133 ff.; Blaurock FS Raiser, 2005, S. 3, 9 ff.; Gehb/Drange/Heckelmann, NZG 2006, 88, 92f; Grunewald/Noack, GmbHR 2005, 189f; Kleindiek ZGR 2006, 335; Krüger, S. 212 ff.; Schön, Der Konzern 2004, 162, 165. Zur Diskussion in Großbritannien vgl. das Referat von Micheler ZGR 2004, 324, $332 \mathrm{ff}$.

Vgl. nur statt vieler BDI/Hengeler Müller S. 19; Blaurock FS Th. Raiser 2005, S. 3, 9 sowie Meyer/Hermes GmbHR 2005, 807 die nach Auswertung empirischer Studien bei über $1000 \mathrm{GmbHs}$ feststellen, dass die Haftungsbeschränkung vor dem Hintergrund einer hohen Insolvenzanfälligkeit der GmbH häufig durch die Besicherungspraxis der Banken ausgehebelt werde.

Priester Die GmbH-Reform in der Diskussion, S. 1 ff. Zum Hintergrund sei noch das Folgende vorgetragen: Mehr als die Hälfte aller jährlichen Unternehmensinsolvenzen betrifft die GmbH, die andere Hälfte verteilt sich auf Einzelunternehmen und die anderen Gesellschaftsformen. In Beziehung gesetzt zu der Zahl der Unternehmen, die in der jeweiligen Rechtsform existieren ergibt dies folgendes Bild: Bei ca. $950000 \mathrm{GmbH}$ (vgl. die Erhebung von Kornblum, GmbHR 2005, 39, 48) fielen in 200419000 GmbHs (Großkomm. GmbHG/Ulmer, 2005, Einl. A 48) in die Insolvenz, das entspricht ca. $2 \%$ der vorhandenen Gesellschaften. Zum Vergleich, die sonst als weniger insolvenzanfällig geltende AG war 2004 mit 415 Insolvenzen bei ca. 14000 Gesellschaften vertreten (Statistik bei Großkomm. GmbHG/Ulmer, 2005, Einl. A 91), das sind immerhin ca. $3 \%$. Bezogen auf die Zahl der vorhandenen Unternehmen liegt damit die Insolvenzquote bei der AG derzeit höher als bei der $\mathrm{GmbH}$, trotz höheren Grundkapitals und strengerer Kapitalschutzregeln. Und noch ein weiterer Aspekt ist interessant: Über $60 \%$ aller $\mathrm{GmbH}-\mathrm{Insolvenzen}$ ereignen sich in den ersten acht Jahren des Bestehens. Vgl. zu dem Vorgenannten auch Fastrich DStR 2006, 656. Kreuzer ZIP 1980, 597 hat die allgemeinen Gläubigerschutzbestimmungen des GmbHG im Zuge der GmbH-Reform von 1980 analysiert. Auch er kam damals zu dem Ergebnis, dass die Erhöhung des Mindeststammkapitals auf 50.000 DM und der Mindesteinzahlungssumme auf 25.000 DM angesichts der Höhe der durchschnittlich in GmbHKonkursen ausgefallenen Forderungen in Millionenhöhe den Gläubigerschutz nicht wesentlich verstärke und auch die vom Rechtsausschuss des Bundestages als Motiv angeführte Verhinderung unsolider Gründungen nicht zu erreichen sein dürfte. Weitere und andere Sicherungen wären nach Meinung des Verfassers effektiver gewesen. 
$\mathrm{fe}^{427}$. Werde das Mindeststammkapital durch unvorhergesehene oder unerwartet hohe Anlaufverluste bereits zu einem frühen Zeitpunkt aufgezehrt oder geschmälert, so seien die Gesellschafter nicht verpflichtet, die Verluste auszugleichen und den dem Schutz der Gläubiger dienenden Haftungsfonds wieder aufzufüllen ${ }^{428}$.

In Bezug auf das Argument des Mindeststammkapitals als „Seriositätsschwelle“ wird auch von den Gegner eines Mindeststammkapitals zwar zugestanden, dass der Einsatz eigenen (Risiko-)Kapitals viele Gründer, insbesondere kleinerer Unternehmen bewegen mag, vorsichtiger und verantwortungsvoller mit dem Gesellschaftsvermögen umzugehen; umgekehrt wird argumentiert, dass unseriöse Gründer sich wohl kaum davon abhalten lassen würden, persönliche Risiken zu übernehmen, deren sie sich nachträglich durch die „Bestattung“ der Gesellschaft entledigen könnten ${ }^{429}$.

Verwiesen wird auch auf die rechtliche und praktische Vereinfachung der Gründung die aus einer Abschaffung der Mindestkapitalisierungspflicht resultierte. Derzeit behindere das Erfordernis des Mindestkapitals die Unternehmensgründung, da die Notwendigkeit, jedenfalls ein bestimmtes Kapital aufzubringen, als „Kostenbelastung“ empfunden werde ${ }^{430}$.

Nicht zuletzt wird auch das Argument des Wettbewerbs der Rechtsordnungen bemüht: Durch die Rechtsprechung de EuGH in Sachen „Centros“4431 und „Inspire Art“ ${ }^{432}$ könne man unter den europäischen Rechtsformen frei wählen und sich etwa einer englischen Limited oder einer französischen S.à.r.1. ${ }^{433}$ bedienen, um die Aufbringung eines Mindeststammkapitals zu umgehen ${ }^{434}$.

Schließlich stünden zahlreiche Ersatzinstrumente, vorwiegend angelsächsischer Herkunft, zur Verfügung die genauso geeignet seien, die Ansprüche der Gläubiger zu sichern ${ }^{435}$

427 BDI/Hengeler Müller S. 19.

428 BDI/Hengeler Müller S. 19. In diese Richtung geht auch die Begründung des franz. Gesetzgebers für die Abschaffung des Mindeststammkapital, Exposé des motifs de projet de loi pour l'initiative économique, S. 3: ,Si l'exigence d'un capital social minimal avait initialement pour but de protéger les créanciers en apportant une garantie face aux engagements, celle-ci est, dans le faits, illusoire puisque le capital soial est le plus souvent dépensé dans les premières semaines d'activité.“; vgl. hierzu auch unten in diesem Abschnitt $§ 3 \mathrm{~V}$ 1. a)

429 BDI/Hengeler Müller S. 19 f.; vgl. dazu auch dazu Haas DStR 2006, 993, Roth, in: FS Doralt, 2004, S. 479, S. 479, 482; Blaurock, in: FS Raiser, 2005, S. 3, 13 f.; s. auch Eidenmüller GmbHR 2005, 433, 436; Krüger, Mindestkapital und Gläubigerschutz, 2005, S. 223 ff.; zur Reform 1980 vgl. Kreuzer ZIP 1980, 597.

430 Dazu Eidenmüller/Engert GmbHR 2005, 433, 435.

431 EuGH v. 9.3.1999, NJW 1999, 2027 ff.

432 EuGH, Entscheidung „Inspire Art“, v. 30.9.2003, DB 2003, 2219, 2222.

433 Dazu Becker, GmbHR 2003, 1120 f.

434 So Meilicke GmbHR 2003, 793, 807 ff.; Triebel BB 2003, Heft 36 Die erste Seite; Bayer BB 2003, 2357, 2366; Kallmeyer GmbHR 2004, 377; Triebel/Otte ZIP 2006, 311 f.; dies. ZIP 2006, 1321.

435 Fastrich, DStR 2006, 656, 658 behauptet indes mit Abschaffung des Mindestkapitals drohe die Haftungsbeschränkung mithilfe einer verschärften Gesellschafter- oder Geschäftsführerhaftung durchlöchert zu werden. 


\section{(iii) Zusätzliche Überlegungen}

Einige Autoren plädieren dafür, nicht die Mindestkapitalisierungspflicht als solche aufzuheben, sondern stattdessen die Zeit und den Umfang der Leistungserbringung freizustellen ${ }^{436}$. Bereits de lege lata werde die reale Kapitalaufbringung teilweise durch gesicherte, nicht sofort zu erfüllende Einzahlungsforderung ersetzt, (etwa in $\S 7$ Abs. 2 Satz 3 GmbHG). Würde die Kapitalaufbringung insgesamt auf ein derartiges System umgestellt, dann würde vor einer Einzahlung auch eine Kapitalerhaltung nicht notwendig sein, so dass Leistungen an die Gesellschafter jedenfalls nicht die Grundsätze der Kapitalerhaltung verletzten ${ }^{437}$.

Umgekehrt wird teilweise vorgeschlagen, eine sofortige vollständige Einzahlung von Bareinlagen zu verlangen. Dem Rechtsverkehr würde durch Verlautbarung des Kapitals im Handelsregister bedeutet, dass die Gesellschafter den genannten Betrag des Kapitals tatsächlich geleistet haben. Unsicherheiten im Hinblick auf die Werthaltigkeit des ausgewiesenen Betrages wären damit zunächst beseitigt. Auch könnten die Gesellschaftern sich sich weiterhin unter bestimmten Voraussetzungen zur Leistung zusätzlicher Einlagen verpflichten ${ }^{438}$.

\section{bbb) (Verdeckte) Sacheinlage}

Die Sacheinlagevorschriften des GmbHG sind bereits bei ihrer Schaffung und auch später trotz Berücksichtigung der erhobenen Einwände bei der GmbH-Reform 1980 - stets kritisiert worden, anfangs noch wegen des Fehlens einer irgendwie gearteten Wertprüfung der einzubringenden Gegenstände vor der Registereintragung, später insbesondere wegen der Frage ob auch bei der Sachkapitalerhöhung ähnliche Wertnachweise und ein Sacheinlagebericht vorzulegen $\operatorname{sind}^{439}$.

In der Folge hat es diverse Änderungsvorschläge für eine Neufassung des Sacheinlagerechts gegeben, die infolge der beabsichtigten Aufgabe der Rechtsfigur der verdeckten Sacheinlage an Bedeutung verlieren werden und daher hier nicht vertieft dargestellt werden sollen. Im Wesentlichen sind drei Einlagemodelle vertreten worden:

Vgl. hierzu auch Haas DStR 2006, 993, 1000 sowie im Einzelnen unten in diesem Abschnitt unter IV. 2 b) bb) aaa)

436 Kallmeyer GmbHR 2004, 377 ff.

437 Joost Die GmbH-Reform in der Diskussion, S. 31, 37.

438 BDI/Hengeler Müller S. 24.

439 Priester Die GmbH-Reform in der Diskussion, S. 14, ders. in Scholz § 57 Rn. 21, § 56 Rn. 89 f. m.w.N. 
Vossius und Wachter ${ }^{440}$ haben vorgeschlagen, dass existierende System der unmittelbaren (teilweisen) Einlageleistungsverpflichtung auf das statutarisch festgeschriebene Haftkapital von wenigstens $25.000 €$ gegen ein solches zu ersetzenden bei dem der Gesellschafter für die von ihm übernommenen Stammeinlage lediglich das Haftungsrisiko übernehmen soll. Das Modell erinnert an das Haftungssystem in der KG; dort kann sich der Kommanditist sich zwar nur durch Einlageleistung enthaften ( $\$ 171$ Abs. 1 HGB). Ob er aber überhaupt eine Einlage erbringen muss und wann er dazu verpflichtet ist, bestimmt sich allein nach dem Gesellschaftsvertrag ${ }^{441}$. Der Kommanditist kann seiner Einlageverpflichtung auch durch Erbringung einer Sacheinlage nachkommen; im Recht der KG ist eine Offenlegung gegenüber dem Handelsregister nicht erforderlich. Eine Wertprüfung findet - wenn überhaupt - erst in einem Haftungsprozess statt, wobei dem Kommanditisten dann im Hinblick auf die (damalige) Werthaltigkeit der Sache die Beweislast trifft ${ }^{442}$. Der Begriff „,verdeckte Sacheinlage“ ist dem Recht der KG daher unbekannt.

Vorgeschlagen wurde des Weiteren auf Wertnachweise gegenüber dem Registergericht gänzlich zu verzichten. Mit dem Wegfall der Nachweispflicht würde auch die Notwendigkeit der Erstellung eines Sachgründungsberichts entfallen. Der Vorschlag hat wesentliche Gemeinsamkeiten mit dem vorgenannten KG-Modell, unterscheidet sich aber insoweit, als an der Offenlegung der Sacheinlage und an deren Leistungszeitpunkt festgehalten wird ${ }^{443}$.

Schließlich wurden eine Vielzahl von Korrekturvorschlägen zur verdeckten Sacheinlage unterbreitet, die mit der Aufgabe des Rechtsinstituts der verdeckten Sacheinlage durch den Regierungsentwurf eines MoMiG im Wesentlichen hinfällig geworden sind ${ }^{444}$.

\footnotetext{
440 Entwurf für eine vollständige Neufassung des GmbH-Gesetzes; abrufbar unter www-gmbhr.de/volltext.htm.

441 K. Schmidt Gesellschaftsrecht 4. Auflage, § 54 I 2, S. 1560 ff.; Priester Die GmbH-Reform in der Diskussion, S. $1,15 \mathrm{ff}$.

442 Baumbach/Hopt $\S 171$ HGB Rn. 10.

443 Priester Die GmbH-Reform in der Diskussion, S. 1, $15 \mathrm{ff}$.

444 Vgl. die Nachweise bei Priester Die GmbH-Reform in der Diskussion, S. 1, 18 ff.
} 


\section{bb) Kapitalerhaltung / Gläubigerschutz}

\section{aaa) Kapitalschutz}

Unabhängig von der Entscheidung Pro oder Contra Mindeststammkapital werden in der Literatur weitere Modelle vertreten, mit denen der Schutz der Gläubiger im GmbH-Recht verbessert werden soll.

\section{(i) Übernahme des Grundsatzes des $§ 57$ Abs. 3 AktG}

Erstens wird vorgeschlagen, den aktienrechtlichen Grundsatz des $§ 57$ Abs. 3 AktG, wonach nur der Bilanzgewinn ausgeschüttet werden kann, in das $\mathrm{GmbH}-\mathrm{Recht}$ zu übernehmen ${ }^{445} \mathrm{Ge}-$ gen die Übernahme des aktienrechtlichen Grundsatzes wird eingewandt, die Übernahme würde einen grundlegenden Bruch des traditionellen Finanzsystems des GmbH-Rechts bedeuten und insbesondere den Gesellschaftern jede Flexibilität ihres Finanzierungsverhaltens neh$\operatorname{men}^{446}$.

\section{(ii) Solvency test}

Ferner wird vorgeschlagen, die Ausschüttung von Gesellschaftsvermögen von der vorherigen Durchführung so genannter Solvenzprüfungen (,,solvency tests“) abhängig zu machen. Solvency Tests sind im neuseeländischen Gesellschaftsrecht ${ }^{447}$ sowie im angloamerikanischen Rechtsraum ${ }^{488}$ bereits seit langem bekannt und haben sich dort offensichtlich bereits bewährt. Anders als die Kapitalerhaltung nach den Vorschriften der $\S 30,31$ GmbHG, wird die Kapitalsicherung im Rahmen des Solvency Tests mittels eines flexiblen, da nicht auf starren (kapitalbezogenen), sondern situativen Ausschüttungsbegrenzungen basierenden Kontrollsystems gewährleistet ${ }^{449}$. Die Unternehmensführung - Geschäftsführer wie Gesellschafter - haben vor

445 Thiessen, ZIP 2007, 253; BDI/Hengeler Müller S. 28.

446 Thiessen, ZIP 2007, 253; BDI/Hengeler Müller S. 28.

447 Vgl. nur Jungmann ZGR 2006, 638, $650 \mathrm{ff}$.

448 Vgl. zum Ganzen umfassend Just, Die englische Limited in der Praxis, 2005; speziell im Rechtsvergleich zur deutschen GmbH Römermann NJW 2006, 2065.

449 Näher dazu Schön Der Konzern 2004, 162, 168 f.; Goette ZGR 2006, 261, 277; Micheler ZGR 2004, 324, 341 ff.; Schall ZIP 2005, 965. Vgl. auch zu den Bestrebungen der Europäischen Union, die Zulässigkeit von Ausschüttungen allgemein von einem Solvency Test abhängig zu machen: Triebel/Otte ZIP 2006, 311, 313 m.w.N.; Habersack ZIP 2006, 445, 447 f. 
einer Ausschüttung zu prüfen, ob die Gesellschaft auch noch nach der Ausschüttung in der Lage sein wird, in absehbarer Zeit ihre Verbindlichkeiten zu erfüllen.

Die Tatsache, dass die Beantwortung vorstehender Frage zwangsläufig auf Prognosen für den weiteren Geschäftsverlauf beruht, ist Grundlage der breiten Kritik die dieses Gläubigerschutzsystem in der deutschen Literatur gefunden hat, denn derartige Prognosen fallen erfahrungsgemäß allzu optimistisch aus ${ }^{450}$. Verlangt man zur Feststellung der Solvabilität hingegen die Aufstellung einer Bilanz, so stellt sich in der Tat die Frage - wie Priester richtigerweise schreibt, ob die praktische Handhabung solcher Solvency Tests einfacher ist, als unsere bisherige Prüfung im Rahmen von $\S 30 \mathrm{GmbHG}^{451}$..

\section{(iii) Wrongful Trading}

Drittens wird vorgeschlagen, im GmbH-Gesetz eine dem angelsächsischen WrongfulTrading-Grundsatz (Sec. 214 UK Insolvency Act) entsprechende insolvenzrechtliche Haftung aufzunehmen, wonach Gesellschafter und Geschäftsführer verpflichtet sind, bei drohender Zahlungsunfähigkeit eine Gefährdung der Gläubiger so weit wie möglich zu verhindern. Bereits der Winter-Bericht hat für den Bereich der börsenfähigen Kapitalgesellschaften angeregt, derartige Vorkehrungen zu treffen, möglicherweise sogar gemeinschaftsrechtlich festzulegen.

In aller Kürze dargestellt ${ }^{452}$, besagt das ,wrongful trading“, dass „,der Insolvenzverwalter die Geschäftsführer und gegebenenfalls die Gesellschafter verantwortlich machen kann, falls diese vor Eintritt der Insolvenz erkannt haben oder hätten erkennen müssen, dass keine vernünftig begründbare Aussicht besteht, die Insolvenz zu vermeiden (,that there was no reasonable prospect that the company would avoid going into insolvent liquidation") und sodann nicht alle erforderlichen Maßnahmen ergriffen haben, um die Verluste der Gläubiger so gering wie möglich zu halten (,took every step with a view to minimising the potential loss to the company's creditors $\left.{ }^{6}\right)^{6453}$.

450 Vgl. nur Joost Die GmbH-Reform in der Diskussion, S. 31, 47 m.v.w.N. sowie Fleischer DStR 2000, 1015, 1018. Umfassend mit der Aussenhaftung der Organmitglieder einer Gesellschaft im europäischen Gesellschaftsrecht (insbesondere in Deutschland und der Schweiz in Abgrenzung zum angloamerikanischen Haftungssystem) befasst sich wiederum Fleischer in ZGR 2004, 437.

451 Priester Die GmbH-Reform in der Diskussion, S. 1 ff. Zur Abgrenzung von Solvenztest und existenvernichtungshaftung vgl. nur Weller DStR 2007, 116 soie ders. DStR 2007, 1166.

452 Wie hier BDI/Hengeler Müller S. 29 f., vgl. auch Schall ZIP 2005, 965. Zum Ganzen umfassend Just, Die englische Limited in der Praxis, 2005.

453 BDI/Hengeler Müller S. 29 f. Die Vorzugswürdigkeit einer angloamerikanischen wrongful trading Haftung gegenüber dem deutschen Gläubigerschutzsystem hinterfragt Fleischer DStR 2000, 1015, 1018 ff.; genauso Happ/Holler DStR 2004, 730; siehe auch Spindler JZ 2006, 839.. Vgl. aber etwa Triebel, BB 2003, Heft 36, 


\section{(iv) Covenants}

Viertens und letztens wird teilweise für eine Aufgabe des gesetzlichen Kapitalschutzes zugunsten der auch heute bereits in der deutschen Praxis üblichen vertraglichen Vereinbarungen zum Schutz der Gläubiger, wie sie vor allem im angloamerikanischen Rechtskreis (,,covenants") verbreitet sind, plädiert. Diese Vereinbarungen haben regelmäßig zum Inhalt, Verpflichtungen zur Erhaltung des Gesellschaftsvermögens, die Gewährung von Sicherheiten und die Führung der Gesellschaft ${ }^{454}$.

Gegen Covenants sind indes wenig praxisgerecht ${ }^{455}$. Wie oben bereits ausgeführt, handelt es sich bei den so genannten Covenants um Individualvereinbarungen zwischen Gläubigern und Gesellschaft. Sie sind damit ungleich aufwendiger als die Bereitstellung eines für alle Gläubiger - gleich ob bekannt oder unbekannt - wirkenden Mindestkapitals und verursachen erhebliche Transaktionskosten. Vor diesem Hintergrund dürften sie allenfalls für Vertragsverhältnisse der Gesellschaft mit Großgläubigern in Betracht kommen, während kleinere Vertragsgläubiger und Anspruchsberechtigte aus gesetzlichen Schuldverhältnissen allenfalls reflexiv begünstigt würden ${ }^{456}$. Wilhelmi ${ }^{457}$ gibt außerdem zu Bedenken, dass gerade die starken Gläubiger sich regelmäßig wohl nicht mit Covenants zufrieden geben würden, sondern vielmehr persönliche Haftungszusagen der Gesellschafter verlangten, die ihrerseits keine, auch nicht reflexive, Wirkung auf die Gläubigergesamtheit hätten ${ }^{458}$.

die erste Seite unter 6., der - wenn auch unter Erwähnung spezifischer Haftungstatbestände - von einem „Privileg der Haftungsbeschränkung“" spricht.

454 Mülbert Der Konzern 2004, 151, 156 f. m.w.N.; vgl.auch BDI/Hengeler Müller S. 26.

455 So bereits Priester Die GmbH-Reform in der Diskussion, S. 1, 7 unter Hinweis auf Goette DStR 2005, 197, 198 und Wilhelmi GmbHR 2006, 13, 15 f. bzw. werden nur von Großgläubigern und Banken eingesetzt Meyer/Hermes GmbHR 2005, 807.

456 Priester Die GmbH-Reform in der Diskussion, S. 1, 7 unter Hinweis auf Goette DStR 2005, 197, 198. Darauf weist auch Fleischer DStR 2000, 1015, 1017 f. hin.

457 Wilhelmi GmbHR 2006, 13, $15 \mathrm{f}$.

458 Vgl. insoweit auch Eidenmüller/Engert GmbHR 2005, 433, 436. 


\section{bbb) Deregulierung des Eigenkapitalsersatzrechts}

\section{(i) Ansicht Hommelhoffs}

Hommelhoff hat auf einer Sondertagung der Gesellschaftsrechtlichen Vereinigung zur GmbHReform umfassend zu beabsichtigten Reform des Eigenkapitalersatzrechts Stellung genommen $^{459}$. Dabei hat er zunächst festgestellt, dass die mannigfach geübte Kritik, dass das Eigenkapitalersatzrecht unübersichtlich, kompliziert und wertungswidersprüchlich sei, nur teilweise begründet, im Wesentlichen jedoch unbegründet $\operatorname{sei}^{460}$.

Die angebliche Unübersichtlichkeit habe ihre Ursache nicht in den Regelungen selbst, sondern sei vielmehr Ausweis für das variantenreiche Fallmaterial, was das Eigenkapitalersatzrecht biete ${ }^{461}$.

Hommelhoff wendet sich gegen eine Totalverwerfung des durch das Eigenkapitalersatzrecht etablierten Gläubigerschutzes. Bei einem Totalverzicht - so Hommelhoff - würden Gesellschafterdarlehen und entsprechende Gesellschafterleistungen, obwohl sie unter besonderen Umständen gewährt oder belassen worden sind, nicht anders behandelt werden als die außenstehender Dritter; es würde „,rechtsunverträglich evident Ungleiches gleich behandelt ${ }^{\star 462}$ werden.

Positiv bewertet Hommelhoff die beabsichtigte Verlagerung der Novellenregeln ins Insolvenzrecht denn hierdurch würde der deutsche Eigenkapitalschutz auf alle juristischen Personen und sonstigen Gesellschaften mit beschränktem Haftungsfonds und damit auch auf jene vergleichbaren Auslandgesellschaften, die ihren tatsächlichen Geschäftsitz in Deutschland haben, erstreckt $t^{463}$.

Demgegenüber lehnt Hommelhoff einen totalen Nachrang sämtlicher Gesellschafterforderungen in der Insolvenz der Gesellschaft - wie vom MoMiG vorgesehen - ebenso ab wie die unterschiedlose Anfechtbarkeit ihrer insolvenznahen Tilgung. Das Prinzip des totalen Nach-

459 Hommelhoff Die GmbH-Reform in der Diskussion, S. 115 ff.; vgl. zu dem Ganzen auch Bayer/Graff DStR 2006, 1654.

460 Hommelhoff Die GmbH-Reform in der Diskussion, S. 115, 116.

461 Hommelhoff Die GmbH-Reform in der Diskussion, S. 115, 116

462 Hommelhoff Die GmbH-Reform in der Diskussion, S. 115, 118 unter Hinweis auf die Rechtsprechung des BGH in BGHZ 90, 381, 388 f. Vgl. hierzu auch K. Schmidt GmbHR 2007, 1.

463 Zur Zulässigkeit einer solchen Erstreckung deutscher Insolvenzregeln auf ausländische Gesellschaften, Bayer BB 2002, 2289 sowie allgemein zur Anwendbarkeit einzelner deutscher Haftungstatbestände auf EUAuslandsgesellschaften Bitter WM 2004, 2190, 2195; vgl. auch Hommelhoff Die GmbH-Reform in der Diskussion, S. 115, 119 ff.; im Ergebnis so auch BDI/Hengeler Müller S. 35, Huber/Habersack BB 2006, 1, 7. 
rangs sämtlicher Gesellschafterforderungen in der Insolvenz der Gesellschaft ohne Rücksicht auf ihren eigenkapitalersetzenden Charakter sei bereits aus rechtspraktischen abzulehnen, da es die Finanzierung der mittelständischen Wirtschaft in Deutschland sowie die Binnenfinanzierung vieler Konzerne nachhaltig belaste. Des Weiteren begegne das Prinzip des totalen Nachrangs sämtlicher Gesellschafterforderungen auch erheblichen rechtsdogmatischen Bedenken: So werde den Gesellschaftern etwa die Freiheit beschnitten, über die rechtliche Ausgestaltung ihrer Finanzmittelzufuhr zu bestimmen und damit über das Risiko autonom zu befinden, dem sie ihren Finanzierungsbeitrag aussetzen wollen ${ }^{464}$.

\section{(ii) Ansicht Hubers und Habersacks}

Die Auffassung von Huber und Habersack ${ }^{465}$ ist der Hommelhoffs diametral entgegengesetzt und entspricht in ihren grundlegenden Thesen dem nunmehr umgesetzten GmbHGReformentwurf. Ein Rückbehalt eigenkapitalersetzender Gesellschafterleistungen ( 39 Abs. 1 Nr. 5 InsO) mit einer entsprechenden Anfechtungsmöglichkeit in der Insolvenz der Gesellschaft ( $\$ 135$ Nr. 2 InsO) sei gerechtfertigt durch die Haftungsbeschränkung im Recht der GmbH-Recht.

\section{(iii) Ansicht Gesmann-Nuissls}

Angesichts der aufgezeigten Detailfragen regt Gesmann-Nuiss $l^{466}$ an, auf die speziellen Rückholmöglichkeiten von zurück geleisteten Gesellschafterdarlehen innerhalb der InsO ( $\$ 135$ InsOE) und dem AnfG ( $\$ 6$ Abs. 1 Satz 1 Nr. 2 AnfG) zu verzichten und stattdessen - neben der Anfechtung wegen vorsätzlicher Gläubigerbenachteiligung (§ 133 InsO; 3 AnfG) - auf die erweiterte Geschäftsführer- beziehungsweise Vorstandshaftung (§ 64 Abs. 2 Satz 3 GmbHGE; $§ 92$ Abs. 3 AktGE), die auch eine insolvenzrechtliche Verankerung erfahren könnte, zu vertrauen ${ }^{467}$.

464 Hommelhoff Die GmbH-Reform in der Diskussion, S. 115, 124 ff., diametral anders Huber/Habersack BB 2006, 1, 2 f.; anders auch Bayer/Graff DStR 2006, 1654, 1657 f.

465 Huber/Habersack BB 2006, 1 ff. sowie Huber Die GmbH-Reform in der Diskussion, S. 137 f.; vgl. auch Altmeppen NJW 2005, 1911, 1914.

466 Gesmann-Nuissl WM 2006, 1756, 1759 f.; anders die Vorschläge von Altmeppen NJW 2005, 1911, 1914 (Ausdehnung der Anfechtungsfrist des $\S 135$ Nr. 2 InsO auf zwei Jahre) und Huber/Habersack BB 2006, 1, 5 f. (Beibehaltung der Frist des $§ 135$ Nr. 2 InsO, aber Verlängerung der Frist des $§ 6$ AnfG).

467 Haas ZIP 2006, 1373 verneint hingegen einen Vorrang des Gesellschaftsrechts und befasst sich umfassend mit den Anfechtungstatbeständen in $§ 133$ Abs 1 InsO (Rechtshandlung des Schuldners, subjektive Tatbestandsmerkmale auf Seiten der Gesellschaft und des Gesellschafters, Erfordernis der Gläubigerbenachteiligung), in $\S 134$ InsO (Begriff der Unentgeltlichkeit allgemein und im Zusammenhang mit Auszahlungen der Gesellschaft an Gesellschafter, insbesondere, Gläubigerbenachteiligung) und in $§ 133 \mathrm{Abs} 2 \mathrm{InsO}$. Vgl. zu 


\section{(iv) Ansicht Meilickes}

Ganz anders sind wiederum die Überlegungen Meilickes $^{468}$. Nach seinem Dafürhalten sind die - nunmehr auch vom Gesetzgeber erkannten - Mängel des Eigenkapitalersatzrechts auch mit den im Referentenentwurf des MoMiG enthaltenen Ansätzen; der Verlagerung der Novellenregelung in das Insolvenzrecht und der Anwendung deutschen Eigenkapitalersatzrechts auf Auslandsgesellschaften nicht zu beheben. Meilicke spricht sich daher für eine ersatzlose Abschaffung des Eigenkapitalersatzrechts aus. Gläubiger von nach ausländischem Recht errichteten Gesellschaften seien in Deutschland in erster Linie durch das Deliktsrecht zu schützen. Neugläubiger überschuldeter Gesellschaften würden über die Haftung aus culpa in contrahendo geschützt. Für Altgläubiger sei eine Harmonisierung durch eine EU-weite WrongfulTrading-Rule anzustreben.

\section{Handelsrechtliche Publizität}

\section{Handelsregister - Neuerungen durch das Gesetz über elektronische Handelsregister und Genossenschaftsregister sowie das Unternehmensregister (EHUG)}

Die Handelsregister werden in Deutschland bei den Amtsgerichten geführt ( $\S 8$ HGB, $\S 125$ Abs. 1 FGG). Das Handelsregister wird - soweit nicht durch landesrechtliche Bestimmungen eine andere Zuweisung erfolgt - von dem Amtsgericht geführt, in dessen Bezirk ein Landgericht seinen Sitz hat und zwar für sämtliche Amtsgerichte in diesem Landgerichtsbezirk $(\S 8$ HGB, $§ 125$ Abs. 1 FGG $)^{469}$.

Das Gesetz über elektronische Handelsregister und Genossenschaftsregister sowie das Unternehmensregister $(E H U G)^{470}$ sieht in Umsetzung der Richtlinie 2003/58/EG vom 15. Juli

der von Gesmann-Nuissl in bezug genommenen erweiterten Geschäftsführerhaftung auch schon oben in diesem Abschnitt unter III. 2. a) aa) aaa).

468 Meilicke GmbHR 2007, 225

469 Keidel/Krafka/Willer S. 1 Süß/Wachter/Terbrack S. 547.

ff.; Zusammenfassend Krafka MittBayNot 2005, 290 sowie

470 Gesetz über elektronische Handelsregister und Genossenschaftsregister sowie das Unternehmensregister v. 10.11.2006 (EHUG), BGBl. I 2006, S. 2553 v. 15.11.2006. 
$2003^{471}$ vor, dass u.a. die Handelsregister ab dem 1. Januar 2007 zwingend elektronisch zu führen $\operatorname{sind}^{472}$.

Bislang waren bei der Gründung der notariell beurkundete Gesellschaftsvertrag und weitere Unterlagen öffentlich beglaubigt in Papierform zum Handelsregister einzureichen und Versicherungen der Geschäftsführer abzugeben. Bei Erbringung von Sacheinlagen mussten des Weiteren die papiernen Unterlagen über die Einbringung und den Wert der Sacheinlagen und ein Sachgründungsbericht vorgelegt werden. Grundsätzlich war ferner zunächst ein Gerichtskostenvorschuss zu leisten. Das Registergericht prüfte, ob der Vorschuss eingegangen ist, die Gesellschaft ordnungsgemäß errichtet und angemeldet wurde. Die Eintragung wurde anschließend im Papierbundesanzeiger und in einer oder mehreren Tageszeitungen auf Kosten der GmbH bekannt gemacht.

Nach dem EHUG werden Handels-, Genossenschafts- und Partnerschaftsregister zum 1. Januar 2007 auf den elektronischen Betrieb umgestellt. Die zur Gründung der GmbH erforderlichen Unterlagen können künftig grundsätzlich nur noch elektronisch beim Handelsregister eingereicht werden. Eine notarielle Beglaubigung der Anmeldungen bleibt erforderlich, kann aber ebenfalls elektronisch erfolgen. Der Notar übermittelt die Anmeldung und die weiteren Dokumente über das elektronische Gerichtspostfach elektronisch an das zuständige Registergericht. Dort können die Daten unmittelbar in die Register übernommen werden, was erheblich zur Beschleunigung beiträgt. Über Anmeldungen zur Eintragung soll „unverzüglich“ entschieden werden. Falls erforderlich, wird die IHK künftig elektronisch beteiligt. Zudem sollen die Ausnahmen vom Erfordernis eines Kostenvorschusses erweitert werden. Handelsregistereintragungen sollen nur noch elektronisch bekannt gemacht werden. Die Daten sind dann für jedermann über das Internet einsehbar.

Unterschieden werden zum einen rechtsbegründende, also eine Änderung der Rechtslage bewirkende Eintragungen (so genannte konstitutive Eintragungen: solche sind etwa die Gründung, Satzungsänderungen und Kapitalmaßnahmen) und lediglich bezeugende, die tatsächlich bereits bestehende Rechtslage offen legende und somit letztlich kundmachende Eintragungen (so genannte deklaratorische Eintragungen: solche sind etwa Geschäftsführerbestellungen und -abberufungen). Die Rechtsfolgen der Publizität des Handelsregisters gegenüber Dritten regelt $\S 15 \mathrm{HGB}^{473}$.

471 ABl. EG Nr. L 221 v. 4.9.2003, S. 13.

$472 \mathrm{Zu}$ den praktischen Auswirkungen des EHUG auf die notarielle Praxis vgl. die ausführliche Darstellung bei Sikora/Schwab MittbayNot 2007, 1 ff. Ebenso Jeep/Wiedemann NJW 2007, 2439, die ausserdem aus richterlicher Sicht berichten. Vgl. zur notariellen Form, Beurkundung und elektronischen Rechtsverkehr Bohrer DNotZ 2008, 39.

473 Vgl. ausführlich MünchKommHGB § 15 Rn. 10 ff.; knapp dargestellt bei Süß/Wachter/Terbrack S. 548. 


\section{Geschäftsbriefe}

Gemäß $\S 35$ a GmbHG haben alle schriftlichen Mitteilungen der Gesellschaft im geschäftlichen Bereich, die dem Außenverhältnis zuzurechnen und individuell adressiert sind, nicht aber Auftragsbestätigungen, Lieferscheinen, Rechnungen und Formularen im Behördenverkehr ( $\$ 35$ a Abs. 2 GmbHG), sofern es sich nicht um Bestellscheine handelt ( 3 35a Abs. 3 GmbHG), Angaben zu der Rechtsform der Gesellschaft, dem Sitz, dem Registergericht und der Registernummer sowie die Namen aller Geschäftsführer mit mindestens einem ausgeschriebenen Vornamen zu enthalten ( $§ 35 \mathrm{a}$ Abs. $1 \mathrm{GmbHG})$. Existiert in der Gesellschaft auBerdem ein Aufsichtsrat so ist auch der vollständige Name des Vorsitzenden anzugeben ( $\$ 35$ a Abs. 1 Satz $1 \mathrm{GmbHG})^{474}$.

Nach dem Willen der Bundesregierung sollen künftig auch inländische Zweigniederlassungen ausländischer Gesellschaften die Angaben nach § 35a Abs. 1 bis 3 auf ihren Geschäftsbriefen machen müssen, und zwar in Form einer doppelten Angabeverpflichtung. Die Angabeverpflichtung bezieht sich sowohl auf die ausländische Haupt- als auch auf die inländische Zweigniederlassung. Dies wird durch Einfügung der Wörter ,für die Angaben bezüglich der Haupt- und Zweigniederlassung“ nach Absätzen 1 bis 3 des $§ 35 \mathrm{a} \mathrm{GmbH} \mathrm{klargestellt.} \mathrm{Damit}$ hat sich der Gesetzgeber in dem bisherigen Meinungsstreit über das Bestehen einer doppelten Angabeverpflichtung zugunsten einer Stärkung der Transparenz und des Gläubigerschutzes entschieden.

Die Neuregelung ist vereinbar mit der „Zweigniederlassungsrichtlinie“ (89/666/EWG) und stellt eine europarechtskonforme Berücksichtigung der aktuellen EuGH-Rechtsprechung dar. Die Pflichtangaben der Gesellschaft auf den Geschäftsbriefen und Bestellscheinen ergeben sich aus dem ausländischen Recht beziehungsweise auch aus der 1. Gesellschaftsrechtlichen Richtlinie (68/151/EWG, ,Publizitätsrichtlinie“). Die Angaben haben in deutscher Sprache zu erfolgen. Deutsche Gesellschaften mit beschränkter Haftung und Auslandsgesellschaften werden damit in vollem Umfang gleichbehandelt ${ }^{475}$.

Die Beachtung der vorgenannten Pflichtangaben nach § 35a GmbHG kann durch das Handelsregister durch Festsetzung von Zwangsgeld eingefordert werden ( 79 Abs. 1 GmbHG). Zivilrechtlich können Verstöße zu einer Rechtscheinhaftung der Gesellschaft für ihre Organe

474 Süß/Wachter/Terbrack S. 548; allgemein dazu Baumbach/Hueck/Zöllner/Noack § 35a, dort insbesondere Rn. 3 ff.

475 Begründung zum Regierungsentwurf, Besonderer Teil, S. 99. 
führen und gegebenenfalls eine Anfechtung aus $\S 119,123$ BGB sowie Schadensersatzansprüche aus Verschulden bei Vertragsschluss sowie eventuelle Ansprüche aus § 826 BGB und $\S 823$ Abs. 2 BGB rechtfertigen ${ }^{476}$.

\section{Gesetzentwurf der Notare Vossius und Wachter}

Der Entwurf von Vossius und Wachter ${ }^{477}$ widmet sich in erster Linie einer Reformierung des existierenden Kapitalschutzsystems im Recht der GmbH. Der Entwurf will das im GmbHG angelegte auf Gläubigerschutz zugeschnittene System des Kapitalschutzes durch ein System des Garantiekapitals ersetzen, vergleichbar dem Haftungssystem des Kommanditisten einer KG oder der limited company by guarantee englischen Rechts. Zur Begründung heißt es in dem Gesetzesentwurf, der Staat reduziere damit die von ihm verlangte Gegenleistung im Tauschgeschäft mit dem Bürger, in dem er nicht mehr auf Vorkasse bestehe. Das so festgelegte Stammkapital der Gesellschaft dient dann nicht mehr primär dem Gläubigerschutz, sondern primär der Bemessung der Beteiligung der Gesellschafter. Mit diesem Ansatz sei zugleich auch der Staat aus der Pflicht entlassen, die Kapitalaufbringung zu kontrollieren ${ }^{478}$.

Der Übergang auf ein Garantiekapital hat naturgemäß auch Auswirkungen auf andere Bereiche, wie etwa die Regelungen zur Geschäftsanteilsübertragung und der Insolvenzsicherung. Mit diesen Aspekten setzt sich der Entwurf auf den Seiten nur kursorisch auseinander, Vorschläge für eine Änderung der Insolvenzordnung werden nicht unterbreitet ${ }^{479}$.

\section{Entwurf eines Gesetzes zur Vereinfachung der Gründung einer Gesellschaft mit beschränkter Haftung; GVGG}

Das Justizministerium Nordrhein-Westfalen ${ }^{480}$ will eine Vereinfachung und Beschleunigung des Gründungsprozesses - das gesamte gerichtliche Verfahren bis zur Eintragung der neuen

476 Süß/Wachter/Terbrack S. 564.

477 Gesetzentwurfs von Vossius/Wachter, online abrufbar unter www.gmbhr.de.

478 Gesetzentwurfs von Vossius/Wachter, online abrufbar unter www.gmbhr.de; vgl. hierzu auch Vossius/Wachter BB 2005, 2539 und Vossius GmbHR 2005, R 373,

479 Gesetzentwurfs von Vossius/Wachter, online abrufbar unter www.gmbhr.de; gl. hierzu auch Vossius/Wachter BB 2005, 2539 und Vossius GmbHR 2005, R 373.

480 Entwurf eines Gesetzes zur Vereinfachung der Gründung einer Gesellschaft mit beschränkter Haftung (GVGG); abrufbar unter justiz.nrw.de /JM/justizpolitik/ schwerpunkte/GmbH_recht/inhalt_gesetzentwurf /index.php. 
Gesellschaft im Handelsregister soll nach der Vorstellung des Entwurfgebers in nur wenigen Tagen abgeschlossen sein - dadurch erreichen, dass es den Gründern eine Mustersatzung zur Verfügung stellt.

Aus denselben Gründen, die auch der Gesetzgeber des Regierungsentwurfs anführt, meint der Entwurfgeber bei Verwendung der Mustersatzung auf eine notarielle Beurkundung des gesamten Gesellschaftsvertrages verzichten zu können. Zugleich werde durch das Benutzen einer Mustersatzung der Prüfungsumfang des Registergerichts reduziert und damit das Eintragungsverfahren beschleunigt ${ }^{481}$.

Wie der Referentenentwurf des BMJ sieht auch der Entwurf des GVVG einen Verzicht auf die Prüfung des Vorliegens besonderer behördlichen Erlaubnisse vor Eintragung einer GmbH im Handelsregister vor. Die Gesellschaft kann damit schon im Handelsregister eingetragen werden, ohne dass eine Erlaubnis vorgelegt werden muss. Es soll nicht mehr erforderlich sein, vor Eintragung der Gesellschaft nachzuweisen, dass eine Genehmigung für den gewählten Unternehmensgegenstand vorliegt. Die bisher notwendige Kontrolle durch das Registergericht kann zu einer erheblichen Verzögerung des Eintragungsvorganges führen. Das gilt namentlich in den Fällen, in welchen die Erteilung der Erlaubnis für den vorgesehenen Unternehmensgegenstand ihrerseits davon abhängt, dass zuvor die Gesellschaft im Handelsregister eingetragen wurde.

Eine weitere Änderung sieht das Gesetz bei den Kosten einer Gründung vor: Es sind pauschalisierte Gebühren für das gesamte gerichtliche Verfahren bei Ersteintragung einer GmbH werden Pauschalgebühren vorgesehen. Auch die Gebühren für die notarielle Beurkundung des Gesellschaftsvertrages würden geringer, vorausgesetzt die Mustersatzung werde verwendet.

481 Demgegenüber hält Priester Die GmbH-Reform in der Diskussion, S. 1, 9 den Gedanken der Bereitstellung einer Mustersatzung insgesamt als verfehlt, da sie den Gründer in ein Korsett vorgefertigter Bestimmungen zwänge und ihm dadurch jede Gestaltungsfreiheit abschneide. Vgl. hierzu auch unten Vierter Abschnitt $\$ 2$ II 3. 


\section{Vorschläge alternativer Rechtsformen neben einer reformierten GmbH}

\section{Basisgesellschaft mit beschränkter Haftung}

Der Entwurf des Justizministeriums Nordrhein-Westfalens ${ }^{482}$ sieht außerdem die Einführung einer neuen unterhalb der $\mathrm{GmbH}$ stehenden Variante der $\mathrm{GmbH}$ vor, der „Basisgesellschaft mit beschränkter Haftung“. Die BmbH soll nicht etwa in einem separaten Gesetz geregelt werden, sondern soll nach dem Willen der Entwurfgeber im GmbHG selbst in neu zu schaffenden $\S \S 12 \mathrm{a}$ bis $12 \mathrm{~h}$ verankert sein. Die wesentlichen Eckpunkte der $\mathrm{BmbH}$ sind die folgenden:

Es können maximal fünf natürliche Personen als Gründer and der $\mathrm{BmbH}$ beteiligt sein. Das von diesen zu leistende Mindeststammkapital beträgt $2.500 €$. Eine Kapitalherabsetzung ist nicht gestattet, wohl aber eine Kapitalerhöhung. Diese soll bis zum Erreichen einer Stammkapitalziffer von $25.000 €$ nur in Geld vollzogen werden können. Danach sollen nach der Vorstellung des Entwurfgebers auch Sacheinlagen möglich sein. Die Eintragung der Basisgesellschaft $\mathrm{mbH}$ ist nur an wenige Prüfungsanforderungen geknüpft. Auch kann sie zur klassischen $\mathrm{GmbH}$ aufsteigen, wenn sie ihr Stammkapital auf mindestens $25.000 €$ erhöht ${ }^{483}$.

\section{Die Unternehmensgründungsgesellschaft} (auch ,Unternehmergesellschaft““ oder ,FlexCap“)

Einen Schritt weiter als der nordrhein-westfälische Vorschlag geht offensichtlich das von MdB Gehb, Drange und Heckelmann ${ }^{484}$ entwickelte Konzept einer „Unternehmensgründergesellschaft" oder auch Unternehmergesellschaft ${ }^{485}$ oder FlexCap ${ }^{486}$. Die UGG ist eine neue Form einer Kapitalgesellschaft, die als unabhängige, eigene Gesellschaftsform neben der $\mathrm{GmbH}$ stehen soll. Anders als die GmbH soll sie unter weitgehendem Verzicht auf Form- und Kapitalvorschriften - es soll kein Mindeststammkapital zu leisten sein - durch rasche Regis-

482 Entwurf eines Gesetzes zur Vereinfachung der Gründung einer Gesellschaft mit beschränkter Haftung (GVGG); abrufbar unter justiz.nrw.de /JM/justizpolitik/ schwerpunkte/GmbH_recht/inhalt_gesetzentwurf /index.php.

483 Vgl. hierzu auch Lutter, Die GmbH-Reform in der Diskussion, S. 211, 220.

484 Gehb/Drange/Heckelmann NZG 2006, 88 ff.; ein Arbeitsentwurf ist abrufbar unter www.uggesellschaft.de/wp-content/uploads/2007/06/arbeitsentwurf-ugg.pdf.

485 Lutter BB-Special 7/2006, 2 sowie ders., Die GmbH-Reform in der Diskussion, S. 211, 219 f.; Priester ZIP 2006, 161 sowie ders. ZIP 2005, 921.

486 Schall/Westhoff GmbHR 2004, R 382. 
tereintragung zur Entstehung gelangen. Für Gläubigerschutz wird nicht durch ein Garantiekapital gesorgt, sondern durch Transparenz sowie durch verschärfte, jedoch elastische Haftungsregeln ${ }^{487}$.

\section{Kommanditgesellschaft mit beschränkter Haftung}

Drygala ${ }^{488}$ will sich das bereits existierende Haftungsregime des Kommanditisten nach $\S \S 171$ ff. HGB nutzbar machen, anstatt mit der UGG beziehungsweise UG oder FlexCap eine grundlegend neue Unternehmensform zu schaffen.

Mit dem Konzept einer (Personen-)Gesellschaft mit beschränkter Haftung, die den Gläubigern statt eines real aufgebrachten Stammkapital ein virtuelles - da noch nicht (unbedingt) eingefordertes - Garantiekapital zur Verfügung stellt, steht Drygala dem Konzept Vossius' und Wachters ${ }^{489}$ nahe, wobei er anders als diese keine Reform des GmbH-Recht damit verknüpft, sondern vielmehr die Vorschriften zu seiner $\mathrm{KmbH}$ - thematisch zutreffend - in den vakanten $\S § 178$ ff. HGB im Anschluss an die typische KG verorten will. Das ermögliche es zugleich, so Drygala, entsprechend der Verfahrensweise in $\S 161$ Abs. 2, 105 Abs. 2 HGB nach vorn auf das Recht der typischen KG und der OHG zu verweisen. Die Regelung könnte sich so auf die Besonderheiten der $\mathrm{KmbH}$ beschränken und damit schlank gehalten werden ${ }^{490}$.

Die $\mathrm{KmbH}$ orientiert sich in erster Linie, insbesondere im Hinblick auf das Haftungssystem, am Recht der typischen KG, in Bezug auf Anteilsübertragung und Vererbung sieht Drygala indes bessere Argumente dafür, dem Recht der OHG zu folgen und von der grundsätzlichen Nichtïbertragbarkeit und Unvererblichkeit auszugehen ${ }^{491}$.

Gesellschafter der KmbH können durch ihre Aufhängung im HGB ausschließlich Gewerbetreibende sein, die freiberuflichen Unternehmen, blieben nach vorherrschendem Verständnis hingegen ausgeschlossen ${ }^{492}$. Da die $\mathrm{KmbH}$ eine Personengesellschaft ist, würde sie ihrer Rechtsnatur nach ebenso wie die typische KG und die OHG Gesamthandsgesellschaft sein. Damit wäre zum einen eine Einpersonengründung ausgeschlossen, denn das Vermögen kann denknotwendig niemals einer einzelnen Person zur gesamten Hand zustehen, zum anderen

487 Berninger/Schnittker in: Eckpunktepapier zur Schaffung der Gesellschaftsform einer Personengesellschaft mit beschränkter Haftung, online abrufbar unter http://www.dihk.de/ index.html?/inhalt/themen/rechtundfairplay/handelsundgesellschaftsrecht/neuerechtsformen.html.

488 Drygala ZIP 2006, 1797, 1801.

489 Siehe dazu oben in diesem Abschnitt unter VI.

490 Drygala ZIP 2006, 1797, 1801.

491 Drygala ZIP 2006, 1797, 1801.

492 Drygala ZIP 2006, 1797, 1801. 
würden sich daraus steuerliche Konsequenzen ergeben, denn Personengesellschaften werden als Steuersubjekte nicht wahrgenommen, die erwirtschafteten Gewinne werden im Personengesellschaftsrecht vielmehr unter dem Gesichtspunkt der Einkommenssteuer bei den Gesellschaftern besteuert ${ }^{493}$.

\section{Kaufmann mit beschränkter Haftung}

Einen ähnlichen Weg wie Drygala geht der Entwurf des Bayerischen Ministeriums der Justiz ${ }^{494}$. Nach den hiernach in das HGB neu einzufügenden $\S \S 4$ bis 4 j soll der Kaufmann - aber auch ein nichtkaufmännischer Einzelunternehmer - seine Haftung durch konstitutive Eintragung in das Handelsregister auf bestimmte Vermögensgegenstände beschränken können, sofern nicht seine Verbindlichkeiten sein Vermögen überschreiten ${ }^{495}$. Der Anmeldung zum Handelsregister ist in der Anlage ein Inventar über das für die Verbindlichkeiten haftende Vermögen beizufügen. Haftendes Vermögen kann grundsätzlich nur durch Einlage und Inventarisierung gebildet werden, außerdem allerdings auch durch dingliche Surrogation. Aus dem haftenden Vermögen können nur Überschüsse entnommen werden und das auch nur soweit auf die Entnahme keine Zahlungsunfähigkeit folgt. Schließlich kann der Kaufmann seines Privilegs der Haftungsbeschränkung verlustig gehen, wenn er gläubigerschützende Pflichten verletzt oder wenn über sein Gesamtvermögen wegen Privatverbindlichkeiten das Insolvenzverfahren eröffnet wird ${ }^{496}$.

493 Vgl. hierzu auch die Würdigung bei Berninger/Schnittker in: Eckpunktepapier zur Schaffung der Gesellschaftsform einer Personengesellschaft mit beschränkter Haftung, online abrufbar unter http://www.dihk.de/index.html?/inhalt/themen/rechtundfairplay/handelsundgesellschaftsrecht/neuerechtsfor men.html.

494 Entwurf eines Gesetzes zur Einführung eines Kaufmanns mit beschränkter Haftung; Stand 30. März 2006; abrufbar unter www.justiz.bayern.de/imeria/md/content/stmj_internet/ministerium /ministerium/ gesetzgebung/kmbh_gesetzentwurf.pdf.

495 Priester Die GmbH-Reform in der Diskussion, S. 1, 10 f.; Lutter, Die GmbH-Reform in der Diskussion, S. 211, 219; vgl. hierzu auch die Würdigung bei Berninger/Schnittker in: Eckpunktepapier zur Schaffung der Gesellschaftsform einer Personengesellschaft mit beschränkter Haftung.

496 Priester Die GmbH-Reform in der Diskussion, S. 1, 10 f.; vgl. hierzu auch die Würdigung bei Berninger/Schnittker in: Eckpunktepapier zur Schaffung der Gesellschaftsform einer Personengesellschaft mit beschränkter Haftung, online abrufbar unter http://www.dihk.de/index.html?/inhalt/themen/ rechtundfairplay/handelsundgesellschaftsrecht/neuerechtsformen.html. 


\section{Personengesellschaft mit beschränkter Haftung}

Schließlich wird von Berninger und Schnittker ${ }^{497}$ die Schaffung einer Personengesellschaft mit beschränkter Haftung vorgeschlagen.

Im Mittelpunkt der Überlegungen steht die Möglichkeit für Personengesellschaften - namentlich die GbR und die OHG - zu einer Haftungsbeschränkung zu optieren. Die Haftungsbeschränkung soll mit Eintragung eines haftungsbeschränkenden Zusatzes in das Handelsregister (z.B. Personengesellschaft $\mathrm{mbH}$ oder $\mathrm{PGmbH}$ oder $\mathrm{PmbH}$ ) begründet werden können. Dieser Zusatz wäre auch im Geschäftsverkehr (z.B. auf Geschäftsbriefen) stets anzugeben.

Um Missbräuche zu verhindern, soll die Ziehung der Option nur solchen Gesellschaften gestattet sein, welche im Zeitpunkt der Option nachweislich ein positives Eigenkapital aufweisen, d.h.: Das Eigenkapital muss die Verbindlichkeiten der Gesellschaft decken, so dass den Gesellschaftsgläubigern kein Haftungssubstrat entzogen wird. Auch soll nach dem Willen der Entwurfgeber die Haftungsbeschränkung grundsätzlich nur für Verbindlichkeiten gelten, die nach der Eintragung der Haftungsbeschränkung im Handelsregister begründet worden sind. Für alle anderen (Alt-)Verbindlichkeiten haften die Gesellschafter (zumindest für einen bestimmten Zeitraum - z.B. 5 Jahre - nach Eintragung der Haftungsbeschränkung) weiterhin unbeschränkt ${ }^{498}$.

Den Schutz der Gläubiger wollen Berninger und Schnittker zum einen durch umfassende Publizitäts- und Offenlegungspflichten nach dem Vorbild des für englische LLPs geltenden Rechts sichern ${ }^{499}$. Danach wäre dann bei Gesellschaften ab einer bestimmten Größe z.B. auch der Gewinnanteil (einschließlich der Vergütungen) desjenigen Gesellschafters offen zu legen, der über die höchste Gewinnbeteiligung verfügt. Zum anderen sind in dem Eckpunktepapier weitgehende Entnahmebeschränkungen vorgesehen. Entnahmen sollen danach nur bei tatsächlich angefallenen Gewinnen und nur, wenn dadurch die Zahlungsfähigkeit der Gesellschaft nicht beeinträchtigt wird, zulässig sein. Bei Verstoß gegen diese Entnahmesperren verlieren sowohl der die Entnahme tätigende als auch ein der Entnahme zustimmender Gesellschafter - dies wird im Regelfall der geschäftsführende Gesellschafter sein - ihren Haftungsschutz. Schließlich sollen für eine PmbH ähnliche Regeln bezüglich des Kapitalersatzes gel-

497 Berninger/Schnittker in: Eckpunktepapier zur Schaffung der Gesellschaftsform einer Personengesellschaft mit beschränkter Haftung, online abrufbar unter http://www.dihk.de/index.html?/inhalt/ hemen/rechtundfairplay/handelsundgesellschaftsrecht/neuerechtsformen.html.

498 Berninger/Schnittker in: Eckpunktepapier zur Schaffung der Gesellschaftsform einer Personengesellschaft mit beschränkter Haftung, online abrufbar unter http://www.dihk.de/index.html?/inhalt/themen /rechtundfairplay/handelsundgesellschaftsrecht/neuerechtsformen.html.

499 Vgl. zu der Geschäftsführerhaftung bei einer Private Limited Company Schröder/Schneider GmbHR 2005, 1288 sowie allgemeiner Teichmann NJW 2006, 2444; Triebel/Otte/ Kimpel BB 2005, 1233. 
ten wie dies für GmbHs der Fall ist. Hierzu soll ein entsprechender Verweis - nach dem Vorbild des für GmbH \& Co. KGs geltenden $§ 172$ a HGB - ins Gesetz aufgenommen werden ${ }^{500}$.

500 Berninger/Schnittker in: Eckpunktepapier zur Schaffung der Gesellschaftsform einer Personengesellschaft mit beschränkter Haftung, online abrufbar unter http://www.dihk.de/index.html?/inhalt/themen /rechtundfairplay/handelsundgesellschaftsrecht/neuerechtsformen.html. 


\section{§ 2 Niederlande}

\section{Einleitung}

Anders als im deutschen Recht ist das Recht der Gesellschaft mit beschränkter Haftung in den Niederlanden nicht in einem Spezialgesetz kodifiziert. Vielmehr ist das Recht der juristischen Personen in den Niederlanden insgesamt im zweiten Buch des niederländischen Bürgerlichen Gesetzbuches („Burgerlijk Wetboek“, im Folgenden nur „NBG“) geregelt ${ }^{501}$. Dabei nehmen die Vorschriften betreffend die Gesellschaft mit beschränkter Haftung nach niederländischem Recht, der so genannten „Besloten vennootschappen“ (im Folgenden „B.V.“), den 5. Titel des zweiten Buches des NBG ein.

Die Gesellschaft mit beschränkter Haftung existiert in den Niederlanden als eigene Rechtform auch erst seit 1971. Vorher kannte das Niederländische Recht als einzige Kapitalgesellschaft nur die „Naamloze vennootschappen“ (im Folgenden „N.V.“), die sowohl großindustriellen Bedürfnissen als auch den Anforderungen von Klein- und Mittelbetrieben gerecht werden musste. Anlass für die Einführung der B.V. war allerdings nicht die mangelnde Kompatibilität der N.V. mit den Belangen des Mittelstandes, sondern vielmehr eine Vorgabe der EU, die mit der Ersten EG-Richtlinie zum Gesellschaftsrecht genaue Abgrenzungskriterien zwischen kleinen und großen Kapitalgesellschaften verlangte, wie es in den anderen Mitgliedstaaten bereits üblich war. Zu erwarten war nämlich, dass fortan EG-Richtlinien zum Gesellschaftsrecht je abwechselnd auf nur eine der beiden Gesellschaftstypen Anwendung beanspruchen würden.

Doch statt die EG-rechtlichen Vorgaben zum Anlass zu nehmen eine neue kleine Kapitalgesellschaft einzuführen, ist dem niederländischen Gesetzgeber nur eine formale Unterscheidung gelungen, B.V. und N.V. ähneln sich bis heute erheblich. Dies kommt bereits in der Terminologie zum Ausdruck. Weiterhin gelten für die Geschäftsleitung und die Anteilsinhaber einer N.V. und einer B.V. die gleichen Regelungen. Ferner gibt es kaum wesentliche Unterschiede zwischen den Gesellschaften etwa hinsichtlich der Gründungsvoraussetzungen, der Satzungsautonomie, der Organisationsverfassung, in Bezug auf Weisungsbefugnisse, Neben-

501 Im Nachfolgenden wird insbesondere Bezug genommen auf die Abhandlung von Hirte/Bücker/Rammeloo/de Kluiver S. 178 ff. sowie Mellert/Verfürth S. 145 ff. zur niederländischen B.V. und N.V. und Süß/Wachter/Rademakers/de Vries S. 1101 ff.; Haarhuis Gesellschaftsrecht Niederlande; zu historischen Anmerkungen in diesem Kapitel vgl. insbesondere Mehring, GmbH-Rechte S. 205 ff und Gotzen, Die GmbH sowie ders., in: Behrens, Die GmbH Rn. NL 1 ff. 
leistungen u.s.w. Die N.V. und die B.V. sind gleichermaßen den Grundätzen unterworfen, die auf das Grundprinzip der „Teilrechtsordnung“ (,Delrechtsorde“) zurückzuführen sind ${ }^{502}$.

Die Parallelität der niederländischen Kapitalgesellschaftsformen N.V. und B.V. kommt auch in der Strukturierung der Titel 4 beziehungsweise Titel 5 des zweiten NBG-Buches zum Tragen $^{503}$ : Eine Vielzahl der auf die N.V. anzuwendenden gesetzlichen Bestimmungen sind wörtlich für die B.V. übernommen worden. Sogar die ,großen“ Kapitalgesellschaften (,structurvennootschappen“), deren Organisationsverfassung der Gesetzgeber durch zwingende Vorschriften völlig abweichend normiert hat sind für B.V. und N.V. gleich ausgestaltet. Schließlich kommt noch hinzu, dass der niederländische Gesetzgeber den Anwendungsbereich von einigen „N.V.-bezogenen“ EG-Richtlinien zum Gesellschaftsrecht auf die B.V. erweitert hat. In diesem Zusammenhang weisen Rammelloo und de Kluiver ${ }^{504}$ noch auf einen weiteren Umstand hin: Für N.V. und B.V. gelten dieselben allgemeinen Normen des zweiten NBG-Buchs. Außer Titel 1 (Allgemeine Bestimmungen) sind das Titel 7 betreffend Verschmelzung und Spaltung („Fusie en Splitsing“), Titel 8, Abteilung 2, betreffend das Untersuchungsrecht (,„.. het recht van enquête“) und Titel 9 betreffend Jahresabschluss und Lagebericht („De jaarrekening en het jaarverslag").

Ungeachtet der vorstehend angeführten Parallelen gibt es dennoch einige prägende, durch den niederländischen Gesetzgeber zwingend normierte Unterschiede zwischen den beiden Kapitalgesellschaftstypen, auf die im Einzelnen in den folgenden Paragraphen eingegangen werden soll. Des Weiteren sind in den seit 2004 vorgelegten Reformvorschlägen betreffend das Recht der B.V. weit reichende Änderungen angelegt, die den Gesellschaftstyp der B.V. weiter konkretisieren und auch endlich eine deutliche Abgrenzung zu der N.V. schaffen sollen.

$502 \mathrm{Zu}$ den unternehmensrechtlichen, wirtschaftsrechtlichen und ethischen Aspekten und deren InterdependenZ Timmerman NJB 2004, S. 1629. Zusammenfassend siehe Hirte/Bücker/Rammeloo/de Kluiver S. 181 f.

504 Hirte/Bücker/Rammeloo/de Kluiver S. 185. 


\section{Gründung der Gesellschaft}

\section{Bestehende Rechtslage}

\section{a) Gründungsvorgang}

Für die Gründung einer B.V. ist ein bestimmtes förmliches Verfahren vorgesehen, das vor allem die Erteilung einer Unbedenklichkeitserklärung des niederländischen Justizministeriums (,Verklaring van geen bezwaar"), die Beurkundung durch einen niederländischen Notar und die Eintragung in das Handelsregister vorsieht.

Abweichend von der in Deutschland oder Frankreich geltenden Regelung wird das niederländische Handelsregister nicht von staatlichen Gerichten, sondern von den für den Sitz der Gesellschaft zuständigen Industrie- und Handelskammern („Kamers van Koophandel“) geführt $^{505}$. Außerdem besteht für bestimmte Vorgänge im Zusammenhang mit der Tätigkeit der Gesellschaft eine Publizitätspflicht im niederländischen Staatsanzeiger („De Nederlandse Staatscourant" $)^{506}$.

Mit Bezug auf die Gründung einer B.V. sollen zunächst nur die formellen Erfordernissen (Abs. 2 von Art. 2:64/175 NBG) aufgezeigt werden. Eine Darstellung der ebenfalls schon während des Gründungsvorgangs interessierenden Ausgestaltung der Satzung soll einem gesonderten Abschnitt (vgl. nachfolgend unter III.) vorbehalten sein.

\section{b) Gründungsvoraussetzungen (oprichtingsvereisten)}

\section{aa) Gründer}

Eine B.V. kann durch einen ${ }^{507}$ oder mehrere Personen errichtet werden. Dabei kann es sich sowohl um natürliche als auch juristische Personen handeln. Anders als im deutschen Recht können allerdings nicht Personengesellschaften als Gründer einer B.V. auftreten. Es ist weder erforderlich, dass die als Gründer handelnden natürlichen Personen die niederländische

505 Mehring GmbHR 1991, 297;

506 Gotzen, Die GmbH S. 4 f.

507 Die Tatsache, dass die Anteile von einer einzigen Person gehalten werden, ist meldepflichtig und wird auch im Handelsregisterauszug publiziert; vgl. nur Mehring, GmbH-Rechte S. 205, 208. Umfassend zur Einpersonen-BV Boschma, De eenpersoons-BV 1997. 
Staatsangehörigkeit besitzen noch dass sie einen Wohnsitz in den Niederlanden haben. Desgleichen gilt für juristische Personen im Hinblick auf deren Verwaltungssitz. Verlangt wird lediglich, dass die Gründer für die Abwicklung des Gründungsvorgangs eine zustellungsfähige Adresse in den Niederlanden angeben. Regelmäßig genügt hierfür die Angabe der Anschrift des beurkundenden - zwingend niederländischen ${ }^{508}$ - Notars.

\section{bb) Präventivkontrolle}

Der oder die Gründer haben zunächst die Satzung zu entwerfen und den Entwurf sodann zusammen mit den Angaben zu den Gründern beim niederländischen Justizministerium zur Prüfung einzureichen. Die Prüfung des Justizministeriums erstreckt sich - anders als noch nach altem Recht, wo eine vollständige Rechtmäßigkeitsprüfung der Satzung erfolgte ${ }^{509}-$ heute nur noch auf die Person der Gründer und deren Absichten, die Gesellschaft zu führen (2. Absatz des Art 2:68 und 2: 179 NBG) $)^{510}$.

Die Unbedenklichkeitserklärung ,darf nur aus dem Grund verweigert werden, dass, unter Beachtung der Vorhabens oder der Vergangenheit der Personen, die die Führung der Gesellschaft bestimmen oder mitbestimmen werden, die Gefahr besteht, dass die Gesellschaft zu unerlaubten Zwecken gebraucht werden oder dass ihre Tätigkeit zur Benachteiligung von Gläubigern führen wird“. Hierbei folgt das Ministerium selbst erarbeiteten Beurteilungsrichtlinien, die - um den tatsächlichen Begebenheiten Rechnung zu tragen - einer regelmäßigen Kontrolle und Änderung unterliegen und deren aktuelle Fassung in den in der niederländischen Fachpresse veröffentlichten so genannten „Departementale standpunten“ ständig verbindlich erläutert und ergänzt wird ${ }^{511}$.

Die Wirksamkeit solcher ,frontloaded control devices" wird in der Literatur indes in Frage gestellt ${ }^{512}$. Denn auch wenn demnach der Umstand, dass die Gründer beziehungsweise die Mitglieder zukünftiger Gesellschaftsorgane wegen Wirtschaftsdelikten verurteilt worden sind, der Gründung einer Gesellschaft entgegensteht, ist es möglich und denkbar, Konsequenzen durch den Einsatz von Strohmännern zu umgehen.

\footnotetext{
508 Vgl. dazu im Einzelnen unten in diesem Abschnitt II. 1. b) cc).

509 Vgl. zu der alten Rechtslage nur Gotzen, Die GmbH S. 8 f.

510 Gotzen, in: Behrens, Die GmbH Rn. NL 14; Mehring, Die GmbH in den Niederlanden, in: Die GmbHRechte in den EG-Staaten, 205, 210; .

511 van Efferink/Ebert/Levedag GmbHR 2004, 880, 881.

512 So die Einschätzung von Hirte/Bücker/Rammeloo/de Kluiver S. 185 unter Hinweis auf die Nachweise bei Asser-Maeijer 2-III, S. 87 ff. und van Schilfgarde/Winter, S. 24 ff.
} 


\section{cc) Notarielle Beurkundung}

Nach der Erteilung der ministeriellen Unbedenklichkeitserklärung folgt die Beurkundung des Gründungsvorgangs und der Satzung durch den Notar. Das niederländische Recht schreibt hierfür zwingend eine Beurkundung durch einen in den Niederlanden ansässigen Notar vor. Die Beurkundung durch einen deutschen Notar ist unzulässig, auch wenn dieser in die vorbereitenden Arbeiten miteinbezogen sein $\operatorname{mag}^{513}$.

\section{dd) (Teilweise) Erfüllung der Einlagepflichten}

Auf die ausgegebenen und gezeichneten Geschäftsanteile ist der Nennbetrag vollständig in Bar einzuzahlen, soweit nicht etwas anderes vereinbart ist (Art. 2: 191 Abs. 1 NBG und 191 a Abs. 1 NBG). Der Gesellschaftsvertrag kann allerdings vorsehen, dass ein Gesellschafter zunächst nur zur Einzahlung von 1/4 des Nennbetrages des ausgegebenen und gezeichneten Geschäftsanteils verpflichtet ist und die übrigen $3 / 4$ erst nach Aufforderung durch die Gesellschaft einzuzahlen braucht (Art. 2: 191 Abs. 1 NBG). Eine vollständige oder teilweise Abbedingung der Einzahlungsverpflichtung ist indes nicht gestattet; auch eine Aufrechnungsmöglichkeit ist gesetzlich ausgeschlossen (Art. 2: 191 Abs. 3 NBG) ${ }^{514}$.

\section{ee) Eintragung im Handelsregister}

Nach der notariellen Gründung muss die Anmeldung zum Handelsregister durch die Geschäftsführer (,,bestuurders“") erfolgen. Hierbei muss eine beglaubigte Kopie der Gründungsurkunde einschließlich Nachweis über die Erbringung der Einlagen und weitere Angaben eingereicht werden. Bei Sachgründungen ist - wie im deutschen Recht - außerdem eine Werthaltigkeitsbescheinigung beizufügen. Die Gesellschaft wird daraufhin im Handelsregister eingetragen $^{515}$. Allerdings hat die Eintragung einer Kapitalgesellschaft in das Handelsregister nach niederländischem Recht im Unterschied zur deutschen Rechtssituation keine konstitutive sondern nur eine deklaratorische Bedeutung. Die Gesellschaft entsteht als juristische Person bereits mit der notariellen Beurkundung der Gründung ${ }^{516}$.

513 van Efferink/Ebert/Levedag GmbHR 2004, 880, 881; Süß/Wachter/Rademakers/de Vries S. 1107; Mehring GmbHR 1991, 297

514 Süß/Wachter/Rademakers/de Vries S. 1117; Bier Ondernemingsrecht 2004, 10 ff.

515 Mellert/Verfürth S. 149.

516 Gotzen, in: Behrens, Die GmbH Rn. NL 15; Mehring, GmbH-Rechte S. 205, 212; vgl auch Hirte/Bücker/Rammeloo/de Kluiver S. 185. 
Nichtsdestotrotz ist die Eintragung in zweierlei Hinsicht bedeutsam: Einmal wird durch die Eintragung die Wirkung der eintragungsfähigen Tatsachen gegenüber Dritten ausgelöst. Zum anderen bringt die Eintragung im Handelsregister zusammen mit der Einzahlung von wenigstens $10 \%$ des Nennwerts auf jeden bei der Gründung von den Gründern gezeichneten Anteil die beschränkte Haftung der Gesellschaftsgründer zum Entstehen.

Eine Veröffentlichung der Satzung im niederländischen Staatsanzeiger („De Nederlandse Staatscourant ${ }^{\circ)}$ ) ist heute im Gegensatz zu der früheren Regelung in den Niederlanden nicht mehr vorgesehen. Die Gesellschaftssatzung braucht nunmehr lediglich noch beim Handelsregister zur Einsichtsnahme durch jedermann hinterlegt zu werden. Diese Hinterlegung wird alsdann im Staatsanzeiger veröffentlicht ${ }^{517}$.

\section{ff) Rechtslage vor Eintragung im Handelsregister - „B.V. i.o.“}

Für die Zeit vor der Eintragung der B.V. ,als solche“ gibt es - ähnlich dem deutschen Recht die Möglichkeit, die Gesellschaft unter ihrem Namen mit dem Zusatz ,i.o.“ (in oprichting) zu führen und bereits als Gesellschaft in Handelsregister eintragen zu lassen. Anders als die deutsche $\mathrm{GmbH}$ i.Gr. beziehungsweise die so genannte Vor-GmbH wird eine B.V. i.o. jedoch lediglich als Personengesellschaft angesehen (beziehungsweise als einzelkaufmännisches Unternehmen bei Alleingesellschaftern), was zur Folge hat, dass die für die B.V. i.o. handelnden Personen persönlich für Gesellschaftsschulden haften (Artt. 2:92 II und 2:203 II NBG). Auch gehen die Rechtsverhältnisse einer B.V. i.o. nicht bei Entstehen der B.V. ,als solche“ automatisch auf diese über, sondern müssen von der B.V. vielmehr übernommen beziehungsweise bestätigt werden (Artt. 2:92 I und 2:203 I NBG). Für vor der Entstehung der B.V. ,als solche“ getätigte Rechtsgeschäfte haften die handelnden Personen auch nach Übernahme der Verbindlichkeiten durch die spätere B.V. weiterhin im Sinne einer Vorbelastungshaftung, wenn ihnen bei Eingehen der Rechtsgeschäfte bewusst war, dass die Gesellschaft auch nach ihrer Entstehung die Verpflichtungen zu erfüllen nicht in der Lage sein wird (Artt. 2:92 III und 2:203 III $\mathrm{NBG})^{518}$.

517 Gotzen, Die GmbH S. 10; ders. in: Behrens, Die GmbH Rn. NL 6; Mehring, GmbH-Rechte S. $205,212$.

518 Siehe zur niederländischen Literatur nur Asser-Maeijer 2-III, S. 87 ff.; van Schilfgarde/Winter, S. 24 ff.; van der Heijden/van der Grinten 1992, Nr. 244-245; zur deutschen Literatur siehe Gotzen, in: Behrens, Die GmbH Rn. NL 16; Mehring, GmbH-Rechte S. 205, 211; ders. GmbHR 1991, 297, 298; Vgl. auch Jansen, GmbHR 1995, 286, 288, der insbesondere die Haftungsverhältnisse in der BV beleuchtet und sich dabei schwerpunktmäßig mit der Haftung der Gründungsgesellschafter; mit deren Haftung gegenüber der Gesellschaft (Stichworte: Kapitalaufbringung, Rechtshandlungen vor oder im Gründungsstadium) und gegenüber den Gläubigern (Stichworte: unzureichende Kapitalausstattung, Haftung vor Abschluß der Gründungsphase und Haftungsbefreiung nach deren Abschluß) befasst. Vgl. zu dem Vorstehendem auch Süß/Wachter/Rademakers/de Vries S. 1108 sowie Mellert/Verfürth S. 150. 


\section{c) Gründungsmängel (oprichtingsgebreken)}

Die Rechtsfolgen von Gründungsmängeln beziehungsweise der Nichtbeachtung vorstehend angesprochenen Gründungsprinzipien sind im ersten Titel des 2. NBG-Buches („Allgemeine Bestimmungen") für alle juristischen Personen einheitlich zusammengefasst. Eine Abgrenzung zwischen Personengesellschaften und Körperschaften findet indes auch in diesem Abschnitt insoweit statt, als bestimmte Rechtsfolgen die Nichteinhaltung bestimmter Erfordernisse verlangen, die nur durch Kapitalgesellschaften zu erfüllen sind. Ein Beispiel hierfür bildet Art. 2:4 NBG, wonach eine juristische Person als nicht entstanden gilt, wenn die „ohne eine von einem Notar unterzeichnete Urkunde oder ohne eine Unbedenklichkeitserklärung“ gegründet wird. Für so genannte ,informelle“ Vereine ist eine notarielle Beurkundung nicht vorgeschrieben und, N.V. und B.V. ausgenommen, unterliegen die im 2. Buch des niederländischen NBG regelten juristischen Personen allesamt nicht der Gründungsvoraussetzung einer Unbedenklichkeitserklärung ${ }^{519}$.

Die drakonisch anmutende Rechtsfolge, dass nämlich eine Gesellschaft von Anfang an als nicht entstanden gilt, wird dadurch entschärft, das dass das Vermögen einer solchen „Fehlerhaften Gesellschaft“ gemäß Art. 2:4 Abs. 4 NBG „,liquidiert (wird) wie das einer (gewöhnlich) aufgelösten juristischen Person in der vorgetäuschten Rechtsform“. Weniger bedeutsame Mängel führen ohnehin gemäß Art 2:21 NBG nur auf Antrag eines Beteiligten oder auf Klage der Staatsanwaltschaft zur einer Auflösung der juristischen Person durch den Richter $(, \text { rechtbank" })^{520}$.

\section{d) Kosten der Gründung}

In den Niederlanden fallen zunächst Notargebühren an, für die Errichtung der B.V. Da sich diese regelmäßig an der Stammkapitalziffer bemessen, dürften sie nach der Abschaffung der Mindestkapitalpflicht allerdings vernachlässigbar sein. Die Gebühr für die ebenfalls bei Gründung beizubringende Unbedenklichkeitsbescheinigung des niederländischen Justizministeriums beträgt knapp $100 €$. Daneben entstehen regelmäßige Kosten für die Eintragung im Handelsregister in Höhe von jährlich ca. 170 €. Schließlich kommen noch hinzu die Kosten

519 van der Heijden/van der Grinten 1992, Nr. 200-242; Hirte/Bücker/Rammeloo/de Kluiver S. 185.

520 Asser-Maeijer 2-III, S. 87 ff. und Schilfgarde/Winter, S. 24 ff.; Gotzen, in: Behrens, Die GmbH Rn. NL 17; Hirte/Bücker/Rammeloo/de Kluiver S. 185. 
der Veröffentlichung im Staatsanzeiger sowie eine Kapitalsteuer in Höhe von 0,55 \% des ausgegebenen Kapitals ${ }^{521}$.

\section{Zu den Reformbestrebungen}

Nach der Vorstellung des niederländischen Gesetzgebers soll künftig auf eine präventive Kontrolle der Satzung, insbesondere der Gründer und des Unternehmensgegenstandes bei der Errichtung der B.V. verzichtet werden können; Art. 2:179 NBG, der die Beibringung einer Unbedenklichkeitserklärung de Justizministerium in diesen Fällen vorsieht, wird ersatzlos gestrichen $^{522}$. Desgleichen gilt für die Präventivkontrolle des Justizministeriums bei Satzungsänderungen; auch diese soll künftig entfallen (Art. 2: $235 \mathrm{NBG})^{523}$.

Des Weiteren sollen Zeitpunkt und Umfang der Einlageleistung künftig durch die Gesellschafter selbst bestimmt werden können. Die Einlagen sind künftig erst nach Aufforderung der Gesellschaft zu erbringen ${ }^{524}$.

\section{Satzung (,,Statuten“6); Stimmbindungsverträge (,,aandeelhoudersovereen- komst $^{*}$ )}

\section{Bestehende Rechtslage}

\section{a) Gesetzlicher Mindestinhalt der Satzung (,,Statuten“)}

Wie in Deutschland und Frankreich bildet die Satzung die Verfassung der Gesellschaft; sie ist der Gründungsurkunde der Gesellschaft beizufügen (Art. 2:66/177 NBG). Anders als im deutschen oder französischen Gesellschaftsrecht sind die gesetzlichen Bestimmungen zur Ausgestaltung der Satzung im niederländischen Gesellschaftsrecht allerdings im Grundsatz nicht dispositiv; nur wenige Bestimmungen sehen vor, dass von ihnen abgewichen werden kann. Dies liegt in erster Linie daran, dass die Regelungen zur niederländischen B.V. - wie bereits oben ausgeführt worden ist - durch umfassende Übernahmen aus dem Recht der niederländi-

\footnotetext{
Süß/Wachter/Rademakers/de Vries S. 1110; Wachter GmbHR 2005, 717, 723.

Begründung des Gesetzesentwurfs, Allgemeiner Teil, S. 12.

523 Begründung des Gesetzesentwurfs, Allgemeiner Teil, S. 12.

524 Begründung des Gesetzesentwurfs, Allgemeiner Teil, S. 12; Vgl. hierzu auch unten in diesem Abschnitt unter V 2. a) aa) ccc) und ddd)
} 
schen Aktiengesellschaft, der N.V. geprägt sind und daher Regelungen im niederländischen B.V.-Recht enthalten sind, die lediglich bei einer Aktiengesellschaft aufgrund des objektivierten Anlegerschutzes notwendig sind ${ }^{525}$.

Ähnlich dem deutschen GmbH-Recht sieht auch das niederländische Recht als gesetzlichen Mindestinhalt einer B.V.-Satzung die Angabe der Firma und des Sitzes sowie des Gegenstandes des Unternehmens vor. Des Weiteren ist die Nennung des Stammkapitals der Gesellschaft in Euro ${ }^{526}$ unter besonderer Bezeichnung von Nennbetrag und Gattung der Anteile erforderlich. Schließlich sind in der Satzung die Beschränkungen hinsichtlich der Übertragbarkeit der Anteile (Art. 2:195 II NBG) (,,blokkeringsregeling“) anzugeben ${ }^{527}$. Ist die Gründung der B.V. im Wege der Sachgründung erfolgt, so ist außerdem der Einlagegegenstand in der Satzung zu beschreiben $^{528}$.

\section{aa) Firma und Sitz}

Im Handelsgesetzbuch ist festgelegt, dass die Firma die Bezeichnung „,besloten vennootschap met beperkte Aansprakelijkheid" beziehungsweise die Abkürzung B.V. enthalten muss. Des Weiteren ist sicherzustellen, dass keine Verwechslungsgefahr mit anderen Unternehmen oder Unklarheit über den Charakter der Gesellschaft besteht.

Neben der Firma kann eine niederländische B.V. auch so genannte Handelsnamen führen ${ }^{529}$; diese müssen allerdings nicht in der Satzung genannt sein. Wird eine Prüfung der Firma und des Handelsnamens im Hinblick auf eine bestehende Verwechslungsgefahr nicht bereits durch die Gründer durchgeführt, so wird in den Niederlanden durch das Ministerium - wie in Deutschland; dort allerdings durch das Amtsgericht -, vor der Eintragung der Firma oder des Handelsnamens durch Anfrage bei der zuständigen Kamer van Koophandel sichergestellt, dass keine Verwechslungsgefahr mit anderen Unternehmen besteht ${ }^{530}$.

Anders als in Deutschland ist der Sitz der B.V. unabhängig vom Ort, an dem die Gesellschaft tatsächlich tätig ist, und kann sich überall in den Niederlanden befinden (Artt. 2:66 und 2:177

\footnotetext{
Süß/Wachter/Rademakers/de Vries $\quad$ S. $\quad 1111 ; \quad$ Mellert/Verfürth $\quad$ S. $\quad 147$; Kuiper/Ruypers/Slangen/Kuiper/Vossestein, S. 161, Artt. 2:67 und 2: 178 NBG.

526 Siehe hierzu auch im Einzelnen unten in diesem Abschnitt unter V 1. a) aa)

527 Boschma/ Schutte-Veenstra 2007 S. 198.

528 Mellert/Verfürth S. 147; Kuiper/Ruypers/Slangen/Kuiper/Vossestein, S. 161, Artt. 2:67 und 2: 178 NBG.

529 van Efferink/Ebert/Levedag GmbHR 2004, 880, 881; Mellert/Verfürth S. 148.

530 Süß/Wachter/Rademakers/de Vries S. 1111; Mehring, GmbH-Rechte S. 205, 209.
} 
III NBG). Da die Niederlande der Gründungstheorie folgen, kann der tatsächliche Verwaltungssitz außerdem auch im Ausland $\operatorname{sein}^{531}$.

\section{bb) Gesellschaftszweck}

Der Gesellschaftsvertrag hat eine Bestimmung über den Gesellschaftszweck (,doel“) zu enthalten (Art. 2: 177 Abs. 1 NBG). Dieser muss die wichtigsten Tätigkeiten der Gesellschaft eindeutig beschreiben. Nicht erforderlich ist, dass im Gesellschaftszweck die der Rechtsform einer B.V. typischerweise innewohnende Ausrichtung, ein Unternehmen zu betreiben und dabei Gewinne zu erzielen, zum Ausdruck kommt, allerdings darf die Absicht der Gewinnerzielung auch nicht qua Satzungsbestimmung ausdrücklich ausgeschlossen $\operatorname{sein}^{532}$.

Die Bestimmung des Gesellschaftszwecks im Gesellschaftsvertrag ist in zweierlei Hinsicht von Bedeutung:

Zum einen hat sich das Gesellschaftskapital - auch wenn das Gesetz an dieses, anders als an das Stammkapital, grundsätzlich keine Mindestanforderungen stellt - grundsätzlich in einem angemessenen Verhältnis zu den aus dem Zweck der Gesellschaft sich ergebenden Tätigkeiten befinden. Ist dies nicht der Fall, so kann das Justizministerium die zur Gründung erforderliche Unbedenklichkeitserklärung verweigern ${ }^{533}$.

Zum anderen dient der Gesellschaftszweck - wie im deutschen Recht - dem Schutz der Gesellschafter durch eine jedenfalls im Innenverhältnis wirkende und gegebenenfalls auch im Außenverhältnis vorwerfbare Begrenzung des zulässigen Handlungsbereichs des Geschäftsführungsorgans ${ }^{534}$.

531 Mellert/Verfürth S. 147; Süß/Wachter/Rademakers/de Vries S. 1111.

532 Asser-Maeijer 2-III, S. 371 ff.; van Schilfgarde/Winter, S. 180 ff.; van der Heijden/van der Grinten 1992; Süß/Wachter/Rademakers/de Vries S. 1113; Mehring, GmbH-Rechte S. 205, 210.

533 Asser-Maeijer 2-III, S. 371 ff.; Gotzen, Die GmbH S. 19; Süß/Wachter/Rademakers/de Vries S. 1113.

534 Gotzen, Die GmbH S. 19; Süß/Wachter/Rademakers/de Vries S. 1113. 


\section{cc) Kapital}

Im niederländischen Recht unterscheidet man zwischen dem Genehmigten Kapital (,maatschappelijk kapitaal“), dem Gezeichneten Kapital (,geplaatst kapitaal“) und dem Eingezahlten Kapital (,gestort kapitaal“) $)^{535}$.

Das Genehmigte Kapital ist das im Gesellschaftsvertrag festgeschriebene Stammkapital der Gesellschaft. Ähnlich dem im angloamerikanischen Recht geläufigen autorisierten Kapital gibt es den Höchstbetrag an, bis zu dem Geschäftsanteile herausgegeben und gezeichnet werden können, ohne dass der Gesellschaftsvertrag abgeändert werden muss ${ }^{536}$.

Das Gezeichnete Kapital ist der Teil des Genehmigten Kapitals, das bei der Gründung oder nachher von den Gesellschaftern übernommen worden ist ${ }^{537}$.

Das Eingezahlte Kapital schließlich ergibt sich aus der Summe der auf das Gezeichnete Kapital tatsächlich erbrachten Einlagen ${ }^{538}$.

Mindestens $20 \%$ des genehmigten Gesellschaftskapitals muss ausgegeben und gezeichnet sein. Abweichend hiervon kann im Gesellschaftsvertrag geregelt werden, dass nur $25 \%$ des Nennbetrags des ausgegebenen und gezeichneten Gesellschaftskapitals eingezahlt sein muss. Stets muss das ausgegebene, gezeichnete und eingezahlte Gesellschaftskapital einer B.V. allerdings als Mindestkapital bei der Gründung $18.000 €$ betragen (Art. 2:178 NBG) ${ }^{539}$.

\section{dd) Anzahl, Nennbetrag und Gattung der Anteile}

Anders als im deutschen Recht gibt es bei der B.V. auch keinen Mindestnennbetrag für die Anteile. Die Nennbeträge der Anteile können von den Gründern daher in der Satzung frei bestimmt werden. Vor diesem Hintergrund können auch verschiedene Gattungen von Antei-

535 Asser-Maeijer 2-III, S. 369 ff.; van Schilfgarde/Winter, S. 187 ff.; van der Heijden/van der Grinten 1992; Süß/Wachter/Rademakers/de Vries S. 1113 f.; Hirte/Bücker/Rammeloo/de Kluiver S. 208; Mellert/Verfürth S. 148; Gotzen, in: Behrens, Die GmbH Rn. NL 11; Mehring, GmbH-Rechte S. 205, 212 f.

536 Asser-Maeijer 2-III, S. 369 ff.; van Schilfgarde/Winter, S. 187 ff.; van der Heijden/van der Grinten 1992, Nr. 225; Süß/Wachter/Rademakers/de Vries S. 1113 f.; Hirte/Bücker/Rammeloo/de Kluiver S. 208; Mellert/Verfürth S. 148; Gotzen, in: Behrens, Die GmbH Rn. NL 11; Mehring, GmbH-Rechte S. 205, 212 f.

537 Süß/Wachter/Rademakers/de Vries S. 1113 f.; Hirte/Bücker/Rammeloo/de Kluiver S. 208; Mellert/Verfürth S. 148; Gotzen, in: Behrens, Die GmbH Rn. NL 11; Mehring, GmbH-Rechte S. 205, 212 f.

538 Süß/Wachter/Rademakers/de Vries S. 1113 f.; Hirte/Bücker/Rammeloo/de Kluiver S. 208; Mellert/Verfürth S. 148; Gotzen, in: Behrens, Die GmbH Rn. NL 11; Mehring, GmbH-Rechte S. 205, 212 f.

539 Süß/Wachter/Rademakers/de Vries S. 1113 f.; Hirte/Bücker/Rammeloo/de Kluiver S. 208; Mellert/Verfürth S. 148 . 
len herausgegeben werden (Artt. 2:92 I und 2:201 I NBG). Darüber hinaus gibt es aber auch die Möglichkeit Vorzugsaktien (,preferente aandelen“), die mit einem Gewinnvorzug ausgestattet sind sowie Prioritätsanteile, die bestimmte, in der Satzung festgelegte Sonderrechte vermitteln, in der Satzung vorzusehen ${ }^{540}$. Die Anteile sind Namensanteile. Anteilsscheine dürfen aber nicht ausgegeben werden ${ }^{541}$.

\section{ee) Dauer der Gesellschaft}

Nach der zwingenden Regelung des Art. 2: 17 NBG wird eine juristische Person, also auch eine Gesellschaft mit beschränkter Haftung, für unbestimmte Zeit gegründet ${ }^{542}$.

\section{b) Fakultativer Inhalt der Satzung (,,Statuten“)}

In der Praxis sind in der Satzung regelmäßig viele weitere Angaben enthalten, etwa über die Gesellschafter- und Geschäftsführerversammlungen, die Gewinnverteilung und das Verhältnis zwischen Satzung und Gesellschafterbeschlüssen. Außerdem werden, sollte die Gesellschaft einen Aufsichtsrat haben, auch Regelungen für den Aufsichtsrat in dem Gesellschaftsvertrag enthalten sein. ${ }^{53}$

\section{Zu den Reformbestrebungen}

\section{a) Kapital}

Der Entwurf verzichtet künftig auf die Nennung des Genehmigten Kapital im Gesellschaftsvertrag. Nicht mehr erforderlich ist außerdem die Ausgabe und Zeichnung von mindestens $20 \%$ des genehmigten Gesellschaftskapitals ${ }^{544}$

\footnotetext{
540 Asser-Maeijer 2-III, S. 356 ff.; van Schilfgarde/Winter, S. 175 ff.; van der Heijden/van der Grinten 1992; Hirte/Bücker/Rammeloo/de Kluiver S. 208.

541 Mehring, GmbH-Rechte S. 205, 215.

542 Asser-Maeijer 2-III, S. 366 ff.; Süß/Wachter/Rademakers/de Vries S. 1114.

543 Süß/Wachter/Rademakers/de Vries S. 1114; Mellert/Verfürth S. 148.

544 Begründung Gesetzentwurf S. $50 \mathrm{f}$.
} 


\section{b) Mustergesellschaftsvertrag}

Nicht weiterverfolgt wurden Überlegungen, im BV-Recht eine gesetzliche Grundlage für die Verwendung einer Mustersatzung nach englischem Vorbild zu schaffen ${ }^{545}$. Zur Begründung heißt es, bereits heute würden in der Praxis „Mustertexte“ verwendet - darunter auch solche der Niederländischen Notarkammer - die die statutarische Gestaltungsfreiheit weitaus besser gewährleisteten als jede gesetzlich vorgefasste Mustersatzung ${ }^{546}$.

Statt der Bereitstellung einer Mustersatzung werden die Möglichkeiten bei der Gestaltung der Satzung erhöht. Im Einzelnen soll die B.V.-Reform den Gesellschaftern eine weitgehende Satzungsautonomie gewährleisten und ihnen die rechtlichen Möglichkeiten bieten, die Gesellschaftsverhältnisse den jeweiligen Bedürfnisse und Interessenlagen der Gesellschafter anzupassen. Die B.V. wird damit - vergleichbar dem gesetzlichen Leitbild in Deutschland und Frankreich - den Personengesellschaften angenähert, jedoch bei Berücksichtigung der aus der Haftungsbeschränkung resultierenden Besonderheiten ${ }^{547}$.

\section{Organisationsverfassung}

\section{Bestehende Rechtslage}

\section{a) Organbegriff}

Art. 2:189a NBG konkretisiert den im Niederländischen Gesetzbuch verwendeten Begriff des „Organs“ für eine bestimmte Anzahl von Regelungen, namentlich Artt. 2:195, 206, 210 Nr. 6 und 239 NBG. Bei den vorgenannten Regelungen handelt es sich um Ermächtigungen einzelner Organe, die grundsätzlichen gesellschaftsrechtlichen Prinzipien der B.V. nachhaltig zu verändern, wie etwa entgegen der im B.V.-Recht verankerten Fungibilität von Geschäftsanteilen eine Vinkulierung von Geschäftsanteilen vorzusehen (Art. 2:195 NBG), die Ausgabe neuer Geschäftsanteile zu reglementieren und die Befugnis zur Ausgabe neuer Geschäftsanteile

545 So schon die Gesetzesbegründung Vorentwurf, Erste Tranche, S. 6 f.; vgl. insoweit auch die Begründung zum Gesetzentwurf S. 8.

546 Vgl. hierzu auch den Überblick bei Zaman Tijdschrift voor Ondernemingsbestuur 2004, 115

547 Gesetzesbegründung Vorentwurf, Erste Tranche, S. 6 f.; Begründung Gesetzentwurf S. 8; vgl. auch Groenewald im Hinblick auf die Flexibilisierung des Unternehmensgegenstandes in Ondernemingsrecht 2004, 25 ff. sowie Meinema Ondernemingsrecht 2004, 36 ff. der in rechtsvergleichender Betrachtung feststellt, dass eine Privatautonomie der Gesellschafter im Niederländischen Recht de lege lata wegen Art. 2: 25 NBG nicht existiert. Siehe schließlich auch Albicher/Mierlo van Tijdschrift vor Ondernemingsbesturr 2005, 122 mit zahlreichen Nachweisen zu den Stellungnahmen zur Ersten Tranche. 
anderweitig zuzuweisen (Art. 2: 206 NBG), eine Entscheidung über die Thesaurierung von Gewinnen oder den Vortrag von Verlusten zu treffen (Art. 2:210 Nr. 6 NBG) oder der Gesellschafterversammlung Weisungen an die Geschäftsführung zu gestatten (Art. 2:239 NBG) ${ }^{548}$.

Ohne die Konkretisierung in Art. 2: 189a NBG wäre es unter Umständen auch außen stehenden Dritten, das heißt, solchen die keine oder nur eine geringe Verbindung zur Gesellschaft haben und insbesondere kein finanzielles Risiko tragen, möglich die vorgenannten Rechte auszuüben ${ }^{549}$.

\section{b) Geschäftsführung (,,bestuur') und Vertretung}

Anders als in Deutschland darf die Gesellschafterversammlung (,AVA“) im Konkreten nicht in die Geschäftsführung der Geschäftsleitung eingreifen. ${ }^{50}$.

Geschäftführer kann auch eine andere juristische Person $\operatorname{sein}^{551}$.

\section{aa) Bestellung und Abberufung}

Die ersten Geschäftsführer werden in der Gründungsurkunde bestellt. Danach erfolgt die Bestellung der Geschäftsführer durch die Gesellschafterversammlung (Art. 2:242 NBG), oder aber, bei Bestehen eines Aufsichtsrats, durch diesen (Art. 2:272 NBG). Die Satzung kann bestimmen, dass der Geschäftsführer einem bestimmten Personenkreis angehören soll oder aber dass die Bestellung durch die Gesellschafterversammlung nur aufgrund eines Vorschlags erfolgen kann ${ }^{552}$. Eine Ausnahme von in der Satzung festgelegten Anforderungen an die Person des Geschäftsführers ist sodann nur noch mit zwei Drittel der Stimmen möglich, vorausgesetzt diese bilden mehr als die Hälfte des genehmigten Kapitals ${ }^{553}$. Für den Fall, dass der

548 Süß/Wachter/Rademakers/de Vries S. 1127 ff.; vgl. auch die Ausführungen in der Gesetzesbegründung Vorentwurf, Erste Tranche, S. 1 ff.

$549 \mathrm{Süß/Wachter/Rademakers/de} \mathrm{Vries} \mathrm{S.} \mathrm{1127,} 1129$ f.; vgl. auch die Ausführungen in der Gesetzesbegründung Vorentwurf, Erste Tranche, S. 1 ff.

550 Hirte/Bücker/Rammeloo/de Kluiver S. 186 f.; vgl. auch Hansmann \& Kraakman 2004 II S. 33 ff.; AsserMaeijer 2-III, S. 399 ff.; Schilfgarde/Winter, S. 128 ff.

551 Kuiper/Ruypers/Slangen/Kuiper/Vossestein, S. 168; Mehring GmbHR 1991, 297, 300.

552 Vgl. van Schilfgarde/Winter, Nr. 45, S. 129. Zum Verhältnis von Geschäftsführer und Gesellschaft siehe Asser-Maeijer 2-III 2000, Nr. 307 ff.; van der Heijden/van der Grinten 1992, Nr. 244-245, de Groot 2003, S. 5 f.; Siehe hierzu auch jüngst Boschma/Schutte-Veenstra 2007 S. 197, 199f.

553 Vgl. van Schilfgarde/Winter, Nr. 45, S. 129; Asser-Maeijer 2-III 2000, Nr. 307 ff.; van der Heijden/van der Grinten 1992, Nr. 244-245; siehe auch Süß/Wachter/Rademakers/de Vries S. 1137. 
Geschäftsführer abwesend beziehungsweise verhindert ist, hat die Satzung ebenfalls zwingend eine Regelung zu treffen ${ }^{554}$.

Gemäß $§ 14$ b Hrb sind die persönlichen Daten jedes Geschäftsführers in das Handelsregister einzutragen. Des Weiteren müssen Datum der Bestellung und der jeweilige Umfang der Vertretungsmacht zur Eintragung ins Handelsregister angemeldet werden ${ }^{55}$.

Die Abberufung der Geschäftsführer erfolgt gemäß Art. 2:244 NBG durch denjenigen, der auch zur Bestellung berechtigt war, d.h. grundsätzlich durch die Gesellschafterversammlung und nach Maßgabe des Art. 2:272 NBG durch den Aufsichtsrat. Eine Abberufung ist jederzeit möglich. Falls die Satzung eine größere Mehrheit bei der Beschlussfassung über die Abberufung vorschreibt, darf diese Mehrheit zwei Drittel der abgegebenen Stimmen, bei Anwesenheit von mehr als der Hälfte des genehmigten Kapitals nicht übersteigen ${ }^{556}$.

\section{bb) Vertretung der Gesellschaft, Aufgaben und Befugnisse}

Gemäß Art. 2:239 NBG sind die Geschäftsführer beauftragt, die Gesellschaft zu führen ${ }^{557}$. Der Umfang ihrer Geschäftsführungsbefugnis wird hierbei - wie zum Teil bereits eingangs erläutert - durch Gesetz, den Gesellschaftszweck und den Gesellschaftsvertrag der B.V. festgelegt. Außerdem kann der Gesellschaftsvertrag vorsehen, dass von der Geschäftsleitung allgemeine Weisung eines anderen Gesellschaftsorgans hinsichtlich der in der Satzung genannten Teilgebiete der Geschäftsführung zu befolgen sind oder aber für bestimmte Handlungen die vorherige Zustimmung der Gesellschafterversammlung einzuholen ist ${ }^{558}$. Im Übrigen handelt die Geschäftsführung in den zuvor beschriebenen Grenzen vollkommen autonom, d.h. eine Einflussnahme der Gesellschafterversammlung oder sonstiger Organe durch konkrete Weisungen ist - anders als im deutschen Recht - nicht gestattet $^{559}$.

554 Mehring, GmbH-Rechte S. 205, 220.

555 Vgl. van Schilfgarde/Winter, Nr. 45, S. 129; Asser-Maeijer 2-III 2000, Nr. 307 ff.; van der Heijden/van der Grinten 1992, Nr. 244-245; Süß/Wachter/Rademakers/de Vries S. 1137 f.

556 Süß/Wachter/Rademakers/de Vries S. 1138.; Allgemein zur Rechtsstellung der Geschäftsführer einer BV Huizink 1989.

557 Hansmann \& Kraakman 2004 II S. 33 ff.; Asser-Maeijer 2-III, S. 399 ff.; Schilfgarde/Winter, S. 128 ff. Hierzu gehört auch insbesondere die ständige Beobachtung der finanziellen Situation der Gesellschaft und Ergreifung entsprechender Maßnahmen in der Krise, siehe dazu Olaerts S. 99 ff.

558 Pitlo/Taaijmakers 2006, S. 205 ff.; Hirte/Bücker/Rammeloo/de $\quad$ Kluiver $\quad$ S. $186 \quad$ f.; Süß/Wachter/Rademakers/de Vries S. 1138.

559 Vgl. Hansmann \& Kraakman 2004 I S. 11 ff. sowie Hansmann \& Kraakman 2004 II S. 46. Siehe auch zu Besonderheiten bei Gesellschafter-Geschäftsführern Pitlo/Taaijmakers 2006, S. 205 ff.; Hirte/Bücker/Rammeloo/de Kluiver S. 186 f.; Süß/Wachter/Rademakers/de Vries S. 1138. 
Die Geschäftsleitung verfügt im Außenverhältnis regelmäßig über die Vertretungsmacht, die ihrer Geschäftsführungsbefugnis im Innenverhältnis entspricht. Auf eine ins Außenverhältnis wirkende Beschränkung oder Bedingung der internen Geschäftsführungsbefugnis kann sich allerdings nur die Gesellschaft berufen (Art. 240 Abs. 3 NBG). Die Geschäftsleitung steht grundsätzlich jeden einzelnen Mitglied der Geschäftsleitung zu, es sei denn die Satzung bestimmt etwas anderes, insbesondere gemeinschaftliche Vertretung oder gar den Ausschluss einzelner Geschäftsführer von der Vertretung der Gesellschaft. Daneben können die Gesellschafter in der Satzung ,,auch anderen Personen als den Mitgliedern der Geschäftsleitung Vertretungsmacht erteilen“ (Art. 2:240 Abs. 4 NBG) $)^{560}$.

\section{cc) Verantwortung und Haftungsregime}

Die Geschäftsführer sind in ihrer Gesamtheit als Organ der Gesellschafterversammlung und gegebenenfalls auch dem Aufsichtsrat und/oder Beirat gegenüber zur Rechenschaft verpflichtet und zeichnen sich für die Wahrnehmung der Geschäftsführung insgesamt verantwortlich ${ }^{561}$. Daneben hat sich jeder Geschäftsführer individuell gegenüber der Gesellschafterversammlung und gegebenenfalls auch dem Aufsichtsrat und/oder Beirat zu verantworten ${ }^{562}$.

Wie im deutschen Recht ist im Hinblick auf die Haftung zwischen der internen Haftung (,,interne aansprakelijkheid“") der Geschäftsführung der Gesellschaft gegenüber und der externen Haftung (,externe aansprakelijkheid“) der Geschäftsführung gegenüber Dritten zu differenzieren $^{563}$ :

Für die Haftung im Innenverhältnis bestimmt Art. 2:9 NBG, dass „Jedes Mitglied der Geschäftsleitung der juristischen Person zur ordnungsgemäßen Erfüllung der ihm übertragenen Aufgaben verpflichtet ist. "Weiter heißt es dort, dass eine Haftung jeden einzelnen Geschäftsführer individuell trifft, soweit die Angelegenheit seinen Aufgabenbereich berührt, ,es sei

560 Zum Ganzen Pitlo/Taaijmakers 2006, S. 205 ff.; siehe auch Van den Ingh 2002 I S. 13 ff.; aus der deutschen Literatur vgl. nur Hirte/Bücker/Rammeloo/de Kluiver S. 187; Süß/Wachter/Rademakers/de Vries S. 1138 jew. m. N.

561 Allgemein und umfassend zur Geschäftsführerhaftung de Groot 2003; zur Entwicklung der Rechtsprechung im Bereich der Geschäftsführerhaftung van Maanen 2004, S. 119 f; siehe auch Hirte/Bücker/Rammeloo/de Kluiver S. 187; Süß/Wachter/Rademakers/de Vries S. 1139; zur Haftung des Geschäftsleistung bei Schlechtleistung vgl. Van den Ingh 2002 II S. 99 ff.; siehe auch den Aufsatz von Lennarts Ondernemingsrecht 2004, 16 ff. Dazu allgemein Olaerts S. 137 ff. Zum Ganzen Borrius 2004, S. 7 ff.

562 Gotzen, in: Behrens, Die GmbH Rn. NL 22. Zur Reichweite des Haftungsrechts und dessen Auswirkungen auf die Geschäftsführungen Kroeze 2005.

563 Siehe dazu umfassend Olaerts S. 142 ff. (interne Haftung) und S. 159 ff. (externe Haftung) m. w. N. sowie Gotzen, in: Behrens, Die GmbH Rn. NL 21; Mehring, GmbH-Rechte S. 205, 220 f.; Hirte/Bücker/Rammeloo/de Kluiver S. 189f. 
denn, dass ihm kein Fehlverhalten vorgeworfen werden kann und es (nicht nachlässig versäumt wurde), Maßnahmen zu treffen, um die Folgen davon abzuwenden“. Vorwerfbar ist dem Geschäftsführer nur ein Verhalten, bei dem die Einsicht und Sorgfalt fehlte, die von jedem durchschnittlichen, seine Aufgaben gewachsenen Geschäftsführer erwartet werden kann. Eine persönliche Haftung kommt allerdings auch in diesen Fällen nur dann in Betracht, wenn dem Geschäftsführer eine schwerwiegende Pflichtverletzung zum Vorwurf gemacht werden $\mathrm{kann}^{564}$.

Gegenüber Dritten haftet die Geschäftsleitung beziehungsweise der Geschäftsführer zum einen für die Erbringung von Steuern und Sozialversicherungsbeiträgen.

Im Gesetz ist außerdem eine Haftung des Geschäftsführers im Insolvenzfall vorgesehen, wenn die „Geschäftsleitung ihre Pflichten offenbar schlecht erfüllt hat und anzunehmen ist, dass dies ein wichtiger Grund für die Insolvenz(gewesen) ist.“ (Art. 2:248 NBG) ${ }^{565}$. Die Ursächlichkeit des Fehlverhaltens des Geschäftsführers für die Insolvenz der Gesellschaft wird (widerlegbar) vermutet, wenn dieser seine Buchführungspflicht nach Maßgabe des Art. 2:10 NBG nicht ordnungsgemäß erfüllt oder seine gemäß Art. 2:394 NBG existierenden Veröffentlichungspflichten verletzt ${ }^{566}$.

Einen weiteren Haftungsgrund bildet Art. 2:249 NBG: Danach haften die Mitglieder der Geschäftsführung gemeinsam und solidarisch für den Schaden, der Dritten entsteht, weil diese auf die (unrichtige) finanzielle Darstellung der Gesellschaft in den veröffentlichten Jahresabschlüssen, Lageberichten und Zwischenabschlüssen vertrauen.

Schließlich können Geschäftsführer selbstverständlich persönlich aufgrund unerlaubter Handlung (Art. 6:162 NBG oder wegen strafbaren Handelns haften. Voraussetzung hierfür ist al-

564 Assink/Olden S. 13; Hirte/Bücker/Rammeloo/de Kluiver S. 190; Süß/Wachter/Rademakers/de Vries S. 1139; Lennarts Ondernemingsrecht 2004, 16, 18; van Schilfgarde/Winter, S. 139. Vgl. auch Jansen GmbHR 1995, 286 ff., der im einzelnen die Haftung der Geschäftsführer der Gesellschaft (und nur dieser) gegenüber für die ordnungsgemäße Geschäftsführung (Haftungsbefreiung durch Entlastung) sowie - bei Schädigungsabsicht - auch aus deliktsrechtlichen Gesichtspunkten erläutert. Eine Haftung der Geschäftsführer Gesellschaftsgläubigern gegenüber sieht Jansen insbesondere für - eigene - unerlaubte Handlungen, für die Zahlungsfähigkeit der Gesellschaft (einschließlich Ausfallhaftung im Konkurs) sowie für Fehlinformationen über die Vermögensverhältnisse der Gesellschaft.

565 Vgl. Olaerts S. 159 ff.; Zur Abgrenzung der Insolvenzhaftung von der internen Haftung vgl. u.a. AsserMaeijer 2-III 2000 Nr. 335 m. w. N. van Schilfgaarde/Winter Nr. 48 einerseits und van der Heijden/van der Grinten 1992, nr. 399.1 und Kortmann/Faber 1996, S. 901ff. andererseits. Siehe auch Hirte/Bücker/Rammeloo/de Kluiver S. 190; Süß/Wachter/Rademakers/de Vries S. 1140.

566 Boschma/Lennarts 1994 S. 285 ff.; Lennarts Ondernemingsrecht 2004, 16, 17; Asser-Maeijer 2-III, S. 432 ff. und van Schilfgarde/Winter, S. 142 ff. 
lerdings, dass dem jeweiligen Geschäftsführer ein persönliches schuldhaftes Verhalten nachzuweisen ist ${ }^{567}$

\section{c) Gesellschafter und Geschäftsanteile}

\section{aa) Rechtsstellung der Gesellschafter}

Die Rechte des individuellen Anteilseigners sind grundsätzlich darauf beschränkt persönlich oder durch einen schriftlich Bevollmächtigten an den Gesellschafterversammlungen der Gesellschaft teilzunehmen, das Wort zu ergreifen und das Stimmrecht auszuüben ${ }^{568}$. Dafür sind seine individuellen Pflichten gleichsam begrenzt und erschöpfen sich grundsätzlich in der Pflicht zur Einzahlung der Einlage auf das von ihnen übernommene Genehmigte Kapital ${ }^{569}$.

\section{bb) Sonderrechte für einzelne Gesellschafter}

Im Grundsatz haben alle Geschäftsanteile den gleichen Umfang an Rechten in ihrem Verhältnis zum Grundkapital der Gesellschaft. Allerdings ermöglicht das niederländische Recht durch Satzungsbestimmung von dieser Regel abzuweichen und verschiedene Anteilsgattungen mit einem unterschiedlichen Umfang an Rechten schaffen (Art. 2:201 Abs. 1 NBG) ${ }^{570}$. Vier Gattungen von Sondergeschäftsanteilen sind zu unterscheiden:

567 Hirte/Bücker/Rammeloo/de Kluiver S. 191; Süß/Wachter/Rademakers/de Vries S. 1141; Lennarts Ondernemingsrecht 2004, 16, 18 sowie Schilfgarde/Winter, S. 146 ff. mit weiteren Angaben zur einschlägigen Judikatur.

Einen Überblick über die individuellen Rechte des Anteilsiegners einer niederländischen BV gibt Slagter 2005 Nr. 67. Siehe dazu auch Olaerts S. 22; Asser-Maeijer 2-III 2000 Nr. 177.

569 Slagter 2005 Nr. 67; Olaerts S. 18; Mehring, GmbH-Rechte S. 205, 216; Hirte/Bücker/Rammeloo/de Kluiver S. 192; Süß/Wachter/Rademakers/de Vries S. 1127 f.; Gotzen, in: Behrens, Die GmbH Rn. NL 36. Zur Rechtsbeziehung der Gesellschafter zur Gesellschaft und deren Vermögen vgl. nur van der Heijden/van der Grinten 1992 Nr. 131; Asser-Maeijer 2-III 2000 Nr. 51; Slagter 2004 S. 424 ff. und Rensen 2005 S. 288 ff.

570 Sie zu den einzelnen Gesellschaftertypen insbesondere auch Olaerts S. 279 ff. m. v. w. N. sowie jüngst Boschma/Schutte-Veenstra 2007 S. 197, 201. Vgl. aus der deutschen Literatur auch Hirte/Bücker/Rammeloo/de Kluiver S. 192; Mellert/Verfürth S. 147; kritisch im Hinblick auf die Erteilung von Sonderrechten äußert sich C.A. Schwarz Aandelen, S. 4 ff., der als Alternative die Schaffung des Rechtsinstituts stimmrechtsloser Anteile vorschlägt; vgl. dazu auch unten in diesem Abschnitt unter 2. a) cc) hhh). 


\section{aaa) Prioritätsgeschäftsanteile}

Geschäftsanteile, die mit besonderen Rechten ausgestattet sind, werden als Prioritätsgeschäftsanteile (,prioriteitsaandelen“) bezeichnet. Besondere Rechte im vorgenannten Sinne können etwa Vorschlagsrechte für Mitglieder der Geschäftsführung oder des Aufsichtsrats sowie Genehmigungsvorbehalte zugunsten der Prioritätsgeschäftsanteilsinhaber sein ${ }^{571}$.

\section{bbb) Vorzugsgeschäftsanteile}

Vorzugsgeschäftsanteile (,preferente aandelen“) sind solche Sondergeschäftsanteile, die das Recht auf eine Vorzugsdividende bis zu einem Prozentsatz ihres Nennbetrages einräumen oder die fest verzinslich sind ${ }^{572}$.

\section{ccc) Klassengeschäftsanteile}

Mit Hilfe von Klassengeschäftsanteilen (,,letter-aandelen“) werden bestimmte (Gesellschafter) Klassen, die unterschiedliche Rechte, etwa beim Dividendenrecht, genießen, durch Buchstabenkennzeichnung voneinander abgegrenzt. Die Identifizierbarkeit unterschiedlicher Gesellschaftergruppen ist insbesondere in Gemeinschaftsunternehmen von praktischer Bedeutung, da in solchen Unternehmen regelmäßig auch getrennte Gesellschafterversammlungen abgehalten werden, in denen beispielsweise über die Übertragung von Klassengeschäftsanteilen abgestimmt wird und die eigene Dividendenrechte haben ${ }^{573}$.

\section{ddd) Bonusgeschäftsanteile}

Schließlich kann die Satzung auch die Begebung so genannter Bonusgeschäftsanteile („,bonusaandelen") vorsehen. Dies sind Geschäftsanteile, die von der Gesellschaft an die Gesellschafter ausgegeben werden, wenn Gewinne thesauriert anstatt ausgeschüttet werden ${ }^{574}$.

571 Olaerts S. 283 f.; Brenninkmeijer 1973 S. 126; Hendriks-Jansen 1982, S. 8; Asser-Maeijer 2-III 2000 Nr. 287; Süß/Wachter/Rademakers/de Vries S. 1114; Hirte/Bücker/Rammeloo/de Kluiver S. 192 f.

572 Olaerts S. 283 f.; Brenninkmeijer 1973 S. 126; Hendriks-Jansen 1982, S. 8; Asser-Maeijer 2-III 2000 Nr. 287; Süß/Wachter/Rademakers/de Vries S. 1114; Hirte/Bücker/Rammeloo/de Kluiver S. $192 \mathrm{f}$.

573 Olaerts S. 279 ff.; Boschma/Schutte-Veenstra 2007 S. 197, 201; Süß/Wachter/Rademakers/de Vries S. 1114; Hirte/Bücker/Rammeloo/de Kluiver S. $192 \mathrm{f}$.

574 Olaerts S. 279 ff.; Boschma/Schutte-Veenstra 2007 S. 197, 201; Süß/Wachter/Rademakers/de Vries S. 1115. 


\section{cc) Inhaber von Geschäftanteilszertifikaten (,Certificering“)}

Eine weitere Besonderheit des niederländischen Rechts ist die Möglichkeit der Trennung von Stimmrecht einerseits und Vermögensrecht (Gewinnanspruch, Anspruch auf Liquidationserlös usw.) andererseits durch Begebung so genannter Geschäftsanteilszertifikate (,certificaten“). Hierbei werden die Geschäftsanteile zunächst einer selbständigen juristischen Person häufig einer Stiftung ${ }^{575}$ - übertragen (,,administratiekantoor $\left.{ }^{6}\right)$. Diese beteiligt sodann Anleger an diesem Geschäftsanteil durch Begebung vorgenannter Geschäftsanteilszertifikate. Die Zertifikatsinhaber sind hierdurch nur mittelbar an der Gesellschaft beteiligt; ihre Rechte, insbesondere die Stimmrechte aus dem Geschäftsanteil, werden durch den administratiekantoor als rechtlichen Eigentümer des Geschäftsanteils quasi treuhänderisch ausgeübt ${ }^{576}$. Die mittelbaren Dividendenrechte der Zertifikatsinhaber an der Gesellschaft werden durch den administratiekantoor beglichen. Trotz nur mittelbaren Beteiligung können auch die Inhaber von Zertifikaten unter den in Art. 2:110 bestimmten Voraussetzungen zur Teilnahme an den Gesellschafterversammlungen berechtigt $\operatorname{sein}^{577}$.

\section{dd) Registrierung der Gesellschafter}

Die Gesellschafter einer B.V. werden in einem so genannten Gesellschafterbuch (,,aandeelhoudersregister") der Gesellschaft registriert, das von der Gesellschaft ständig zu aktualisieren ist. Wie in Deutschland, so kennt auch das niederländische GmbH-Recht - anders als im Aktienrecht - keine verbrieften Geschäftsanteilsscheine (ex. Art. 2:175 Abs. 1 NBG). Einziger Ausweis (nicht Nachweis) der Gesellschafterstellung ist somit der Eintrag des jeweiligen Gesellschafters unter Angabe des Geschäftanteilsbesitzes in das Gesellschafterbuch. Die Gesellschaft ist verpflichtet, einem Gesellschafter kostenlos einen Auszug aus dem Gesellschafterbuch zur Verfügung zu stellen. Dieser Auszug ist wie bereits erwähnt aber kein belastbarer Beweis für die im Gesellschafterbuch verbrieften Rechte. Nach Art. 152 Abs. 2 Bürgerliches Gesetzbuch zur Zivilprozessordnung haben der Auszug wie auch das Gesellschafterbuch nur freie Beweiskraft ${ }^{578}$.

575 Vgl. zu den neuesten Entwicklungen auf dem Gebiet der Certificering von Geschäftsanteilen nur Ondernemingsrecht 2004, nr. 12, Sonderheft; vgl. auch Olaerts S. 286 ff. m. w. N. sowie allgemein Van den Ingh 1991.

576 Asser-Maeijer 2-III, S. 570 ff. und van Schilfgarde/Winter, S. 182 ff. Zur Geeignetheit solcher Geschäftsanteilszertifikate zur Verhinderung feindlicher Übernahmen Schwarz, C.A. 2004 S. $220 \mathrm{ff}$.

577 Siehe dazu insgesamt Van den Ingh 1991; vgl. aus der deutschen Literatur Hirte/Bücker/Rammeloo/de Kluiver S. 193.

578 Süß/Wachter/Rademakers/de Vries S. 1128. 


\section{ee) Geschäftsanteile der B.V.}

\section{aaa) Zulässigkeit der Übertragung}

Die Übertragung von Geschäftsanteilen ist gemäß Art. 2:195 Abs. 1 NBG nur unter bestimmten Voraussetzungen gestattet. Danach ist ein Gesellschafter insbesondere nur dann in seiner Verfügung frei, wenn er beabsichtigt, seine Geschäftsanteile auf bestimmte, im Gesetz genannte Personen zu übertragen, nämlich an den Ehepartner des übertragungswilligen Gesellschafters, an seinen eingetragenen Partner, an seine leiblichen und seine angeheirateten Verwandten in gerader Linie und beschränkt an solche in der Seitenlinie, an einen anderen Gesellschafter und an die Gesellschaft. Im Gesellschaftsvertrag kann außerdem bestimmt werden, dass eine freie Übertragung auch auf leibliche und angeheiratete Verwandte in der Seitenlinie oder auf Verwandte dritten oder vierten Grades möglich sein soll. Für jede andere Übertragung hat der Gesellschaftsvertrag zwingend Beschränkungen vorzusehen (so genannte „,blokkeringsregeling“6) ${ }^{579}$.

\section{bbb) Beschränkungen}

Nach Art. 2:195 NBG sind alternativ oder kumulativ die folgenden Beschränkungen für die Übertragung von Geschäftsanteilen an Nichtverwandte oder Nichtgesellschafter im Gesellschaftsvertrag vorzusehen ${ }^{580}$ :

Zum einen mag der Gesellschaftsvertrag einen Zustimmungsvorbehalt zugunsten eines Gesellschaftsorgans vorsehen (,goedkeuringsregeling“, Art. 2:195 Abs. 4 NBG). In einem solchen Fall hat die Übertragung innerhalb von drei Monaten nach Erhalt der Zustimmung zu erfolgen. Die Zustimmung gilt als erteilt, wenn das Organ, das die Übertragung billigen soll, nicht gleichzeitig mit der Verweigerung der Zustimmung den übertragungswilligen Gesellschaftern einen oder mehrere Interessenten nennt, die bereit sind, die betroffenen Geschäftsanteile gegen Barzahlung zu kaufen ${ }^{581}$.

Zum anderen mag die Beschränkung darin bestehen, dass der übertragungswillige Gesellschafter verpflichtet wird, seine Geschäftsanteile zunächst einem Mitgesellschafter anzubieten (so genannte Andienungspflicht der Geschäftsanteile; ,aanbiedingsregeling“). Für den Fall, dass die übrigen Gesellschafter das Angebot nicht annehmen, kann der Gesellschaftsvertrag

\footnotetext{
579 Boschma/Schutte-Veenstra 2007 S. 197, 198; Süß/Wachter/Rademakers/de Vries S. 1128.

580 Süß/Wachter/Rademakers/de Vries S. 1128.

581 Boschma/Schutte-Veenstra 2007 S. 197, 198 f.; Süß/Wachter/Rademakers/de Vries S. 1128.
} 
außerdem bestimmen, dass die Geschäftsanteile noch einem anderen, von einem laut Gesellschaftsvertrag dazu befugten Organ angewiesenen Interessenten angedient werden müssen. Der übertragungswillige Gesellschafter hat in diesem Fall allerdings das Recht, sein Angebot innerhalb eines Monats, nachdem ihm bekannt wurde, an wen und für welchen Preis er die Geschäftsanteile übertragen kann, zu widerrufen. Stellt sich heraus, dass nicht alle Geschäftsanteile gegen Barzahlung gekauft worden sind, hat der Gesellschafter innerhalb von drei Monaten die Gelegenheit, die Geschäftsanteile an jeden Dritten zu verkaufen und zu übertragen. ${ }^{582}$

Einen zusätzlichen Schutz erfährt der übertragungswillige Gesellschafter durch Art. 2:195 Abs. 6 NBG. Danach ist der Gesellschafter, der seine Geschäftsanteile zu übertragen beabsichtigt, stets berechtigt, deren Wert durch einen Sachverständigen feststellen lassen.

Der Erwerb von Geschäftsanteilen durch die Gesellschaft selbst ist in Abs. 7 geregelt. Danach darf die Gesellschaft sich nur mit Zustimmung der Gesellschafter als Interessent melden.

Keinesfalls dürfen die statutarisch eingerichteten Übertragungsbeschränkungen zur Unmöglichkeit der Übertragbarkeit der Geschäftsanteile führen, sei es dass eine Übertragung in dem Gesellschaftsvertrag ausdrücklich ausgeschlossen wird oder aber faktisch unmöglich gemacht wird, indem die Übertragung nur zu nicht hinnehmbaren Bedingungen - welcher Art auch immer - ermöglicht wird.

Unklar sind die Rechtsfolgen einer entgegen der vorgeschriebenen Beschränkungen vorgenommenen Übertragung. Zum Teil wird vertreten, die Übertragung von Geschäftsanteilen bei Nichteinhaltung existierender Restriktionsregelungen sei insgesamt unwirksam, mit der Folge, dass der „neue“ Gesellschafter nie Eigentümer der Geschäftsanteile geworden ist und dementsprechend auch keine Gesellschafterrechte auszuüben berechtigt ist. Andere Autoren wollen danach differenzieren, ob der Erwerber der Geschäftsanteile in gutem Glauben gehandelt hat und ihm unter weiteren bestimmten Voraussetzungen die Möglichkeit geben, sich gegen die Unbefugtheit der früheren Gesellschafter zu wehren ${ }^{583}$.

\section{ccc) Andienungspflicht}

Nach Art. 2:195a NBG kann der Gesellschaftsvertrag einer B.V. außerdem bestimmen, dass ein Gesellschafter bei Eintritt in seiner Person begründeter Umstände, wie beispielsweise

\footnotetext{
582 Boschma/Schutte-Veenstra 2007 S. 197, 198 f.; Süß/Wachter/Rademakers/de Vries S. 1128.

583 Vgl. hierzu nur Asser-Maeijer 2-III, Nr. 216.
} 
zeitweiliger oder dauerhafter Zahlungsunfähigkeit verpflichtet ist, seine Geschäftsanteile den anderen Gesellschaftern anzudienen. Auch kann für einen solchen Fall geregelt sein, dass der betroffene Gesellschafter für die Dauer der Andienungspflicht sein Stimmrecht oder sein Recht auf Teilnahme an der Gesellschafterversammlung verliert. Kommt der Gesellschafter seiner Andienungspflicht nicht nach, so kann der Gesellschaftsvertrag schließlich bestimmen, dass ihm die Geschäftsanteile zu entziehen sind beziehungsweise die Gesellschaft an seiner Statt unwiderruflich bevollmächtigt wird, die Geschäftsanteile anzubieten und zu übertragen. In allen vorgenannten Fällen bleibt es dem betroffenen Gesellschafter unbenommen, einen Sachverständigen herbeizurufen, um den Wert der Geschäftsanteile feststellen zu lassen ${ }^{584}$.

\section{ddd) Öffentlich-rechtliche Beschränkungen}

Öffentlich-rechtliche Beschränkungen für die Veräußerung von Gesellschaftsanteilen existieren nicht im Niederländischen Recht.

\section{eee) Form der Übertragung}

Die Übertragung von Geschäftsanteilen hat durch eine dazu befugte Person (ex Art. 3:84 NBG) in notarieller Form vor einem in den Niederlanden ansässigen Notar zu erfolgen (Art. 2:196 Abs. 1 NBG). In der Übertragungsurkunde müssen zwingend Angaben zu der Art des Rechtsgeschäfts - Anteilskauf oder Übertragung - den Vertragsparteien, Zahl und Art der Geschäftsanteile sowie der Gesellschaft an der die Beteiligung existiert, enthalten $\operatorname{sein}^{585}$.

\section{fff) Anerkennung der Übertragung}

Wie im deutschen Recht ist die Übertragung im Verhältnis der Vertragsparteien - vorausgesetzt, dass keine anders lautenden Bedingungen im Geschäftsanteilskauf- und/oder Übertragungsvertrag vereinbart sind - mit Vertragsschluss wirksam. Im Verhältnis zur Gesellschaft wird der Erwerber zwar ebenfalls unmittelbar mit der Übertragung Inhaber des Geschäftsan-

584 Süß/Wachter/Rademakers/de Vries S. $1128 \mathrm{ff}$.

585 Süß/Wachter/Rademakers/de Vries S. 1129 f.; Die Geschäftsanteile einer B.V. können auch Gegenstand einer anderen Verfügung, namentlich einer Verpfändung oder eines Nießbrauchs sein. Hierbei sind grundsätzlich dieselben Grundsätze, insbesondere im Hinblick auf die Art und Weise der Verpfändung bzw. der Einräumung des Nießbrauchs zu beachten wie bei der Übertragung. Vgl. mfassend hierzu Hamers, J.J.A., Verpanding van aandelen en de beslotenheid van kapitaalvennootschappen, 1996; in aller Kürze finden sich auch Ausführungen hierzu bei Hirte/Bücker/Rammeloo/de Kluiver S. 210. 
teils, doch rückt er erst mit der Anerkennung des Rechtsgeschäfts durch die Gesellschaft auch in die Rechtsposition eines Gesellschafters der Gesellschaft ein, Art. 2:196a NBG. Die Anerkennung kann auf zweierlei Weise erfolgen: Zum einen mag die Gesellschaft eine Abschrift oder einen Auszug der Übertragungsurkunde unterschreiben, zum anderen mag die Gesellschaft die Übertragung durch Eintragung der neuen und Löschung der alten Gesellschafter im Gesellschafterbuch anerkennen ${ }^{586}$.

\section{ff) Gesellschafterbeschlüsse}

\section{aaa) Gesellschafterversammlung}

Für alle Angelegenheiten innerhalb der Grenzen des Gesetzes und des Gesellschaftsvertrages, die nicht der Geschäftsführung oder anderen zugewiesen sind, ist die Gesellschafterversammlung zuständig (Art. 2:217 Abs. 1 NBG) ${ }^{587}$. Nach Art. 2:218 Abs. 2 NBG hat jährlich wenigstens eine Gesellschafterversammlung, und zwar innerhalb von sechs Monaten nach Abschluss des Geschäftsjahres, stattzufinden, es sei denn, der Gesellschaftsvertrag sieht eine kürzere Frist vor. Gleich dem deutschen Gesellschaftsrecht, wird während dieser Gesellschafterversammlung regelmäßig der Jahresabschluss der Gesellschaft besprochen und festgestellt ${ }^{588}$.

\section{bbb) Einberufung und Formalien}

\section{(i) Befugnis zur Einberufung der Gesellschafterversammlung}

In der Regel erfolgt die Einberufung der Gesellschafterversammlung durch die Geschäftsführung, in besonderen Fällen durch den Aufsichtsrat, falls ein solcher in der Gesellschaft existiert und gegebenenfalls durch weitere in der Satzung bestimmte andere Subjekte (Art. 2:218, 219, 224 NBG) $)^{589}$. Daneben sind die Gesellschafter oder Inhaber von Geschäftsanteilszertifi-

586 Süß/Wachter/Rademakers/de Vries S. 1130.

587 Insbesondere ist die Gesellschafterversammlung zuständig für die Feststellung des Jahresabschlusses und Dividendenausschüttungen; Satzungsänderungen sowie - soweit es sich nicht um eine Strukturgesellschaft handelt - für die Bestellung und Abberufung von Geschäftsführern. Vgl. nur van Efferink/Ebert/Levedag GmbHR 2004, 880, 887 sowie Kuiper/Ruypers/Slangen/Kuiper/Vossestein, S. 166.

588 Asser-Maeijer 2-III Kap. 5; van Schilfgarde/Winter, S. 62 ff.; Süß/Wachter/Rademakers/de Vries S. 1131; Mehring, GmbH-Rechte S. 205, 218; Gotzen, in: Behrens, Die GmbH Rn. NL 30; Hirte/Bücker/Rammeloo/de Kluiver S. 194.

589 Asser-Maeijer 2-III Kap. 5; van Schilfgarde/Winter, S. 62 ff.; Gotzen, in: Behrens, Die GmbH Rn. NL 30; Hirte/Bücker/Rammeloo/de Kluiver S. 194. 
katen, die unter Mitwirkung der Gesellschaft emittiert wurden und zusammen mehr als $10 \%$ des gezeichneten Kapitals vertreten, berechtigt, bei Gericht die Einberufung einer Gesellschafterversammlung zu beantragen (Art. 2:220 Abs. 1 NBG). Eine positive Bescheidung des Antrags setzt zweierlei voraus: Zum einen, die Feststellung des Gerichts, dass die Geschäftsführung (oder der Aufsichtsrat beziehungsweise das sonst vorgesehene Organ) der schriftlichen Bitte der Gesellschafter nach Einberufung einer Gesellschafterversammlung innerhalb von sechs Wochen nicht entsprochen hat. Zum anderen den Nachweis eines berechtigten Interesses der Gesellschafter an der Einberufung der Gesellschafterversammlung. Gibt das Gericht dem Antrag statt so bestimmt es zugleich Frist und Form des Einberufungsschreibens ${ }^{590}$.

Ein Gesellschafter ist nach Art. 2:222 NBG, auch ohne dass er einen bestimmten Anteil des Kapitals vertritt, zur Einberufung einer Gesellschafterversammlung berechtigt, wenn es das zur Einberufung der Gesellschafterversammlung gemäß Art. 2:219 NBG befugte Organ versäumt, zur jährlichen Gesellschafterversammlung zu laden. Auch in diesem Fall hat der Gesellschafter allerdings zunächst einen Antrag bei Gericht zu stellen, das darüber zu entscheiden hat, ob der Gesellschafter dazu befugt gewesen ist ${ }^{591}$.

\section{(ii) Einberufungsformalitäten}

Die Einberufung der Gesellschafterversammlung erfolgt entweder per Brief an die im Gesellschaftsbuch eingetragenen Gesellschafter oder, falls die Gesellschaft Inhaber von Geschäftsanteilszertifikaten hat, die unter Mitwirkung der Gesellschaft emittiert wurden, durch Anzeige in einer nationalen Tageszeitung, es sei denn, der Gesellschaftsvertrag schreibt eine andere Regelung für die Einberufung der Inhaber von Geschäftsanteilszertifikaten vor (Art. 2:223 NBG). Die Einladung zur Gesellschafterversammlung hat eine Liste der Themen zu enthalten, die in der Gesellschafterversammlung zur Diskussion gestellt werden sollen. Eine Beschlussfassung zu Themen, die nicht in der Einberufung erwähnt werden oder die nicht auf ähnliche Weise unter Einhaltung der für die Einberufung geltenden Frist angemeldet worden sind, ist ansonsten nur mit den Stimmen, die das gesamte gezeichnete Kapital vertreten gestattet ${ }^{592}$.

Ist die Einberufung durch Anzeige in einer nationalen Tageszeitung erfolgt, so hat der Inhalt der Einberufung die in Art. 2:224 NBG beschriebene Form zu erfüllen. Ist die Einberufung formwidrig erfolgt, so sind die auf der Gesellschafterversammlung gefassten Beschlüsse an-

590 Süß/Wachter/Rademakers/de Vries S. 1131; Hirte/Bücker/Rammeloo/de Kluiver S. 194; Mehring, GmbHRechte S. 205, 218.

591 Asser-Maeijer 2-III Kap. 5; van Schilfgarde/Winter, S. 62 ff.; Süß/Wachter/Rademakers/de Vries S. 1131.

592 Asser-Maeijer 2-III Kap. 5; van Schilfgarde/Winter, S. 62 ff.; Süß/Wachter/Rademakers/de Vries S. 1130 f. 
fechtbar (Art. 2:15 NBG). Alle Beschlüsse der Gesellschafterversammlung sind von der Geschäftsführung schriftlich niederzulegen ${ }^{593}$.

Die Einberufung der Gesellschafterversammlung ist mit einer Frist von mindestens 15 Tagen vor dem Tag, an dem sie stattfindet, zu bewirken. Falls die Gesellschafterversammlung verspätet oder überhaupt nicht einberufen wird, können auf der Gesellschafterversammlung grundsätzlich keine gültigen Beschlüsse gefasst werden, es sei denn, dass das ganze gezeichnete Kapital vertreten ist ${ }^{594}$.

\section{(iii) Ort der Gesellschafterversammlung}

Die Gesellschafterversammlung muss grundsätzlich in den Niederlanden stattfinden, entweder an dem Ort, an dem die B.V. ihren satzungsmäßigen Sitz hat oder an einem Ort, den der Gesellschaftsvertrag bestimmt. Bei allseitigem Einverständnis sind die Gesellschafter allerdings frei, Gesellschafterversammlung an jedem anderen Ort, auch im Ausland, abzuhalten oder aber (einstimmige) Beschlüsse außerhalb einer Gesellschafterversammlung zu fassen ${ }^{595}$.

\section{ccc) Stimmrecht und Vertretung ${ }^{596}$}

Jeder Gesellschafter ist stets berechtigt, persönlich oder durch einen schriftlich Bevollmächtigten an den Gesellschafterversammlungen teilzunehmen, zu sprechen und sein Stimmrecht auszuüben $^{597}$. Der Gesellschaftsvertrag kann das Recht des Gesellschafters, sich vertreten zu lassen beschränken, nicht aber gänzlich ausschließen. Im Hinblick auf die Vertretung des Gesellschafters durch einen Rechtsanwalt, Notar, Notaranwärter oder Wirtschaftsprüfer ist auch eine Beschränkung nicht gestattet (Art. 2:227 Abs. 1 NBG) ${ }^{598}$.

593 Asser-Maeijer 2-III Kap. 5; van Schilfgarde/Winter, S. 62 ff.; Süß/Wachter/Rademakers/de Vries S. 1131; Gotzen, in: Behrens, Die GmbH Rn. NL $30 \mathrm{f}$.

594 Süß/Wachter/Rademakers/de Vries S. 1132; Mehring, GmbH-Rechte S. 205, 219; Gotzen, in: Behrens, Die GmbH Rn. NL 30.

595 Asser-Maeijer 2-III Kap. 5; van Schilfgarde/Winter, S. 62 ff.; Süß/Wachter/Rademakers/de Vries S. 1132; Mehring, GmbH-Rechte S. 205, 219; Gotzen, in: Behrens, Die GmbH Rn. NL 30.

596 Vgl. zum Ganzen Olaerts S. 265 ff.; siehe auch Maeijer 1964; Van der Heijden/van der Grinten 1992 Nr. 172.1; Mendel 1997, S. 207-215; Asser-Maeijer 2-III 2000, Nr. 287; Dortmond 2000 II, S. 11; van Schilfgaarde/Winter, Nr. 67; Slagter 2005, S. 14.

597 In seiner Stimmrechtsausübung ist der Gesellschafter im Prinzip unbeschränkt; er kann auch zuungunsten der Gesellschaft entscheiden HRN NJ 1944/465 (Wennex); HRN NJ 1960/472 (Distilleerderij Melchers) sowie HRN NJ 1960/473 (Aurora).

598 Süß/Wachter/Rademakers/de Vries S. 1132 f.; Mehring, GmbH-Rechte S. 205, 219; Gotzen, in: Behrens, Die GmbH Rn. NL 31. 
Im Gesetz normierte Beispiele für mögliche Beschränkungen des Teilnahmerechts des Gesellschafters an einer Gesellschafterversammlung finden sich in Art. 2:195n und 195a NBG. Nach Maßgabe des Art. 2:195n NBG mag dem Gesellschafter das Recht auf Teilnahme an der Gesellschafterversammlung verweigert werden, wenn dieser bestimmte qualitative Eigenschaften nicht mehr hat. Art. 2:195a NBG beschreibt den Fall, dass der Gesellschafter aus irgendeinem Grunde verpflichtet ist, seine Geschäftsanteile den anderen Gesellschaftern anzudienen. In einem derartigen Fall kann der Gesellschaftsvertrag bestimmen, dass der Gesellschafter für die Dauer der Andienungspflicht nicht an der Gesellschafterversammlung teilnehmen oder sein Stimmrecht ausüben darf ${ }^{599}$.

Auch der Inhaber eines Geschäftsanteilszertifikats, das unter Mitwirkung der Gesellschaft emittiert wurde, hat das Recht persönlich oder durch einen schriftlich Bevollmächtigten an den Gesellschafterversammlungen teilzunehmen und zu sprechen; allein ein Stimmrechtrecht steht ihm nicht $\mathrm{zu}^{600}$.

Der Gesellschaftsvertrag kann das Teilnahmerecht der Gesellschafter davon abhängig machen, dass diese die Geschäftsführung der B.V. über ihre Anwesenheit bei der Gesellschafterversammlung informieren. Ist eine solche Informationspflicht im Gesellschaftsvertrag vorgesehen, so hat die Einladung zur Gesellschafterversammlung eine Frist zu bestimmen, in welcher der Gesellschafter die Geschäftsführung über seine Anwesenheit zu informieren hat. Diese Frist darf nicht kürzer sein als drei Tage vor dem Tag, an dem die Gesellschafterversammlung stattfinden soll ${ }^{601}$.

Geschäftsführung und Aufsichtsrat (falls ein solcher existiert) nehmen eine Beraterfunktion in der Gesellschafterversammlung ein (vgl. Art. 2:227 Abs. 4 NBG). Aus diesem Grund sind sie zwingend vor jedem Tagesordnungspunkt zu hören beziehungsweise ist ihnen vor jedem Tagesordnungspunkt Gelegenheit zur Stellungnahme zu geben, vor allem, wenn die Gesellschafterversammlung nicht von der Geschäftsführung oder vom Aufsichtsrat selbst einberufen worden ist. Beschlüsse zu Tagesordnungspunkten, zu denen der Geschäftsführung oder dem Aufsichtsrat nicht die Gelegenheit zur Stellungnahme geboten wurde, sind gemäß Art. 2:15 a NBG anfechtbar ${ }^{602}$.

Ungeachtet des Vorstehenden gilt, dass nur Gesellschafter über ein Stimmrecht verfügen und jeder Gesellschafter mindestens eine Stimme besitzt (Art. 2:228 Abs. 1 NBG). Ist das genehmigte Kapital in Geschäftsanteile mit jeweils demselben Betrag zerlegt, so bestimmt sich das

599 Mehring, GmbH-Rechte S. 205, 219; Gotzen, in: Behrens, Die GmbH Rn. NL 31 und 33 f.

600 Mellert/Verfürth S. 154.

601 Asser-Maeijer 2-III Kap. 5; van Schilfgarde/Winter, S. 62 ff.; Süß/Wachter/Rademakers/de Vries S. 1133.

602 Süß/Wachter/Rademakers/de Vries S. 1133; Gotzen, in: Behrens, Die GmbH Rn. NL 30, $31 \mathrm{f}$. 
jeweilige Stimmgewicht nach der Anzahl der Geschäftsanteile (Art. 2:228 Abs. 2 NBG). Ist das genehmigte Kapital in Geschäftsanteile mit unterschiedlichen Beträgen zerlegt, so ist die Anzahl der Stimmen jedes Gesellschafters durch Division des höchsten Betrages durch den niedrigsten Betrag der vorhandenen Geschäftsanteile zu ermitteln (Art. 2:228 Abs. 3 NBG). Da eine Stimme nicht teilbar ist, werden nur volle Quotienten gezählt. Der Gesellschaftsvertrag kann das Stimmrecht selbst oder aber das Stimmgewicht eines Gesellschafters beschränken. Nicht selten wird die Ausübung des Stimmrechts an die Einhaltung weiterer bestimmter umschriebener Bedingungen geknüpft. Die Gesellschaft selbst oder ihre Tochtergesellschaften dürfen ihr Stimmrecht nicht ausüben, soweit eigene Geschäftsanteile betroffen sind ${ }^{603}$.

Grundsätzlich werden die Beschlüsse der Gesellschafter mit absoluter Mehrheit der abgegebenen Stimmen gefasst. Der Gesellschaftsvertrag kann aber für alle oder einzelne Beschlussgegenstände andere Mehrheiten vorsehen oder Gesellschafterbeschlüsse gar der Einstimmigkeit unterwerfen, z.B. Beschlüsse Verschmelzungen oder Satzungsänderungen betreffend. Sofern der Gesellschaftsvertrag oder das Gesetz nichts anderes bestimmt, müssen bei der Beschlussfassung grundsätzlich nicht bestimmte, das Kapital der Gesellschaft vertretende Gesellschafterquoren anwesend sein. Auch hier sind allerdings abweichende Regelungen im Gesellschaftsvertrag gestattet, etwa der Art, dass ein bestimmter Teil des Kapitals der Gesellschaft vertreten sein muss, um gültige Beschlüsse fassen zu können ${ }^{604}$.

Die Geschäftsführung haben die gefassten Gesellschafterbeschlüsse zu protokollieren und in den Geschäftsräumen der Gesellschaft zur Einsichtnahme auszulegen ${ }^{605}$. Außerdem muss die Gesellschaft auf Bitten der Gesellschafter zum Selbstkostenpreis eine Abschrift oder einen Auszug der Beschlüsse zur Verfügung stellen ${ }^{606}$.

603 Süß/Wachter/Rademakers/de Vries S. 1133; Mehring, GmbH-Rechte S. 205, 219.

604 Gotzen, in: Behrens, Die GmbH Rn. NL $31 \mathrm{f}$.

605 Das Niederländische BG selbst kennt keine Regelung zur Protokollführung bei Gesellschafterversammlungen; auch nicht bei Einpersonengesellschaften. Die Pflicht zur Protokollierung ergibt sich vielmehr aufgrund der 16. EG-Richtlinie (Sechzehnte Richtlinie 93/47/EWG der Kommission vom 22. Juni 1993 zur Anpassung der Anhänge II, III, V, VI und VII der Richtlinie 76/768/EWG des Rates zur Angleichung der Rechtsvorschriften der Mitgliedstaaten über kosmetische Mittel an den technischen Fortschritt ABl. L 203 vom 13.8.1993, S. 24), vgl. nur Mehring, GmbH-Rechte S. 205, 219 sowie Gotzen, in: Behrens, Die GmbH Rn. NL 32. Zum Ganzen vgl. auch Süß/Wachter/Rademakers/de Vries S. 1133.

Süß/Wachter/Rademakers/de Vries S. 1133 f.; Mehring, GmbH-Rechte S. 205, 219. 


\section{ddd) Stimmbindungsverträge (,,aandeelhoudersovereenkomst"“)}

Häufig werden in der Praxis zwischen den Anteileigner Stimmbindungsvereinbarungen getroffen $^{607}$. Das niederländische Recht ist bei der Gestaltung derartiger Stimmbindungsverträge äußerst liberal; unzulässig sind allerdings Stimmbindungsverträge die gegen Gesetz oder Satzung verstoßen. Desgleichen gilt für Stimmbindungsverträge, bei denen die sich daraus ergebenden Beschlüsse mit dem Gesetz oder den Vorschriften der Satzung nicht vereinbar sind. Ist der Stimmbindungsvertrag wirksam, so bindet er die Parteien; Verstöße gegen die Vereinbarung sind strafbewehrt (Bußgeld oder Schadensersatzpflicht). Denkbar ist unter gewissen Umständen auch die richterliche Anordnung eines Stimmrechtsausübungsver- oder -gebots ${ }^{608}$.

\section{gg) Verantwortung und Haftung}

Wie im deutschen Recht begründet die im Grundsatz bestehende Allzuständigkeit der Gesellschafterversammlung für Angelegenheiten der Gesellschaft keine entsprechenden Verpflichtungen. Die Gesellschafter sind auch nach Maßgabe des niederländischen Rechts allein zur Einzahlung ihrer Geschäftsanteile verpflichtet und haften entsprechend für nichts anderes als für diese Einzahlung ${ }^{609}$. Ausnahmsweise haften die Gesellschafter für verbotswidrige Ausschüttungen ${ }^{610}$.

\section{d) Das Enquêterecht und die Gesellschafterklage im niederländischen Recht}

Das Niederländische Recht kennt keine Gesellschafterklage zur Durchsetzung von Forderungen gegen die Gesellschaft. Allerdings ist in Titel 8, Abschnitt 2 des zweiten Buches des Nie-

607 Siehe dazu umfassend Dortmond 2000 II; Brenninkmeijer 1973; Asser-Maeijer 2-III, S. 371 ff.; Van Schilfgaarde/Winter, S. 187 ff.; Hirte/Bücker/Rammeloo/de Kluiver S. 186.

608 Dortmond 2000 II; Brenninkmeijer 1973; Hendriks-Jansen 1982 S. 6 ff.; Hirte/Bücker/Rammeloo/de Kluiver S. 186.

${ }^{609}$ Anderes mag insbesondere in der Krise der Gesellschaft gelten, vgl. Olaerts dort insb. S.265 ff. sowie zur Aussenhaftung S. 292 ff. m. zahlreichen w. N.; siehe auch den Überblick bei Bras S. 480 ff.; Mellert/Verfürth S. 156; Kuiper/Ruypers/Slangen/Kuiper/Vossestein, S. 166

610 Siehe hierzu umfassend Olaerts Vennootschappelijke beleidsbepaling in geval van financiele moeilijkheden de positie van bestuurders en aandeelhouders, Diss. 2007, diese allerdings einen Schwerpunkt setzend auf die Verantwortlichkeit der Gesellschafter in der Krise der Gesellschaft; Mellert/Verfürth S. 156; Kuiper/Ruypers/Slangen/Kuiper/Vossestein, S. 166. Vgl. zur Haftung der Gesellschafter auch umfassend Jansen GmbHR 1995, 286 ff., er erläutert die Voraussetzungen, unter welchen Gesellschafter (speziell herrschende Gesellschafter) nach Gründung der Gesellschaft und deren Gläubigern gegenüber haften, wobei es um die Haftung bei unredlichem Verhalten gegenüber der Gesellschaft und bei unerlaubten Handlungen (hierfür nennt er Beispiele) gegenüber den Gläubigern, um „Zahl ein - Zahl aus“-Geschäfte, ohne Einzahlung vergebene Bonusanteile und die Dividendenauszahlung in Form von Anteilen (so genannte Stock-Dividende) geht. 
derländischen BG ein Sonderprüfungsrecht - Recht der Untersuchung (,recht van enquête") vorgesehen, das es Gesellschaftern, die mindestens ein Zehntel des gezeichneten Kapitals vertreten, gestattet, einen Untersuchungsantrag bei der Kammer für Unternehmenssachen des gerechtshof Amsterdam („Ondernemingskamer") zu stellen ${ }^{611}$. Daneben haben Gesellschaftern einer B.V., die zusammen mindestens ein Drittel des gekennzeichneten Kapitals auf sich vereinen, nach Maßgabe der Artt. 2:335 ff. NBG die Möglichkeit, gegen einen Mitgesellschafter, der den Gesellschafterinteressen schadet, mit dem Ziel vorzugehen, dass dieser ihnen ihre Anteile abnimmt oder seine Anteile überträgt. Ein solches Vorgehen kommt allerdings nur als ultima ratio in Betracht und setzt daher stets voraus, dass eine Fortsetzung der Gesellschaft mit dem Schädiger auch unter Einschränkung von dessen Gesellschafterrechten nicht mehr zumutbar ist ${ }^{612}$.

\section{e) Aufsichtsrat}

Wie in Deutschland unterscheidet das niederländische Recht zwischen obligatorischem (Art. 2:263 NBG) und fakultativem (Art. 2:250 NBG) Aufsichtsrat ${ }^{613}$.

\section{aa) Bestellung und Abberufung}

Die Bestellung der Aufsichtsratsmitglieder folgt demselben Schema wie die Bestellung der Geschäftsführer. Ist aufgrund entsprechender Satzungsregelungen bereits bei Gründung ein Aufsichtsrat zu bestellen, so erfolgt die Bestellung in der Gründungsurkunde. Hiernach werden die Aufsichtsratsmitglieder durch die Gesellschafterversammlung, oder aber, bei großen B.V.s mit obligatorischem Aufsichtsrat nach Maßgabe des Art. 2:268 NBG bestellt ${ }^{614}$. Auch

611 Vgl. dazu nur Boschma/Schutte-Veenstra 2007 S. 197, 204. Peters/Dechow GmbHR 2007, 236 regen an auch für das deutsche GmbH-Recht die Einführung eines Sonderprüfungsrechts für Minderheitsgesellschafter nach aktienrechtlichem Vorbild an. Die aktienrechtlichen Regelungen seien über $\S 46 \mathrm{Nr} 6$ und 8 GmbHG analog auf die Gesellschaftermehrheit bei der GmbH anzuwenden. Für die Minderheitsgesellschafter lasse sich dieses Recht hingegen nicht aus dem GmbHG ableiten, weder de lege lata noch de lege ferenda. Dies wäre nach Ansicht Peters/Dechow jedoch im Hinblick auf die europaweite Vereinheitlichung und zur Stärkung der Minderheitenrechte wünschenswert. Das Sonderprüfungsrecht sei insbesondere auch neben dem allgemeinen Informationsrecht des Minderheitsgesellschafters gemäß § 51a, § 51b GmbHG sinnvoll, da es einen weiteren Anwendungsbereich und eine größere Reichweite habe.

612 Vgl. in deutscher Sprache hierzu Banerjea, S. 250; in niederländischer Sprache ist von P.G.F.A. Geerts, eine erschöpfende Behandlung unter dem Titel „Enkele formele aspecten van het enqêterecht“ (diss.) Groningen 2004, erschienen; vgl. für einen Überblick auch Asser-Maeijer 2-III, Kap. XII.3 und Schilfgarde/Winter, Kap. 12 sowie Assink 2006 S. 307 ff.

613 Mellert/Verfürth S. 154; Süß/Wachter/Rademakers/de Vries S. 1143 ff.; Gotzen, in: Behrens, Die GmbH Rn. NL 25 ff.; Mehring, GmbH-Rechte S. 205, 221 ff; Hirte/Bücker/Rammeloo/de Kluiver S. 194 ff.

614 Das früher geltende Kooptationssystem mit Vetorechten (Art. 268 Abs. 2 S. 1 NBG a.F.) wurde 2004 abgeschafft. Danach wurden die Mitglieder de Aufsichtsrats - soweit nicht bereits durch die Gründungsurkunde 
bei der Aufsichtsratswahl kann die Satzung bestimmen, dass die Aufsichtsratsmitglieder bestimmten Anforderungen genügen sollen. Die Kompetenz zur Aufsichtsratsbestellung kann durch Satzungsregelung für maximal ein Drittel der Mitglieder auf einen Dritten übertragen werden ${ }^{615}$.

Zur Abberufung ist grundsätzlich - wie bei den Geschäftsführern - derjenige berechtigt, der auch berechtigt ist, die Mitglieder des Aufsichtsrats zu bestellen ${ }^{616}$

\section{bb) Aufgaben und Pflichten}

Der Aufsichtsrat hat zunächst die Aufgabe, die Geschäftsführung zu überwachen. Daneben obliegt dem Aufsichtsrat auch die Vertretung der Gesellschaft gegenüber den Geschäftsführern. Damit im Zusammenhang steht auch die Berechtigung des Aufsichtsrats jeden Geschäftsführer jederzeit zu suspendieren (Art. 2:257 NBG) ${ }^{617}$.

Der Aufsichtsrat haftet, gleich einem Geschäftsführer nach Maßgabe der Art. 2:9, 241 und 248 NBG. Stellen die von der Gesellschaft veröffentlichten Jahresabschlüsse die Finanzlage der Gesellschaft unrichtig dar, so haften die Aufsichtsratsmitglieder Dritten gegenüber solidarisch neben den Geschäftsführern für den aufgrund dessen entstandenen Schaden (Art. 2:260 NBG). Nach Art. 2:260 NBG besteht allerdings die Möglichkeit, dass einzelne Aufsichtsratsmitglieder sich exkulpieren, indem sie den Nachweis erbringen, dass die fehlerhaften Angaben ohne ihr Wissen und ihr Zutun vorgenommen worden sind ${ }^{618}$. Schließlich werden Aufsichtsratsmitglieder, die geschäftsführende Handlungen vornehmen, auch bezüglich der sich aus der Geschäftsführungstätigkeit ergebenden Rechte und Pflichten als Geschäftsführer wahrgenommen ${ }^{619}$.

bestellt - vom Aufsichtsrat selbst berufen. Vgl. zur alten Rechtslage noch Gotzen, in: Behrens, Die GmbH Rn. NL 26 sowie Mehring, GmbH-Rechte S. 205, 222.

615 Portengen WPNR 2007, 940, 944 ff.; Dortmond Süß/Wachter/Rademakers/de Vries S. 1144; Hirte/Bücker/Rammeloolde Kluiver S. 195 f.; Gotzen, in: Behrens, Die GmbH Rn. NL 26; Mehring, GmbHRechte S. 205, 222; Mellert/Verfürth S. 154 f. Süß/Wachter/Rademakers/de Vries S. 1144; Hirte/Bücker/Rammeloo/de Kluiver S. 196; Gotzen, in: Behrens, Die GmbH Rn. NL 26; Mehring, GmbH-Rechte S. 205, 222.

617 Portengen WPNR 2007, 940, 946; Süß/Wachter/Rademakers/de Vries S. 1144; Hirte/Bücker/Rammeloo/de Kluiver S. $195 \mathrm{f}$.

618 Portengen WPNR 2007, 940, 946; Süß/Wachter/Rademakers/de Vries S. 1144; Hirte/Bücker/Rammeloo/de Kluiver S. 196; Gotzen, in: Behrens, Die GmbH Rn. NL 28; Mehring, GmbH-Rechte S. 205, 223.

619 Süß/Wachter/Rademakers/de Vries S. 1144; Hirte/Bücker/Rammeloolde Kluiver S. 196. 


\section{cc) Aufsichtsrat bei der großen B.V.}

Bei Erfüllung der in Art. 2:263 Abs. 2 NBG genannten Voraussetzungen spricht man von einer „großen Gesellschaft“ mit der Folge, dass in der Gesellschaft die Errichtung eines Aufsichtsrats obligatorisch ist. Nach Maßgabe des Art. 2:263 Abs. 2 NBG ist eine große Gesellschaft eine B.V., die kumulativ die folgenden Voraussetzungen ${ }^{620}$ erfüllt:

- Das gezeichnete Kapital muss zusammen mit den Rücklagen laut Bilanz mindestens 16 Mio. $€$ betragen;

- die Gesellschaft oder ein abhängiges Unternehmen hat aufgrund gesetzlicher Vorgaben einen Betriebsrat (,ondernemingsraad“) gebildet und

- bei der Gesellschaft oder bei den von ihr abhängigen Unternehmen zusammen sind in der Regel 100 Arbeitnehmer in den Niederlanden ${ }^{621}$ beschäftigt.

Die „Abhängigkeit“ eines Unternehmens im vorgenannten Sinne wird in Art. 2:262 NBG definiert. Erfüllt eine Gesellschaft die Voraussetzungen des Art. 2:263 Abs. 2 NBG, so hat die Geschäftsführung dies innerhalb von zwei Monaten nach Feststellung des Jahresabschlusses beim Handelsregister anzumelden. Erfüllt eine B.V. diese Voraussetzungen ununterbrochen über einen Zeitraum von drei Jahren, so finden die Vorschriften der Strukturregelung (,structuurregeling") Anwendung, die in den Art. 2:262 bis 274 NBG insbesondere eine Erweiterung der Rechte des Aufsichtsrats, wie z.B. die Befugnis Geschäftsführer zu bestellen und abzuberufen (Art. 2:272 NBG), vorsehen ${ }^{622}$.

Erfüllt die B.V. nicht länger die Voraussetzungen des Art. 263 Abs. 2 NBG, so wird sie als große Gesellschaft aus dem Handelsregister gelöscht. Allerdings wirken die Strukturregelungen über einen Zeitraum von wenigstens drei Jahren auch nach Wegfall der Voraussetzungen fort. Erfüllt die B.V. während dieser drei Jahre erneut die Anforderungen des Art. 2:263 Abs. 2 NBG, so leben die damit im Zusammenhang stehenden vorstehend beschriebenen Rechte und Pflichten einer ,großen Gesellschaft“" wieder auf ${ }^{623}$.

${ }^{620}$ Vgl. zu nachstehenden Voraussetzungen Süß/Wachter/Rademakers/de Vries S. 1144 f.; Hirte/Bücker/Rammeloo/de Kluiver S. 198; Mellert/Verfürth S. 152; zu der alten Rechtslage vgl. Gotzen, in: Behrens, Die GmbH Rn. NL 25; Mehring, GmbH-Rechte S. 205, 221.

621 Arbeitnehmer außerhalb der Niederlande werden nicht erfasst; vgl. hierzu nur Mellert/Verfürth S. 152.

622 Süß/Wachter/Rademakers/de Vries S. 1145.

623 Süß/Wachter/Rademakers/de Vries S. 1145; Hirte/Bücker/Rammeloo/de Kluiver S. 198; Mellert/Verfürth S. 152. 


\section{Zu den Reformbestrebungen}

\section{a) Reformansätze des Entwurfs eines Gesetzes zur Vereinfachung und Flexibilisierung des B.V.-Rechts (,,Wet vereenvoudiging en flexibilisering bv-recht“)}

\section{aa) Erweiterung des gesetzlichen Organbegriffs (Art. 2:189a NBG)}

Die Systematik des Gesetzes, eine Konkretisierung des Organbegriffs, bestimmten Regelungen, die den Grundprinzipien des B.V.-Rechts widersprechende Maßnahmen ermöglichen, voranzustellen, wurde beibehalten. Allerdings wurde die Definition im Hinblick auf der Kreis der Berechtigten sowie die in Bezug genommen Regelungen wie folgt erweitert:

Art. 2:189a NBG-E nennt als befugtes Organ nunmehr auch Gesellschafterversammlungen von Anteilsinhabern eines bestimmten Namens oder Typs. Hierdurch wird es Gesellschaftern eines bestimmten Geschäftsanteilstyps ermöglicht die in Bezug genommenen Rechte auszuüben, ohne dass hierfür ein neues Organ geschaffen werden muss ${ }^{624}$.

Des Weiteren wurde der Begriff der Gesellschafterversammlung durch den der Hauptversammlung ersetzt. In Buch 2 des NBG wird bereits nach bestehender Rechtslage regelmäßig nur auf die Hauptversammlung und nicht auf die Gesellschafterversammlung Bezug genommen, da es so auch anderen (Nicht-Gesellschaftern) möglich ist, an der Versammlung teilzunehmen. Insoweit handelt es sich bei der letztgenannten Veränderung lediglich um eine redaktionelle Anpassung, die bislang noch nicht vorgenommen worden $\operatorname{war}^{625}$.

\section{bb) Geschäftsführung und Vertretung}

\section{aaa) Bestellung und Abberufung (Artt. 2:242, 244, NBG)}

Um künftig einzelnen Gesellschaftern oder einer bestimmte Gruppe von Gesellschaftern die Möglichkeit zu geben, einen „eigenen“ Geschäftsführer zu bestellen, wurde Art. 2:242 NBG wie folgt ergänzt: „Die Bestellung der Geschäftsführer erfolgt bei Gründung der Gesellschaft in der Gründungsurkunde, später durch die Gesellschafterversammlung oder, falls der Gesellschaftsvertrag Entsprechendes bestimmt, durch eine Versammlung von Inhabern einer

624 Gesetzesbegründung Erste Tranche, S. 15 f.; Begründung des Gesetzesentwurfs, Besonderer Teil, S. 53 f. 625 Gesetzesbegründung Erste Tranche, S. 15 f.; Begründung des Gesetzesentwurfs, Besonderer Teil, S. 54. 
bestimmten Art von Geschäftsanteilen, vorausgesetzt, es ist sichergestellt, dass jeder Anteilsinhaber jedenfalls an der Benennung eines Geschäftsführers partizipiert." Weiterhin gilt, dass in den Fällen in denen ein Aufsichtsrat existiert, dieser für die Bestellung der Geschäftsführer zuständig ist (Art. 2:272 NBG) und Satz 2 des Art. 2:242 NBG-E stellt klar, dass in diesen Fällen auch die Ermächtigung einzelner Gesellschaftergruppen „,ihren“ Geschäftsführer zu bestellen, nicht gilt ${ }^{626}$.

Nach Art. 2:242 Absatz 2 NBG-E ist es weiterhin möglich, bestimmte Vorgaben betreffend die Person des zu bestellenden Geschäftsführers in die Satzung aufzunehmen. Auf die Erfüllung der Vorgaben kann auch weiterhin mit zwei Drittel der abgegeben Stimmen verzichtet werden. Weggefallen ist lediglich die Bezugnahme auf ein Quorum von mindestens der Hälfte des genehmigten Kapitals beim Verzicht auf die satzungsmäßigen Anforderungen, da Art. 2:231 NBG-E nunmehr grundsätzlich für satzungsändernde Beschlüsse bestimmt, dass eine Mehrheit von zwei Drittel der abgegebenen Stimmen ausreicht ${ }^{627}$.

Als Gegengewicht zu der neu geschaffenen Möglichkeit, qua Satzungsbestimmung einer bestimmten Gesellschaftergruppe die Bestellungskompetenz zu erteilen, wurde in Art. 2:244 NBG-E vorgesehen, dass durch entsprechende Satzungsbestimmung die Abberufungskompetenz einem anderen Organ als der Gesellschafterversammlung zu gewiesen werden kann, falls sich nicht ohnehin der Aufsichtsrat nach Art. 2:272 NBG für Bestellung und Abberufung gleichermaßen zuständig zeigt ${ }^{628}$.

Mit Abs. 4 von Art. 2:244 NBG-E nimmt der Entwurfgeber die Gesellschafter zunächst in die Pflicht, Regelungen für den Fall vorzusehen, dass die Gesellschaft aufgrund des Ausscheidens oder der Indisponibilität aller oder wesentlicher Geschäftsführer führungslos wird, gibt ihnen indes gleichzeitig hierdurch die Möglichkeit „stellvertretende Geschäftsführer“ zu schaffen. Mit der Vorschrift beabsichtigt der Entwurfgeber nicht zuletzt auch eine praktische Erleichterung der Geschäftsführung in Joint Venture-Gesellschaften, in denen jeder der Partner regelmäßig seinen ,eigenen“ Geschäftsführer bestellt. In solchen Gesellschaften - so die Vorstellung des Entwurfgebers mag eine gemäß Art. 2:244 Abs. 4 NBG-E geschaffene Übergangsvorschrift geeignet sein, das dem Joint Venture immanente Gleichgewicht der Interessen bei Abwesenheit eines der Geschäftsführer in der Geschäftsführung aufrecht zu erhalten ${ }^{629}$.

${ }^{626}$ Begründung des Gesetzesentwurfs, Besonderer Teil, S. 114 ff.; vgl. hierzu auch Portengen WPNR 2007, 940, 944 ff.; siehe dazu Boschma/Schutte-Veenstra 2007 S. 197, 200 f. 


\section{bbb) Vorschlagsrecht}

Als verzichtbar erklärt der Entwurf die gemäß Art. 2:243 NBG vorgeschriebene Notwendigkeit bei Einräumung eines Vorschlagsrechts in der Satzung die Benennung mindestens zweier Kandidaten vorzusehen. In der Praxis hat sich gezeigt, dass der zweite vorgeschlagene Kandidat als realistische Option regelmäßig ausfiel. Von einer kompletten Streichung des Art. 2:243 NBG, wie durch die Expertengruppe angeregt, hat der Entwurfgeber indes abgesehen. Anders als die Expertengruppe ist der Entwurfgeber der Ansicht, dass die Durchbrechung des Bestellungsrechts der Gesellschafterversammlung, das zu den maßgeblichen Gesellschafterrechten zählt, durch Einräumung bindender Vorschlagsrechte einer expliziten - wenn auch nur klarstellenden - Regelung in Gesetz bedarf ${ }^{630}$.

In Absatz 2 wird dem Umstand Rechnung getragen, dass ein durch die Satzung festgelegtes (bindendes) Vorschlagsrecht jedenfalls durch Beschlussfassung mit satzungsändernder Mehrheit durchbrochen können werden muss ${ }^{631}$.

In einem neuen Absatz 3 ist des Weiteren vorgesehen, dass die Bestellung des vorgeschlagenen Geschäftsführers qua separaten Beschluss erfolgt, der Annahme des Beschlusses also regelmäßig der Bestellungsakt zu folgen hat ${ }^{632}$.

cc) Gesellschafter und Geschäftsanteile

\section{aaa) Jährliche Gesellschafterversammlung (Art. 2:218 NBG)}

In der Praxis war bislang unklar, inwieweit die jährliche Gesellschafterversammlung gemäß Art. 2:218 NBG auch nach Maßgabe des Art. 2:238 NBG durch Beschlussfassung außerhalb einer (ordentlichen) Gesellschafterversammlung abgehalten werden kann. Dies hat der Entwurfgeber nunmehr durch eine eindeutige Bezugnahme auf die Möglichkeit der Beschlussfassung gemäß Art. 2:238 NBG in Art. 2:218 NBG klargestellt. Zur Begründung heißt es, dass keine zwingenden Gründe für eine Beschlussfassung in einer Gesellschafterversammlung gesprochen hätten, insbesondere keine Minderheitenschutzrechte eine Gesellschafterversammlung erforderlich machten, da eine Beschlussfassung nach Maßgabe des Art. 2:238 NBG nur mit schriftlicher Zustimmung aller Gesellschafter möglich ist ${ }^{633}$.

630 Begründung des Gesetzesentwurfs, Besonderer Teil, S. $116 \mathrm{f}$.

631 Begründung des Gesetzesentwurfs, Besonderer Teil, S. 117.

632 Begründung des Gesetzesentwurfs, Besonderer Teil, S. $117 \mathrm{f}$.

633 Begründung des Gesetzesentwurfs, Besonderer Teil, S. 96 f. 


\section{bbb) Einberufung und Formalitäten}

\section{(i) Befugnis zur Einberufung der Gesellschafterversammlung (Art. 2:220 NBG)}

Unberührt bleibt die generelle Zuständigkeit von Geschäftsführung und Aufsichtsrat gemäß Art. 2:219 NBG die Gesellschafterversammlung einzuberufen, wobei nach wie vor durch Regelung in der Satzung auch anderen, beispielsweise einzelnen Gesellschaftern, diese Befugnis übertragen werden kann.

Daneben war es den Gesellschaftern bislang nur möglich bei Gericht um eine Ermächtigung zur Einberufung einer Gesellschafterversammlung zu ersuchen und dies auch nur, wenn die Gesellschafter alleine oder in Gemeinschaft mit anderen Gesellschaftern mindestens $10 \%$ des gezeichneten Kapitals auf sich vereinten (Art. 2:220 NBG).

Art. 2:220 NBG-E sieht nunmehr vor, dass Gesellschafter die alleine oder in Gemeinschaft mit anderen Gesellschaftern ein Quorum von mindestens $1 \%$ des gezeichneten Kapitals erreichen, unmittelbar bei der Geschäftsführung beziehungsweise dem Aufsichtsrat die Einberufung einer Gesellschafterversammlung beantragen können. Erst wenn die Aufforderung des Gesellschafters unerwidert bleibt, ist künftig ein Gang zu Gericht erforderlich, um sodann die Ermächtigung zur Einberufung der Gesellschafterversammlung zu erhalten ${ }^{634}$.

Mit der Gesetzesänderung zielt der Entwurfgeber auf eine Stärkung der Minderheitenrechte. Zugleich harmonisiert er die im Zusammenhang mit der Gesellschafterversammlung stehenden Gesellschafterrechte, indem er die Möglichkeiten bei Einberufung der Gesellschafterversammlung mit den bereits existierenden Einflussnahmemöglichkeiten bei Aufstellung der Tagesordnung synchronisiert (Art. 2:224 a NBG). Art. 2:224 a NBG besagt, dass Gesellschaftern die alleine oder in Gemeinschaft mit anderen Gesellschaftern mindestens $10 \%$ des gezeichneten Kapitals auf sich vereinen, berechtigt sind, die Geschäftsführung beziehungsweise den Aufsichtsrat anzuweisen, einen bestimmten Tagesordnungspunktes in die Agenda aufzunehmen ${ }^{635}$.

Anders als im deutschen Recht hat der einzelne Gesellschafter auch künftig nicht das Recht selbst eine Gesellschafterversammlung einzuberufen, wenn Geschäftsführung und Aufsichts-

634 Begründung des Gesetzesentwurfs, Besonderer Teil, S. 97.

635 Begründung des Gesetzesentwurfs, Besonderer Teil, S. 97 f. 
rat untätig bleiben. Der Entwurfgeber hat bewusst auf eine solche Regelung verzichtet, da er befürchtete, dass Unklarheiten im Hinblick auf die Wirksamkeit der Einberufung und in der Folge auch im Hinblick auf die Wirksamkeit der gefassten Beschlüsse entstehen könnten ${ }^{636}$.

(ii) Einberufungsformalitäten (Art. 2:223, 225 NBG)

Art. 2:223 NBG wurde im Hinblick auf die neu geschaffene Möglichkeit beziehungsweise Notwendigkeit in Artt. 2:227, 197, 198 NBG-E (vgl. hierzu unten ccc)) auch NichtGesellschaftern, wie etwa Inhabern von Geschäftsanteilszertifikaten, die Teilnahme an Gesellschafterversammlungen zu ermöglichen, ergänzt. Nunmehr ist eine Einladung zur Gesellschafterversammlung sowohl an die registrierten Gesellschafter, Nießbraucher und Pfandgläubiger als auch die registrierten Geschäftsanteilszertifikatsinhaber zu versenden ${ }^{637}$.

Unter Berücksichtigung praktischer Notwendigkeiten wurde die Einberufungsfrist des Art. 2:225 NBG von 15 Tagen auf acht Tage vor Stattfinden der Gesellschafterversammlung verkürzt. Die Anregung der Expertengruppe, Gesellschaften die Möglichkeit zu geben, in ihrer Satzung andere Fristen vorzusehen, wurde aus Minderheitsschutzgründen nicht übernommen. Eine Mindesteinberufungsfrist von acht Tagen sei notwendig, um den Gesellschaftern die Möglichkeit zu geben, sich auf die Tagesordnungspunkte angemessen vorzubereiten. Auch würden kurzfristige Beschlussfassungen, für die insbesondere in Ein-Mann-Gesellschaften oder solchen mit nur wenigen Gesellschaftern ein berechtigtes Interesse existieren mag, durch das Festhalten an einer Mindesteinberufungsfrist nicht verhindert oder unnötig erschwert, da es den Gesellschaftern gemäß Art. 2:238 NBG regelmäßig offen stehe, außerhalb einer Gesellschafterversammlung und damit ohne Berücksichtigung der Ladungsfristen zu entscheiden (Vgl. hierzu auch unten unter eee) $)^{638}$.

\section{(iii) Ort der Gesellschafterversammlung (Art. 2:226 NBG)}

Künftig ist den Gesellschaftern möglich, in der Satzung auch einen Versammlungsort außerhalb der Niederlande vorzusehen. Um sicherzustellen, dass alle teilnahmeberechtigten Personen mit dem Ort, an dem die Gesellschafterversammlungen stattfinden sollen einverstanden sind, wird für die Schaffung einer entsprechenden Satzungsbestimmung eine einstimmige Beschlussfassung in der Gesellschafterversammlung sowie die schriftliche Zustimmung der

636 Gesetzesbegründung Erste Tranche S. 17 f. und Begründung des Gesetzesentwurfs, Besonderer Teil, S. 98.

637 Begründung des Gesetzesentwurfs, Besonderer Teil, S. 98.

638 Begründung des Gesetzesentwurfs, Besonderer Teil, S. 99 f. 
übrigen (nicht stimmberechtigten) Teilnahmeberechtigten, wie beispielsweise Geschäftsführern und Aufsichtsratsmitgliedern sowie Nießbrauchern und Pfandgläubigern ohne Stimmrecht in der Gesellschafterversammlung, verlangt. Auch dann ist die Abhaltung an einem an einem anderen als dem in der Satzung festgelegten Ort möglich, wenn sämtliche Teilnahmeberechtigten, das heißt auch Geschäftsführer und Aufsichtsratsmitglieder sowie Nießbrauchern und Pfandgläubigern - und nicht nur wie bislang das gesamte gezeichnete Kapital hiermit einverstanden $\operatorname{sind}^{639}$.

Mit vorstehender Gesetzesänderung bleibt der Entwurfgeber hinter den Vorstellungen der Expertengruppe zurück, die empfohlen hatte, die Bestimmung eines ausländischen Versammlungsortes in der Satzung durch einfachen satzungsändernden Beschluss zuzulassen ${ }^{640}$.

\section{ccc) Teilnahmerechte anderer Personen als Gesellschafter}

\section{(Art. 2:227 Abs. 2 und 4, Art. 197 Abs. 4 und Art. 198 Abs. 4 NBG)}

Art. 2:227 Abs. 2 und 4, Art. 197 Abs. 4 und Art. 198 Abs. 4 NBG-E gewähren Inhabern besonderer Rechte, wie etwa Inhabern von Geschäftsanteilszertifikaten, Nießbrauchern und Pfandgläubigern, sowie Geschäftsführern und Aufsichtsratsmitgliedern, zusätzliche Mitwirkungsrechte, beziehungsweise geben der Gesellschaft die Möglichkeit durch entsprechende Satzungsregelungen solche Mitwirkungsrechte einzuräumen ${ }^{641}$.

\section{(i) Art. 2:227 Abs. 2 NBG-E}

Art. 2:227 NBG befasst sich mit dem Recht von Gesellschaftern und Nicht-Gesellschaftern, an Gesellschafterversammlungen der Gesellschaft teilzunehmen und dort das Wort zu führen. Nach Art. 2:227 Abs. 2 NBG war es insbesondere auch Inhabern so genannter Geschäftsanteilszertifikate, die unter Mitwirkung der Gesellschaft emittiert wurden (so genannte „,bewilligde certificaten") gestattet, an Gesellschafterversammlungen der Gesellschaft teilzuneh$\operatorname{men}^{642}$.

Geschäftsanteilszertifikate werden Dritten, regelmäßig sind dies Arbeitnehmer im Rahmen von Mitarbeiterbeteiligungsprogrammen oder Kapitalgebern, gewährt, um diese an der Gesellschaft wirtschaftlich zu beteiligen, ohne ihnen gleichzeitig die einem Geschäftsanteil im-

639 Begründung des Gesetzesentwurfs, Besonderer Teil, S. 100.

640 Begründung des Gesetzesentwurfs, Besonderer Teil, S. 102.

641 Begründung des Gesetzesentwurfs, Besonderer Teil, S. $102 \mathrm{ff}$.

642 Vgl. hierzu bereits oben in diesem Abschnitt IV. 1. c) cc). 
manenten Gesellschafterrechte, wie insbesondere Kontroll- und Mitwirkungsrechte einräumen zu müssen, die ansonsten mit der Begebung eines Geschäftsanteils verbunden sind ${ }^{643}$.

Im Niederländischen Recht werden Geschäftsanteilszertifikate, die unter Mitwirkung der Gesellschaft emittiert wurden (,,bewilligde certificaten“), und solche, die nicht unter Mitwirkung der Gesellschaft emittiert wurden (so genannte „onbewilligde certificaten“), unterschieden. Für erstere gelten besondere Rechte und Befugnisse nach dem NBG, wie etwa das Teilnahmerecht an Gesellschafterversammlungen (Art. 2:227 Abs. 2 NBG), das Informationsrechte im Hinblick auf die Einberufung der Gesellschafterversammlung (Art. 2:224 Abs. 1 NBG) sowie das Recht bei Gericht um Ermächtigung zu ersuchen, selbst eine Gesellschafterversammlung einberufen zu können (Art. 2:220 NBG). Allerdings können auch solche Geschäftsanteilszertifikate die nicht unter Mitwirkung der Gesellschaft emittiert wurden, bestimmte Teilnahmerechte gewähren. Dies wurde bislang vom NBG nicht in ausreichender Weise erfasst ${ }^{644}$.

Mit der B.V. Reform wurden nunmehr explizite Bezugnahmen auf Geschäftsanteilszertifikate, die unter Mitwirkung der Gesellschaft emittiert wurden, wie etwa in Art. 2:238 NBG, durch allgemeinere Bezugnahmen auf „Teilnahmeberechtigte“ ersetzt $^{645}$.

Hierdurch ist die Notwendigkeit entstanden, Art. 2: 227 NBG neu zu fassen, um der Gesellschaft künftig eine Identifizierung der „teilnahmeberechtigten“ besser ermöglichen zu können.

Der geänderte Art. 2:227 Abs. 2 NBG-E beseitigt etwaige Unklarheiten indem er der Gesellschaft künftig die Möglichkeit eröffnet, die aufgrund entsprechender Satzungsbestimmungen zur Teilnahme und Mitwirkung an der Gesellschafterversammlung der Gesellschaft berechtigten Inhabern von Geschäftsanteilszertifikaten durch Begebung auf den Namen lautender Geschäftsanteilszertifikate zu identifizieren. Des Weiteren sieht der Entwurf eines geänderten Art. 2:227 Abs. 2 NBG-E vor, dass in der Satzung bestimmt werden kann, dass eine Ausübung des Teilnahmerechts erst dann möglich sein soll, wenn der Berechtigte nach Maßgabe des Art. 2:194 NBG-E registriert worden ist ${ }^{646}$.

\footnotetext{
643 Vgl. hierzu bereits oben in diesem Abschnitt IV. 1. c) cc).

644 Vgl. umfassend zu dem Thema Certificering von Geschäftsanteilen nur Ondernemingsrecht 2004, nr. 12, Sonderheft; Asser-Maeijer 2-III, S. 570 ff. und Schilfgarde/Winter, S. 182 ff. sowie die Ausführungen oben in diesem Abschnitt IV. 1. c) cc).

645 Begründung des Gesetzesentwurfs, Besonderer Teil, S. 102.

646 Begründung des Gesetzesentwurfs, Besonderer Teil, S. 102 f.
} 
(ii) Art. 2:197 Abs. 4 und Art. 2:198 Abs. 4 NBG-E

Art. 2:197 Abs. 4 und Art. 2:198 Abs. 4 NBG-E sehen vor, dass bestimmten Nießbraucher und Pfandgläubiger künftig dieselben gesetzlichen Rechte zustehen, wie Geschäftsanteilszertifikatsinhaber, denen ein Teilnahmerecht nach Maßgabe des Art. 2:227 Abs. 2 NBG-E eingeräumt worden ist. Hierzu wurde der Wortlaut der Art. 2:197 Abs. 4 und Art. 2:198 Abs. 4 NBG-E der neuen Regelung in Art. 2:227 Abs. 2 NBG-E angepasst. Wegen der Begründung wird daher auch vollumfänglich auf die Begründung zu Art. 2:227 Abs. 2 NBG-E verwie$\operatorname{sen}^{647}$.

(iii) Art. 2:227 Abs. 4 NBG-E

Gemäß Art. 2:227 Abs. 4 NBG-E gilt die Beratungspflicht durch Geschäftsführung und Aufsichtsrat nicht im Beschlussverfahren nach Art. 2:238 NBG. Zur Begründung heißt es, die Sanktion des Art. 2:15 a NBG bei Nichtbefolgung des Beratungserfordernisses stehe im Widerspruch zu den Formerleichterungen die Art. 2:238 NBG gerade eröffne ${ }^{648}$.

(iv) Art. 2:227 Abs. 5 NBG-E

Der neue Absatz 5 des Art. 2:227 NBG-E ermöglicht der Gesellschaft in ihrer Satzung die Verpflichtung eines jeden Teilnahmeberechtigten aufzunehmen, sein Erscheinen bei der Gesellschafterversammlung bei den Geschäftsführern der Gesellschaft anzumelden. Art. 2:227 Abs. 5 NBG-E ergänzt und erweitert insoweit Art. 2:227 Abs. 3 NBG, der besagt, dass ein Gesellschafter nicht berechtigt ist, an Gesellschafterversammlungen teilzunehmen, solange er ihm obliegende satzungsmäßige oder gesetzliche Pflichten nicht befolgt ${ }^{649}$.

\section{ddd) Registrierung der Inhaber von Geschäftsanteilszertifikaten} mit Teilnahmerecht an der Hauptversammlung (Art. 2:194 NBG)

Mit der Möglichkeit der Gesellschaft gemäß Art. 2:227 Abs. 2 NBG-E künftig Geschäftsanteilszertifikate mit Hauptversammlungsteilnahmerecht zu begeben (Vgl. hierzu auch oben in

647 Begründung des Gesetzesentwurfs, Besonderer Teil, S. 74 (2:197 Abs. 4 NBG-E) und 76 (Art. 2:198 Abs. 4 NBG-E).

648 Begründung des Gesetzesentwurfs, Besonderer Teil, S. $104 \mathrm{f}$.

649 Begründung des Gesetzesentwurfs, Besonderer Teil, S. $105 \mathrm{f}$. 
diesem Abschnitt IV. 1. c) cc)), ist die Notwendigkeit entstanden, Mechanismen vorzusehen, die gewährleisten, dass die Gesellschaft über die Begebung solcher Zertifikate informiert und über die Identität der Berechtigten in Kenntnis gesetzt wird. Diesem Zweck dient Art. 2:194 NBG-E. Art. 2:194 NBG-E legt der Geschäftsführung in Anlehnung an Art. 2:194 NBG die Pflicht zur Führung eines Registers auf, in dem sämtliche Zertifikatsinhaber mit Hauptversammlungsteilnahmerecht mit Namen und Adressen gelistet sind ${ }^{650}$.

Der Entwurf sieht vor, dass die Führung des vorgenannten Registers primär durch die Geschäftsführung wahrgenommen wird, da auch sie es ist, die sich für die Vorbereitung der Hauptversammlung als solches verantwortlich zeichnet. In der Praxis mag allerdings auf Antrag des Zertifikatsinhabers auch ein Gesellschafter mit Verwaltungsbefugnissen für die Eintragung in das Register Sorge tragen.

Auf Grundlage des Art. 2:227 Abs. 2 NBG-E kann in der Satzung bestimmt werden, dass eine Ausübung des Teilnahmerechts erst dann möglich ist, wenn die Registrierung im Register erfolgt ist ${ }^{651}$.

Gleich Art. 2:194 NBG sind die Zertifikatsinhaber mit Teilnahmerecht aufgrund des Absatzes 2 des Art. 2:194 NBG-E berechtigt, von der Gesellschaft einen kostenlosen Registerauszug zu verlangen, der ihre Berechtigung ausweist ${ }^{652}$.

eee) Gesellschafterbeschlïisse

\section{(i) Gesellschafterversammlung}

In Gesellschaften mit einem beschränkten Gesellschafterkreis wird es regelmäßig nicht notwendig sein, die Entscheidungsfindung in Gesellschafterversammlungen vorzunehmen. Bei Ein-Mann-Gesellschaften fehlt es gänzlich an einer solchen Notwendigkeit, da in einem solchen Fall kein Diskussionsbedarf besteht. Vor diesem Hintergrund war bereits in Art. 2:238 NBG alter Fassung vorgesehen, dass eine schriftliche einstimmige Beschlussfassung aller Gesellschafter auch außerhalb einer Gesellschafterversammlung möglich ist, vorausgesetzt diese Möglichkeit war in der Satzung der Gesellschaft vorgesehen ${ }^{653}$.

650 Begründung des Gesetzesentwurfs, Besonderer Teil, S. 61 f.; siehe dazu auch Portengen WPNR 2007, 940, $947 \mathrm{ff}$.

651 Begründung des Gesetzesentwurfs, Besonderer Teil, S. 61.

652 Gesetzesbegründung Erste Tranche S. 16; Begründung des Gesetzesentwurfs, Besonderer Teil, S. $61 \mathrm{f}$.

653 Vgl. hierzu bereits die Ausführungen in diesem Abschnitt unter IV. 1. c) ff) bbb) (ii) und (iii). 
Da die Beteiligung sämtlicher Gesellschafter, wie im ursprünglichen Art. 2:238 NBG durch das Erfordernis der allgemeinen Stimmabgabe vorgesehen, eine entsprechende Ermächtigung in der Satzung zur Fassung eines Beschlusses im Beschlussverfahren überflüssig macht, hat der Entwurfgeber dieses Erfordernis zugunsten eines allgemeinen Zustimmungserfordernisses aller Teilnahmeberechtigten, d.h. auch der Geschäftsführer und Aufsichtsratsmitglieder sowie Inhabern von Sonderrechten, aufgegeben und in einem neuen Absatz 2 nunmehr umgekehrt die Möglichkeit geschaffen in der Satzung solche Beschlussinhalte festzulegen, die gerade nicht in einem Beschlussverfahren nach Art. 2:238 NBG gefasst werden können sollen ${ }^{654}$.

\section{(ii) Stimmrecht und Vertretung}

Nach der Vorstellung des Gesetzgebers soll das Stimmrecht in der Gesellschafterversammlung künftig an den Geschäftsanteil anknüpfen und nicht - wie bisher - an die Gesellschafterstellung.

Inhaltlich unverändert geblieben sind Art. 2:228 Abs. 2 und 3 NBG, die Regelungen für die Bestimmung der Anzahl der Stimmrechte jedes Gesellschafters für ein in Geschäftsanteile mit jeweils gleichem Nennbetrag sowie für ein in Geschäftsanteile mit unterschiedlichem Nennbetrag zerlegtes genehmigtes Kapital, enthalten ${ }^{655}$. Art. 2:228 Abs. 4 und 5 NBG, nach denen nach engen Vorgaben und Beschränkungen die Festlegung von Mehrfachstimmrechten möglich war, werden durch eine flexiblere Regelung in den Art. 2:228 Abs. 4 und insbesondere 5 NBG-E ersetzt. Hiernach hat die Gesellschaft die Möglichkeit - beschränkt allein durch die gesetzlich festgelegte Untergrenze von einer Stimme je Geschäftsanteil (Abs. 1) - von den Bestimmungen der Abs. 2 und 3 abzuweichen und das Stimmrecht in der Satzung nach den Bedürfnissen der Gesellschaft und deren Anteilsinhabern flexibel auszuformen ${ }^{656}$.

Beibehalten wurde die Regelung in Art. 2:230 NBG, wonach Beschlüsse, für die der Gesellschaftsvertrag keine größere Mehrheit bestimmt, mit absoluter Mehrheit der abgegebenen Stimmen gefasst werden. Allerdings wurde nunmehr im Hinblick auf im Gesetz normierte größere Mehrheitserfordernisse klargestellt, dass die Grundregel des Art. 2:230 NBG auch insoweit überlagert wird ${ }^{657}$.

654 Begründung des Gesetzesentwurfs, Besonderer Teil, S. $110 \mathrm{ff}$.

655 Begründung des Gesetzesentwurfs, Besonderer Teil, S. 106.

656 Begründung des Gesetzesentwurfs, Besonderer Teil, S. 106; vgl. hierzu auch Portengen WPNR 2007, 940 ff.

657 Begründung des Gesetzesentwurfs, Besonderer Teil, S. 110. 
Des Weiteren sieht Art. 2:231 NBG-E nunmehr grundsätzlich eine zwei Drittel Mehrheit der abgegebenen Stimmen für satzungsändernde Beschlüsse vor ${ }^{658}$.

\section{fff) Weisungsbefugnisse der Gesellschafterversammlung (Art. 2:239 NBG)}

Nach derzeitiger Rechtslage kann die Satzung bestimmen, dass die Geschäftsführer den Weisungen eines anderen Organs Folge leisten müssen. Weisungen konnten bislang allerdings nur im Hinblick auf allgemeine Leitlinien oder durch die Satzung konkret bestimmte Bereiche erteilt werden. Dies hat insbesondere in Konzernsachverhalten, wo die Muttergesellschaft regelmäßig, ungeachtet der Einschränkungen des Art. 2:239 NBG alter Fassung, umfassend von ihrem Weisungsrecht Gebrauch macht zu Unsicherheiten geführt ${ }^{659}$.

In Art. 2:239 NBG-E wird diesem Umstand Rechnung getragen und auf eine Unterscheidung zwischen generellen und konkreten Weisungen verzichtet. Künftig hat der Geschäftsführer danach - vorausgesetzt die Satzung sieht dies vor - sämtliche Weisungen eines anderen Organs zu befolgen, es sei denn, ,diese stehen im Widerspruch zu den Belangen der Gesellschaft und den mit dieser verbundenen Geschäften"6600.

\section{ggg) Geschäftsanteile der B.V.}

In Betreff der Geschäftsanteile der B.V. waren insbesondere die gesetzlichen Regelungen zur Nachschusspflicht der Gesellschafter (Art. 2:192 NBG), der Vinkulierung von Geschäftsanteilen (,Blokkeringsregeling“) (Art. 2:195 NBG), satzungsmäßigen Andienungspflichten (Art. 2:195a NBG) sowie der Anknüpfung der Ausübung von Gesellschafterrechten an das Erfüllen satzungsmäßig festgelegter Bedingungen (Art. 2:195b NBG) Ziel gesetzgeberischer Reformbestrebungen. Hierbei war der Entwurfgeber gehalten die zuvor beschriebene Interdependenz vorgenannter Bestimmungen zu berücksichtigen. So kann - wie gesehen - etwa eine satzungsmäßig bestimmte Andienungspflicht genauso wirken wie eine Vinkulierung des Geschäftsanteils. Auch waren bei der Änderung der vorstehenden Regelungen stets auch die Wechselwirkungen mit den übrigen Regelungen zu beachten ${ }^{661}$.

658 Ohne weitere Begründung, allein unter Berufung auf den notwendigen Schutz von Minderheitsgesellschaftern und anderen Teilnahmeberechtigten kritisiert Leemrijse Tijdschrift vor Ondernemingsbestuur 2005, 39, 46 die vorgesehen Mehrheitserfordernisse als unzureichend.

659 Vgl. hierzu die Ausführungen in diesem Abschnitt unter IV. 1. b).

660 Begründung des Gesetzesentwurfs, Besonderer Teil, S. 110.

661 Gesetzesbegründung Zweite Tranche S. 1.; Begründung des Gesetzesentwurfs, Besonderer Teil, S. 55 ff. (Art. 2:192 NBG-E); S. 62 ff. (Art. 2:195 NBG-E) und S. 68 ff. (Art. 2:195 a NBG-E); siehe hierzu auch 


\section{(i) Beschränkungen}

Nach dem neuen Art. 2:195 NBG-E ist die Übertragung von Geschäftsanteilen kraft Gesetzes beschränkt (,Blokkeringsregeling“); die Beschränkung kann allerdings durch entsprechende Regelung in der Satzung abgemildert oder gänzlich aufgehoben werden. Die Gesellschafter sollen künftig nach Maßgabe des Art. 2:195 NBG-E frei entscheiden können, ob sie Übertragungsbeschränkungen in der Satzung vorsehen wollen und - gesetzt dem Fall die Entscheidung fällt zugunsten von Übertragungsbeschränkungen - außerdem einen größeren Spielraum haben bei der Frage, wie diese ausgestaltet sein sollen ${ }^{662}$. Geklärt ist nunmehr auch, dass eine Übertragung, die im Widerspruch zu festgelegten Übertragungsbeschränkungen steht, stets unwirksam ist ${ }^{663}$.

Unabhängig von der Neuregelung des Art. 2:195 NBG-E ist es den Gesellschaftern auch weiterhin möglich, den (relativ) geschlossenen Charakter der B.V. zu erhalten, da es den Gesellschaftern unbenommen bleibt, keine Geschäftsanteilszertifikate auszugeben sowie Art. 2:175 NBG vorschreibt, dass die Geschäftsanteile auf den Namen der Inhaber lauten müssen (Art. 2:175 NBG) $)^{664}$. Art. 2:195 NBG-E selbst gestattet den Gesellschaftern außerdem, die Unübertragbarkeit der Geschäftsanteile für einen bestimmten Zeitraum, in Einzelfällen für einen Zeitraum von bis zu 20 Jahren, in der Satzung vorzusehen (Art. 2:195 Abs. 3 NBG-E) ${ }^{665}$.

Es bleibt allerdings bei der gesetzlichen Vorgabe, dass eine statutarische Übertragungsbeschränkung keinesfalls wie eine Übertragungssperre wirken darf, d.h. dass eine Übertragungsbeschränkung die Übertragbarkeit weder ausdrücklich noch faktisch, etwa durch das Verknüpfen untragbarer Nachteile mit dem Übertragungsvorgang, wie beispielsweise die Festlegung eines niedrigen Preises für den zu übertragenden Geschäftsanteil oder die Vorsehung unverhältnismäßig langer Wartefristen für die Übertragung, ausschließen darf (vgl. Art. 2:195 Abs. 3 NBG-E sowie Art. 2:195 Abs. 8 a.F.). Führt eine Übertragungsbeschränkung in vorgenanntem Sinne zur (faktischen) Unübertragbarkeit der Geschäftsanteile, so findet sie keine Anwendung. Dem betroffenen Gesellschafter ist es gemäß Art. 2:343 Abs. 2 NBG in

van Veen WPNR 2007, 950 ff. und Boschma/Schutte-Veenstra 2007 S. 197, 203 sowie Zuidgeest WFR 2007, 1162 jew. m. w. N..

Begründung des Gesetzesentwurfs, Besonderer Teil, S. 62 ff.; siehe dazu auch ausführlich Boschma/Schutte-Veenstra 2007 S. 197, 199f.

663 Vgl. hierzu insb. auch Schwarz C.A. Ondernimingsrecht 2004, 30, 34 sowie ders. S. 75 ff., der eine Aufhebung der blokkeringsregeling auch de lege lata für möglich hält. Siehe aus der jüngeren Literatur nur van Veen WPNR 2007, $950 \mathrm{ff}$.

665 Begründung des Gesetzesentwurfs, Besonderer Teil, S. 64. 
einem solchen Fall außerdem gestattet, gegen Übernahme seiner Geschäftsanteile durch die übrigen Gesellschafter aus der Gesellschaft auszuscheiden. Diese Möglichkeit hat den Vorteil für den ausscheidenden Gesellschafter, dass die zurückbleibenden Gesellschafter verpflichtet sind, seinen Geschäftsanteil zu einem angemessenen Preis (im Zweifel zum Verkehrswert) zu übernehmen ${ }^{666}$.

Beibehalten wird schließlich das Recht des Gesellschafters, der seine Geschäftsanteile übertragen möchte, einen Sachverständigen zu ersuchen, den Wert der Geschäftsanteile festzustellen (vgl. Art. 2:195 Abs. 1 NBG-E sowie Art. 2:195 Abs. 6 NBG a.F.) ${ }^{667}$

Mit der Abschaffung der Beschränkungspflicht in Art. 2:195 NBG-E wird eine Vielzahl praktischer Probleme aufgehoben. So sind die Gesellschafter künftig etwa nicht mehr gezwungen Gesellschaftervereinbarungen abzuschließen, um sich von bestimmten Rechte und Pflichten, die aus statutarischen Restriktionsregelungen resultieren, zu befreien, sondern können vielmehr selbst entscheiden, ob sie solche Vereinbarungen in der Satzung oder einzelvertraglich treffen wollen ${ }^{668}$.

\section{(ii) Andienungspflicht}

Artikel 2:195a NBG gibt den Gesellschaftern die Möglichkeit, in der Satzung für bestimmte Fälle, wie etwa für das Nichtgenügen satzungsmäßiger persönlicher oder sachlicher Anforderungen an die Gesellschafterstellung, für den Bankrott oder die Belastung und für den Übergang von Anteilen anders als durch rechtsgeschäftliche Übertragung (insbesondere durch Erbfall), Andienungs- und Übertragungsverpflichtungen des betroffenen Gesellschafter vorzusehen. Beispiele für gesetzliche Gründe, die Verpflichtung anzubieten und zu übertragen sind in Anlehnung der aktienrechtlichen Vorschriften, der Bankrott oder die Insolvenz eines Gesellschafters und die Pfändung der Anteile. Die Begründung einer Andienungs- und Übertragungsverpflichtung in der Satzung kommt im Grunde genommen der Schaffung zusätzlicher Leistungspflichten nach Maßgabe des Art. 2:192 NBG gleich. Insoweit gilt, dass Art. 2:195a NBG lex specialis in Bezug auf Art. 2:192 NBG ist ${ }^{669}$.

\footnotetext{
666 Begründung des Gesetzesentwurfs, Besonderer Teil, S. 65.

667 Begründung des Gesetzesentwurfs, Besonderer Teil, S. 62 f.

668 Schwarz C. A. Ondernimingsrecht 2004, 30 ff. sowie bereits de lege lata für eine flexible Handhabung ders. insb. S. $75 \mathrm{ff}$.

669 Begründung des Gesetzesentwurfs, Besonderer Teil, S. 68 f.; Siehe hierzu auch van Veen WPNR 2007, 950, $955 \mathrm{ff}$
} 
Auf Empfehlung der Expertengruppe sind zwei erläuternde Gestaltungshinweise in die Bestimmung aufgenommen worden. Zum einen ist klargestellt, dass die Fälle, in denen eine Verpflichtung zur Andienung und Übertragung gelten soll, in der Satzung festzulegen sind ${ }^{670}$. Zum anderen ist in Nummer 1 und 3 klargestellt, dass die Verpflichtung zur Andienung und Übertragung sich auch auf Teile eines Anteil beziehen mag. Im Hinblick auf den Schutz der betroffenen Gesellschafter und der Minderheitsgesellschafter gilt zunächst das zu Art. 2:192 NBG Gesagte entsprechend. Zusätzlich wird dem zur Andienung- beziehungsweise Übertragung verpflichteten Gesellschafter ermöglicht einen unabhängigen Prüfer mit der Bewertung seines Anteils zu betrauen. Dadurch wird vermieden, dass der sich in einer Zwangslage befindliche Gesellschafter unangemessen benachteiligt wird ${ }^{671}$.

\section{(iii) Entziehung der Gesellschafterrechte}

Auf Grund von Artikel 2:195b NBG können die Gesellschafter persönliche und sachliche Anforderungen an die Geschäftsanteilsinhaberschaft stellen. Die Nichterfüllung beziehungsweise Beachtung dieser statutarischen Qualitätsanforderungen wird mit der Aufhebung des Stimmrechts, des Rechts zur Teilnahme an der Hauptversammlung und des Dividendenrechts sanktioniert. Die Expertengruppe hatte vorgeschlagen, dass die Satzung bestimmen können solle, dass ein Organ der Gesellschaft Befreiung von der Erfüllung einer der Anforderung bewilligen können solle. Dieser Vorschlag ist in den Gesetzentwurf aufgenommen worden ${ }^{672}$.

Zum Schutz der Minderheitsaktionäre gegen die Aufstellung statutarischer Qualitätsanforderungen, zu deren Erfüllung sie von vornherein nicht in der Lage wären, kann wiederum auf die Ausführungen zu den Artikeln 2:192, 195 und 195a verwiesen werden ${ }^{673}$. So bedarf:

- die Festlegung von Qualitätsanforderungen an die Anteilsinhaberschaft beziehungsweise den Anteilsinhaber einer entsprechenden Satzungsbestimmung und damit des Einverständnisses wenigstens von zwei Dritteln der Gesellschafter (es sei denn der Gesellschaftsvertrag schreibt gemäß Art. 2:231 NBG eine höhere Mehrheit vor).

670 Die Verpflichtung zur Festlegung solcher Pflichten in der Satzung ergibt sich freilich bereits aus der Historie der Norm; vgl. nur Kamerstukken II, 1998-1999, 26, 277, Nr. 3, P. 8.

671 Begründung des Gesetzesentwurfs, Besonderer Teil, S. 68.

672 Begründung des Gesetzesentwurfs, Besonderer Teil, S. 71. Vgl. dazu van Veen WPNR 2007, $950,957 \mathrm{f}$.

673 Vgl. bereits oben unter ggg) sowie Begründung des Gesetzesentwurfs, Besonderer Teil, S. 55 ff. (Art. 2:192 NBG-E); S. 62 ff. (Art. 2:195 NBG-E) und S. 68 ff. (Art. 2:195 a NBG-E). 
- Des Weiteren steht dem durch die Qualitätsanforderungen in seinen Übertragungsrechten beschränkten Gesellschafter ein Austrittsrecht aus der Gesellschaft nach Maßgabe des Art. 2:343 NBG zu.

Aufgrund der Regelung des Art. 2:195b NBG kann es zu einem Stillstand in der Gesellschaft kommen, nämlich dann wenn sämtliche Gesellschafter die in der Satzung festgelegten Qualitätsanforderungen nicht mehr erfüllen und hierdurch ihr Stimmrecht in der Gesellschafterversammlung verlieren.

Daher ist in Abs. 2 des Art. 195b vorgesehen, dass die Sanktion des Verlustes des Stimmrechts und des Rechts auf Teilnahme an der Hauptversammlung entfällt, sobald keiner der Gesellschafter mehr die in der Satzung festgelegten Anforderungen erfüllt. In der hiernach möglichen Gesellschafterversammlung haben die Gesellschafter die Gelegenheit die Satzung den neuen Gegebenheiten anzupassen, insbesondere die Qualitätsanforderungen aufzuheben oder zu reduzieren ${ }^{674}$.

\section{hhh) Stimmrechtslose Geschäftsanteile}

Anders als noch der amtliche Vorentwurf ${ }^{675}$ sieht der Entwurf eines Gesetzes zur Vereinfachung und Flexibilisierung des B.V.-Rechts ${ }^{676}$ die Einführung stimmrechtsloser Anteile vor ${ }^{677}$. Im Rahmen der Erarbeitung des Vorentwurfs war die Einführung stimmrechtloser Anteile in der niederländischen B.V. zwar auch bereits diskutiert ${ }^{678}$, im Ergebnis aber mit der Begründung abgelehnt worden, die Nachteile der Einführung einer solchen neuen Geschäftsanteilsgattung, wie etwa die schwierige Abgrenzung stimmrechtloser Anteile zu statutarischen Gewinnbezugsrechten sowie die Frage, ob nicht den Inhabern solcher Anteile weitere (Gesellschafter-)Rechte einzuräumen seien, wie etwa ein Teilnahmerecht an Gesellschafterversammlungen oder ein Abfindungsanspruch bei Ausscheiden aus der Gesellschaft, würden die Vorteile, namentlich die Möglichkeit einer reinen Kapitalbeteiligung von Arbeitnehmern oder externen Kreditgeber, wie Banken, überwiegen ${ }^{679}$. Nach der damaligen Auffassung des Ge-

\footnotetext{
674 Begründung des Gesetzesentwurfs, Besonderer Teil, S. $71 \mathrm{f}$.

675 Gesetzesbegründung Vorentwurf, Erste Tranche, S. 25 f.

676 Gesetzesbegründung Entwurf, Allgemeiner Teil, S. 14; Besonderer Teil $107 \mathrm{ff}$.

677 Für eine Einführung stimmrechtsloser Anteile hatte sich 1990 unter anderem auch bereits C.A. Schwarz Aandelen, ausgesprochen, siehe dort auch zahlreiche Nachweise zu noch älterer Literatur. Siehe auch jüngst Portengen WPNR 2007, 940, 942 ff.; ten Berg Ondernemingsrecht 2007, 341 und Boschma/SchutteVeenstra 2007 S. 197, $201 \mathrm{f}$.

678 Die Diskussion geht - wie gesehen - auch noch weiter zurück, siehe C.A. Schwarz Aandelen, S. 6 sowie die Hinweise zu noch älterer Literatur a. a. O. in Fn. 16.

679 Gesetzesbegründung Entwurf, Allgemeiner Teil, S. 14; Besonderer Teil $107 \mathrm{ff}$.
} 
setzgebers genügte die Möglichkeit der Erteilung von Gewinnbezugsrechten sowie der Begebung von Geschäftsanteilzertifikaten, um vergleichbare Ergebnisse zu erzielen (vgl. Art. 3:259 Abs. 1 NBG ${ }^{680}$.

Diese Einschätzung hält der Gesetzgeber nicht aufrecht ${ }^{681}$. Der Entwurf ist nunmehr getragen von der Auffassung, dass trotz vorgenannter Möglichkeiten, eine Notwendigkeit zur Schaffung stimmrechtloser Anteile besteht. Insbesondere vermöge auch das mit der Neufassung des Art. 2:228 NBG eingeführte „flexible Stimmrecht“ nicht das Rechtsinstitut stimmrechtsloser Anteile zu ersetzen. Auch Geschäftsanteilzertifikate oder andere Beteiligungsrechte, die qualitativ unterhalb einer Vollmitgliedschaft stehen, würden nicht dieselbe Klarheit bieten im Hinblick auf die (fehlende) Stimmberechtigung wie stimmrechtlose Anteile ${ }^{682}$.

Der Entwurfgeber war offensichtlich bemüht, eine einfache Regelung zur Begebung stimmrechtsloser Anteile zu schaffen, die die Regelung über die Gestaltung eines flexiblen Stimmrechts in der Satzung mit einbezieht. So gibt es in dem Entwurf keine Ausnahmen vom Stimmverbot, etwa bei der Beschlussfassung über Grundlagengeschäfte, wie es zum Teil in anderen Ländern geregelt ist. Damit sollen die von der Expertengruppe beschworenen und bei dem Vorentwurf für den Verzicht auf die Einführung stimmrechtsloser Anteile maßgeblichen (Abgrenzungs-)Schwierigkeiten vermieden werden ${ }^{683}$.

Nach dem neuen Art. 2:228 Abs. 5 NBG kann die Stimmrechtslosigkeit eines Anteils vor dessen Ausgabe bestimmt werden. Nach der Ausgabe kann dem Geschäftsanteil beziehungsweise der Gattung von Geschäftsanteilen nur noch mit Zustimmung aller von dem Beschluss betroffenen Gesellschafter die Stimmberechtigung entzogen werden. Der Inhaber eines stimmrechtslosen Anteils ist kein Gesellschafter zweiter Klasse, sondern besitzt sämtliche mit der Mitgliedschaft in der B.V. verbundenen (Gesellschafter-)Rechte, mit Ausnahme eben des Stimmrechts; insbesondere ist er berechtigt, an Gesellschafterversammlungen teilzunehmen und Dividenden zu erhalten ${ }^{684}$. Des Weiteren ist in dem Entwurf vorgesehen, dass die Inhaber stimmrechtsloser Anteile gemäß Art. 2:346 NBG unter vereinfachten Bedingungen berechtigt sein sollen, ihr Enquêterecht auszuüben. Schließlich haben die Inhaber stimmrechtsloser Anteile die Möglichkeit, auf Grundlage des Art. 2:15 NBG einen Beschluss durch einen Richter für nichtig erklären zu lassen oder ein entsprechendes Gerichtsverfahren anzustrengen ${ }^{685}$.

${ }^{680}$ Gesetzesbegründung Vorentwurf, Erste Tranche, S. 11 und 23 f.; kritisch auch schon C.A. Schwarz Aandelen S. 4 ff.

681 Nicht zuletzt wegen der Kritik aus der Literatur vgl. nur Verbrugh Ondernemingsrecht 2006, 618 m.w.N. sowie jüngst Portengen WPNR 2007, 940, 942 ff. und ten Berg Ondernemingsrecht 2007, 341.

682 Gesetzesbegründung Entwurf, Allgemeiner Teil, S. 14; Besonderer Teil 107 ff.

683 Gesetzesbegründung Entwurf, Allgemeiner Teil, S. 15; Besonderer Teil $107 \mathrm{ff}$.

684 Gesetzesbegründung Entwurf, Allgemeiner Teil, S. 15; Besonderer Teil 108 f.

685 Gesetzesbegründung Entwurf, Allgemeiner Teil, S. 15; Besonderer Teil 109. 
Im Zusammenhang mit der Einführung stimmrechtsloser Anteile sind auch die Artikel 2:24d, 63a, 152, 175, 190, 194, 206a, 242, 252, 262 und 346 NGB angepasst worden. Insoweit wird auf die Besprechung an den entsprechenden Stellen verwiesen.

\section{dd) Das Enquêterecht und die Gesellschafterklage im niederländischen Recht}

Der Gesetzgeber hat erkannt, dass sich die existierende Regelung zur Gesellschafterklage („Geschillenregeling“) in Abschnitt 1 des zweiten Buches des niederländischen Gesetzbuches in der Praxis als untauglich erwiesen hat ${ }^{686}$. Seit Inkrafttreten der Regelung wurden nur ungefähr 15 Verfahren durchgeführt. Die Ursachen für diese mangelhafte Bilanz meint der Gesetzgeber identifiziert zu haben: zum einen in der überlangen Verfahrensdauer, zum anderen in den Beschränkungen, denen ein Ausschluss oder der Austritt eines Mitgesellschafters in der Vergangenheit de lege lata unterliegt (Art. 2:336 NBG) ${ }^{687}$. Der Gesetzentwurf sieht umfassende Änderungen der Artt. 2:336 ff. NBG vor ${ }^{688}$. Zu den wesentlichen Änderungen zählen zum einen die beabsichtigte Konzentration der Verfahren bei dem Gericht am Sitz der Gesellschaft durch Regelung einer ausschließlichen Gerichtstandes und durch die Erweiterung der Entscheidungszuständigkeiten des Richters erster Instanz (vgl. Art. 2:336 NBG-E) ${ }^{689}$; zum anderen die Regelung von Ausnahmetatbeständen, die es den Gesellschaftern gestatten, künftig den (Gesellschafter-)Klageweg für bestimmte Bestimmungen in der Satzung auszuschließen beziehungsweise zu eröffnen (Art. 2:337 NBG) ${ }^{690}$. Schließlich war es in der Vergangenheit oft so, dass Kläger die Klageerhebung scheuten, da es den Beklagten möglich war, die Folgen eines stattgebenden Urteils durch Einlegung von Rechtsmitteln weit aufzuschieben. Art. 2:338 NBG-E sieht daher nunmehr vor, dass eine Entscheidung für vorläufig vollstreckbar erklärt werden kann ${ }^{691}$. Die Folgen eines (stattgebenden) Urteils werden in den Artt. 2:339 ff. NBG-E ${ }^{692}$ geregelt; hierzu wurden insbesondere drei neue Artikel (Artt. 2: 343 a bis c NBG) ${ }^{693}$ ins Niederländische Gesetzbuch eingefügt, die unter anderem die Pflichten der Beklagten regeln und Vereinfachungen bei der Abwicklung durch Festlegung der Übertragungsparameter (wie etwa des Abfindungsbetrages usw.) vorsehen. Weitere vereinfachende Verfahrensänderungen finden sich unter anderem in Art. 2:343 NBG ${ }^{694}$.

686 Begründung des Gesetzesentwurfs, Allgemeiner Teil, S. 21.

687 Begründung des Gesetzesentwurfs, Allgemeiner Teil, S. $21 \mathrm{f}$.

688 Siehe dazu im Einzelnen auch Roest WPNR 2007, 959 ff. m. w. N.

689 Begründung des Gesetzesentwurfs, Besonderer Teil, S. 124 f. Roest WPNR 2007, 959, $961 \mathrm{f}$.

690 Begründung des Gesetzesentwurfs, Besonderer Teil, S. 125 f.; Roest WPNR 2007, 959, 962.

691 Begründung des Gesetzesentwurfs, Besonderer Teil, S. 128 f.; Boschma/Schutte-Veenstra 2007 S. $197,204$.

692 Begründung des Gesetzesentwurfs, Besonderer Teil, S. $129 \mathrm{ff}$.

693 Begründung des Gesetzesentwurfs, Besonderer Teil, S. 136 ff.; Roest WPNR 2007, 959, 962 ff.

694 Begründung des Gesetzesentwurfs, Besonderer Teil, S. 136 ff.; Roest WPNR 2007, 959, 961. 


\section{ee) Aufsichtsrat}

Mit dem Entwurf des Art. 2:252 NBG-E sorgt der Entwurfgeber für einen Gleichlauf der Bestellungskompetenzen, indem er in Art. 2:252 NBG-E - wie bereits in Art. 2:242 NBG-E, die Bestellung der Geschäftsführer betreffend - vorsieht, dass die grundsätzlich der Gesellschafterversammlung zustehende Bestellungskompetenz, einzelnen Gesellschaftern oder bestimmten Gruppen von Gesellschaftern zugewiesen werden kann. Möglich ist auch, dass nur für die Bestellung eines Teils der Aufsichtsratsmitglieder eine anderweitige Zuordnung der Kompetenzen (auch auf Dritte) erfolgt und für wenigstens zwei Drittel der Aufsichtsratsmitglieder die Kompetenz bei der Gesellschafterversammlung verbleibt, Art. 2:253 NBG-E. Gänzlich ausgeschlossen ist das Verfahren des Art. 2:252 NBG-E, wenn die Errichtung des Aufsichtrats zwingend nach Maßgabe des Art. 2:268 NBG erfolgt. Wie in Art. 2:242, 243 NBG-E soll schließlich auch bei der Bestellung der Aufsichtsratsmitglieder nach Maßgabe des Art. 2:252 Abs. 2 NBG-E die Pflicht zur Nennung mehrerer Kandidaten zur Wahl eines Aufsichtsratsmitglied künftig entfallen ${ }^{695}$.

Die Neutralität des Aufsichtsratsmitglieds - so heißt es in der Gesetzesbegründung ${ }^{696}$ - werde durch die Bestellung eines Aufsichtsratsmitglieds durch einzelne Gesellschafter oder Gesellschaftergruppen nicht in Frage gestellt. An verschiedenen Stellen im Gesetz fänden sich Richtlinien, die die Unabhängigkeit des Aufsichtsratsmitglieds garantierten. So beschreibe etwa Art. 2:250 Abs. 2 NBG konkret die dem Aufsichtsrat zugewiesenen Aufgaben und verlange, dass jedes einzelnen Aufsichtratsmitglied sich der Erfüllung dieser Aufgaben zum Wohle der Gesellschaft und der von dieser verfolgten Ziele verschreibe ${ }^{697}$.

Synchronisiert werden die Regelungen zu Geschäftsführern und Aufsichtsratsmitgliedern auch im Hinblick auf die Notwendigkeit zur Schaffung von Regelungen für den Fall der Indisponibilität aller oder einiger Aufsichtsratsmitglieder (Art. 2:252 Abs. 4 NBG-E; vgl. insoweit auch Art. 2:244 Abs. 4 NBG-E) ${ }^{698}$.

Wie die Bestimmungen zur Bestellung der Aufsichtsratsmitglieder, so werden auch die Regelungen zur Suspendierung und Abberufung derselben den Vorschriften betreffend die Geschäftsführer angepasst. So kann die Satzung künftig gemäß Art. 2:254 NBG-E bestimmen,

695 Gesetzesbegründung Erste Tranche S. 37; Begründung des Gesetzesentwurfs, Besonderer Teil, S. 120 ff.

696 Begründung des Gesetzesentwurfs, Besonderer Teil, S. 122.

697 Begründung des Gesetzesentwurfs, Besonderer Teil, S. 121.

698 Begründung des Gesetzesentwurfs, Besonderer Teil, S. $121 \mathrm{f}$. 
dass ein Aufsichtsratsmitglied außer von seinem Besteller (vgl. insoweit die Änderungen des Art. 2:257 NBG-E ${ }^{699}$ ) auch von der Gesellschafterversammlung suspendiert oder abberufen werden $\mathrm{kann}^{700}$ (vgl. hierzu auch Art. 2:244 NBG-E) $)^{701}$.

\section{b) Reformüberlegungen in Praxis und Literatur}

\section{aa) Geschäftsführung und Vertretung}

\section{aaa) Vertretung der Gesellschaft, Aufgaben und Befugnisse}

Weiter noch als die Vorschläge des Entwurfs geht der Gedanke, dass in der Satzung der BV geregelt können werden soll, dass sämtliche Geschäftsführungsbefugnisse auf die Gesellschafterversammlung übertragen sind; die B.V. mithin ohne Geschäftsführer auskommt, sondern durch die Gesellschafterversammlung vertreten wird. Der Vorschlag den namentlich Timmermanns $^{702}$ und Van Duuren ${ }^{703}$ unterbreitet haben, impliziert eine komplette Neuausrichtung des Gesetzes auf eine (Geschäfts-)führerlose BV; das Haftungsregime sowie die Formalitäten betreffend die interne Beschlussfassung und die Gesellschafterversammlungen müssten umgeschrieben werden.

\section{bbb) Verantwortung und Haftungsregime}

\section{(i) Einführung einer Wrongful Trading Haftung des Geschäftsführers}

In der Literatur wird zum Teil eine Verschärfung der Haftung des Geschäftsführers und gegebenenfalls der Gesellschafter nach dem Vorbild der angelsächsischen „,wrongful trading“ $\mathrm{Ru}$ le gefordert. ${ }^{704}$

699 Begründung des Gesetzesentwurfs, Besonderer Teil, S. 122 f.

700 Begründung des Gesetzesentwurfs, Besonderer Teil, S. 122.

701 Begründung des Gesetzesentwurfs, Besonderer Teil, S. 118.

702 Timmermann Ondernemingsrecht 2004, $27 \mathrm{f}$.

703 Vgl. die Nachweise bei Verbrugh Ondernemingsrecht 2006, 618 ff.

704 Zum Rechtsinstitut des wrongful trading, seinen Hintergünden und praktischen Auswirkungen sowie Konsequenzen bei einer Einbindung in das niederländische Rechtssystem vgl. nur Olaerts S. 229 mit zahlreichen Hinweisen zur niederländischen und angloamerikanischen Literatur. Siehe punktuell auf die Reformbestrebungen bezogen Lennarts Ondernemingsrecht 2004, 16, 19 f.; Timmermann Ondernemingsrecht 2003, 42 und Ähnliche Überlegungen werden auch in der deutsche Literatur angestellt. Zu den Einzelheiten einer solchen Haftung vgl. die entsprechenden Ausführungen unter $§ 1$ IV. 2. b) bb) aaa) (iii). 
Die niederländischen Befürworter der Aufnahme einer solchen Haftungsnorm in das Regelungswerk der B.V., namentlich Lennarts und Timmermann, schlagen vor, hierfür die Regelung des Art. 2:248 NBG zu ändern und die Wendung ,,belangrijke oorzaak van het faillissement“ („,bedeutsame Ursache für die Insolvenz“) durch die Aussage „,belangrijke oorzaak van het tekort“ (,,bedeutsame Ursache für den Mangel“) zu ersetzen ${ }^{705}$.

\section{(ii) Einführung von Ausschlussgründen}

Die verschärfte Insolvenzverschleppungshaftung auf der Grundlage des wrongful tradings soll nach der Vorstellung einiger Autoren einhergehen mit der Möglichkeit der Verhängung mehrjähriger Berufsverbote, so wie sie in England nach Maßgabe des Company Directors Disqualification Acts im Zusammenhang mit der Insolvenzverschleppung ausgesprochen werden können ${ }^{706}$.

\section{bb) Gesellschafter und Geschäftsanteile}

In Ergänzung des neu gefassten Art. 2:238 NBG, der eine Beschlussfassung auch außerhalb von Gesellschafterversammlungen möglich macht, wird vorgeschlagen die Erstellung einer Niederschrift zum Wirksamkeitserfordernis für den Beschluss zu machen. Des Weiteren wird vorgeschlagen, dass eine Beschlussfassung dann in einer Gesellschafterversammlung stattfinden müsse, wenn auch nur ein Gesellschafter di Abhaltung einer Gesellschafterversammlung verlangt ${ }^{707}$.

705 Lennarts Ondernemingsrecht 2004, 16, 20; Timmermann Ondernemingsrecht 2003, 42; daneben beleuchten Lennarts/Timmermann De NV 1997, 308 und Boschma/Lennarts 1994 S. 285 ff. außerdem die deutsche Regelung der Überschuldungshaftung.

706 Lennarts Ondernemingsrecht 2004, 16, 20 f. Vgl. Disqualified Directors Register, abrufbar unter www.companieshouse.gov.uk; siehe dazu aus der „,deutschen“ Literatur Gernoth, Pseudo Foreign Companies - Who Art Thou?, 2005, S. 159 ff; Siehe hierzu Fleischer, WM 2004, 157, 160 f.; Hirte/Lanzius/Mock, in: Lutter, Arbeitskreis Kapital in Europa, 2006, D I; Lanzius, ZInsO 2004, 296 ff.; Boyle \& Birds', Company Law, Rdn. $15.16 .1 \mathrm{ff}$.

707 Timmermann Ondernemingsrecht 2004, 27 f. 


\section{Finanzverfassung}

\section{Bestehende Rechtslage}

\section{a) Kapitalaufbringung}

\section{aa) Stammkapital}

Gemäß Art. 2:178 Abs. 2 NBG muss das genehmigte Kapital, das gezeichnete Kapital und das davon eingezahlte Kapital bei der Gründung der Gesellschaft mindestens das gesetzlich vorgeschriebene Mindestkapital von derzeit $18.000 €$ abbilden. Vom genehmigten Kapital müssen mindestens $20 \%$ ausgegeben und gezeichnet sein (Art. 2:178 Abs. 4 NBG). In der Gründungsurkunde sind außerdem die Übernehmer der Geschäftsanteile, die Anzahl der jeweils übernommenen Geschäftsanteile sowie die darauf bereits geleisteten Einlagen zu benennen ${ }^{708}$.

\section{bb) Bareinlagen}

Anders als nach deutschem Recht ist eine Einzahlung der Stammeinlagen in Geld auch schon vor oder während der Gründung gestattet. In einem solchen Fall ist allerdings bei Gründung dem Notar eine Bankbestätigung vorzulegen, die bestätigt, dass die Beträge, die auf die bei der Gründung zu übernehmenden Geschäftsanteile eingezahlt werden müssen, entweder unmittelbar nach der Gründung zur Verfügung der Gesellschaft stehen oder zu einem gleichen Zeitpunkt, frühestens fünf Monate vor der Gründung, einem separaten Konto gutgeschrieben worden sind, welches nach der Gründung ausschließlich zur Verfügung der Gesellschaft steht (Art. 2:203a NBG) ${ }^{709}$.

Die Einzahlung der Einlagen ist auch in fremder Währung ist zulässig, dies allerdings nur wenn die Gründungsurkunde dies gestattet. Nach der Gründung kann eine Einzahlung von Stammeinlagen nur noch mit dem Einverständnis der Gesellschaft in fremder Währung erfolgen und dies auch nur dann mit Erfüllungswirkung, wenn die Werthaltigkeit des Einzah-

708 Vgl. zum Ganzen Süß/Wachter/Rademakers/de Vries S. 1117; Hirte/Bücker/Rammeloo/de Kluiver S. 208; Bier Ondernemingsrecht 2004, 10 ff.; Asser-Maeijer 2-III, Kap. III; Schilfgarde/Winter, Kap. 3 sowie Gotzen, in: Behrens, Die GmbH Rn. NL 40 ff. und Mehring, GmbH-Rechte S. 205, 212 ff.

709 Süß/Wachter/Rademakers/de Vries S. 1117; Asser-Maeijer 2-III, Kap. III; Schilfgarde/Winter, Kap. 3. 
lungsbetrages gemäß Art. 2:203 a NBG durch Angabe des Wechselkurses am betreffenden Tag nachgewiesen wird ${ }^{710}$.

\section{cc) Sacheinlagen}

Wie nach deutschem Recht werden als Sacheinlagen zur Sicherung der Kapitalaufbringung nur solche Vermögensgegenstände anerkannt, denen ein nach wirtschaftlichen Maßstäben feststellbarer Wert innewohnt. Unproblematisch ist danach die Einlage von Eigentum an beweglichen und unbeweglichen Sachen sowie grundstücksgleichen Rechten aber auch von Forderungen mit einem feststellbaren wirtschaftlichen Wert. Zulässig ist des Weiteren die Einbringung von Immaterialgüterrechten, obwohl gerade hier eine Feststellung des Wertes regelmäßig Schwierigkeiten bereitet, wie etwa die Einbringung des Goodwills und das KnowHow eines Unternehmens sowie Rechte wie Patente, Marken und Lizenzen. Die Verpflichtung zur Erbringung von Arbeits- oder Dienstleistungen werden als Sacheinlage nicht anerkannt. Andererseits kann eine Forderung aufgrund schon ausgeübter Arbeit oder geleisteter Dienste durchaus eine geeignete Sacheinlage sein. Für die Fälligkeit der Sacheinlagen bestimmt Art. 2:191b Abs. 2 NBG, dass diese unverzüglich nach Übernahme des Geschäftsanteils, oder nach dem Tag an dem ein Nachschuss ausgeschrieben oder vereinbart wurde, vollständig zu erbringen $\operatorname{sind}^{711}$.

Sollen die Gründung als Sachgründung erfolgen, so haben die Gründer den Gegenstand der Sacheinlage unter Angabe des Wertes und der Bewertungsmethode, die üblichen Methoden entsprechen muss, in der Gründungsurkunde zu beschreiben (Art. 2:204a NBG). Außerdem wird der Gründungsurkunde ein von den Gründern zu erstellender Bericht, ähnlich dem deutschen Sachgründungsbericht, beigefügt, der zum Zeitpunkt der Gründung nicht älter als fünf Monate sein darf, wenigstens aber einen Monat vor Antrag der Unbedenklichkeitserklärung aufgestellt sein muss. Der Bericht ist nach seiner Erstellung in den Geschäftsräumen der Gesellschaft für die Gesellschafter und Inhaber von Geschäftsanteilsscheinen zu Einsichtnahme auszulegen. Der in dem Sachgründungsbericht ermittelte Wert der Sacheinlage sowie die Angemessenheit des Wertes für den einzuzahlenden Betrag ist durch einen Wirtschaftsprüfer festzustellen. Auch dieser Prüfvermerk ist in die Gründungsurkunde aufzunehmen ${ }^{712}$.

710 Süß/Wachter/Rademakers/de Vries S. 1117; Bier Ondernemingsrecht 2004, 10 ff.; Asser-Maeijer 2-III, Kap. III; Schilfgarde/Winter, Kap. 3.

711 Süß/Wachter/Rademakers/de Vries S. 1118; Bier Ondernemingsrecht 2004, 10 ff.; Asser-Maeijer 2-III, Kap. III; Schilfgarde/Winter, Kap. 3.

712 Süß/Wachter/Rademakers/de Vries S. 1118; Bier Ondernemingsrecht 2004, 10 ff.; Asser-Maeijer 2-III, Kap. III; Schilfgarde/Winter, Kap. 3. 
Ein Gesellschafter kann (nachträglich) nicht verpflichtet werden, mehr als den Nennbetrag des Geschäftsanteils einzuzahlen, auch nicht, wenn dies mit satzungsändernder Mehrheit beschlossen und so in den Gesellschaftsvertrag festgeschrieben wird (Art. 2:192 NBG) ${ }^{713}$.

\section{dd) Nachgründung}

Die Nähe der B.V. zur niederländischen N.V. wird ein weiteres Mal belegt durch die Vorschrift des Art. 2:204c NBG, in dem die in Deutschland nur für Aktiengesellschaften bekannte Nachgründung geregelt ist.

Danach bedürfen Rechtsgeschäfte die die Gesellschaft im zeitlichen Zusammenhang mit ihrer Gründung tätigt, der Zustimmung der Gesellschafterversammlung oder der Erklärung eines Wirtschaftsprüfers i. S. v. Art. 2:204c Abs. 3 NBG, wenn das Rechtsgeschäft Vermögensgegenstände betrifft, die ein Jahr vor der Gründung oder nachher einem Gründer oder Gesellschafter gehört haben und das Rechtsgeschäft innerhalb von zwei Jahren nach der Eintragung der Gesellschaft ins Handelsregister geschlossen wurde. Wird die Einholung der Zustimmung oder der Erklärung i. S. v. Art. 2:204c Abs. 3 NBG versäumt, besteht gemäß Art. 2:204c NBG die Möglichkeit, das Rechtsgeschäft zu Gunsten der Gesellschaft für nichtig zu erklären ${ }^{714}$.

Wird vor Abschluss des Rechtsgeschäfts, die Zustimmung der Gesellschafterversammlung eingeholt, so hat die Gesellschaft - wie bei der Sacheinlagevereinbarung - zuvor einen Bericht über die zu erwerbenden Gütern und die zu erbringende Gegenleistung zu erstellen. Anders als bei dem Sachgründungsbericht nach Maßgabe des Art. 2:204a NBG wird dieser Bericht von der Geschäftsführung der Gesellschaft unterschrieben. Auch dieser Bericht wird durch einen Wirtschaftsprüfer, insbesondere im Hinblick auf die Bewertung von Gegenstand und Gegenleistung überprüft. Schließlich werden der Bericht und der Prüfungsvermerk in den Gesellschaftsräumen der Gesellschaft für die Gesellschafter und die Inhaber von Geschäftsanteilszertifikaten zur Einsichtnahme ausgelegt. Des Weiteren ist in einem Zeitraum von acht Tagen nach Abschluss des Rechtsgeschäfts oder Erteilung der Erlaubnis, eine Abschrift der Erklärung des Wirtschaftsprüfers beim Handelsregister zu hinterlegen ${ }^{715}$.

713 Allerdings haften die Gesellschafter für den Differenzbetrag, wenn der Wert der Einlage unter dem Nennbetrag des dafür ausgegebenen Kapitals liegt. Jansen GmbHR 1995, 286; Süß/Wachter/Rademakers/de Vries S. 1118; Bier Ondernemingsrecht 2004, 10 ff.; siehe hierzu auch unten bei dem Aspekt der „Nachschusspflicht".

714 Asser-Maeijer 2-III, Kap. III; Schilfgarde/Winter, Kap. 3.; Süß/Wachter/Rademakers/de Vries S. 1118; Bier Ondernemingsrecht 2004, $10 \mathrm{ff}$.

715 Asser-Maeijer 2-III, Kap. III; Schilfgarde/Winter, Kap. 3.; Süß/Wachter/Rademakers/de Vries S. 1118; Bier Ondernemingsrecht 2004, 10 ff. 


\section{ee) Nachschusspflicht}

Anders als in Deutschland ist die Vereinbarung von Nachschusspflichten in den Niederlanden auch gegen den Willen einzelner Gesellschafter mit einer Mehrheit von zwei Dritteln der abgegebenen Stimmen gestattet (Art. 2:192 NBG). Allerdings wirkt eine solche mehrheitlich getroffene Entscheidung nicht zulasten der unterliegenden Minderheit; widerspricht ein Gesellschafter der Nachschusspflicht, so ist dieser nicht an die Verpflichtung gebunden ${ }^{716}$.

\section{b) Kapitalerhaltung}

\section{aa) Kapitalschutz}

Nach niederländischem Recht haftet den Gläubigern gegenüber, wie in Deutschland und Frankreich auch, allein die B.V. mit ihrem Gesellschaftsvermögen. Die Gesellschafter haften im Grundsatz allein für die Einzahlung ihrer Einlage. Daher ist es für Gläubiger besonders wichtig, dass die Gesellschaft über genügend Kapital verfügt, um ihre Verbindlichkeiten zu erfüllen. Einen Minimalschutz bietet die Verpflichtung, die Gesellschaft bei Gründung mit einem Mindestkapital von $18.000 €$ auszustatten. Daneben schreibt das Gesetz die Bildung von Rücklagen vor. Hierbei werden gesetzliche und statutarische Rücklagen unterschieden. Mindestkapital und Rücklagen bilden zusammen das gebundene Kapital der Gesellschaft ${ }^{717}$.

Nach Art. 2:216 Abs. 2 NBG darf ein Jahresüberschuss nur dann an die Gesellschafter und andere Berechtigte ausgeschüttet werden, soweit das Eigenkapital größer ist als der eingezahlte und abgerufene Teil des Kapitals, vermehrt um die Rücklagen, die aufgrund des Gesetzes oder des Gesellschaftsvertrages gebildet werden müssen. Weiteren Schutz gewährt der niederländische Gesetzgeber durch Beschränkungen des Erwerbs von eigenen Anteilen durch die Gesellschaft und die Kapitalherabsetzung ${ }^{718}$.

\footnotetext{
716 Asser-Maeijer 2-III, Kap. III; Schilfgarde/Winter, Kap. 3.; Süß/Wachter/Rademakers/de Vries S. 1118; Gotzen, in: Behrens, Die GmbH Rn. NL 40.

717 Bier Ondernemingsrecht 2004, 10, 14 f.; Gotzen, in: Behrens, Die GmbH Rn. NL 42; Süß/Wachter/Rademakers/de Vries S. 1120.

718 Asser-Maeijer 2-III, Kap. III; Schilfgarde/Winter, Kap. 3.; Süß/Wachter/Rademakers/de Vries S. 1120 und $1122 \mathrm{f}$.
} 


\section{bb) Eigenkapitalersatzrecht}

Das niederländische Recht kennt im Gegensatz zum deutschen Recht keine Eigenkapitalersetzenden Darlehen ${ }^{719}$.

\section{c) Eigene Anteile}

Art. 2:205 NBG enthält ein Übernahmeverbot für eigene Anteile, das heißt es ist einer niederländischen B.V. prinzipiell verwehrt, Geschäftsanteile bei oder nach der Gründung bei sich selber unterzubringen oder an sich selbst auszugeben ${ }^{720}$.

Nicht verboten ist hingegen der Erwerb eigener Anteile, wenn die Einlagen auf die Anteile voll geleistet sind und die Gesellschaft die Geschäftsanteile unentgeltlich oder bis zu einer im Gesellschaftsvertrag festgelegten Höchstgrenze erwirbt (Art. 2:207 NBG). Auch muss der Erwerb eigener Anteile im Gesellschaftsvertrag generell vorgesehen sein und die Gesellschafterversammlung oder ein anderes (aufgrund des Gesellschaftsvertrages ernanntes) Organ den konkreten Erwerb autorisieren. Weitere Voraussetzung für einen solchen Erwerb ist, dass das Eigenkapital, abzüglich des Erwerbspreises der Geschäftsanteile, nicht geringer ist als das eingezahlte und abgerufene Kapital, vermehrt um die Rücklagen, die die Gesellschaft aufgrund des Gesetzes oder des Gesellschaftsvertrages zu bilden hat. Außerdem darf der Nennbetrag der zu erwerbenden und schon von der Gesellschaft und ihren Tochtergesellschaften gemeinsam gehaltenen Geschäftsanteile nicht mehr als die Hälfte des gezeichneten Kapitals betragen $^{721}$.

719 Süß/Wachter/Rademakers/de Vries S. 1120; Mellert/Verfürth S. 151; Mehring Gesellschaftsrecht Rn, 269.

720 Süß/Wachter/Rademakers/de Vries S. 1120; Hirte/Bücker/Rammeloo/de Kluiver S. 214 f.

721 Asser-Maeijer 2-III, Kap. III; Schilfgarde/Winter, Kap. 3.; Süß/Wachter/Rademakers/de Vries S. 1120; Gotzen in Behrens, Die GmbH, Rn. NL 42; Hirte/Bücker/Rammeloo/de Kluiver S. $214 \mathrm{f}$. 


\section{Reformvorschläge}

\section{a) Reformansätze des Entwurfs eines Gesetzes zur Vereinfachung und Flexibilisierung des B.V.-Rechts (,Wet vereenvoudiging en flexibilisering bv-recht*6)}

aa) Kapitalaufbringung

\section{aaa) Vorbemerkung}

Bislang basierte das niederländische Rechtssystem - gleich dem deutschen Recht und im Einklang mit den kontinentaleuropäischen Vorgaben ${ }^{722}$ - auf den Grundsätzen der (Mindest-) Kapitalaufbringung und der Kapitalerhaltung. Für die Errichtung einer Gesellschaft mit beschränkter Haftung nach niederländischem Recht war die Aufbringung eines Mindestkapitals von $18.000 €$ erforderlich (Art. 2:178 Abs. 2 NBG). Ausschüttungen an die Gesellschafter waren nur eingeschränkt, nämlich nur dann möglich, wenn hierdurch das Stammkapital nicht geschmälert wird ${ }^{723}$.

Mit dem hier vorgelegten Entwurf ${ }^{724}$ hat der niederländische Gesetzgeber das existierende (europäische) System des Kapitalschutzes zugunsten des anwenderfreundlicheren angelsächsischen Systems aufgegeben. Konkret beinhalten die wichtigsten Änderungen des BV-Rechts die Abschaffung des Mindestkapitals, die Einführung eines Solvenztests anhand einer vereinfachten Bilanzprüfung (so genannter „Balance Sheet Test“) für alle Formen der Auskehrung von Gesellschaftsvermögen an Gesellschafter im Zusammenhang mit verschärften Haftungsnormen für die Geschäftsführer und Rückerstattungspflichten der Gesellschafter.

Ebenso ist die bisher vorgeschriebene Bankbestätigung, die in der Praxis als erhebliche Einschränkung empfunden wurde, nicht mehr erforderlich und wird daher abgeschafft (Art. 2:203a $\mathrm{NBG}^{725}$ ). Dasselbe trifft auf die schwierige Regelung hinsichtlich der Geschäfte mit Gesellschaftern in der Gründungsphase zu (Nachgründung, Art. 2:204c NBG ${ }^{726}$ ) und die Regelung hinsichtlich der Mittelzuwendung gegenüber Dritten (Art. 2:207c $\mathrm{NBG}^{727}$ ).

\footnotetext{
Vgl. insoweit nur die zweite gesellschaftsrechtliche Richtlinie („Kapitalrichtlinie“) von 1976, Richtlinie 77/91/EWG v. 13.12.1976.

723 Vgl. hierzu im Einzelnen oben in diesem Abschnitt V. 1. b) aa).

724 Gesetzesbegründung Entwurf, Allgemeiner Teil, S. 34; Besonderer Teil 50 ff.

725 Gesetzesbegründung Entwurf, Besonderer Teil 77.

726 Gesetzesbegründung Entwurf, Besonderer Teil $79 \mathrm{f}$.

727 Gesetzesbegründung Entwurf, Besonderer Teil $83 \mathrm{f}$.
} 


\section{bbb) Stammkapital}

Auch nach dem Willen des Entwurfs ${ }^{728}$ bleibt es dabei: Die Errichtung einer B.V. soll künftig auch ohne Beibringung eines Mindeststammkapitals möglich sein (Art. 2:178 NBG). Die Gründer - oder, bei einer späteren Ausgabe von Geschäftsanteilen, das hierzu berechtigte Organ - haben die Höhe der auf die ausgegebenen Anteile zu zahlenden Einlage zu bestim$\operatorname{men}^{729}$.

Die fehlende gesetzliche Festlegung eines dem Gesellschaftszweck entsprechenden adäquaten Gesellschaftsvermögens hat zur Folge, dass bereits bei der Errichtung das Anfangsvermögen der Gesellschaft durch die Gründungskosten aufgezehrt, d.h. negativ sein mag. Nichtsdestotrotz hat sich der Niederländische Gesetzgeber gegen eine Regelung entschieden, die wenigstens ein positives Anfangsvermögen verlangt. Nach der Überzeugung des Gesetzgebers reicht die Ausfallhaftung der Geschäftsführer aufgrund des Art. 2:203 Abs. 3 NBG aus, um ein adäquates Vermögen der Gesellschaft sicherzustellen. Dies wird in Absatz 4 des Art. 2:203 NBG-E nochmals ausdrücklich klargestellt. Gemäß Art. 2:203 Abs. 3 NBG haftet ein Geschäftsführer anstelle der Gesellschaft für eine Verbindlichkeit, wenn er bei deren Eingehung wusste oder wissen musste, dass die Gesellschaft sie nicht zu erfüllen vermag ${ }^{730}$

\section{ccc) Bareinlagen}

Etwas anderes gilt für die auf das Stammkapital zu leistenden Einlagen; sie haben stets positiv zu sein. Die Aufhebung des Mindestkapitalerfordernisses hat allerdings zur Folge, dass eine B.V. künftig mit sehr geringem Anfangskapital, im Extremfall mit zwei Geschäftsanteilen mit einem Nennwert von jeweils $0.01 €$ errichtet werden kann. Das gezeichnete Kapital und die darauf eingezahlte Einlage sind in der Gründungsurkunde (nicht im Gesellschaftsvertrag) zu erwähnen. Die möglicherweise geringe Kapitalausstattung der Gesellschaft ist damit sichtbar für den Rechtsverkehr ${ }^{731}$.

Die Einlagen sind künftig erst nach Aufforderung der Gesellschaft zu erbringen. Das kann zur Folge haben, dass bei Errichtung das Stammkapital nur durch Einbuchung entsprechender ausstehender Forderungen gegen die Gesellschafter abgebildet werden kann. Die Forderung

\footnotetext{
728 Begründung des Gesetzesentwurfs, Allgemeiner Teil, S. 33. Einen zusammenfassenden Überblick über die in der dritten Tranche des Vorentwurfs enthaltenen Reformvorschläge gibt Bier Ondernemingsrecht 2006, 350 .

729 Begründung des Gesetzesentwurfs, Allgemeiner Teil, S. 33, Besonderer Teil S. 50 f.

730 Begründung des Gesetzesentwurfs, Besonderer Teil, S. 77.

731 Begründung des Gesetzesentwurfs, Allgemeiner Teil, S. 34; Besonderer Teil S. 50 f.
} 
auf Erbringung der Einlagen verjährt wie bisher nach 5 Jahren (Art. 2:307 Abs. 1 NBG). Die Frist wird gehemmt durch schriftliche Anmahnung der Einlageforderung (Art. 2:317 NBG). Weitergehenden Forderungen nach einer Verlängerung der Verjährungsfrist auf 20 Jahre hat der Gesetzgeber damit eine Absage erteilt ${ }^{732}$.

\section{ddd) Sacheinlagen}

Bei Erbringung einer Sacheinlage, soll nach dem Willen des Gesetzgebers künftig kein Prüfergutachten mehr erforderlich sein. Jedoch enthält die im Vorentwurf vorgeschlagene Regelung einige spezifische Richtlinien in Bezug auf die Anerkennung der Sacheinlage, unter anderem eine Beschreibung des einzubringenden Gegenstandes durch den Geschäftsführer. Wenn sich ergibt, dass der Wert des Vermögensgegenstandes niedriger ist als der Betrag der Einlageverpflichtung, ist der Gesellschafter verpflichtet, den Wertunterschied in Geld auszugleichen (Art. 2:204a und 204b NBG) ${ }^{733}$.

Anders als noch bei Erarbeitung des amtlichen Vorentwurfs beabsichtigt, will der Gesetzgeber nunmehr an dem Verbot der Einlagenerbringung durch Leistung von Arbeitskraft oder Dienstleistungen festhalten (vgl. Art. 2:191b NBG). Hintergrund für die Beibehaltung dieses Verbots sind Bewertungsschwierigkeiten bei der Umschreibung der Arbeits- oder Dienstleistungen in Kapital ${ }^{734}$.

\section{eee) Nachschusspflicht}

Entgegen dem noch im amtlichen Vorentwurf ${ }^{735}$ verfolgten Ansatz, die Entscheidung über die Aufnahme weiterer statutarischer Verpflichtungen und deren Reichweite, in die Hände der Gesellschafterversammlung zu legen, hält der Entwurf ${ }^{736}$ an der Regelung des bestehenden Art. 2:192 NBG fest, wonach die Aufnahme weiterer, neben der Einlageverpflichtung stehender statutarischer (Nachschuss-)Pflichten gegen den Willen eines Gesellschafters unzulässig ist. Art. 2:192 NBG in der Fassung des Vorentwurfs sah noch vor, dass die Gesellschafter berechtigt sein sollten mit qualifizierter Mehrheit auch gegen den Willen einzelner Gesellschafter die Aufnahme weiterer Verpflichtungen der Gesellschafter gegenüber der Gesell-

\footnotetext{
732 Begründung des Gesetzesentwurfs, Allgemeiner Teil, S. 34; Besonderer Teil S. 50 f.

733 Begründung des Gesetzesentwurfs, Allgemeiner Teil, S. 34; Besonderer Teil S. 77 f.

734 Begründung des Gesetzesentwurfs, Allgemeiner Teil, S. 35.

735 Gesetzesbegründung Zweite Tranche S. 9. Siehe dazu auch die Ausführungen bei van Veen WPNR 2007, 950, $953 \mathrm{ff}$.

736 Begründung des Gesetzesentwurfs, Besonderer Teil S. 55; van Veen WPNR 2007, 950, $953 \mathrm{ff}$.
} 
schaft und auch im Verhältnis der Gesellschafter zueinander zu beschließen. In der Begründung des Entwurfs heißt es hierzu, dass der Umstand, dass einige Anteilsinhaber durch die statutarischen (Zusatz-)Verpflichtungen nicht gebunden sind, in der Praxis keine Probleme bereitet ${ }^{737}$.

Festgehalten wird an der Unterscheidung von statutarischen Verpflichtungen und solchen, die aufgrund von Gesellschaftervereinbarungen bestehen. Die Gesellschafter sollen allerdings künftig nach Maßgabe von Art. 2:192 NBG-E in der Lage sein, die Inhalte der Gesellschaftsvereinbarungen in die Satzung aufzunehmen und sie damit zu gesellschaftsvertraglichen Verpflichtungen umzuqualifizieren. Dergleichen „statutarische Gesellschaftervereinbarungen“ sind rechtlich Satzungsbestimmungen, die als solche auch nur mittels mit qualifizierter Mehrheit zu fassendem Beschluss neu zu fassen, abzuändern oder aufzuheben sind. Im Gegensatz zu ,gewöhnlichen“ Gesellschaftervereinbarungen entfalten sie Wirkung nicht allein im Verhältnis der bereits existierenden Gesellschafter zueinander sondern auch gegenüber künftig der Gesellschaft beitretenden Gesellschaftern. Deren Schutz vor unzumutbaren Belastungen wird gewährleistet durch die Publizität des Gesellschaftsvertrages; jedermann hat die Möglichkeit sich vor dem Beitritt in eine Gesellschaft über deren Satzungsbestimmungen durch Einsichtnahme bei dem Handelsregister zu informieren. Dies setzt selbstverständlich voraus, dass sich sämtliche Verpflichtungen unmittelbar aus der Satzung ergeben; der Möglichkeit Gesellschaftervereinbarungen mittels bloßem Verweis in der Satzung satzungsgleiche Geltung zu verschaffen, hat der Gesetzgeber aus diesem Grunde genauso eine Absage erteilt, wie der Empfehlung der Expertengruppe, eine bestimmbare Verpflichtung in der Satzung genügen zu lassen ${ }^{738}$.

Die Gesellschafter können in der Satzung einem bestimmten Organ der Gesellschaft besondere Befugnisse erteilen. Aus denselben Gründen, die es unmöglich machen, statutarische Verpflichtungen mittels bloßen Verweises in der Satzung zu begründen, sind auch in einem solchem Fall die Befugnisse des Organs explizit in der Satzung zu bestimmen ${ }^{739}$.

\section{fff) Nennwertlose Anteile}

Mit der Abschaffung des Mindestkapitals und der Einführung des Solvenztests stellt sich die Frage, inwieweit nunmehr auch die Möglichkeit besteht Geschäftsanteile ohne Nennwert zu begeben. Dieser Frage soll hier nicht weiter nachgegangen werden; sie ist allerdings bereits

\footnotetext{
737 Begründung des Gesetzesentwurfs, Allgemeiner Teil, S. 17 ff., 19; Besonderer Teil S. 55.

738 Begründung des Gesetzesentwurfs, Allgemeiner Teil, S. 20; Besonderer Teil S. 56.

739 Begründung des Gesetzesentwurfs, Allgemeiner Teil, S. 21; Besonderer Teil S. 56 f.
} 
Thema diverser wissenschaftlicher Untersuchungen und wurde auch vom niederländischen Gesetzgeber in einem Anhang zum Gesetzentwurf diskutiert ${ }^{740}$.

\section{ggg) Nachgründung}

Als Folgeänderung zu Art. 2:204a und b NBG betreffend die Werthaltigkeit von Sacheinlagen, ist künftig auch bei der Nachgründung eine Bescheinigung eines Wirtschaftsprüfers über den Wert des Vermögensgegenstandes nicht mehr erforderlich ${ }^{741}$.

\section{bb) Kapitalerhaltung}

Mit der Abschaffung des Kapitalbegriffs hat sich auch der Vermögensbegriff des niederländischen Gesellschaftsrechts zwangsläufig geändert. Das freie Vermögen der Gesellschaft, also das, was ohne Verletzung von Gläubigerschutzrechten an die Gesellschafter ausgeschüttet werden kann, ist nicht mehr unter Heranziehung eines zu erhaltenden Mindestkapitals zu ermitteln, sondern bedarf nunmehr einer Bewertung der Stabilität beziehungsweise der Liquidität der Gesellschaft als solches. Die Feststellung des ausschüttbaren Vermögens erfolgt durch die Geschäftsführer auf der Grundlage eines so genannten Ausschüttungstests. Danach darf eine Ausschüttung nur erfolgen, wenn die Gesellschaft auch noch nach der Ausschüttung in der Lage ist, in absehbarer Zeit ihre Verbindlichkeiten zu erfüllen ${ }^{742}$.

\section{aaa) Ausschüttungstest}

Der niederländische Ausschüttungstest steht dem noch im Vorentwurf ${ }^{743}$ enthaltenen britischen Solvency Test nahe, verzichtet aber auf die im zweistufigen angelsächsischen System neben dem Solvenztest durchzuführende (vereinfachte) Bilanzierung des Gesellschaftsvermögens $^{744}$.

740 Begründung des Gesetzesentwurfs, Allgemeiner Teil, S. 29.

741 Begründung des Gesetzesentwurfs, Besonderer Teil S. $79 \mathrm{f}$.

742 Begründung des Gesetzesentwurfs, Allgemeiner Teil, S. 36 ff.; Besonderer Teil S. 86 ff.. Siehe zu Ganzen auch Lennarts WPNR 2007, 966 ff., van der Zanden WPNR 2007, 975 ff. sowie jüngst Verkerk O \& F 2008, 43 ff. jeweils m. zahlreichen Hinweisen zu weiterer Literatur.

743 Gesetzesbegründung Dritte Tranche S. 1, 6 ff., $20 \mathrm{ff}$. und $25 \mathrm{ff}$.

744 Begründung des Gesetzesentwurfs, Allgemeiner Teil, S. 36 ff.; Besonderer Teil S. 88 f.; siehe dazu nur Lennarts WPNR 2007, 966, 969 ff. sowie jüngst Verkerk O \& F 2008, 43 ff. jeweils m. zahlreichen Hinweisen zu weiterer Literatur. 
Im Wesentlichen kritisiert der Entwurfgeber die mangelnde Flexibilität des Bilanztests bei der Ermittlung des ausschüttbaren Vermögens. Nicht berücksichtigt würden Umstände, die auch bei einem Negativvermögen der Gesellschaft Ausschüttungen rechtfertigen würden. Auch blieben Situationen außer Betracht, in denen die Gesellschaft trotz eines belasteten Eigenkapitals zahlungsfähig sei. Schließlich stünde der administrative Aufwand der mit der Bilanzierung des Eigenkapitals verbunden sei, im Widerspruch zu der Vereinfachung, die man mit der Abschaffung der Mindestkapitalisierungspflicht bezwecke ${ }^{745}$.

Der in dem Vorentwurf in Anlehnung an das britische Vorbild als Solvenztest beziehungsweise Liquiditätstest bezeichnete Test zur Ermittlung des ausschüttbaren Vermögens wird in dem Entwurf zwar beibehalten, allerdings mit der Maßgabe, dass nicht nur die Liquidität der Gesellschaft zu betrachten ist, sondern auch andere finanzielle Maßgaben, die bestimmend sein können für die künftige Zahlungsfähigkeit der Gesellschaft zu berücksichtigen sind ${ }^{746}$.

Im Ergebnis wird von den Geschäftsführern eine Prognoseentscheidung abverlangt, die ihre Grenze dort findet, wo die Geschäftsführer aufgrund der (zu erwartenden) Zahlungsunfähigkeit der Gesellschaft zur Beantragung der Eröffnung eines Insolvenzverfahrens verpflichtet wären ${ }^{747}$.

Wie bereits im Vorentwurf ${ }^{748}$ vorgesehen soll der Ausschüttungstest sich nicht auf Kapitalmaßnahmen beschränken, sondern vielmehr sämtliche Maßnahmen erfassen bei denen Gesellschaftsvermögen ausgeschüttet wird, das heißt selbstverständlich bei Ausschüttungen an die Gesellschafter (Art. 2:216 Abs. 1 NBG), aber auch bei der Rückgewähr von Einlagen im Zusammenhang mit einer Kapitalherabsetzung (Art. 2:208 NBG) und bei dem Erwerb eigener Anteile (Art. 2:207 NBG) ${ }^{749}$.

\section{bbb) Haftung der Geschäftsführer und Rückzahlungspflicht der Begünstigten}

Geschäftsführer haften nach Maßgabe von Art. 2:216 Abs. 3 NBG, wenn sie einen Ausschüttungsbeschluss vollziehen, obgleich sie wissen oder wissen mussten, dass die Gesellschaft zahlungsunfähig ist oder durch die Ausschüttung nicht mehr in der Lage ist existierende Ver-

\footnotetext{
745 Begründung des Gesetzesentwurfs, Allgemeiner Teil, S. 37; Besonderer Teil S. 86 ff.; Lennarts WPNR 2007, 966, $967 \mathrm{f}$.

746 Begründung des Gesetzesentwurfs, Allgemeiner Teil, S. 36 f.

747 Begründung des Gesetzesentwurfs, Allgemeiner Teil, S. 37.

748 Gesetzesbegründung Dritte Tranche S. 1, 6 ff., 20 ff. und $25 \mathrm{ff}$.

749 Begründung des Gesetzesentwurfs, Allgemeiner Teil, S. 36 ff.; Besonderer Teil S. 86 ff.
} 
bindlichkeiten zu zahlen. Die Verantwortlichkeit der Geschäftsführer ist folglich eingeschränkt durch die Vorhersehbarkeit der Liquiditätssituation der Gesellschaft zum Zeitpunkt der Ausschüttung. Die Haftung der Geschäftsführer ist eine Innenhaftung gegenüber der Gesellschaft und auf den Ausschüttungsbetrag beschränkt ${ }^{750}$.

Die im Vorentwurf ${ }^{751}$ vorgesehene Beweislastumkehr zuungunsten der Geschäftsführer innerhalb der ersten zwölf Monate nach der Ausschüttung ${ }^{752}$ hat der Entwurfgeber nicht übernommen. Die Haftung der Geschäftsführer wird hierdurch nicht weiter gezogen als unbedingt notwendig. Wenn die Gesellschaft tatsächlich insolvent wird, können die Geschäftsführer auch nach Maßgabe von Art. 2:248 NBG unter bestimmten Bedingungen wegen der Insolvenzverursachung in die Haftung genommen werden $^{753}$.

Wird die Gesellschaft innerhalb von zwölf Monaten nach Ausschüttung insolvent, so haften die Gesellschafter und andere Begünstigte neben den Geschäftsführern auf Rückerstattung des Ausschüttungsbetrages. Durch den offenen Wortlaut in Art. 216 Abs. 3 „eine Ausschüttung“ wird nochmals klargestellt, dass sämtliche innerhalb eines Jahres vor Insolvenz der Gesellschaft getätigten Ausschüttungen zurückgefordert werden können ${ }^{754}$.

Art. 2:216 Abs. 4 NBG sieht eine gesamtschuldnerische Mithaftung desjenigen vor, der die Geschäftsführer zu der pflichtwidrigen Ausschüttung bestimmt hat ${ }^{755}$.

\section{cc) Eigene Anteile}

Die Beschränkung in Art. 2:207 NBG, die es der Gesellschaft bislang verwehrte mehr als 50\% des gezeichneten Kapitals zu erwerben, wird aufgehoben. Der Erwerb eigener Anteile wird unter die Bedingung gestellt, dass die erworbenen Anteile in Übereinstimmung mit Art. 2: 216 NBG an die Gesellschafter übertragen werden ${ }^{756}$.

750 Siehe ausführlich dazu Lennarts WPNR 2007, 966, 969 ff.; van der Zanden WPNR 2007, 975 ff.; sowie jüngst Verkerk O \& F 2008, 43 ff.

751 Gesetzesbegründung Dritte Tranche S. 25 ff.

752 Art. 2: 216 Abs. 3 NBG-E des Vorentwurfs.

753 Begründung des Gesetzesentwurfs, Besonderer Teil S. 92 f.; Lennarts WPNR 2007, 966, 969 ff.

754 Begründung des Gesetzesentwurfs, Besonderer Teil S. 92 f.

755 Begründung des Gesetzesentwurfs, Besonderer Teil S. 94; siehe hierzu auch Lennarts WPNR 2007, 966, 972 ff. und Verkerk O \& F 2008, 43, 52 f.

756 Begründung des Gesetzesentwurfs, Besonderer Teil S. 80. 


\section{b) Reformüberlegungen in Praxis und Literatur}

In der niederländischen Literatur ${ }^{757}$ wurde die Diskussion um Sinnhaftigkeit und Sinnlosigkeit einer Mindestkapitalpflicht im Wesentlichen mit denselben Argumenten geführt wie in Deutschland ${ }^{758}$; auch hier wurde in erster Linie auf die Ineffizienz und mangelnde Praktikabilität des bisherigen Systems hingewiesen ${ }^{759}$.

Zum einen wurde eingewandt, dass das Mindestkapital Gläubigern der Gesellschaft keinen ausreichenden Schutz biete. Die bisherige Regelung biete insbesondere keine Gewähr dafür, dass das Stammkapital zum Zeitpunkt der Inanspruchnahme der Gesellschaft durch die Gläubiger noch in der im Gesellschaftsvertrag benannten Höhe existiere und nicht bereits durch entstandene Verluste aufgezehrt worden sei, sondern verhindere nur, dass das Kapital an die Gesellschafter zurückgezahlt worden sei. Außerdem sei ein Betrag in Höhe von $18.000 €$ eine willkürliche Grenze, die Art und Umfang der Geschäftstätigkeit der BV nicht in Betracht zie$\mathrm{he}^{760}$.

Zum anderen wurde verwiesen auf die Praxis bei der Bestimmung des an die Gesellschafter ausschüttbaren Vermögens. Dort würde regelmäßig auf den festgestellten Vorjahresabschluss abgestellt. Diese Zahlen wiederum würden regelmäßig nach Fassung des Gewinnverwendungsbeschlusses durch die Gesellschafter ermittelt. Auch dienten die internationalen Berichtstandards (IFRS) nicht dem Kapitalschutz ${ }^{761}$.

Schließlich seien einige Elemente des bisherigen Kapitalschutzsrechts in der Praxis nicht gut handelbar und bildeten infolgedessen eine unnötige Belastung der Geschäftsbetriebe. In dieser Hinsicht seien insbesondere die Regelungen zur Nachgründung (Artikel 204c) und das Verbot auf finanzieller Mittelgewährung an Dritte (Artikel 207c) zu nennen ${ }^{762}$.

\footnotetext{
757 Einen Überblick über die Anfänge der Diskussion gibt Fleming Ondernemingsrecht 2004, 537, 541.

758 Vgl. hierzu oben in diesem Abschnitt § 1 IV. 2. b) aa) (i) - (iii).

759 Vgl. zu einzelnen Aspekten van der Sangen/Raaijmakers Tijdschrift voor Ondernemingsbestuur 2004, 247 ff. sowie Beckmann Ondernemingsrecht 2004, 22 ff.; siehe auch Boschma/Lennarts/Schutte-Veenstrarapport 2005 mit Ausführungen über alternative Kapitalsicherungssysteme.

760 van der Sangen/Raaijmakers Tijdschrift voor Ondernemingsbestuur 2004, 247, 249 f.; Beckmann Ondernemingsrecht 2004, 22, 23.

761 van der Sangen/Raaijmakers Tijdschrift voor Ondernemingsbestuur 2004, 247, 248 f.; Beckmann Ondernemingsrecht 2004, 22, $23 \mathrm{f}$..

762 Vgl. nur Bier Ondernemingsrecht 2004, 10 ff.
} 


\section{Handelsrechtliche Publizität}

\section{Handelsregister}

Die niederländischen Vorschriften über die Publizität der Gesellschaften sind aufgrund europäischer Vorgaben weitestgehend identisch mit den Regelungen in den anderen Mitgliedstaa$\operatorname{ten}^{763}$.

Anders als in Deutschland und in Frankreich werden die Handelsregister in den Niederlanden von der Industrie- und Handelskammer (,Kamer van Koophandel“) geführt ${ }^{764}$. Sämtliche dort eingetragenen Informationen, sind online abrufbar ${ }^{765}$. Daneben können Handelsregisterauszüge, Gesellschaftsverträge, Gründungsurkunden usw. außerdem über eine allgemeine, nationale Telefonnummer 0900-1234567 abgerufen werden. Nach Anpassung der nationalen Vorschriften an die Vorgaben der Richtlinie 2003/58/EG zur Änderung der Richtlinie 68/151/EWG des Rates in Bezug auf die Offenlegungspflichten von Gesellschaften bestimmter Rechtsformen ist ein offizieller Auszug aus dem Handelsregister auch in Englisch erhält$\operatorname{lich}^{766}$.

Registereintragungen haben nach niederländischem Recht nur eine deklaratorische Bedeutung. Die in anderen Ländern - etwa in Deutschland - vor Eintragung durch den Registerrichter vorzunehmende Rechtmäßigkeitskontrolle wird in den Niederlanden durch eine präventive behördliche Rechtmäßigkeitskontrolle ersetzt, deren Abschluss durch die Erteilung einer Unbedenklichkeitsbescheinigung konstitutiv wirkt ${ }^{767}$.

Das Handelsregister ist ein Register mit öffentlichem Glauben. Nach Ablauf einer Frist von 15 Tagen können die Umstände, die im Handelsregister registriert sind, Dritten entgegengehalten werden, ohne dass es auf deren Kenntnis ankäme. Andererseits schützt das niederländische Recht auch die negative Publizität des Registers ${ }^{768}$, das heißt Umstände, die nicht im Handelsregister eingetragen sind, können Dritten nur entgegengehalten werden, wenn diese sie kannten ${ }^{769}$.

\footnotetext{
763 Süß/Wachter/Rademakers/de Vries S. 1124 ff.; Gotzen in: Behrens Die GmbH Rn. NL 6 ff.

764 Mehring GmbHR 1991, 297, 298.

765 Süß/Wachter/Rademakers/de Vries S. 1125.

766 Süß/Wachter/Rademakers/de Vries S. 1124.

767 Süß/Wachter/Rademakers/de Vries S. 1125; Gotzen in: Behrens Die GmbH Rn. NL 6 ff, 9; vgl. auch Meijers, Handboek Handelsregister, S. 26.

768 Vergleichbar $\$ 15$ GmbHG.

769 Süß/Wachter/Rademakers/de Vries S. 1125; Gotzen in: Behrens Die GmbH Rn. NL 6 ff, 9.
} 


\section{Geschäftsbriefe}

Auf allen außenwirksamen Dokumenten (Bekanntmachungen, Druckwerken, Werbung etc.) muss die vollständige Firma und der Sitz der Gesellschaft angegeben sein (Art. 2:186 Abs. 1 NBG). Daneben haben gemäß Art. $25 \mathrm{HrgW}$ alle Briefe, Aufträge, Rechnungen und Kostenvoranschläge Angaben die Registernummer des Unternehmens oder der juristischen Person zu enthalten ${ }^{770}$.

\section{Vorschläge alternativer Rechtsformen neben einer reformierten B.V.}

Wie in Deutschland auch, wird auch in den Niederlanden von einigen Autoren eine (allzu radikale) Reformierung des BV-Rechts abgelehnt und stattdessen die Schaffung einer neuen Gesellschaftsform neben beziehungsweise unterhalb der B.V. empfohlen. Namentlich $\mathrm{McC} a-$ hery und Vermeulen ${ }^{771}$ plädieren für die Schaffung einer Personengesellschaft mit beschränkter Haftung nach dem Muster der amerikanischen beziehungsweise britischen „Limited Liability Company ${ }^{6} 772$.

Inhaltlich entspricht die Niederländische LLP nach den Vorstellungen McCaherys und Vermeulens eher der britischen denn der amerikanischen Schwester, wobei man sich insbesondere die Erfahrungen des britischen Gesetzgebers bei Einführung der LLP nutzbar machen will ${ }^{773}$. Danach soll die Niederländische LLP ohne Mindestkapital durch Registrierung der Gründungsurkunde (äquivalent dem ,incorporation document“ im britischen Recht) mit dem Handelsregister gegründet werden können; eine notarielle Beurkundung der Satzung oder von Übertragungsvorgängen ist nicht vorgesehen. Die Vermögensbindung würde sich an den Regeln der BV orientieren ${ }^{774}$.

Die Einführung einer Niederländischen LLP neben einer reformierten B.V. wird auch in dem amtlichen Entwurf diskutiert, im Ergebnis aber abgelehnt ${ }^{775}$. Zum einen sei die Praxis bereits vertraut mit der B.V. Die Schaffung einer alternativen Gesellschaftsform würde Unterneh-

\footnotetext{
770 Süß/Wachter/Rademakers/de Vries S. 1148; Mehring, GmbH-Rechte S. 205, 209.

771 McCahery/Vermeulen Ondernemingsrecht 2005, $382 \mathrm{ff}$.

772 Nicht die Personengesellschaft mit beschränkter Haftung sondern die Personengesellschaft im Lichte der BV-Reform beleuchtet Salomons Ondernemingsrecht 2006, 509; siehe auch Boschma/Lennarts/SchutteVeenstrarapport 2005 mit Ausführungen über alternative Kapitalsicherungssysteme.

773 McCahery/Vermeulen Ondernemingsrecht 2005, 382, 387 f.; zu den Unterschieden zwischen amerikanischer und britischer LLP vgl. auch Salomons Ondernemingsrecht 2006, 509. Zur britischen PLC Schröder/Schneider GmbHR 2005, 1288 sowie Teichmann NJW 2006, 2444 und Triebel/Otte/ Kimpel BB 2005, 1233.

774 McCahery/Vermeulen Ondernemingsrecht 2005, 382, $389 \mathrm{f}$.

775 Begründung des Gesetzesentwurfs, Allgemeiner Teil, S. 5.
} 
mern und Beratern vor ganz neue womöglich nicht zu bewältigende Herausforderungen stellen. Des Weiteren sei die Bedeutung der existierenden Rechtsprechung und Literatur zur B.V. nicht zu unterschätzen; sie biete eine Rechtsicherheit im Ungang mit der B.V., die mit einer neuen Gesellschaftsform erst wieder gewonnen werden müsste. Schließlich gab es auch praktische Erwägungen, denn die Schaffung einer neuen Gesellschaftsform hätte wahrscheinlich erheblich länger gedauert als die Reformierung einer bereits bestehenden Regelung. Auch hätten nationale und internationale Fragestellungen ohnehin kurzfristig eine Anpassung der B.V. verlangt ${ }^{776}$.

Eine im Auftrag des Wissenschaftlichen Untersuchungs- und Dokumentationszentrum (,Wetenschappelijk Onderzoek- en Documentatiecentrum“ - WODC) von J.M. Fernández und M. van Olffen durchgeführte Untersuchung zur Rechtsform und Praxis der anglo-amerikanischen LLC bzw. LLP und deren mögliche Einführung in den Niederlanden ${ }^{777}$, gibt der Einschätzung des niederländischen Gesetzgebers Recht. Die Untersuchung gelangt zu dem Ergebnis, dass die Einführung einer neuen Rechtsform nach dem Vorbild der LLC bzw. LLP in einem reformierten Niederländischen BV-Recht nicht sinnvoll ist, da die Rechtsform der LLC bzw. LLP sich systematisch nicht ohne Weiteres in das dem BV-Recht immanente System von beschränkter Haftung und Transparenz einfügen lasse ${ }^{778}$. Vorgeschlagen wird stattdessen eine stärkere Flexibilisierung des BV-Rechts, insbesondere im Hinblick auf Struktur und Organisationsverfassung der $\mathrm{BV}^{779}$, sowie eine Fortsetzung und Intensivierung der Überlegungen zur stärkeren Konturierung des Zusammenspiels von beschränkter Haftung und Transparenz im niederländischen BV-Gesellschaftsrecht ${ }^{780}$.

776 Begründung des Gesetzesentwurfs, Allgemeiner Teil, S. 5.

777 J.M. Fernández/M. van Olffen, Eindrapport Beschrijving rechtsvorm en gebruik LLP's WODC, Onderzoekcentrum Onderneming en Recht, Faculteit der Rechtgeleerdheid, Nijmegen 2007, abrufbar unter http://www.wodc.nl/onderzoeksdatabase/beschrijving-rechtsvorm-en-gebruik-llps.aspx. WOCD Eindrapport dort insb. S. 87 ff., $95 \mathrm{ff}$.

779 WOCD Eindrapport Samenvatting XIII Ziffer 2 und XVI Nr. 10 sowie insb. S. 87 ff. und 95 ff.

780 WOCD Eindrapport Samenvatting XIII Ziffer 2 und XVI Nr. 10 sowie insb. S. 87 ff. und 95 ff. 


\section{§ 3 Frankreich}

\section{Einleitung}

In Frankreich wurde eine Reform des GmbH-Rechts bereits im Jahre 2003 durchgeführt. Hintergrund der Reformbemühungen war - anders als in Deutschland und den Niederlanden allerdings weniger der Wettbewerb der europäischen Gesellschaftsrechte als vielmehr das Bemühen die Errichtung von Unternehmen zu erleichtern und die nationale Wirtschaft zu fördern ${ }^{781}$

\section{Gründung der Gesellschaft}

\section{Gründungsvorgang}

Die Gründung einer französischen S.à.r.l setzt gemäß Art. L. 1832 Abs. 2 C.com wie jedwede sonstige gesellschaftsrechtliche Betätigung die Unterzeichung eines (Gesellschafts-)Vertrages (,contrat de société") durch zwei oder mehrere Personen voraus ${ }^{782}$. Beabsichtigt nur eine Person die Gründung der S.à.r.l (dann allerdings „Entreprise unipersonnelle à responsabilité limitée - E.u.r.l“ genannt), so besteht der Gründungsakt allein in dessen einseitiger Willenserklärung ${ }^{783}$. Die Rechtspersönlichkeit einer juristischen Person erlangt die Gesellschaft allerdings erst mit ihrer Eintragung in das Handelsregister ${ }^{784}$.

781 Siehe dazu die amtliche Begründung zu dem Gesetz (Loi pour l'initiative économique, LIE). Bericht des Senats No. 217 v. 19. März 2003, S. 37 ff. und Bericht der Nationalversammlung No. 572, Teil II v. 28. Januar 2003 zu Art. 1. Vgl. auch Brocard Rev. Sociétés 2004, p. 825. Weitere Angaben zu dem Gesetzgebungsverfahren finden sich auch bei Becker GmbHR 2003, 706, 1120 und Meyer/Ludwig GmbHR 2005, 346 und 459. Zur Geschichte der S.à.r.l. vgl. nur kurz Behrens in Behrens Die GmbH Rn. F 1 f. sowie bei Cozian/Viandier/Deboissy Rn. 997 ff.

Lefebvre Rn. 5101 („Affectio societatis“); siehe auch Cozian/Viandier/Deboissy rechtsformunabhängig dargestellt unter Rn. 104 ff. und konkret zur S.à.r.l. unter Rn. 1007; Guyon, Les sociétés, Traité des contrats, p. 39 ; Libchaber, La société, contrat spécial, p. 281 ; Mellert/Verfürth S. 121, Sonnenberger/Autexier S. 189; Sonnenberger S. 185. Cozian/Viandier/Deboissy Rn. 104 ff. ; Guyon, Les sociétés, Traité des contrats, p. 39 ; Libchaber, La société, contrat spécial, p. 281.

784 Becker GmbHR 2003, 706; Süß/Wachter/Karst S. 802 f.; Mellert/Verfürth S. 121 f., Maier-Bridou Die $\mathrm{GmbH}$ in Frankreich, in: Die GmbH-Rechte in den EG-Staaten, 77, 79 ff. Cozian/Viandier/Deboissy Rn. 190. Umfassende Darstellung des französischen Gesellschaftsrechts in deutscher Sprache auch bei Chaussade-Klein, Gesellschaftsrecht in Frankreich; in französischer Sprache ist insbesondere auf den Cozian/Viandier/Deboissy hinzuweisen. 


\section{Gründungsvoraussetzungen}

\section{a) Gründer}

Die S.à.r.l kann von einem oder mehreren Gesellschafter gegründet werden (Art. L. 223-1 Abs. 1 C.com) ${ }^{785}$. Maximal können 100 Gesellschafter an einer S.à.r.l. beteiligt sein (Art. L 223-3 C.com ${ }^{786}$. Für landwirtschaftliche Genossenschaften sowie für Handwerkergenossenschaften in der Rechtsform einer S.à.r.l. gilt eine Mindestgesellschafterzahl, nämlich von vier Gesellschaftern für die landwirtschaftliche Genossenschaft und von zwei Gesellschaftern für die Handwerkergenossenschaft ${ }^{787}$. Wird die gesetzliche Höchstgrenze von 100 Gesellschaftern überschritten, so innerhalb eines Jahres entweder die Anzahl der Gesellschafter auf die gesetzliche Höchstzahl zu reduzieren oder die S.à.r.l in eine S.A. umzuwandeln. (Art. 223-3 C.com). Geschieht dies nicht innerhalb der genannten Jahresfrist, so wird die S.à.r.l. von Gesetzes wegen aufgelöst und abgewickelt ${ }^{788}$

An die Person des Gesellschafters einer S.à.r.l. werden keine besonderen Anforderungen gestellt, insbesondere muss ein Gesellschafter einer S.à.r.l. nicht selbst Kaufmann $\operatorname{sein}^{789}$. Der Grund für die Offenheit des französischen Rechts bei der Frage der Eignung einer Person als Gesellschafter einer S.à.r.l. liegt darin, dass die Beteiligung an der S.à.r.l. in erster Linie als Kapitalanlage verstanden wird, anders als in Deutschland oder den Niederlanden, wo der personalistische Gedanke im Vordergrund steht ${ }^{790}$. Als Gesellschafter kommen neben natürlichen Personen auch juristische Personen in Betracht ${ }^{791}$. Nicht gestattet ist allerdings, dass eine

785 Lefebvre Rn. 5066; Cozian/Viandier/Deboissy Rn. 1002; zur Einpersonengesellschaft in Frankreich, der sog. ,entreprise unipersonelle à responsabilité limitée“ - „EURL“ vgl. die ausführlichen Ausführungen bei Lefebvre Rn. 6300 ff. sowie bei Cozian/Viandier/Deboissy Rn. 1078 ff. letzterer auch mit weiteren Nachweisen zu Literatur und Rechtsprechung.

786 Lefebvre Rn. 5067; Cozian/Viandier/Deboissy Rn. 1002. Früher waren maximal 50 Gesellschafter gestattet vgl. nur Behrens in Behrens Die GmbH Rn. F 10 und Maier-Bridou Die GmbH in Frankreich, in: Die GmbH-Rechte in den EG-Staaten, 77, 80. Gesetz 83-657 vom 20. Juli 1983, Art. 7; vgl. auch hierzu Lefebvre Rn. 5066.

788 Lefebvre Rn. 5067; Cozian/Viandier/Deboissy Rn. 1002; Süß/Wachter/Karst S. 805 f.; Mellert/Verfürth S. 122; Behrens Die GmbH Rn. F 10 und Maier-Bridou Die GmbH in Frankreich, in: Die GmbH-Rechte in den EG-Staaten, 77, 80.

789 Lefebvre Rn. 5053; die Gesellschaft ihrerseits ist - wie im deutschen Recht - Formkaufmann, d.h. sie ist Kaufmann, auch wenn ihr Unternehmensgegenstand eine nicht-kaufmännische Tätigkeit beschreibt, Lefebvre Rn. 5061.

790 Lefebvre Rn. 5053 ff. Unter Bezugnahme auf die Artt. 389-5 und 459 Abs. 3 des C. civ. soll nach Auffassung von Lefebvre Rn. 5054 auch die Übernahme von Geschäftsanteilen durch Minderjährige gestattet sein. Die vorgenannten Artikel ermöglichen Minderjährigen - ohne Unterschied im Hinblick auf die Gesellschaftsform - eine Beteiligung an Grundstücksgesellschaften und Investmentfonds. Besonderheiten gelten für Familiengesellschaften, siehe Lefebvre Rn. 5056.

791 Letztere dürfen allerdings nicht Gesellschafter einer S.à.r.l. sein, die medizinische Labortätigkeiten zum Gegenstand hat Lefebvre Rn. 5059 unter Hinweis auf Art. L 6212-4 des Code de la santé publique - Gesetz betreffend die öffentliche Gesundheit. 
S.à.r.l an einer S.à.r.l als Alleingesellschafterin beteiligt ist, wenn sie ihrerseits lediglich eine einzige natürliche Person als Alleingesellschafterin hat (Art. 223-5 C.Com) ${ }^{792}$.

Auch ausländische natürliche oder juristische Personen können Gesellschafter einer französischen S.à.r.l sein, ohne im Besitz einer französischen Kaufmannbescheinigung (,carte de commercant $^{*}$ ) $\mathrm{zu}$ sein $^{793}$. Allerdings, sind da die Beteiligung als Kapitalanlage verstanden wird, die gesetzlichen Vorschriften betreffend Auslandsinvestitionen zu beachten ${ }^{794}$.

\section{b) (Teilweise) Erfüllung der Einlagepflichten}

Noch vor der Gründung der Gesellschaft (d.h. vor Unterzeichnung des Gesellschaftsvertrages) ist auf jede Einlage mindestens 1/5 des Nennbetrages zu erbringen (Art. L 223-7 Abs. 4, Art. D 22 Abs. 1 C.com. $)^{795}$.

\section{c) Abschluss des Gesellschaftsvertrages}

Der Gesellschaftsvertrag muss schriftlich abgefasst sein (Art. 1835 C.Civ.) und ist von sämtlichen Gesellschaftern zu unterzeichnen ${ }^{796}$; eine notarielle Beurkundung ist - anders als in Deutschland - grundsätzlich nicht erforderlich ${ }^{797}$. Wird der Gesellschaftsvertrag allerdings nur schriftlich gefasst, so sind wenigstens so viele Originale zu erstellen, wie zur Niederlegung am Gesellschaftssitz sowie zur Vornahme der diversen Gründungsformalitäten ${ }^{798}$ erforderlich $\operatorname{sind}^{799}$. Eine Kopie des Gesellschaftsvertrages ist jedem einzelnen Gesellschafter auszuhändi-

792 Süß/Wachter/Karst S. 805 f.; Mellert/Verfürth S. 122; Behrens Die GmbH Rn. F 10 und Maier-Bridou Die $\mathrm{GmbH}$ in Frankreich, in: Die GmbH-Rechte in den EG-Staaten, 77, $79 \mathrm{f}$.

793 Lefebvre Rn. 5057.

794 Lefebvre Rn. 330 f.; Süß/Wachter/Karst S. 806.

795 Siehe hierzu auch sogleich unten in diesem Abschnitt III. 1. e) und später auch unten V. 1 b) und c) sowie Lefebvre Rn. 5072 und 5075 und Süß/Wachter/Karst S. 812; Mellert/Verfürth S. 125. Bis 2001 sah das Gesetz noch vor, dass das die Einlagen vollständig zu erbringen sind; vgl. dazu nur Behrens Die GmbH Rn. F 13 und Maier-Bridou Die GmbH in Frankreich, in: Die GmbH-Rechte in den EG-Staaten, 77, 80.

796 Lefebvre Rn. 5133; Cozian/Viandier/Deboissy Rn. 104 ff.; Guyon, Les sociétés, Traité des contrats, p. 39 ff.; Libchaber, La société, contrat spécial, p. $281 \mathrm{ff}$.

797 Lefebvre Rn. 5130; Libchaber, La société, contrat spécial, p. 281 ff.; Süß/Wachter/Karst S. 810 f.; Mellert/Verfürth S. 122; Behrens Die GmbH Rn. F 11 und Maier-Bridou Die GmbH in Frankreich, in: Die GmbH-Rechte in den EG-Staaten, 77, 80.

798 Siehe hierzu nachstehend in diesem Abschnitt unter d).

799 Seit dem 9. Mai 2007 ist es allerdings nicht mehr erforderlich ein Original des Gesellschaftsvertrages beim Handelsregister zu hinterlegen (Art R 123-103, geändert durch Erlass 2007-750). Daher reicht es künftig aus, zwei Originale zu fertigen; eines für das Sozialarchiv (,archives sociales“) und eines für die Steruerbehörde. Nichtsdestotrotz werden in der Praxis regelmäßig noch weitere Originale notwendig sein, sei es weil Marken angemeldet werden müssen oder andere Formalitäten zu erledigen sind; vgl. hierzu auch Lefebvre Rn. 5132. 
gen $^{800}$. Ausnahmsweise, nämlich bei der Einbringung eines Grundstücks oder eines Pachtvertrags mit einer Laufzeit von mehr als zwölf Jahren in die Gesellschaft, schreibt das Gesetz die notarielle Beurkundung des Gesellschaftsvertrags vor ${ }^{801}$. Auch empfiehlt sich eine notarielle Beurkundung des Gesellschaftsvertrages, wenn dieser zwischen Ehegatten geschlossen wird, da auf diese Weise vermieden werden kann, dass die erbrachten Einlagen als verdeckte Schenkungen qualifiziert und damit als nichtig angesehen werden können (Art. 1832-1 Abs. 2 C.Civ. $)^{802}$.

Die Wirksamkeit des Gesellschaftsvertrages richtet sich grundsätzlich nach den allgemeinen zivilrechtlichen Regeln, d.h. der Vertrag setzt wie jeder Vertrag die übereinstimmenden Willenserklärungen mindestens zweier in ihrer Rechtsfähigkeit unbeschränkter Vertragspartner (d.h. der künftigen Gesellschafter) voraus ${ }^{803}$. Zum anderen müssen Vertragsgegenstand und Gesellschaftszweck (,cause du contrat de société") in hinreichender Weise konkretisiert sein und dürfen nicht gegen das Gesetz verstoßen. Schließlich muss bei Gründung der Gesellschaft der gemeinsame Wille vorhanden sein, den Gesellschaftszweck nachhaltig im Interesse sämtlicher Gesellschafter zu verfolgen (so genannte „Affectio societatis“) ${ }^{804}$.

Fehlt es an einem schriftlichen Gesellschaftsvertrag in der vorgetragenen Form und hat die Gesellschaft ihre Geschäftstätigkeit begonnen, so liegt eine „faktische Gesellschaft“ („société créée de fait") die grundsätzlich nach den für die S.à.r.l. geltenden Grundsätzen behandelt wird $^{805}$

\section{d) Formalitäten nach Unterzeichnung des Gesellschaftsvertrages}

Auf dem Weg zur Anerkennung der S.à.r.l. als juristische Person sind nach Unterzeichnung des Gesellschaftsvertrages noch weitere zahlreiche Formalitäten zu erledigen. Häufig werden

800 Lefebvre Rn. 5135. Dieses Recht gilt auch für spätere Versionen des Gesellschaftsvertrages. Auf Verlangen eines Gesellschafters hat der Geschäftsführer eine von ihm beglaubigte, aktuelle Fassung des Gesellschaftsvertrages, nebst Liste der Geschäftsführer und ggfs. der bestellten Wirtschaftsprüfer auszuhändigen. Die dem Gesellschafter für die Begebung des Gesellschaftsvertrages in Rechnung gestellten Kosten dürfen 0,30 $€$ nicht übersteigen, siehe Lefebvre Rn. 5136. Süß/Wachter/Karst S. 810 f.; Mellert/Verfürth S. 122; Maier-Bridou Die GmbH in Frankreich, in: Die GmbH-Rechte in den EG-Staaten, 77, 80.

802 Süß/Wachter/Karst S. 810 f.; Mellert/Verfürth S. 122.

803 Lefebvre Rn. 5051.

804 Lefebvre Rn. 5051; Süß/Wachter/Karst S. 810.

805 Süß/Wachter/Karst S. 810; vgl. auch Behrens in Behrens Die GmbH Rn. F 16, der an dieser Stelle auch Ausführungen zu Gründungsmängeln im Allgemeinen macht. 
in der Praxis aus Vereinfachungs- und Beschleunigungsgründen und um zu vermeiden, dass es angesichts der komplexen Regelungsmaterie zu Versäumnissen kommt, professionelle Dienstleister (,Agence des formalités“) mit der Erledigung sämtlicher Formalitäten im Zusammenhang mit der Gesellschaftsgründung beauftragt $t^{806}$.

\section{e) Veröffentlichung der Gründungsanzeige}

Die Gründung der Gesellschaft ist in einem amtlichen Mitteilungsblatt (,journal d'annonces légales"), das in dem Département erscheint, in welchem sich der Gesellschaftssitz befindet unter Angabe der Firma, der Rechtsform, der Höhe des Stammkapitals und sofern einschlägig, der Bewertung der darauf erbrachten Sacheinlagen, des Gesellschaftssitzes und des für die Gesellschaft zuständigen Handelsregisters, des Unternehmensgegenstandes, der vorgesehenen Dauer der Gesellschaft sowie unter Nennung von Name, Vorname und Anschrift der Gesellschafter, Organmitglieder sowie des zuständigen Wirtschaftsprüfers (,commissaire aux comptes $^{6 \text { ) }}$ und etwaiger Generalbevollmächtigter (Art. D 285 C.com), zu veröffentlichen ${ }^{807}$.

Die Gründungsanzeige ist durch einen speziell bevollmächtigten Gründungsgesellschafter zu unterzeichnen (Art. D 285 Abs. 2 C.com). Wird der Gesellschaftsvertrag notariell beurkundet, so hat der beurkundende Notar die Anzeige zu unterzeichnen (Art. D 285 Abs. 2 C.com). Zwar besteht keine gesetzlich vorgeschriebene Frist für die Veröffentlichung der Gründungsanzeige. Da diese jedoch formelle Voraussetzung für die Eintragung der Gesellschaft in das Handelsregister ist, liegt es regelmäßig im Interesse der Gründungsgesellschafter, die Gründungsanzeige unverzüglich nach Unterzeichnung des Gesellschaftsvertrages zu veröffentlichen, wobei es nach der herrschenden Meinung ausreicht, dem Antrag auf Eintragung der Gesellschaft in das Handelsregister einen Nachweis über die bevorstehende Veröffentlichung (etwa in Gestalt einer verbindlichen Bestätigung des Verlags in Verbindung mit der zu veröffentlichenden Mitteilung) beizufügen ${ }^{808}$.

806 Süß/Wachter/Karst S. 803; siehe auch Cozian/Viandier/Deboissy Rn. 201 ff. m. zahlreichen w.N. zum frz. Literatur und Rechtsprechung.

807 Süß/Wachter/Karst S. 803 f.; Cozian/Viandier/Deboissy Rn. 190 ff. und 1007.

808 Süß/Wachter/Karst S. 803 f.; Cozian/Viandier/Deboissy Rn. 190 ff. und 1007. 


\section{f) Einreichung beim Handelsregister}

Die Gesellschaft ist nach Unterzeichnung des Gesellschaftsvertrages durch die Gründungsgesellschafter und Leistung der Einlagen zur Eintragung in das Handelsregister bei dem örtlich zuständigen Centre de Formalités des Entreprises (CFE) anzumelden. Neben einem ausgefüllten Formblatt (,liasse“) sind gemäß Art 48 Décret 84-406 vom 30. Mai 1984 einzureichen: der Gesellschaftsvertrag - zweifach im Original, sofern es sich um privatschriftliche Urkunden handelt, in zweifacher Ausfertigung bei notarieller Beurkundung - die Bestellungsurkunden hinsichtlich der Gesellschaftsorgane in zweifacher Abschrift, sofern die Benennung nicht bereits im Gesellschaftsvertrag erfolgt ist, sowie gegebenenfalls eine zweifache Ausfertigung des Sachgründungsberichts im Fall der Einbringung der übernommenen Stammeinlage im Wege der Sacheinlage. Die Anmeldung und Einreichung der vorstehenden Unterlagen kann auch elektronisch via Internet (,déclaration d'entreprise par internet $\left.D I E^{6}\right)$ erfolgen ${ }^{809}$.

Das CFE prüft die eingereichten Unterlagen und leitet sie binnen eines Tages an den Urkundsbeamten des örtlich für die Gesellschaft zuständigen Handelsregisters (,greffe du tribunal de commerce“) weiter (Décret 96-650 v. 19. Juli 1996, Art. 4 Abs. 2). Soweit das beim CFE eingereichte Anlagenkonvolut für die Gründung (,demande d'immatriculation complète") vollständig und richtig ist, überreicht das CFE der Gesellschaft außerdem binnen 24 Stunden nach Anmeldung kostenlos einen Beleg über die Unternehmensgründung („récépissé de création d'entreprise - $\left.R C E^{\prime \prime}\right)$. Dieser Beleg bestätigt, dass sich die Gesellschaft im Gründungsstadium befindet, und erlaubt dem Gründer, alle notwendigen Schritte bei öffentlichen oder privaten Institutionen zu erledigen, wie etwa den Zugriff auf das Gesellschaftskonto oder die Stellung des Antrages auf Einrichtung eines Telefonanschlusses. Innerhalb eines Tages wird der Gesellschaft in Gründung somit eine gesetzmäßige Existenz - vergleichbar der deutschen GmbH in Gründung - verliehen, wenn auch (noch) nicht als Gesellschaft mit beschränkter Haftung (daher auch der Begriff der „Blitz-S.à.r.l.“ “ 810$)^{811}$. Der Antrag auf Eintragung der Gesellschaft in das örtlich zuständige Handelsregister (registre du commerce et des sociétés - RCS) wird schließlich nochmals durch den Urkundsbeamten des Handelsregisters überprüft. Liegen die Eintragungsvoraussetzungen nach seiner Prüfung aller-

809 Cozian/Viandier/Deboissy Rn. 190 ff.; Süß/Wachter/Karst S. 812; Mellert/Verfürth S. 126.

810 Vgl. zu dem Begriff nur Becker GmbHR 2003, 706.

811 Da die Gesellschaft zu diesem Zeitpunkt - wie in Deutschland - als solche nicht existiert, haften in diesem Stadium die für die Gesellschaften handelnden Personen neben der Gesellschaft als Gesamtschuldner. Vgl. nur Mellert/Verfürth S. 126 sowie Chaussade-Klein, Gesellschaftsrecht in Frankreich, S. 19 f.; Merle Sociétés commerciales Rn. 78 ff. und Cozian/Viandier/Deboissy Rn. 492 ff. und Rn. 1007. 
dings vor, so erfolgt die Eintragung in das Handelsregister in der Regel innerhalb kurzer Zeit $^{812}$.

\section{g) Vorgründungsgesellschaft}

Die S.à.r.l. als solche mit beschränkter Haftung entsteht wie die deutsche GmbH erst mit Eintragung im Handelsregister und Erteilung eines die Existenz der Gesellschaft ausweisenden Handelsregisterauszugs (,Extrait $K$ bis $\left.^{6}\right)^{813}$. Oftmals mag es allerdings erforderlich sein, Rechtshandlungen im Namen und auf Rechnung der in Gründung befindlichen Gesellschaft bereits vor deren Eintragung oder gar vor der Unterzeichnung des Gesellschaftsvertrages vorzunehmen (z.B. Abschluss eines gewerblichen Mietvertrages über Geschäftsräume, bail commercial). Da die Gesellschaft als solche zu diesem Zeitpunkt allerdings noch nicht existiert, wird sie durch derartige Rechtshandlungen auch nicht verpflichtet. Grundsätzlich haften daher auch nach Eintragung der Gesellschaft allein die handelnden Personen für die Erfüllung der eingegangenen Verbindlichkeiten, ungeachtet ihres Auftretens im Namen und auf Rechung der zu gründenden Gesellschaft (Art. L 210-6 C.com) ${ }^{814}$. Da dieser (Schwebe-)Zustand für Gesellschafter wie auch Vertragspartner gleichermaßen unbefriedigend ist, hat der französische Gesetzgeber mit Décret vom 23. März 1967 sowie Décret 78-704 vom 3. Juli 1078 die Möglichkeit geschaffen, im Gesellschaftsvertrag die Erklärung der Gründungsgesellschafter aufzunehmen, dass Verpflichtete der vorgenommenen Rechtshandlungen die (künftige) Gesellschaft ist. In einem solchen Fall ist jedem der Gründungsgesellschafter vor Unterzeichung des Gesellschaftsvertrages eine Übersicht der vorgenommenen Rechtshandlungen und der daraus resultierenden Verpflichtungen vorzulegen. Des Weiteren ist diese Aufstellung im Fall der Gründung der S.à.r.l. als Anhang zum Gesellschaftsvertrag zu nehmen ${ }^{815}$.

Nach Auffassung der französischen Finanzverwaltung reicht die bloße Verständigung der (künftigen) Gesellschafter über die Gründung der Gesellschaft indes nicht aus, eine Vorgründungsgesellschaft (société en formation) zu begründen. Vielmehr sei erforderlich, dass bereits Gründungsmaßnahmen eingeleitet worden sind, wie etwa die Erbringung der Einlagen ${ }^{816}$.

812 Cozian/Viandier/Deboissy Rn. 193 ff.; Süß/Wachter/Karst S. 812; Mellert/Verfürth S. 126.

813 Cozian/Viandier/Deboissy Rn. 190 und 201; Mellert/Verfürth, Wettbewerb der Gesellschaftsformen, S. 126; Chaussade-Klein, Gesellschaftsrecht in Frankreich, S. 19 f. und Merle Sociétés commerciales Rn. $78 \mathrm{ff}$.

814 Cozian/Viandier/Deboissy Rn. 201 ff., 492 ff. und 1007; Mellert/Verfürth, Wettbewerb der Gesellschaftsformen, S. 126; Chaussade-Klein, Gesellschaftsrecht in Frankreich, S. 19 f. und Merle Sociétés commerciales Rn. $78 \mathrm{ff}$.

815 Süß/Wachter/Karst S. 805; Mellert/Verfürth S. 126 f.; Behrens in Behrens Die GmbH Rn. F 15.

$816 \mathrm{Süß/Wachter/Karst} \mathrm{S.} 805$. 


\section{Kosten der Gründung}

Da in Frankreich die Einschaltung eines Notars oder Rechtsanwalts nicht zwingend vorgesehen ist, insbesondere der Gesellschaftsvertrag - anders als in Deutschland - keiner notarieller Beurkundung bedarf, existieren keine festen gesetzlichen Gebühren für die Gründungsberatung. Ohne Einholung externer Beratungsleistungen fallen daher ausschließlich die Kosten für die Registereintragung (ca. $60 €$ ) und die Veröffentlichung (ca. 100 bis $150 €$ ) an. Wird ein Berater mandatiert, so bemessen sich die Kosten anhand der vereinbarten Honorarvereinbarung. In einfachen Fällen bewegen sich die Beratungskosten in der Praxis nach Einschätzung von Wachter wohl in einer Größenordnung zwischen 200 und $500 €^{817}$.

\section{Gesellschaftsvertrag}

\section{Gesetzlicher Mindestinhalt des Gesellschaftsvertrages}

Der notwendige Inhalt des Gesellschaftsvertrages der S.à.r.l ergibt sich aus Art. L 210-2, L 223-7 und L 223-9, Art. R 223-3 Abs. 2 und Art. D 22 C.com ${ }^{818}$. Danach muss der Gesellschaftsvertrag zunächst Rechtsform, Dauer, Sitz und Unternehmensgegenstand der Gesellschaft nennen. Außerdem hat der Gesellschaftsvertrag den Betrag des Stammkapitals zu enthalten und Angaben darüber zu machen wie das Stammkapital in Geschäftsanteile zerlegt ist. Schließlich sind die auf das Stammkapital geleisteten Einlagen zu beziffern sowie gegebenenfalls bei Erbringung von Sacheinlagen eine Bewertung selbiger im Gesellschaftsvertrag vorzunehmen $^{819}$.

Mit Gesetz 2005-882 vom 2.8.2005 zur Förderung kleinerer und mittlerer Unternehmen $(\mathrm{PME})^{820}$ hat der französische Gesetzgeber die Möglichkeit der Verwendung einer amtlichen Mustersatzung bei Gründung einer Ein-Mann-S.à.r.l., bei der die Geschäftsführung durch den Alleingesellschafter wahrgenommen wird, eingeführt. (Art. L 223-1 Abs. 2 Satz 3 C.com) ${ }^{821}$.

817 Wachter GmbHR 2005, 717, 723; Karst in Süß/Wachter, Hdb des internationalen GmbH-Rechts, S. 806.

818 Siehe hierzu im Einzelnen Lefebvre Rn. 5131, sowie Cozian/Viandier/Deboissy Rn. 104 ff. und 1000 ff.; Guyon, Les sociétés, Traité des contrats, p. 39 ff.; Libchaber, La société, contrat spécial, p. $281 \mathrm{ff}$.

819 Lefebvre Rn. 5131; Cozian/Viandier/Deboissy Rn. 104 ff. und 1000 ff.; Guyon, Les sociétés, Traité des contrats, p. 39, 40 ff.; Libchaber, La société, contrat spécial, p 281 ff. ; Süß/Wachter/Karst S. 806; Mellert/Verfürth S. 122; Maier-Bridou Die GmbH in Frankreich, in: Die GmbH-Rechte in den EG-Staaten, 77, 80; Behrens in Behrens Die GmbH Rn. F 11.

820 Gesetz 2005-882 v. 2.8.2005, Art.33.

821 Die Mustersatzung wurde mit Décret 2006-301 v. 9.3.2006 veröffentlicht; vgl. hierzu Süß/Wachter/Karst S. 807. 


\section{a) Firma; Rechtsformzusatz}

Nach Art. L 210-2 C.com gehört die Firma der S.à.r.l. (,dénomination sociale“, Art. L 223-1 Abs. 3 C.com) zum zwingenden Mindestinhalt des Gesellschaftsvertrages. Wie in Deutschland muss der Firma der Gesellschaft zwingend die Angabe der Rechtsform folgen, entweder in ausgeschriebener (société à responsabilité limitée) oder abgekürzter (S.à.r.l.) Form (Art. L 223-1 Abs. 3 C.com $)^{822}$. Des Weiteren ist regelmäßig im Anschluss an die Rechtsformbezeichnung das Gesellschaftskapital zu benennen ${ }^{823}$. Verfügt die Gesellschaft lediglich über einen Gesellschafter, so kann anstelle der Bezeichnung als S.à.r.l. klarstellend auch der Rechtsformzusatz E.u.r.l. (entreprise unipersonelle à responsabilité limitée) geführt werden. Bei der Wahl der Firma sind die Gesellschafter grundsätzlich unbeschränkt, es sei denn es werden Rechte Dritter durch die Firma beeinträchtigt. Daraus folgt, dass die Firma wie in Deutschland auch, jedenfalls Unterscheidungskraft besitzen muss und nicht über den tatsächlichen Geschäftsbetrieb der Gesellschaft hinweg täuschen darf ${ }^{824}$.

Wird in der Firma der Gesellschaft auf einem genehmigungspflichtigen Unternehmensgegenstand Bezug genommen, so ist zu beachten, dass eine solche Bezugnahme nur dann zulässig ist, wenn die Voraussetzungen für die Ausübung dieser Tätigkeiten und die staatliche Genehmigung vorliegen ${ }^{825}$.

\section{b) Sitz}

Der statutarische Sitz der Gesellschaft befindet sich grundsätzlich am Ort der tatsächlichen Geschäftsleitung der Gesellschaft, d.h. dort, wo sich die Geschäftsleitung sowie die Hauptverwaltung der Gesellschaft tatsächlich befinden ${ }^{826}$. Mit der Festlegung des Firmensitzes wird zugleich eine Bestimmung darüber getroffen, welches Recht auf die Tätigkeiten der Gesell-

${ }^{822}$ Lefebvre Rn. 5102; vgl. auch CA Paris 28-5-1999 RJDA 12/99 Nr. 1344 im Hinblick auf das Fehlen des Rechtsformzusatzes. Ist Gegenstand des Unternehmens ein freier Beruf, der gesetzlichen oder standesrechtlichen Regeln unterliegt oder dessen Berufsbezeichnung geschützt ist, so hat der Rechtsformzusatz ,société d'exercice libéral à responsabilitée“ oder abgekürzt „Selarl“ zu lauten; Gesetz 90-1258 vom 31. Dezember 1990, Art. 2; siehe Lefebvre a. a. O.

823 Lefebvre Rn. 5102

824 Lefebvre Rn. 5102; Süß/Wachter/Karst S. 806; Mellert/Verfürth S. 122; Maier-Bridou Die GmbH in Frankreich, in: Die GmbH-Rechte in den EG-Staaten, 77, 80.

$825 \mathrm{Süß/Wachter/Karst} \mathrm{S.} 807$.

826 Nach weitverbreiteter Auffassung schadet allerdings ein Auseinanderfallen von Satzungs- und tatsächlichem Verwalzungssitz nicht; vgl. Recq/Hoffmann GmbHR 2004, 1070, 1071. 
schaft und die Gesellschaft selbst Anwendung findet, welche Gerichte zuständig sind im Fall von Rechtstreitigkeiten oder der Liquidation der Gesellschaft, welche Nationalität die Gesellschaft hat sowie an welchem Ort die gesetzlichen Publikationspflichten zu erfüllen sind. Die Festlegung eines außerhalb Frankreichs liegenden Sitzes ist bisher trotz der Entscheidungen des EuGH in Sachen Überseering und Inspire Art nicht gestattet ${ }^{827}$.

\section{c) Gesellschaftszweck; Unternehmensgegenstand}

Prinzipiell darf eine S.à.r.l. jeden Unternehmensgegenstand (,objet social“) haben, solange derselbe tatsächlich realisierbar und rechtmäßig ist und nicht gegen die guten Sitten verstößt (Art. 1833 C.com) ${ }^{828}$. Versicherungsunternehmens und Banken ist es allerdings untersagt, die Rechtsform der S.à.r.l. anzunehmen ${ }^{829}$. Die Missachtung dieses Verbots führt zur Nichtigkeit der Gesellschaft ${ }^{830}$. Demgegenüber darf die gewerbliche Grundstiucksverwaltung nur in der Rechtsform der S.à.r.l. betrieben werden (Décret 63-683 v. 13. Juli 1963, Art. 1). Andere Tätigkeiten, etwa im medizinisch-pharmazeutischen Bereich, dürfen schließlich nur dann durch eine S.à.r.l. ausgeübt werden, wenn diese beziehungsweise ihre Gesellschafter oder Geschäftsführer über entsprechende (persönliche beziehungsweise fachliche) Kompetenzen verfügen $^{831}$.

\section{d) Dauer der Gesellschaft}

Art. L 210-2 C.com. bestimmt, dass eine S.à.r.l., beginnend mit ihrer Eintragung in das Handelsregister (Art. D 2 Abs. 1 C.com.), maximal auf die Dauer von 99 Jahren eingegangen werden darf. Innerhalb dieses Zeitrahmens können die Gesellschafter die Dauer der Gesellschaft allerdings beliebig gestalten. Eine einmal im Gesellschaftsvertrag festgelegte Dauer

827 Süß/Wachter/Karst S. 808; Mellert/Verfürth S. 122 f. Neugegründete Gesellschaften können ihren Sitz vorübergehend auch bei dem Geschäftsführer angeben, bis geeignete Geschäftsräume gefunden sind, Auch die Begründung eines Firmensitzes über eine so genannte Domilizierungsgesellschaft (société de domiciliation) - dies ist nichts anderes als eine Briefkastengesellschaftsadresse - ist gestattet. Vgl. Maier-Bridou Die GmbH in Frankreich, in: Die GmbH-Rechte in den EG-Staaten, 77, 81 und Karst a.a.O. Zum grundsätzlich ohne Konsequenzen bleibenden Auseinanderfallen von statutarischem und tatsächlichem Sitz Recq/Hoffmann GmbHR 2004, 1070, 1071. Lefebvre Rn. 5061; Cozian/Viandier/Deboissy Rn. 113 ff. und 1000 ff..

829 Lefebvre Rn. 5062; Cozian/Viandier/Deboissy Rn. 1001; Süß/Wachter/Karst S. 808 f.; Mellert/Verfürth S. 123. Aufgrund einer veralteten aber bis zum heutigen Tage geltenden Regelung, ist es auch Tabakhändlern nicht gestattet, die Rechtsform der S.à.r.l. anzunehmen; vgl. hierzu Rép. Calvet: JO AN 21 déc. 1996, p. 6297 sowie Bull. Joly 1997, p. 43.

831 Lefebvre Rn. 5063; Süß/Wachter/Karst S. 808 f. 
können die Gesellschafter jederzeit durch Beschluss ändern oder etwa über die vorzeitige Beendigung der Gesellschaft beschließen ${ }^{832}$.

\section{e) Stammkapital; Einlagen}

Eine S.à.r.l. hat im Gesellschaftsvertrag niederzulegen, wie hoch das Stammkapital der Gesellschaft ist (Art. L 210-2 C.com.) und wie viele Geschäftsanteile hiervon auf die einzelnen Gesellschafter entfallen (Art. L 23-7 Abs. 3 C.com.) ${ }^{833}$. Die ausgegebenen Geschäftsanteile müssen alle den gleichen, mangels gesetzlicher Vorgabe von den Gesellschaftern frei festsetzbaren Nennwert haben (Art. L 223-2 Abs. 1 C.com.) ${ }^{834}$. Eine ausdrückliche Erwähnung des Nennwerts im Gesellschaftsvertrag ist nicht erforderlich ${ }^{835}$.

Seit der Reform des Rechts der S.à.r.l. im August des Jahres $2003^{836}$ bestehen keine Mindestanforderungen mehr an die von den Gesellschaftern bei Gründung festzusetzende Höhe des Stammkapitals; bis zu dieser Reform betrug das Mindeststammkapital $7.500 €$ (Art. 223-2 C.com. ${ }^{837}$. Danach kann eine S.à.r.l. auch mit einem Stammkapital von lediglich einem Cent gegründet werden (oft verwendet wird in diesem Zusammenhang die Bezeichnung der so genannten Ein-Euro-S.à.r.l. $)^{838}$. In der Praxis verfügen allerdings auch die nach der Reform neu gegründeten S.à.r.l. regelmäßig über ein weit höheres Stammkapital. Ungeachtet der Reform gelten für S.à.r.l., die im Finanzierungs- und Kreditierungsbereich tätig sind, wie etwa Finanzierungs- oder Investitionsgesellschaften oder Banken außerdem weiterhin gesetzliche Mindestanforderungen an das Stammkapital ${ }^{839}$.

832 Süß/Wachter/Karst S. 809; Maier-Bridou Die GmbH in Frankreich, in: Die GmbH-Rechte in den EGStaaten, 77, 82; Behrens in Behrens Die GmbH Rn. F 11.

833 Lefebvre Rn. 5070 und 5095; p. 49 ff. und. Nach Auffassung von Lefebvre Rn. 5098 ist auch die Begebung von „Vorzugsgeschäftsanteilen“ gestattet, Geschäftsanteilen also, die womöglich im Hinblick auf Gesellschafterrechte beschränkt, dafür aber (vorzugsweise) gewinnberechtigt sind.

834 Lefebvre Rn. 5093. Davon unabhängig ausgestaltet werden kann das Gewicht des einzelnen Geschäftsanteils im Hinblick auf Gewinnbezugsrechte nd Stimmrechte etc.; Lefebvre a.a.O.

835 Lefebvre Rn. 5094; Süß/Wachter/Karst S. 809; Maier-Bridou Die GmbH in Frankreich, in: Die GmbHRechte in den EG-Staaten, 77, 82; Behrens in Behrens Die GmbH Rn. F 11.

836 Wirtschaftsförderungsgesetz 2003-721 vom 1. August 2003.

837 Süß/Wachter/Karst S. 809; Mellert/Verfürth S. 124; zum alten Recht (50.000 FF) und dessen Entwicklung (noch 1984 wurde das Mindeststammkapital von 20.000 FF auf 50.000 FF erhöht) vgl. Behrens in Behrens Die GmbH Rn. F 11 sowie Maier-Bridou Die GmbH in Frankreich, in: Die GmbH-Rechte in den EGStaaten, 77, 81.

838 Das Erfordernis wenigstens einen Cent aufzubringen folgt aus der Verpflichtung, dass mindestens ein Geschäftsanteil übernommen werden muss, siehe Art. L-223-2; Lefebvre Rn. 5070. Vgl. dazu auch Lutter GmbHR 2005, 1, 3; Wachter GmbHR 2003 R 377; unzutreffend Recq/Hoffmann GmbHR 2004, 1070, 1071, nach deren Dafürhalten mindestens 1 Euro zu erbingen ist.

839 Süß/Wachter/Karst S. 809. 
Zulässig ist auch die Festlegung eines variablen Stammkapitals im Gesellschaftsvertrag ${ }^{840}$. Zur Sicherung der Kapitalaufbringung und der Kapitalerhaltung darf allerdings die Summe der erbrachten Stammeinlagen im Laufe des Bestehens der S.à.r.l. zu keinem Zeitpunkt geringer sein als 1/10 des im Gesellschaftsvertrag ausgewiesenen Stammkapitals (Art. L 231-1 ff. C.com $)^{841}$. Anzugeben ist des weiteren ein Höchstbetrag bis zu dessen Erreichen Einlagen auf das Stammkapital erbracht werden können, ohne dass es einer förmlichen Erhöhung des Stammkapitals unter Beachtung der Kapitalerhöhungsregeln (Art. L 223-30 ff. C.com.) bedarf ${ }^{842}$.

Wie in Deutschland ist eine Volleinzahlung von Bareinlagen im Zeitpunkt der Gründung der Gesellschaft nicht erforderlich; anders als bei Vereinbarung einer Sacheinlage, die auch in Frankreich bereits bei Gründung voll eingebracht sein muss ${ }^{843}$. Art. L 223-7 Abs. 1 C.com. bestimmt insoweit, dass lediglich 1/5 der Bareinlage erbracht sein muss; der Rest ist auf Anforderung des Geschäftsführers innerhalb von fünf Jahren seit Eintragung der Gesellschaft in das Handelsregister zu erbringen, sofern nicht der Gesellschaftsvertrag eine kürzere Frist vor$\operatorname{sieht}^{844}$.

\section{Fakultativer Inhalt des Gesellschaftsvertrages}

Im Gesellschaftsvertrag können vom vorstehend beschriebenen Mindestinhalt abweichende oder zusätzliche Regelungen etwa in Bezug auf die Geschäftsführung, deren Befugnisse und Grenzen, gegenseitige Rechte und Verpflichtungen zwischen der Gesellschaft und den Gesellschaftern oder den Gesellschaftern untereinander, wie etwa gegenseitige Mitteilungspflichten, Vinkulierungen der Geschäftsanteile, Mehrheitsverhältnisse bei der Beschlussfassung in der Gesellschafterversammlung; Gewinn- und Verlustverteilung in Abweichung vom Verhältnis der Anteile oder aber Voraussetzungen und Bedingungen der Liquidation der Gesellschaft ${ }^{845}$.

840 Grundsatzurteil der Cour d'appel Douai: vgl. CA Douai, 23 sept. 1999 : Bull. Joly 2000, p. 718; bestätigt durch das Ministerium der Justiz: Rép. Min. Souvet Nr. 12626: Bull. Joly 1999, p. 921. Siehe auch J.-M. Bahans RJC 1999, p. 310 sowie Lefebvre Rn. 5072. Cozian/Viandier/Deboissy Rn. 1003. In diesem Fall finden die Regeln betreffend die Gesellschaft bürgerlichen Rechts Anwendung, vgl. Art. 231 -1 ff. C.com. Lefebvre Rn. 5072; Süß/Wachter/Karst S. 809; Behrens in Behrens Die GmbH Rn. F 11.

842 Mithin ist das dem französischen Recht bekannte variable Stammkapital vergleichbar dem im deutschen Aktienrecht angelegten genehmigten Kapital, das nunmehr auch in die deutschen Reformüberlegungen zu einer Modernisierung des GmbH-Rechts aufgenommen wurde; vgl. dazu bereits oben Zweiter Abschnitt $§ 1$ II. sowie zum französischen Recht Lefebvre Rn. 5072 mit Nachweisen zur einschlägigen Rechtsprechung. Lefebvre Rn. 5093.

844 Siehe dazu bereits oben in diesem Abschnitt II. 2. b) und später auch unten V. 1 b) und c). Vgl. auch Lefebvre Rn. 5072 und 5075; Süß/Wachter/Karst S. 809 und 812 f. sowie Mellert/Verfürth S. 124 f.

845 Aufzählung bei Süß/Wachter/Karst S. 810; vgl. auch Maier-Bridou Die GmbH in Frankreich, in: Die GmbH-Rechte in den EG-Staaten, 77, 82, der empfiehlt bei einer Beteiligung ausländischer Gesellschafter 


\section{Organisationsverfassung}

\section{Geschäftsführer}

Die S.à.r.l. wird durch einen oder mehrere Geschäftsführer (gérant/s) vertreten ${ }^{846}$. Eine gesetzliche Höchstzahl existiert nicht. Sind mehrere Geschäftsführer in einer Gesellschaft bestellt, so können die Gesellschafter deren (Einzel-)Befugnisse in dem Gesellschaftsvertrag regeln. Geschäftsführer können sowohl Gesellschafter als auch Nicht-Gesellschafter sein (Art. L 22318 Abs. 2 C.com. $)^{847}$. Anders als in den Niederlanden können wie in Deutschland allerdings nur natürliche Personen Geschäftsführer sein (Art. L. 223-18 Abs. 1 C.com) ${ }^{848}$. Mit Ausnahme unter Vormundschaft oder Pflegschaft stehender Personen können alle natürlichen Personen auch Geschäftsführer sein; sogar Minderjährigen ist der Zugang zum Geschäftsführeramtprinzipiell nicht verwehrt ${ }^{849}$. Zulässig ist, dass ein ausländischer Staatsbürger Geschäftsführer einer S.à.r.l. wird, vorausgesetzt, dass er einen festen Wohnsitz in Frankreich hat oder aber Inhaber einer speziellen Kaufmannsbescheinigung für Ausländer (,carte de commercant étranger $^{\text {") }}$ ist $^{850}$. Ungeachtet der vorstehenden Voraussetzungen ist es stets möglich, dass ein Staatsangehöriger eines EU- oder EWR-Mitgliedstaats die Gesellschaft als Geschäftsführer vertritt. Werden in berufs- und/oder gewerberechtlichen Vorschriften bestimmte Anforderungen an die Ausübung einer Tätigkeit gestellt, so haben auch die Geschäftsführer diese Anforderungen in ihrer Person zu erfüllen. Schließlich kann nicht Geschäftsführer sein, wer wegen einschlägiger Delikte, wie etwa Bankrott, Betrug und Untreue, verurteilt worden ist ${ }^{851}$. Der Gesellschaftvertrag kann bestimmte Bedingungen im Hinblick auf die Person des Gesellschafters postulieren, wie etwa eine bestimmte berufliche Qualifikation oder das Unterschreiten einer bestimmten Altersgrenze ${ }^{852}$. Auch kann der Gesellschaftsvertrag Inkompatibilitäten

oder Geschäftsführer den Gesellschaftsvertrag relativ ausführlich zu fassen, damit diese den Gesellschaftsvertrag als eine Art „Kurzanleitung“ für die Geschäftsführung verwenden können. Ein durchaus verallgemeinerungsfähiger Ansatz.

846 Lefebvre Rn. 5005 und 5250 sowie Cozian/Viandier/Deboissy Rn. 1009.

847 Lefebvre Rn. 5252; Cozian/Viandier/Deboissy Rn. 1011.

848 Lefebvre Rn. 5254; Süß/Wachter/Karst S. 831; Maier-Bridou Die GmbH in Frankreich, in: Die GmbHRechte in den EG-Staaten, 77, 86.

849 Wobei allerdings die Geeignetheit nicht geschäftsfähiger Minderjähriger von Lefebvre Rn. 5255 zurecht bezweifelt wird.

850 Lefebvre Rn. 5258; Süß/Wachter/Karst S. 831.

851 Cozian/Viandier/Deboissy Rn. 1011; Süß/Wachter/Karst S. 831. Beschränkungen können ferener bestehen für bestimmte Berufsgruppen, wie etwa Rechtsanwälte und Wirtschaftsprüfer. Letztere sind nicht befugt Geschäftsführer einer Gesellschaft zu sein, die von ihnen innerhalb der letzten fünf Jahre geprüft worden ist. Siehe hierzu auch Behrens in Behrens Die GmbH Rn. F 18.

852 Cozian/Viandier/Deboissy Rn. 1011; Lefebvre Rn. 5265. Die Zugangsbeschänkung aufgrund in der Person des Geschäftsführeranwärters liegender Gründe mag auch in Frankreich aus Gleichbehandlungsgründen 
beschreiben, wie etwa die gleichzeitige Wahrnehmung einer Geschäftsführung in einer anderen Gesellschaft ${ }^{853}$.

\section{a) Bestellung und Abberufung}

Die Geschäftsführer werden bei Gründung der S.à.r.l. im Gesellschaftsvertrag selbst oder in einem gesonderten Rechtsakt bestellt (Art. 223-18 Abs. 2 C.com.) ${ }^{854}$. Später erfolgt die Bestellung und Abberufung durch Beschluss der Gesellschafter, die mehr als $50 \%$ des Stammkapitals auf sich vereinigen ${ }^{855}$. Wird in einem ersten Wahlgang das vorgenannte Quorum nicht erreicht, so bestimmt Art. 223-18 Abs. 2 in Verbindung mit Art. L 223-29 C.com, das im zweiten Wahlgang die einfache Mehrheit der abgegebenen Stimmen genügen soll ${ }^{856}$. Im Übrigen sind die Gesellschafter frei, die Modalitäten der Bestellung und Abberufung der Geschäftsführer im Gesellschaftsvertrag frei zu regeln, insbesondere größeren Mehrheiten für die Bestellung und/oder Abberufung vorzusehen ${ }^{857}$. Die Bestellung bedarf der (ausdrücklichen oder stillschweigenden) Annahme durch den Geschäftsführer ${ }^{858}$.

Eine Beendigung des Geschäftsführeramtes durch Amtsniederlegung ist im Code de Commerce nicht vorgesehen, daher können die Gesellschafter die Modalitäten einer solchen Amtniederlegung im Gesellschaftsvertrag frei bestimmen ${ }^{859}$.

Bestellung und Abberufung eines Geschäftsführers sind zur Eintragung in das Handelsregister anzumelden; die Eintragung wirkt Dritten gegenüber konstitutiv. Außerdem sind für die Wirksamkeit des Bestellungs- und/oder Abberufungsaktes gegenüber Dritten weitere Publizi-

problematisch sein, denn das deutsche AGG geht auf europäische Vorgaben zurück, die auch in Frankreich umgesetzt worden sind.

853 Lefebvre Rn. 5265; Cozian/Viandier/Deboissy Rn. 1011.

854 Lefebvre Rn. 5273; Cozian/Viandier/Deboissy Rn. 1012.

855 Lefebvre Rn. 5005 und 5274. Zwar ist die Bestellung eines Geschäftsführers auch in Frankreich jederzeit ohen Angabe von Gründen widerruflich. Doch löst in Frankreich wie in Deutschland eine willkürliche Abberufung unter Umständen Schadensersatzansprüche des Geschäftsfühers aus, Lefebvre Rn. 5306; Cozian/Viandier/Deboissy Rn. 1014; Die Willkür der Abberufung ist vom betroffenen Geschäftsführer nachzuweisen: CA Caen, 19 mai 2005: Dr. sociétés oct. 2005 Nr. 181, obs. J. Monnet; vgl. zu einzelnen Problemfällen Lefebvre Rn. 5307 ff. und Cozian/Viandier/Deboissy Rn. 1014 ff. jeweils mit zahlreichen Nachweisen zur Rechtsprechung und Hinweisen zur Praxis.

856 Lefebvre Rn. 5274; Cozian/Viandier/Deboissy Rn. 1011 und 1014.

857 Süß/Wachter/Karst S. 831; Behrens in Behrens Die GmbH Rn. F 18.

858 Lefebvre Rn. 5276 ; Cozian/Viandier/Deboissy Rn. 1014.

859 Lefebvre Rn. 5324. Fehlt es an einer entsprechenden Ermächtigung in der Satzung, so muss nach richtiger Auffassung, eine Amtsniederlegung - soweit sie nicht zur Unzeit und nicht willkürlich geschieht - dennoch möglich sein; siehe so Lefebvre a. a. O. Das Mandat des Geschäftsführers endet - existiert keine anderslautende Regelung in der Satzung - mit der Beendigung der Gesellschaft (Art. L 223-18 C.com). Wird der Geschäftsführer nur für eine befristete Dauer ernannt, so hat er kein Recht auf Wiederbestellung: Cass. Com 17. décembre 2002: Bull. Joly 2003, p. 307 mit Anm. P. le Cannu. 
tätspflichten, wie etwa die Veröffentlichung in einem amtlichen Mitteilungsblatt, das am Sitz der Gesellschaft erscheint, sowie im BODACC ${ }^{860}$ zu erfüllen $^{861}$.

\section{b) Vertretung der Gesellschaft; Aufgaben und Befugnisse}

Der oder die Geschäftsführer vertreten die Gesellschaft umfassend im Rechtsverkehr (Art. L 223-18 Abs. 5 C.com.) $)^{862}$. Im Innenverhältnis sind die Geschäftsführer insoweit beschränkt, als sie die Gesellschaft grundsätzlich nur im Rahmen ihres Unternehmensgegenstandes wirksam binden können ${ }^{863}$. Eine Geltendmachung des Missbrauchs der Vertretungsmacht und damit der fehlenden Bindung an den durch den Geschäftsführer geschlossenen Vertrag aus diesem Grunde gegenüber dem jeweiligen Geschäftspartner ist indes nur möglich, wenn dieser positive Kenntnis davon hatte, dass das Geschäft nicht dem Unternehmensgegenstand der Gesellschaft unterfällt (Art. L 223-18 Abs. 5 C.com.) ${ }^{864}$. Genauso ist es grundsätzlich möglich weitere Beschränkungen der Geschäftsführungsbefugnis im Gesellschaftsvertrag vorzusehen, doch auch sie wirken nur im Innenverhältnis; Dritten gegenüber sind auch diese Beschränkungen nicht entgegensetzbar, nicht zuletzt, da die Beschränkungen nicht, etwa durch Eintragung in das Handelsregister, veröffentlichbar sind (Art. L 221-4 Abs. 2, L 221-5 Abs. 3, L 223-18 Abs. 6 und 7 C.com) ${ }^{865}$. Außerhalb des Gesellschaftsvertrages stehende bzw. ausgesprochene Beschränkungen der Geschäftsführungsbefugnis binden den Geschäftsführer nicht, es sei denn der Gesellschafterbeschluss dieses Inhalts ist zum Zwecke der Änderung des Gesellschaftsvertrages mit entsprechender Mehrheit gefasst worden ${ }^{866}$.

Anders als nach deutschem Recht bilden mehrere Geschäftsführer einer französischen S.à.r.l. nicht qua Gesetz ein Kollektivorgan. Vielmehr ist jeder Geschäftsführer einer S.à.r.l. gemäß Art. L 223-18 C.com. stets einzeln und selbstständig zur Vertretung der Gesellschaft befugt, unabhängig davon, wie viele andere Geschäftsführer in der Gesellschaft bestellt worden sind;

860 Bulletin Officiel Des Annonces Civiles et Commerciales.

861 Cozian/Viandier/Deboissy Rn. 190 ff., 268 und Rn. 1012; Süß/Wachter/Karst S. 831 f.; Mellert/Verfürth S. 131; Behrens in Behrens Die GmbH Rn. F 18; Maier-Bridou Die GmbH in Frankreich, in: Die GmbHRechte in den EG-Staaten, 77, 87.

862 Cozian/Viandier/Deboissy Rn. $1024 \mathrm{ff}$.

863 Cozian/Viandier/Deboissy Rn. 277 und Rn. 1024.

864 Vgl. hierzu Lefebvre Rn. 5005 sowie Cozian/Viandier/Deboissy Rn. 1024. Positive Kenntnis liegt allerdings in den Fällen unzweifelhaft vor, in denen der Geschäftsführer Maßnahmen ergreift, die in die ausschließliche gesetzliche Zuständigkeit der Gesellschafter fallen, wie etwa Satzungsänderungen, Lefebvre Rn. 5366. Im Falle mehrerer Geschäftsführer wirkt auch der Widerspruch eines Mitgeschäftsführers gegenüber einem Dritten, wenn dieser ihn kannte. Siehe dazu Lefebvre Rn. 5367; Maier-Bridou Die GmbH in Frankreich, in: Die GmbH-Rechte in den EG-Staaten, 77, 86 und Behrens in Behrens Die GmbH Rn. F 19.

865 Cozian/Viandier/Deboissy Rn. 1024; Süß/Wachter/Karst S. 833; Maier-Bridou Die GmbH in Frankreich, in: Die GmbH-Rechte in den EG-Staaten, 77, 86 und Behrens in Behrens Die GmbH Rn. F 19.

866 CA Versailles 31-10-2002 Nr. 00-71 RJDA 3/03 Nr. 269 und Cass. Com. 28-11-2006 Nr. 1330 RJDA 4/07 Nr. 371; siehe dazu auch Lefebvre Rn. 5360 sowie Cozian/Viandier/Deboissy Rn. 1025. 
ein dem deutschen Recht vergleichbares Selbstkontrahierungs- oder Mehrfachvertretungsverbot existiert nicht im französischen Recht (vgl. auch Art. L 221- 4 und L 221-5 C.com.) ${ }^{867}$.

Neben der Vertretung der Gesellschaft im Rechtsverkehr ist es die Aufgabe der Geschäftsführung, sicherzustellen, dass die Gesellschaft die Gesetze und behördlichen Auflagen etc. befolgt $^{868}$. Ferner hat der Geschäftsführer die wirtschaftlichen Geschicke der Gesellschaft zu beobachten und gegebenenfalls die Gesellschafter über eine Schieflage der Gesellschaft zu informieren, spätestens aber, wenn das Reinvermögen der Gesellschaft unter die Hälfte des nominalen Stammkapitals absinkt (Art. L 223-42 Abs. 1 C.com ${ }^{869}$.

\section{c) Verantwortung und Haftungsregime}

Die Geschäftsführer haften gemäß Art. 223-22 Abs. 1 C.com einzeln oder gegebenenfalls gesamtschuldnerisch der Gesellschaft gegenüber für die Verletzung gesetzlicher und gesellschaftsvertraglicher Bestimmungen oder sonstigen Pflichtverletzungen bei Ausübung der Geschäftsführertätigkeit ${ }^{870}$. Nach Maßgabe des Art. 223-22 Abs. 1 C.com kommt eine Haftung des Geschäftsführers auch gegenüber Dritten in Betracht ${ }^{871}$. Eine solche unmittelbare persönliche Haftung der Geschäftsführer ist allerdings nur denkbar in Konstellationen, in denen dem Geschäftsführer das schädigende Verhalten auch persönlich zuzurechnen ist ${ }^{872}$. Da der Geschäftsführer regelmäßig als Organ der Gesellschaft und für diese handelt, ist dieser grundsätzlich auch das fehlerhafte Handeln des Geschäftsführers zuzurechnen, so dass die unmittelbare persönliche Haftung des Geschäftsführers Ausnahmecharakter besitzt. Eine solche haftungsbegründende Ausnahme wäre beispielsweise die Verletzung gesetzlicher oder gesellschaftsvertraglicher Bestimmungen oder die Verwirklichung strafbewehrter Tatbestände ${ }^{873}$. In

867 Lefebvre Rn. 5250 und 5362; Cozian/Viandier/Deboissy Rn. 1026; Süß/Wachter/Karst S. 832; Mellert/Verfürth S. 131; Maier-Bridou Die GmbH in Frankreich, in: Die GmbH-Rechte in den EG-Staaten, 77, 86; In einem französischen Handelsregisterauszug findet man daher auch keine Angaben zur Vertretungsmacht der Geschäftsführer, siehe hierzu auch Maier GmbHR 1990, 379, 381. Eine Ausnahme gilt hinsichtlich des Jahresabschlusses und des Geschäftsführungsberichts; diese sind von allen Geschäftsführern gemeinsam zu erstellen; Art. 223-26 C. com.; Cass. Com 21-3-1995 RJDA 6/95 Nr. 724; siehe auch Lefebvre Rn. 5362.

In diesem Zusammenhang ist der Geschäftsführer sogar berechtigt, den Gesellschaftsvertrag zu ändern um in mit zwingenden gesetzlichen Vorschriften in einklnag zu bringen. Die Änderungen hat stehen allerdings unter dem Vorbehalt der Zustimmung durch die Gesellschafterversammlung. Lefebvre Rn. 5363. Süß/Wachter/Karst S. 832 f.; Behrens in Behrens Die GmbH Rn. F 19.

870 Cass. Com., 7. octobre 1997: Bull. Joly 1997, p. 1074, obs. J.-J. Daigre: Verantwortlichkeit eines Geschäftsführers bei fehlerhafter Geschäftsführung; Siehe auch Lefebvre Rn. 5430 ff. und Cozian/Viandier/Deboissy Rn. 1022.

871 Siehe dazu Behrens in Behrens Die GmbH Rn. F 20 und Becker GmbHR 2003, 162, die auch zu der zivilrechtlichen Haftung des Geschäftsführers Stellung nimmt.

872 Lefebvre Rn. 5431.

873 Lefebvre Rn. 5432; zu der strafrechtlichen Verantwortlichkeit der Geschäftsführer vgl. Lefebvre Rn. 5460 f. 
der Insolvenz der Gesellschaft haftet die Geschäftsleitung - ordnungsgemäß bestellte und auch faktische - nach denselben Grundsätzen für die Schulden der Gesellschaft ${ }^{874}$.

\section{Gesellschafter und Geschäftsanteile}

\section{a) Rechtsstellung der Gesellschafter}

Wie in Deutschland und den Niederlanden ist auch in Frankreich der Gesellschafter kein eigenes, selbständig handelndes Gesellschaftsorgan sondern kann seine Rechte grundsätzlich nur im Rahmen einer Gesellschafterversammlung (Assemblée) ausüben ${ }^{875}$. Da der französische Gesetzgeber die Beteiligung an einer S.à.r.l. lediglich als eine Form der Kapitalanlage versteht, sind die Einflussnahmemöglichkeiten der Gesellschafter auf die Geschäftsführung eher gering. In erster Linie stehen den Gesellschaftern vor dem Hintergrund des zuvor Gesagten Kontrollrechte sowie Auskunfts- und Informationsrechte zu, die dazu dienen sollen, sein Interesse an einer Beteiligung am Unternehmensgewinn zu sichern ${ }^{876}$.

Einzige Verpflichtung der Gesellschafter ist die Erbringung der von ihnen übernommenen Stammeinlage. Beschränkt auf diese Einlage ist grundsätzlich auch die Haftung der Gesellschafter für Gesellschaftsverbindlichkeiten, es sei denn, weitergehende Verlustausgleichsund/oder Nachschusspflichten sind im Gesellschaftsvertrag vorgesehen ${ }^{877}$.

874 Süß/Wachter/Karst S. 832; Mellert/Verfürth S. 131; Maier GmbHR 1990, 379, 381; Behrens Die GmbH Rn. F 20. $\mathrm{Zu}$ der arbeitsrechtlichen, sozialversicherungsrechtlichen und steuerrrechtlichen Stellung des Geschäftsführers in Frankreich vgl.nur Ranke; Pélissier/Supiot/Jeammaud, sowie den kurzen Überblick bei Maier-Bridou Die GmbH in Frankreich, in: Die GmbH-Rechte in den EG-Staaten, 77, 88 ff.

875 Ausführlich zu den Mitgliedsrechten Lefebvre Rn. 6010 ff. sowie Cozian/Viandier/Deboissy Rn. 662 ff. und 1031 ff.; Vgl. auch Süß/Wachter/Karst S. 820; Mellert/Verfürth S. 132; Behrens in Behrens Die GmbH Rn. F 23.

876 Lefebvre Rn. 5500; Süß/Wachter/Karst S. 820; Behrens in Behrens Die GmbH Rn. F 23; nach den einzelnen Informationsrechten differenzierend: Cozian/Viandier/Deboissy Rn. 662 ff. und 1031 mit zahlreichen Nachweisen zur Rechtsprechung.

877 Lefebvre Rn. 5100; Siehe dazu auch unten in diesem Abschnitt IV. 2. d) sowie die Ausführungen bei Behrens in Behrens Die GmbH Rn. F 31. 


\section{b) Registrierung der Gesellschafter}

Anders als nach deutschen oder niederländischen Recht ist die Führung eines Gesellschafterregisters oder aber eine Verpflichtung zur Einreichung einer stets zu aktualisierenden Liste der Gesellschafter im französischen Recht nicht vorgesehen ${ }^{878}$.

\section{c) Gesellschafterbeschlüsse}

Gesellschafterbeschlüsse („décisions collectives“) werden gemäß Art. L 223-27 Abs. 1 C.com. grundsätzlich in Versammlungen (,assemblées“) gefasst ${ }^{879}$. Mit Ausnahme der Beschlüsse betreffend die Feststellung des Jahresabschlusses, die Genehmigung des Inventars sowie des Geschäftsführungsberichtes, die zwingend im Rahmen einer ordentlichen Gesellschafterversammlung (,assemblée ordinaire annuelle“) zu treffen sind (Art. L 223-27 Abs. 1 C.com.), können Beschlussfassungen in allen übrigen Fällen aber auch auf andere Weise, wie etwa im Wege des Umlaufverfahrens oder in sonstiger, im Gesellschaftsvertrag festzulegender Weise erfolgen (Art. L 223-27 Abs. 1 C.com. $)^{880}$.

\section{aa) Gesellschafterversammlung}

Die Gesellschafterversammlung bildet - wie in Deutschland - das zentrale Willenbildungsorgan der Gesellschaft. Ihre Entscheidungskompetenz in Angelegenheiten der Gesellschaft ist umfassend, soweit nicht einzelne Angelegenheiten der Gesellschaft im Gesellschaftsvertrag oder qua Beschluss der Geschäftsführung zugewiesen sind ${ }^{881}$.

Eine Gesellschafterversammlung ist mindestens einmal jährlich zur Beschlussfassung über den Jahresabschluss abzuhalten ${ }^{882}$. Daneben ist die Abhaltung einer Gesellschafterversammlung erforderlich, wenn das Eigenkapital die Hälfte des Gesellschaftskapitals unterschreitet ${ }^{883}$.

878 Süß/Wachter/Karst S. 821; Behrens in Behrens Die GmbH Rn. F 28.

879 Vgl. hierzu ausführlich Lefebvre Rn. 5650 ff.; Süß/Wachter/Karst S. 826; Behrens in Behrens Die GmbH Rn. F 25; Maier-Bridou Die GmbH in Frankreich, in: Die GmbH-Rechte in den EG-Staaten, 77, 91.

880 Lefebvre Rn. 5651; Süß/Wachter/Karst S. 826; Maier-Bridou Die GmbH in Frankreich, in: Die GmbHRechte in den EG-Staaten, 77, 91; Guyon Droit des affaires Rn. 507. Ein weiterer Vorteil des französischen Rechts ist, dass es einer Beurkundung oder Beglaubigung eines Gesellschafterbeschlusses oder der Anmeldung, unabhängig vom Inhalt des Beschlusses, nicht bedarf; Recq/Hoffmann GmbHR 2004, 1070, 1074.

881 Cozian/Viandier/Deboissy Rn. 1034 ff.; Süß/Wachter/Karst S. 826; Mellert/Verfürth S. 132; Behrens in Behrens Die GmbH Rn. F 23.

882 Lefebvre Rn. 5666; Cozian/Viandier/Deboissy Rn. 1035. Mit der Einberufung zur ordentlichen Gesellschafterversammlung hat der Geschäftsführer den Jahresabschluss nebst Anhängen, Bestandsliste, Geschäftsführungsbericht; Vorschlag der zu fassenden Gesellschafterbeschlüsse sowie den Bericht des Wirtschaftsprüfers 


\section{bb) Einberufung und Formalien}

Die Einberufung der Gesellschafterversammlung erfolgt regelmäßig durch den Geschäftsführer. Sind für die Gesellschaft mehrere Geschäftsführer bestellt, so ist grundsätzlich jeder Geschäftsführer einzeln zur Einberufung berechtigt (Art. L 223-18 Abs. 4 C.com.) ${ }^{884}$. Allerdings kann bei einer Vertretung der Gesellschaft durch mehrere Geschäftsführer die Zuständigkeit für die Einberufung der Gesellschafterversammlung im Gesellschafsvertrag einem der Geschäftsführer exklusiv übertragen $\operatorname{sein}^{885}$. In Abwesenheit des Geschäftsführers wird die Gesellschafterversammlung durch den Abschlussprüfer einberufen. Bleibt der Geschäftsführer trotz Einberufungsverlangens eines der Gesellschafter untätig, so kann der Gesellschafter beim Präsidenten des Handelsgerichts die Bestellung eines Bevollmächtigten beantragen, der eine Gesellschafterversammlung einberuft und die Tagesordnung aufstellt ${ }^{886}$. Schließlich ist auch im Falle des Versterbens des einzigen Geschäftsführers die Einberufung sowohl dem Abschlussprüfer als auch jedem Gesellschafter ohne Anrufung des Gerichts gestattet ${ }^{887}$.

Die Gesellschafter sind mindestens 15 Tage vor der Versammlung durch eingeschriebenen Brief einzuladen ${ }^{888}$. Mit der Einladung sind die Gesellschafter über Tagesordnung (Art. R 223-20 Abs. 1 C. com.), Tag, Ort ${ }^{889}$ und Zeitpunkt der Versammlung zu informieren (Art. D 38 Abs. 1 C.com. $)^{890}$. Wird die Einladung zur ordentlichen Gesellschafterversammlung ausgesprochen, so sind mit der Einladung außerdem Jahresabschluss, Geschäftsführungsbericht, Inventar und etwaige Beschlussvorlagen sowie gegebenenfalls der Bericht des Wirtschaftsprüfers zu übermitteln (Art. L 23-26 Abs. 2 C.com.) ${ }^{891}$.

zu übermitteln. In allen anderen Fällen ist mit der Einberufung stets auch der Vorschlagstext der zu fassenden Gesellschafterbeschlüsse, ein Geschäftsführungsbericht sowie ggfs. ein Bericht des Abschlussprüfers zu übermitteln, siehe dazu Lefebvre Rn. 5680.

883 Behrens in Behrens Die GmbH Rn. F 24; siehe hierzu auch schon oben in diesem Abschnitt IV. 1. c).

884 Lefebvre Rn. 5655; Süß/Wachter/Karst S. 826; Behrens in Behrens Die GmbH Rn. F 24; Maier-Bridou Die GmbH in Frankreich, in: Die GmbH-Rechte in den EG-Staaten, 77, 91; Ausführlichst zur Einberufung und Abhaltung einer gesellschafterversammlung Cozian/Viandier/Deboissy Rn. 1033 ff.

885 Lefebvre Rn. 5655; Süß/Wachter/Karst S. 827.

886 Vgl. dazu im einzelnen Lefebvre Rn. 5656.

887 Lefebvre Rn. 5655.

888 Cozian/Viandier/Deboissy Rn. 1035; Lefebvre Rn. 5658; allerdings dürfte auch eine mündliche Einberufung der Gesellschafterversammlung genügen, wenn alle Gesellschafter anwesend sind und sich mit dem Stattfinden einer Gesellschafterversammlung einverstanden erklären; siehe Lefebvre a. a. O.

889 Die Bestimmung eines anderen Ortes als des Gesellschaftssitzes als Versammlungsort ist - vorausgesetzt die Satzung regelt nicht Gegenteiliges - nicht unzulässig, soweit die Bestimmung auf nachvollziehbaren Gründen beruht und nicht allein die Benachteiligung eines Gesellschafters bezweckt; CA Paris 15-6-1989 BRDA 15/89 S. 20; Lefebvre Rn. 5661.

891 Cozian/Viandier/Deboissy Rn. 1035; Süß/Wachter/Karst S. 827; Behrens in Behrens Die GmbH Rn. F 24. 
Eine Verletzung der vorgenannten Einberufungsformalitäten führt zur Anfechtbarkeit der in der Gesellschafterversammlung gefassten Beschlüsse, es sei denn, sämtliche Gesellschafter waren gleichwohl anwesend oder wirksam vertreten (Art. L 223-27 Abs. 5 C.com.) ${ }^{892}$.

\section{cc) Stimmrecht und Vertretung}

Jeder Gesellschafter hat ein unbeschränkbares Recht auf Teilnahme an den Gesellschafterversammlungen, persönlich oder gemittelt durch einen Vertreter ${ }^{893}$. Bestimmungen des Gesellschaftsvertrages, die der Wahrnehmung des Teilnahmerechts entgegenstehen, sind unwirksam (Art. L 223-28 Abs. 1 und 2 C.com.) ${ }^{894}$. Desgleichen gilt für das Teilnahmerecht des Wirtschaftsprüfers der Gesellschaft, welches in Art. 223-39 Abs. 2 C.com. gesetzlich verankert is $^{895}$.

Die Möglichkeit der Vertretung in der Gesellschafterversammlung ist beschränkt und nach Maßgabe des Art. 223-28 Abs. 2 C.com. nur für zwei Fallkonstellationen vorgesehen, nämlich zum einen im Wege der Vertretung durch den Ehegatten des jeweiligen Gesellschafters oder zum andere durch einen anderen Gesellschafter. Allerdings ist die Regelung des Art. 223-28 Abs. 2 C.com. dispositiv und mag durch entsprechende Bestimmungen im Gesellschaftsvertrag ergänzt werden (vgl. Art. 223-28 Abs. 3 C.com. $)^{896}$.

Nach Art. L 223-28 Abs. 1 C.com. gewährt jeder Geschäftsanteil eine Stimme. Abweichende Regelungen im Gesellschaftsvertrag, insbesondere die Festlegung von Mehrfachstimmrechten sowie die Vorsehung stimmrechtsloser Anteile, sind nicht gestattet ${ }^{897}$.

Wenn der Gesellschaftsvertrag nichts anderes bestimmt ${ }^{898}$, bedürfen so genannte einfache Gesellschafterbeschlüsse (,décisions collectives ordinaires“) in einem ersten Wahlgang der

892 Cass. Com., 5. décembre 2000: D. aff. 2001, p. 239 obs. A Lienhard ; RJDA 2001, Nr. 175 ; Lefebvre Rn. 5663; Süß/Wachter/Karst S. 827; Behrens in Behrens Die GmbH Rn. F 24; Cozian/Viandier/Deboissy Rn. 1035. Außerdem kann der Geschäftsführer für eine fehlerhaft einberufene oder abgehaltene Gesellschafterversammlung in Regress genommen werden: Cass. Crim., 6. septembre 2000: Bull. Joly 2001, p. 41.

893 Lefebvre Rn. 5689; Ausführlich zu den Modalitäten der Stimmabgabe Cozian/Viandier/Deboissy Rn. 1035 ff.

894 Lefebvre Rn. 5689; Cozian/Viandier/Deboissy Rn. 1033 und Rn. 1061.

$895 \mathrm{Süß/Wachter/Karst} \mathrm{S.} \mathrm{826;} \mathrm{Behrens} \mathrm{in} \mathrm{Behrens} \mathrm{Die} \mathrm{GmbH} \mathrm{Rn.} \mathrm{F} 28$ ff.

896 Lefebvre Rn. 5691; Süß/Wachter/Karst S. 826 f.; Behrens in Behrens Die GmbH Rn. F 25.

897 Lefebvre Rn. 5697; Cozian/Viandier/Deboissy Rn. 1033 und Rn. 1061; Süß/Wachter/Karst S. 827 f.; Behrens in Behrens Die GmbH Rn. F 25; Maier-Bridou Die GmbH in Frankreich, in: Die GmbH-Rechte in den EG-Staaten, 77, 91 f. Zur Loslösung des Gewinnbezugsrechts von den übrigen dem Geschäftsanteil immanenten Gesellschafterrechten, insb. Dem Stimmrecht, vgl. CA Paris 17-11-1965 Gaz. Pal. 1966 I S. 231.

Eine Erhöhung der Mehrheitserfordernisse, z. B. auf 3/4 oder 2/3 der abgegebenen Stimmen ist ohne weiteres gestattet CA Douai 9-2-1973 J. soc. 1973.318 m. Anm Bosvieux; CA Lyon 9-12-1971 Gaz. Pal. 1972 I S. 393. In diesem Zusammenhang ist nach Auffassung von Lefebvre Rn. 5776 zu beachten, dass ein erhöhtes 
Mehrheit von mindestens der Hälfte der auf das Stammkapital entfallenden Stimmen. Im zweiten Wahlgang genügt die einfache Mehrheit der abgegebenen Stimmen (Art. L 223-29 C.com. $)^{899}$.

Eine qualifizierte Mehrheit von mindestens 3/4 der auf das Stammkapital entfallenden Stimmen ist für so genannte außerordentliche Gesellschafterbeschlüsse (,décisions collectives extraordinaires") vorgesehen. Außerordentliche Gesellschafterbeschlüsse sind solche $\mathrm{Be}-$ schlüsse, die mittelbar oder unmittelbar Änderungen des Gesellschaftsvertrags zum Inhalt haben (Art. L 223-30 Abs. 2 C.com. ${ }^{900}$, wie etwa Kapitalerhöhungs ${ }^{901}$ - und herabsetzungsbeschlüsse $\mathrm{e}^{902}$ oder Umwandlungsbeschlüsse $\mathrm{e}^{903}$.

\section{dd) Beschlussregister}

Die Beschlüsse der Gesellschafterversammlung sind in einem besonderen Beschlussregister festzuhalten ${ }^{904}$.

\section{d) Verantwortung und Haftung}

Auch im französischen Recht ist ein Gesellschafter neben der Erbringung der von diesem übernommenen Stammeinlage nicht zur Ausübung seiner Befugnisse, insbesondere zur Geschäftsführung oder Kontrolle selbiger, verpflichtet ${ }^{905}$. Spiegelbildlich hierzu ist auch seine Haftung für Gesellschaftsverbindlichkeiten grundsätzlich auf die übernommene Einlage be-

Mehrheitserfordernis nur dann effektiv ist, wenn es nicht durch erneute Beschlussfassung - ohne Berücksichtigung statutarischer Quoren - umgangen werden kann. Hierfür ist u. U, eine explizite Regelung im Gesellschaftsvertrag vorzusehen; siehe dazu CA Rennes 11-7-1995 RJDA 12/95 Nr. 1379 und Cass. Com. 212-1997 RJDA 2/98 Nr. 182.

899 Lefebvre Rn. 5770 ff.; vgl. auch Süß/Wachter/Karst S. 827 f.; Behrens in Behrens Die GmbH Rn. F 25; Maier-Bridou Die GmbH in Frankreich, in: Die GmbH-Rechte in den EG-Staaten, 77, 92. Einen Überblick über Voraussetzungen und Folgen eines Missbrauchs von (Minderheits-)Stimmrechten in französischen Kapitalgesellschaften gibt Bellinghausen RIW 1997, 101.

900 Ausführlich zu den außerordentlichen Gesellschafterbeschlüssen Lefebvre Rn. 5800 ff.; vgl. auch Süß/Wachter/Karst S. 828; Behrens in Behrens Die GmbH Rn. F 25; Maier-Bridou Die GmbH in Frankreich, in: Die GmbH-Rechte in den EG-Staaten, 77, 92.

901 Lefebvre Rn. 5820 ff.

902 Lefebvre Rn. $5835 \mathrm{ff}$.

903 Lefebvre Rn. 5845 ff.

904 Art. R 221-3 unter Bezugnahme auf Art. R 223-24 Abs. 3 C. com.; siehe dazu Lefebvre Rn. 5705 ff. Vgl. auch Süß/Wachter/Karst S. 828; Behrens in Behrens Die GmbH Rn. F 25 Maier-Bridou Die GmbH in Frankreich, in: Die GmbH-Rechte in den EG-Staaten, 77, $91 \mathrm{f}$.

905 Vgl. ausführlich zum Pflichtenkatalog der Gesellschafter einer S.à.r.l. Lefebvre Rn. 6030 ff., der in Rn. 6046 auch die strafrechtliche Verantwortlichkeit der Gesellschafter beschreibt. 
schränkt (Art. 223-1 Abs. 1 C.com.) ${ }^{906}$. Die Gefahr einer persönlichen Inanspruchnahme über die jeweilige Einlage hinaus besteht nur für den Fall, in der der Gesellschafter selbständig eine eigene Verbindlichkeit begründet oder diese faktisch durch entsprechende Einflussnahme oder Unterlassung notwendiger Maßnahmen übernimmt; dann mag der Gesellschafter unter Umständen sogar unbegrenzt für die Schulden der insolventen Gesellschaft haften ${ }^{907}$.

\section{e) Übertragung von Geschäftsanteilen}

Der Verkauf und die Übertragung (,cession“) von Geschäftsanteilen (,parts sociales“) einer S.à.r.l. ist ein zivilrechtlicher Akt (,acte civil ${ }^{\circ)}$ - schuldrechtlich ein Rechtskauf - auf den grundsätzlich das allgemeine Kaufrecht Anwendung findet ${ }^{908}$. In gewissen Konstellationen, beispielsweise wenn der Erwerb der Geschäftsanteile einer S.à.r.l. durch eine Handelsgesellschaft (,société commerciale“) erfolgt, gelten jedoch Besonderheiten, mit der Folge dass die Übertragung als Handelsgeschäft (,,acte commercial“") qualifiziert wird ${ }^{909}$.

Zur Übertragung der Anteile ist grundsätzlich ein privatschriftlicher oder notarieller Übertragungsakt erforderlich (Art. L 221-14 unter Bezugnahme auf Art. L 223-17 C.com) ${ }^{910}$. Allerdings wird die Übertragung im Verhältnis der Parteien untereinander mit deren Einigung zum Zeitpunkt der Übertragung wirksam ohne dass es eines schriftlichen Aktes bedarf ${ }^{911}$. Für die Wirksamkeit gegenüber der Gesellschaft bedarf es noch der Niederschrift des Übertragungsaktes in einer privatschriftlichen oder notariellen Urkunde und der Anzeige gegenüber der Gesellschaft (Art. L 221-14 i. V. m. Art. L 223-17 C.com.) ${ }^{912}$. Dritten gegenüber entfaltet die Übertragung ihre Wirksamkeit erst in dem Moment, in dem die Übertragungsurkunde beim zuständigen Handelsregister eingereicht worden ist ${ }^{913}$.

906 Süß/Wachter/Karst S. 821; B Behrens in Behrens Die GmbH Rn. F 31.; Tillmanns IWB Fach 5 Frankreich Gruppe 3, S. 547, 551. Im Falle der Abtretung des Geschäftsanteils vor vollständiger Erbringung der Einlage bleibt der Zedent gesamtschuldnerisch mit dem Zessionar zur Einlageleistung verpflichtet, CA Lyon 9-62005 Nr. 04-2345 RJDA 7/06 Nr. 798; kritisch hierzu Lefebvre Rn. 6031.

907 Lefebvre Rn. 6040; Süß/Wachter/Karst S. 821; Behrens in Behrens Die GmbH Rn. F 20; Tillmanns IWB Fach 5 Frankreich Gruppe 3, S. 547, 551.

908 Vgl. die ausführliche Darstellung bei Lefebvre Rn. 6120 ff. und bei Cozian/Viandier/Deboissy Rn. 1044 ff.

909 Süß/Wachter/Karst S. 822; Maier-Bridou Die GmbH in Frankreich, in: Die GmbH-Rechte in den EGStaaten, 77, $83 \mathrm{f}$.

910 Lefebvre Rn. 6122; Cozian/Viandier/Deboissy Rn. 1044.

911 Cass. Com. 10-13-1992 RJDA 7/92 Nr. 710; CA Versailles 19-9-1996 RJDA 3/97 Nr. 366; CA Paris 17-92004 Nr. 03-1599 RJDA 3/05 Nr. 268.

912 Lefebvre Rn. 6123; Cozian/Viandier/Deboissy Rn. 1044.

913 Lefebvre Rn. 6125; Cozian/Viandier/Deboissy Rn. 1044; Süß/Wachter/Karst S. 822; Mellert/Verfürth S. 138; Maier-Bridou Die GmbH in Frankreich, in: Die GmbH-Rechte in den EG-Staaten, 77, 84; Behrens in Behrens Die GmbH Rn. F 29. 
Die Übertragung der Geschäftsanteile einer S.à.r.l. auf gesellschaftsfremde Dritte bedarf grundsätzlich der Zustimmung (,Agrément“) der übrigen Gesellschafter, die mindestens die Hälfte des Stammkapitals auf sich vereinigen (Art. L 210-1 Abs. 2 C.com.) ${ }^{914}$.

Anders liegt es bei einer Übertragung von Geschäftsanteilen auf Personen, die bereits Gesellschafter sind ${ }^{915}$ oder die Ehegatte oder Verwandter auf- und absteigender Linie des veräußerungswilligen Gesellschafters sind. Hier sieht da Gesetz keine vergleichbaren Einschränkungen vor; die freie Übertragbarkeit auf Ehegatten und Verwandte auf- und absteigender Linie ist in Art. L 223-13 Abs. 1 C.com.) sogar ausdrücklich gesetzlich geregelt. Eine Einschränkung der Übertragbarkeit auch auf diese Personen ist allerdings auch hier durch entsprechende Regelungen im Gesellschaftsvertrag möglich (Art. L 23-13 Abs. 2 C.com.) ${ }^{916}$. Besonderheiten gelten auch für den Erwerb von Todes wegen und in der Liquidation der Gesellschaft $^{917}$.

\section{Weitere Organe}

Geschäftsführung und Gesellschafterversammlung sind die einzigen Organe, die das französische $\mathrm{GmbH}-\mathrm{Recht}$ kennt ${ }^{918}$. Zwar besteht aufgrund der vertraglichen Gestaltungsfreiheit durchaus die Möglichkeit weitere Gremien (wie etwa einen Beirat oder Aufsichtsrat) zu schaffen, doch ist das eher unüblich, gerade auch weil die Form der S.à.r.l. oftmals bewusst wegen ihrer einfachen Organstruktur gewählt wird ${ }^{919}$. Auch wären die Kompetenzen eines solchen fakultativen Organs beschränkt; insbesondere dürften diesem keine Kompetenzen anderer Gesellschaftsorgane zugewiesen sein oder gar eigene Entscheidungsbefugnisse zustehen $^{920}$.

914 Im Einzelnen siehe dazu Lefebvre Rn. 6130 ff.; dort finden sich auch Angaben zu anderen Vinkulierungsgestaltungen. Einen Überblick geben auch Cozian/Viandier/Deboissy Rn. 1047 f, dieser auch mit Nachweisen zur Rechtsprechung sowie in deutscher Sprache Süß/Wachter/Karst S. 822; Maier-Bridou Die GmbH in Frankreich, in: Die GmbH-Rechte in den EG-Staaten, 77, 84; Behrens in Behrens Die GmbH Rn. F 29.

915 Siehe dazu Lefebvre Rn. 6148 ff.; Cozian/Viandier/Deboissy Rn. 1045 mit weiteren Nachweisen zur Rechtsprechung.

916 Lefebvre Rn. 6130; Süß/Wachter/Karst S. 823; Behrens in Behrens Die GmbH Rn. F 29.

917 Siehe nur Lefebvre Rn. $6160 \mathrm{ff}$.

918 Auch die Bestellung von Prokuristen ist dem französischen Recht unbekannt, siehe nur Maier-Bridou Die GmbH in Frankreich, in: Die GmbH-Rechte in den EG-Staaten, 77, 88.

919 Bis 1966 war die Bestellung eines Aufsichtsrats allerdings sogar gesetzlich vorgesehen, siehe dazu MaierBridou Die GmbH in Frankreich, in: Die GmbH-Rechte in den EG-Staaten, 77, $87 \mathrm{f}$.

920 Süß/Wachter/Karst S. 833; Mellert/Verfürth S. 132. 


\section{Finanzverfassung}

\section{Kapitalaufbringung}

\section{a) Stammkapital}

Seit Inkrafttreten des Wirtschaftförderungsgesetzes vom 1. August 2003 besteht bei der S.à.r.l. keine gesetzlich verankerte Mindestkapitalpflicht mehr; zuvor war für eine S.à.r.l. ein Mindestkapital von $7.500 €$ erforderlich (Art. L 223-2 c.com.). Faktisch gibt es allerdings weiterhin die Verpflichtung der Gesellschafter, die Gesellschaft mit einem Mindeststammkapital von wenigstens $0,01 €$ auszustatten, da auf ein Stammkapital nicht ganz verzichtet werden kann ${ }^{921}$.

\section{b) Bareinlage}

Bis 2001 war das statutarisch bestimmte Gesellschaftskapital - unabhängig davon ob es im Wege der Bareinlage (,,apport en numéraire“) oder im Wege der Sacheinlage (,,apport en nature“) zu erbringen war - bereits bei der Gründung vollständig aufzubringen (Art. L 223-7 C.Com. a.F.). Nunmehr genügt es - soweit Bareinlagen zu leisten sind - wenn der jeweilige Gesellschafter mindestens 1/5 der übernommenen Stammeinlage vor Gründung der Gesellschaft (d.h. vor Unterzeichnung des Gesellschaftsvertrages) erbringt ${ }^{922}$. Die Erbringung - wenigstens eines Teils - der Einlage vor der Unterzeichnung des Gesellschaftsvertrages, ist notwendig, da Art. R 223-3, Abs. 2 C.com. die Aufnahme einer Erklärung über die Erbringung der Einlagen in der Satzung vorschreibt ${ }^{923}$. Die Bareinlagen sind in entsprechender Höhe innerhalb von acht Tagen nach Unterzeichnung des Gesellschaftsvertrages im Namen der in Gründung befindlichen Gesellschaft entweder bei der Caisse des dépôts et consignations, einem Notar oder einer Bank ${ }^{924}$ eingezahlt werden (Art. L 223-7 Abs. 4, Art. D 22 Abs. 1

921 Vgl. hierzu auch schon oben in diesem Abschnitt III. 1. e) sowie Cozian/Viandier/Deboissy Rn. 1003 ff.; Lefebvre Rn. 5070; Süß/Wachter/Karst S. 811; Lutter GmbHR 2005, 1, 3; unzutreffend Recq/Hoffmann GmbHR 2004, 1070, 1071, denen zufolge das Stammkapital mindestens 1 Euro betragen muss.

922 Cozian/Viandier/Deboissy Rn. 121 und insb. 1004.

923 Lefebvre Rn. 5076; Cozian/Viandier/Deboissy Rn. 1004.

924 Die Banken, die berechtigt sind, die Einlageleistungen anzunehmen müssen von der französischen Bankenaufsicht (Comité des établissements de crédit) akkreditiert sein. Dies gilt nach streitiger Auffassung auch für Banken aus Mitgliedsländern der Europäischen Union; vgl. nur Lefebvre Rn. 5076. 
C.com. $)^{925}$. Von der Verpflichtung zur Leistung der Einlagen können die Gesellschafter nicht befreit werden; auch die Aufrechnung gegen den Anspruch der Gesellschaft ist nicht gestattet $^{926}$.

\section{c) Sacheinlage}

Sacheinlagen (,,apport en nature $\left.{ }^{69}\right)^{927}$ müssen - ähnlich wie nach $§ 5$ Abs. 4 GmbHG - mit ihrem Wert im Gesellschaftsvertrag bezeichnet sein (Art. L 223-9 Abs. 1 C.com.) ${ }^{928}$. Als Sacheinlagen können - wie in Deutschland - alle vermögenswerten (beweglichen, unbeweglichen, körperlichen oder unkörperlichen) Gegenstände eingebracht werden ${ }^{929}$. Darüber hinaus ist auch die Einbringung von Know-How und Arbeits- und Dienstleistungen gestattet ${ }^{930}$. Die Bewertung der Sacheinlage erfolgt grundsätzlich durch einen Wirtschaftsprüfer ${ }^{931}$; der Sachgründungsbericht ist als Anhang zum Gesellschaftsvertrag zu nehmen ${ }^{932}$. Die Gesellschafter sind allerdings nicht an die Bewertung des Wirtschaftsprüfers gebunden; bewerten sie den einzubringenden Vermögensgegenstand allerdings höher als vom Wirtschaftsprüfer vorgeschlagen, so haften sie auf die Dauer von 5 Jahren solidarisch für den Differenzbetrag ${ }^{933}$. Die Gründer der S.à.r.l. können per einstimmigen Beschluss auch gänzlich auf die Erstellung eines Sachgründungsberichts verzichten, wenn der Wert jedes einzelnen einzubringenden Vermögensgegenstandes unter 7.500 € liegt und der Wert der Sacheinlagen insgesamt die Hälfte des Stammkapitals nicht übersteigt (Art. L 223-9 Abs. 2 C.com. $)^{934}$.

925 Lefebvre Rn. 5076. Süß/Wachter/Karst S. 812; Mellert/Verfürth S. 125; zur alten Rechtslage Maier-Bridou Die GmbH in Frankreich, in: Die GmbH-Rechte in den EG-Staaten, 77, $81 \mathrm{f}$; Behrens in Behrens Die GmbH Rn. F 13.

926 Cass. Com. RJDA 10/98 Nr. 1144; Lefebvre Rn. 5077

927 Zur Werthaltigkeit einer Sacheinlage im Wege der Nutzungsüberlassung siehe CA Aix 31-5-1951 JCP 1952 II Nr. 6792 m. Anm. Bastian.

928 Cozian/Viandier/Deboissy Rn. 1004.

929 Lefebvre Rn. 5082;.

930 Lefebvre Rn. 5090. Die Bedingungen zu denen Know-How und Arbeits- und Dienstleistungen als Einlage eingebracht werden, sind im Gesellschaftsvertrag genau zu bestimmen; auch sind die im gegenzug gewährten Geschäftsanteile genau zu bezeichnen. Fehlt esan einer entsprechenden Satzungsbestimmung, so gilt die Einlage als nicht erbracht, Cass. Com 14-12-2004 Nr. 1830 RDJA 4/05 Nr. 383.

931 Bestellung und Verantwortungsregime der Wirtschaftsprüfer beschreiben Lefebvre Rn. 5084 und 5085.

932 Lefebvre Rn. 5082. Nach Aussage der franz. Wirtschaftsprüferkammer (Compagnie nationale des commissaires aux comptes) ist der Bruttowert bei der Bewertung sowohl der 7.500er Grenze als auch bei der Berechnung des Erreichens der Häfte des Stammkapitals zugrundezulegen; vgl. Bull. CNCC uni 2000 S. 231 ff.

933 Lefebvre Rn. 5086; Cozian/Viandier/Deboissy Rn. 1004.

934 Cozian/Viandier/Deboissy Rn. 1004; Süß/Wachter/Karst S. 813; Maier-Bridou Die GmbH in Frankreich, in: Die GmbH-Rechte in den EG-Staaten, 77, 81 f.; Behrens in Behrens Die GmbH Rn. F 13. Anders als im deutschen Recht ist dem französischen Recht das Rechtsinstitut der verdeckten Sacheinlage gänzlich unbekannt, siehe dazu auch Recq/Hoffmann GmbHR 2004, 1070, 1071. 


\section{d) Nachschusspflicht}

Das Institut der Nachschüsse existiert im französischen Recht nicht. Dort kann allerdings die Gesellschaft mit variablem Kapital ausgestattet werden, so dass auch hier weitere Einlagen ohne Änderung der Satzung eingefordert werden können ${ }^{935}$.

\section{Kapitalerhaltung}

\section{a) Kapitalschutz}

Den Grundsatz der Kapitalerhaltung (,principe de l'intangibilité du capital social“) kennt auch die französische Rechtsordnung. So dürfen nur bilanzmäßig ausgewiesene Gewinne beziehungsweise Gewinnvorträge abzüglich etwaiger Verlustvorträge oder freier Reserven ausgezahlt werde, fiktive Dividenden sind zurückzuerstatten, wenn dem Gesellschafter dies bekannt war oder hätte bekannt sein müssen ${ }^{936}$.

Ein weiteres Mittel zur Erhaltung des Gesellschaftskapitals ist das grundsätzliche Verbot der Einlagenrückgewähr durch Erwerb eigener Anteile (Art. L 223-34 Abs. 4 Satz 1 C.com.) ${ }^{937}$

Ist das Reinvermögen (,capitaux propres“) der Gesellschaft durch Verluste auf unter die Hälfte des im Gesellschaftsvertrag ausgewiesenen Stammkapitals reduziert worden, so hat die Gesellschafterversammlung innerhalb von vier Monaten darüber zu beschließen, ob die Gesellschaft aufgelöst werden soll (Art. L 223-42 Abs. 1 C.com.) ${ }^{938}$. Falls sich die Gesellschafter gegen eine Auflösung entscheiden, muss das Reinvermögen der Gesellschaft bis zum Ende des zweiten Geschäftsjahres, welches auf dasjenige folgt, in welchem das Absinken des Rein-

935 Maier-Bridou Die GmbH in Frankreich, in: Die GmbH-Rechte in den EG-Staaten, 77, 85; vgl. auch insbesondere Behrens in Behrens Die GmbH Rn. F 31 und 35, der auch auf die Möglichkeit der Veinbarung von Nebenleistungspflichten hinweist.

936 Lefebvre Rn. 5078; Cozian/Viandier/Deboissy Rn. 836 ff. und Rn. 1069; Süß/Wachter/Karst S. 814; MaierBridou Die GmbH in Frankreich, in: Die GmbH-Rechte in den EG-Staaten, 77, 85; Behrens Die GmbH Rn. F 37; Oelkers GesRZ 2004, 360 und 2005, 27. Kommt es nicht innerhalb von sechs Monaten nach der Errichtung zur Eintragung der Gesellschaft, so können die Gesellschafter die Rückzahlung ihrer Einlage verlangen (Art. L 223-8 Abs. 2 C.com.), vgl. hierzu auch Cass. Com. 23-3-1982, Bull. civ. IV Nr. 120. Siehe hierzu auch unten in diesem Abschnitt unter V. 3.

938 Cozian/Viandier/Deboissy Rn. 836 ff. und Rn. 1069; Süß/Wachter/Karst S. 814; Mellert/Verfürth S. 130; Behrens Die GmbH Rn. F 37. 
vermögens festgestellt wurde, wieder die Hälfte des Gesellschaftskapitals erreicht haben. Dies kann entweder durch Zuführung neuen frischen Kapital geschehen oder aber durch Herabsenkung des Stammkapitals auf (mindestens) den Wert des tatsächlichen Reinvermögen (Art. L 223-42 Abs. 2 C.com.) $)^{939}$.

\section{b) Eigenkapitalersatzrecht}

Wie in den Niederlanden ist auch in Frankreich das Eigenkapitalersatzrecht nicht ausdrücklich gesetzlich geregelt ${ }^{940}$.

\section{Eigene Anteile}

Wie bereits oben kurz erwähnt, ist der Erwerb eigener Anteile durch die Gesellschaft nur ausnahmsweise, nämlich zum Zwecke der Durchführung einer Kapitalherabsetzung gestattet (Art. L 223-34 Abs. 4 Satz 1 und 2 i. V. m. Art. L 223-14 Abs. 4 C.com.) ${ }^{941}$.

\section{Handelsrechtliche Publizität}

\section{Handelsregister}

Aufgrund der Vereinheitlichung der Publizitätspflichten in Europa ${ }^{942}$ entspricht auch das französische Recht in den wesentlichen Punkten der in Deutschland und den Niederlanden geltenden Rechtslage.

Auch in Frankreich ist primäres Mittel der Publizität die Hinterlegung (dépot) und die Eintragung (immatriculation) beim Handels- und Gesellschaftsregister. Diese werden in Frankreich dezentral beim jeweils regional zuständigen französischen Handelsgericht (,tribunaux de commerce") geführt. Die Handels- und Gesellschaftsregister genießen öffentlichen Glauben (Art. L 123, II C.com), allerdings werden die eingereichten Unterlagen durch den Registerbe-

939 Süß/Wachter/Karst S. 814; Mellert/Verfürth S. $130 \mathrm{f}$.

940 Vgl. nur Süß/Wachter/Karst S. 811 ff.; Maier-Bridou Die GmbH in Frankreich, in: Die GmbH-Rechte in den EG-Staaten, 77, 85 f.; Behrens in Behrens Die GmbH Rn. F 37.

941 Lefebvre Rn. 6144; Süß/Wachter/Karst S. 814; Behrens Die GmbH Rn. F 37.

942 Vgl. die Erste und Elfte gesellschaftsrechtliche Richtlinie des Rates der EG; Einzelheiten hierzu unten in diesem Abschnitt unter $\S 4$ 2. a) und h). 
amten (greffier) nur auf ihre Vollständigkeit hin überprüft; anders als in Deutschland bezieht sich die Prüfungspflicht des Registerbeamten nicht auch auf die Gesetzmäßigkeit der einzutragenden Vorgänge ${ }^{943}$. Eine weitere Veröffentlichung erfolgt in gesetzlichen Bekanntmachungsblättern sowie dem BODACC, dem Bulletin officiel des annonces civiles et commerciales, einer dem deutschen Bundesanzeiger vergleichbaren Einrichtung ${ }^{944}$.

Handelsregisterauszüge (,extrait Kbis“) können entweder beim zuständigen Urkundsbeamten oder gegebenenfalls auch online ${ }^{945}$ angefordert werden ${ }^{946}$.

Auch im französischen Recht hat die Eintragung der S.à.r.l. im Hinblick auf die Erlangung der Rechtspersönlichkeit konstitutive Wirkung; im Übrigen sind die Eintragungen überwiegend deklaratorisch und dann vor allem negativ, das heißt - ähnlich der Regelung in $\S 15$ GmbHG - können eintragungspflichtige, aber (noch) nicht eingetragene Umstände Dritten, die im Hinblick auf die eingetragenen Tatsachen gutgläubig sind, nicht entgegengehalten werden $^{947}$.

\section{Geschäftsbriefe}

Alle Geschäftsbriefen, die an einen bestimmten Empfänger gerichtet werden, haben neben der Firma der Gesellschaft, Angaben zu deren Rechtsform und die Höhe des Stammkapitals zu enthalten (Art. D 28 C.com.) ${ }^{948}$. Die Angabe des Sitzes der Gesellschaft, des zuständigen RCS und der Eintragungsnummer sowie des beziehungsweise der Geschäftsführer der Gesellschaft ist hingegen fakultativ. Die in Liquidation befindliche Gesellschaft wird - wie in Deutschland - durch den Zusatz „société en liquidation“ gekennzeichnet. Statt des Geschäftsführers ist in diesem Fall zwingend der bestellte Liquidator auf dem Schriftstïck zu nennen (Art. L 237-2 Abs. 1 C.com. $)^{949}$.

943 Cozian/Viandier/Deboissy Rn. 190 ff.; Maier-Bridou Die GmbH in Frankreich, in: Die GmbH-Rechte in den EG-Staaten, 77, 93 f.; Behrens Die GmbH Rn. F 6 f.

944 Lefebvre Rn. 5142 und Cozian/Viandier/Deboissy Rn. 197.

945 www.infogreffe.fr.

946 Süß/Wachter/Karst S. 817.

947 Cozian/Viandier/Deboissy Rn. 190 ff.; Süß/Wachter/Karst S. 817; Maier-Bridou Die GmbH in Frankreich, in: Die GmbH-Rechte in den EG-Staaten, 77, 93 f.; Behrens Die GmbH Rn. F 9.

948 Anders als im Recht der französischen Aktinegesellschaft (S.A.) kann ein ungerades Stammkapital auf Geschäftsbriefen nicht aufgerundet werden, sondern ist unter Angabe etwaiger Dezimalstellen zu führen, Lefebvre Rn. 5073.

949 Lefebvre Rn. 5073; Süß/Wachter/Karst S. 833 f; Behrens Die GmbH Rn. F 7. 


\section{§ 4 Europäisches Gesellschaftsrecht}

\section{Europäisierung des Gesellschaftsrechts}

\section{Rechtsangleichung}

Die nationalen Gesellschaftsrechte werden zunehmend durch europäische Vorgaben geprägt ${ }^{950}$. Dies gilt insbesondere für das Kapitalgesellschaftsrecht, dem das Hauptaugenmerk des Europäischen Gesetzgebers gilt. Bisher hatten die gesellschaftsrechtlichen Angleichungsbemühungen der Europäischen Gemeinschaft hier allerdings in erster Linie die Vereinheitlichung des Rechts der Aktiengesellschaften zum Gegenstand, während die GmbH-Rechte und das Recht der KGaA nur teilweise in die Überlegungen einbezogen worden sind ${ }^{951}$. Betroffen von den Angleichungsmaßnahmen der europäischen Gemeinschaft sind insbesondere die folgenden materiellrechtlichen Inhalte ${ }^{952}$ :

- die handelsrechtliche Publizität für Gesellschaften und Zweigniederlassungen (Erste und Elfte Richtlinie);

- die Gesellschaftsgründung, einschließlich der Gründung von Einpersonengesellschaften (Erste, Zweite und Zwölfte Richtlinie);

- der aktienrechtliche Kapitalschutz (Zweite Richtlinie);

- die Verfassung der Aktiengesellschaft (Fünfte Richtlinie);

- die Kompetenzen der Gesellschaftsorgane (Erste und Fünfte Richtlinie);

- die Mitbestimmung von Arbeitnehmervertretern (Fünfte Richtlinie);

- die Stellung der Aktionäre (Zweite und Fünfte Richtlinie);

- die Rechnungslegung in der Einzelgesellschaft, einschließlich Abschlussprüfung, Prüferbefähigung und Publizität (Vierte, Fünfte und Achte Richtlinie);

950 Auch wenn der Prozess der Vereinheitlichung des Europäischen Gesellschaftsrechts sicherlich bereits weit fortgeschritten ist, so ist sicherlich bei weitem noch nicht beendet. Im Rahmen der vorliegenden Untersuchung kann daher nur ein Überblick über den derzeitigen Stand des Europäischen Gesellschaftsrechts gegeben werden. Umfassend zum Europäischen Gesellschaftsrecht Behrens, Gesellschaftsrecht, in: Dauses (Hrsg.), Handbuch des EG-Wirtschaftsrechts, 5/2004, S. 575-628; Lutter Europäisches Unternehmensrecht, 4. Aufl. 1996, Habersack, Europäisches Gesellschaftsrecht, 3. Aufl. 2006 sowie Schwarz.

951 Behrens Die Europäisierung des Gesellschaftsrechts, in: Die GmbH-Rechte in den EG-Staaten, 1, 2 ff., ders., Gesellschaftsrecht, in: Dauses (Hrsg.), Handbuch des EG-Wirtschaftsrechts, 5/2004, S. 575 ff.; Die Anstrengungen der nationalen Gesetzgeber im Wettbewerb der (europäischen) Gesellschaftsrechte beleuchtet Eidenmüller in FS Heldrich 2005, S. 581 ff.

952 Vorstehende Übersicht gab es auch schon bei Behrens Die Europäisierung des Gesellschaftsrechts, in: Die GmbH-Rechte in den EG-Staaten, 1, 2 ff. 
- die Verschmelzung beziehungsweise Spaltung von Gesellschaften (Dritte und Sechste Richtlinie);

- die Auflösung und Liquidation (Vierzehnte Richtlinie);

- das Konzernrecht, einschließlich der Konzernbildung durch Übernahmeangebote, der Konzernrechnungslegung und der Konzernmitbestimmung (Siebte, Neunte und Dreizehnte Richtlinie $)^{953}$.

\section{Richtlinien}

Auf der Grundlage von Art. 54 Abs. 3 lit. g EWGV, der es den Gemeinschaftsorganen gestattet ,soweit erforderlich die Schutzbestimmungen zu koordinieren, die in den Mitgliedstaaten den Gesellschaften im Sinne des Art. 58 Abs. 2 EWGV im Interesse der Gesellschafter sowie Dritter vorgeschrieben sind, um diese Bestimmungen gleichwertig zu gestalten“, sind bisher folgende Richtlinien, die direkt oder indirekt auch das Recht der GmbH, S.à.r.l. und der B.V. berühren, von den Gemeinschaftsorganen vorgeschlagen und teilweise auch verabschiedet und von den Mitgliedstaaten bereits durchgeführt worden ${ }^{954}$ :

\section{a) Erste gesellschaftsrechtliche Richtlinie 68/151/EWG - Publizitätsrichtlinie}

Die Erste gesellschaftsrechtliche Richtlinie von $1968^{955}$ gilt für AG, KGaA und GmbH gleichermaßen. Sie regelt zum einen die Publizität bestimmter gesellschaftsrechtlicher Verhältnisse sowie die Mittel und Wirkungen der Publizität. Daneben wurde in der Richtlinie der Grundsatz der sachlich unbeschränkten und unbeschränkbaren Vertretungsmacht der Gesellschaftsorgane verankert. Ein weiteres Umsetzungsziel der Richtlinie war die Begrenzung der Gründe, die nach nationalem Recht zur Nichtigkeit einer Gesellschaft führen ${ }^{956}$.

953 Auflistung von Behrens Die Europäisierung des Gesellschaftsrechts, in: Die GmbH-Rechte in den EGStaaten, 1, 5., ders., Gesellschaftsrecht, in: Dauses (Hrsg.), Handbuch des EG-Wirtschaftsrechts, 5/2004, S. $560 \mathrm{f}$.

954 Behrens Die Europäisierung des Gesellschaftsrechts, in: Die GmbH-Rechte in den EG-Staaten, 1, 5; ders., Gesellschaftsrecht, in: Dauses (Hrsg.), Handbuch des EG-Wirtschaftsrechts, 5/2004, S. 575 ff.

955 Erste Richtlinie zur Koordinierung der Schutzbestimmungen, die in den Mitgliedstaaten den Gesellschaften i.S. des Art. 58 Abs. 2 des Vertrages im Interesse der Gesellschafter sowie Dritter vorgeschrieben sind, um diese Bestimmungen gleichwertig zu gestalten (68/151/EWG) ABl 1968 L 65/8.

956 Behrens Die Europäisierung des Gesellschaftsrechts, in: Die GmbH-Rechte in den EG-Staaten, 1, 6; ausführlich hierzu Lutter Europäisches Unternehmensrecht, 4. Aufl. 1996, Habersack, Europäisches Gesellschaftsrecht, 3. Aufl. 2006 sowie Schwarz. 


\section{b) Zweite gesellschaftsrechtliche Richtlinie 77/91/EWG -Kapitalrichtlinie}

Die Zweite gesellschaftsrechtliche Richtlinie von $1976^{957}$ betrifft nur Aktiengesellschaften. Der erste Teil, der sich mit Fragen der Gründung und des Satzungsinhalts befasst, ist entsprechend auch nur für das Recht der Aktiengesellschaften relevant. Der zweite wesentliche Teil der Regelung befasst sich indes mit dem Gesellschaftskapital und enthält neben dem Bekenntnis des europäischen Gesetzgebers zum Konzept eines festen Mindestkapitals Regelungen zur Kapitalaufbringung und -erhaltung. Zwar ist eine Erstreckung der Kapitalrichtlinie auf die $\mathrm{GmbH}$ oder ähnliche ausländische Gesellschaftsformen derzeit nicht beabsichtigt. Doch streitet das Bekenntnis des Europäischen Gesetzgebers für das Konzept eines festen Mindestkapitals für den Erhalt eines solchen auch im Recht der GmbH. Dies umso mehr, als der Europäische Gesetzgeber dieses Bekenntnis in den Statuten der Europäischen Aktiengesellschaft von 2001 und der Europäischen Genossenschaft von 2003 erneuert hat, wenn er dort ein Mindeststammkapital von $120.000 €$ respektive $30.000 €$ verlangt $^{958}$.

\section{c) Dritte gesellschaftsrechtliche Richtlinie 78/855/EWG - Fusionsrichtlinie}

Die Dritte gesellschaftsrechtliche Richtlinie ${ }^{959}$ gilt wiederum ausschließlich für Aktiengesellschaften und regelt die Verschmelzung und gewisse fusionsähnliche Vorgänge innerhalb eines Mitgliedsstaates ${ }^{960}$.

\section{d) Vierte gesellschaftsrechtliche Richtlinie 78/660/EWG - Jahresabschlussrichtlinie}

Die Vierte gesellschaftsrechtliche Richtlinie ${ }^{961}$ ist im Zusammenhang mit der Siebten Richtlinie, der so genannte „Konzernrechnungslegungsrichtlinie““962 sowie der Richtlinie 2006/46/EG

957 Zweite Richtlinie zur Koordinierung der Schutzbestimmungen, die in den Mitgliedstaaten den Gesellschaften i.S. des Art. 58 Abs. 2 des Vertrages im Interesse der Gesellschafter sowie Dritter für die Gründung der Aktiengesellschaft sowie der Erhaltung und Änderung ihres Kapitals vorgeschrieben sind, um diese Bestimmungen gleichwertig zu gestalten (77/91/EWG) AB1 1977 L 26/1.

Behrens Die Europäisierung des Gesellschaftsrechts, in: Die GmbH-Rechte in den EG-Staaten, 1, 7; ausführlich hierzu Lutter Europäisches Unternehmensrecht, 4. Aufl. 1996, Habersack, Europäisches Gesellschaftsrecht, 3. Aufl. 2006 sowie Schwarz.

959 Dritte Richtlinie gemäß Art. 54 Abs. 3 lt. g des Vertrages betreffend die Verschmelzung von Aktiengesellschaften (78/855/EWG) ABl 1978 L 295/36.

960 Behrens Die Europäisierung des Gesellschaftsrechts, in: Die GmbH-Rechte in den EG-Staaten, 1, 7 f.; ausführlich hierzu Lutter Europäisches Unternehmensrecht, 4. Aufl. 1996, Habersack, Europäisches Gesellschaftsrecht, 3. Aufl. 2006 sowie Schwarz.

961 Vierte Richtlinie aufgrund von Art. 54 Abs. 3 lit g des Vertrages über den Jahresabschluss von Gesellschaften bestimmter Rechtsformen (78/660/EWG) AB1 1978 L 222/11.

962 Siehe hierzu sogleich unter $\mathrm{f})$. 
zur Abänderung der Richtlinien 78/660/EWG und 83/349/EWG hinsichtlich der Jahresabschlüsse bestimmter Arten von Unternehmen und konsolidierter Abschlüsse ${ }^{963} \mathrm{zu}$ lesen. Die Richtlinie betrifft alle Kapitalgesellschaften sowie Personengesellschaften, deren persönliche haftende Gesellschafter ausschließlich Kapitalgesellschaften $\operatorname{sind}^{964}$. Sie enthält Vorgaben für die Gliederung und den Inhalt des Jahresabschlusses und des Lageberichts und stellt einheitliche Grundsätze der Aufstellung der Rechnungsunterlagen auf. Des Weiteren enthält die Richtlinie Bestimmungen über die Bewertungsmethoden und die Offenlegung der vorgenannten Unterlagen ${ }^{965}$.

\section{e) Sechste gesellschaftsrechtliche Richtlinie 82/891/EWG - Spaltungsrichtlinie}

Hintergrund der Sechsten Richtlinie ${ }^{966}$ war die Sorge des Europäischen Gesetzgebers, dass die mit der Fusionsrichtlinie 78/855/EWG bezüglich der Verschmelzung von Aktiengesellschaften den Aktionären und Gläubigern gegebenen Garantien durch Vollziehung der Umwandlung im Wege der artverwandten Spaltung umgangen würden. Entsprechend gewährleistet die Spaltungsrichtlinie Aktionären und Gläubigern für den Fall der Spaltung einen gleichwertigen Schutz, wie ihn die Fusionsrichtlinie bei Verschmelzungen gewährt. Der Anwendungsbereich der Richtlinie ist wie bei der Fusionsrichtlinie auf Aktiengesellschaften beschränkt. Auch richtet sich die Regelung zwangsläufig nur an diejenigen Mitgliedstaaten, in denen das Rechtsinstitut der Spaltung überhaupt existiert ${ }^{967}$.

963 Siehe hierzu sogleich unter $\mathrm{n}$ ).

964 Da die Personengesellschaften deren persönliche haftende Gesellschafter ausschließlich Kapitalgesellschaften sind, wie etwa bei der $\mathrm{GmbH} \& \mathrm{Co}$. KG und ähnlichen europäischen Gesellschaftsformen nicht ausdrücklich in der Vierten Richtlinie erwähnt sind, haben einige nationale Gesetzgeber eine Erstreckung der Jahresabschlussrichtlinie auch auf diese Gesellschaftsformen abgelehnt. Die Notwendigkeit der Einbeziehung auch solcher Personengesellschaften an denen als persönlich haftende Gesellschafter ausschließlich Kapitalgesellschaften beteiligt sind, hat der Europäische Gesetzgeber daher mit Richtlinie vom 8.11.1990, der so genannte „GmbH \& Co. KG-Richtlinie“ klargestellt.

965 Behrens Die Europäisierung des Gesellschaftsrechts, in: Die GmbH-Rechte in den EG-Staaten, 1, 8 f.; ausführlich hierzu Lutter Europäisches Unternehmensrecht, 4. Aufl. 1996, Habersack, Europäisches Gesellschaftsrecht, 3. Aufl. 2006 sowie Schwarz.

966 Sechste Richtlinie gemäß Art. 54 Abs. 3 lit g des Vertrages betreffend die Spaltung von Aktiengesellschaften (82/891/EWG) AB1 1982 L 378/47.

967 Behrens Die Europäisierung des Gesellschaftsrechts, in: Die GmbH-Rechte in den EG-Staaten, 1, 10; ausführlich hierzu Lutter Europäisches Unternehmensrecht, 4. Aufl. 1996, Habersack, Europäisches Gesellschaftsrecht, 3. Aufl. 2006 sowie Schwarz. 


\section{f) Siebte gesellschaftsrechtliche Richtlinie 83/349/EWG - Konzernrechnungslegungs- richtlinie}

Wie bereits oben ausgeführt, ergänzt die Siebte Richtlinie ${ }^{968}$ die Vierte Richtlinie und trägt dem Umstand Rechnung, dass eine bedeutende Anzahl von Gesellschaften Unternehmenszusammenschlüssen angehört. Damit die Informationen über die finanziellen Verhältnisse dieser Unternehmenszusammenschlüsse in gleicher Weise wie beim Einzelabschluss zur Kenntnis der Gesellschafter und Dritter gebracht wird, verpflichtet die Richtlinie verbundene Unternehmen, einen konsolidierter Abschluss zu erstellen ${ }^{969}$.

\section{g) Achte gesellschaftsrechtliche Richtlinie 84/253/EWG - Prüferbefähigungsrichtlinie}

Die Achte Richtlinie ${ }^{970}$ regelt die für Abschlussprüfer geltenden Qualifikationsvoraussetzungen, um die Gleichwertigkeit der in der Vierten und Siebten Richtlinie vorgesehenen Pflichtprüfungen, insbesondere des (konsolidierten) Jahresabschlusses von Gesellschaften sowie der Prüfung der Übereinstimmung des Lageberichts mit diesem Jahresabschluss sicherzustellen ${ }^{971}$.

\section{h) Elfte gesellschaftsrechtliche Richtlinie 89/666/EWG - Publizitätsrichtlinie für Zweig- niederlassungen}

Mit der Elften Richtlinie ${ }^{972}$ dehnt der Europäische Gesetzgeber die in der Publizitätsrichtlinie (Erste Richtlinie) und den Bilanzrichtlinien (Vierte und Siebte Richtlinie) für Kapitalgesellschaften vorgesehenen Publizitätspflichten auf Zweigniederlassungen aus, um auch solche

968 Siebente Richtlinie aufgrund von Art. 54 Abs. 3 lit g des Vertrages über den konsolidierten Abschluss (83/349/EWG) ABl 1983 L 193/1.

969 Behrens Die Europäisierung des Gesellschaftsrechts, in: Die GmbH-Rechte in den EG-Staaten, 1, 10 f.; ausführlich hierzu Lutter Europäisches Unternehmensrecht, 4. Aufl. 1996, Habersack, Europäisches Gesellschaftsrecht, 3. Aufl. 2006 sowie Schwarz.

970 Achte Richtlinie aufgrund von Art. 54 Abs. 3 lit g des Vertrages über die Zulassung der mit der Pflichtprüfung des Jahresabschlusses von Gesellschaften bestimmter Rechtsformen beauftragten Personen (84/253/EWG) AB1 1984 L 126/20

971 Behrens Die Europäisierung des Gesellschaftsrechts, in: Die GmbH-Rechte in den EG-Staaten, 1, 11 f.; ausführlich hierzu Lutter Europäisches Unternehmensrecht, 4. Aufl. 1996, Habersack, Europäisches Gesellschaftsrecht, 3. Aufl. 2006 sowie Schwarz.

972 Elfte Richtlinie des Rates über die Offenlegung von Zweigniederlassungen, die in einem Mitgliedstaat von Gesellschaften bestimmter Rechtsformen errichtet wurden, die dem Recht eines anderen Staates unterliegen, (89/666/EWG) AB1. 1989 L 395/36. 
Gesellschaften zu erfassen, die sich in einem anderen Mitgliedstaat durch Zweigniederlassungen betätigen und nicht mittels einer Tochtergesellschaft ${ }^{973}$.

\section{i) Zwölfte gesellschaftsrechtliche Richtlinie 89/667/EWG - Einpersonengesellschafts- richtlinie}

Am 20. Dezember $1989^{974}$ hat der Rat der Europäischen Gemeinschaft die Einpersonengesellschaftsrichtlinie beschlossen, mit der die Gründung einer Gesellschaft mit beschränkter Haftung mit nur einem Gesellschafter ermöglicht wird ${ }^{975}$. Die Regelung enthält Vorgaben für die Offenlegung der Alleingesellschafterstellung und sieht Einschränkungen für den Fall vor, dass der Alleingesellschafter seinerseits eine juristische Person ist.

\section{j) Richtlinie 2005/56/EG betreffend der Verschmelzung von Kapitalgesellschaften aus verschiedenen Mitgliedstaaten - Verschmelzungsrichtlinie}

Mit dieser Richtlinie ${ }^{976}$ wird die grenzüberschreitende Verschmelzung von Kapitalgesellschaften ermöglicht. Die Richtlinie schreibt vor, dass die Rechtsvorschriften der Mitgliedstaaten die grenzüberschreitende Verschmelzung einer Kapitalgesellschaft aus einem Mitgliedstaat mit einer Kapitalgesellschaft aus einem anderen Mitgliedstaat gestatten müssen, wenn das innerstaatliche Recht der betreffenden Mitgliedstaaten Verschmelzungen zwischen Unternehmen solcher Rechtsformen erlaubt. Deutschland hat die Richtlinie am 25. April 2007, als erster Mitgliedsstaat der EU, mit dem Zweiten Gesetz zur Änderung des Umwandlungsgesetzes (2. UmwÄndG) in nationales Recht umgesetzt. Durch dieses Gesetz werden die $\S \S 122$ a bis 1221 in das Umwandlungsgesetz eingefügt, in denen das Vorgehen bei grenzüberschreitenden Verschmelzungen unter Beteiligung deutscher Kapitalgesellschaften (AG, GmbH, KGaA und ,deutsche SE“) geregelt wird. Damit schafft der deutsche Gesetzgeber für grenzüberschreitende Verschmelzungen einen Rechtsrahmen, der weitgehend dem bekannten Verfahren bei Verschmelzungen von Kapitalgesellschaften in Deutschland entspricht. Besonder-

973 Behrens Die Europäisierung des Gesellschaftsrechts, in: Die GmbH-Rechte in den EG-Staaten, 1, 13; ausführlich hierzu Lutter Europäisches Unternehmensrecht, 4. Aufl. 1996, Habersack, Europäisches Gesellschaftsrecht, 3. Aufl. 2006 sowie Schwarz.

Zwölfte gesellschaftsrechtliche Richtlinie des Rates betreffend Gesellschaften mit beschränkter Haftung mit einem einzigen Gesellschafter (89/667/EWG) ABl 1989 L 395/40.

975 Behrens Die Europäisierung des Gesellschaftsrechts, in: Die GmbH-Rechte in den EG-Staaten, 1, 14; ausführlich hierzu Lutter Europäisches Unternehmensrecht, 4. Aufl. 1996, Habersack, Europäisches Gesellschaftsrecht, 3. Aufl. 2006 sowie Schwarz.

976 Richtlinie des Europäischen Parlaments und des Rates über die Verschmelzung von Kapitalgesellschaften aus verschiedenen Mitgliedstaaten (2005/56/EG) Abl. 2005 L 310/1. 
heiten gelten unter anderem bei der Beteiligung der Arbeitnehmer, bei den Angaben im Verschmelzungsbericht und bei der wechselseitigen Registrierung der Verschmelzung im In- und Ausland.

Die übrigen Mitgliedsstaaten der Europäischen Gemeinschaft haben noch bis zum Dezember 2007 Zeit für die Umsetzung der Richtlinie. In den anderen europäischen Ländern sind bislang noch keine entsprechenden Gesetze in Kraft getreten, es bestehen allerdings zum Teil, so etwa auch in den Niederlanden ${ }^{977}$ bereits konkrete Entwürfe.

\section{k) Richtlinie 2003/58/EG zur Änderung der Richtlinie 68/151/EWG des Rates in Bezug auf die Offenlegungspflichten von Gesellschaften bestimmter Rechtsformen}

Mit der Richtlinie 2003/58/EG ${ }^{978}$ setzt der Europäische Gesetzgeber Vorschläge der so genannten „SLIM-Gruppe“ (Simpler Legislation for the Internal Market) um, die insbesondere eine Vereinfachung der mit der Ersten gesellschaftsrechtlichen Richtlinie geschaffenen Publizität verlangten. Eingeführt wird mit der Richtlinie zunächst die Möglichkeit der elektronischen Erfassung zu veröffentlichender gesellschaftsrechtlicher Pflichtangaben. Des Weiteren wird der grenzüberschreitende Zugang zu vorgenannten Unternehmensinformationen erleichtert, indem zusätzlich zur obligatorischen Offenlegung in einer der im Mitgliedstaat des Unternehmens zugelassenen Sprachen die freiwillige Eintragung der erforderlichen Urkunden und Angaben in weiteren Sprachen gestattet wird ${ }^{979}$.

\section{l) Richtlinie 2004/25/EG betreffend Übernahmeangebote}

Die Übernahmerichtlinie ${ }^{980}$ legt allgemeine Grundsätze fest, die bei Unternehmensübernahmen und dem Erwerb der Kontrolle über börsennotierte Gesellschaften einzuhalten sind. Dazu gehören vor allem das Gleichbehandlungsgebot, das Transparenzgebot und die Vermeidung von Marktverzerrungen. Demgemäß enthält die Richtlinie einerseits Regelungen, die Infor-

977 Wetsvoorstel grensoverschrijdende fusie (10e Richtlijn), abrufbar unter http://www.justitie.nl /images/wv\%20grensoverschrijdende\%20fusie_7683_tcm34-79262.pdf.

978 Richtlinie des Europäischen Parlaments und des Rates zur Änderung der Richtlinie 68/151/EWG des Rates in Bezug auf die Offenlegungspflichten von Gesellschaften bestimmter Rechtsformen (2003/58/EG) ABl. 2003 L 221/13.

979 Richtlinie 2003/58/EG des Europäischen Parlaments und des Rates vom 15. Juli 2003 zur Änderung der Richtlinie 68/151/EWG des Rates in Bezug auf die Offenlegungspflichten von Gesellschaften bestimmter Rechtsformen, Amtsblatt Nr. L 221 vom 04/09/2003 S. 0013 - 0016, online abrufbar unter http://www.jura.uni-augsburg.de/prof/moellers/materialien/4_gesellschaftsrecht.

980 Richtlinie betreffend Übernahmeangebote (2004/25/EG) Abl. 2004 L 142/12. 
mations- und Schutzrechte für den Bieter vorsehen; andererseits werden Minderheitsgesellschafter geschützt, indem der Bieter verpflichtet wird in bestimmten Konstellationen ein Angebots zum Erwerb der Aktien aller Aktionäre abzugeben: Schließlich enthält die Richtlinie Vorgaben, wie sich Vorstand und Aufsichtsrat einer Zielgesellschaft bei einer drohenden Übernahme zu verhalten haben (Stichwort: Vereitelungsverbot) ${ }^{981}$.

\section{m) Richtlinie 2006/43/EG über Abschlussprüfungen von Jahresabschlüssen und konso- lidierten Abschlüssen, zur Änderung der Richtlinien 78/660/EWG und 83/349/EWG des Rates und zur Aufhebung der Richtlinie 84/253/EWG des Rates}

Zweck der vorliegenden Richtlinie ${ }^{982}$ ist eine - wenn auch nicht vollständige - Harmonisierung der Anforderungen an die Abschlussprüfung. Zwar hatte der Europäische Gesetzgeber mit der Prüferbefähigungsrichtlinie und der Jahresabschlussrichtlinie sowohl Prüfungsinhalte, Bewertungsmethoden als auch Person und Qualifikation des Prüfers bereits weitestgehend harmonisiert. Doch war die Abschlussprüfung selbst nicht harmonisiert, so dass nach wie vor erhebliche Unterschiede bei der Aufstellung und Prüfung des Jahrsabschlusses existierten ${ }^{983}$.

\section{n) Richtlinie 2006/46/EG zur Abänderung der Richtlinien 78/660/EWG und} 83/349/EWG hinsichtlich der Jahresabschlüsse bestimmter Arten von Unternehmen und

\section{konsolidierter Abschlüsse}

Mit der Richtlinie 2006/46EG ${ }^{984}$ hat die Europäische Kommission vier grundlegende Überarbeitungen der EU-Rechnungslegungsrichtlinien (vierte gesellschaftsrechtliche Richtlinie 78/660/EWG und siebte gesellschaftsrechtliche Richtlinie 83/349 EWG) vorgenommen, mit denen das Vertrauen in die Vorlage von Unternehmensabschlüssen gestärkt werden soll. So wird zum einen festgeschrieben, dass die Vorstandsmitglieder gemeinsam für die Abschlüsse

981 Vgl. hierzu insbesondere die Ausführungen auf http://www.jura.uniaugsburg.de/prof/moellers/materialien/4 gesellschaftsrecht, sowie Behrens Die Europäisierung des Gesellschaftsrechts, in: Die GmbH-Rechte in den EG-Staaten, 1, 14.

982 Richtlinie über Abschlussprüfungen von Jahresabschlüssen und konsolidierten Abschlüssen, zur Änderung der Richtlinien 78/660/EWG und 83/349/EWG des Rates und zur Aufhebung der Richtlinie 84/253/EWG des Rates (2006/43/EG) AB1. 2006 L 157/87.

983 Richtlinie 2006/43/EG v. 17.15.2006, ABl. Nr. L 157/87 v. 6.9 .2006 online abrufbar unter http://www.jura.uni-augsburg.de/prof/moellers/materialien/4_gesellschaftsrecht.

984 Richtlinie des Europäischen Parlaments und des Rates zur Änderung der Richtlinien des Rates 78/660/EWG über den Jahresabschluss von Gesellschaften bestimmter Rechtsformen, 83/349/EWG über den konsolidierten Abschluss, 86/635/EWG über den Jahresabschluss und den konsolidierten Abschluss von Banken und anderen Finanzinstituten und 91/674/EWG über den Jahresabschluss und den konsolidierten Abschluss von Versicherungsunternehmen (Text von Bedeutung für den EWR) (2006/46/EG) Abl. 2006 L 224/1 
und wesentliche Nichtfinanzinformationen verantwortlich sind. Zweitens sollen die Geschäfte nichtbörsennotierter Unternehmen mit verbundenen Parteien transparenter gestaltet werden. Drittens soll sichergestellt werden, dass alle Unternehmen vollständige Informationen über außerbilanzielle Vereinbarungen vorlegen. Dazu zählen auch die "Special Purpose Vehicles" (Zweckgesellschaften), die unter Umständen in Offshore-Ländern belegen sind und viertens sollen die börsennotierten Gesellschaften schließlich eine jährliche „Corporate Governance“Erklärung abgeben ${ }^{985}$. Diese Änderungen gehen zurück auf Vorstellungen, die in dem Aktionsplan der Kommission auf dem Gebiet des Gesellschaftsrechts enthalten sind, der im Mai 2003 veröffentlicht wurde ${ }^{986}$.

o) Richtlinie 2006/68/EG des Europäischen Parlaments und des Rates vom 6. September 2006 zur Änderung der Richtlinie 77/91/EWG des Rates in Bezug auf die Gründung von Aktiengesellschaften und die Erhaltung und Änderung ihres Kapitals

Die Richtlinie 2006/68/EG ${ }^{987}$ ändert die Bestimmungen der zweiten Gesellschaftsrechtsrichtlinie von 1976, die sich auf die Gründung von Aktiengesellschaften sowie die Erhaltung und Änderung ihres Kapitals beziehen. Der Vorschlag ist Teil des von der Kommission im Mai 2003 vorgelegten Aktionsplans für Gesellschaftsrecht und Corporate Governance ${ }^{988}$. So soll etwa künftig in bestimmten Fällen bei Gesellschaftsgründungen oder Kapitalerhöhungen auf eine Bewertung der Sacheinlagen durch einen Experten verzichtet werden können. Des Weiteren werden zur Senkung des Verwaltungsaufwands bei der Emission neuer Aktien die derzeitigen Vorschriften über die Beschränkung oder den Ausschluss von Bezugsrechten gelockert; gleichzeitig sollen die Aktionäre vor einer Wertminderung ihres Aktienbestandes geschützt werden. Das Verbot, wonach eine Gesellschaft Dritte beim Erwerb ihrer Aktien nicht finanziell unterstützen darf, soll teilweise gelockert werden. Auch sollen Ausschluss- und Andienungsrechte eingeführt werden (d.h. Mehrheitsaktionäre sollen unter bestimmten Bedingungen das Recht erhalten, Minderheitsaktionären ihre Anteile zu einem angemessenen Preis abzukaufen während Minderheitsaktionäre das Recht erhalten sollen, vom Mehrheitsaktionär die Übernahme ihrer Aktien zu verlangen). Schließlich soll Aktiengesellschaften künftig der Erwerb eigener Aktien bis in Höhe ihrer ausschüttungsfähigen Rücklagen gestattet werden.

985 Vgl. hierzu auch die systematische Aufarbeitung des Europäischen Gesellschaftsrechts auf den Internetseiten des Instituts von Professor Möller in Augsburg http://www.jura.uniaugsburg.de/prof/moellers/materialien/4_gesellschaftsrecht.

986 Sie hierzu sogleich unter 3. b).

987 Richtlinie des Europäischen Parlaments und des Rates zur Änderung der Richtlinie 77/91/EWG des Rates in Bezug auf Gründung von Aktiengesellschaften und die Erhaltung und Änderung ihres Kapitals (2006/68/EG) Abl. 2006 L 264/32.

988 Sie hierzu sogleich unter 3. b). 
Parallel zu den vorgenannten Erleichterungen, enthält die Richtlinie strenge Bestimmungen zum Aktionärsschutz.

Bemerkenswert für die hier angestellte Untersuchung ist, dass der Europäische Gesetzgeber auch hier, bei allen Änderungen der Kapitalrichtlinie, am Konzept eines festen Mindestkapitals festzuhalten scheint; jedenfalls enthält die Richtlinie keinerlei Ausführungen zur Beibehaltung oder Aufgabe des in der zweiten Richtlinie enthaltenen Erfordernisses eines Mindestgrundkapitals.

\section{Arbeitspapiere, Konsultationen}

Schließlich finden sich diverse Arbeitspapiere und Konsultationen zu aktuellen europäischen Vorhaben, meist mit dem Ziel der Umsetzung in einer Richtlinie:

\section{a) Bericht der Hochrangigen Gruppe von Experten auf dem Gebiet des Gesellschafts- rechts über moderne gesellschaftsrechtliche Rahmenbedingungen in Europa}

Der Bericht der Hochrangigen Gruppe von Experten auf dem Gebiet des Gesellschaftsrechts über moderne gesellschaftsrechtliche Rahmenbedingungen in Europa (Bericht der „WinterGruppe“ $)^{989}$, der auf Anforderung der Kommission im November 2002 erstattet worden ist, befasst sich mit Fragen der Unternehmensführung, Unternehmensgruppen und Unternehmenspyramiden, Unternehmensumstrukturierung und Unternehmensmobilität, sowie mit europäischen Unternehmensformen, wie etwa die Europäische Privatgesellschaft und Genossenschaften. Detailliert nimmt der Bericht auch Stellung zu der Frage der Kapitalaufbringung und Kapitalerhaltung bei Aktiengesellschaften.

Im Ergebnis stellen die Experten fest, dass die Aufbringung eines Mindestgrundkapitals den Schutz der Gläubiger nicht gewährleisten könne, sondern „die einzige Funktion“ des Mindestgrundkapitals ,,in der Abschreckung vor einer leichtfertigen Gründung von (Kapitalgesellschaften) besteht“. Die Winter-Gruppe sei nicht davon überzeugt, dass das Mindestgrundkapital in seiner derzeitigen Höhe ,irgend eine andere nützliche Funktion erfüllt““. Nachteilige Auswirkungen des Mindestgrundkapitals seien jedoch nicht ersichtlich. Das Mindestgrundkapital solle daher ,weder abgeschafft noch angehoben werden“.

989 Online abrufbar bei http://www.jura.uni-augsburg.de/prof/moellers/materialien/4_gesellschaftsrecht /Hochrangige_Expertengruppe_4_11_2002/. 
Als alternatives Kapitalerhaltungssystem, das ohne Mindeststammkapital auskommt, schlägt die Winter-Gruppe die Einführung eines zweistufigen Solvenztests nach englischem Vorbild vor. In einem ersten Schritt ist das Eigenkapital der Gesellschaft mittels einer vereinfachten Bilanzierung, einem so genannter ,balance sheet test“ in Augenschein zu nehmen. Danach darf die Gesellschaft keine Ausschüttungen vornehmen, wenn ihr Eigenkapital, vermindert um die gesetzlichen und satzungsmäßig bestimmten Rücklagen, negativ ist oder durch die Ausschüttung negativ werden würde. Sodann hat die Unternehmensführung auf der Grundlage eines so genannten Solvency Tests zu ermitteln, ob eine Ausschüttung an die Gesellschafter erfolgen darf. Entscheidend ist, ob die Gesellschaft nach der Ausschüttung noch in der Lage ist, in absehbarer Zeit ihre Verbindlichkeiten zu erfüllen.

Von deutscher Seite ist den Aussagen der Winter-Gruppe zum Mindestgrundkapital widersprochen worden; der niederländische Gesetzgeber hingegen hat die Ausführungen der Winter-Gruppe zum Anlass genommen, sein Kapitalaufbringungs und -schutzsystem grundlegend zu reformieren ${ }^{990}$.

\section{b) Aktionsplan "Modernisierung des Gesellschaftsrechts und Verbesserung der Corpo- rate Governance in der EU"}

Der Aktionsplan ${ }^{991}$ ist die Antwort der Kommission auf den vorgenannten Abschlussbericht der „Winter-Gruppe“. Er erläutert, warum die regulatorischen Rahmenbedingungen für Gesellschaftsrecht und Corporate Governance nach Ansicht der Kommission modernisiert werden müssen. Es bedürfe neuer Initiativen, die entweder darauf abzielen, das bestehende Gesellschaftsrechtsinstrumentarium der EU zu modernisieren, oder darauf, das Rahmenwerk der EU mit einer begrenzten Anzahl neuer, maßgeschneiderter Instrumente zu ergänzen. Im Hinblick auf die Aussagen der Winter-Gruppe zum Mindestgrundkapital hat die Kommission sich in ihrem Aktionsplan von 2003 zwar nicht festgelegt, aber erkennen lassen, dass sie der Winter-Gruppe insoweit möglicherweise folgen wird ${ }^{992}$.

990 Arbeitsgruppe Europäisches Gesellschaftsrecht ZIP 2003, 863; vgl. auch die Überlegungen bei BDI/Hengeler Müller Rn. 38 ff.; vgl. zu der niederländischen Haltung insb. die Gesetzesbegründung zum Gesetzesentwurf, Allgemeiner Teil, S. 31; sowie aus der Literatur Bier Ondernemingsrecht 2004, 10, 13.

991 Mitteilung der Kommission vom 21. 5. 2003, KOM 2003, 284 endg., S. 19 und Anhang 1, S. 28; dazu Wiesner, ZIP 2003, 977, 979. Online abrufbar unter http://www.jura.uniaugsburg.de/prof/moellers/materialien/4_gesellschaftsrecht/150_aktionsplan_gesr_corp_gov/.

992 Vgl. insoweit auch die Überlegungen bei BDI/Hengeler Müller Rn. 38 ff.. 


\section{c) Aktionsplan "Vereinfachung des Unternehmensumfeldes für Gesellschaften"}

Im Rahmen der Initiative „Bessere Rechtsetzung“ hatte die Europäische Kommission in einer Mitteilung am 12. Juli 2007 Maßnahmen zur Vereinfachung der Rahmenbedingungen für EUUnternehmen in den Bereichen Gesellschaftsrecht, Rechnungslegung und Abschlussprüfung vorgestellt. Die Pläne sahen als erste Option den Abbau und die Beseitigung als überholt oder überzogen erachteter Verwaltungsvorschriften vor; als zweite Option war die Vereinfachung, Reduzierung und Revision der existierenden Regelungen vorgeschlagen worden ${ }^{993}$. Das Europäische Parlament, die Mitgliedstaaten und die interessierten Kreise waren aufgerufen, zu der Mitteilung und ihren Anhängen bis Mitte Oktober 2007 Stellung zu nehmen ${ }^{994}$.

Aufgrund der Reaktionen auf die Mitteilung der Kommission, einer Stellungnahme des Ministerrates vom 22. November 2007 und den ersten Äußerungen im Europäischen Parlament, ist der Europäischen Kommission die Option 1 - Abbau und die Beseitigung als überholt oder überzogen erachteter Verwaltungsvorschriften - die eine starke Renationalisierung des Unternehmensrechts zur Folge gehabt hätte, als Maßnahme zur Vereinfachung der Rahmenbedingungen für EU-Unternehmen faktisch versperrt worden ${ }^{995}$. Vielmehr sind in 2008 neue Legislativvorschläge zu erwarten. Dazu zählen neben Vorschlägen zur Erleichterung im Bilanzrecht und der Abschlussprüfung insbesondere Erleichterungen im Anwendungsbereich der Zweigniederlassungsrichtlinie sowie bei den Formalitäten der grenzüberschreitenden Verschmelzung und Spaltung.

Nach den Reaktionen auf die Mitteilung der Kommission nicht mehr von einer Streichung betroffen ist ferner die Kapitalrichtlinie. Sie sieht sich indes insoweit einer Überholung ausgesetzt, als die Europäische Kommission Anfang 2008 eine KPMG-Studie zu den Grundvoraussetzungen der Kapitalaufbringung und -erhaltung veröffentlichen will, die mit an Sicherheit grenzender Wahrscheinlichkeit Konsultationen nach sich ziehen wird ${ }^{996}$.

\footnotetext{
993 Abrufbar unter http://ec.europa.eu/internal_market/company/simplification/index_de.htm.

994 Aus der Mitteilung der Europäischen Kommission, abrufbar unter http://ec.europa.eu/internal_market/company/simplification/index_de.htm.

995 So die Einschätzung von Schmidt-Gerdts in Status:Recht 01/2008, S. 13.

996 Vgl. Schmidt-Gerdts in Status:Recht 01/2008, S. 13.
} 


\section{Die Europäische Privatgesellschaft oder Société Privée Européenne}

\section{Vorbemerkung}

Die Gesellschaft mit beschränkter Haftung ist die Gesellschaftsform, die in Europa am häufigsten anzutreffen ist. Diese Tatsache hat schon früh Überlegungen begünstigt, eine entsprechende supranationale Gesellschaftsform auf europäischer Ebene zu schaffen ${ }^{997}$. Die Europäische Kommission hatte bereits im Jahr 2005 eine Machbarkeitsstudie hinsichtlich der Einführung der so genannte Europäischen Privatgesellschaft oder Société Privée Européenne (EPG/SPE) veröffentlicht ${ }^{998}$. Die Prüfung, ob die Europäische Privatgesellschaft eingeführt werden soll, dauert derzeit noch an. Die Kommission hat aber im Rahmen der Konsultationen zu den zukünftigen Schwerpunkten im Bereich Gesellschaftsrecht und Corporate Governance bereits einen Bedarf für ein EPG festgestellt. Auch die im Zeitraum vom 20. Juli bis 31. Oktober 2007 durchgeführte öffentliche Konsultation der Kommission zu den Einzelheiten eines EPG-Statuts hatte eine breite Zustimmung zum Dossier ergeben ${ }^{999}$. Die Experten der Kommission sollen nun bis Ende Januar die Folgen der einzelnen Optionen abschätzen und die favorisierten Bestandteile des Statuts anlässlich einer Konferenz am 10. März 2008 zur Diskussion stellen. Nach diesem Praxistest, spätestens aber - wie der Binnenmarktkommissar McGreevy am 3. Oktober 2007 versicherte - bis Mitte 2008 dürfte die Europäische Kommission einen finalisierten Verordnungsvorschlag zur Schaffung eines EPG-Statuts vorlegen ${ }^{1000}$.

\section{Eckpunkte}

Am 2.10.2006 wurde im Rechtsausschuss der Entwurf eines Initiativberichts für das Statut einer Europäischen Privatgesellschaft $(E P G)^{1001}$ vorgestellt. Diese neue Rechtsform soll vor

997 Ausgehend von den Überlegungen zur Schaffung einer europäischen Gesellschaftsform mit beschränkter Haftung hat Hommelhoff WM 1997, 2101 eigene Eckpunkte der Ausgestaltung einer supranationalen, auf EG-Recht beruhenden europäischen Gesellschaftsform, die er als „Societe fermee Europeenne“ bezeichnet, entwickelt. Dies betrifft ua das Problem der Mitbestimmung, die Grundstruktur des Gläubigerschutzes, Satzungsstrenge und Minderheitenschutz.

998 Abschlussbericht, Machbarkeitsstudie über ein europäisches Statut für KMU, http://ec.europa.eu/enterprise/ entrepreneurship/craft/craft-priorities/doc/de_resume_rapport_final.pdf.

999 Vgl. Schmidt-Gerdts in Status:Recht 01/2008, S. 13.

1000 Schmidt-Gerdts in Status:Recht 01/2008, S. 13.

${ }^{1001}$ Vgl. zur deutschen Literatur zur EPG insb. Teichmann, Stellungnahme vor dem Rechtsausschuss des Europäischen Parlaments zur Einführung einer Europäischen Privatgesellschaft vom 22. Juni 2006, http://www.europarl.europa.eu/comparl/juri/hearings/20060622/teichmann_de.pdf sowie Dejmek, NZG 2001, 878, 883 und Steinberger, Sonderbeilage zu Heft 37 BB 2006, 26, 31; letzterer mit vielen weiteren 
allem für kleine und mittlere Unternehmen zur Verfügung stehen. $\mathrm{Zu}$ den verschiedenen im Entwurf enthaltenen Empfehlungen zählen insbesondere ${ }^{1002}$ :

- gemeinschaftsrechtliche Ausgestaltung des Statuts der EPG auf der der Grundlage einer Verordnung;

- Gründung durch eine oder mehrere natürliche oder juristische Personen und Eintragung in das nationale Handelsregister;

- Möglichkeit von Umwandlung, Sitzverlegung, Formwechsel in eine Europäische Aktiengesellschaft entsprechend dem bestehenden Gemeinschaftsrecht;

- Gewährung von Rechtspersönlichkeit;

- beschränkte Haftung auf das Gesellschaftsvermögen (Mindestkapital $10.000 €$ );

- Wahlmöglichkeit zwischen dualistischer oder monistischer Unternehmensstruktur;

- Vorgabe von Mustersatzungen als Anhang der Verordnung ${ }^{1003}$;

- Vorgabe für die Stellung und Haftung des Geschäftsführers (Haftungsmaßstab soll die vernünftigerweise zu fordernde Sorgfalt sein);

- Vorgaben für Ausschüttungen;

- Rechnungslegung richtet sich nach den bereits harmonisierten Rechnungslegungsrichtlinien;

- Auflösung, Insolvenz richten sich nach Vorschriften des Verwaltungssitzes der Gesellschaft;

- Berücksichtigung der bestehenden Arbeitnehmermitbestimmungsrechte des jeweiligen Sitzstaates der Gesellschaft bei Gründung und Umwandlung.

Nachweisen. In den Niederlanden haben sich ebenfalls eine Vielzahl von Autoren mit der EPG befasst, auf die insbesonder van der Sangen Tijdschrift voor Ondernemingsbestuur 2004, 211 verweist.

1002 Der vollständige Text des Initiativberichtes findet sich unter http://www.europarl.europa.eu/meetdocs/ 2004_2009/documents/pr/630/630485/630485de.pdf. Vgl. dazu Schmidt-Kessel, Neues aus Brüssel, Stand: 26.10.2006, zitiert nach juris); Umfassende Darstellung auch bei Haas in: Hommelhoff, / Helms, (Hrsg.) Europäische Privatgesellschaft, Wege in die Europäische Privatgesellschaft, 2001, S. 155.

1003 Zu Mustersatzungen siehe Dejmek, NZG 2001, 878, 880. 


\section{Europäische Alternativen zur EPG}

\section{Die Europa AG - SE}

Mit der Schaffung der Europa-AG (Societas Europae - SE) ${ }^{1004}$ ist die Europäische Union im europäischen Gesellschaftsrecht vorangeschritten. ${ }^{1005}$ Man ging davon aus, dass für große Publikumsgesellschaften ein höherer Bedarf für eine europäische Gesellschaftsform bestehen würde. ${ }^{1006}$ Angesichts der Bedeutung von kleinen und mittleren Unternehmen für die wirtschaftliche Entwicklung in Europa, ${ }^{1007}$ ließe sich somit die Frage aufwerfen, inwiefern solche Unternehmen auf die Rechtsform der SE zurückgreifen könnten.

Es wird allerdings schnell ersichtlich, dass die SE keine wirkliche Alternative für kleine und mittlere Unternehmen darstellt. Das liegt zum einen an der Hürde des hohen Stammkapitals (mindestens $120.000 €$ ), außerdem an dem häufig problematischen Mehrstaatlichkeitsvorbehalt. ${ }^{1008}$

\section{Europäische Wirtschaftliche Interessensvereinigung (EWIV)}

Neben der SE könnte auch die EWIV eine gangbare Alternative zur Einführung der EPG darstellen. Die EWIV entsteht mit dem Abschluss eines Gründungsvertrages zwischen mindestens zwei Mitgliedern aus verschiedenen Mitgliedstaaten der EG (Art. 4 Abs. 2 EWIV-VO) und mit ihrer Eintragung. Bereits aus dem Erfordernis, der Mehrstaatlichkeit wird jedoch deutlich, dass die EWIV keine vollwertige Alternative zur EPG darstellen kann. Das Interesse von kleinen und mittleren Unternehmen dürfte häufig dahin gehen, im Ausland Tochterunter-

1004 Am 8. 10. 2001 wurde die Verordnung über das Statut der Europäischen Gesellschaft (SEVO) erlassen, die am 8. 10. 2004 in Kraft getreten ist. Mit der SEVO wurde die SE als erste Europäische Kapitalgesellschaft eingeführt, Verordnung (EG) Nr. 2157/2001, ABl. L 294/1 v. 10. 11. 2001.

1005 Zuvor war bereits die Europäische wirtschaftliche Interessenvereinigung (EWIV) eingeführt worden. Damit gibt es bislang drei supranationale Rechtsformen: Neben der EWIV, die Europäische Aktiengesellschaft (SE) auch noch die Europäische Genossenschaft (SCE).

1006 Kritisch dazu Krause, EuZW 2003, 747, 749.

1007 Dazu Dejmek, NZG 2001, 878, 879; Krause, EuZW 2003, 747, 748.

1008 Vgl. Bachmann, ZGR 2001, 351, 372; Krause, EuZW 2003, 747, 750; siehe außerdem Steinberger, Sonderbeilage zu Heft 37 BB 2006, 26, 31, der zudem von einem erhöhten Beratungsaufwand der SE ausgeht, der auf der schwierigen Verknüpfung von europäischem und nationalem Recht beruhe (unter Verweis auf Art. 9 SE-VO). 
nehmen zu gründen, ${ }^{1009}$ wobei es von Vorteil wäre, wenn diese Tochtergesellschaften nach denselben Regeln gegründet und geleitete werden könnten. ${ }^{1010}$

Gegenüber der EPG hätte ein EWIV zudem den Nachteil, dass die Mitglieder einer EWIV nach Art. 24 Abs. 1 EWIV-VO einer persönlichen Haftung unterworfen sind. ${ }^{1011}$

\section{Weitere Alternativen zur EPG}

Die Möglichkeiten nach der Verschmelzungsrichtlinie ${ }^{1012}$ können ebenso wenig wie Sitzverlegungsoptionen aufgrund der geplanten 14. Richtlinie eine Alternative zur Schaffung einer EPG darstellen. ${ }^{1013}$ Die Verschmelzung beziehungsweise die Sitzverlegung entspricht nicht dem Interesse von kleinen und mittleren Unternehmen, Tochtergesellschaften im Ausland nach nationalem Vorbild zu gründen.

Aus demselben Grund vermag auch der deutsche Vorschlag eines Gesetzes zum Internationalen Privatrecht der Gesellschaften, Vereine und juristischen Personen ${ }^{1014}$ keine Alternative zur Schaffung einer EPG zu bieten. Vom BMJ erarbeitet um in der Schwebezeit der geplanten Sitzverlegungsrichtlinie existierende Rechtslücken zu überwinden, stellt der Referentenentwurf lediglich eine Kodifizierung der in Europa bereits qua europäischer Rechtsprechung ${ }^{1015}$ faktisch geltenden Gründungstheorie dar. So enthält der Referentenentwurf zwar Regelungen, die gleich der EPG eine identitätswahrende Sitzverlegung über die Grenze gestatten, doch geht die Sitzverlegung nach dem Gesetz zum Internationalen Privatrecht der Gesellschaften, Vereine und juristischen Personen regelmäßig mit einem grenzüberschreitenden Rechtsformwechsel einher und setzt zudem entsprechende Regelungen in der betroffenen Rechtsordnung voraus. Anders als bei der EPG ist eine europaweit einheitliche Gesellschaftsform auch nach diesem Referentenentwurf nicht darstellbar.

\footnotetext{
1009 Teichmann, aaO), sub I; Steinberger, Sonderbeilage zu Heft 37 BB 2006, 26, 31.

1010 Teichmann, aaO, sub I.

1011 Krause, EuZW 2003, 747, 748; Steinberger, Sonderbeilage zu Heft 37 BB 2006, 26, 31. Vgl. dazu auch den Versuch von Schön, RabelsZ 64 (2000), 1, 6, aus einer „Gesamtschau“ von Publizitätsrichtlinie und EWIVVerordnung auf ein europäisches „Grundprinzip der unbeschränkten Haftung bei gemeinsamer unternehmerischer Tätigkeit“" zu schließen. Skeptisch dazu Bachmann, ZGR 2001, 351, 374 m.w.N.

1012 Richtlinie 2005/56/EG über die Verschmelzung von Kapitalgesellschaften aus verschiedenen Mitgliedsstaaten (,Verschmelzungsrichtlinie“), am 6. Oktober 2005 verabschiedet und am 25. November 2005 veröffentlicht.

1013 Teichmann, aaO, sub I; Steinberger, Sonderbeilage zu Heft 37 BB 2006, 26, 31.

1014 vgl. Referentenentwurf vom 7. Januar 2008 für ein Gesetz zum Internationalen Privatrecht der Gesellschaften, Vereine und juristischen Personen; abrufbar unter http://www.bmj.de/enid/ 29822660d3b7c055b ca2e36f8b868768,0/Internationales_Privatrecht/Internationales_Gesellschaftsrecht_1fh.html.

1015 Vgl. die EUGH-Rechtsprechung in der Angelegenheit Überseering und Inspire Art a.a.O.
} 


\section{Vierter Abschnitt \\ Rechtsvergleich und Schlussfolgerungen}

\section{$\S 1$ Allgemeines}

\section{Rechtsgrundlagen}

Nur in Deutschland ist die Rechtsform der Gesellschaft mit beschränkter Haftung in einem eigenständigen Gesetz geregelt. In den Niederlanden finden sich die Vorschriften zu B.V. im Zivilgesetzbuch; in Frankreich sind die Regelungen zur S.à.r.l. in einem rechtsformübergreifenden Handelsgesetzbuch kodifiziert.

Überlagert werden die nationalen Rechte aller drei Länder durch europäisches Recht, wie etwa die erste, vierte, siebte, elfte und zwölfte europäische Richtlinie auf dem Gebiet des Gesellschaftsrechts; diese haben zumindest in Teilbereichen auch schon für eine gewisse Vereinheitlichung der rechtlichen Rahmenbedingungen gesorgt ${ }^{1016}$.

\section{Praktische Bedeutung}

Die Rechtsform der Gesellschaft mit beschränkter Haftung ist sowohl in Deutschland, als auch in den Niederlanden und Frankreich eine beliebte und dementsprechend auch weit verbreitete Rechtsform. Zum Bestand der einzelnen nationalen Gesellschaften mit beschränkter Haftung liegt angesichts der unterschiedlichen Anknüpfungspunkte für derartige Erhebungen ${ }^{1017}$ keine eindeutige Statistik vor, auszugehen ist allerdings von der Existenz von ca. 977.091 ${ }^{1018} \mathrm{GmbH}$ in Deutschland, ca. 500.000 BVs in den Niederlanden ${ }^{1019}$ und in Frankreich von etwa 400.000 S.à.r.l.s. ${ }^{1020}$

\footnotetext{
${ }^{1016}$ Vgl. hierzu im Einzelnen oben Dritter Abschnitt § 4 I. 2. Siehe auch Wachter GmbHR 2005, 717, 720 f.; Bayer BB 2004, 1 ff.

${ }^{1017}$ In Deutschland wurden etwa - mangels bundeseinheitlich erfasster Daten - die Geschäftsübersichten der Amtsgerichte in Angelegenheiten der Freiwilligen Gerichtsbarkeit ausgewertet.

1018 Siehe dazu Meyer GmbHR 2004, 1417, 1419; Stand 1.1.2006: Kornblum GmbHR 2008, 19, siehe auch ders. GmbHR 2006, 28; Scholz/Westermann Einl. Rn. 28.

${ }^{1019}$ Vgl. zum Erfolgsmodell B.V. nur Grinten, $v$. $d$. in v. d. Heijden, Handboek voor de Naamloze en de Besloten Vennootschap, Zwolle 1989.

${ }^{1020} \mathrm{Süß/Wachter/Karst} \mathrm{S.} 802$.
} 
Mischformen zwischen Kapital- und Personengesellschaften, wie die in Deutschland weit verbreitete $\mathrm{GmbH} \& \mathrm{Co} . \mathrm{KG}^{1021}$, haben sich in den Niederlanden und Frankreich nicht in gleicher Weise durchsetzen können ${ }^{1022}$. Dies ist insoweit verwunderlich als in dem Niederländischen Reformentwurf mit dem Vorschlag zur Schaffung einer Niederländischen Limited Liability Partnership (LLP) ebenfalls eine hybride Gesellschaftsform als Alternative zu einer umfassenden B.V.-Reform erwogen worden ist ${ }^{1023}$. Aus gesellschaftsrechtlicher Sicht liegt der besondere Reiz einer hybriden Rechtsform darin, dass sie Unternehmensgründern gleichzeitig den Haftungsschutz einer Kapitalgesellschaft und die flexiblen Organisationsstrukturen einer Personengesellschaft vermittelt. Der ausschlaggebende Grund für die Entscheidung zugunsten einer solchen Rechtsform liegt aber regelmäßig in deren steuerrechtlicher Behandlung ${ }^{1024}$, denn obwohl sie in wesentlichen Punkten einer typischen Kapitalgesellschaft ähnelt, ist es möglich, sie steuerlich wie eine Personengesellschaft behandeln zu lassen ${ }^{1025}$.

\section{§ 2 Gründung der Gesellschaft}

\section{Rechtsvergleich}

\section{Gründungsvorgang}

In allen drei hier untersuchten Ländern ist zur Errichtung einer Gesellschaft mit beschränkter Haftung der förmliche Abschluss eines Gesellschaftsvertrages erforderlich ${ }^{1026}$. Die Errichtung der Gesellschaft ist in allen drei Ländern zur Eintragung im Handelsregister anzumelden ${ }^{1027}$. Anders als in Deutschland und den Niederlanden erfolgt die Anmeldung in Frankreich allerdings nicht unmittelbar bei dem Registergericht, sondern ist vielmehr bei dem örtlich zuständigen Centre de formalités des entreprises (CFE) vorzunehmen. Das CFE prüft die einge-

${ }^{1021}$ Zur ausländischen Kapitalgesellschaft \& Co. KG vgl. Binz/Mayer GmbHR 2003, 249, zur Ltd. und Co. KG zuletzt Süß, GmbHR 2005, 673; Werner GmbHR 2005, 288. Die Änderungen, die sich für die Praxis der GmbH \& Co. KG aufgrund des MoMiG ergeben untersucht Ehinger BB 2006, 2701.

1022 Wachter GmbHR 2005, 717, 721; Bayer BB 2004, 1, 4; Vgl. zum niederländischen Recht nur J.J.A. Hamers/L.P.W. van Vliet, Inleiding personenvennootschaapen 3. A. 2007 m. zahlreichen w. N.

1023 Vgl. oben Dritter Abschnitt § 2 VII.

${ }^{1024}$ Dies ist zugegebenermaßen in den Niederlanden von nachrangiger Bedeutung, da dort die Einkommenssteuer höher ist als sie Körperschaftsteuer.

${ }^{1025}$ Vgl. hierzu auch schon Berninger/Schnittker in: Eckpunktepapier zur Schaffung der Gesellschaftsform einer Personengesellschaft mit beschränkter Haftung, online abrufbar unter http://www.dihk.de/index.html?/inhalt/hemen/rechtundfairplay/handelsundgesellschaftsrecht/neuerechts formen.html.

1026 Vgl. hierzu im Einzelnen sogleich unter 2.b).

1027 Vgl. im Einzelnen sogleich unter 2.d). 
reichten Unterlagen und leitet den Antrag dann an das jeweilige Registre du Commerce et Société (RCS) weiter, welches sodann die Eintragung veranlasst ${ }^{1028}$.

Die Handelsregisteranmeldung und Eintragung wird in Deutschland und den Niederlanden regelmäßig durch den den Gesellschaftsvertrag beurkundenden Notar überwacht; in Frankreich wird die Registrierung hingegen durch die Beteiligten selbst oder deren Beratern vollzogen $^{1029}$.

Die Handelsregisteranmeldung hat in allen hier untersuchten Ländern zahlreichen formellen Vorgaben zu genügen, die sich aber im praktischen Ergebnis nur wenig unterscheiden. In den Niederlanden und Frankreich erfolgt die Anmeldung nach amtlich vorgeschriebenen Formula$\operatorname{ren}^{1030}$.

Bislang war in den Niederlanden der Anmeldung außerdem eine Unbedenklichkeitsbescheinigung des Justizministeriums beizufügen. Diese gab Auskunft darüber, ob aufgrund von Straftaten, Insolvenzen oder anderen Umständen Zweifel an der Seriosität der Gründer bestehen. Nach dem Entwurf eines Gesetzes zur Vereinfachung und Flexibilisierung des B.V.Rechts (,Wet vereenvoudiging en flexibilisering bv-recht“) soll eine präventive Überprüfung der Gründer künftig entfallen; die Beibringung einer Unbedenklichkeitserklärung des Justizministeriums soll danach künftig nicht mehr erforderlich sein ${ }^{1031}$.

\section{Gründungsvoraussetzungen}

\section{a) Gründer}

Sowohl in Deutschland als auch in den Niederlanden und in Frankreich können Gründer einer Gesellschaft mit beschränkter Haftung in- und ausländische natürliche und juristische Personen $\operatorname{sein}^{1032}$.

Sind Ausländer in den Niederlanden an der Errichtung einer B.V. beteiligt, so haben sie allerdings eine schriftliche Leumundsbescheinigung einer ausländischen Bank vorzulegen (,bank

\footnotetext{
1028 Wachter GmbHR 2005, 717, 722; Reichel ZRP 2004, 184. Vgl. auch umfassend Schwanna.

1029 Wachter GmbHR 2005, 717, 722; Reichel ZRP 2004, 184. Schwanna.

1030 Siehe dazu bereits oben Dritter Abschnitt $\S 1$ I. 1. b) dd), § 2 II 1. b) ee) und $\S 3$ II. 2. f); Wachter GmbHR 2005, 717, 722; Reichel ZRP 2004, 184..

1031 Vgl. Dritter Abschnitt $\$ 2$ II 1) b) bb) und 2.

1032 Vgl. Dritter Abschnitt $\S 1$ I. 1. b) aa), $\S 2$ II 1. b) aa) und $\S 3$ II. 2. a).
} 
letter of good standing"). Ferner haben sie in einem letter of intent zu versichern, dass sie nicht die Absicht haben, die Geschäftsanteile innerhalb eines Jahres zu verkaufen ${ }^{1033}$.

Die Errichtung einer Einpersonengesellschaft ist nach Umsetzung der zwölften gesellschaftsrechtlichen Richtlinie ${ }^{1034}$ in allen drei hier untersuchten Ländern gestattet ${ }^{1035}$. In Frankreich (Art. L.223-1 C.com.) ist allerdings die Errichtung einer Einpersonengesellschaft durch eine andere Einpersonengesellschaft nicht erlaubt, weshalb die E.u.r.l. als Konzernbaustein regelmäßig nicht in Frage kommt ${ }^{1036}$. In den Niederlanden ist die Tatsache, dass die Anteile an einer B.V. von nur einer Person gehalten werden, meldepflichtig und wird im Handelsregister gesondert ausgewiesen (Art. 14g Handelsregisterverordnung) ${ }^{1037}$.

Im Unterschied zur deutschen GmbH und niederländischen B.V. ist die Zahl der Gesellschafter einer S.à.r.l. in Frankreich auf 100 begrenzt (Art. L 223-3 C.com.) ${ }^{1038}$. Wird die Grenze überschritten, so ist die S.à.r.l. in eine S.A. umzuwandeln; anderenfalls wird sie nach Ablauf einer Gnadenfrist von zwei Jahren automatisch aufgelöst ${ }^{1039}$.

\section{b) Abschluss des Gesellschaftsvertrages / Notarielle Beurkundung}

Für die Gründung einer Gesellschaft mit beschränkter Haftung ist in allen drei Ländern der förmliche Abschluss eines Gesellschaftsvertrages erforderlich. Die einzuhaltende Form ist außer in Frankreich (Art. $1835 \mathrm{CC}$ ) - die der notariellen Beurkundung ${ }^{1040}$. Diese hat in Deutschland und den Niederlanden jeweils vor einem inländischen Notar zu erfolgen. In Deutschland wird die Rechtmäßigkeit einer durch einen ausländischen Notar beurkundeten Gründung diskutiert; in den Niederlanden wird eine solche indes nicht anerkannt (Art. 3:31 NBG) ${ }^{1041}$.

1033 Wachter GmbHR 2005, 717, 721 f.; Schwanna.

${ }^{1034}$ Zwölfte Richtlinie v. 22.12.1989 (89/67/EWG); abgedruckt u.a. bei Habersack, Europäisches Gesellschaftsrecht, 1999; Lutter, Europäisches Unternehmensrecht, 4. Auflage, 1996; Schwarz.

1035 Dritter Abschnitt $\S 1$ I. 1. b) aa), § 2 II 1. b) aa) und $\S 3$ II. 2. a).

${ }^{1036}$ Dritter Abschnitt \& 3 II. 2. a).

${ }^{1037}$ Dritter Abschnitt § 2 II 1. b) aa). Wachter GmbHR 2005, 717, 722; vgl. auch Schwanna.

${ }^{1038}$ Vgl. hierzu oben Dritter Abschnitt § 3 II. 2. a); Wachter GmbHR 2005, 717, 722; Schwanna.

${ }^{1039}$ Vgl. hierzu oben Dritter Abschnitt \& 3 II. 2. a)

${ }^{1040}$ Dritter Abschnitt $\$ 1$ I. 1. b) bb), § 2 II 1. b) cc) und $\S 3$ II. 2. c).

${ }^{1041}$ Dritter Abschnitt § 1 I. 1. b) bb), § 2 II 1. b) cc). Die Gründe die für eine Beurkundung im Ausland sprechen sind überwiegend Kostengründe. In Deutschland sind die Notare an eine Gebührenordnung gebunden, die für Beurkundungsvorgänge regelmäßig als Bezugsgröße für die Gebührenberechnung die Stammkapitalzifer zugrunde legt. Bei hohen Kapitalsummen mangelt es den deutschen Notaren an der Flexibilität, einen Rabatt auf die enstehenden Kosten zu geben und dies obgleich sich deren Tätigkeit in Abhängigkeit von der Stammkapitalziffer nicht grundlegend ändert. Wachter GmbHR 2005, 717, 722. Vgl. insoweit auch Kallmeyer DB 2004, 636, der die Rechtslage der englischen Limited der deutschen GmbH bzw. GmbH \& Co KG gegenüberstellt. $\mathrm{Ob}$ eine Beurkundung - wenigstens von Geschäftsanteilsübertragungen - durch 
In Frankreich ist eine notarielle Beurkundung des Gründungsmantels nur im Falle einer Sachgründung erforderlich, wenn das Verkehrsgeschäft mit dem der Vermögensgegenstand eingebracht werden soll, seinerseits eine notarielle Beurkundung verlangt; etwa bei der Einbringung eines Grundstücks in die Gesellschaft. Darüber hinaus können Zweckmäßigkeitserwägungen eine Beurkundung der Gesellschaftsvertrages nahe legen, wenn etwa die Errichtung der Gesellschaft durch Ehegatten (s. Art. 1832-1 CC) oder Familienangehörige (s. Art. 854 CC) erfolgt $^{1042}$.

Auch in Deutschland kann künftig auf eine Beurkundung des Gesellschaftsvertrages verzichtet werden, allerdings nur dann, wenn einer der in der Anlage zum reformierten GmbHG zur Verfügung gestellten Mustergesellschaftsverträge verwendet wird. Dann ist nur eine öffentliche Beglaubigung der Unterschriften erforderlich.

Eine rechtsgeschäftliche Vertretung bei Abschluss des Gesellschaftsvertrages ist in allen drei Ländern gestattet. In Frankreich ist hierfür allerdings die Begebung einer Spezialvollmacht erforderlich, die ausdrücklich auch die Bevollmächtigung zur Errichtung der konkreten Gesellschaft enthält ${ }^{1043}$. In Deutschland und den Niederlanden reicht eine Generalvollmacht aus. Dabei ist in Deutschland zur wirksamen Bevollmächtigung allerdings die notarielle Beglaubigung der Vollmacht erforderlich. In den Niederlanden (Art. 2:176 NBG) und in Frankreich reicht eine schriftlich erteilte Vollmacht aus ${ }^{1044}$.

\section{c) (Teilweise) Erfüllung der Einlagepflichten}

In Frankreich ist auf jede Einlage mindestens 1/5 des Nennbetrages vor Gründung der Gesellschaft (d.h. vor Unterzeichnung des Gesellschaftsvertrages) zu erbringen (Art. L 223-7 Abs. 4, Art. D 22 Abs. 1 C.com.). In Deutschland ist vor Anmeldung der Gesellschaft wenigstens ein Viertel des Nennbetrags eines Geschäftsanteils einzuzahlen; insgesamt aber wenigstens soviel, dass der Gesamtbetrag des eingezahlten Geldeinlagen zuzüglich der Geschäftsanteile für die Sacheinlagen zu leisten sind, die Hälfte des Mindestkapitals von nunmehr $10.000 €$ erreicht (§ 7 Abs. 2 S. 1 GmbHG). In den Niederlanden war bislang ebenfalls vor Anmeldung

Schweizer Notare auch künftig von den deutschen Registergerichten akzeptiert werden wird, ist vor dem Hintergrund der Abschaffung des Beurkundungserfordernisses solcher Übertragungen in der Schweiz fraglich. Dieser Frage hier nachzugehen, würde indes den Rahmen dieser Abhandlung sprengen.

1042 Siehe Dritter Abschnitt § 3 II. 2. c). Schwanna; Wachter GmbHR 2005, 717, 722.

1043 Wachter GmbHR 2005, 717, 722.

1044 Dritter Abschnitt $\S 1$ I. 1. b) bb), $\S 2$ II 1. b) cc) und $\S 3$ II. 2. c). Vgl. auch Schwanna; Wachter GmbHR 2005, 717, 722 . 
auf jede Einlage mindestens ein Viertel und insgesamt das gesetzliche Mindestkapital von $18.000 €$ einzuzahlen (Art 2: 178 und Art. 2: 191 NBG). Mit der Abschaffung des Mindestkapitals sind auf jeden Geschäftsanteil nunmehr nur noch wenigstens 0,01 $€$ bei Anforderung durch die Gesellschaft zu entrichten ${ }^{1045}$.

\section{d) Anmeldung zum Handelsregister}

Nach der Errichtung ist die Gesellschaft zum Handelsregister anzumelden. Anders als in Deutschland und in den Niederlanden muss die Handelsregisteranmeldung in Frankreich nicht in öffentlich beglaubigter Form abgegeben werden ${ }^{1046}$. Sowohl in Frankreich als auch in Deutschland wirkt die Eintragung konstitutiv, das heißt, die Gesellschaft als solche entsteht erst mit ihrer Eintragung. In den Niederlanden kommt der Eintragung im Hinblick auf die Gesellschaft selbst nur deklaratorische Bedeutung zu, bedeutungsvoll ist sie jedoch auch in den Niederlanden im Hinblick auf die beschränkte Haftung der Gesellschafter und der Geschäftsführung auf das Gesellschaftsvermögen ${ }^{1047}$.

\section{e) Sicherheitsleistung bei Einpersonen-GmbH}

Nur in Deutschland wurde bislang bei der Errichtung einer GmbH durch nur einen Gesellschafter in Betreff noch ausstehender Stammeinlagen die Erbringung einer Sicherheit in Form des $§ 232$ BGB oder eines gleichwertigen Sicherungsmittels, § 7 Abs. 2 S. 3 GmbHG, verlangt. Künftig soll auch in Deutschland eine solche Sicherheitsleistung nicht mehr erforderlich $\operatorname{sein}^{1048}$.

\section{f) Staatliche Genehmigungen}

Die Gründung selbst bedarf in keinem der untersuchten Länder einer staatlichen Genehmigung; genehmigungsbedürftig kann allerdings die beabsichtigte Tätigkeit der Gesellschaft

1045 Dritter Abschnitt $\S 1$ I. 1. b) cc), $\S 2$ II 1. b) dd) sowie d) und $\S 3$ II. 2. b). Vgl. hierzu auch unten in diesem Abschnitt $\S 5$ I. 1. b) und c).

1046 Dritter Abschnitt $\S 1$ I. 1. b) dd), $\S 2$ II 1. b) ee) und $\S 3$ II. 2. f).

1047 Dritter Abschnitt $\$ 2$ II 1. b) ee); Wachter GmbHR 2005, 717, 722 und 726. Vgl. insoweit auch Schwanna; Kallmeyer DB 2004, 636, der die Rechtslage der englischen Limited der deutschen GmbH bzw. GmbH \& Co KG gegenüberstellt.

1048 Dritter Abschnitt $§ 1$ I. 2. a) bb) bbb). 
$\operatorname{sein}^{1049}$. Das Vorliegen der Genehmigung ist in den Niederlanden und Frankreich im Rahmen des Gründungsverfahrens nachzuweisen; in Deutschland ist de lege ferenda eine Beibringung der Genehmigungsurkunde nicht mehr erforderlich ${ }^{1050}$. Art und Umfang der genehmigungsbedürftigen Rechtsgeschäfte sind - mit Ausnahme solcher genehmigungspflichtiger Geschäfte für die es bereits auf europäischer Ebene einheitliche Genehmigungsverfahren gibt - in Deutschland, den Niederlanden und Frankreich verschieden und richtet sich nach den Bestimmungen des jeweiligen nationalen Gewerberechts ${ }^{1051}$.

\section{Kosten der Gründung}

Die Kosten der Gründung sind in allen drei Ländern überschaubar ${ }^{1052}$. In Deutschland und den Niederlanden fallen Notargebühren an, da der Gesellschaftsvertrag grundsätzlich der Beurkundung bedarf; diese sind abhängig von der Kapitalausstattung der Gesellschaft sowie einer Vielzahl weiterer Faktoren wie etwa, ob es sich um eine Einpersonen- oder eine Mehrpersonen-GmbH handeln soll, und betragen bei Zugrundelegung des in den Niederlanden und in Deutschland jeweils de lege lata geltenden gesetzlichen Mindestkapitals zwischen 300 und $850 €^{1053}$.

In Frankreich und de lege ferenda auch in Deutschland bei Gründung einer „Muster“-GmbH ist die Einschaltung eines Notars oder Rechtsanwalts nicht zwingend vorgesehen. Feste gesetzliche Gebühren für die Gründungsberatung bestehen demnach nicht. Durch die Abschaffung des Mindeststammkapitals in den Niederlanden ist außerdem eine deutliche Verbilligung der notariellen Errichtung zu erwarten ${ }^{1054}$. Es bleiben die Kosten für externe Berater, falls solche hinzugezogen werden; in einfachen Fällen bewegen sich diese in der Praxis wohl in einer Größenordnung zwischen 500 und $1000 €^{1055}$.

Hinzu kommen in allen drei Ländern Kosten, die im Zusammenhang mit der Eintragung der Gesellschaft im jeweiligen Register und der Veröffentlichung in einem der nationalen Gesellschaftsblätter stehen; sie bewegen sich zwischen 100 und $300 €^{1056}$.

\footnotetext{
1049 Dritter Abschnitt $\S 1$ I. 1. b) ee), $\S 2$ II 1. b) bb) und $\S 3$ III. 1. a).

${ }^{1050}$ Dritter Abschnitt $\S 1$ I. 1. b) ee) und 2. a) bb) ccc), $\S 2$ II 1. b) bb) und $\S 3$ III. 1. a).

1051 Dritter Abschnitt $\S 1$ I. 1. b) ee), $\S 2$ II 1. b) bb) und $\S 3$ III. 1. a). Schwanna; Wachter GmbHR 2005, 717, 722.

1052 Dritter Abschnitt $\$ 1$ I. 1. c), § 2 II 1. d) und $\S 3$ II. 3.

1053 Dritter Abschnitt § 1 I. 1. c), § 2 II 1. d). Schwanna; Wachter GmbHR 2005, 717, 723.

1054 Dritter Abschnitt $\S 1$ II. 2. a) aa) und 2. a) bb) ccc), $\S 2$ II 1. d) und $\S 3$ II. 3.

1055 Dritter Abschnitt § 1 I. 1. c), § 2 II 1. d) und § 3 II. 3. Schwanna; Wachter GmbHR 2005, 717, 723.

1056 Dritter Abschnitt § 1 I. 1. c), § 2 II 1. d) und § 3 II. 3. Schwanna; Wachter GmbHR 2005, 717, 723.
} 


\section{Schlussfolgerungen}

\section{Gründungsvorgang}

Die in Deutschland und den Niederlanden beabsichtigte Systemumstellung von einer ,frontloaded control“ zu einer „backloaded control“ ist ein legitimer und richtiger Schritt hin zu einer Beschleunigung des Gründungsverfahrens. Solange an der Aufbringung eines Mindeststammkapitals (in Deutschland) und der notariellen Beurkundung des Gesellschaftsvertrages (in Deutschland und in den Niederlanden) festgehalten wird, kann weder auf eine Mitwirkung von Notaren noch (vernünftigerweise) von Rechtsanwälten und Wirtschaftsberatern verzichtet werden. Angesichts dessen ist die behördliche beziehungsweise gerichtliche Kontrolle wohl auch die einzige Stellschraube, mit der eine Beschleunigung des Gründungsverfahrens erreicht werden mag. Hinzu kommt, dass die von Behörden und Gericht erbrachte Leistung keine Dienstleistung dem Gründer gegenüber ist und somit - anders als die Leistungen des Notars und weiterer Berater - der einzige (Zeit-)Faktor während des Gründungsverfahrens ist, der von diesem auch kaum beeinflusst werden kann.

Unabhängig von der Frage der Beibehaltung, Beschränkung oder Abschaffung einer vor- oder nachgelagerten behördlichen beziehungsweise gerichtlichen Kontrolle, dürfte die Einführung eines Standardformulars eines Gesellschaftsvertrages zu einer weiteren Beschleunigung des Registrierungsverfahrens führen, da sich eine umfassende Prüfung des Vertrages durch das Registergericht erübrigen dürfte ${ }^{1057}$.

Die weiteren Überlegungen, wie etwa die Konzentration der Registerführung, die zwangsläufig mit der Umstellung der Register auf den elektronischen Betrieb (virtuell) erfolgen wird oder die Förderung der fachlichen Spezialisierung bei den Registerrichtern und Rechtspflegern oder schließlich die Einführung eines ,express service“ nach dem Vorbild des englischen Companies House, sind ebenfalls unbedingt geeignet eine Beschleunigung des Gründungsvorgangs zu bewirken. Dies sind allerdings eher tatsächliche Notwendigkeiten, die kaum durch eine Verankerung im Bundesgesetz bewirkt werden können ${ }^{1058}$.

$1057 \mathrm{Zu}$ den Nachweisen in der Literatur vgl. oben Dritter Abschnitt $\S 1$ I. 2. a) und b) sowie $\S 2$ II 2. Siehe hierzu auch unten in diesem Abschnitt $\S 3$ I. 3 und II. 3.

$1058 \mathrm{Zu}$ den Nachweisen in der Literatur vgl. oben Dritter Abschnitt $\S 1$ I. 2. a) und b) sowie $\S 2$ II 2. 


\section{Gründungsvoraussetzungen}

\section{a) Gründer}

Wachter $^{1059}$ hatte sich unter Hinweis auf die in Deutschland bestehenden Schwierigkeiten bei der Beteiligung ausländischer Personen an der Gründung einer deutschen $\mathrm{GmbH}$ für die ausdrückliche Zulassung ausländischer Personen als Geschäftsführer oder Gesellschafter einer deutschen $\mathrm{GmbH}$ ausgesprochen ${ }^{1060}$. Dieser Forderung ist nicht nur in Deutschland sondern auch in den Niederlanden nachzukommen. In den Niederlanden wird auch bei Gründung danach unterschieden, ob die Gründern Niederländer oder Ausländer sind. Eine Unterscheidung zwischen ausländischen und inländischen Gründern oder Geschäftsführern ist in einer globalisierten Welt kaum noch nachzuvollziehen; der insoweit nahe liegende Verzicht auf eine Unterscheidung würde zudem das Gründungsverfahren vereinfachen und beschleunigen.

\section{b) Staatliche Genehmigung}

Es steht wohl ersichtlich außer Frage und bedarf keiner längeren Ausführungen an dieser Stelle, dass die Regelung in Deutschland, wonach bei der Errichtung einer Gesellschaft die Beibringung einer gewerberechtlichen Genehmigung nicht mehr erforderlich sein soll, der französischen und der niederländischen Regelung vorzuziehen ist. Die Verpflichtung bei Anmeldung eine Genehmigungsurkunde vorzulegen führt zwangsläufig zu Verzögerungen, da die zuständigen Behörden die Voraussetzungen einer Genehmigung von Amts wegen festzustellen und ihre Entscheidungen in dem dazu vorgesehenen Verfahren unter Anhörung der Beteiligten zu treffen haben. Erhebliche Verzögerungen sind selbst dann nicht auszuschließen, falls die Voraussetzungen einer Genehmigung unstreitig vorliegen. Zwingende Gründe die andererseits für eine präventive Kontrolle des Vorliegens gewerberechtlicher Voraussetzungen sprechen würden, sind nicht ersichtlich. Insbesondere sprechen auch keine Gläubigerschutzgesichtspunkte für eine Beibehaltung der vorgelagerten Kontrolle, denn auch unabhängig von der Eintragung ist es der Gesellschaft nicht gestattet, ohne (gewerberechtliche) Erlaubnis in einem erlaubnispflichtigen Gewerbe tätig zu sein. Umgekehrt kann eine Gesellschaft auch schon vor ihrer Eintragung (gegebenenfalls als Vor-GmbH) tätig sein, wenn ihr die Erlaubnis bereits erteilt worden ist. Daher sollte die präventive Kontrolle der Gründer zugunsten einer nachgelagerten gewerberechtlichen Kontrolle aufgegeben werden ${ }^{1061}$.

1059 Wachter, Die GmbH-Reform in der Diskussion, S. 55, 107 f.

1060 Vgl. hierzu auch oben Dritter Abschnitt $\$ 1$ I. 2. b).

1061 Vgl. hierzu auch schon die Ausführungen des BDI/Hengeler Müller S. 13 sowie oben Dritter Abschnitt $\S 1$ I. 2. b). 


\section{c) Abschluss des Gesellschaftsvertrages / Notarielle Beurkundung}

Der (gesetzliche) Zweck der notariellen Beurkundung ist in allen drei Ländern im Wesentlichen gleich und hat drei Zielrichtungen: zum einen dient die notarielle Beurkundung der Warnung und Bewahrung der Beteiligten vor übereilten Entscheidungen durch deren umfassende Beratung und Belehrung (Beratungs- und Warnfunktion); zweitens soll mit der notariellen Beurkundung eine Richtigkeits- beziehungsweise Gültigkeitsgewähr erreicht werden, indem der Notar rechtliche Schwierigkeiten überwindet, die bei Nichtbeachtung gegebenenfalls zur Unwirksamkeit des Rechtsgeschäfts geführt hätten (Richtigkeits- beziehungsweise Gültigkeitsgewähr)und drittens soll (regelmäßig wegen der wirtschaftlichen Bedeutung des Rechtsgeschäfts) auch eine Beweissicherung ermöglicht werden (Beweissicherungsfunktion) $)^{1062}$.

Unterstellt die notarielle Beurkundung vermochte den genannten Vorgaben prinzipiell gerecht $\mathrm{zu}$ werden ${ }^{1063}$, so vermag das dennoch die gesetzliche Vorgabe einer notariellen Beurkundung bei der Feststellung des Gesellschaftsvertrages einer $\mathrm{GmbH}$ nicht zu rechtfertigen, und zwar aus den folgenden Erwägungen:

Sicherlich sind (auch) Notare in der Lage, die Beteiligten einer Gesellschaftsgründung umfassend und sachgerecht zu belehren und zu beraten und so vor übereilten Entscheidungen zu warnen und möglicherweise auch von der einen oder anderen rechtlich oder wirtschaftlich nachteiligen Entscheidung abzuhalten und sicherlich mag dieser Schutz in Einzelfällen zweckmäßig und erforderlich sein. Nicht ersichtlich ist allerdings weshalb diese Dienstleistung durch einen Notar erbracht werden muss. Eine umfassendere und daher ohnehin in der Praxis unumgängliche Beratung kann genauso gut durch andere Berater erfolgen, die dann auch zu den wirtschaftlichen und steuerlichen Folgen der beabsichtigten Gründung Stellung beziehen. In der Praxis ist es zudem häufig ohnehin so, dass der Berater in Vollmacht der Gründungsgesellschafter die Beurkundung bei dem Notar vollzieht, so dass die Warnfunktion der Beurkundung auch hier ins Leere läuft ${ }^{1064}$.

Die Beweissicherungsfunktion und Richtigkeits- beziehungsweise Gültigkeitsgewähr einer notariellen Beurkundung wird in gleicher Weise durch die Gründungsprüfung des Handelsre-

1062 Dritter Abschnitt $\$ 1$ I. 1. b) bb) und 2. bb) aaa) sowie zur Beurkundungspflicht bei Geschäftsanteilsübertragungen III 2. b) bb) ccc), § 2 II 1. b) cc) und $\S 3$ II. 2. c); BDI/Hengeler Müller S. 44. Zur Dreidimensionalität des Urkundsbegriffs vgl. Bohrer DNotZ 2008, 39, 42.

1063 Dass dies umstritten ist, darauf weisen BDI/Hengeler Müller S. 44 hin.

1064 Vgl. auch BDI/Hengeler Müller S. 44 hin. 
gisters erfüllt. An der Anmeldung zum Handelsregister, der (grundsätzlichen) Prüfung des Gesellschaftsvertrages und seiner Änderungen durch das Registergericht, der Eintragung in das Register und den sich daraus jeweils ergebenden Rechtsfolgen (konstitutive Wirkung der Registereintragung) halten - soweit ersichtlich die Gesetzgeber Deutschland und der Niederlande auch in Zukunft fest ${ }^{1065}$.

Schließlich sind auch die praktischen Erfahrungen in Frankreich, wo seit 2004 kein gesetzliches Erfordernis der notariellen Beurkundung von Gesellschaftsverträgen mehr existiert zu berücksichtigen. Irgendwelche Nachteile für die Beteiligten oder den Rechtsverkehr hieraus sind nicht bekannt geworden. Besonderheiten des deutschen oder Niederländischen $\mathrm{GmbH}$ Rechts, die abweichend vom dem französischen Recht die notarielle Beurkundung erfordern, sind nicht ersichtlich ${ }^{1066}$.

Die Aufgabe der gesetzliche Vorgabe einer notariellen Beurkundung der Gesellschaftsverträge würde zum einen zu einer erheblichen Vereinfachung des Verfahrens; zum anderen zu einer nicht unerheblichen Verbilligung der Gründung und aller späteren Änderungen des Gesellschaftsvertrages führen. Den Beteiligten bliebe es außerdem weiterhin unbenommen, die Beratung von Notaren in Anspruch zu nehmen und die von ihnen geschlossenen Vereinbarungen notariell beurkunden lassen ${ }^{1067}$.

\section{d) (Teilweise) Erfüllung der Einlagepflichten}

Einzugehen ist außerdem auf die Frage der Fälligkeit der Einlagen, die in den Niederlanden künftig in das Ermessen der Gesellschafter gestellt werden soll. In Deutschland ist insoweit vorgeschlagen worden, die Pflicht zur Aufbringung und Erhaltung des Stammkapitals ganz aufzugeben und stattdessen zu einem Haftungssystem nachgelagerter Wertkontrolle überzugehen, in dem die Gesellschafter für nicht erbrachte oder zurückgewährte Einlagen in der Insolvenz der Gesellschaft in Anspruch zu nehmen sind ${ }^{1068}$. Gegen einen derart radikalen Systemwechsel, den im Übrigen auch der niederländische Gesetzgeber so nicht verfolgt, denn

\footnotetext{
1065 Inwieweit richtigerweise daran festzuhalten ist, ist in Abhängigkeit zu der hier in diesem Abschnitt diskutierten Frage zu beantworten, nämlich inwieweit ein Notar bei dem Gründungsvorgang zu beteiligen ist. Je größer der Einsatz und die Verantwortlichkeit des Notars, desto kleiner die Erforderlichkeit einer materiellen Prüfung der Richtigkeit der Anmeldung durch das Registergericht; vgl. hierzu auch unten unter $\S 2$ II 2 e).

1066 BDI/Hengeler Müller S. 44.

1067 BDI/Hengeler Müller S. 45.

1068 Vgl. oben die Vorschläge zur Einführung einer KmbH sowie kürzlich auch Bayer ZGR 2007, $220,234 \mathrm{f}$. und so ähnlich $J$. Vetter Reform des gesellschaftsrechtlichen Gläubigerschutzes, in: Verhandlungen und Berichte des 66. DJT, Bd. II, S. P 116.
} 
auch dort sind die Einlagen spätestens nach 5 Jahren (dann verjährt die Forderung; ein Verzicht auf die Erbringung der Einlage ist nicht gestattet) zu erbringen und nicht etwa erst in der Insolvenz, spricht bereits, dass sich das aus Grundsätzen der Kapitalaufbringung und erhaltung zusammengesetzte Gläubigerschutzkonzept grundsätzlich bewährt hat. Auch auf europäischer Ebene hat man zuletzt nur eine Modernisierung des bestehenden Systems nicht aber dessen Abschaffung angeregt ${ }^{1069}$. $\mathrm{Zu}$ empfehlen ist dem deutschen Gesetzgeber allerdings, es den niederländischen und französischen Nachbarn gleichzutun und von einer Pflicht zur sofortiger (teilweisen) Erfüllung der Einlagepflichten abzusehen. Diese Empfehlung mag allerdings auch verspätet kommen, denn mit dem Vorschlag einer Unternehmergesellschaft (haftungsbeschränkt) hat der deutsche Gesetzgeber letztlich nichts anderes getan, als die Pflicht zur (teilweisen) Erfüllung der Einlagen zum Zeitpunkt der Anmeldung aufzuheben ${ }^{1070}$

\section{e) Anmeldung zum Handelsregister}

An dem Beglaubigungserfordernis bei der Anmeldung sollte in Deutschland und in den Niederlanden festgehalten werden, denn nur so lässt sich ohne erneute Prüfung bei Gericht die Identität des Unterzeichners nachvollziehen und die Vertretungsberechtigung des Unterzeichners überprüfen. Zu erwägen ist vielmehr, die Reichweite der notariellen Beglaubigungsfunktion zu erweitern, wie es bereits in der (ausländischen) Praxis zum Teil bei der Zeichnung gesellschaftsrechtlicher Dokumente üblich ist, und den Notar zu verpflichten bei der Zeichnung durch ein Organ der Gesellschaft nicht nur dessen Identität sondern zugleich auch die Vertretungsberechtigung der unterzeichnenden Person zu versichern. So wäre eine nochmalige Überprüfung der Vertretungsverhältnisse des Registergerichts vor Eintragung überflüssig und könnte vermieden werden.

Mit der Umstellung der Registerverfahren in Deutschland und den Niederlanden auf eine backloaded control reduziert sich die Gründungsprüfung der Registergerichte auf die Kontrolle des Gesellschaftsvertrages, der Geschäftsführer und der Gründungsgesellschafter. Würde man - so wie Wachter ${ }^{1071}$ es im Hinblick auf die Kontrolle der ordnungsgemäßen Kapitalaufbringung vorschlägt - die Verantwortlichkeit der Prüfung schlichtweg auf den beurkundenden ${ }^{1072}$ Notar übertragen und diesen für die Ordnungsgemäßheit der gesamten Gründungsprüfung in die unbeschränkte und unbeschränkbare persönliche Haftung nehmen, so brauchte das

\footnotetext{
1069 Eine entsprechende Änderung der zweiten Richtlinie ist jüngst in Kraft getreten.

1070 Siehe hierzu auch die Überlegungen in diesem Abschnitt unter $§ 5$ II. 3.

1071 Vgl. im Einzelnen nur Wachter, Die GmbH-Reform in der Diskussion, S. 55, 104. Dazu auch Schwanna.

1072 Wird künftig auf eine Beurkundung des Gesellschaftsvertrages verzichtet, wie oben vom Verfasser unter c) vorgeschlagen, so bleibt es selbstverständlich bei der umfassenden (nachgelagerten) Prüfungspflicht der Registergerichte.
} 
Registergericht bei der Anmeldung nur noch eine formale Kontrolle des Gründungsvorgangs vorzunehmen. Dann aber käme auch eine Umqualifizierung der rechtlichen Wirkung der Gründungsanmeldung von einer konstitutiven zu einer nur noch deklaratorischen Wirkung in Betracht. Für die Entstehung der Gesellschaft mit beschränkter Haftung als solches könnte an die Feststellung des Gesellschaftsvertrages angeknüpft werden.

\section{§ 3 Gesellschaftsvertrag}

\section{Rechtsvergleich}

\section{Sprache des Gesellschaftsvertrages}

Da der Gesellschaftsvertrag zur Prüfung beim Handelsregister einzureichen ist, ist wenigstens eine Abschrift hiervon in der jeweiligen Amtssprache abzufassen. Allerdings ist heutzutage die mehrsprachige Abfassung des Gesellschaftsvertrages üblich geworden. In Deutschland und Frankreich gibt es auch keine gesetzliche Regelung, die der Abfassung des Gesellschaftsvertrages in einer ausländischen Sprache entgegenstünde, vorausgesetzt, der beurkundende Notar ist dieser Sprache mächtig. Dann allerdings bedarf es, wie gesagt, einer Übersetzung des Vertrages zur Vorlage beim Handelsregister ${ }^{1073}$.

\section{Gesetzlicher Mindestinhalt}

\section{a) Firma}

Das Firmenrecht ist - bei allen Unterschieden im Detail ${ }^{1074}$ - in allen hier untersuchten Ländern ähnlich und dabei vor allem sehr liberal. Die Firma ist grundsätzlich frei wählbar; verboten ist es allerdings eine Bezeichnung zu führen, die den Rechtsverkehr irrezuführen oder zu täuschen vermag oder aber mit der Firma einer anderen Gesellschaft identisch ist oder die Rechte Dritter (z.B. Marken- oder Namenrecht) noch sonstige öffentliche Interessen (z.B. gute Sitten) verletzt.

1073 Dritter Abschnitt $\$ 1$ II., § 2 III. und $\S 3$ III. Wachter GmbHR 2005, 717, 723 f.; Schwanna.

1074 Vgl. hierzu im Einzelnen oben Dritter Abschnitt $\S 1$ II. 1. a) aa), § 2 III 1. a) aa) und $\S 3$ III. 1. a). 
Gemeinsam ist dem Firmenrecht aller drei Länder außerdem, dass in der Firma ein Rechtsformzusatz zu führen ist. Dabei ist es ausreichend, dass eine allgemein anerkannte Abkürzung verwendet wird ${ }^{1075}$.

\section{b) Sitz und Geschäftsanschrift}

Nunmehr ist es auch deutschen Gesellschaften gestattet, einen Verwaltungssitz zu wählen, der nicht notwendig mit dem Satzungssitz übereinstimmt und auch im Ausland liegen kann. In den Niederlanden, wo man der Gründungstheorie folgt, war dies auch vor der BV-Reform möglich. In Frankreich hält man trotz der EuGH-Rechtsprechung und den Anpassungen anderer nationaler Rechte an der Regelung fest, wonach der Verwaltungssitz einer französischen Gesellschaft nicht im Ausland liegen darf ${ }^{1076}$.

\section{c) Stammkapital und Einlagen}

Eine Bezeichnung des Stammkapitals im Gesellschaftsvertrag ist de lege ferenda nur noch in Deutschland und in Frankreich Pflicht. In den Niederlanden hält man die Angabe des Genehmigten Kapitals im Gesellschaftsvertrag für entbehrlich. Auch die Notwendigkeit wenigstens $20 \%$ des genehmigten Kapitals auszugeben und zu zeichnen soll künftig entfallen ${ }^{1077}$.

\section{Mustergesellschaftsvertrag}

Für unkomplizierte Standardgründungen stellt der deutsche Gesetzgeber künftig als Anlage zum GmbHG eine vollständige Gründungsdokumentation, bestehend aus Mustergesellschaftsvertrag, Handelsregisteranmeldung, Niederschrift der Gesellschafterversammlung und Gesellschafterliste zur Verfügung. Entscheiden sich die Gründer für die Verwendung dieses Musters, so ist eine notarielle Beurkundung des Gesellschaftsvertrages nicht mehr erforderlich, verlangt wird dann lediglich die öffentliche Beglaubigung der Unterschriften der Grün-

1075 Dritter Abschnitt $\S 1$ II. 1. a) aa), § 2 III 1. a) aa) und $\S 3$ III. 1. a). Wachter GmbHR 2005, 717, 723; siehe auch oben Dritter Abschnitt $\S 1$ II. 1. a) aa), § 2 III 1. a) aa) und $\S 3$ III. 1. a).

1076 Vgl. hierzu im Einzelnen oben Dritter Abschnitt $\S 1$ II. 1. a) bb) und 2. a) bb), § 2 III 1. a) bb) und $\S 3$ III. 1. b).

1077 Vgl. hierzu im Einzelnen oben Dritter Abschnitt $§ 1$ II. 1. a) dd) und ee), § 2 III 1. a) cc) und dd) und $\S 3$ III. 1. e). 
der ${ }^{1078}$. In Frankreich wurde bereits $2005^{1079}$ eine solche Mustersatzung eingeführt und 2006 zur Verwendung veröffentlicht ${ }^{1080}$

\section{Schlussfolgerungen}

\section{Firma}

Die Ähnlichkeit der Firmenrechte und insbesondere die in allen Ländern gegebene Möglichkeit allgemein anerkannte Abkürzungen zu verwenden, gibt Anlass, darüber nachzudenken, ob der Rechtsformzusatz künftig nicht im Interesse der Markttransparenz durch einen klarstellenden Zusatz ergänzt werden sollte (zum Beispiel NL B.V., GER GmbH und F S.à.r.1.). Die derzeit verwendeten Abkürzungen können durchaus - zwar nicht im Verhältnis der hier untersuchten Gesellschaften zueinander - aber im Verhältnis zu anderen europäischen Gesellschaftsformen, wie etwa bei der $\mathrm{GmbH}$, die als solche auch in Liechtenstein und so ähnlich auch in Österreich existiert oder bei der S.à.r.l., die in gleicher Weise von Gesellschaften aus Frankreich und Luxemburg verwendet wird oder bei der B.V. die eine namensgleiche beziehungsweise namensähnliche Schwester in Belgien hat, Verwechslungen hervorrufen ${ }^{1081}$.

\section{Sitz und Geschäftsanschrift}

Angesichts der immer stärkeren Angleichung der europäischen Gesellschaftsrechte, stellt sich die Frage, inwieweit die ausländische Kapitalgesellschaftsform mit Sitz im Inland tatsächlich ein zukunftsweisendes Geschäftsmodell ist. In der Praxis sind die sich heute noch unterscheidenden Aspekte der Kapitalisierung der Gesellschaft beziehungsweise die gesetzliche Regelung von Kapitalaufbringungs- und Kapitalerhaltungsfragen, häufig nicht die den Wettbewerb entscheidenden Faktoren. Vielmehr interessiert die Gründer die sachliche Geeignetheit der Gesellschaftsform, das heißt die Kompatibilität der Gesellschaftsform mit den inländischen steuerlichen, bilanziellen und wirtschaftlichen Begebenheiten und - was (gerade in Frankreich) nicht zu unterschätzen ist - die sprachliche Kompatibilität der Gesellschaftsform. Aus den vorgenannten Gründen ist die in Deutschland neu geschaffene und in den Niederlanden

1078 Siehe oben Dritter Abschnitt § 1 II. 2. a) aa).

1079 Gesetz 2005-882 v. 2.8.2005, Art. 33.

1080 Décret 2006-301 v. 9.3.2006; siehe auch schon oben Dritter Abschnitt § 3 III. 1. e); vgl hierzu auch die Ausführungen bei Karsten GmbHR 2007, 958, 961 f. sowie Wachter GmbHR 2005, 717, 723.

1081 Im Ergebnis so wie hier auch schon Wachter GmbHR 2005, 717, 723. 
bisher bereits existierende Möglichkeit eines ausländischen Gesellschaftssitzes sicherlich kein entscheidender Vorteil des jeweiligen nationalen Gesellschaftsrechts.

\section{Mustergesellschaftsvertrag}

Für die Einführung eines Standardformulars eines Gesellschaftsvertrages, das einen gesetzlich vorgesehenen Inhalt aufweist, spricht, dass sich die Prüfung des Vertrages durch das Registergericht oder eine Behörde, die in allen drei Ländern vorgesehen ist, wenn schon nicht erübrigen würde, so doch vereinfachen und mithin beschleunigen ließe. Die Prüfung des Registergerichts beziehungsweise der Behörde wäre darauf beschränkt, den eingereichten Mustervertrag auf etwaige Abweichungen zum Muster zu überprüfen ${ }^{1082}$. Wollte man auch diese Prüfung vermeiden, dann müsste man für den Fall der nicht angemeldeten Abweichung vom Muster eine Sanktion vorsehen, etwa dergestalt, dass bei einer späteren Feststellung einer solchen Abweichung die Gesellschaft von Amts wegen gelöscht werden darf und zusätzlich, etwa in der Insolvenz der Gesellschaft, Durchgriffsansprüche gegen Gesellschafter und Geschäftsführung bestehen.

Im Hinblick auf das vom deutschen Gesetzgeber bereitgestellte Standardformular ist anzumerken, dass die Vorgabe eines Unternehmensgegenstandes nicht praxisgerecht ist, zumal die drei vorgestellten Alternativen (Handel mit Waren, die Produktion von Waren, Dienstleistungen) nach bisheriger Rechtslage mangels Individualisierung nicht eintragungsfähig sind ${ }^{1083}$. Angesichts der Bandbreite möglicher und auch gesetzmäßiger Geschäftsfelder empfiehlt es sich, den Satzungsbestandteil „Unternehmensgegenstand“ auszuklammern und den Mustergesellschaftsvertrag auf die Vorgabe von Stammkapital und Stammeinlagen zu beschränken. Schließlich wäre unter dem Aspekt des Wettbewerbs der Rechtsordnungen dem deutschen Gesetzgeber zu empfehlen, das Standardformular des Gesellschaftsvertrages auch in englischer Sprache beziehungsweise in einer bilingualen Fassung gesetzlich zu verankern.

Der Einwand, bereits heute halte jeder Notar eine oder mehrere „Mustersatzungen“ für Unternehmensgründer bereit, die sich in der Praxis bewährt hätten und vom Handelsregister problemlos eingetragen würden ${ }^{1084}$, verfängt insoweit nicht, als ein solcher externer Mustergesellschaftsvertrag der vollumfänglichen Prüfung des Registergerichts unterläge und somit keinen Beschleunigungseffekt hätte. Den würde man allenfalls erzielen können, wenn man den Notar

1082 Vgl.die Nachweise im Dritten Abschnitt $\$ 1$ II. 2. b).

1083 Vgl. hierzu auch die Nachweise Dritter Abschnitt $§ 1$ II. 1. b).

${ }^{1084}$ Vgl. insoweit oben Dritter Abschnitt $\S 1$ II. 2. b) und $\S 2$ III 2). 
persönlich für den Inhalt des Vertrages in die Haftung nähme ${ }^{1085}$. Hinzu kommt, dass die Stellung des Notars sich in Deutschland, Frankreich und den Niederlanden unterscheidet. In Deutschland, wo der Notar ein Instrument der Rechtspflege ist, ist noch am ehesten eine Einbindung desselben in den Gründungsprozess denkbar ${ }^{1086}$.

\section{§ 4 Organisationsverfassung}

\section{Rechtsvergleich}

\section{Geschäftsführer}

\section{a) Bestellung und Abberufung}

$\mathrm{Zu}$ Geschäftsführern können in Frankreich und Deutschland nur natürliche Personen bestellt werden; in den Niederlanden können auch juristische Personen die Geschäftsführung übernehmen. Als Eignungsvoraussetzung verlangen alle drei Rechtsordnungen, dass der Geschäftsführer amtsfähig ist, d.h. es sich um eine unbeschränkt geschäftsfähige Person handelt. Gestattet ist in allen drei Ländern dass der Geschäftsführer Ausländer ist, unabhängig davon wo er seinen Wohnsitz beziehungsweise Sitz unterhält ${ }^{1087}$.

Personen die wegen einschlägiger (Vermögens-)Delikte vorbestraft sind, können in Deutschland und Frankreich grundsätzlich vorübergehend nicht zum Geschäftsführer bestellt werden. Einheitliche Kriterien dafür, welche Straftaten eine Person als Geschäftsführer disqualifizieren bestehen nicht ${ }^{1088}$. In Frankreich führen Verurteilungen wegen Bankrotts, Betrugs und Untreue zur Disqualifikation; in Deutschland sind de lege lata Verurteilungen wegen Bankrotts, Verletzung der Buchführungspflichten, Gläubigerbegünstigung und Schuldnerbegünstigung wesentlich ${ }^{1089}$. Der Regierungsentwurf des MoMiG sieht eine Ausdehnung des insoweit einschlägigen $\S 6$ Abs. 2 S. 3 GmbHG auf weitere Wirtschaftsdelikte, namentlich auf Verurteilungen wegen Insolvenzverschleppung sowie die Erklärung falscher Angaben bei der Ge-

\footnotetext{
1085 Nochmals: Dies gilt selbstverständlich nur, wenn die Beteiligung eines Notars - anders als hier vorgeschlagen oben unter $\S 2$ II. 2. c) vorgeschlagen wird - weiterhin notwendig bleibt.

1086 Siehe auch zur Einschränkung der Privatautonomie durch Mustersatzungen Karsten GmbHR 2006, 57, der nach Auswertung von $250 \mathrm{GmbH}$ Gesellschaftsverträgen aus dem Bereich des mittelständischen Handwerks, an der Notwendigkeit einer standardisierten Satzung festhält.

1087 Vgl. hierzu im Einzelnen oben Dritter Abschnitt § 1 III. 1. a) aa), § 2 IV 1. b) aa) und § 3 IV. 1. a).

1088 Siehe oben Dritter Abschnitt § 1 III. 1. a) aa) und § 3 IV. 1. a).

1089 Vgl. hierzu oben Dritter Abschnitt $\$ 3$ IV. 1. a).
} 
sellschaftsgründung ( $\S \S 399-401 \mathrm{AktG}$ und $\S \S 82,84 \mathrm{GmbHG}$ ) vor. Darüber hinaus sollen nach dem Willen des deutschen Gesetzgebers künftig auch strafrechtliche Verurteilungen im Ausland berücksichtigt werden, wenn sie mit den in Deutschland einschlägigen Straftaten vergleichbar sind ${ }^{1090}$.

In den Niederlanden gibt es bislang keine vergleichbare Regelung ${ }^{1091}$; in der Literatur wird allerdings teilweise verlangt, für pflichtwidrig handelnde Geschäftsführer die Verhängung mehrjähriger Berufsverbote vorzusehen, so wie sie in England nach Maßgabe des Company Directors Disqualification Acts möglich sind (s. Sec. 18 Company Directors Disqualification Act 1986) ${ }^{1092}$.

Die Bestellung der Geschäftführer obliegt der Gesellschafterversammlung und erfolgt entweder bei Gründung der Gesellschaft oder durch einen gesonderten Gesellschafterbeschluss. Hierbei können die Gesellschafter als Geschäftsführer einen aus ihrer Mitte oder auch einen Dritte bestellen ${ }^{1093}$.

Die Wirkung der Eintragung im Handelsregister ist in allen Ländern nicht konstitutiv, sondern gibt allein die anzumeldende Änderung wieder, hat also nur deklaratorische Bedeutung ${ }^{1094}$.

\section{b) Vertretung der Gesellschaft; Aufgaben und Befugnisse}

Die Vertretungsbefugnis der Geschäftsführer wird regelmäßig in der Satzung festgelegt. Fehlt es an einer entsprechenden Regelung, sind die Geschäftsführer in den Niederlanden (Art. 2:240 NBG) und in Frankreich (Art. L 223-18 C.com.) grundsätzlich einzeln zur Vertretung berechtigt. In Deutschland ( $\$ 35$ Abs. 2 Satz 2 GmbHG) gilt dagegen der Grundsatz der Gesamtvertretung ${ }^{1095}$.

Die Vertretungsbefugnis, sprich das rechtliche Können im Außenverhältnis, ist in allen drei untersuchten Ländern unbeschränkt und kann im Interesse des Rechtsverkehrs mit Wirkung

\footnotetext{
${ }^{1090}$ Siehe Dritter Abschnitt $\S 1$ III. 1. a) aa) und 2. a) aa) bbb) und in der Literatur die Nachweise unter b) aa) bbb).

1091 Vgl. oben Dritter Abschnitt $§ 2$ IV 1. b) aa).

1092 Disqualified Directors Register, abrufbar unter www.companieshouse.gov.uk; siehe dazu Gernoth, Pseudo Foreign Companies - Who Art Thou?, 2005, S. 159 ff; Siehe hierzu Fleischer, WM 2004, 157, 160 f.; Hirte/Lanzius/Mock, in: Lutter, Arbeitskreis Kapital in Europa, 2006, D I; Lanzius, ZInsO 2004, 296 ff.; Boyle \& Birds', Company Law, Rdn. 15.16.1 ff sowie die Nachweise oben Dritter Abschnitt § 2 IV 2. b) aa). Dritter Abschnitt $\$ 1$ III. 1. a) aa), § 2 IV 1. b) aa) und $\S 3$ IV. 1. a).

1094 Dritter Abschnitt $\S 1$ III. 1. a) aa), § 2 IV 1. b) aa) und $\S 3$ IV. 1. a).

1095 Siehe Dritter Abschnitt $\S 1$ III. 1. a) bb), $\S 2$ IV 1. b) bb) und $\S 3$ IV. 1. b).
} 
gegenüber (gutgläubigen) Dritten auch nicht eingeschränkt werden. Etwas anderes gilt für die Geschäftsführungsbefugnis, also das rechtliche Dürfen gegenüber Gesellschaft und Gesellschaftern; diese ist in allen Ländern weitgehend regelbar. Das umfassende Weisungsrecht der Gesellschafterversammlung wie es dem deutschen Rechtssystem immanent ist, ist in Frankreich und den Niederlanden unbekannt; dort handeln die Geschäftsführer grundsätzlich selbständig und eigenverantwortlich ${ }^{1096}$.

Das Verbot von Insichgeschäften der Geschäftsführer ist nur in den Niederlanden (Art. 2: 256 NBG) und in Deutschland ( $\$ 181$ BGB) gesetzlich geregelt. Allerdings ist es Geschäftsführern auch in Frankreich aufgrund allgemeiner Erwägungen nicht gestattet, als Vertreter der $\mathrm{GmbH}$ mit sich selbst oder als Vertreter eines Dritten Rechtsgeschäfts abzuschließen. Die Satzung kann hiervon abweichende Regelungen treffen; zulässig sind Insichgeschäfte im Regelfall auch dann, wenn sie gegenüber den Gesellschaftern umfassend offen gelegt worden sind und die Gesellschafterversammlung dem Geschäft zugestimmt hat ${ }^{1097}$.

\section{c) Verantwortung und Haftungsregime}

Deutsche Geschäftführer haften grundsätzlich nur der Gesellschaft gegenüber, gegebenenfalls gesamtschuldnerisch, und zwar dann wenn sie ihre Pflichten nicht mit der Sorgfalt eines ordentlichen Geschäftsmannes erfüllen und hierdurch der Gesellschaft ein Schaden entsteht. In die Haftung geraten kann der Geschäftsführer allerdings auch gegenüber Gesellschaftern und Dritten, insbesondere wegen Maßnahmen beziehungsweise unterlassener Maßnahmen im Vorfeld einer Krise der Gesellschaft beispielsweise nach Maßgabe des § 64 GmbHG wegen verspäteter Beantragung der Eröffnung des Insolvenzverfahrens oder wegen der Schmälerung des Massevermögens aufgrund von Zahlungen, die der Geschäftsführer nach Insolvenzreife der Gesellschaft (Zahlungsunfähigkeit oder Überschuldung) noch getätigt hat. Künftig soll den deutschen Geschäftsführer eine Ersatzpflicht auch dann treffen, wenn er durch Zahlungen an die Gesellschafter die Zahlungsunfähigkeit der Gesellschaft erst herbeiführt ( 64 Abs. 2 Satz $3 \mathrm{GmbHGE).} \mathrm{Eine} \mathrm{Exculpationsmöglichkeit} \mathrm{hat} \mathrm{der} \mathrm{Geschäftsführer,} \mathrm{dem} \mathrm{es} \mathrm{gelingt}$ nachzuweisen, dass die Zahlungsunfähigkeit oder die Ursächlichkeit der Zahlung für die Zahlungsunfähigkeit der Gesellschaft aus Sicht eines sorgfältigen Geschäftsführers nicht erkennbar war ${ }^{1098}$.

\footnotetext{
1096 Siehe Dritter Abschnitt $§ 1$ III. 1. a) bb), § 2 IV 1. b) bb) und § 3 IV. 1. b). Vgl. aber auch die Reformbestrebungen in den Niederlanden den Gesellschaftern einen größeren Einfluss zu gewähren unter Dritter Abschnitt § 2 IV 2. a) cc) fff). Siehe auch Wachter GmbHR 2005, 717, 729.

1097 Siehe Dritter Abschnitt $§ 1$ III. 1. a) bb), § 2 IV 1. b) bb) und § 3 IV. 1. b).

1098 Siehe Dritter Abschnitt $\S 1$ III. 1. a) cc) und 2. a) aa) aaa) und in der Literatur die Nachweise bei 2. b) aa) aaa).
} 
In den Niederlanden gilt ein ähnliches Haftungssystem wie es in Deutschland existiert beziehungsweise de lege ferenda entstehen soll. Die Geschäftsführer haften grundsätzlich der Gesellschaft gegenüber für die sorgfältige Erfüllung der ihnen obliegenden Aufgaben. Bei Gesamtvertretung besteht eine gesamtschuldnerische Haftung der betroffenen Geschäftsführer, es sei denn der nur aufgrund der Gesamtvertretungsanordnung mitverhaftete Geschäftsführer weist nach, dass ihm kein Versäumnis vorgeworfen werden kann. Gegenüber Dritten haftet die Geschäftsleitung unter anderem im Insolvenzfall. Vergleichbar der Haftung die in Deutschland de lege ferenda gelten soll, haftet der Geschäftsführer in den Niederlanden für Pflichtverletzungen, die (mit)ursächlich für die Insolvenz der Gesellschaft gewesen sind ${ }^{1099}$.

In Frankreich haften die Geschäftsführer der Gesellschaft aber auch Gesellschaftern und Dritten gegenüber einzeln oder gegebenenfalls gesamtschuldnerisch für die Verletzung gesetzlicher und gesellschaftsvertraglicher Bestimmungen oder aufgrund sonstiger Pflichtverletzungen bei Ausübung der Geschäftsführertätigkeit. Die Haftung setzt sich in der Insolvenz der Gesellschaft fort; neben allen anderen Personen die faktisch maßgeblichen Einfluss auf die Geschäftsführung ausgeübt haben, können die Geschäftsführer in der Insolvenz persönlich für die Schulden der Gesellschaft in Anspruch genommen werden ${ }^{1100}$.

\section{Gesellschafter und Geschäftsanteile}

\section{a) Rechtsstellung der Gesellschafter}

In allen drei Ländern werden die Rechte des einzelnen Gesellschafters einerseits von denen der Gesellschaftergesamtheit andererseits unterschieden. Die Rechte und Pflichten des einzelnen Gesellschafters sind von ihrer Art her Ansprüche und Verantwortlichkeiten, die mit der (wirtschaftlichen) Beteiligung des Gesellschafters im Zusammenhang stehen. Wenn hingegen die Gesellschaftergesamtheit angesprochen wird, so sind damit in allen drei Ländern die Rechte der Gesamtheit der Gesellschafter als oberstes Willensbildungsorgan der Gesellschaft. gemeint. Die Gesellschafter können ihre Befugnisse als Gesellschaftergesamtheit im Gesellschaftsvertrag beliebig festlegen. Unentziehbar und unübertragbar sind Entscheidungen zu grundlegenden Fragen sowie zu Änderungen der Satzung; ansonsten können die Gesellschafter die ihnen zustehenden Befugnisse beliebig auf andere Organe (z.B. Geschäftsführer, Bei-

1099 Siehe Dritter Abschnitt $\$ 2$ IV 1. b) cc); Siehe dort auch die Überlegungen in der Literatur, das Haftungsregime nach angloamerikanischem Vorbild zu verschärfen Dritter Abschnitt § 2 IV 2. b) aa) bbb).

1100 Siehe Dritter Abschnitt $\$ 3$ IV. 1. c). 
rat) durch Satzungsangelegenheit übertragen ${ }^{1101}$. Anders als in Frankreich und in den Niederlanden können die Gesellschafter in Deutschland außerdem über ihr umfassendes Weisungsrecht jederzeit in das operative Geschehen der Gesellschaft eingreifen ${ }^{1102}$. In den Niederlanden wird bislang ${ }^{1103}$ danach unterschieden, ob abstrakte Weisungen, etwa im Hinblick auf allgemeine Leitlinien, oder konkrete, die Geschäftsführung betreffende Weisungen, abgegeben werden sollten. In jedem Fall hatte das Weisungsrecht der Gesellschafter oder eines anderen Organs in der Satzung zu stehen. Künftig ${ }^{1104}$ soll es eine Unterscheidung zwischen generellen und konkreten Weisungen nicht mehr geben; der Geschäftsführer soll - vorausgesetzt die Satzung sieht dies vor - künftig auch in den Niederlanden sämtliche Weisungen eines anderen Organs zu befolgen haben, es sei denn ,diese stehen im Widerspruch zu den Belangen der Gesellschaft und den mit dieser verbundenen Geschäften“"1105.

\section{b) Registrierung der Gesellschafter}

Da die Gesellschafter, mit Ausnahme des Alleingesellschafters einer niederländischen EinPersonen-B.V., nicht in den Handelsregistern eingetragen werden, ist die Führung von Gesellschaftsbüchern oder Gesellschafterlisten weit verbreitet; so etwa auch in Deutschland und den Niederlanden ${ }^{1106}$. In Deutschland soll die Gesellschafterliste künftig einen Rechtsschein setzen für die Anteilsinhaberschaft und so einen gutgläubigen Anteilserwerb ermöglichen. In den Niederlanden dient das Gesellschaftsbuch lediglich der Information der Gesellschaft und ihrer Gesellschafter ${ }^{1107}$. In Frankreich ist die Führung eines Gesellschafterregisters oder einer stets zu Liste der Gesellschafter nicht vorgesehen ${ }^{1108}$.

1101 Siehe Dritter Abschnitt $\S 1$ III. 1. b) aa), § 2 IV 1. c) aa) und $\S 3$ IV. 2. a).

1102 Dritter Abschnitt $\S 1$ III. 1. b) aa).

1103 Dritter Abschnitt $\$ 2$ IV 1. c).

1104 Siehe Dritter Abschnitt $\S 2$ IV 2. a) cc).

1105 Zum Ganzen vgl. auch die Nachweise zur Literatur oben Dritter Abschnitt $\S 1$ III. 1. b), § 2 IV 1. c) und $\S 3$ IV. 2. sowie statt aller zusammenfassend Wachter GmbHR 2005, 717, 729.

1106 Siehe Dritter Abschnitt $\S 1$ III. 1. b) bb) und § 2 IV 1. c) dd).

1107 Dritter Abschnitt § 2 IV 1. c) dd); vgl. auch Wachter GmbHR 2005, 717, 728.

1108 Siehe Dritter Abschnitt $\$ 3$ IV. 2. b). 


\section{c) Gesellschafterversammlung}

Wie zuvor bereits gesagt, ist die Binnenorganisation in den Gesellschaften weitgehend frei gestaltbar, so dass die Bestimmungen des jeweiligen nationalen Gesellschaftsrechts nur insoweit zur Anwendung gelangen, als die Satzung keine vorrangigen Regelungen enthält ${ }^{1109}$.

Die Gesellschafterversammlung ist jeweils das oberste Organ der Gesellschaft, auch wenn sie - wie gesehen - in den einzelnen Ländern durchaus verschieden mächtig ist. Mindestens einmal jährlich findet eine ordentliche Gesellschafterversammlung statt, in der der Jahresabschluss festgestellt und über die Gewinnverwendung entschieden wird. Darüber hinaus ist stets auf Verlangen einer bestimmten Minderheit der Gesellschafter eine Gesellschafterversammlung einzuberufen. Die Anforderungen an die Minderheit sind in den einzelnen Ländern unterschiedlich: in Deutschland und den Niederlanden (Art. 2:220 NBG) genügen $10 \%$, in Frankreich sind $25 \%$ erforderlich (Art. L 23-27 C.com.) ${ }^{1110}$. Die Modalitäten der Einberufung und der Abhaltung der Gesellschafterversammlung werden üblicherweise in der Satzung geregelt, am größten sind hier die Gestaltungsmöglichkeiten im deutschen Recht ${ }^{1111}$.

\section{d) Gesellschafterbeschlüsse}

Soweit durch das Gesetz oder die Satzung nicht etwas Abweichendes geregelt wird, genügt für die Gesellschafterbeschlüsse grundsätzlich die einfache Mehrheit der abgegebenen Stimmen. Für Satzungsänderungen und Kapitalmaßnahmen schreibt das Gesetz weitergehende Mehrheitserfordernisse von 2/3 (Frankreich Art. L 23-29 und Art. L 223-30 C.com) beziehungsweise $3 / 4$ (Deutschland und Niederlande [Art. 2:230 ff. NBG]) ${ }^{1112}$. Der Entwurf des Niederländischen Reformgesetzes sieht künftig für vorgenannte Beschlüsse ebenfalls eine 2/3 Mehrheit der abgegebenen Stimmen vor ${ }^{1113}$.

Grundsätzlich steht das Stimmrecht den Gesellschaftern (vorbehaltlich etwaiger Regelungen in der Satzung) entsprechend ihrer Beteiligung zu. In den Niederlanden (Art. 2:228 NBG) und Frankreich (Art. L 223-28 C.com.) hat jedoch grundsätzlich jeder Geschäftsanteil die gleiche

${ }^{1109}$ Dritter Abschnitt $\S 1$ III. 1. b) cc) bbb, § 2 IV 1. c) ff) aaa) und $\S 3$ IV. 2 c) aa). Zusammenfassend Wachter GmbHR 2005, 717, 728.

1110 Wachter GmbHR 2005, 717, 728.

1111 Siehe oben Dritter Abschnitt $\$ 1$ III. 1. b) cc) bbb), $\$ 2$ IV 1. c) ff) aaa) und $\S 3$ IV. 2 c) aa).

1112 Siehe oben Dritter Abschnitt $\S 1$ III. 1. b) cc) bbb), $\$ 2$ IV 1. c) ff) aaa) und $\S 3$ IV. 2 c) aa). Zusammenfassend Wachter GmbHR 2005, 717, 728.

1113 Siehe oben Dritter Abschnitt $\$ 2$ IV 2. a) cc) eee). 
Stimme $^{1114}$. In Deutschland orientiert sich das Stimmgewicht an der Bedeutung des Geschäftsanteils, dort gewährt (künftig) jeder Euro eines Geschäftsanteils eine Stimme ${ }^{1115}$.

Soweit die Satzung nicht etwas Abweichendes bestimmt, ist eine Stimmrechtsvertretung bei Gesellschafterversammlungen grundsätzlich zulässig; Stimmrechtsvollmachten bedürfen zu ihrer Wirksamkeit jedoch regelmäßig der Schriftform ${ }^{1116}$.

Gesellschafterbeschlüsse sind grundsätzlich formlos möglich. Lediglich für Satzungsänderungen ist in Deutschland und den Niederlanden eine notarielle Beurkundung erforderlich, anders als in Frankreich, wo auch in einem solchen Fall Schriftform ausreichend ist. Jede Satzungsänderung ist zur Eintragung beim Handelsregister anzumelden; ihre Eintragung im Handelsregister wirkt in allen drei Ländern konstitutiv ${ }^{1117}$. In den Niederlanden war bislang für Satzungsänderungen zusätzlich eine Unbedenklichkeitsbescheinigung des Justizministeriums erforderlich (Art. 2: 235 NBG); diese Voraussetzung soll de lege ferenda allerdings entfallen ${ }^{1118}$.

\section{e) Verantwortung und Haftung}

In allen drei Ländern besteht die primäre Verantwortlichkeit der Gesellschafter darin, ihre übernommene Einlageverpflichtung zu erfüllen ${ }^{1119}$ Daneben haften Gesellschafter in Deutschland und in Frankreich auch dann, wenn sie auf die Geschäftsführung Einfluss nehmen oder dies faktisch selber ausüben ${ }^{1120}$. In Deutschland ist der Fall des geschäftsführenden Gesellschafters nunmehr für den Fall der „Führungslosigkeit der Gesellschaft“ wegen Ausfalls des Geschäftsführers explizit geregelt worden. Künftig hat jeder Gesellschafter den Platz des Geschäftsführers bei dessen Ausfall einzunehmen; Willenserklärungen und Zustellung entgegenzunehmen und gegebenenfalls Insolvenzantrag zu stellen ${ }^{1121}$.

1114 Dritter Abschnitt $\S 2$ IV 1. c) ff) ccc) und $\S 3$ IV. 2 c) cc). Vgl. auch hierzu van Duuren Ondernemingsrecht 2004, 4, 8.

1115 Siehe oben Dritter Abschnitt $\S 1$ III. 1. b) cc) ddd).

1116 Siehe oben Dritter Abschnitt $\$ 1$ III. 1. b) cc) ddd), $\$ 2$ IV 1. c) ff) ccc) und $\S 3$ IV. 2 c) cc).

1117 Siehe oben Dritter Abschnitt $\$ 1$ III. 1. b) cc) ddd), § 2 IV 1. c) ff) ccc) und $\S 3$ IV. 2 c) cc).

1118 Dritter Abschnitt $\S 2$ IV 2. a) cc) eee); vgl. zum Ganzen zusammenfassend Wachter GmbHR 2005, 717, 729.

1119 Vgl. oben Dritter Abschnitt $§ 1$ III. 1. b) dd), § 2 IV 1. c) gg) und $\S 3$ IV. 2 d).

1120 Siehe Dritter Abschnitt $\S 1$ III. 1. b) cc) ddd) und $\S 3$ IV. 2 c) cc).

1121 Dritter Abschnitt $\S 1$ III. 2. a) bb) bbb); zu den Vorschlägen in der Literatur vgl. Dritter Abschnitt $§ 1$ III. 2. b) bb) bbb). 


\section{f) Geschäftsanteile}

\section{aa) Allgemeines}

Die Geschäftsanteile an einer GmbH, B.V. oder S.à.r.l. sind grundsätzlich frei veräußerlich und übertragbar $^{122}$. Allerdings ist bei der Übertragung der Geschäftsanteile einer S.à.r.l. auf gesellschaftsfremde Dritte grundsätzlich zuvor die Zustimmung (,agrément") der übrigen Gesellschafter, die mindestens die Hälfte des Stammkapitals auf sich vereinigen (Art. L 210-1 Abs. 2 C.com.) erforderlich ${ }^{1123}$. In der Satzung können die Gesellschafter Erschwernisse für die Übertragung von Geschäftsanteilen vorsehen ${ }^{1124}$. In den Niederlanden war die Aufnahme die Übertragung beschränkender Regelungen, wie etwa die Vorsehung eines Vorkaufsrechts oder eines Zustimmungsvorbehalts bislang sogar Pflicht (Art. 2: $195 \mathrm{NBG})^{1125}$.

\section{bb) Übertragungsmodalitäten / Beschränkungen}

Die Übertragung von Geschäftsanteilen bedarf zu ihrer Wirksamkeit in Deutschland ( $\$ 15$ GmbHG) und den Niederlanden (Art. 2: 196 NBG) der notariellen Beurkundung ${ }^{1126}$. In Frankreich (Art. L 23-17 und Art. L 221-14 C.com.) hingegen ist die Übertragung auch ohne Einhaltung einer Form gestattet. Faktisch ist allerdings auch in Frankreich zur Übertragung von Geschäftsanteilen wenigstens die Einhaltung der Schriftform erforderlich, da die mit dem Anteilserwerb verknüpften Publizitätserfordernisse gegenüber der Gesellschaft die Errichtung einer schriftlichen Urkunde beziehungsweise Registrierung bei der Gesellschaft verlangen ${ }^{1127}$.

In allen drei Ländern ist die Offenlegung der Anteilsübertragung gegenüber der Gesellschaft beziehungsweise gegenüber Dritten erforderlich ${ }^{1128}$. Unterschiedlich sind allerdings die Rechtsfolgen, die ein Unterlassen der Abtretungsanzeige bedingt: in Frankreich (Art. 223-14 C.com. $)^{1129}$ ist die Abtretungsanzeige echtes Wirksamkeitserfordernis, d.h. solange die Anzeige nicht ordnungsgemäß erfolgt, bleibt die Abtretung unwirksam. In den Niederlanden (Art.

\footnotetext{
${ }^{1122}$ Vgl. oben Dritter Abschnitt $\S 1$ III. 1. b) ee), § 2 IV 1. c) ee) und $\S 3$ IV. 2 e).

1123 Siehe Dritter Abschnitt $\$ 3$ IV. 2 e).

1124 Vgl. oben Dritter Abschnitt $\S 1$ III. 1. b) ee), § 2 IV 1. c) ee) und $\S 3$ IV. 2 e).

1125 Vgl. oben Dritter Abschnitt § 2 IV 1. c) ee) und 2. a) cc) ggg); siehe zu Vorstehenden de lege lata auch Wachter GmbHR 2005, 717, 728.

1126 Vgl. oben Dritter Abschnitt § 1 III. 1. b) ee), § 2 IV 1. c) ee). Wachter GmbHR 2005, 717, 728; zu dem Zusammenhang zwischen Gestaltungsfreiheit und fehlender Möglichkeit zum formlosen Handel von GmbH-Anteilen vgl. auch Hadding ZIP 2003, 2133; Walz/Fembacher NZG 2003, 1134.

1127 Vgl. oben Dritter Abschnitt § 3 IV. 2 e). Behrens Die GmbH-Reform in der Diskussion, S. 195, 199.

1128 Vgl. oben Dritter Abschnitt $\S 1$ III. 1. b) ee), § 2 IV 1. c) ee) und $\S 3$ IV. 2 e).

${ }^{1129}$ Dritter Abschnitt $\$ 3$ IV. 2 e).
} 
2: 196 a und b NBG) und in Deutschland ( $(16 \text { GmbHG) })^{1130}$ ist der Übertragungsvorgang auch ohne Anzeige wirksam, allerdings ist die ordnungsgemäße Anzeige Voraussetzung dafür, dass die Rechte aus dem Geschäftsanteil ausgeübt werden können ${ }^{1131}$.

Gesetzliche Vorkaufsrechte zugunsten der anderen Gesellschafter sind in keinem der hier untersuchten Länder vorgesehen, werden aber üblicherweise in entsprechenden Satzungsklauseln vorgesehen ${ }^{1132}$.

\section{g) Stimmrechtslose Anteile}

In Deutschland und Frankreich gibt es bereits de lege lata stimmrechtlose Anteile. Hierbei gilt, dass wenigstens ein Anteil mit Stimmrecht existieren muss ${ }^{1133}$. In den Niederlanden ist, anders als noch im amtlichen Vorentwurf ${ }^{134}$ angedacht in dem Entwurf eines Gesetzes zur Vereinfachung und Flexibilisierung des B.V.-Rechts die Einführung stimmrechtsloser Anteile vorgesehen $^{1135}$.

\section{Aufsichtsrat und weitere Organe}

Die Gesellschaften mit beschränkter Haftung in Deutschland, den Niederlanden und Frankreich sind im Grundsatz zweigliederig aufgebaut, ein Aufsichtsrat und sonstige Organe sind nicht vorgesehen ${ }^{1136}$. Lediglich bei Erreichen bestimmter Arbeitnehmer-Schwellenwerte besteht in den Niederlanden und in Deutschland eine Verpflichtung zur Bildung entsprechender Kontrollorgane ${ }^{1137}$. In allen drei hier untersuchten Ländern ist es den Gesellschaftern hingegen

\footnotetext{
1130 Dritter Abschnitt $\S 1$ III. 1. b) ee) und $\S 2$ IV 1. c) ee).

1131 Siehe hierzu auch Wachter GmbHR 2005, 717, 728; vgl. außerdem hierzu Behrens Die GmbH-Reform in der Diskussion, S. 195, 199 f.

1132 Vgl. oben Dritter Abschnitt § 1 III. 1. b) ee), § 2 IV 1. c) ee) und § 3 IV. 2 e). Wachter GmbHR 2005, 717, 728. Vgl. insoweit auch Kallmeyer DB 2004, 636, der die Rechtslage der englischen Limited der deutschen GmbH bzw. GmbH \& Co KG gegenüberstellt.

1133 Gesetzesbegründung Vorentwurf, Erste Tranche, S. 25 f.

1134 Gesetzesbegründung Vorentwurf, Erste Tranche, S. 25 f.

1135 Gesetzesbegründung Entwurf, Allgemeiner Teil, S. 14; Besonderer Teil 107 ff. Siehe auch die Ausführungen oben Vgl. oben Dritter Abschnitt § 2 IV 2. a) cc) hhh). Vgl zur Zweckmäßigkeit stimmrechtloser Anteile nur C.A. Schwarz Aandelen sowie dort S. 6 Fn. 16 auch die Nachweise zur Handhabung in anderen europäischen Ländern.

1136 Vgl. oben Dritter Abschnitt $\S 1$ III. 1. c), § 2 IV 1. e) und $\S 3$ IV. 3.

1137 Vgl. oben Dritter Abschnitt § 1 III. 1. c), § 2 IV 1. e).
} 
unbenommen im Gesellschaftsvertrag die Einrichtung eines Aufsichtsrats oder Beirats vorzusehen $^{1138}$.

\section{Schlussfolgerungen}

\section{Geschäftsführer}

\section{a) Bestellung und Abberufung}

Die in den Niederlanden bestehende Möglichkeit, auch juristische Personen in die Geschäftsführung zu berufen, ist ein großes Asset der B.V. als Baustein in Konzernstrukturen. Anders als in Deutschland und in Frankreich ist in den Niederlanden eine „Ketten“bestellung der Geschäftsführer der Obergesellschaft auch in die Geschäftsführung aller abhängigen Unternehmen - wie es in Konzernen durchaus üblich ist - nicht erforderlich. Derzeit ist es in Deutschland und in Frankreich so, dass ein Wechsel der Geschäftsführung einer Obergesellschaft häufig durch mehrere Ebenen durchschlägt und daher gleich in unzähligen Gesellschaften zu beschließen und - mit den entsprechenden finanziellen Folgen - zur Eintragung in den jeweiligen Registern anzumelden ist. Eine solche Situation könnte durch Bestellung der Obergesellschaft als Geschäftsführer in sämtlichen Untergesellschaften vermieden werden. Hinzu kommt, dass bei einer solchen Mehrfachbestellung von Geschäftsführern in Konzernunternehmen regelmäßig eine Befreiung von den Beschränkungen des Selbstkontrahierens erforderlich wird, die nicht in allen Ländern als gesetzlicher Grundsatz existiert und daher zu Missverständnissen führen mag. Schließlich würde eine Zulassung von juristischen Personen auch nicht zu einer Verkürzung des Gläubigerschutzes führen, da am Ende der Geschäftsführerkette auch in den Niederlanden naturgemäß stets eine natürliche Person steht; im Gegenteil wird mit einer Gesellschaft in der Geschäftsführung regelmäßig in Haftungsfällen ein solventerer Anspruchsgegner zur Verfügung stehen, als er in der Person einer natürlichen Person existierte.

Die Regelung in Deutschland und Frankreich, wonach einschlägig vorbestrafte Personen nicht zu Geschäftsführern bestellt werden können, vermittelt eine Sicherheit „,des ersten Anscheins“. Auf diese sollte auch in den Niederlanden nicht verzichtet werden, ganz gleich ob

1138 Siehe oben Dritter Abschnitt $\S 1$ III. 1. c), § 2 IV 1. e) und § 3 IV. 3; zusammenfassend Wachter GmbHR 2005, 717, 730 . 
dies nach dem deutsch-französischen Konzept oder nach Maßgabe des englischen Company Directors Disqualification Acts geschieht ${ }^{1139}$.

\section{b) Publizität der Vertretungsverhältnisse}

Trotz europäischer Vorgaben, unterscheidet sich die Publizität der Handelsregister - zwar nicht bei den hier untersuchten Ländern - aber etwa im Verhältnis zu beispielsweise der Publizitätswirkung beziehungsweise des Publizitätsumfangs des englischen Companies House erheblich. Dieses (europäische) Versäumnis ist bereits an dieser Stelle und nicht erst unten bei der Behandlung der handelsrechtlichen Publizität zu erwähnen, da die fehlende Vergleichbarkeit der Register vor allen Dingen bei der verlässlichen Feststellung der Vertretungsverhältnisse in den nationalen Gesellschaften immer wieder Schwierigkeiten hervorruft. So können die Vertretungsverhältnisse in englischen Gesellschaften nicht anhand des Companies HouseAuszugs ermittelt werden, sondern müssen durch Beibringung eines Company's Secretary Certificate versichert werden. Die Schaffung eines einheitlichen europäischen Vertretungsnachweises mit öffentlichem Glauben würde hier die Rechtssicherheit sicherlich erhöhen und könnte den Rechtsverkehr mit ausländischen Unternehmen erleichtern ${ }^{1140}$.

\section{c) Verantwortung und Haftung}

Im Zuge der in den Niederlanden und in Deutschland geführten Reformdiskussion wurde auch eine Erstreckung der insolvenzrechtlichen Haftung der Geschäftsführer und gegebenenfalls auch der Gesellschafter auf Maßnahmen vor Eintritt einer (voraussehbaren) Insolvenz diskutiert, die eine Gefährdung der Gläubiger erst verursachen oder verschärfen, vergleichbar den ,wrongful trading“ Grundsätzen des englischen Rechts. Verwiesen wurde auch auf Anregungen des Winter-Berichts, die in dieselbe Richtung gingen ${ }^{1141}$. Der deutsche Ansatz, der letztlich mit einer Vorverlagerung der de lege lata auf $\S 64 \mathrm{GmbHG}$ beruhenden insolvenzrechtlichen Haftung arbeitet, kommt indes zu demselben Ergebnis wie der Ansatz im englischen Recht, allerdings liegt die Ersatzpflicht - anders als im englischen Recht - nicht im Ermessen des Gerichts (,the court ... may declare that the person is to be liable to make such

${ }^{1139} \mathrm{Zu}$ den Erwägungen in der Literatur und Praxis siehe oben Dritter Abschnitt $§ 1$ III. 2. a), § 2 IV 2. a) bb) und $\S 3$ IV. 1.

1140 Diese Forderung hat auch schon Wachter GmbHR 2005, 717, 729 geäußert. Vgl. auch ders. DB 2004, 2795 sowie die Erwägungen oben Dritter Abschnitt § 1 III. 2. a), § 2 IV 2. a) bb) und § 3 IV. 1.

${ }^{1141}$ Siehe hierzu oben siehe oben Dritter Abschnitt \$ 4 I. 3. a); vgl. zu der Thematik im niederländischen Recht auch van Duuren Ondernemingsrecht 2004, 4, 6 f.; aus dem deutschen Recht sei nur BDI/Hengeler Müller S. 29 f. erwähnt. 
contribution (if any) to the company's assets as the court thinks proper") und führt damit zu klareren Ergebnissen - für Geschäftsführer und für Gläubiger. Er ist daher dem englischen Ansatz vorzuziehen ${ }^{142}$. Desgleichen gilt für die Niederländische Lösung; im Grunde genommen enthält sie bereits de lege lata eine dem englischen wrongful trading entsprechende Regelung ${ }^{1143}$. Einzig die Erfassung der so genannten ,shadow directors“ mag als Vorteil der englischen Regelung gewertet werden. Sie sind den „faktischen Geschäftsführer“ in Deutschland ähnlich, gehen aber darüber hinaus und erfassen jede, auch juristische Person, welche die Tätigkeiten der Gesellschaft beeinflusst. Vor diesem Hintergrund ist eine Verschärfung der Geschäftsführerhaftung in Anlehnung an angloamerikanische Haftungsmaßstäbe nicht erforderlich.

\section{Gesellschafter und Geschäftsanteile}

\section{a) Rechtsstellung der Gesellschafter}

Da es in Kapitalgesellschaften möglich ist und auch regelmäßig in der Praxis passiert, dass der Geschäftsführer selbst nicht an der Gesellschaft beteiligt ist, also als „Fremder“ die Belange der Gesellschaft bestimmt; ist es in allen hier untersuchten Länder so, dass die Gesellschafter in der Gesellschafterversammlung oberstes Organ der Gesellschaft sind und damit über grundlegende Entscheidungen befinden. In kleinen Kapitalgesellschaften genügt dieses Beteiligungsrecht indes nicht um das Risiko und den Einsatz der Gesellschafter angemessen zu würdigen. Anders als in einer Aktiengesellschaft, die als „Kapitalsammelbecken“ auch, beziehungsweise überwiegend solche Aktionäre besitzt, die ihre Beteiligung ausschließlich als Finanzanlage verstehen - so wie es in Frankreich auch das Verständnis von der Beteiligung an einer S.à.r.l. zu sein scheint ${ }^{1144}$ - ist der typische Gesellschafter einer GmbH jemand, der auch etwas von der Geschäftstätigkeit der Gesellschaft versteht, oftmals selbst in dem Geschäftsbereich, sei es als geschäftsführender Gesellschafter oder aber als Mitbegründer oder Mitarbeiter des Unternehmens, tätig ist. Ihn - wenn nur die gesetzlich vorgeschriebene ordentliche Gesellschafterversammlung abgehalten wird - nur einmal im Geschäftsjahr zu beteiligen, ist vor diesem Hintergrund kaum nachzuvollziehen. Die Erweiterung des Weisungsrechts durch das Niederländische Reformgesetz ist insoweit uneingeschränkt zu begrüBen. Allerdings hätte damit auch eine Erweiterung der Befugnisse im Vorfeld einer Gesell-

\footnotetext{
1142 Siehe auch die Überlegungen oben Dritter Abschnitt $\S 1$ III. 1. a) cc) und 2. a) aa) aaa) und in der Literatur die Nachweise bei 2. b) aa) aaa).

1143 Siehe Dritter Abschnitt $\S 2$ IV 1. b) cc); Siehe dort auch die Überlegungen in der Literatur, das Haftungsregime nach angloamerikanischem Vorbild zu verschärfen Dritter Abschnitt § 2 IV 2. b) aa) bbb).

1144 Siehe hierzu oben Dritter Abschnitt $\$ 3$ IV 2. a), „Beteiligung als Kapitalanlage“.
} 
schafterversammlung einhergehen sollen. Auch nach neuem Niederländischen Recht ist es einem Gesellschafter nämlich nicht möglich, unmittelbar eine Gesellschafterversammlung einzuberufen; vielmehr ist nur einer Gesellschaftergesamtheit von 1\% des gezeichneten Kapitals gestattet, bei der Geschäftsführung beziehungsweise dem Aufsichtsrat um die Einberufung einer Gesellschafterversammlung zu ersuchen. Bleibt die Aufforderung des Gesellschafters unerwidert, ist die Einberufung der Gesellschafterversammlung gerichtlich erzwingbar ${ }^{1145}$.

\section{b) Registrierung der Gesellschafter}

Mit der geplanten aufgewerteten Gesellschafterliste (nur derjenige soll künftig als Gesellschafter gelten, der in die Gesellschafterliste eingetragen ist) als Rechtsscheinsträger soll künftig der gutgläubige Erwerb von Geschäftsanteilen möglich sein. Die Einreichung der Gesellschafterliste wird durch eine einklagbare Verpflichtung der Gesellschaft gegenüber Neugesellschaftern sowie die Einbindung des Notars bei Veränderungen in den Personen der Gesellschafter an denen dieser beteiligt ist, zu gewährleisten versucht. Diese Gewähr vermögen die in den Niederlanden existierenden Gesellschaftsbücher nicht zu bieten; ihr Inhalt dient lediglich der Information der Gesellschaft und ihrer Gesellschafter ${ }^{146}$.

Doch auch die nach den Vorstellungen des deutschen Gesetzgebers reformierte Gesellschafterliste ist als Rechtsscheinsträger ungeeignet, denn auch hier bestehen Möglichkeiten, diese Publizität zu umgehen, etwa indem ein Treuhänder die Anteile hält. Der Treuhänder kann dann seinen Sitz im Ausland haben, was es wiederum erschwert, sich über die Gesellschaft zu informieren ${ }^{1147}$. Auch können weiterhin die Geschäftsführer Änderungen der Gesellschafterliste anmelden, wenn kein Notar an den Veränderungen in der Personen der Gesellschafter beteiligt ist ${ }^{1148}$.

Nach dem Vorstehenden ist festzuhalten, dass der Ansatz des deutschen Gesetzgebers nicht genügt. Will er den gutgläubigen Anteilserwerb, der in der Sache sicherlich zu begrüßen ist, da er Rechtsicherheit und eine Kostenminimierung durch den verminderten Transaktionsaufwand (keine Due Diligence in Bezug auf die Kette ununterbrochener Anteilsübertragungen mehr erforderlich) bringt, so ist ihm zu empfehlen, die Wirksamkeit der Anteilsübertragung von der Eintragung ins Handelsregister abhängig zu machen ${ }^{1149}$.

1145 Dritter Abschnitt $\S 2$ IV 2. a) cc) aaa) und bbb).

1146 Siehe Dritter Abschnitt $\S 2$ IV 1. c) dd); Wachter GmbHR 2005, 717, 728.

1147 Dierksmeier/Scharbert BB 2006, 1517.

1148 Siehe oben Dritter Abschnitt § 1 III 2. a) bb) aaa) und b) bb) aaa).

1149 So auch BDI/Hengeler Müller S. 38 f.; Flesner BZG 2006, 641, 643; Breitenstein/Meyding BB 2007, 1457, 1460; weitere Nachweise oben Dritter Abschnitt $\$ 1$ III 2. a) bb) aaa) und b) bb) aaa). 


\section{c) Gesellschafterversammlung / Gesellschafterbeschlïsse}

Die Modalitäten sollten nach deutschem Vorbild weitestgehend in der Satzung gestaltet werden können. Die Niederlande haben hier eine zu begrüßende Neuerung geschaffen, indem sie Gesellschafterversammlung bei entsprechender Satzungsbestimmung auch im Ausland stattfinden lassen wollen und künftig, bei einstimmigem Einverständnis auch Beschlussfassungen außerhalb von Gesellschafterversammlungen gestatten wollen. Diese Reform trägt insbesondere der Rolle der Gesellschaft mit beschränkter Haftung als (internationaler) Konzernbaustein Rechnung. Vor dem Hintergrund dieses Umstandes sowie der Überlegung, dass die Gesellschafter Eigentümer der Gesellschaft sind, sollte das Niederländische Recht noch weiter für Gestaltungen durch die Gesellschaftergesamtheit geöffnet werden; bei Bestimmung entsprechender Beschlussmehrheiten käme auch der in diesem Zusammenhang oft bemühte Minderheitenschutz nicht zu kurz ${ }^{1150}$.

\section{d) Verantwortung und Haftung}

Eine Verantwortlichkeit der Gesellschafter wegen des Aus- beziehungsweise Wegfalls der Geschäftsführung kennt nur das deutsche Recht in der de lege ferenda angedachten Ausprägung. Zwar kennt auch Frankreich das Rechtsinstitut der faktischen Geschäftsführung, doch wird im französischen Recht bei Vorliegen einer solchen lediglich reagiert, eine solche faktische Geschäftführung allerdings nicht antizipiert, etwa indem sie den Gesellschaftern zur Pflicht gemacht wird. Das deutsche Modell der geschäftsführenden Gesellschafter hat den Charme, dass dem Missbrauch des Grundsatzes der Fremdorganschaft, der darin besteht, dass die Gesellschaft in der Insolvenz durch wiederholte Ab- und Neubestellungen im Ausland sitzender Geschäftsführer führungslos gestellt und damit taub und blind für Zustellungsversuche von Behörden und Gläubigern gemacht wird, ein Ende gesetzt wird. Auch ist der Gedanke der der Neuregelung zugrunde liegt, nämlich der Gesellschafter(-versammlung) als Herre(i)n der Gesellschaft, dogmatisch ein richtiger, weshalb es bisher nicht nachzuvollziehen war, weshalb es den Gesellschaftern ermöglicht wurde sich - nach Erbringung ihrer Einlage gänzlich aus der Verantwortung zu ziehen. Dem Vorschlag des deutschen Gesetzgebers ist daher zu folgen; eine Gesellschaft mit beschränkter Haftung hat künftig daher wenigstens so viele (Ersatz-)Geschäftsführer, wie sie Gesellschafter besitzt ${ }^{1151}$.

1150 Siehe oben Dritter Abschnitt $\S 1$ III. 1. b) cc) bbb) sowie $\S 2$ IV 1. c) ff) aaa) und 2. a) cc) bbb) und eee).

1151 Vgl. auch die Überlegungen oben Dritter Abschnitt $\S 1$ III. 2. a) bb) bbb); zu den Vorschlägen in der Literatur vgl. Dritter Abschnitt $\S 1$ III. 2. b) bb) bbb). 


\section{e) Geschäftsanteile}

Hier stellt sich dieselbe Frage wie oben unter $\S 2$ II b), nämlich inwieweit eine gesetzliche Vorgabe der Beurkundung des Übertragungsvorganges zu rechtfertigen ist. Neben den bereits angesprochenen Aspekten einer notariellen Beurkundung, die - wie oben bereits dargestellt allesamt anders als durch notarielle Beurkundung abgebildet werden können, werden vor allem zwei weitere Überlegungen bei der Geschäftsanteilsübertragung angeführt.

Die erste Überlegung betrifft nur das deutsche Beurkundungserfordernis und geht auf einen Gedanken des historischen Gesetzgebers zurück; er hatte mit der Beurkundung, den „spekulativen Handel mit Geschäftsanteilen“ verhindern wollen ${ }^{1152}$. Die andere Überlegung wird auch in den Niederlanden angeführt ${ }^{1153}$ und betrifft den Anlegerschutz; mit der notariellen Beurkundung sollen Anleger vor dem Erwerb riskanter oder verlustbringender Beteiligungen geschützt werden ${ }^{1154}$.

Die vom historischen Gesetzgeber verfolgte Absicht, den spekulativen Handel mit Geschäftsanteilen durch die notarielle Beurkundung verhindern zu wollen, dürfte gescheitert sein, denn nach Auffassung des Verfassers gibt es einen solchen (spekulativen) Handel bereits. Auch die Annahme, das Erfordernis der notariellen Beurkundung sei erforderlich, um den Schutz der Anleger zu gewährleisten, verfängt nicht, denn würde der Anlegerschutz tatsächlich die notarielle Beurkundung erfordern, so wäre nicht einzusehen, weshalb zwar die Übertragung von Geschäftsanteilen, nicht aber die Übertragung von Anteilen an Personengesellschaften der notariellen Form unterworfen wird. Auch ließe sich nicht erklären, warum im Ausland, wie etwa in Frankreich eine Übertragung auch ohne Einhaltung einer Form gestattet wird.

Mit dem Verzicht auf eine notarielle Beurkundung würde das Verfahren der Geschäftsanteilsübertragung erleichtert und verbilligt. Zudem ließen sich Rechtsunsicherheiten ausräumen, die im Zusammenhang mit (ebenfalls $\mathrm{zu}$ beurkundenden oder nicht $\mathrm{zu}$ beurkundenden) schuldrechtlichen Nebenabreden stehen. Der Nachteil einer formfreien Übertragung wäre sicherlich die Verminderung der Transparenz der Anteilsinhaberschaft, da ein „Nachweis“ der Inhaberschaft von Anteilen durch die Vorlage einer Kette von notariell beurkundeten Abtretungen nicht mehr möglich wäre. Andererseits ließe sich dieser Mangel an Transparenz behe-

1152 Vgl. insoweit oben Dritter Abschnitt $§ 1$ III. 1. b) ee).

1153 van Duuren Ondernemingsrecht 2004, 4, 7.

1154 Vgl. insoweit oben Dritter Abschnitt $\$ 2$ IV 1. c) ee). 
ben, wenn man mit der hier vertretenen Auffassung eine Eintragung der Anteilsinhaber in das Handelsregisterblatt verlangte ${ }^{1155}$.

\section{$\S 5$ Finanzverfassung}

\section{Rechtsvergleich}

\section{Kapitalaufbringung}

\section{a) Stammkapital}

Nur noch in Deutschland ist - auch nach der GmbH-Reform ein bestimmtes Mindestkapital, nämlich in Höhe von immerhin noch $10.000 €$ vorgesehen. Damit hat der deutsche Gesetzgeber das Kapitalerfordernis dem europäischen Durchschnitt angenähert. Das Mindestkapital in den Niederlanden beträgt derzeit noch $18.000 €$ (Art. 2:178 NBG), in der Schweiz 20.000 SFr. (ca. $13.000 €$ ) (Art. 773 OR), in Italien $10.000 €$ (Art. 2463 CC), in Spanien $3.012 €$ (Art. 4 LSRL) und in Polen 50.000 PLN (ca. $12.000 €)^{1156}$.

In Frankreich existiert seit dem 1. Januar 2004 keine Mindestkapitalisierungspflicht mehr (Art. 223-2 C.com.) und auch in den Niederlanden soll nach dem Willen des Gesetzgebers die Bereitstellung eines Mindeststammkapitals künftig verzichtbar sein. Anders als in Frankreich sind in den Niederlanden allerdings auch die aus der Abschaffung des Mindestkapitals resultierenden Folgefragen (z.B. für die Kapitalerhaltung, die Zulässigkeit von Kapitalmaßnahmen, die persönliche Haftung der Geschäftsführer und Gesellschafter und die Insolvenzantragspflichten) ausdrücklich geregelt worden; in Frankreich sind diese Folgefragen bis heute weitgehend ungeklärt ${ }^{1157}$.

${ }^{1155}$ Vgl. hierzu auch oben Dritter Abschnitt $\S 1$ III. 2. b) bb) ccc); So oder so ähnlich wie hier BDI/Hengeler Müller S. 38 f.; Flesner BZG 2006, 641, 643; Breitenstein/Meyding BB 2007, 1457, 1460. Allgemein zu der Abwägung Beurkundung ja oder nein: vgl. auch Hadding ZIP 2003, 2133; Walz/Fembacher NZG 2003, 1134 .

1156 Siehe oben Dritter Abschnitt $\S 1$ IV. 1. a) aa) und 2. a) aa) aaa) und b) aa) aaa) sowie $\S 2$ V 1. a) aa) und 2. a) aa) aaa) und bbb) sowie $\S 3$ V. 1. a) sowie die Nachweise bei Wachter GmbHR 2005, 717, $724 \mathrm{f}$.

1157 Vgl. dazu oben Dritter Abschnitt $\S 2$ V 2. a) aa) aaa) und bbb) sowie $\$ 3$ V. 1. a). Siehe auch Wachter GmbHR 2005, 717, 724; Oelkers GesRZ 2004, 360 und 2005, 27. Vgl. insoweit auch Kallmeyer DB 2004, 636, der die Rechtslage der englischen Limited der deutschen GmbH bzw. GmbH \& Co KG gegenüberstellt. 


\section{b) Bareinlagen}

Wie bereits oben (\$ 22. c)) ausgeführt ist in allen drei Ländern nur die teilweise Erfüllung der (Bar-)Einlagepflichten erforderlich ${ }^{1158}$. In Frankreich ist bereits vor der Errichtung der Gesellschaft durch Unterzeichnung des Gesellschaftsvertrages mindestens 1/5 des Nennbetrages der jeweils übernommenen Einlageverpflichtung zu erfüllen (Art. L 223-7 Abs. 4, Art. D 22 Abs. 1 C.com. $)^{1159}$. In Deutschland ist nach Errichtung aber vor Anmeldung der Gesellschaft wenigstens ein Viertel des Nennbetrags zu zahlen; insgesamt aber wenigstens soviel, dass der Gesamtbetrag des eingezahlten Geldeinlagen zuzüglich der Geschäftsanteile für die Sacheinlagen zu leisten sind, die Hälfte des Mindestkapitals von nunmehr $10.000 €$ erreicht ( 7 Abs. 2 S. $1 \mathrm{GmbHG})^{1160}$. In den Niederlanden ist nach Abschaffung der Mindestkapitalisierungspflicht nur vorgeschrieben, dass eine positive Leistung auf den jeweiligen Geschäftsanteil, also wenigstens ein Betrag von 0,01 € geleistet wird. Selbst diese, im Extremfall 0,01€ sind künftig nicht sofort zu leisten, sondern erst nach entsprechender Aufforderung durch die Gesellschaft fällig. Die Einforderung hat innerhalb von fünf Jahren zu erfolgen, da nach dieser Zeit der Anspruch der Gesellschaft auf Einzahlung verjährt ${ }^{1161}$.

Gesetzliche Regelungen über eine Mindesteinlage und zur Teilbarkeit der Einlage bestanden bislang nur in Deutschland, nicht aber in den Niederlanden oder Frankreich. Mit der Abschaffung der Mindesteinlage ist auch die Notwendigkeit der Regelung der Teilbarkeit der Einlage in Deutschland weggefallen ${ }^{1162}$

\section{c) Sacheinlagen}

Die Erbringung von Sacheinlagen ist im Grundsatz in allen Ländern zulässig; allerdings sind die Anforderungen an die Zulässigkeit einer Sacheinlage und deren Bewertung im Einzelnen sehr unterschiedlich geregelt ${ }^{1163}$.

In allen drei hier untersuchten Ländern ist der Gegenstand der Sacheinlage grundsätzlich im Gesellschaftsvertrag zu bezeichnen ${ }^{1164}$. In Deutschland und den Niederlanden haben die Ge-

1158 Siehe oben Dritter Abschnitt $\S 1$ IV. 1. a) bb) sowie $\S 2$ V 1. a) bb) sowie $\S 3$ V. 1. b).

1159 Dritter Abschnitt $\$ 3$ V. 1. b).

1160 Dritter Abschnitt $\S 1$ IV. 1. a) bb) und 2. a) aa) und cc); siehe auch die Nachweise zur Literatur in b) aa) aaa).

1161 Dritter Abschnitt $\$ 2$ V 2. a) aa) ccc) und b).

1162 Dritter Abschnitt $\S 1$ IV. 1. a) bb) und 2. a) aa) und cc); siehe auch die Nachweise zur Literatur in b) aa) aaa); zusammenfassend Wachter GmbHR 2005, 717, 725.

1163 Siehe oben Dritter Abschnitt $\S 1$ IV. 1. a) cc) sowie $\S 2$ V 1. a) cc) sowie $\S 3$ V. 1. c).

1164 Siehe oben Dritter Abschnitt $\S 1$ IV. 1. a) cc) sowie $\S 2$ V 1. a) cc) sowie $\S 3$ V. 1. c). 
sellschafter zusätzlich die für die Angemessenheit der Leistungen für Sacheinlagen wesentlichen Umstände in einem Sachgründungsbericht darzustellen ${ }^{1165}$.

Der Wert der Sacheinlage muss in allen Ländern in geeigneter Form nachgewiesen werden ${ }^{1166}$. In Frankreich hat eine Bewertung durch einen speziellen Prüfer („Commissaire aux apports“) zu erfolgen ${ }^{167}$. Bis zur Reform war in den Niederlanden die Bestätigung eines Wirtschaftsprüfers zur Werthaltigkeit der Einlage gesetzlich vorgesehen ${ }^{168}$.

Künftig greift schließlich in allen drei hier untersuchten Ländern eine Differenzhaftung, wenn der Wert der Sacheinlage den Betrag der geschuldeten (Stamm-)Einlage nicht erreicht ${ }^{1169}$.

\section{d) Nachschusspflicht}

Die Aufnahme weiterer, neben der Einlageverpflichtung stehender statutarischer (Nachschuss-)Pflichten ist in den Niederlanden mit zwei Drittel Mehrheit möglich. Allerdings bindet eine solche mehrheitliche Entscheidung lediglich diejenigen Gesellschafter, die sich mit ihr einverstanden erklären; widerspricht ein Gesellschafter der Nachschusspflicht, so ist dieser nicht an die Verpflichtung gebunden ${ }^{1170}$. In Deutschland ist die Belastung der Gesellschafter einer $\mathrm{GmbH}$ mit weiteren Leistungspflichten nur mit Zustimmung sämtlicher beteiligter Gesellschafter möglich ( $\$ 53$ Abs. $3 \mathrm{GmbHG})^{1171}$. In Frankreich ist das Institut der Nachschüsse im Sinne von nicht dem Kapital zuzurechnenden Eigenmitteln gänzlich unbekannt. Dort besteht allerdings die Möglichkeit, die Gesellschaft mit variablem Kapital auszustatten, so dass auch hier weitere Einlagen ohne Änderung der Satzung eingefordert werden können ${ }^{1172}$.

\section{e) Nachgründung}

Der Fall der Nachgründung ist in Deutschland lediglich für die Aktiengesellschaft gesetzlich geregelt, in Frankreich ist die Rechtsfigur gänzlich unbekannt. Die Fälle eines Zurückfließens

1165 Dritter Abschnitt $\S 1$ IV. 1. a) cc) sowie $\S 2$ V 1. a) cc).

1166 Wachter GmbHR 2005, 717, 725.

1167 Dritter Abschnitt $\$ 3$ V. 1. c) sowie Wachter GmbHR 2005, 717, 725.

1168 Dritter Abschnitt $\$ 2$ V 1. a) cc) und 2. a) aa) ddd); vgl. auch b) im Hinblick auf die Reformüberlegungen in Praxis und Literatur sowie zusammenfassend zu den Rechten in allen drei hier untersuchten Länder Wachter GmbHR 2005, 717, 725.

1169 Siehe oben Dritter Abschnitt $§ 1$ IV. 1. a) cc) sowie $\S 2$ V 1. a) cc) sowie $\S 3$ V. 1. c).

1170 Vgl. hierzu oben Dritter Abschnitt $\$ 2$ V 1. a) dd).

1171 Siehe auch oben Dritter Abschnitt $\S 1$ IV. 1. a).

1172 Siehe oben Dritter Abschnitt $\$ 3$ V. 1. d). 
der Einlage aufgrund eines nach vorheriger Absprache im zeitlichen Zusammenhang mit der Gründung zwischen Gesellschaft und Gesellschafter geschlossenen Rechtsgeschäfts werden in Deutschland über die Grundsätze der verdeckten Sacheinlage gelöst, die nunmehr auch im Gesetz ihre ausdrückliche Verankerung finden soll ${ }^{1173}$. In den Niederlanden liegt eine Nachgründung vor, wenn die Gesellschaft innerhalb von zwei Jahren nach der Gründung der Gesellschaft von einem Gesellschafter Vermögensgegenstände erwirbt ${ }^{1174}$. Der Erwerb bedarf in einem solchen Fall der Genehmigung der Gesellschafterversammlung ${ }^{1175}$. Wie bei der Erbringung von Sacheinlagen ist auch bei der Nachgründung in den Niederlanden künftig eine Bescheinigung eines Wirtschaftsprüfers über den Wert des Vermögensgegenstandes nicht mehr erforderlich ${ }^{1176}$.

\section{Kapitalerhaltung / Gläubigerschutz}

\section{a) Kapitalschutz}

In Deutschland, dem einzigen Land, in dem noch eine Mindestkapitalisierungspflicht existiert, gilt auch nach der Reform der Grundsatz, dass das Vermögen der Gesellschaft, das (rechnerisch) zur Erhaltung des Stammkapitals erforderlich ist, nicht an die Gesellschafter zurückgezahlt werden darf. Neu ist lediglich die Rückkehr zu einer bilanziellen Betrachtungsweise bei der Feststellung des in der Gesellschaft befindlichen Vermögens. Auf eine tatsächliche Bereitstellung des Vermögens kommt es nicht mehr an; geschützt wird allein die wertmäßige Abbildung des Stammkapitals ${ }^{1177}$.

Das französische Gesellschaftsrecht, das seit 2004 ohne ein Mindeststammkapital auskommt, schützt das Gesellschaftsvermögen insgesamt, indem es den Gesellschaftern verboten ist, gebundenes Vermögen auszuzahlen; eine Ausschüttung darf in Frankreich nur aus den bilanzmäßig ausgewiesenen Gewinnen beziehungsweise Gewinnvorträgen abzüglich etwaiger Verlustvorträge oder freier Reserven erfolgen ${ }^{1178}$.

In den Niederlanden galt bis zur B.V.-Reform eine ähnliche Regelung wie in Deutschland. Ausschüttungen waren nur insoweit gestattet, als das Eigenkapital hierdurch nicht geschmä-

1173 Siehe oben Dritter Abschnitt $\S 1$ IV. 1. a) ee) sowie $\S 3$ V. 1.

1174 Vgl. die Ausführungen oben Dritter Abschnitt $\S$ sowie $\S 2$ V 1. a) dd).

1175 Dritter Abschnitt $§ 2$ V 1. a) dd); Wachter GmbHR 2005, 717, 725 f.

1176 Vgl. dazu im Einzelnen auch schon oben Dritter Abschnitt $\$ 2$ V 2. a) aa) ggg).

1177 Siehe oben Dritter Abschnitt $\S 1$ IV. 1. b) und 2. a) bb) sowie b) bb).

1178 Dritter Abschnitt $\$ 3$ V. 2. 
lert wird. Nach der Abschaffung der Mindestkapitalisierungspflicht knüpft das Kapitalerhaltungsgebot zwangsläufig nicht mehr an die Existenz eines Eigenkapitals der Gesellschaft an, sondern stellt darauf ab, dass die Gesellschaft auch nach der Ausschüttung in der Lage ist, in absehbarer Zeit ihre Verbindlichkeiten zu erfüllen. Ausschüttungen die innerhalb eines Jahres vor der Insolvenz der Gesellschaft getätigt worden sind, gelten (widerlegbar) als in Kenntnis der (künftigen) Zahlungsunfähigkeit der Gesellschaft entrichtet und sind durch die Gesellschafter beziehungsweise die anderen Begünstigten zurückzuerstatten ${ }^{1179}$.

\section{b) Eigenkapitalersetzende Darlehen}

Mit dem Regierungsentwurf zum MoMiG wird die Rechtsfigur des eigenkapitalersetzenden Gesellschaftsdarlehens aufgehoben; die Rechtsprechungs- und Gesetzesregeln über die kapitalersetzenden Gesellschafterdarlehen ( $\S \S 32 \mathrm{a}, 32 \mathrm{~b} \mathrm{GmbHG})$ werden ins Insolvenzrecht verlagert; die Rechtsprechungsregeln zu $\S 30 \mathrm{GmbHG}$ aufgehoben. Die bisherige Unterscheidung zwischen „kapitalersetzenden“ und „,normalen“ Gesellschafterdarlehen wird es nach dem Willen des Gesetzgebers nicht mehr geben ${ }^{1180}$. In den Niederlanden und in Frankreich waren Eigenkapitalersetzende Darlehen schon bisher als solches nicht bekannt. Gleichwohl kann es auch dort dazu kommen, dass Gesellschafterdarlehen im Verhältnis zu anderen Gläubigern der Gesellschaft als nachrangig behandelt werden ${ }^{1181}$.

\section{Haftungsbeschränkte Unternehmergesellschaft}

Der Regierungsentwurf führt eine neue Einstiegsvariante der $\mathrm{GmbH}$, die haftungsbeschränkte Unternehmergesellschaft ( $§ 5 \mathrm{a} \mathrm{GmbHG}$ ) ein, die den Bedürfnissen von Existenzgründern, die am Anfang nur sehr wenig Stammkapital haben und benötigen (z.B. im Dienstleistungsbereich) Rechnung tragen soll. Um den Rechtsverkehr zu schützen, muss eine $\mathrm{GmbH}$, die ohne Einhaltung des Mindeststammkapitals gegründet wird, in ihrer Firma aber den Rechtsformzusatz,,Unternehmergesellschaft (haftungsbeschränkt)“ oder die Abkürzung „UG (haftungsbeschränkt)“ enthalten. Zudem hat die Gesellschaft für Unternehmensgründer in ihrer Bilanz eine gesetzliche Rücklage zu bilden, in die jeweils ein Viertel des Jahresüberschusses einzu-

1179 Vgl. die Ausführungen oben Dritter Abschnitt $§ 2$ V 1. b) und 2. a) bb).

1180 Siehe oben Dritter Abschnitt $\S 1$ IV. 1. b) und 2. a) bb) sowie b) bb) bbb).

1181 Dritter Abschnitt $\S 2$ V 1. b) und 2. a) bb) und $\S 3$ V. 2. Zum Ganzen vermittelt Wachter GmbHR 2005, 717, 725 einen knappen Überblick. 
stellen ist. Wird das Mindeststammkapital durch eine Umwandlung der Rücklagen in haftendes Stammkapital von mind. $10.000 €$ erreicht, erlischt diese Verpflichtung ${ }^{1182}$.

\section{Eigene Anteile}

Der Erwerb eigener Anteile ist in Deutschland ( $\$ 33 \mathrm{GmbHG})$ und den Niederlanden (Art. 2: 207 NBG) unter eingeschränkten Voraussetzungen zulässig. Verkürzt dargestellt, setzt die Zulässigkeit des Erwerbs sowohl in Deutschland als auch in den Niederlanden voraus, dass alle Einlagen der Gesellschafter vollständig erbracht worden sind und das Kapital der Gesellschaft durch den Anteilserwerb nicht berührt wird ${ }^{1183}$. In Frankreich (Art. L. 223-24 C.com.) dagegen ist der Erwerb eigener Anteile grundsätzlich nicht gestattet und nur ausnahmsweise, nämlich für den Fall des Rückerwerbs eigener Geschäftsanteile durch die Gesellschaft zum Zwecke der Durchführung einer Kapitalherabsetzung erlaubt ${ }^{1184}$.

\section{Schlussfolgerungen}

\section{Kapitalaufbringung}

\section{a) Stammkapital}

Der Grundsatz der Mindestkapitalisierung galt bislang in allen drei der hier untersuchten Rechtsordnungen und war - soweit ersichtlich - bisher auch in den übrigen europäischen Rechtsordnungen überwiegend anerkannt. Auch auf Ebene des europäischen Gesetzgebers hielt man beim Erlass von Richtlinien und Verordnungen in Laufe der Jahre ersichtlich am Konzept der Kapitalaufbringung fest. In der Kapitalrichtlinie ${ }^{1185}$ aus dem Jahr 1976 war für die Errichtung von Aktiengesellschaften die Aufbringung eines Mindestkapitals von $25.000 €$ vorgeschrieben. Eine Europäische Aktiengesellschaft erfordert seit $2001^{1186}$ die Bereitstellung

1182 Siehe oben Dritter Abschnitt $§ 1$ IV. 2. a) cc).

1183 Vgl. zu den Einzelheiten Dritter Abschnitt $\$ 1$ IV. 1. c) und $\S 2$ V. 1. c) sowie 2. a) cc). Siehe auch Wachter GmbHR 2005, 717, 726.

1184 Siehe Dritter Abschnitt $\$ 3$ V. 3.

1185 Zweite Richtlinie v. 13.12.1976 (77/191/EWG); abgedruckt u.a. bei Habersack, Europäisches Gesellschaftsrecht, 1999; Lutter, Europäisches Unternehmensrecht, 4. Auflage, 1996; Schwarz. Siehe auch oben Dritter Abschnitt § 4 I 2. b).

1186 Verordnung EG Nr. 2157/2001 des Rates über das Statut der Europäischen Gesellschaft v. 8.10.2001, ABL. EG L 294 v. 10.11.2001 S. 1ff. Siehe auch oben Dritter Abschnitt § 4 III 1. 
eines Mindestkapitals von $120.000 €$. Für die Errichtung einer Genossenschaft ist schließlich nach Maßgabe der Verordnung über das Statut der Europäischen Genossenschaft vom Juli $2003^{1187}$ ein Mindestgrundkapital von $30.000 €$ erforderlich. Zuletzt wurde am 6. September 2006 eine Richtlinie 2006/68/EG des Europäischen Parlaments und des Rates vom 6. September $2006^{1188}$ zur Änderung der zweiten Gesellschaftsrechtsrichtlinie von 1976 verabschiedet, mit der die bisherigen Anforderungen an die Kapitalaufbringung und -erhaltung in einzelnen Teilbereichen maßvoll gelockert werden ${ }^{1189}$. Am Konzept des Mindestkapitals als solchem hält die Änderungsrichtlinie aber unverändert fest ${ }^{1190}$. Nach Auffassung des Verfassers sollte auch in Zukunft an der Kapitalisierungspflicht festgehalten werden und zwar aus den folgenden Erwägungen:

Von den Gegnern einer Mindestkapitalisierungspflicht wird in erster Linie eingewandt, dass das Stammkapital in der jetzigen Form zu niedrig sei um seiner Funktion als Haftkapital gerecht werden zu können und sich somit seine Wirkung - ob gewollt (Warnfunktion vor leichtfertigen Gründungen) oder ungewollt - allein darauf beschränke, die Gründung von Kapitalgesellschaften zu verkomplizieren oder gar - etwa bei Kleinunternehmen - zu verhindern ${ }^{1191}$.

Das Verständnis des Mindestkapitals als Haftungsmasse, die den Gläubigern der Kapitalgesellschaft als Ausgleich für die grundsätzliche Beschränkung der persönlichen Haftung der Gesellschafter auf die Aufbringung des Stammkapitals dient ${ }^{192}$, greift nach der hier vertretenen Auffassung allerdings zu kurz. Denn, zum einen steht den Gläubigern nicht nur das Vermögen der Gesellschaft in Höhe des Stammkapitals zur Verfügung, sondern das gesamte Gesellschaftsvermögen einschließlich des Stammkapitals ${ }^{1193}$; zum anderen soll das aufzubringende Vermögen in erster Linie eben nicht den Gläubigern sondern der Gesellschaft zu gute kommen, ihr zunächst als Startkapital für die Aufnahme des Geschäftsbetriebs dienen und bei Fortführung der Gesellschaft die Gewinnung geschäftlichen Vertrauens sichern ${ }^{1194}$. Die Haftungsfunktion des Stammkapitals ist sicherlich auch eine Funktion des Stammkapitals, aller-

1187 Verordnung EG Nr. 1435/2003 des Rates über das Statut der Europäischen Genossenschaft v. 22.7.2003, ABL. EG L 207 v. 18.8.2003 S. $1 \mathrm{ff}$.

1188 RICHTLINIE 2006/68/EG DES EUROPÄISCHEN PARLAMENTS UND DES RATES vom 6. September 2006 zur Änderung der Richtlinie 77/91/EWG des Rates in Bezug auf die Gründung von Aktiengesellschaften und die Erhaltung und Änderung ihres Kapitals, Amtsblatt der Europäischen Union vom 25. September 2006 L 264/32.

1189 Siehe dazu Maul/Eggenhofer/Lanfermann BB-Special 6/2004, 5 und die Stellungnahme des Handelsrechtsausschusses des DAV NZG 2005, 426 und 548.

1190 Wachter GmbHR 2005, 717, 724.

1191 Vgl. hierzu schon oben Dritter Abschnitt $\$ 1$ IV. 2. b) aa) aaa) (ii).

1192 So aber noch der RefE eines MindestKapG, S. 6; vgl. hierzu auch Rowedder/Schmidt-Leithoff $§ 5$ Rn. 2 und Barta GmbHR 2005, 657, 659 sowie Bauer Gläubigerschutz durch eine formelle Nennkapitalziffer - Kapitalgesellschaftsrechtliche Notwendigkeit oder überholtes Konzept? S. 25 ff. m. w. N.

1193 Barta GmbHR 2005, 657, 659.

1194 Barta GmbHR 2005, 657, 659. 
dings keine primär beabsichtigte sondern vielmehr ein Reflex des Auftretens der Gesellschaft im Rechts- und Geschäftsverkehr ${ }^{1195}$.

So ist auch zu erklären, dass das Stammkapital steten Veränderungen in der Substanz unterliegt, je nach dem ob der Gesellschaftszweck ein höheres oder ein niedrigeres „Sondervermögen“ verlangt. Das Stammkapital ist eben nicht gedacht ,als ein unveränderliches Polster, das als Reserve für die Sicherung der Gläubiger in der Gesellschaft gehalten wird“"1196 sondern variiert um das Vertrauen des jeweiligen Vertragspartners aber auch der Kreditgeber und Investoren zu sichern.

Dies ist auch der Grund, warum das Mindestkapital zahlreicher operativ tätiger Kapitalgesellschaften deutlich über dem gesetzlich geforderten Mindestbetrag liegt ${ }^{1197}$. Dabei ist die Bereitschaft der Gesellschafter zur Verfügung Stellung eines signifikanten Stammkapitals naturgemäß in der Startphase gering, da die Verluste der Gesellschaft mangels Umsatz sofort das Eigenkapital der Gesellschaft berühren und die Gesellschafter diesem Risiko möglichst wenig ihres Vermögens durch Eigenkapitaleinlage in die Gesellschaft und Haftungsbeschränkung ihres Privatvermögens aussetzen wollen ${ }^{1198}$. Später liegt die Entscheidung über die Höhe des Stammkapitals nur noch in beschränktem Maße bei den Gesellschaftern; dann wird schon der Geschäftsverkehr eine dem konkreten Risiko des verfolgten Gesellschafszwecks entsprechende Eigenkapitalausstattung verlangen ${ }^{1199}$.

Nun mag man einwenden, dass gerade die vorstehenden Ausführungen zum eigentlichen Zweck eines (Mindest-)Stammkapitals eine gesetzliche Vorschrift eines Mindestbetrages für das Stammkapital bei Gründung der Gesellschaft obsolet erscheinen lasse und - wie zuvor beschrieben - sprechen tatsächlich gute Gründe dafür, dass der Markt die notwendige Eigenkapitalausstattung von Gesellschaften selbständig reguliert. Allerdings lässt dieser Einwand außer Acht, dass die Annahme (einer Selbstregulierung durch entsprechende Einforderung des Marktes) nur für vertragliche Gläubiger gilt; nur diese können Einfluss auf die Kapitalisierung der Gesellschaft nehmen, gesetzliche Gläubiger haben diese Möglichkeit nicht ${ }^{1200}$. Ein weiteres Argument für die Beibehaltung einer Mindestkapitalisierungspflicht ist der Beitrag, den sie leistet, die Gesellschaftsformen der GmbH und AG für kapitalintensivere Unterneh-

1195 Barta GmbHR 2005, 657, 659; vgl. auch Flume § 8 IV 2a, S. 286; Rowedder/Schmidt-Leithoff § 5 Rn. 2; a.A. Bitter ZHR 186 (2004), 302, 303 ff. m. w. N.

1196 Barta GmbHR 2005, 657, 659; vgl. auch Bauer S. 25 ff.

1197 Siehe die Beispiele von Aktiengesellschaften bei Eidenmüller/Engert AG 2005, 97, 98 Fn. 12.

1198 Barta GmbHR 2005, 657, 660.

1199 So bereits Barta GmbHR 2005, 657, 660 unter Hinweis auf die historische Entstehung von Kapitalgesellschaften als „Kapitalsammelbecken“ zur Verwirklichung großer globaler Unternehmungen.

1200 Eidenmüller/Engert GmbHR 2005, 433, 435 f. 
mungen zu reservieren (Stichwort der Seriositätsschwelle ${ }^{1201}$ ). Schließlich dürfte die Bestimmung eines Mindeststammkapitals das Risiko eines Missbrauchs der Rechtsform durch Verwendung der Kapitalgesellschaft mit ihrer Haftungsbeschränkung ohne oder mit nur geringem als Stammkapital gesichertem Eigenkapital minimieren. Auch widerspricht eine Abschaffung des Mindeststammkapitals der gesetzgeberischen Tendenz, insbesondere im Steuer- und Bankrecht, das Eigenkapital zu stärken beziehungsweise ein starkes Eigenkapital einzufordern oder Vorteile an das Vorhandensein eines starken Eigenkapitals zu knüpfen (Stichworte sind hier BASEL II usw.). Schließlich zeigen die Erfahrungen in Frankreich mit der Abschaffung des Mindeststammkapitals, dass die erhofften Vorteile sich nicht realisieren. Zwar hat sich dort die Gründung einer Gesellschaft vereinfacht, doch wurde mit der Abschaffung des Mindestkapitals dem Ansehen der S.à.r.l. sehr geschadet und ein Boom von Unternehmensneugründungen blieb aus ${ }^{1202}$.

Nicht hinreichend berücksichtigt wurden in der Diskussion um die Reduzierung oder gar Abschaffung des Mindestkapitals schließlich die Folgefragen: So wird etwa die Krisenwarnfunktion nach $\S 49$ Abs. 3 GmbHG beziehungsweise Art. L 223-42 Abs. 1 C.com ${ }^{1203}$ durch eine Herabsetzung oder gar Abschaffung ersichtlich eingeschränkt, der Vorsorgefunktion der Kapitalerhaltung kann bei nahezu nicht existierendem Eigenkapital ebenfalls wohl kaum angemessen Rechnung getragen werden ${ }^{1204}$. Weiterhin verringert sich bei einer Reduzierung oder Abschaffung des Stammkapitals der Zeitraum zwischen dem Eingreifen einer Ausschüttungssperre, die nach allen hier vertretenen Modellen (sei es über Solvenzprüfungen oder nach Maßgabe des $§ 30 \mathrm{GmbHG}$ ) das Eigenkapital der Gesellschaft in Bezug nimmt und dem Vorliegen einer Überschuldung beziehungsweise Insolvenz ${ }^{1205}$.

$\mathrm{Zu}$ guter letzt ist zu fragen, ob die Kleinunternehmen, denen letztlich man den Zugang zu der haftungsbeschränkten GmbH durch Herabsetzung oder Abschaffung des Stammkapitals ermöglichen will, einer solchen Haftungsbeschränkung überhaupt bedürfen. Die Haftungsbeschränkung ist vor allem für solche Unternehmen interessant, in denen der Geschäftsbetrieb erhebliche Risiken mit sich bringt. Vergleichsweise risikoarme Aktivitäten können demgegenüber durchaus auch in einer Rechtform ohne Haftungsbeschränkung ausgeübt werden. Unternehmen aus dem Dienstleistungsbereich (die in der Gesetzesbegründung des Regierungsentwurfs zum MoMiG ausdrücklich als diejenigen Unternehmen in Bezug genommen

1201 Zur Seriositätsschwelle vgl. Haas DStR 2006, 993, Roth, in: FS Doralt, 2004, S. 479, S. 479, 482; Blaurock, in: FS Raiser, 2005, S. 3, 13 f.; s. auch Eidenmüller GmbHR 2005, 433, 436; Krüger, Mindestkapital und Gläubigerschutz, 2005, S. 223 ff.

1202 Bormann, GmbHR 2006, 1021, 1022; Breitenstein/Meyding BB 2006, 1457, 1458; Wilhelmi GmbHR 2006, 13, 21; Vossius/Wachter BB 2005, 2539.

1203 Vgl. hierzu oben Dritter Abschnitt $§ 1$ IV. 2. a) aa) aaa) (i) und Dritter Abschnitt $\$ 2$ IV 1. b).

1204 Bormann, GmbHR 2006, 1021, 1022.

1205 Bormann, GmbHR 2006, 1021, 1023. 
sind, denen der Zugang zur GmbH durch Herabsenkung des Stammkapitals ermöglicht werden soll), sind solche risikoarmen Unternehmen. Bei diesen Gesellschaften besteht der Wert des Unternehmens meist aus dem Know-How der Gründer oder deren Mitarbeitern, Anlaufverluste durch notwendige Sachinvestitionen können regelmäßig vermieden werden oder finden in einem überschaubaren Rahmen statt. Auch sind aufgrund des regelmäßig geringen Anlagevermögens größere Verlustrisiken regelmäßig ausgeschlossen. Zwar lässt sich bei kaum einer Tätigkeit die Gefahr einer Inanspruchnahme ganz ausschließen; im Zusammenhang mit der Erbringung von Dienstleistungen stehende Risiken sind jedoch häufig versicherbar, so dass allein ihretwegen die Haftungsbeschränkung nicht gebraucht wird ${ }^{1206}$

\section{b) Kapitalaufbringungsrecht}

Ganz anders ist nach Einschätzung des Verfassers die Reform der Kapitalaufbringung zu beurteilen. Das Kapitalaufbringungsrecht hatte insbesondere in Deutschland eine im Vergleich zu den in anderen europäischen Ländern, wie auch in Frankreich und den Niederlanden existierenden Kapitalaufbringungsregelungen, eine nicht mehr praxisgerechte Komplexität erreicht ${ }^{1207}$. Die Folge war dass in zahlreichen Gerichtsentscheidungen immer neue Einzelfragen der Kapitalaufbringung aufgeworfen wurden ${ }^{1208}$. In Frankreich und den Niederlanden scheint das Konzept der Kapitalaufbringung offensichtlich weniger streitanfällig. Unterstellt dies hätte nicht allein mit der dortigen zurückhaltenderen Streitkultur zu tun oder etwa damit, dass die dortigen Gesellschafter weniger zu einer Umgehung der gesetzlichen Regelungen neigten, liegt es nahe, dass einfach die rechtlichen Rahmenbedingungen in Frankreich und den Niederlanden einfacher und transparenter sind beziehungsweise es bislang waren ${ }^{1209}$. Mit der $\mathrm{Ab}$ schaffung beziehungsweise Normierung des Rechtsinstituts der „verdeckten Sacheinlage“ hat der deutsche Gesetzgeber einen wichtigen Schritt hin zu einer Erhöhung der Rechtssicherheit im Bereich der Kapitalaufbringung geleistet. Durch die Einführung einer bereits dem deutschen Aktienrecht bekannten Differenzhaftung bei Einbringung von Sacheinlagen hat der deutsche Gesetzgeber zudem sein Gesellschaftsrecht mit dem der europäischen Nachbarn harmonisiert. Schließlich ermöglicht die Wiederkehr der bilanziellen Betrachtungsweise in Zukunft auch in Deutschland die Aufbringung von Kapital durch Einbuchung entsprechender valider Forderungen statt sofortiger Leistung in Geld. $\mathrm{Zu}$ erwägen wäre in Ergänzung der stattgefundenen Reformen, die Verjährungsfristen für Einlageforderungen allgemein zu verkürzen. In Deutschland verjährt der Anspruch der Gesellschaft auf Leistung der Einlagen erst

1206 Eidenmüller/Engert GmbHR 2005, 433, 434 ff.

1207 Anderer Auffassung ist allerdings Goette ZGR 2006, 261, 274.

1208 Wachter GmbHR 2005, 717, 724.

1209 Wachter GmbHR 2005, 717, 724. 
in zehn Jahren von seiner Entstehung an ${ }^{1210}$; in Frankreich und den Niederlanden bereits nach 5 Jahren $^{1211}$.

\section{c) Nachschusspflicht}

Der Nachteil der deutschen Regelung ist sicherlich, dass sie weniger flexibel ist, als die in der französischen Rechtsordnung verankerte Möglichkeit, die Gesellschaft mit variablem Kapital auszustatten und insbesondere die niederländische Lösung über eine Beschlussmehrheit. Nach dem deutschen Prinzip sind einzelne Gesellschafter in der Lage, die Beschlussfassung in dieser Angelegenheit zu blockieren. Diese Blockademöglichkeit einzelner Gesellschafter vermeidet die Lösung des niederländischen Gesetzgebers, wonach ein einzelner Gesellschafter die Satzungsänderung zwar zu verhindern nicht imstande ist, allerdings, sollte er mit der Änderung nicht einverstanden sein und gegen diese stimmen, die Änderung in seiner Person nicht gilt. Schwierigkeiten bereitet die letztgenannte Lösung allein, da die Unterscheidung von einbezogenen und nicht einbezogenen Gesellschaftern nur schwierig zu bewerkstelligen ist $^{1212}$. Nichtsdestotrotz überwiegen die Vorteile einer flexiblen Nachschussregelung; ihr ist auch in Deutschland zu folgen. Die Niederländische Lösung ist aufgrund ihrer Flexibilität auch einer weiteren denkbaren Lösung vorzuziehen, die die Kommission Gesellschaftsrecht am Beispiel der Europäischen Genossenschaft vorgeschlagen hat. In der Europäischen Genossenschaft steht Minderheitsgesellschafter in besonderen Fällen ein Austrittsrecht zu, wenn sie bestimmten Satzungsänderungen widersprechen. So besteht ein solches Austrittsrecht etwa unter anderem bei Satzungsänderungen, mit denen neue Verpflichtungen eingeführt, oder vorhandene Verpflichtungen der Gesellschafter wesentlich erweitert werden (Punkt 2 des Ar-

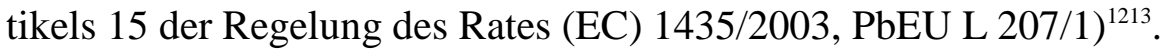

\section{Kapitalerhaltung / Gläubigerschutz}

Für die Aufgabe des Rückzahlungsverbots für das Stammkapital und damit korrespondierender Erstattungsansprüche von Geschäftsführern und Gesellschaftern zugunsten einer Umstellung des Kapitalschutzes auf einen Solvenztest, spricht sicherlich die höhere Flexibilität des letztgenannten Systems. Den Preis hierfür zahlen allerdings die Gläubiger, denn deren Schutz

\footnotetext{
$1210 \S 19$ Abs. 6 GmbHG, eingefügt durch Art. 13 Abs. 2 des Gsetzes zur Anpasung von Verjährungsvorschriften an das Gesetz zur Modernisierung des Schuldrechts vom 9.12.2004 , BGBl. I 2004, 3214. Siehe dazu Sontheimer DStR 2005, 834; Wagner, ZIP 2005, 558.

1211 Wachter GmbHR 2005, 717, 724; van Duuren Ondernemingsrecht 2004, 4, 6.

1212 Begründung des Vorentwurfs 2. Tranche, S. 12.

1213 Begründung des Vorentwurfs 2. Tranche, S. 12.
} 
steht und fällt mit der - je nach Ausgestaltung des Solvenztests - mehr oder weniger hohen Prognose(un)sicherheit. Wollte man dieselbe Qualität des Gläubigerschutzes wie bei der Konzeption des festen Eigenkapitals erreichen, so müsste man schon die Aufstellung einer Bilanz verlangen, da anders die Solvalibilität nicht festgestellt werden kann. Eine verkürzte Bilanz - wie in dem Niederländischen Entwurfs eines GmbH-Reformgesetzes vorgesehen reichte hierfür nicht aus ${ }^{1214}$. Vorzuziehen ist das deutsche Modell einer Vorverlagerung des Insolvenzschutzes nach Maßgabe des $\S 64$ GmbHG. Der erweiterte $\S 64$ GmbHG richtet sich hingegen gegen den Abzug von Vermögenswerten, welche die Gesellschaft bei objektiver Betrachtung zur Erfüllung ihrer Verbindlichkeiten benötigt. Damit steht der neue $\S 64$ GmbHG dem ,solvency test“ nahe, ohne den Nachteil zu haben, dass allein die Prognose des Geschäftsführers darüber befindet, inwieweit das Gesellschaftsvermögen künftige Zahlungspflichten noch abzudecken vermag. Im Ergebnis erfasst der erweiterte $\S 64 \mathrm{GmbHG}$ einen Teilbereich der Haftung, die unter dem Stichwort „existenzvernichtender Eingriff“ bekannt geworden ist. Allerdings setzt $\S 64 \mathrm{GmbHGE}$ nicht beim Gesellschafter als Empfänger der existenzbedrohenden Vermögensverschiebung an, sondern beim Geschäftsführer als deren Auslöser oder Gehilfen ${ }^{1215}$.

\section{Unternehmergesellschaft}

Die Einführung der Unternehmergesellschaft (UG) gehört zu den bemerkenswertesten Neuerungen im Recht der GmbH. Der deutsche Gesetzgeber hat mit dieser Variante der GmbH, Existenzgründern in der Startphase, in der naturgemäß das Eigenkapital der Gesellschafter am gefährdetesten ist, eine Alternative zur englischen Limited bieten wollen, die gänzlich ohne (Risiko-)Kapital auskommt. In Kombination mit der Vereinfachung der Gründung unter Verwendung der Mustersatzung soll die UG nach dem Willen der Bundesregierung jungen Existenzgründern ermöglichen, schnell, flexibel, einfach und kostengünstig eine Gesellschaft zu errichten. Dass die so angelegte Unternehmergesellschaft geeignet ist, den ihr angedachten Zweck zu erfüllen und damit in einen echten Wettbewerb mit der Limited sowie anderen Gesellschaftsformen ohne Mindestkapitalisierungspflicht $\mathrm{zu}$ treten, dürfte außer Zweifel stehen ${ }^{1216}$. Allerdings wäre der zu erwartende Erfolg ein zweifelhafter, denn das vorgestellte Konzept einer Unternehmergesellschaft unter völligem Verzicht auf ein Stammkapital ohne

1214 Joost, Die GmbH-Reform in der Diskussion, S. 31, $32 \mathrm{f}$.

1215 Begründung des Regierungsentwurfs, S. 106.

1216 Teilweise anderer Auffassung Freitag/Riemenschneider ZIP 2007, 1485, 1491 f., die nicht glauben, dass die UG schneller gegründet werden kann als eine $\mathrm{GmbH}$, da die Dauer des Eintragungsverfahrens in erster Linie mit der dünnen Personaldecke beim Amtsgericht zusammenhänge. 
besondere Gläubigerschutzvorschriften steht im diametralen Widerspruch zu dem Haftungsmodell einer Gesellschaft mit beschränkter Haftung ${ }^{1217}$.

Bei einer Gesellschaft mit beschränkter Haftung werden unternehmerische Risiken auf die Gesellschaft verlagert. Diese Verlagerung des Unternehmensrisikos bedingt einen Ausgleich, der entweder durch Beteiligung des Unternehmers am Risiko durch die Vorgabe eines Mindestkapitals (so das bisherige Gläubigerschutzkonzept in Deutschland) oder durch Schaffung strenger Vorgaben hinsichtlich Publizität und unternehmerischer Verantwortlichkeit, wie dies künftig verstärkt bei der Niederländischen B.V. verwirklicht werden soll, gewährleistet wird. Wie zuvor bereits diskutiert wurde, haben beide Ansätze verschiedene Vor- und Nachteile. Für die Unternehmergesellschaft (haftungsbeschränkt) ist jedoch keiner dieser Ansätze vorgesehen. Nach Maßgabe des Entwurfs wird das Kapitalaufbringungserfordernis aufgegeben, ohne an anderer Stelle einen Ausgleich hierfür zu schaffen. Vielmehr gelten für die Unternehmergesellschaft dieselben Vorgaben wie für die Voll-GmbH, mit dem Unterschied, dass letztere ja gerade über ein Mindesthaftkapital verfügt. Der einzige gläubigerschützende Aspekt, nämlich ein Viertel des Jahresgewinns in eine gesetzliche Rückstellung aufzunehmen, fällt aus, wenn - und auch das ist in Missbrauchsabsicht darstellbar - das Unternehmen keine Gewinne realisiert. Im Ergebnis ist daher der Verzicht auf ein Mindestkapital in der Form einer Unternehmergesellschaft nur dann vertretbar, wenn man die Konsequenzen zieht und dem Verzicht andere gesellschafts- und insolvenzrechtliche Maßnahmen gegenüberstellt ${ }^{1218}$.

Schließlich ist nach dem Vorgenannten, die Unternehmergesellschaft auch nur dann im $\mathrm{GmbH}-\mathrm{Gesetz}$ richtig verortet, wenn es sich - wie der Gesetzentwurf konsequenterweise auch andeutet - bei der Unternehmergesellschaft um ein Durchgangsstadium hin zur „Voll$\mathrm{GmbH}^{\prime \prime}$ handelt. Dies sollte explizit - etwa durch Setzung einer Frist innerhalb derer das Mindeststammkapitals aufgebracht sein soll - im Gesetz festgeschrieben werden. Wollte man es Gesellschaftern ermöglichen, dauerhaft Beteiligter einer Unternehmergesellschaft zu sein, dann wäre für diese ein neues Gesetz zu schaffen, wie es $G e h b^{1219}$ für die Unternehmensgründungsgesellschaft (UGG) vorschlägt. In diesem müssten die Besonderheiten der Unternehmergesellschaft (Kein Mindeststammkapital, kaum gläubigerschützende Vorschriften) in angemessener Weise geregelt sein. Insoweit genügt allerdings bereits, dass durch Schaffung einer eigenen Rechtsgrundlage, eine Täuschung des Rechtsverkehrs durch die vermeintliche Vergleichbarkeit mit der „Voll-GmbH“ vermieden wird. Um den Interimscharakter der Un-

1217 Vgl. auch Freitag/Riemenschneider ZIP 2007, 1485, 1491 f., die insbesondere die Benachteiligung von Verbauchern, Kleinunternehmern und nicht-rechtsgeschäftlichen Gläubigern kritisieren.

1218 Stellungnahme des Bundesrates zum Entwurf eines Gesetzes zur Modernisierung des GmbH-Rechts und zur Bekämpfung von Missbräuchen (MoMiG) vom 6. Juli 2007, BR- Drucksache 354/07. Siehe hierzu auch Wilhelm DB 2007, 1510, 1513 der mit der Einführung der UG ebenfalls nur die Aufgabe des Mindeststammkapitalerfordernisses verbindet.

1219 Siehe oben Dritter Abschnitt § 1 VIII. 2. 
ternehmergesellschaft besser zu dokumentieren, sollte schließlich ein Rechtsformzusatz gewählt werden, der den mobilen Charakter der neuen Gesellschaftsform besser beschreibt. Der vom Bundesrat vorgeschlagene Rechtsformzusatz „Gesellschaft mit beschränkter Haftung (ohne Mindest-stammkapital)“ beziehungsweise die Abkürzung „GmbH (o.M.)“ scheint hierfür gut geeignet zu $\operatorname{sein}^{1220}$.

\section{§ 6 Handelsrechtliche Publizität}

\section{Rechtsvergleich}

\section{Handelsregister}

Das Handelsregisterrecht ist aufgrund europäischer Vorgaben weitgehend vereinheitlicht worden $^{1221}$. Trotzdem bestehen bis heute immer noch erhebliche Unterschiede im Hinblick auf die Aufgaben der Handelsregister und den Inhalt der Eintragungen ${ }^{1222}$. Allen Handelsregistern gemein ist die Funktion als Informationsgeber aller interessierten Teilnehmer des Rechtsverkehrs. In Deutschland obliegen den Handelsregistern daneben weit reichende materiell rechtliche Prüfungsaufgaben im Zusammenhang mit der Eintragung von Gesellschaften und gesellschaftsrechtlichen Änderungen, die im Zusammenhang mit der Verfassung der Gesellschaft stehen ${ }^{1223}$. In Frankreich werden die eingereichten Unterlagen hingegen durch den Registerbeamten nur auf ihre Vollständigkeit hin überprüft ${ }^{1224}$. Gar keine Prüfungsaufgaben hat das Handelsregister in den Niederlanden; dort wird die präventive Rechtmäßigkeitskontrolle durch Behörden wahrgenommen, deren Prüfungsergebnis wird durch die Erteilung einer Unbedenklichkeitsbescheinigung für das Handelsregister verbindlich festgestellt ${ }^{1225}$. Die vorgenannten Unterscheide zwischen den nationalen Registern sind von entscheidender Bedeutung für die Verlässlichkeit der in den Handelsregister eingetragenen Informationen ${ }^{1226}$.

1220 Stellungnahme des Bundesrates zum Entwurf eines Gesetzes zur Modernisierung des GmbH-Rechts und zur Bekämpfung von Missbräuchen (MoMiG) vom 6. Juli 2007, BR- Drucksache 354/07.

1221 Keidel/Krafka/Willer S. 1 ff.; Zusammenfassend Krafka MittBayNot 2005, 290 sowie Wachter GmbHR 2005, 717, 726.

1222 Siehe im Einzelnen hierzu oben Dritter Abschnitt $\S 1$ V. 1., § 2 VI 1. und $\S 3$ VI. 1.

1223 Dritter Abschnitt $\$ 1$ V. $1 .$.

1224 Dritter Abschnitt $\$ 3$ VI. 1.

1225 Dritter Abschnitt $\$ 2$ VI 1.

1226 Dritter Abschnitt $\S 1$ V. 1., § 2 VI 1. und $\S 3$ VI. 1. Vgl. auch zum Ganzen Keidel/Krafka/Willer S. 1 ff.; Krafka MittBayNot 2005, 290 sowie im Besonderen Wachter GmbHR 2005, 717, 726. 
Die Institution „Handelsregister“ gibt es schon seit langem; in den meisten Ländern besteht eine gesonderte gesetzliche Regelung für das Handelsregister, in den Niederlanden ist dies das Gesetz über Handelsregister („Handelsregisterwet") m 8. Februar 1996 und Handelsregisterverordnung (,Handelsregisterbesluit“) vom 18. September 1997, in Frankreich die Verordnung Nr. 84-406 vom 30. Mai 1984 und in Deutschland die Handelsregisterverordnung vom 12. August 1937, zuletzt geändert durch das Gesetz über elektronische Handelsregister und Genossenschaftsregister sowie das Unternehmensregister vom 10. November $2006^{1227}$.

Die Handelsregister werden in Deutschland und in Frankreich von den Gerichten geführt. In den Niederlanden sind dagegen die Handelskammern (kamers van koophandel) für die Führung der Handelsregister zuständig ${ }^{1228}$.

Mit Neufassung der Publizitätsrichtlinie ${ }^{1229}$ im Juli 2003 sind die Handelsregister in allen europäischen Mitgliedsstaaten ab dem 1. Januar $2007^{1230}$ elektronisch zu führen ${ }^{1231}$.

Die Eintragungsdauer angemeldeter Sachverhalte ist naturgemäß in erheblichem Umfang vom jeweiligen Einzelfall abhängig. Unabhängig davon ist allerdings mit der Umstellung der Registergerichte auf elektronische Registerführung künftig mit einer Verkürzung der Eintragungsdauer zu rechnen. In einigen Registergerichten in Deutschland gelingt so beispielsweise die Eintragung einer neu errichteten $\mathrm{GmbH}$ innerhalb weniger Tage. In den Niederlanden erfolgt die Eintragung im Regelfall gleichfalls innerhalb weniger Tage. In Frankreich beträgt die Eintragungsdauer meist ein bis zwei Wochen. Allerdings erhalten die Gründer dort am Tag des Eingangs der Gründungsunterlagen vom Register eine amtliche Eingangsbestätigung, die im Rechtsverkehr bereits als Nachweis über die Gesellschaft in Gründung anerkannt wird $^{1232}$. Bei einem Vergleich der Eintragungsdauer in den einzelnen Ländern muss man selbstverständlich auch berücksichtigen, welche Leistung des Registergerichts in dieser Zeit erbracht wird ${ }^{1233}$. Die bloß formelle Registrierung einer neuen Gesellschaft wie sie in den Niederlanden erfolgt, nimmt naturgemäß weniger Zeit in Anspruch als eine materiell rechtli-

1227 Keidel/Krafka/Willer S. 1 ff.; Krafka MittBayNot 2005, 290; Wachter GmbHR 2005, 717, 726.

1228 Dritter Abschnitt $\$ 1$ V. 1., § 2 VI 1. und § 3 VI. 1. Keidel/Krafka/Willer S. 1 ff.; Krafka MittBayNot 2005, 290; Wachter GmbHR 2005, 717, 726.

1229 Publizitätsrichtlinie, erste Richtlinie v. 9.3.1968 (68/151/EWG), abgedruckt u.a. bei Habersack, Europäisches Gesellschaftsrecht, 1999; Lutter, Europäisches Unternehmensrecht, 4. Auflage, 1996; Schwarz; siehe oben Dritter Abschnitt § 4 I. 2. a).

1230 Siehe dazu Gesetzestext und Begründung des Gesetzes über elektronische Handelsregister und Genossenschaftsregister sowie das Unternehmensregister (EHUG), abrufbar unter www.gmbhr.de/volltext.htm.; vgl. hierzu auch Noack notar 2005, 14 sowie die Ausführungen hierzu oben Dritter Abschnitt $§ 1$ V. 1.

1231 Richtlinie 2003/58 des Europäischen Parlaments und des Rates in Bezug auf Offenlegungspflichten von Gesellschaften bestimmter Rechtsformen, AB1 Nr. L 221/13 v. 4.9.2003, siehe oben Dritter Abschnitt $\$ 4$ I. 2. k). Vgl. dazu auch Heneweer FGPRax 2004, 259; Schemmann GPR 2004, 92; Scholz EuZW 2004, 172.

1232 Vgl. dazu Dritter Abschnitt § 3 VI. 1. So wie hier auch schon Wachter GmbHR 2005, 717, 727.

1233 Wachter GmbHR 2005, 717, 727. 
che Prüfung der Vollständigkeit und Richtigkeit der Gesellschaftsgründung, wie sie in Deutschland von den Registergerichten geleistet wird ${ }^{1234}$.

Die Handelsregister können von jedermann ohne Angaben von Gründen oder gar unter Nachweis eines berechtigten Interesses eingesehen werden ${ }^{1235}$. Eine Online-Einsicht war in Frankreich und den Niederlanden auch schon vor der Neufassung der Publizitätsrichtlinie ${ }^{1236}$ im Juli 2003 möglich ${ }^{1237}$. In Deutschland gilt dies erst seit Januar 2007 und auch nur im Hinblick auf das Gesellschaftsblatt der Gesellschaft sowie solche Dokumente, die nach dem 1. Januar 2007 bei dem Registergericht eingereicht worden sind; ältere Dokumente sind nach wie vor und werden auch in Zukunft wohl nicht mehr elektronisch erfasst ${ }^{1238}$.

Zusätzlich zu der Eintragung im Handelsregister werden wesentliche Unternehmensnachrichten in allen drei Ländern in einem amtlichen (elektronischen) Bekanntmachungsblatt veröffentlicht ${ }^{1239}$.

\section{Geschäftsbriefe}

In Umsetzung europäischer Vorgaben sind in allen Ländern bestimmte Mindestangaben auf den Geschäftsbriefen vorzusehen ${ }^{1240}$. So ist zum Schutz des Rechtsverkehrs auf den Geschäftsbriefen wenigstens die Rechtsform der Gesellschaft, ihr Sitz, das Registergericht und die Nummer der Eintragung anzugeben ${ }^{1241}$. In Frankreich (Art. L 238-3 C.com.) und in Deutschland ( $\$ 35 \mathrm{a} \mathrm{GmbHG)}$ ist darüber hinaus das gezeichnete und eingezahlte Kapital der Gesellschaft anzugeben ${ }^{1242}$. So ist es den Geschäftspartnern deutscher und französischer Gesellschaften möglich anhand der Geschäftsbriefe die Kapitalisierung der Gesellschaft zu erkennen $^{1243}$.

\footnotetext{
1234 Wachter GmbHR 2005, 717, 727; ders. Die GmbH-Reform in der Diskussion, S. 55, 66.

1235 Wachter GmbHR 2005, 717, 727.

1236 Publizitätsrichtlinie, erste Richtlinie v. 9.3.1968 (68/151/EWG), abgedruckt u.a. bei Habersack, Europäisches Gesellschaftsrecht, 1999; Lutter, Europäisches Unternehmensrecht, 4. Auflage, 1996; Schwarz. Vgl. oben Dritter Abschnitt $\S 4$ I. 2. a).

1237 Dritter Abschnitt $§ 2$ VI 1. und § 3 VI. 1.

1238 Dritter Abschnitt $\S 1$ V. 1. Siehe dazu auch Wachter GmbHR 2005, 717, 727.

1239 Dritter Abschnitt $\S 1$ V. 1., § 2 VI 1. und § 3 VI. 1. Vgl. zu Vorstehendem auch Keidel/Krafka/Willer S. 1 ff.; Krafka MittBayNot 2005, 290; Wachter GmbHR 2005, 717, 727.

1240 Siehe zu den Einzelheiten oben Dritter Abschnitt $\S 1$ V. 2., § 2 VI 2. und $\S 3$ VI. 2 sowie Wachter GmbHR 2005, 717, 727.

1241 Siehe Art. 4 der europäischen Publizitätsrichtlinie, erste Richtlinie v. 9.3.1968 (68/151/EWG); abgedruckt u.a. bei Habersack, Europäisches Gesellschaftsrecht, 1999; Lutter, Europäisches Unternehmensrecht, 4. Auflage, 1996; Schwarz. Vgl. oben Dritter Abschnitt § 4 I. 2. a).

1242 Dritter Abschnitt $\S 1$ V. 2. und $\S 3$ VI. 2; siehe auch Wachter GmbHR 2005, 717, 727.

1243 Wachter GmbHR 2005, 717, 727.
} 
Eine Gesellschaft, die auf ihren Geschäftsbriefen die gesetzlich geforderten Mindestangaben versäumt, hat mit einem Zwangsgeld oder einer sonstigen Geldbuße zu rechnen. Die Sanktion liegt regelmäßig im Ermessen des Registergerichts und ist der Höhe nach in den einzelnen Ländern unterschiedlich geregelt. Das höchste Zwangsgeld kann in Deutschland festgesetzt werden und beträgt bis zu $5.000 €^{1244}$.

\section{Schlussfolgerungen}

\section{Handelsregister}

Nicht vorgeschrieben aufgrund europäischer Vorgaben ist eine grenzüberschreitende Vernetzung der nationalen Register ${ }^{1245}$. Dies wäre allerdings vor allem im Hinblick auf den Austausch zwischen den Handelsregistern der ausländischen Hauptniederlassungen und der inländischen Zweigniederlassung zu empfehlen ${ }^{1246}$.

\section{Geschäftsbriefe}

Der Gedanke des europäischen Gesetzgebers durch die verpflichtende Angabe der Rechtsform der Gesellschaft, ihres Sitz, des Registergerichts und der Nummer der Eintragung den Schutz des Rechtsverkehres sicherzustellen ist in der Sache zu begrüßen, allein die Umsetzung des gesetzgeberischen Ziels ist in der Praxis problematisch, denn das in den Mitgliedstaaten bislang vorgesehene Kontroll- sowie Ordnungs- und Zwangsmittelsystem erweist sich weitgehend als wirkungslos ${ }^{1247}$. Einer der maßgeblichen Gründe hierfür ist zum einen, dass die zuständigen Registergerichte im Regelfall kaum einmal von unrichtigen oder unvollständigen Geschäftsbriefen erfahren. Wird ein Verstoß doch einmal aufgedeckt, so hat die Gesellschaft die Möglichkeit, den Geschäftsbrief auch noch nachträglich an die gesetzlichen Vorgaben anzupassen. Schließlich erscheint die Höhe der Sanktion in keiner Weise geeignet, die Gesellschaften tatsächlich zur Einhaltung der Offenlegungspflichten anzuhalten. Wirkungsvollere Sanktionen könnten etwa die ausdrückliche gesetzliche Anordnung der persönlichen Haftung der Geschäftsführer sein oder die Vorsehung einer Registersperre für den Fall, dass die Geschäftsbriefe dem Registergericht nicht regelmäßig zur Prüfung eingereicht werden oder die Verpflichtung der Abschlussprüfer, die Ordnungsmäßigkeit der Geschäftsbriefe zur prüfen

1244 Dritter Abschnitt § 1 V. 2.; siehe auch Wachter GmbHR 2005, 717, 727.

1245 Siehe insoweit auch oben Dritter Abschnitt § 1 V. 1., § 2 VI 1. und § 3 VI. 1 sowie bei $§ 4$ I. 2.

1246 So wie hier auch schon Wachter GmbHR 2005, 717, 726.

1247 So auch schon die Beobachtung von Wachter GmbHR 2005, 717, $727 \mathrm{f}$. 
und im Bericht darzulegen oder aber die Löschung der Gesellschaft von Amts wegen bei wiederholtem Pflichtverstoß ${ }^{1248}$. Eine harte Sanktion bestünde schließlich auch darin, die in dem Brief enthaltenen Willenserklärungen bei einem Verstoß gegen die Publizitätsvorgaben nichtig beziehungsweise anfechtbar zu stellen.

\section{$\S 7$ Vorschläge alternativer Rechtsformen}

Soweit ersichtlich wurde nur in Deutschland ernsthaft die Schaffung einer neuen, effizienten Rechtsform neben der existierenden $\mathrm{GmbH}$ alternativ oder aber ergänzend zur mehr oder weniger umfassenden Reform des $\mathrm{GmbH}$-Rechts diskutiert ${ }^{1249}$. Die Reformgesetzgeber in den Niederlanden ${ }^{1250}$ und Frankreich haben ihre Überlegungen soweit ersichtlich von vorneherein auf eine Reform des GmbH-Rechts beschränkt, diese aber sodann zum Teil erheblich einschneidender für die existierende Rechtsform vollzogen als dies in Deutschland geschehen ist, wie beispielsweise der Verzicht auf eine Bereitstellung des bisher vorgeschriebenen Mindeststammkapitals in diesen Ländern zeigt. Dies ist umso verwunderlicher, als es für eine solche legislatorische Strategie bereits ausländische Vorbilder gibt. So hat etwa Spanien im Jahre 2003 die Sociedad Limitada Nueva Empresa (S.L.N.E.) als Alternative zu der bekannten Sociedad de Responsabilidad Limitada (S.L. beziehungsweise S.R.L.) geschaffen ${ }^{1251}$.

In Deutschland haben Bayern ${ }^{1252}$ und Nordrhein-Westfalen ${ }^{1253}$ sowie verschiedene Fraktionen des deutschen Bundestages ${ }^{1254}$ und Rechtslehrer ${ }^{1255}$ ihre Vorschläge für die „Anreicherung“ 1256 der Rechtsformenlandschaft unterbreitet. Allen Vorschlägen gemein ist, dass die neue Rechtsform ohne oder aber mit geringem Mindestkapital binnen 24 Stunden errichtet werden soll, ohne dass hierbei erhebliche Gründungskosten entstehen.

Diese Vorgaben lassen sich indes nach der hier vertretenen Auffassung auch mit einer reformierten $\mathrm{GmbH}$ verwirklichen, ohne dass diese - wie teilweise angenommen wird ${ }^{1257}$ - hier-

\footnotetext{
1248 Vgl. auch Wachter GmbHR 2005, 717, $727 \mathrm{f}$.

1249 Siehe zu den Einzelheiten oben Dritter Abschnitt $§ 1$ VIII.

1250 Dort wurde im Auftrag des Wissenschaftlichen Untersuchungs- und Dokumentationszentrum („Wetenschappelijk Onderzoek- en Documentatiecentrum“ - WODC) eine Untersuchung zur Rechtsform und Praxis der anglo-amerikanischen LLC bzw. LLP und deren mögliche Einführung in den Niederlanden durchgeführt, mit dem Ergebnis, dass die Einführung einer alternativen Rechtsform nicht empfohlen wird; siehe dazu oben Dritter Abschnitt $\S 2$ VII.

1251 Ley 7/2003, de 1 de abril, BOE núm. 79 de 2 abril, Sec. 1, pag. 12679.

1252 Vgl. hierzu im Einzelnen oben Dritter Abschnitt $\$ 1$ VIII 4.

1253 Vgl. hierzu im Einzelnen oben Dritter Abschnitt $\$ 1$ VIII 1.

1254 Vgl. hierzu im Einzelnen oben Dritter Abschnitt $\S 1$ VIII 2 und 5.

1255 Vgl. hierzu im Einzelnen oben Dritter Abschnitt $§ 1$ VIII 3.

1256 Offensichtlich skeptisch Eidenmüller ZGR 2007, 168, $180 \mathrm{f}$.

1257 Drygala ZIP 2006, 1797, 1798.
} 
durch ihrer (erfolgreichen) Identität beraubt würde ${ }^{1258}$. Die beabsichtigten und im Einzelnen zuvor im Rechtsvergleich diskutierten Reformansätze weisen den richtigen Weg in eine insbesondere bei den Gründungsvoraussetzungen verschlankte Gesellschaftsform.

Eine Flankierung der GmbH, und zwar auch der Niederländischen oder französischen Rechts, durch eine oder mehrere Rechtformen würde diese in gleicher Weise schwächen, wie dies die Britische Ltd. derzeit tut, nur würde der „Sargnagel“ des (deutschen) GmbH-Rechts dann eben keine ausländische sondern eine deutsche Unternehmergesellschaft beziehungsweise Unternehmensgründungsgesellschaft $\operatorname{sein}^{1259}$. Gleichzeitig - so wendet Eidenmüller wohl nicht ganz zu Unrecht unter Bezugnahme auf entsprechende Erfahrungen mit der spanischen S.L.N.E. ein - sei keineswegs sicher, dass die Flucht in die Ltd. durch die Schaffung einer entsprechenden deutschen Unternehmensform gestoppt würde ${ }^{1260}$.

\section{§ 8 Europäisches Gesellschaftsrecht}

Wie bereits in $\S 4$ des dritten Abschnitts dargestellt, haben die europäischen gesellschaftsrechtlichen Richtlinien bereits manche Gemeinsamkeiten zwischen den nationalen Rechtsformen begründet ${ }^{1261}$. Diese Tatsache, flankiert von der Rechtsprechung des EuGH ${ }^{1262}$ betreffend das grenzüberschreitende Tätigwerden von Gesellschaften, wirft die Frage auf, inwieweit überhaupt noch ein rechtliches oder gar wirtschaftliches Bedürfnis nach einer europäischen Gesellschaft mit beschränkter Haftung besteht ${ }^{1263}$.

Mit dieser Frage hat sich Teichmann in einer Stellungnahme vor dem Europäischen Parlament auseinandergesetzt und ein Bedürfnis für eine EPG mit folgenden Argumenten bejaht ${ }^{1264}$.

Erstens wecke die Verwendung einer ausländischen Rechtsform als „Briefkastengesellschaft“ (,pseudo foreign company“) bei Geschäftspartnern naturgemäß besonderes Misstrauen. Es

1258 So wie hier auch Eidenmüller ZGR 2007, 168, 181.

1259 Genauso im Ergebnis auch K. Schmidt DB 2006, 1096 sowie Eidenmüller ZGR 2007, 168, 181.

1260 Eidenmüller ZGR 2007, 168, $181 \mathrm{f}$.

1261 Vgl. hierzu oben Dritter Abschnitt $\$ 4$.

1262 Centros - EuGH, 9. 3. 1999 - Rs. C -212/97; Überseering - EuGH, 5. 11. 2002 - Rs. C-208/00; Inspire Art EuGH v. 30. 9. 2003 - Rs. C - 167/01.

1263 Vgl. den Gedankengang bei Steinberger, Sonderbeilage zu Heft 37 BB 2006, 26, 31.

1264 Teichmann, Stellungnahme vor dem Rechtsausschuss des Europäischen Parlaments zur Einführung einer Europäischen Privatgesellschaft vom 22. Juni 2006, http://www.europarl.europa.eu/comparl/juri/hearings/ 20060622/teichmann_de.pdf. 
stehe unausgesprochen immer die Frage im Raum, ob es möglicherweise unredliche Gründe dafür gebe, dass nicht die nationale Rechtsform des Inlandes verwendet wurde ${ }^{1265}$.

Zweitens hätten viele Mitgliedstaaten außerdem den Nachteil, dass ihre Rechtsformen in anderen Staaten kaum bekannt seien. Dies gelte insbesondere für die neu beigetretenen Staaten. Damit erleideten die kleinen und mittleren Unternehmen aus den Beitrittsstaaten einen Wettbewerbsnachteil, denn sie seien faktisch gezwungen, die Rechtsform eines der ,,alten“ Mitgliedstaaten zu verwenden, um deren Bekanntheitsgrad nutzen zu können. Sie müssten damit eine für sie fremde Rechtsordnung anwenden, was zu höheren Beratungskosten führe ${ }^{1266}$.

Drittens sei, auch wenn ein Auseinanderfallen von Verwaltungssitz und Registersitz unter dem Schutz der Niederlassungsfreiheit möglich sei, europarechtlich noch nicht geklärt, wo genau die Grenze zwischen dem Heimatrecht der Gesellschaft und dem Recht am Tätigkeitsort verlaufe. Die Mitgliedstaaten könnten einer ausländischen Gesellschaft Beschränkungen im Interesse des Gläubigerschutzes auferlegen, soweit sie geeignet und erforderlich seien. Wie nationale Gesetzgeber und Gerichte mit dieser Öffnungsklausel jeweils umgingen, sei ungewiss. Die Gefahr einer Überlagerung des Heimatrechts durch unterschiedliche nationale Schutzregeln sei jedenfalls durchaus real und schaffe Rechtsunsicherheit ${ }^{1267}$.

Viertens bleibe, selbst wenn ausländische Gerichte das Heimatrecht der Gesellschaft respektierten und anwendeten, offen, ob sie es richtig anwenden. Die Interpretation fremder Rechtsregeln durch ein Gericht, das mit diesen Regeln nicht vertraut sei, berge immer ein erhöhtes Risiko von Fehlentscheidungen. Das konkrete Ergebnis von Gerichtsentscheidungen sei damit nur schwer vorhersehbar. Noch weniger sei sichergestellt, dass die Gerichte in allen Mitgliedstaaten ein und dieselbe Frage auch einheitlich entschieden. Gegen die möglicherweise fehlerhafte Interpretation des Heimatrechts durch ausländische Gerichte gebe es aber keine prozessualen Mittel. Ein Rekurs zu den Gerichten des Heimatstaates existiere nicht. Auch der Weg zum Europäischen Gerichtshof sei versperrt; denn für die Auslegung nationalen Rechts sei dieser nicht zuständig ${ }^{1268}$.

Diese Argumentation kann weitestgehend gefolgt werden. In der Tat ist zu erwarten, dass von einer EPG mehr Vertrauen ausgestrahlt wird, als von einer „Briefkasten-GmbH/S.à.r.l. oder B.V.“. Freilich besteht auch bei der EPG die Gefahr unterschiedlicher Rechtsanwendung in den Mitgliedstaaten, jedenfalls solange, wie eine Klärung strittiger Rechtsfragen durch den EuGH nicht erfolgt ist. Entscheidend für die Einführung der EPG spricht jedenfalls die hohe

1265 Teichmann, aaO, sub II.1; siehe schon Dejmek, NZG 2001, 878, 883; ebenso Steinberger, Sonderbeilage zu Heft 37 BB 2006, 26, 31; vgl. auch Westermann GmbHR 2005, 4.

1266 Teichmann, aaO, sub II.2; Steinberger, Sonderbeilage zu Heft 37 BB 2006, 26, 31.

1267 Teichmann, aaO, sub II.3.

1268 Teichmann, aaO, sub II.4. 
Flexibilität die die Verordnung den Gründern bei der Ausgestaltung der Gesellschaft bietet. Den Gründern ist es gestattet, in der Satzung die Rechte der Gesellschafter, die Ausgestaltung der Geschlossenheit, die Befugnisse der Gesellschaftsorgane und die Übertragbarkeit der Anteile frei zu regeln. Von einer strikten Trennung von Anteilsinhaberschaft und Geschäftsführung ist keine Rede ${ }^{1269}$. Für die Einführung der EPG spricht außerdem die zu erwartenden geringeren Beratungskosten ${ }^{1270}$. Schließlich ist, wie bereits im Zusammenhang mit dem flexiblen Geschäftssitz einer $\mathrm{GmbH}$ angesprochen ${ }^{1271}$, für die Gründer insbesondere die Kompatibilität der Gesellschaftsform mit den inländischen steuerlichen, bilanziellen und wirtschaftlichen Vorgaben relevant. Diese Kompatibilität ließe sich in einer supranationalen Gesellschaftsform ohne weiteres verwirklichen. Auch die sprachlichen (und rechtlichen ${ }^{1272}$ ) Barrieren eines ausländischen Rechtsystems spielten dann keine Rolle.

1269 van Duuren Ondernemingsrecht 2004, 4, 9.

1270 Steinberger, Sonderbeilage zu Heft 37 BB 2006, 26, 31.

1271 Vgl. oben in diesem Abschnitt $§ 3$ II. 2.

1272 ...auf der Unkenntnis der Gesellschafter und Geschäftsführer des fremden Rechtsystems beruhende... 


\section{Fünfter Abschnitt}

\section{Zusammenfassung}

Eine optimal reformierte ,europäische“ Gesellschaft mit beschränkter Haftung vereint das Beste aus den existierenden Rechtssystemen. Die hier vorgenommene Untersuchung hat viele bereits de lege lata existierende Gemeinsamkeiten in den Rechtssystemen offenbart und noch mehr de lege ferenda entstehende Gemeinsamkeiten aufgedeckt. Die wenigen unterschiedlichen Ansätze sowie Reformüberlegungen, die vom Gesetzgeber nicht berücksichtigt worden sind oder bisher weder in der Legislative noch in der Praxis und Literatur angestellt worden sind, wurden in der hier durchgeführten Untersuchung gegenübergestellt, mit dem folgenden Ergebnis:

1. Statt der Schaffung neuer hybrider Gesellschaftsformen als Alternative zur nationalen Gesellschaft mit beschränkter Haftung, ist insbesondere in Frankreich und den Niederlanden die verstärkte kombinierte Nutzung der bereits existierenden Rechtsformen zu erwägen. Eine niederländische B.V. \& Co. KG oder französische S.à.r.l. \& Co. KG sollte allerdings auch steuerliche Vorzüge erhalten, damit sie sich in gleicher Weise durchsetzen kann, wie dies bereits in Deutschland geschehen ist.

2. Die Registerführung ist in allen drei Ländern weiter zu konzentrieren; die fachliche Spezialisierung bei den Registerrichtern und Rechtspflegern ist zu fördern und schließlich ist auch ein „express service“ nach dem Vorbild des englischen Companies House einzuführen.

3. Die Beteiligung ausländischer Personen an der Gründung einer deutschen GmbH sowie die Bekleidung von Geschäftsführer- oder Gesellschafterpositionen durch ausländische Personen sollte ausdrücklich zugelassen werden.

4. Die Prüfung des Vorliegens staatlicher Genehmigungen bei Gründung sollte in den Niederlanden und Frankreich - wie de lege ferenda in Deutschland - zugunsten einer nachgelagerten Kontrolle aufgegeben werden. Bei einer vorgelagerten Kontrolle ließen sich Verzögerungen selbst dann nicht auszuschließen, falls die Voraussetzungen einer Genehmigung unstreitig vorliegen. Zwingende Gründe die andererseits für eine präventive Kontrolle des Vorliegens gewerberechtlicher Voraussetzungen sprechen würden, sind nicht ersichtlich. 
5. Eine gesetzliche Vorgabe einer notariellen Beurkundung bei der Feststellung des Gesellschaftsvertrages einer GmbH ist auch mit den Schutzzwecken der Beurkundung nicht zu rechtfertigen. Die Aufgabe der gesetzliche Vorgabe einer notariellen Beurkundung der Gesellschaftsverträge würde zum einen zu einer erheblichen Vereinfachung des Verfahrens; zum anderen zu einer nicht unerheblichen Verbilligung der Gründung und aller späteren Änderungen des Gesellschaftsvertrages führen. Den Beteiligten bliebe es außerdem weiterhin unbenommen, die Beratung von Notaren in Anspruch zu nehmen und die von ihnen geschlossenen Vereinbarungen notariell beurkunden lassen.

6. Die Pflicht zur sofortiger (teilweisen) Erfüllung der Einlagepflichten ist aufzuheben. Sie ist einerseits ungeeignet, den Gläubigern Schutz zu gewähren, andererseits führt sie zu Prüfungsobliegenheiten der offiziellen Stellen, Notare und Registergerichte und damit zwangsläufig auch zu Verzögerungen des Gründungsvorgangs.

7. An dem Beglaubigungserfordernis bei der Anmeldung sollte in Deutschland und in den Niederlanden festgehalten werden, denn nur so lässt sich ohne erneute Prüfung bei Gericht die Identität des Unterzeichners nachvollziehen und die Vertretungsberechtigung des Unterzeichners überprüfen. Die Reichweite der notariellen Beglaubigungsfunktion ist im Gegenteil sogar zu erweitern um eine Verpflichtung des Notars bei der Zeichnung durch ein Organ der Gesellschaft nicht nur dessen Identität sondern zugleich auch die Vertretungsberechtigung der unterzeichnenden Person zu versichern. So wäre eine nochmalige Überprüfung der Vertretungsverhältnisse des Registergerichts vor Eintragung überflüssig und könnte vermieden werden.

8. Mit der Umstellung der Registerverfahren in Deutschland und den Niederlanden auf eine backloaded control reduziert sich die Gründungsprüfung der Registergerichte auf die Kontrolle des Gesellschaftsvertrages, der Geschäftsführer und der Gründungsgesellschafter. Würde die Verantwortlichkeit der Gründungsprüfung insgesamt auf den beurkundenden Notar übertragen, so würde die Notwendigkeit einer Prüfung durch das Registergericht bei der Anmeldung gänzlich entfallen; sich nur auf formale Aspekte beschränken können. Die Gesellschaft würde bereits mit ihrer Errichtung durch Feststellung des Gesellschaftsvertrages entstehen; die Eintragung hätte nur noch deklaratorische Wirkung.

9. Die Rechtsformzusätze der Firmen sind im Interesse der Markttransparenz durch einen klarstellenden Zusatz zu ergänzen (zum Beispiel NL B.V., GER GmbH und F S.à.r.l.). Die derzeit verwendeten Abkürzungen können Verwechslungen hervorrufen. 
10. Den Gründern einer Gesellschaft mit beschränkter Haftung ist ein Standardformular eines Gesellschaftsvertrages, das einen gesetzlich vorgesehenen Inhalt aufweist zur Verfügung zu stellen. Hierdurch würde sich die Prüfung des Vertrages durch das Registergericht oder eine Behörde wenn schon nicht erübrigen, so doch vereinfachen und mithin beschleunigen. Die Prüfung des Registergerichts beziehungsweise der Behörde wäre darauf beschränkt, den eingereichten Mustervertrag auf etwaige Abweichungen zum Muster zu überprüfen. Auch diese Prüfung ließe sich vermeiden, wenn man eine Abweichung bei späterer Feststellung mit einer Amtslöschung der Firma und zusätzlich Durchgriffsansprüche gegen Gesellschafter und Geschäftsführung sanktionieren würde.

11. Die in den Niederlanden bestehende Möglichkeit, auch juristische Personen in die Geschäftsführung zu berufen, sollte auch in Deutschland und Frankreich bestehen. Durch die Bestellung juristischer Personen in die Geschäftsführung würden „Ketten“bestellungen und -abberufungen der meist personenidentischen Geschäftsführer der Obergesellschaft und der Konzernuntergesellschaften aufgrund von Geschäftsführungswechseln vermieden. Hinzu kommt, dass eine Befreiung von den Beschränkungen des Selbstkontrahierens und der Doppelvertretung gemäß $§ 181$ BGB, der als gesetzlicher Grundsatz gar nicht in allen Ländern existiert, wodurch es in der Praxis häufig zu Missverständnissen kommt, dann nicht mehr erforderlich wäre. Schließlich würde mit einer Gesellschaft in der Geschäftsführung regelmäßig in Haftungsfällen ein solventerer Anspruchsgegner zur Verfügung stehen, als er in der Person einer natürlichen Person existierte.

12. Die Regelung in Deutschland und Frankreich, wonach einschlägig vorbestrafte Personen nicht zu Geschäftsführern bestellt werden können, vermittelt eine Sicherheit „des ersten Anscheins“. Auf diese sollte auch in den Niederlanden nicht verzichtet werden, ganz gleich ob dies nach dem deutsch-französischen Konzept oder nach Maßgabe des englischen Company Directors Disqualification Acts geschieht.

13. Die Erweiterung der Gesellschafterrechte sowie der Rechte der Gesellschafterversammlung in den Niederlanden ist nach dem deutschen gesetzlichen Vorbild weiter auszubauen. So sollten insbesondere die Einberufungsrechte offener und unmittelbarer ausgestaltet werden.

14. Die Gesellschafterliste beziehungsweise das Gesellschafterbuch in den Niederlanden ist aufzuwerten. Es ist gegebenenfalls auch zu erwägen die Gesellschafterliste durch Eintragung der Gesellschafter auf dem Registerblatt zu ersetzen. Will man den gutgläubigen Anteilserwerb ermöglich, so ist indes zu empfehlen, dass nicht die Gesellschafterliste als 
Rechtsscheinsträger verwendet wird, sondern vielmehr die Wirksamkeit der Anteilsübertragung von der Eintragung ins Handelsregister abhängig gemacht wird.

15. Die Modalitäten zur Einberufung und Abhaltung einer Gesellschafterversammlung sind zur besseren Verwendung der Gesellschaft mit beschränkter Haftung als (internationaler) Konzernbaustein sowie unter Berücksichtigung des Umstandes, dass die Gesellschafter Eigentümer der Gesellschaft sind, noch weiter für flexible Gestaltungen durch die Gesellschaftergesamtheit zu öffnen; der Minderheitenschutz wäre über die Bestimmung entsprechender Beschlussmehrheiten zu sichern.

16. Das deutsche Modell einer (Ersatz-)Verantwortlichkeit der Gesellschafter wegen des Ausbeziehungsweise Wegfalls der Geschäftsführung ist auch in den Niederlanden und Frankreich zu implementieren. Es hat den Charme, dass dem Missbrauch des Grundsatzes der Fremdorganschaft, der darin besteht, dass die Gesellschaft in der Insolvenz durch wiederholte Ab- und Neubestellungen im Ausland sitzender Geschäftsführer führungslos gestellt und damit taub und blind für Zustellungsversuche von Behörden und Gläubigern gemacht wird, ein Ende gesetzt wird. Auch ist der Gedanke der der Neuregelung zugrunde liegt, nämlich der Gesellschafter(-versammlung) als Herre(i)n der Gesellschaft, dogmatisch richtig.

17. Eine gesetzliche Vorgabe der Beurkundung des Anteilsübertragungsvorganges ist ebenso wenig zu rechtfertigen wie das Beurkundungserfordernis bei der Feststellung des Gesellschaftsvertrages. Hier gilt das oben Gesagte entsprechend. Daneben sprechen gegen ein Beurkundungserfordernis bei Geschäftsanteilsübertragungen zum einen die Tatsache, dass das historische Verständnis der GmbH als ,geschlossener“ Gesellschaft, deren „Geschlossenheit" durch Erschwerung der Fungibilität der Anteile zu sichern sei, sich geändert hat. Zum anderen greift auch nicht der Gedanke des Anlegerschutzes, denn würde dieser tatsächlich die notarielle Beurkundung erfordern, so wäre nicht einzusehen, weshalb zwar die Übertragung von Geschäftsanteilen, nicht aber die Übertragung von Anteilen an Personengesellschaften der notariellen Form unterworfen wird. Der Nachteil einer formfreien Übertragung wäre sicherlich die Verminderung der Transparenz der Anteilsinhaberschaft, da ein „Nachweis“ der Inhaberschaft von Anteilen durch die Vorlage einer Kette von notariell beurkundeten Abtretungen nicht mehr möglich wäre. Andererseits ließe sich dieser Mangel an Transparenz beheben, wenn man mit der hier vertretenen Auffassung eine Eintragung der Anteilsinhaber in das Handelsregisterblatt verlangte.

18. Auch in Zukunft ist an der Mindestkapitalisierungspflicht festzuhalten. Das Verständnis der Gegner vom Mindestkapital als Haftungsmasse, die den Gläubigern der Kapitalgesell- 
schaft als Ausgleich für die grundsätzliche Beschränkung der persönlichen Haftung der Gesellschafter auf die Aufbringung des Stammkapitals dient, greift zu kurz. Denn, zum einen steht den Gläubigern nicht nur das Vermögen der Gesellschaft in Höhe des Stammkapitals zur Verfügung, sondern das gesamte Gesellschaftsvermögen einschließlich des Stammkapitals; zum anderen soll das aufzubringende Vermögen in erster Linie eben nicht den Gläubigern sondern der Gesellschaft zu gute kommen, ihr zunächst als Startkapital für die Aufnahme des Geschäftsbetriebs dienen und bei Fortführung der Gesellschaft die Gewinnung geschäftlichen Vertrauens sichern. Die Haftungsfunktion des Stammkapitals ist sicherlich auch eine Funktion des Stammkapitals, allerdings keine primär beabsichtigte sondern vielmehr ein Reflex des Auftretens der Gesellschaft im Rechts- und Geschäftsverkehr. Trotz des Marktzwanges zur Schaffung eines Mindestkapitals ist auch eine gesetzliche Vorgabe erforderlich und zweckmäßig. Denn zum einen greift diese Annahme (einer Selbstregulierung durch entsprechende Einforderung des Marktes) nur für vertragliche Gläubiger; nur diese können Einfluss auf die Kapitalisierung der Gesellschaft nehmen, gesetzliche Gläubiger haben diese Möglichkeit nicht. Zum anderen ist ein Beitrag des Mindeststammkapitals, die Gesellschaftsformen der GmbH und AG für kapitalintensivere Unternehmungen zu reservieren (Stichwort der Seriositätsschwelle). Schließlich dürfte die Bestimmung eines Mindeststammkapitals das Risiko eines Missbrauchs der Rechtsform durch Verwendung der Kapitalgesellschaft mit ihrer Haftungsbeschränkung ohne oder mit nur geringem als Stammkapital gesichertem Eigenkapital minimieren.

Nicht hinreichend berücksichtigt wurden in der Diskussion um die Reduzierung oder gar Abschaffung des Mindestkapitals schließlich die Folgefragen, wie etwa die an das Mindeststammkapital anknüpfende Krisenwarnfunktion des $\S 49$ Abs. 3 GmbHG beziehungsweise Art. L 223-42 Abs. 1 C.com. Diese würden durch eine Herabsetzung oder gar Abschaffung ersichtlich eingeschränkt, der Vorsorgefunktion der Kapitalerhaltung kann bei nahezu nicht existierendem Eigenkapital ebenfalls wohl kaum angemessen Rechnung getragen werden. Weiterhin verringert sich bei einer Reduzierung oder Abschaffung des Stammkapitals der Zeitraum zwischen dem Eingreifen einer Ausschüttungssperre und dem Vorliegen einer Überschuldung beziehungsweise Insolvenz.

Auch ist die Abschaffung des Mindeststammkapitals nicht erforderlich, um Kleinunternehmen zu fördern, denen diese bedürfen keiner Haftungsbeschränkung zum Betrieb ihres Geschäfts. Die Haftungsbeschränkung ist vor allem für solche Unternehmen interessant, in denen der Geschäftsbetrieb erhebliche Risiken mit sich bringt. Vergleichsweise risikoarme Aktivitäten können demgegenüber durchaus auch in einer Rechtsform ohne Haftungsbeschränkung ausgeübt werden. Unternehmen aus dem Dienstleistungsbereich sind solche risikoarmen Unternehmen. Bei diesen Gesellschaften besteht der Wert des Unter- 
nehmens meist aus dem Know-How der Gründer oder deren Mitarbeitern, Anlaufverluste durch notwendige Sachinvestitionen können regelmäßig vermieden werden oder finden in einem überschaubaren Rahmen statt. Auch sind aufgrund des regelmäßig geringen Anlagevermögens größere Verlustrisiken regelmäßig ausgeschlossen. Die bei kaum einer Tätigkeit bestehende Haftungsgefahr ist versicherbar, so dass allein ihretwegen die Haftungsbeschränkung nicht gebraucht wird.

19. Das Kapitalaufbringungsrecht ist weiter $\mathrm{zu}$ vereinheitlichen; insbesondere hat sich das deutsche Kapitalaufbringungsrecht an den gesetzlichen Modellen der Nachbarländer zu orientieren. Durch die Einführung einer Differenzhaftung bei Einbringung von Sacheinlagen ist ein erster Schritt hin zu einer Harmonisierung getan. In Ergänzung hierzu ist zu erwägen, die Verjährungsfristen für Einlageforderungen allgemein zu verkürzen.

20. Die Nachschusspflichten sind auch in Deutschland nach dem Niederländischen Vorschlag zu reformieren. Die Niederländische Lösung vermeidet Blockaden notwendiger und von der Mehrheit gewollter Finanzierungsmaßnahmen, indem ein einzelner Gesellschafter die Satzungsänderung zwar zu verhindern nicht imstande ist, allerdings, sollte er mit der Änderung nicht einverstanden sein und gegen diese stimmen, die Änderung in seiner Person nicht gilt. Die Transparenzschwierigkeiten, die die Niederländische Lösung bietet, sind zugunsten der Flexibilität der Lösung hinzunehmen. Sie übertrifft auch das Modell der Kommission Gesellschaftsrecht, wonach Minderheitsgesellschafter in besonderen Fällen ein Austrittsrecht zustehen soll, wenn sie bestimmten Satzungsänderungen widersprechen.

21. Statt der Einführung eines Solvenztests nach angelsächsischem Vorbild, der eine Prognoseentscheidung der Geschäftsführer auf (mehr oder weniger) unsicherer Grundlage beinhaltet, ist eine Vorverlagerung des Schutzes den § 64 GmbHG (wohlgemerkt unter Berücksichtigung eines existierenden Mindeststammkapitals) gewährt, auch in den Niederlanden und in Frankreich zu implementieren. § 64 GmbHGE steht dem „,solvency test“ nahe, ohne den Nachteil zu haben, dass allein die Prognose des Geschäftsführers darüber befindet, inwieweit das Gesellschaftsvermögen künftige Zahlungspflichten noch abzudecken vermag, da er auf einer zugrundezulegenden Bilanz basiert.

22. Die Einführung der Unternehmergesellschaft (UG) nach Vorstellung des deutschen Gesetzgebers ist unausgegoren, denn viele der sich in diesem Zusammenhang ergebenden Folgefragen bleiben ungeklärt. Das vorgestellte Konzept einer Unternehmergesellschaft unter völligem Verzicht auf ein Stammkapital ohne besondere Gläubigerschutzvorschriften steht im diametralen Widerspruch zu dem Haftungsmodell einer Gesellschaft mit beschränkter Haftung, da es keinen Ausgleich, sei es durch Beteiligung des Unternehmers 
am Risiko durch die Vorgabe eines Mindestkapitals oder durch Schaffung strenger Vorgaben hinsichtlich Publizität und unternehmerischer Verantwortlichkeit vorsieht. Schließlich bedarf es einer Klarstellung des Charakters der Unternehmergesellschaft als Durchgangsstadium zur „Voll-GmbH“. Zum einen sollte eine Frist innerhalb derer das Mindeststammkapitals aufgebracht sein soll im Gesetz festgeschrieben werden; zum anderen sollte der Unternehmergesellschaft ein Rechtsformzusatz gegeben werden, der den mobilen Charakter der neuen Gesellschaftsform besser beschreibt, wie etwa der vom Bundesrat vorgeschlagene Rechtsformzusatz „Gesellschaft mit beschränkter Haftung (ohne Mindeststammkapital)“ beziehungsweise die Abkürzung „GmbH (o.M.)“.

23. Im Hinblick auf den Austausch zwischen den Handelsregistern der ausländischen Hauptniederlassungen und der inländischen Zweigniederlassung ist eine grenzüberschreitende Vernetzung der nationalen Register zu empfehlen.

24. Der Gedanke des europäischen Gesetzgebers durch die verpflichtende Angabe der Rechtsform der Gesellschaft, ihres Sitz, des Registergerichts und der Nummer der Eintragung den Schutz des Rechtsverkehres sicherzustellen ist zu begrüßen, ihm ist allerdings ein effektiveres Kontroll- sowie Ordnungs- und Zwangsmittelsystem zur Seite zu stellen. Neben der materiellen Erhöhung der Sanktion ist die ausdrückliche gesetzliche Anordnung der persönlichen Haftung der Geschäftsführer für den Fall einer Zuwiderhandlung vorzusehen. Auch ist eine Registersperre für den Fall anzudrohen, dass die Geschäftsbriefe dem Registergericht nicht regelmäßig zur Prüfung eingereicht werden. Eine weitere Maßnahme ist die in die Pflichtnahme der Abschlussprüfer, die Ordnungsmäßigkeit der Geschäftsbriefe zur prüfen und im Bericht darzulegen. Schließlich ist zu erwägen die Löschung der Gesellschaft von Amts wegen bei wiederholtem Pflichtverstoß sowie die in dem Brief enthaltenen Willenserklärungen bei einem Verstoß gegen die Publizitätsvorgaben nichtig beziehungsweise anfechtbar zu stellen.

25. Eine Alternative zu den nationalen GmbHs ist nicht erforderlich und auch nicht zweckmäßig vor dem Hintergrund des „Wettbewerbs der Gesellschaftsformen“. Zum einen lassen sich die mit einer alternativen Rechtsform angestrebten Vorteile auch mit einer reformierten $\mathrm{GmbH}$ verwirklichen, ohne dass diese hierdurch ihrer (erfolgreichen) Identität beraubt würde. Zum anderen würde eine Flankierung der nationalen GmbHs nicht zwangsläufig deren Attraktivität für ausländische Gründer erhöhen und keinesfalls würde eine alternative Rechtform die Fortexistenz der nationalen GmbHs sicherstellen; im Gegenteil würde sie nur einen weiteren „Sargnagel“ der nationalen GmbH-Rechte bedeuten. 
26. Voranzutreiben ist allerdings die Schaffung einer supranationalen Gesellschaftsform, einer europäischen Gesellschaft mit beschränkter Haftung. Ein Bedürfnis besteht trotz fortschreitender Angleichung der Gesellschaftsrechte und der Ermöglichung grenzüberschreitender Betätigungen. Hierfür sprechen Gesichtspunkte der Verlässlichkeit, der Bekanntheit, der Rechtssicherheit und der infolge der wachsenden Rechtssicherheit und Rechtsgleichheit zu erwartenden geringeren Beratungskosten.

Nach alledem würde die Schaffung einer supranationalen Gesellschaftsform die weitreichendste und nach dem Ergebnis dieser Untersuchung auch valideste Neuerung der nationalen Gesellschaftsrechte darstellen. Eine einfache supranationale Rechtsform, wie sie als Konzept dem Entwurf eines Initiativberichts für das Statut einer Europäischen Privatgesellschaft (EPG) zugrunde liegt, wäre ein ideales Instrument für zahlreiche kleine und mittlere Unternehmen in Deutschland, den Niederlanden und Frankreich gleichermaßen, die Vorteile des europäischen Binnenmarktes im Rechtskleid einer Gesellschaft mit beschränkter Haftung auch tatsächlich nutzen zu können. Die nationalen Reformen sind in dem diskutierten Maße voranzutreiben, doch sollte ihr Fokus nicht der „Wettbewerb der Rechtsformen“ sein. 


\section{§ 1 Synopse zum deutschen GmbHG}

\begin{tabular}{|c|c|}
\hline Bisherige Fassung (Stand: 10. November 2006) & Geplante Fassung (Stand: 23. Mai 2007) \\
\hline $\begin{array}{l}\text { \$ } 2 \text { Form des Gesellschaftsvertrages } \\
\text { (1) Der Gesellschaftsvertrag bedarf notarieller Form. } \\
\text { Er ist von sämtlichen Gesellschaftern zu unterzeich- } \\
\text { nen. }\end{array}$ & $\begin{array}{l}\text { § } 2 \text { Form des Gesellschaftsvertrages } \\
\text { (1) Der Gesellschaftsvertrag bedarf notarieller Form. } \\
\text { Er ist von sämtlichen Gesellschaftern zu unterzeich- } \\
\text { nen. } \\
\text { (1a) Wird das in der Anlage } 1 \text { bestimmte Muster ver- } \\
\text { wendet, so genügt es, wenn der Gesellschaftsvertrag } \\
\text { schriftlich abgefasst und die Unterschriften der Gesell- } \\
\text { schafter öffentlich beglaubigt } \\
\text { werden. } \\
\text { (2) Die Unterzeichnung durch Bevollmächtigte ist nur } \\
\text { auf Grund einer notariell errichteten oder beglaubigten } \\
\text { Vollmacht zulässig. }\end{array}$ \\
\hline $\begin{array}{l}\text { § } 3 \text { Inhalt des Gesellschaftsvertrages } \\
\text { (1) Der Gesellschaftsvertrag muss enthalten: } \\
\text { 1. die Firma und den Sitz der Gesellschaft, } \\
\text { 2. den Gegenstand des Unternehmens, } \\
\text { 3. den Betrag des Stammkapitals } \\
\text { 4. den Betrag der von jedem Gesellschafter auf das } \\
\text { Stammkapital zu leistenden Einlage (Stammeinlage). } \\
\text { (2) Soll das Unternehmen auf eine gewisse Zeit be- } \\
\text { schränkt sein oder sollen den Gesellschaftern außer der } \\
\text { Leistung von Kapitaleinlagen noch andere Verpflich- } \\
\text { tungen gegenüber der Gesellschaft auferlegt werden, } \\
\text { so bedürfen auch diese Bestimmungen der Aufnahme } \\
\text { in den Gesellschaftsvertrag. }\end{array}$ & $\begin{array}{l}\text { § } 3 \text { Inhalt des Gesellschaftsvertrages } \\
\text { (1) Der Gesellschaftsvertrag muss enthalten: } \\
\text { 1. die Firma und den Sitz der Gesellschaft, } \\
\text { 2. den Gegenstand des Unternehmens, } \\
\text { 3. den Betrag des Stammkapitals, } \\
\text { 4. die Zahl und die Nennbeträge der Geschäftsanteile, } \\
\text { die jeder Gesellschafter gegen Einlage auf das Stamm- } \\
\text { kapital (Stammeinlage) übernimmt. } \\
\text { (2) Soll das Unternehmen auf eine gewisse Zeit be- } \\
\text { schränkt sein oder sollen den Gesellschaftern außer der } \\
\text { Leistung von Kapitaleinlagen noch andere Verpflich- } \\
\text { tungen gegenüber der Gesellschaft auferlegt werden, } \\
\text { so bedürfen auch diese Bestimmungen der Aufnahme } \\
\text { in den Gesellschaftsvertrag. }\end{array}$ \\
\hline $\begin{array}{l}\text { § 4a Sitz der Gesellschaft } \\
\text { (1) Sitz der Gesellschaft ist der Ort, den der Gesell- } \\
\text { schaftsvertrag bestimmt. } \\
\text { (2) Als Sitz der Gesellschaft hat der Gesellschaftsver- } \\
\text { trag in der Regel den Ort, an dem die Gesellschaft } \\
\text { einen Betrieb hat, oder den Ort zu bestimmen, an dem } \\
\text { sich die Geschäftsleitung befindet oder die Verwaltung } \\
\text { geführt wird. }\end{array}$ & $\begin{array}{l}\text { \$ 4a Sitz der Gesellschaft. } \\
\text { (1) Sitz der Gesellschaft ist der Ort im Inland, den der } \\
\text { Gesellschaftsvertrag } \\
\text { bestimmt. } \\
\text { (2) [weggefallen] }\end{array}$ \\
\hline
\end{tabular}




\section{§ 5 Stammkapital; Stammeinlage}

(1) Das Stammkapital der Gesellschaft muss mindestens fünfundzwanzigtausend Euro, die Stammeinlage jedes Gesellschafters muss mindestens hundert Euro betragen.

(2) Kein Gesellschafter kann bei Errichtung der Gesellschaft mehrere Stammeinlagen übernehmen.

(3) Der Betrag der Stammeinlage kann für die einzelnen Gesellschafter verschieden bestimmt werden. Er muss in Euro durch fünfzig teilbar sein. Der Gesamtbetrag der Stammeinlagen muss mit dem Stammkapital übereinstimmen.

(4) Sollen Sacheinlagen geleistet werden, so müssen der Gegenstand der Sacheinlage und der Betrag der Stammeinlage, auf die sich die Sacheinlage bezieht, im Gesellschaftsvertrag festgesetzt werden. Die Gesellschafter haben in einem Sachgründungsbericht die für die Angemessenheit der Leistungen für Sacheinlagen wesentlichen Umstände darzulegen und beim Übergang eines Unternehmens auf die Gesellschaft die Jahresergebnisse der beiden letzten Geschäftsjahre anzugeben.

\section{§ 5a Unternehmergesellschaft}

$[\ldots]$

\section{§ 5 Stammkapital; Stammeinlage}

(1) Das Stammkapital der Gesellschaft muss mindestens Euro 10000 Euro betragen.

(2) Der Nennbetrag jedes Geschäftsanteils muss auf volle Euro lauten. Ein Gesellschafter kann bei Errichtung der Gesellschaft mehrere Geschäftsanteile übernehmen.

(3) Die Höhe der Nennbeträge der einzelnen Geschäftsanteile kann verschieden bestimmt werden. Die Summe der Nennbeträge aller Geschäftsanteile muss mit dem Stammkapital übereinstimmen

(4) Sollen Sacheinlagen geleistet werden, so müssen der Gegenstand der Sacheinlage und der Nennbetrag des Geschäftsanteils, auf den sich die Sacheinlage bezieht, im Gesellschaftsvertrag festgesetzt werden. Die Gesellschafter haben in einem Sachgründungsbericht die für die Angemessenheit der Leistungen für Sacheinlagen wesentlichen Umstände darzulegen und beim Übergang eines Unternehmens auf die Gesellschaft die Jahresergebnisse der beiden letzten Geschäftsjahre anzugeben.

\section{§ 5a Unternehmergesellschaft}

(1) Eine Gesellschaft, die mit einem Stammkapital gegründet wird, das den Betrag des Mindeststammkapitals nach $\S 5$ Abs. 1 unterschreitet, muss in der Firma abweichend von $\S 4$ den Rechtsformzusatz „Unternehmergesellschaft (haftungsbeschränkt)“ oder „UG (haftungsbeschränkt)“ führen.

(2) Abweichend von $\S 7$ Abs. 2 darf die Anmeldung erst erfolgen, wenn das Stammkapital in voller Höhe eingezahlt ist. Sacheinlagen sind ausgeschlossen.

(3) In der Bilanz des nach den $\S \S 242,264$ des Handelsgesetzbuchs aufzustellenden Jahresabschlusses ist eine gesetzliche Rücklage zu bilden, in die ein Viertel des um einen Verlustvortrag aus dem Vorjahr geminderten Jahresüberschusses einzustellen ist. Die Rücklage darf nur für Zwecke des § 57c verwandt werden.

(4) Abweichend von § 49 Abs. 3 muss die Versammlung der Gesellschafter bei drohender Zahlungsunfähigkeit unverzüglich einberufen werden.

(5) Erhöht die Gesellschaft ihr Stammkapital so, dass es den Betrag des Mindeststammkapitals nach $\S 5$ Abs. 1 erreicht oder übersteigt, finden die Absätze 1 bis 4 keine Anwendung mehr; die Firma nach Absatz 1 darf beibehalten werden. 
(1) Die Gesellschaft muss einen oder mehrere Geschäftsführer haben.

(2) Geschäftsführer kann nur eine natürliche, unbeschränkt geschäftsfähige Person sein. Ein Betreuter, der bei der Besorgung seiner Vermögensangelegenheiten ganz oder teilweise einem Einwilligungsvorbehalt (§ 1903 des Bürgerlichen Gesetzbuchs) unterliegt, kann nicht Geschäftsführer sein. Wer wegen einer Straftat nach den $\S \S 283$ bis 283 d des Strafgesetzbuchs verurteilt worden ist, kann auf die Dauer von fünf Jahren seit der Rechtskraft des Urteils nicht Geschäftsführer sein; in die Frist wird die Zeit nicht eingerechnet, in welcher der Täter auf behördliche Anordnung in einer Anstalt verwahrt worden ist. Wem durch gerichtliches Urteil oder durch vollziehbare Entscheidung einer Verwaltungsbehörde die Ausübung eines Berufs, Berufszweigs, Gewerbes oder Gewerbezweigs untersagt worden ist, kann für die Zeit, für welche das Verbot wirksam ist, bei einer Gesellschaft, deren Unternehmensgegenstand ganz oder teilweise mit dem Gegenstand des Verbots übereinstimmt, nicht Geschäftsführer sein.

(3) $\mathrm{Zu} \mathrm{Geschäftsführern} \mathrm{können} \mathrm{Gesellschafter} \mathrm{oder}$ andere Personen bestellt werden. Die Bestellung erfolgt entweder im Gesellschaftsvertrag oder nach Maßgabe der Bestimmungen des dritten Abschnitts.

(4) Ist im Gesellschaftsvertrag bestimmt, dass sämtliche Gesellschafter zur Geschäftsführung berechtigt sein sollen, so gelten nur die der Gesellschaft bei Festsetzung dieser Bestimmung angehörenden Personen als die bestellten Geschäftsführer.
(1) Die Gesellschaft muss einen oder mehrere Geschäftsführer haben.

(2) Geschäftsführer kann nur eine natürliche, unbeschränkt geschäftsfähige Person sein. Geschäftsführer kann nicht sein, wer

1. als Betreuter bei der Besorgung seiner Vermögensangelegenheiten ganz oder teilweise einem Einwilligungsvorbehalt ( $\$ 1903$ des Bürgerlichen Gesetzbuchs) unterliegt,

2. aufgrund eines gerichtlichen Urteils oder einer vollziehbaren Entscheidung einer Verwaltungsbehörde einen Beruf, einen Berufszweig, ein Gewerbe oder einen Gewerbezweig nicht ausüben darf, sofern der Unternehmensgegenstand ganz oder teilweise mit dem Gegenstand des Verbots übereinstimmt,

3. wegen einer oder mehrerer vorsätzlich begangener Straftaten

a) des Unterlassens der Stellung des Antrags auf Eröffnung des Insolvenzverfahrens (Insolvenzverschleppung),

b) nach den $\S \S 283$ bis 283 d des Strafgesetzbuchs (Insolvenzstraftaten),

c) der falschen Angaben nach $\S 82$ dieses Gesetzes oder $\S 399$ des Aktiengesetzes,

d) der unrichtigen Darstellung nach $\S 400$ des Aktiengesetzes, § 331 des Handelsgesetzbuchs, § 313 des Umwandlungsgesetzes oder $\S 17$ des Publizitätsgesetzes oder

e) nach den $\S \S 265 b, 266$ oder $\S 266 a$ des Strafgesetzbuchs zu einer Freiheitsstrafe von mindestens einem Jahr verurteilt worden ist; dieser Ausschluss gilt für die Dauer von fünf Jahren seit der Rechtskraft des Urteils, wobei die Zeit nicht eingerechnet wird, in welcher der Täter auf behördliche Anordnung in einer Anstalt verwahrt worden ist. Satz 2 Nr. 3 gilt entsprechend bei einer Verurteilung im Ausland wegen einer Tat, die mit den in Satz 2 Nr. 3 genannten Taten vergleichbar ist.

(3) $\mathrm{Zu}$ Geschäftsführern können Gesellschafter oder andere Personen bestellt werden. Die Bestellung erfolgt entweder im Gesellschaftsvertrag oder nach Maßgabe der Bestimmungen des dritten Abschnitts.

(4) Ist im Gesellschaftsvertrag bestimmt, dass sämtliche Gesellschafter zur Geschäftsführung berechtigt sein sollen, so gelten nur die der Gesellschaft bei Festsetzung dieser Bestimmung angehörenden Personen als die bestellten Geschäftsführer. 


\section{\$ 7 Anmeldung}

(1) Die Gesellschaft ist bei dem Gericht, in dessen Bezirk sie ihren Sitz hat, zur Eintragung in das Handelsregister anzumelden.

(2) Die Anmeldung darf erst erfolgen, wenn auf jede Stammeinlage, soweit nicht Sacheinlagen vereinbart sind, ein Viertel des Nennbetrags eingezahlt ist. Insgesamt muss auf das Stammkapital mindestens soviel eingezahlt sein, dass der Gesamtbetrag der eingezahlten Geldeinlagen zuzüglich des Gesamtbetrags der Stammeinlagen, für die Sacheinlagen zu leisten sind, die Hälfte des Mindeststammkapitals gemäß $§ 5$ Abs. 1 erreicht. Wird die Gesellschaft nur durch eine Person errichtet, so darf die Anmeldung erst erfolgen, wenn mindestens die nach den Sätzen 1 und 2 vorgeschriebenen Einzahlungen geleistet sind und der Gesellschafter für den übrigen Teil der Geldeinlage eine Sicherung bestellt hat.

(3) Die Sacheinlagen sind vor der Anmeldung der Gesellschaft zur Eintragung in das Handelsregister so an die Gesellschaft zu bewirken, dass sie endgültig zur freien Verfügung der Geschäftsführer stehen.

\section{§ 8 Inhalt der Anmeldung}

(1) Der Anmeldung müssen beigefügt sein:

1. der Gesellschaftsvertrag und im Fall des $\S 2$ Abs. 2 die Vollmachten der Vertreter, welche den Gesellschaftsvertrag unterzeichnet haben, oder eine beglaubigte Abschrift dieser Urkunden,

2. die Legitimation der Geschäftsführer, sofern dieselben nicht im Gesellschaftsvertrag bestellt sind,

3. eine von den Anmeldenden unterschriebene Liste der Gesellschafter, aus welcher Name, Vorname, Geburtsdatum und Wohnort der letzteren sowie der Betrag der von einem jeden derselben übernommenen Stammeinlage ersichtlich ist,

4. im Fall des $§ 5$ Abs. 4 die Verträge, die den Festsetzungen zugrunde liegen oder zu ihrer Ausführung geschlossen worden sind, und der Sachgründungsbericht,

5. wenn Sacheinlagen vereinbart sind, Unterlagen darüber, dass der Wert der Sacheinlagen den Betrag der dafür übernommenen Stammeinlagen erreicht,

6. in dem Fall, dass der Gegenstand des Unternehmens der staatlichen Genehmigung bedarf, die Genehmigungsurkunde.

\section{§ 7 Anmeldung}

(1) Die Gesellschaft ist bei dem Gericht, in dessen Bezirk sie ihren Sitz hat, zur Eintragung in das Handelsregister anzumelden.

(2) Die Anmeldung darf erst erfolgen, wenn jeden Geschäftsanteil, soweit nicht Sacheinlagen vereinbart sind, ein Viertel des Nennbetrags eingezahlt ist. Insgesamt muss auf das Stammkapital mindestens soviel eingezahlt sein, dass der Gesamtbetrag der eingezahlten Geldeinlagen zuzüglich des Gesamtnennbetrags der Geschäftsanteile, für die Sacheinlagen zu leisten sind, die Hälfte des Mindeststammkapitals gemäß $\S 5$ Abs. 1 erreicht. [...] Für die Anmeldung können im Fall des $\S 2$ Abs. 1a die Muster der Anlage 2 verwendet werden.

(3) Die Sacheinlagen sind vor der Anmeldung der Gesellschaft zur Eintragung in das Handelsregister so an die Gesellschaft zu bewirken, dass sie endgültig zur freien Verfügung der Geschäftsführer stehen.

\section{§ 8 Inhalt der Anmeldung}

(1) Der Anmeldung müssen beigefügt sein:

1. der Gesellschaftsvertrag und im Fall des $\S 2$ Abs. 2 die Vollmachten der Vertreter, welche den Gesellschaftsvertrag unterzeichnet haben, oder eine beglaubigte Abschrift dieser Urkunden,

2. die Legitimation der Geschäftsführer, sofern dieselben nicht im Gesellschaftsvertrag bestellt sind,

3. eine von den Anmeldenden unterschriebene Liste der Gesellschafter, aus welcher Name, Vorname, Geburtsdatum und Wohnort der letzteren sowie die Nennbeträge und die laufenden Nummern der von einem jeden derselben übernommenen Geschäftsanteile ersichtlich sind,

4. im Fall des $\S 5$ Abs. 4 die Verträge, die den Festsetzungen zugrunde liegen oder zu ihrer Ausführung geschlossen worden sind, und der Sachgründungsbericht,

5. wenn Sacheinlagen vereinbart sind, Unterlagen darüber, dass der Wert der Sacheinlagen den Nennbetrag der dafür übernommenen Geschäftsanteile erreicht.

6. [weggefallen] 
(2) In der Anmeldung ist die Versicherung abzugeben, dass die in $\S 7$ Abs. 2 und 3 bezeichneten Leistungen auf die Stammeinlagen bewirkt sind und dass der Gegenstand der Leistungen sich endgültig in der freien Verfügung der Geschäftsführer befindet. Wird die Gesellschaft nur durch eine Person errichtet und die Geldeinlage nicht voll eingezahlt, so ist auch zu versichern, dass die nach $\S 7$ Abs. 2 Satz 3 erforderliche Sicherung bestellt ist.

(3) In der Anmeldung haben die Geschäftsführer zu versichern, dass keine Umstände vorliegen, die ihrer Bestellung nach $\S \quad 6$ Abs. 2 Satz 3 und 4entgegenstehen, und dass sie über ihre unbeschränkte Auskunftspflicht gegenüber dem Gericht belehrt worden sind. Die Belehrung nach $\S 51$ Abs. 2 des Gesetzes über das Zentralregister und das Erziehungsregister in der Fassung der Bekanntmachung vom 22. Juli 1976 (BGBl. I S. 2005) kann auch durch einen Notar vorgenommen werden.

(4) In der Anmeldung ist ferner anzugeben, welche Vertretungsbefugnis die Geschäftsführer haben.

(5) Für die Einreichung von Unterlagen nach diesem Gesetz gilt $\S 12$ Abs. 2 des Handelsgesetzbuchs entsprechend.

\section{§ 9 Geldeinlage statt Sacheinlage}

(1) Erreicht der Wert einer Sacheinlage im Zeitpunkt der Anmeldung der Gesellschaft zur Eintragung in das Handelsregister nicht den Betrag der dafür übernommenen Stammeinlage, hat der Gesellschafter in Höhe des Fehlbetrags eine Einlage in Geld zu leisten.

(2) Der Anspruch der Gesellschaft verjährt in zehn Jahren seit der Eintragung der Gesellschaft in das Handelsregister.

\section{§ 9a Ersatzansprüche der Gesellschaft}

(1) Werden zum Zweck der Errichtung der Gesellschaft falsche Angaben gemacht, so haben die Gesellschafter und Geschäftsführer der Gesellschaft als Gesamtschuldner fehlende Einzahlungen zu leisten, eine Vergütung, die nicht unter den Gründungsaufwand
(2) In der Anmeldung ist die Versicherung abzugeben, dass die in $\S 7$ Abs. 2 und 3 bezeichneten Leistungen auf die Geschäftsanteile bewirkt sind und dass der Gegenstand der Leistungen sich endgültig in der freien Verfügung der Geschäftsführer befindet. Die vor Einlage getroffene Vereinbarung einer Leistung an den Gesellschafter, die wirtschaftlich einer Einlagenrückgewähr entspricht und die nicht bereits als verdeckte Sacheinlage nach $\S 19$ Abs. 4 zu beurteilen ist, steht der Erfüllung der Einlagenschuld nicht entgegen, wenn sie durch einen vollwertigen Gegenleistungs- oder Rückgewähranspruch gedeckt ist. Das Gericht kann bei erheblichen Zweifeln an der Richtigkeit der Versicherung Nachweise (unter anderem Einzahlungsbelege) verlangen.

(3) In der Anmeldung haben die Geschäftsführer zu versichern, dass keine Umstände vorliegen, die ihrer Bestellung nach $\S 6$ Abs. 2 Satz 2 Nr. 2 und 3 sowie Satz 3 entgegenstehen, und dass sie über ihre unbeschränkte Auskunftspflicht gegenüber dem Gericht belehrt worden sind. Die Belehrung nach $\S 53$ Abs. 2 des Bundeszentralregistergesetzes kann schriftlich vorgenommen werden; sie kann auch durch einen Notar oder einen im Ausland bestellten Notar, durch einen Vertreter eines vergleichbaren rechtsberatenden Berufs oder einen Konsularbeamten erfolgen.

(4) In der Anmeldung sind ferner anzugeben

1. eine inländische Geschäftsanschrift,

2. Art und Umfang der Vertretungsbefugnis der Geschäftsführer.

(5) Für die Einreichung von Unterlagen nach diesem Gesetz gilt $\S 12$ Abs. 2 des Handelsgesetzbuchs entsprechend.

\section{§ 9 Geldeinlage statt Sacheinlage}

(1) Erreicht der Wert einer Sacheinlage im Zeitpunkt der Anmeldung der Gesellschaft zur Eintragung in das Handelsregister nicht den Nennbetrag des dafür übernommenen Geschäftsanteils, hat der Gesellschafter in Höhe des Fehlbetrags eine Einlage in Geld zu leisten. Sonstige Ansprüche bleiben unberührt.

(2) Der Anspruch der Gesellschaft nach Absatz 1 Satz 1 verjährt in zehn Jahren seit der Eintragung der Gesellschaft in das Handelsregister.

\section{§ 9a Ersatzansprüche der Gesellschaft}

(1) Werden zum Zweck der Errichtung der Gesellschaft falsche Angaben gemacht, so haben die Gesellschafter und Geschäftsführer der Gesellschaft als Gesamtschuldner fehlende Einzahlungen zu leisten, eine Vergütung, die nicht unter den Gründungsaufwand 
aufgenommen ist, zu ersetzen und für den sonst entstehenden Schaden Ersatz zu leisten.

(2) Wird die Gesellschaft von Gesellschaftern durch Einlagen oder Gründungsaufwand vorsätzlich oder aus grober Fahrlässigkeit geschädigt, so sind ihr alle Gesellschafter als Gesamtschuldner zum Ersatz verpflichtet.

(3) Von diesen Verpflichtungen ist ein Gesellschafter oder ein Geschäftsführer befreit, wenn er die die Ersatzpflicht begründenden Tatsachen weder kannte noch bei Anwendung der Sorgfalt eines ordentlichen Geschäftsmannes kennen musste.

(4) Neben den Gesellschaftern sind in gleicher Weise Personen verantwortlich, für deren Rechnung die Gesellschafter Stammeinlagen übernommen haben. Sie können sich auf ihre eigene Unkenntnis nicht wegen solcher Umstände berufen, die ein für ihre Rechnung handelnder Gesellschafter kannte oder bei Anwendung der Sorgfalt eines ordentlichen Geschäftsmannes kennen musste.

\section{§ 9c Ablehung der Eintragung}

(1) Ist die Gesellschaft nicht ordnungsgemäß errichtet und angemeldet, so hat das Gericht die Eintragung abzulehnen. Dies gilt auch, wenn Sacheinlagen überbewertet worden sind.

(2) Wegen einer mangelhaften, fehlenden oder nichtigen Bestimmung des Gesellschaftsvertrages darf das Gericht die Eintragung nach Absatz 1 nur ablehnen, soweit diese Bestimmung, ihr Fehlen oder ihre Nichtigkeit

1. Tatsachen oder Rechtsverhältnisse betrifft, die nach $\S 3$ Abs. 1 oder auf Grund anderer zwingender gesetzlicher Vorschriften in dem Gesellschaftsvertrag bestimmt sein müssen oder die in das Handelsregister einzutragen oder von dem Gericht bekanntzumachen sind,

2. Vorschriften verletzt, die ausschließlich oder überwiegend zum Schutze der Gläubiger der Gesellschaft oder sonst im öffentlichen Interesse gegeben sind, oder

3. die Nichtigkeit des Gesellschaftsvertrages zur Folge hat.

\section{§ 10 Eintragung in das Handelsregister}

(1) Bei der Eintragung in das Handelsregister sind die Firma und der Sitz der Gesellschaft, der Gegenstand des Unternehmens, die Höhe des Stammkapitals, der Tag des Abschlusses des Gesellschaftsvertrags und die Personen der Geschäftsführer anzugeben. Ferner ist einzutragen, welche Vertretungsbefugnis die Ge- aufgenommen ist, zu ersetzen und für den sonst entstehenden Schaden Ersatz zu leisten.

(2) Wird die Gesellschaft von Gesellschaftern durch Einlagen oder Gründungsaufwand vorsätzlich oder aus grober Fahrlässigkeit geschädigt, so sind ihr alle Gesellschafter als Gesamtschuldner zum Ersatz verpflichtet.

(3) Von diesen Verpflichtungen ist ein Gesellschafter oder ein Geschäftsführer befreit, wenn er die die Ersatzpflicht begründenden Tatsachen weder kannte noch bei Anwendung der Sorgfalt eines ordentlichen Geschäftsmannes kennen musste.

(4) Neben den Gesellschaftern sind in gleicher Weise Personen verantwortlich, für deren Rechnung die Gesellschafter Geschäftsanteile übernommen haben. Sie können sich auf ihre eigene Unkenntnis nicht wegen solcher Umstände berufen, die ein für ihre Rechnung handelnder Gesellschafter kannte oder bei Anwendung der Sorgfalt eines ordentlichen Geschäftsmannes kennen musste.

\section{§ 9c Ablehung der Eintragung}

(1) Ist die Gesellschaft nicht ordnungsgemäß errichtet und angemeldet, so hat das Gericht die Eintragung abzulehnen. Dies gilt auch, wenn Sacheinlagen nicht unwesentlich überbewertet worden sind.

(2) Wegen einer mangelhaften, fehlenden oder nichtigen Bestimmung des Gesellschaftsvertrages darf das Gericht die Eintragung nach Absatz 1 nur ablehnen, soweit diese Bestimmung, ihr Fehlen oder ihre Nichtigkeit

1. Tatsachen oder Rechtsverhältnisse betrifft, die nach $\S 3$ Abs. 1 oder auf Grund anderer zwingender gesetzlicher Vorschriften in dem Gesellschaftsvertrag bestimmt sein müssen oder die in das Handelsregister einzutragen oder von dem Gericht bekanntzumachen sind,

2. Vorschriften verletzt, die ausschließlich oder überwiegend zum Schutze der Gläubiger der Gesellschaft oder sonst im öffentlichen Interesse gegeben sind, oder

3. die Nichtigkeit des Gesellschaftsvertrages zur Folge hat.

\section{$\S 10$ Eintragung in das Handelsregister}

(1) Bei der Eintragung in das Handelsregister sind die Firma und der Sitz der Gesellschaft, eine inländische Geschäftsanschrift, der Gegenstand des Unternehmens, die Höhe des Stammkapitals, der Tag des Abschlusses des Gesellschaftsvertrags und die Personen der Geschäftsführer anzugeben. Ferner ist einzutragen, wel- 
schäftsführer haben.

(2) Enthält der Gesellschaftsvertrag eine Bestimmung über die Zeitdauer der Gesellschaft, so ist auch diese Bestimmung einzutragen.

(3) [weggefallen]

\section{§ 14 Geschäftsanteil}

Der Geschäftsanteil jedes Gesellschafters bestimmt sich nach dem Betrag der von ihm übernommenen Stammeinlage.

§ 16 Rechtsstellung von Veräußerer und Erwerber

(1) Der Gesellschaft gegenüber gilt im Fall der Veräußerung des Geschäftsanteils nur derjenige als Erwerber, dessen Erwerb unter Nachweis des Übergangs bei der Gesellschaft angemeldet ist.

(2) Die vor der Anmeldung von der Gesellschaft gegenüber dem Veräußerer oder von dem letzteren gegenüber der Gesellschaft in bezug auf das Gesellschaftsverhältnis vorgenommenen Rechtshandlungen muß der Erwerber gegen sich gelten lassen.

(3) Für die zur Zeit der Anmeldung auf den Geschäftsanteil rückständigen Leistungen ist der Erwerber neben dem Veräußerer verhaftet. che Vertretungsbefugnis die Geschäftsführer haben.

(2) Enthält der Gesellschaftsvertrag eine Bestimmung über die Zeitdauer der Gesellschaft, so ist auch diese Bestimmung einzutragen. Wenn eine Person, die für Zustellungen an die Gesellschaft empfangsberechtigt ist, mit einer inländischen Anschrift zur Eintragung in das Handelsregister angemeldet wird, sind auch diese Angaben einzutragen; Dritten gegenüber gilt die Empfangsberechtigung als fortbestehend, bis sie im Handelsregister gelöscht und die Löschung bekannt gemacht worden ist, es sei denn, dass die fehlende Empfangsberechtigung dem Dritten bekannt war.

(3) [weggefallen]

\section{$\S 14$ Einlagepflicht}

Auf jeden Geschäftsanteil ist eine Einlage zu leisten. Die Höhe der zu leistenden Einlage richtet sich nach dem bei der Errichtung der Gesellschaft im Gesellschaftsvertrag festgesetzten Nennbetrag des Geschäftsanteils. Im Fall der Kapitalerhöhung bestimmt sich die Höhe der zu leistenden Einlage nach dem in der Übernahmeerklärung festgesetzten Nennbetrag des Geschäftsanteils

§ 16 Rechtsstellung bei Wechsel der Gesellschafter oder Veränderung des Umfangs ihrer Beteiligung; Erwerb vom Nichtberechtigten

(1) Im Verhältnis zur Gesellschaft gilt im Fall einer Veränderung in den Personen der Gesellschafter oder des Umfangs ihrer Beteiligung als Inhaber eines Geschäftsanteils nur, wer als solcher in der im Handelsregister aufgenommenen Gesellschafterliste ( $\$ 40)$ eingetragen ist. Eine vom Erwerber in Bezug auf das Gesellschaftsverhältnis vorgenommene Rechtshandlung gilt als von Anfang an wirksam, wenn die Liste unverzüglich nach Vornahme der Rechtshandlung in das Handelsregister aufgenommen wird.

(2) Für Einlageverpflichtungen, die in dem Zeitpunkt rückständig sind, ab dem der Erwerber gem. Absatz 1 Satz 1 im Verhältnis zur Gesellschaft als Inhaber des Geschäftsanteils gilt, haftet der Erwerber neben dem Veräußerer.

(3) Der Erwerber kann einen Geschäftsanteil oder ein Recht daran durch Rechtsgeschäft wirksam vom Nichtberechtigten erwerben, wenn der Veräußerer als Inhaber des Geschäftsanteils in der im Handelsregister aufgenommenen Gesellschafterliste eingetragen ist. Dies gilt nicht, wenn die Liste zum Zeitpunkt des Erwerbs hinsichtlich des Geschäftsanteils weniger als drei Jahre unrichtig und die Unrichtigkeit dem Berechtigten nicht zuzurechnen ist. Ein gutgläubiger Erwerb ist ferner nicht möglich, wenn dem Erwerber die man- 


\section{§ 17 Veräußerung von Teilen eines Geschäftsanteils}

(1) Die Veräußerung von Teilen eines Geschäftsanteils kann nur mit Genehmigung der Gesellschaft stattfinden.

(2) Die Genehmigung bedarf der schriftlichen Form; sie muß die Person des Erwerbers und den Betrag bezeichnen, welcher von der Stammeinlage des ungeteilten Geschäftsanteils auf jeden der durch die Teilung entstehenden Geschäftsanteile entfällt.

(3) Im Gesellschaftsvertrag kann bestimmt werden, daß für die Veräußerung von Teilen eines Geschäftsanteils an andere Gesellschafter, sowie für die Teilung von Geschäftsanteilen verstorbener Gesellschafter unter deren Erben eine Genehmigung der Gesellschaft nicht erforderlich ist.

(4) Die Bestimmungen in $\S 5$ Abs. 1 und 3 über den Betragder Stammeinlagen finden bei der Teilung von Geschäftsanteilen entsprechende Anwendung.

(5) Eine gleichzeitige Übertragung mehrerer Teile von Geschäftsanteilen eines Gesellschafters an denselben Erwerber ist unzulässig.

(6) Außer dem Fall der Veräußerung und Vererbung findet eine Teilung von Geschäftsanteilen nicht statt. Sie kann im Gesellschaftsvertrag auch für diese Fälle ausgeschlossen werden.

\section{$\S 19$ Einzahlung auf die Stammeinlage}

(1) Die Einzahlungen auf die Stammeinlagen sind nach dem Verhältnis der Geldeinlagen zu leisten.

(2) Von der Verpflichtung zur Leistung der Einlagen können die Gesellschafter nicht befreit werden. Gegen den Anspruch der Gesellschaft ist die Aufrechnung nicht zulässig. An dem Gegenstand einer Sacheinlage kann wegen Forderungen, welche sich nicht auf den Gegenstand beziehen, kein Zurückbehaltungsrecht geltend gemacht werden.

(3) Durch eine Kapitalherabsetzung können die Gesellschafter von der Verpflichtung zur Leistung von Einlagen höchstens in Höhe des Betrags befreit wer- gelnde Berechtigung bekannt oder infolge grober Fahrlässigkeit unbekannt ist oder der Liste ein Widerspruch zugeordnet ist. Die Zuordnung eines Widerspruchs erfolgt aufgrund einer einstweiligen Verfügung oder aufgrund einer Bewilligung desjenigen, gegen dessen Berechtigung sich der Widerspruch richtet. Eine Gefährdung des Rechts des Widersprechenden muss nicht glaubhaft gemacht werden.

$\S 17$ Veräußerung von Teilen eines Geschäftsanteils

[weggefallen]

\section{§ 19 Einzahlung auf die Stammeinlage}

(1) Die Einzahlungen auf die Stammeinlagen sind nach dem Verhältnis der Geldeinlagen zu leisten.

(2) Von der Verpflichtung zur Leistung der Einlagen können die Gesellschafter nicht befreit werden. Gegen den Anspruch der Gesellschaft ist die Aufrechnung nur zulässig mit einer Forderung aus der Überlassung von Vermögensgegenständen, deren Anrechnung auf die Einlageverpflichtung nach $\S 5$ Abs. 4 Satz 1 vereinbart worden ist. An dem Gegenstand einer Sacheinlage kann wegen Forderungen, welche sich nicht auf den Gegenstand beziehen, kein Zurückbehaltungsrecht geltend gemacht werden.

(3) Durch eine Kapitalherabsetzung können die Gesellschafter von der Verpflichtung zur Leistung von Einlagen höchstens in Höhe des Betrags befreit wer- 
den, um den das Stammkapital herabgesetzt worden ist.

(4) Vereinigen sich innerhalb von drei Jahren nach der Eintragung der Gesellschaft in das Handelsregister alle Geschäftsanteile in der Hand eines Gesellschafters oder daneben in der Hand der Gesellschaft, so hat der Gesellschafter innerhalb von drei Monaten seit der Vereinigung der Geschäftsanteile alle Geldeinlagen voll einzuzahlen oder der Gesellschaft für die Zahlung der noch ausstehenden Beträge eine Sicherung zu bestellen oder einen Teil der Geschäftsanteile an einen Dritten zu übertragen.

(5) Eine Leistung auf die Stammeinlage, welche nicht in Geld besteht oder welche durch Aufrechnung einer für die Überlassung von Vermögensgegenständen $\mathrm{zu}$ gewährenden Vergütung bewirkt wird, befreit den Gesellschafter von seiner Verpflichtung nur, soweit sie in Ausführung einer nach $\S 5$ Abs. 4 Satz 1 getroffenen Bestimmung erfolgt.

(6) Der Anspruch der Gesellschaft auf Leistung der Einlagen verjährt in zehn Jahren von seiner Entstehung an. Wird das Insolvenzverfahren über das Vermögen der Gesellschaft eröffnet, so tritt die Verjährung nicht vor Ablauf von sechs Monaten ab dem Zeitpunkt der Eröffnung ein.

\section{§ 22 Haftung der Rechtsvorgänger}

(1) Wegen des von dem ausgeschlossenen Gesellschafter nicht bezahlten Betrags der Stammeinlage ist der Gesellschaft der letzte und jeder frühere, bei der $\mathrm{Ge}-$ sellschaft angemeldete Rechtsvorgänger des Ausgeschlossenen verhaftet.

(2) Ein früherer Rechtsvorgänger haftet nur, soweit die Zahlung von dessen Rechtsnachfolger nicht zu erlangen ist; dies ist bis zum Beweis des Gegenteils anzunehmen, wenn der letztere die Zahlung nicht bis zum Ablauf eines Monats geleistet hat, nachdem an ihn die Zahlungsaufforderung und an den Rechtsvorgänger die Benachrichtigung von derselben erfolgt ist.

(3) Die Haftpflicht des Rechtsvorgängers ist auf die innerhalb der Frist von fünf Jahren auf die Stammeinlage eingeforderten Einzahlungen beschränkt. Die Frist beginnt mit dem Tage, an welchem der Übergang des Geschäftsanteils auf den Rechtsnachfolger ordnungsmäßig angemeldet ist.

(4) Der Rechtsvorgänger erwirbt gegen Zahlung des den, um den das Stammkapital herabgesetzt worden ist.

(4) Ist eine Geldeinlage eines Gesellschafters bei wirtschaftlicher Betrachtung und aufgrund einer im $\mathrm{Zu}$ sammenhang mit der Übernahme der Geldeinlage getroffenen Abrede vollständig oder teilweise als Sacheinlage zu bewerten (verdeckte Sacheinlage), so steht das der Erfüllung der Einlagenschuld nicht entgegen. § 9 gilt in diesem Fall entsprechend, wenn der Wert des Vermögensgegenstandes im Zeitpunkt der Anmeldung der Gesellschaft zur Eintragung in das Handelsregister oder im Zeitpunkt seiner Überlassung an die Gesellschaft, falls diese später erfolgt, nicht den entsprechenden Betrag der übernommenen Stammeinlage erreicht. Die Beweislast für die Werthaltigkeit des Vermögensgegenstandes trägt der Gesellschafter. Die Verjährung des Anspruchs der Gesellschaft beginnt nicht vor dem Zeitpunkt der Überlassung des Vermögensgegenstandes.

(5) Der Anspruch der Gesellschaft auf Leistung der Einlagen verjährt in zehn Jahren von seiner Entstehung an. Wird das Insolvenzverfahren über das Vermögen der Gesellschaft eröffnet, so tritt die Verjährung nicht vor Ablauf von sechs Monaten ab dem Zeitpunkt der Eröffnung ein.

\section{§ 22 Haftung der Rechtsvorgänger}

(1) Für eine von dem ausgeschlossenen Gesellschafter nicht erfüllte Einlageverpflichtung haftet der Gesellschaft auch der letzte und jeder frühere Rechtsvorgänger des Ausgeschlossenen, der im Verhältnis zu ihr als Inhaber des Geschäftsanteils gilt.

(2) Ein früherer Rechtsvorgänger haftet nur, soweit die Zahlung von dessen Rechtsnachfolger nicht zu erlangen ist; dies ist bis zum Beweis des Gegenteils anzunehmen, wenn der letztere die Zahlung nicht bis zum Ablauf eines Monats geleistet hat, nachdem an ihn die Zahlungsaufforderung und an den Rechtsvorgänger die Benachrichtigung von derselben erfolgt ist.

(3) Die Haftung des Rechtsvorgängers ist auf die innerhalb der Frist von fünf Jahren auf die Einlageverpflichtung eingeforderten Leistungen beschränkt. Die Frist beginnt mit demTag, ab welchem der Rechtsnachfolger im Verhältnis zur Gesellschaft als Inhaber des Geschäftsanteils gilt.

(4) Der Rechtsvorgänger erwirbt gegen Zahlung des 
rückständigen Betrags den Geschäftsanteil des ausgeschlossenen Gesellschafters.

\section{$\S 26$ Nachschusspflicht}

(1) Im Gesellschaftsvertrag kann bestimmt werden, dass die Gesellschafter über den Betrag der Stammeinlagen hinaus die Einforderung von weiteren Einzahlungen (Nachschüssen) beschließen können.

(2) Die Einzahlung der Nachschüsse hat nach Verhältnis der Geschäftsanteile zu erfolgen.

(3) Die Nachschusspflicht kann im Gesellschaftsvertrag auf einen bestimmten, nach Verhältnis der Geschäftsanteile festzusetzenden Betrag beschränkt werden.

\section{§ 30 Rückzahlungen}

(1) Das zur Erhaltung des Stammkapitals erforderliche Vermögen der Gesellschaft darf an die Gesellschafter nicht ausgezahlt werden.

(2) Eingezahlte Nachschüsse können, soweit sie nicht zur Deckung eines Verlustes am Stammkapital erforderlich sind, an die Gesellschafter zurückgezahlt werden. Die Zurückzahlung darf nicht vor Ablauf von drei Monaten erfolgen, nachdem der Rückzahlungsbeschluss nach $\S 12$ bekannt gemacht ist. Im Fall des $\S$ 28 Abs. 2 ist die Zurückzahlung von Nachschüssen vor der Volleinzahlung des Stammkapitals unzulässig. Zurückgezahlte Nachschüsse gelten als nicht eingezogen.

\section{§ 31 Erstattung von verbotenen Rückzahlungen}

(1) Zahlungen, welche den Vorschriften des $\S 30 \mathrm{zu}-$ wider geleistet sind, müssen der Gesellschaft erstattet werden.

(2) War der Empfänger in gutem Glauben, so kann die Erstattung nur insoweit verlangt werden, als sie zur Befriedigung der Gesellschaftsgläubiger erforderlich ist.

(3) Ist die Erstattung von dem Empfänger nicht zu erlangen, so haften für den $\mathrm{zu}$ erstattenden Betrag, soweit er zur Befriedigung der Gesellschaftsgläubiger rückständigen Betrags den Geschäftsanteil des ausgeschlossenen Gesellschafters.

\section{§ 26 Nachschusspflicht}

(1) Im Gesellschaftsvertrag kann bestimmt werden, dass die Gesellschafter über die Nennbeträge der Geschäftsanteile hinaus die Einforderung von weiteren Einzahlungen (Nachschüssen) beschließen können.

(2) Die Einzahlung der Nachschüsse hat nach Verhältnis der Geschäftsanteile zu erfolgen.

(3) Die Nachschusspflicht kann im Gesellschaftsvertrag auf einen bestimmten, nach Verhältnis der Geschäftsanteile festzusetzenden Betrag beschränkt werden.

\section{§ 30 Rückzahlungen}

(1) Das zur Erhaltung des Stammkapitals erforderliche Vermögen der Gesellschaft darf an die Gesellschafter nicht ausgezahlt werden. Satz 1 gilt nicht bei Leistungen, die zwischen den Vertragsteilen eines Beherrschungs- oder Gewinnabführungsvertrags ( $\$ 291$ des Aktiengesetzes) erfolgen oder durch einen vollwertigen Gegen-leistungs- oder Rückgewähranspruch gegen den Gesellschafter gedeckt sind. Satz 1 ist zudem nicht anzuwenden auf die Rückgewähr eines Gesellschafterdarlehens und Leistungen auf Forderungen aus Rechtshandlungen, die einem Gesellschafterdarlehen wirtschaftlich entsprechen

(2) Eingezahlte Nachschüsse können, soweit sie nicht zur Deckung eines Verlustes am Stammkapital erforderlich sind, an die Gesellschafter zurückgezahlt werden. Die Zurückzahlung darf nicht vor Ablauf von drei Monaten erfolgen, nachdem der Rückzahlungsbeschluss nach $\S 12$ bekannt gemacht ist. Im Fall des $\S$ 28 Abs. 2 ist die Zurückzahlung von Nachschüssen vor der Volleinzahlung des Stammkapitals unzulässig. Zurückgezahlte Nachschüsse gelten als nicht eingezogen.

\section{§ 31 Erstattung von verbotenen Rückzahlungen}

(1) Zahlungen, welche den Vorschriften des $\S 30 \mathrm{zu}-$ wider geleistet sind, müssen der Gesellschaft erstattet werden.

(2) War der Empfänger in gutem Glauben, so kann die Erstattung nur insoweit verlangt werden, als sie zur Befriedigung der Gesellschaftsgläubiger erforderlich ist.

(3) Ist die Erstattung von dem Empfänger nicht $\mathrm{zu}$ erlangen, so haften für den zu erstattenden Betrag, soweit er zur Befriedigung der Gesellschaftsgläubiger 
erforderlich ist, die übrigen Gesellschafter nach Verhältnis ihrer Geschäftsanteile. Beiträge, welche von einzelnen Gesellschaftern nicht zu erlangen sind, werden nach dem bezeichneten Verhältnis auf die übrigen verteilt.

(4) Zahlungen, welche auf Grund der vorstehenden Bestimmungen zu leisten sind, können den Verpflichteten nicht erlassen werden.

(5) Die Ansprüche der Gesellschaft verjähren in den Fällen des Absatzes 1 in zehn Jahren sowie in den Fällen des Absatzes 3 in fünf Jahren. Die Verjährung beginnt mit dem Ablauf des Tages, an welchem die Zahlung, deren Erstattung beansprucht wird, geleistet ist. In den Fällen des Absatzes 1 findet $\S 19$ Abs. 6 Satz 2 entsprechende Anwendung.

(6) Für die in den Fällen des Absatzes 3 geleistete Erstattung einer Zahlung sind den Gesellschaftern die Geschäftsführer, welchen in betreff der geleisteten Zahlung ein Verschulden zur Last fällt, solidarisch zum Ersatz verpflichtet. Die Bestimmungen in $\S 43$ Abs. 1 und 4 finden entsprechende Anwendung.

\section{§ 32a Rückgewähr von Darlehen}

(1) Hat ein Gesellschafter der Gesellschaft in einem Zeitpunkt, in dem ihr die Gesellschafter als ordentliche Kaufleute Eigenkapital zugeführt hätten (Krise der Gesellschaft), statt dessen ein Darlehen gewährt, so kann er den Anspruch auf Rückgewähr des Darlehens im Insolvenzverfahren über das Vermögen der Gesellschaft nur als nachrangiger Insolvenzgläubiger geltend machen.

(2) Hat ein Dritter der Gesellschaft in einem Zeitpunkt, in dem ihr die Gesellschafter als ordentliche Kaufleute Eigenkapital zugeführt hätten, statt dessen ein Darlehen gewährt und hat ihm ein Gesellschafter für die Rückgewähr des Darlehens eine Sicherung bestellt oder hat er sich dafür verbürgt, so kann der Dritte im Insolvenzverfahren über das Vermögen der Gesellschaft nur für den Betrag verhältnismäßige Befriedigung verlangen, mit dem er bei der Inanspruchnahme der Sicherung oder des Bürgen ausgefallen ist.

(3) Diese Vorschriften gelten sinngemäß für andere Rechtshandlungen eines Gesellschafters oder eines Dritten, die der Darlehensgewährung nach Absatz 1 oder 2 wirtschaftlich entsprechen. Die Regeln über den Eigenkapitalersatz gelten nicht für den nicht geschäftsführenden Gesellschafter, der mit zehn vom Hundert oder weniger am Stammkapital beteiligt ist. Erwirbt ein Darlehensgeber in der Krise der Gesellschaft Geschäftsanteile zum Zweck der Überwindung der Krise, führt dies für seine bestehenden oder neugewährten Kredite nicht zur Anwendung der Regeln über den Eigenkapitalersatz. erforderlich ist, die übrigen Gesellschafter nach Verhältnis ihrer Geschäftsanteile. Beiträge, welche von einzelnen Gesellschaftern nicht zu erlangen sind, werden nach dem bezeichneten Verhältnis auf die übrigen verteilt.

(4) Zahlungen, welche auf Grund der vorstehenden Bestimmungen zu leisten sind, können den Verpflichteten nicht erlassen werden.

(5) Die Ansprüche der Gesellschaft verjähren in den Fällen des Absatzes 1 in zehn Jahren sowie in den Fällen des Absatzes 3 in fünf Jahren. Die Verjährung beginnt mit dem Ablauf des Tages, an welchem die Zahlung, deren Erstattung beansprucht wird, geleistet ist. In den Fällen des Absatzes 1 findet $\S 19$ Abs. 5 Satz 2 entsprechende Anwendung.

(6) Für die in den Fällen des Absatzes 3 geleistete Erstattung einer Zahlung sind den Gesellschaftern die Geschäftsführer, welchen in betreff der geleisteten Zahlung ein Verschulden zur Last fällt, solidarisch zum Ersatz verpflichtet. Die Bestimmungen in $\S 43$ Abs. 1 und 4 finden entsprechende Anwendung.

\section{$\S 32 \mathrm{a} \mathrm{GmbHG}$}

[weggefallen] 


\section{§ 32b Haftung für zurückgezahlte Darlehen}

Hat die Gesellschaft im Fall des $\S 32$ a Abs. 2, 3 das Darlehen im letzten Jahr vor dem Antrag auf Eröffnung des Insolvenzverfahrens oder nach diesem Antrag zurückgezahlt, so hat der Gesellschafter, der die Sicherung bestellt hatte oder als Bürge haftete, der Gesellschaft den zurückgezahlten Betrag zu erstatten; $\S 146$ der Insolvenzordnung gilt entsprechend. Die Verpflichtung besteht nur bis zur Höhe des Betrags, mit dem der Gesellschafter als Bürge haftete oder der dem Wert der von ihm bestellten Sicherung im Zeitpunkt der Rückzahlung des Darlehens entspricht. Der Gesellschafter wird von der Verpflichtung frei, wenn er die Gegenstände, die dem Gläubiger als Sicherung gedient hatten, der Gesellschaft zu ihrer Befriedigung zur Verfügung stellt. Diese Vorschriften gelten sinngemäß für andere Rechtshandlungen, die der Darlehensgewährung wirtschaftlich entsprechen.

\section{§ 35 Vertretung durch Geschäftsführer}

(1) Die Gesellschaft wird durch die Geschäftsführer gerichtlich und außergerichtlich vertreten.

(2) Dieselben haben in der durch den Gesellschaftsvertrag bestimmten Form ihre Willenserklärungen kundzugeben und für die Gesellschaft zu zeichnen. Ist nichts darüber bestimmt, so muß die Erklärung und Zeichnung durch sämtliche Geschäftsführer erfolgen. Ist der Gesellschaft gegenüber eine Willenserklärung abzugeben, so genügt es, wenn dieselbe an einen der Geschäftsführer erfolgt.

(3) Die Zeichnung geschieht in der Weise, dass die Zeichnenden zu der Firma der Gesellschaft ihre Namensunterschrift beifügen.

(4) Befinden sich alle Geschäftsanteile der Gesellschaft in der Hand eines Gesellschafters oder daneben in der Hand der Gesellschaft und ist er zugleich deren alleiniger Geschäftsführer, so ist auf seine Rechtsgeschäfte mit der Gesellschaft $\S 181$ des Bürgerlichen Gesetzbuchs anzuwenden. Rechtsgeschäfte zwischen ihm und der von ihm vertretenen Gesellschaft sind, auch wenn er nicht alleiniger Geschäftsführer ist, unverzüglich nach ihrer Vornahme in eine Niederschrift

\section{§ 32b GmbHG}

[weggefallen]

\section{$\S 35$ Vertretung durch Geschäftsführer}

(1) Die Gesellschaft wird durch die Geschäftsführer gerichtlich und außergerichtlich vertreten. Hat eine Gesellschaft keinen Geschäftsführer (Führungslosigkeit), wird die Gesellschaft für den Fall, dass ihr gegenüber Willenserklärungen abgegeben oder Schriftstücke zugestellt werden, durch die Mitglieder des Aufsichtsrats ( $\$ 52$ ) oder, wenn kein Aufsichtsrat bestellt ist, durch die Gesellschafter vertreten.

(2) Sind mehrere Geschäftsführer bestellt, sind sie alle nur gemeinschaftlich zur Vertretung der Gesellschaft befugt, es sei denn, dass der Gesellschaftsvertrag etwas anderes bestimmt. Ist der Gesellschaft gegenüber eine Willenserklärung abzugeben, genügt die Abgabe gegenüber einem Vertreter der Gesellschaft nach Absatz 1. An die Vertreter der Gesellschaft nach Absatz 1 können unter der im Handelsregister eingetragenen Geschäftsanschrift Willenserklärungen abgegeben und Schriftstücke für die Gesellschaft zugestellt werden. Unabhängig hiervon kann die Zustellung auch unter der eingetragenen Anschrift der empfangsberechtigten Person nach $\S 10$ Abs. 2 Satz 2 erfolgen

(3) Befinden sich alle Geschäftsanteile der Gesellschaft in der Hand eines Gesellschafters oder daneben in der Hand der Gesellschaft und ist er zugleich deren alleiniger Geschäftsführer, so ist auf seine Rechtsgeschäfte mit der Gesellschaft $\S 181$ des Bürgerlichen Gesetzbuchs anzuwenden. Rechtsgeschäfte zwischen ihm und der von ihm vertretenen Gesellschaft sind, auch wenn er nicht alleiniger Geschäftsführer ist, unverzüglich nach ihrer Vornahme in eine Niederschrift aufzunehmen. 
aufzunehmen.

\section{§ 35a Angaben auf Geschäftsbriefen}

(1) Auf allen Geschäftsbriefen gleichviel welcher Form, die an einen bestimmten Empfänger gerichtet werden, müssen die Rechtsform und der Sitz der Gesellschaft, das Registergericht des Sitzes der Gesellschaft und die Nummer, unter der die Gesellschaft in das Handelsregister eingetragen ist, sowie alle Geschäftsführer und, sofern die Gesellschaft einen Aufsichtsrat gebildet und dieser einen Vorsitzenden hat, der Vorsitzende es Aufsichtsrats mit dem Familiennamen und mindestens einem ausgeschriebenen Vornamen angegeben werden. Werden Angaben über das Kapital der Gesellschaft gemacht, so müssen in jedem Fall das Stammkapital sowie, wenn nicht alle in Geld zu leistenden Einlagen eingezahlt sind, der Gesamtbetrag der ausstehenden Einlagen angegeben werden.

(2) Der Angaben nach Absatz 1 Satz 1 bedarf es nicht bei Mitteilungen oder Berichten, die im Rahmen einer bestehenden Geschäftsverbindung ergehen und für die üblicherweise Vordrucke verwendet werden, in denen lediglich die im Einzelfall erforderlichen besonderen Angaben eingefügt zu werden brauchen.

(3) Bestellscheine gelten als Geschäftsbriefe im Sinne des Absatzes 1. Absatz 2 ist auf sie nicht anzuwenden.

(4) Auf allen Geschäftsbriefen und Bestellscheinen, die von einer Zweigniederlassung einer Gesellschaft mit beschränkter Haftung mit Sitz im Ausland verwendet werden, müssen das Register, bei dem die Zweigniederlassung geführt wird, und die Nummer des Registereintrags angegeben werden; im übrigen gelten die Vorschriften der Absätze 1 bis 3 soweit nicht das ausländische Recht Abweichungen nötig macht. Befindet sich die ausländische Gesellschaft in Liquidation, so sind auch diese Tatsache sowie alle Liquidatoren anzugeben.

\section{§ 36 Wirkung der Vertretung}

Die Gesellschaft wird durch die in ihrem Namen von den Geschäftsführern vorgenommenen Rechtsgeschäfte berechtigt und verpflichtet; es ist gleichgültig, ob das Geschäft ausdrücklich im Namen der Gesellschaft vorgenommen worden ist, oder ob die Umstände ergeben, dass es nach dem Willen der Beteiligten für die Gesellschaft vorgenommen werden sollte.

\section{§ 39 Anmeldung der Geschäftsführer}

(1) Jede Änderung in den Personen der Geschäftsführer sowie die Beendigung der Vertretungsbefugnis eines Geschäftsführers ist zur Eintragung in das Handelsregister anzumelden.

\section{§ 35a Angaben auf Geschäftsbriefen}

(1) Auf allen Geschäftsbriefen gleichviel welcher Form, die an einen bestimmten Empfänger gerichtet werden, müssen die Rechtsform und der Sitz der Gesellschaft, das Registergericht des Sitzes der Gesellschaft und die Nummer, unter der die Gesellschaft in das Handelsregister eingetragen ist, sowie alle $\mathrm{Ge}$ schäftsführer und, sofern die Gesellschaft einen Aufsichtsrat gebildet und dieser einen Vorsitzenden hat, der Vorsitzende es Aufsichtsrats mit dem Familiennamen und mindestens einem ausgeschriebenen Vornamen angegeben werden. Werden Angaben über das Kapital der Gesellschaft gemacht, so müssen in jedem Fall das Stammkapital sowie, wenn nicht alle in Geld zu leistenden Einlagen eingezahlt sind, der Gesamtbetrag der ausstehenden Einlagen angegeben werden.

(2) Der Angaben nach Absatz 1 Satz 1 bedarf es nicht bei Mitteilungen oder Berichten, die im Rahmen einer bestehenden Geschäftsverbindung ergehen und für die üblicherweise Vordrucke verwendet werden, in denen lediglich die im Einzelfall erforderlichen besonderen Angaben eingefügt zu werden brauchen.

(3) Bestellscheine gelten als Geschäftsbriefe im Sinne des Absatzes 1. Absatz 2 ist auf sie nicht anzuwenden.

(4) Auf allen Geschäftsbriefen und Bestellscheinen, die von einer Zweigniederlassung einer Gesellschaft mit beschränkter Haftung mit Sitz im Ausland verwendet werden, müssen das Register, bei dem die Zweigniederlassung geführt wird, und die Nummer des Registereintrags angegeben werden; im übrigen gelten die Vorschriften der Absätze 1 bis 3 für die Angaben bezüglich der Haupt- und der Zweigniederlassung, soweit nicht das ausländische Recht Abweichungen nötig macht. Befindet sich die ausländische Gesellschaft in Liquidation, so sind auch diese Tatsache sowie alle Liquidatoren anzugeben.

\section{$\S 36$ Wirkung der Vertretung}

[weggefallen]

\section{§ 39 Anmeldung der Geschäftsführer}

(1) Jede Änderung in den Personen der Geschäftsführer sowie die Beendigung der Vertretungsbefugnis eines Geschäftsführers ist zur Eintragung in das Handelsregister anzumelden. 
(2) Der Anmeldung sind die Urkunden über die Bestellung der Geschäftsführer oder über die Beendigung der Vertretungsbefugnis in Urschrift oder öffentlich beglaubigter Abschrift beizufügen.

(3) Die neuen Geschäftsführer haben in der Anmeldung $\mathrm{zu}$ versichern, dass keine Umstände vorliegen, die ihrer Bestellung nach $\S 6$ Abs. 2 Satz 3 und 4 entgegenstehen und dass sie über ihre unbeschränkte Auskunftspflicht gegenüber dem Gericht belehrt worden sind. $§ 8$ Abs. 3 Satz 2 ist anzuwenden.

(4) (weggefallen)

\section{$\S 40$ Liste der Gesellschafter}

(1) Die Geschäftsführer haben nach jeder Veränderung in den Personen der Gesellschafter oder des Umfangs ihrer Beteiligung unverzüglich eine von ihnen unterschriebene Liste der Gesellschafter, aus welcher Name, Vorname, Geburtsdatum und Wohnort der letzteren sowie ihre Stammeinlagen zu entnehmen sind, zum Handelsregister einzureichen. Hat ein Notar einen Vertrag über die Abtretung eines Geschäftsanteils nach $\S 15$ Abs. 3 beurkundet, so hat er diese Abtretung unverzüglich dem Registergericht anzuzeigen.

(2) Geschäftsführer, welche die ihnen nach Absatz 1 obliegende Pflicht verletzen, haften den Gläubigern der Gesellschaft für den daraus entstandenen Schaden als Gesamtschuldner.

\section{§ 46 Aufgabenkreis der Gesellschafter}

Der Bestimmung der Gesellschafter unterliegen:

1. die Feststellung des Jahresabschlusses und die Verwendung des Ergebnisses;

1a. die Entscheidung über die Offenlegung eines Einzelabschlusses nach internationalen Rechnungslegungsstandards ( $§ 325$ Abs. 2a des Handelsgesetzbuchs) und über die Billigung des von den Geschäftsführern aufgestellten Abschlusses;
(2) Der Anmeldung sind die Urkunden über die Bestellung der Geschäftsführer oder über die Beendigung der Vertretungsbefugnis in Urschrift oder öffentlich beglaubigter Abschrift beizufügen.

(3) Die neuen Geschäftsführer haben in der Anmeldung zu versichern, dass keine Umstände vorliegen, die ihrer Bestellung nach $\S 6$ Abs. 2 Satz 2 Nr. 2 und 3 sowie Satz 3 entgegenstehen und dass sie über ihre unbeschränkte Auskunftspflicht gegenüber dem Gericht belehrt worden sind. $\S 8$ Abs. 3 Satz 2 ist anzuwenden.

(4) (weggefallen)

\section{§ 40 Liste der Gesellschafter}

(1) Die Geschäftsführer haben unverzüglich nach Wirksamwerden jeder Veränderung in den Personen der Gesellschafter oder des Umfangs ihrer Beteiligung eine von ihnen unterschriebene Liste der Gesellschafter zum Handelsregister einzureichen, aus welcher Name, Vorname, Geburtsdatum und Wohnort der letzteren sowie die Nennbeträge und die laufenden Nummern der von einem jeden derselben übernommenen Geschäftsanteile zu entnehmen sind. Die Änderung der Liste durch die Geschäftsführer erfolgt auf Mitteilung und Nachweis.

(2) Hat ein Notar an Veränderungen nach Absatz 1 Satz 1 mitgewirkt, hat er unverzüglich nach deren Wirksamwerden ohne Rücksicht auf etwaige später eintretende Unwirksamkeitsgründe die Liste anstelle der Geschäftsführer zu unterschreiben, zum Handelsregister einzureichen und eine Abschrift der geänderten Liste an die Gesellschaft zu übermitteln. Die Liste muss mit der Bescheinigung des Notars versehen sein, dass die geänderten Eintragungen den Veränderungen entsprechen, an denen er mitgewirkt hat, und die übrigen Eintragungen mit dem Inhalt der zuletzt im Handelsregister aufgenommenen Liste übereinstimmen.

(3) Geschäftsführer, welche die ihnen nach Absatz 1 obliegende Pflicht verletzen, haften denjenigen, deren Beteiligung sich geändert hat, und den Gläubigern der Gesellschaft für den daraus entstandenen Schaden als Gesamtschuldner.

\section{§ 46 Aufgabenkreis der Gesellschafter}

Der Bestimmung der Gesellschafter unterliegen:

1. die Feststellung des Jahresabschlusses und die Verwendung des Ergebnisses;

1a. die Entscheidung über die Offenlegung eines Einzelabschlusses nach internationalen Rechnungslegungsstandards ( $\$ 325$ Abs. 2a des Handelsgesetzbuchs) und über die Billigung des von den Geschäftsführern aufgestellten Abschlusses; 
1b. die Billigung eines von den Geschäftsführern aufgestellten Konzernabschlusses;

2. die Einforderung von Einzahlungen auf die Stammeinlagen;

3. die Rückzahlung von Nachschüssen;

4. die Teilung sowie die Einziehung von Geschäftsanteilen;

5. die Bestellung und die Abberufung von Geschäftsführern sowie die Entlastung derselben;

6. die Maßregeln zur Prüfung und Überwachung der Geschäftsführung;

7. die Bestellung von Prokuristen und von Handlungsbevollmächtigten zum gesamten Geschäftsbetrieb;

8. die Geltendmachung von Ersatzansprüchen, welche der Gesellschaft aus der Gründung oder Geschäftsführung gegen Geschäftsführer oder Gesellschafter zustehen, sowie die Vertretung der Gesellschaft in Prozessen, welche sie gegen die Geschäftsführer zu führen hat.

\section{§ 47 Abstimmung}

(1) Die von den Gesellschaftern in den Angelegenheiten der Gesellschaft $\mathrm{zu}$ treffenden Bestimmungen erfolgen durch Beschlussfassung nach der Mehrheit der abgegebenen Stimmen.

(2) Jede fünfzig Euro eines Geschäftsanteils gewähren eine Stimme.

(3) Vollmachten bedürfen zu ihrer Gültigkeit der Textform.

(4) Ein Gesellschafter, welcher durch die Beschlussfassung entlastet oder von einer Verbindlichkeit befreit werden soll, hat hierbei kein Stimmrecht und darf ein solches auch nicht für andere ausüben. Dasselbe gilt von einer Beschlussfassung, welche die Vornahme eines Rechtsgeschäfts oder die Einleitung oder Erledigung eines Rechtsstreits gegenüber einem Gesellschafter betrifft.

\section{§ 53 Form der Satzungsänderung}

(1) Eine Abänderung des Gesellschaftsvertrags kann nur durch Beschluss der Gesellschafter erfolgen.

(2) Der Beschluss muss notariell beurkundet werden, derselbe bedarf einer Mehrheit von drei Vierteilen der abgegebenen Stimmen. Der Gesellschaftsvertrag kann noch andere Erfordernisse aufstellen. 1b. die Billigung eines von den Geschäftsführern aufgestellten Konzernabschlusses;

2. die Einforderung der Einlagen;

3. die Rückzahlung von Nachschüssen;

4. die Teilung, die Zusammenlegung sowie die Einziehung von Geschäftsanteilen;

5. die Bestellung und die Abberufung von Geschäftsführern sowie die Entlastung derselben;

6. die Maßregeln zur Prüfung und Überwachung der Geschäftsführung;

7. die Bestellung von Prokuristen und von Handlungsbevollmächtigten zum gesamten Geschäftsbetrieb;

8. die Geltendmachung von Ersatzansprüchen, welche der Gesellschaft aus der Gründung oder Geschäftsführung gegen Geschäftsführer oder Gesellschafter zustehen, sowie die Vertretung der Gesellschaft in Prozessen, welche sie gegen die Geschäftsführer zu führen hat.

\section{§ 47 Abstimmung}

(1) Die von den Gesellschaftern in den Angelegenheiten der Gesellschaft $\mathrm{zu}$ treffenden Bestimmungen erfolgen durch Beschlussfassung nach der Mehrheit der abgegebenen Stimmen.

(2) Jeder Euro eines Geschäftsanteils gewährt eine Stimme.

(3) Vollmachten bedürfen zu ihrer Gültigkeit der Textform.

(4) Ein Gesellschafter, welcher durch die Beschlussfassung entlastet oder von einer Verbindlichkeit befreit werden soll, hat hierbei kein Stimmrecht und darf ein solches auch nicht für andere ausüben. Dasselbe gilt von einer Beschlussfassung, welche die Vornahme eines Rechtsgeschäfts oder die Einleitung oder Erledigung eines Rechtsstreits gegenüber einem Gesellschafter betrifft.

\section{§ 53 Form der Satzungsänderung}

(1) Eine Abänderung des Gesellschaftsvertrags kann nur durch Beschluss der Gesellschafter erfolgen.

(2) Der Beschluss muss notariell beurkundet werden, derselbe bedarf einer Mehrheit von drei Vierteilen der abgegebenen Stimmen. Anstelle der notariellen Beurkundung reicht eine von dem Geschäftsführer unterzeichnete Niederschrift aus, wenn der Beschluss bei 
(3) Eine Vermehrung der den Gesellschaftern nach dem Gesellschaftsvertrag obliegenden Leistungen kann nur mit Zustimmung sämtlicher beteiligter $\mathrm{Ge}$ sellschafter beschlossen werden.

\section{§ 55 Erhöhung des Stammkapitals}

(1) Wird eine Erhöhung des Stammkapitals beschlossen, so bedarf es zur Übernahme jeder auf das erhöhte Kapital zu leistenden Stammeinlage einer notariell aufgenommenen oder beglaubigten Erklärung des Übernehmers.

(2) Zur Übernahme einer Stammeinlage können von der Gesellschaft die bisherigen Gesellschafter oder andere Personen, welche durch die Übernahme ihren Beitritt zu der Gesellschaft erklären, zugelassen werden. Im letzteren Fall sind außer dem Betrag der Stammeinlage auch sonstige Leistungen, $\mathrm{zu}$ welchen der Beitretende nach dem Gesellschaftsvertrag verpflichtet sein soll, in der in Absatz 1 bezeichneten Urkunde ersichtlich zu machen.

(3) Wird von einem der Gesellschaft bereits angehörenden Gesellschafter eine Stammeinlage auf das erhöhte Kapital übernommen, so erwirbt derselbe einen weiteren Geschäftsanteil.

(4) Die Bestimmungen in $\S 5$ Abs. 1 und 3 über den Betrag der Stammeinlagen, die Bestimmung in $\S 5$ Abs. 2 über die Unzulässigkeit der Übernahme mehrerer Stammeinlagen sowie die Bestimmungen in $\S 19$ Abs. 6 über die Verjährung finden auch hinsichtlich der auf das erhöhte Kapital zu leistenden Stammeinlagen Anwendung.

\section{§5 Kapitalerhöhung mit Sacheinlage}

(1) Sollen Sacheinlagen geleistet werden, so müssen ihr Gegenstand und der Betrag der Stammeinlage, auf die sich die Sacheinlage bezieht, im Beschluss über die Erhöhung des Stammkapitals festgesetzt werden. Die Festsetzung ist in die in $\S 55$ Abs. 1 bezeichnete Erklärung des Übernehmers aufzunehmen.

(2) Die $\S \S 9$ und 19 Abs. 5 finden ${ }^{\circ}$ entsprechende Anwendung. einem Gesellschaftsvertrag im Sinne des $§ 2$ Abs. 1a die Änderung der Firma oder der Höhe des Stammkapitals ohne Sacheinlagen, die Verlegung des Sitzes oder die Auswahl eines anderen Unternehmensgegenstandes aus dem in Anlage 1 bestimmten Muster zum Gegenstand hat und an der Gesellschaft nicht mehr als drei Gesellschafter beteiligt sind. Der Gesellschaftsvertrag kann noch andere Erfordernisse aufstellen.

(3) Eine Vermehrung der den Gesellschaftern nach dem Gesellschaftsvertrag obliegenden Leistungen kann nur mit Zustimmung sämtlicher beteiligter Gesellschafter beschlossen werden.

\section{§55 Erhöhung des Stammkapitals}

(1) Wird eine Erhöhung des Stammkapitals beschlossen, so bedarf es zur Übernahme jedes Geschäftsanteils an dem erhöhten Kapital einer notariell aufgenommenen oder beglaubigten Erklärung des Übernehmers.

(2) Zur Übernahme eines Geschäftsanteils können von der Gesellschaft die bisherigen Gesellschafter oder andere Personen, welche durch die Übernahme ihren Beitritt zu der Gesellschaft erklären, zugelassen werden. Im letzteren Fall sind außer dem Nennbetrag des Geschäftsanteils auch sonstige Leistungen, zu welchen der Beitretende nach dem Gesellschaftsvertrag verpflichtet sein soll, in der in Absatz 1 bezeichneten Urkunde ersichtlich zu machen.

(3) Wird von einem der Gesellschaft bereits angehörenden Gesellschafter ein Geschäftsanteil an dem erhöhten Kapital übernommen, so erwirbt derselbe einen weiteren Geschäftsanteil.

(4) Die Bestimmungen in $\S 5$ Abs. 2 und 3 über die Nennbeträge der Geschäftsanteile sowie die Bestimmungen in $\S 19$ Abs. 5 über die Verjährung des Anspruchs der Gesellschaft auf Leistung der Einlagen sind auch hinsichtlich der an dem erhöhten Kapital übernommenen Geschäftsanteile anzuwenden.

\section{§56 Kapitalerhöhung mit Sacheinlage}

(1) Sollen Sacheinlagen geleistet werden, so müssen ihr Gegenstand und der Nennbetrag des Geschäftsanteils, auf den sich die Sacheinlage bezieht, im Beschluss über die Erhöhung des Stammkapitals festgesetzt werden. Die Festsetzung ist in die in $\S 55$ Abs. 1 bezeichnete Erklärung des Übernehmers aufzunehmen.

(2) Die $\S \S 9$ und 19 Abs. 2 Satz 2 und Abs. 4 finden ontsprechende Anwendung. 


\section{§ 56a Leistungen auf das neue Stammkapital}

Für die Leistungen der Einlagen auf das neue Stammkapital und die Bestellung einer Sicherung findet $\$ 7$ Abs. 2 Satz 1 und 3, Abs. 3 entsprechende Anwendung

\section{\$ 57 Anmeldung der Erhöhung}

(1) Die beschlossene Erhöhung des Stammkapitals ist zur Eintragung in das Handelsregister anzumelden, nachdem das erhöhte Kapital durch Übernahme von Stammeinlagen gedeckt ist.

(2) In der Anmeldung ist die Versicherung abzugeben, dass die Einlagen auf das neue Stammkapital nach $\S 7$ Abs. 2 Satz 1 und 3, Abs. 3 bewirkt sind und dass der Gegenstand der Leistungen sich endgültig in der freien Verfügung der Geschäftsführer befindet. Für die Anmeldung findet im übrigen $\S 8$ Abs. 2 Satz 2 entsprechende Anwendung.

(3) Der Anmeldung sind beizufügen:

1. die in $\S 55$ Abs. 1 bezeichneten Erklärungen oder eine beglaubigte Abschrift derselben;

2. eine von den Anmeldenden unterschriebene Liste der Personen, welche die neuen Stammeinlagen übernommen haben; aus der Liste muss der Betrag der von jedem übernommenen Einlage ersichtlich sein;

3. bei einer Kapitalerhöhung mit Sacheinlagen die Verträge, die den Festsetzungen nach $\S 56$ zugrunde liegen oder zu ihrer Ausführung geschlossen worden sind.

(4) Für die Verantwortlichkeit der Geschäftsführer, welche die Kapitalerhöhung zur Eintragung in das Handelsregister angemeldet haben, finden $\S 9 \mathrm{a}$ Abs. 1 und $3, \S 9 \mathrm{~b}$ entsprechende Anwendung.

\section{§ 57b Bekanntmachung der Eintragung der Kapi- talerhöhung}

In die Bekanntmachung der Eintragung der Kapitalerhöhung sind außer deren Inhalt die bei einer Kapitalerhöhung mit Sacheinlagen vorgesehenen Festsetzungen aufzunehmen. Bei der Bekanntmachung dieser Festsetzungen genügt die Bezugnahme auf die beim Gericht eingereichten Urkunden.

\section{§ 57h Arten der Kapitalerhöhung}

(1) Die Kapitalerhöhung kann vorbehaltlich des § 571 Abs. 2 durch Bildung neuer Geschäftsanteile oder durch Erhöhung des Nennbetrags der Geschäftsanteile ausgeführt werden. Die neuen Geschäftsanteile und die Geschäftsanteile, deren Nennbetrag erhöht wird, können auf jeden durch zehn teilbaren Betrag, müssen

\section{§ 56a Leistungen auf das neue Stammkapital}

Für die Leistungen der Einlagen auf das neue Stammkapital findet $\S 7$ Abs. 2 Satz 1 und Abs. 3 entsprechende Anwendung

\section{$\S 57$ Anmeldung der Erhöhung}

(1) Die beschlossene Erhöhung des Stammkapitals ist zur Eintragung in das Handelsregister anzumelden, nachdem das erhöhte Kapital durch Übernahme von Geschäftsanteilen gedeckt ist.

(2) In der Anmeldung ist die Versicherung abzugeben, dass die Einlagen auf das neue Stammkapital nach $\S 7$ Abs. 2 Satz 1 und 3, Abs. 3 bewirkt sind und dass der Gegenstand der Leistungen sich endgültig in der freien Verfügung der Geschäftsführer befindet. $§ 8$ Abs. 2 Satz 2 und 3 gilt entsprechend.

(3) Der Anmeldung sind beizufügen:

1. die in $\S 55$ Abs. 1 bezeichneten Erklärungen oder eine beglaubigte Abschrift derselben;

2. eine von den Anmeldenden unterschriebene Liste der Personen, welche die neuen Geschäftsanteile übernommen haben; aus der Liste müssen die Nennbeträge der von jedem übernommenen Geschäftsanteile ersichtlich sein;

3. bei einer Kapitalerhöhung mit Sacheinlagen die Verträge, die den Festsetzungen nach $\S 56$ zugrunde liegen oder zu ihrer Ausführung geschlossen worden sind.

(4) Für die Verantwortlichkeit der Geschäftsführer, welche die Kapitalerhöhung zur Eintragung in das Handelsregister angemeldet haben, finden $\S 9 \mathrm{a}$ Abs. 1 und $3, \S 9 \mathrm{~b}$ entsprechende Anwendung.

§ 57b Bekanntmachung der Eintragung der Kapitalerhöhung

[weggefallen]

\section{§ 57h Arten der Kapitalerhöhung}

(1) Die Kapitalerhöhung kann vorbehaltlich des § 571 Abs. 2 durch Bildung neuer Geschäftsanteile oder durch Erhöhung des Nennbetrags der Geschäftsanteile ausgeführt werden. Die neuen Geschäftsanteile und die Geschäftsanteile, deren Nennbetrag erhöht wird, müssen auf einen Betrag gestellt werden, der auf volle 
jedoch auf mindestens fünfzig Euro gestellt werden.

(2) Der Beschluss über die Erhöhung des Stammkapitals muss die Art der Erhöhung angeben. 2Soweit die Kapitalerhöhung durch Erhöhung des Nennbetrags der Geschäftsanteile ausgeführt werden soll, ist sie so zu bemessen, dass durch sie auf keinen Geschäftsanteil, dessen Nennbetrag erhöht wird, Beträge entfallen, die durch die Erhöhung des Nennbetrags des Geschäftsanteils nicht gedeckt werden können.

\section{§ 57 I Teilnahme an Erhöhung des Stammkapitals}

(1) Eigene Geschäftsanteile nehmen an der Erhöhung des Stammkapitals teil.

(2) Teileingezahlte Geschäftsanteile nehmen entsprechend ihrem Nennbetrag an der Erhöhung des Stammkapitals teil. Bei ihnen kann die Kapitalerhöhung nur durch Erhöhung des Nennbetrags der Geschäftsanteile ausgeführt werden. Sind neben teileingezahlten Geschäftsanteilen vollständig eingezahlte Geschäftsanteile vorhanden, so kann bei diesen die Kapitalerhöhung durch Erhöhung des Nennbetrags der Geschäftsanteile und durch Bildung neuer Geschäftsanteile ausgeführt werden. Die Geschäftsanteile, deren Nennbetrag erhöht wird, können auf jeden durch fünf teilbaren Betrag gestellt werden.

\section{§ 58 Herabsetzung des Stammkapitals}

(1) Eine Herabsetzung des Stammkapitals kann nu unter Beobachtung der nachstehenden Bestimmungen erfolgen:

1. der Beschluss auf Herabsetzung des Stammkapitals muss von den Geschäftsführern zu drei verschiedenen Malen in den Gesellschaftsblättern bekannt gemacht werden; in diesen Bekanntmachungen sind zugleich die Gläubiger der Gesellschaft aufzufordern, sich bei derselben zu melden; die aus den Handelsbüchern der Gesellschaft ersichtlichen oder in anderer Weise bekannten Gläubiger sind durch besondere Mitteilung zur Anmeldung aufzufordern;

2. die Gläubiger, welche sich bei der Gesellschaft melden und der Herabsetzung nicht zustimmen, sind wegen der erhobenen Ansprüche zu befriedigen oder sicherzustellen;

3. die Anmeldung des Herabsetzungsbeschlusses zur Eintragung in das Handelsregister erfolgt nicht vor Ablauf eines Jahres seit dem Tage, an welchem die Aufforderung der Gläubiger in den Gesellschaftsblättern zum dritten Mal stattgefunden hat;

4. mit der Anmeldung sind die Bekanntmachungen des Beschlusses einzureichen; zugleich haben die $\mathrm{Ge}$ schäftsführer die Versicherung abzugeben, dass die Gläubiger, welche sich bei der Gesellschaft gemeldet
Euro lautet"

(2) Der Beschluss über die Erhöhung des Stammkapitals muss die Art der Erhöhung angeben. 2Soweit die Kapitalerhöhung durch Erhöhung des Nennbetrags der Geschäftsanteile ausgeführt werden soll, ist sie so zu bemessen, dass durch sie auf keinen Geschäftsanteil, dessen Nennbetrag erhöht wird, Beträge entfallen, die durch die Erhöhung des Nennbetrags des Geschäftsanteils nicht gedeckt werden können.

\section{§ 57 I Teilnahme an Erhöhung des Stammkapitals}

(1) Eigene Geschäftsanteile nehmen an der Erhöhung des Stammkapitals teil.

(2) Teileingezahlte Geschäftsanteile nehmen entsprechend ihrem Nennbetrag an der Erhöhung des Stammkapitals teil. Bei ihnen kann die Kapitalerhöhung nur durch Erhöhung des Nennbetrags der Geschäftsanteile ausgeführt werden. Sind neben teileingezahlten Geschäftsanteilen vollständig eingezahlte Geschäftsanteile vorhanden, so kann bei diesen die Kapitalerhöhung durch Erhöhung des Nennbetrags der Geschäftsanteile und durch Bildung neuer Geschäftsanteile ausgeführt werden. Die Geschäftsanteile, deren Nennbetrag erhöht wird, können auf jeden Betrag gestellt werden, der auf volle Euro lautet.

\section{§ 58 Herabsetzung des Stammkapitals}

(1) Eine Herabsetzung des Stammkapitals kann nur unter Beobachtung der nachstehenden Bestimmungen erfolgen:

1. der Beschluss auf Herabsetzung des Stammkapitals muss von den Geschäftsführern zu drei verschiedenen Malen in den Gesellschaftsblättern bekannt gemacht werden; in diesen Bekanntmachungen sind zugleich die Gläubiger der Gesellschaft aufzufordern, sich bei derselben zu melden; die aus den Handelsbüchern der Gesellschaft ersichtlichen oder in anderer Weise bekannten Gläubiger sind durch besondere Mitteilung zur Anmeldung aufzufordern;

2. die Gläubiger, welche sich bei der Gesellschaft melden und der Herabsetzung nicht zustimmen, sind wegen der erhobenen Ansprüche zu befriedigen oder sicherzustellen;

3. die Anmeldung des Herabsetzungsbeschlusses zur Eintragung in das Handelsregister erfolgt nicht vor Ablauf eines Jahres seit dem Tage, an welchem die Aufforderung der Gläubiger in den Gesellschaftsblättern zum dritten Mal stattgefunden hat;

4. mit der Anmeldung sind die Bekanntmachungen des Beschlusses einzureichen; zugleich haben die $\mathrm{Ge}$ schäftsführer die Versicherung abzugeben, dass die Gläubiger, welche sich bei der Gesellschaft gemeldet 
und der Herabsetzung nicht zugestimmt haben, befriedigt oder sichergestellt sind.

(2) Die Bestimmung in $\S 5$ Abs. 1 über den Mindestbetrag des Stammkapitals bleibt unberührt. Erfolgt die Herabsetzung zum Zweck der Zurückzahlung von Stammeinlagen oder zum Zweck des Erlasses der auf diese geschuldeten Einzahlungen, so darf der verbleibende Betrag der Stammeinlagen nicht unter den in $\S 5$ Abs. 1 und 3 bezeichneten Betrag herabgehen.

\section{§ 58a Vereinfachte Kapitalherabsetzung}

(1) Eine Herabsetzung des Stammkapitals, die dazu dienen soll, Wertminderungen auszugleichen oder sonstige Verluste zu decken, kann als vereinfachte Kapitalherabsetzung vorgenommen werden.

(2) Die vereinfachte Kapitalherabsetzung ist nur zulässig, nachdem der Teil der Kapital- und Gewinnrücklagen, der zusammen über zehn vom Hundert des nach der Herabsetzung verbleibenden Stammkapitals hinausgeht, vorweg aufgelöst ist. Sie ist nicht zulässig, solange ein Gewinnvortrag vorhanden ist.

(3) Im Beschluss über die vereinfachte Kapitalherabsetzung sind die Nennbeträge der Geschäftsanteile dem herabgesetzten Stammkapital anzupassen. Die Geschäftsanteile können auf jeden durch zehn teilbaren Betrag, müssen jedoch auf mindestens fünfzig Euro gestellt werden. Geschäftsanteile, deren Nennbetrag durch die Herabsetzung unter fünfzig Euro sinken würde, sind von den Geschäftsführern zu gemeinschaftlichen Geschäftsanteilen zu vereinigen, wenn die Einlagen auf die Geschäftsanteile voll geleistet, die Geschäftsanteile nicht mit einer Nachschusspflicht oder mit Rechten Dritter belastet und nach dem Gesellschaftsvertrag nicht mit verschiedenen Rechten und Pflichten ausgestattet sind. Die Erklärung über die Vereinigung der Geschäftsanteile bedarf der notariellen Beurkundung. Die Vereinigung wird mit der Eintragung des Beschlusses über die Kapitalherabsetzung in das Handelsregister wirksam.

(4) Das Stammkapital kann unter den in $\S 5$ Abs. 1 bestimmten Mindestnennbetrag herabgesetzt werden, wenn dieser durch eine Kapitalerhöhung wieder erreicht wird, die zugleich mit der Kapitalherabsetzung beschlossen ist und bei der Sacheinlagen nicht festgesetzt sind. Die Beschlüsse sind nichtig, wenn sie nicht binnen drei Monaten nach der Beschlussfassung in das Handelsregister eingetragen worden sind. Der Lauf der Frist ist gehemmt, solange eine Anfechtungs- oder Nichtigkeitsklage rechtshängig ist oder eine zur Kapitalherabsetzung oder Kapitalerhöhung beantragte staatliche Genehmigung noch nicht erteilt ist. Die Beschlüsse sollen nur zusammen in das Handelsregister eingetragen werden. und der Herabsetzung nicht zugestimmt haben, befriedigt oder sichergestellt sind.

(2) Die Bestimmung in $\S 5$ Abs. 1 über den Mindestbetrag des Stammkapitals bleibt unberührt. Erfolgt die Herabsetzung zum Zweck der Zurückzahlung von Einlagen oder zum Zweck des Erlasses zu leistender Einlagen, dürfen die verbleibenden Nennbeträge der Geschäftsanteile nicht unter den in $\S 5$ Abs. 2 und 3 bezeichneten Betrag herabgehen.

\section{§ 58a Vereinfachte Kapitalherabsetzung}

(1) Eine Herabsetzung des Stammkapitals, die dazu dienen soll, Wertminderungen auszugleichen oder sonstige Verluste zu decken, kann als vereinfachte Kapitalherabsetzung vorgenommen werden.

(2) Die vereinfachte Kapitalherabsetzung ist nur zulässig, nachdem der Teil der Kapital- und Gewinnrücklagen, der zusammen über zehn vom Hundert des nach der Herabsetzung verbleibenden Stammkapitals hinausgeht, vorweg aufgelöst ist. Sie ist nicht zulässig, solange ein Gewinnvortrag vorhanden ist.

(3) Im Beschluss über die vereinfachte Kapitalherabsetzung sind die Nennbeträge der Geschäftsanteile dem herabgesetzten Stammkapital anzupassen. [...] Die Geschäftsanteile müssen auf einen Betrag gestellt werden, der auf volle Euro lautet.

(4) Das Stammkapital kann unter den in $\S 5$ Abs. 1 bestimmten Mindestnennbetrag herabgesetzt werden, wenn dieser durch eine Kapitalerhöhung wieder erreicht wird, die zugleich mit der Kapitalherabsetzung beschlossen ist und bei der Sacheinlagen nicht festgesetzt sind. Die Beschlüsse sind nichtig, wenn sie nicht binnen drei Monaten nach der Beschlussfassung in das Handelsregister eingetragen worden sind. Der Lauf der Frist ist gehemmt, solange eine Anfechtungs- oder Nichtigkeitsklage rechtshängig ist oder eine zur Kapitalherabsetzung oder Kapitalerhöhung beantragte staatliche Genehmigung noch nicht erteilt ist. Die Beschlüsse sollen nur zusammen in das Handelsregister eingetragen werden. 
(5) Neben den $\S \S 53$ und 54 über die Abänderung des Gesellschaftsvertrags gelten die $\S \S 58 \mathrm{~b}$ bis $58 \mathrm{f}$.

\section{$\S 58$ f Kapitalherabsetzung bei gleichzeitiger Erhö- hung des Stammkapitals}

(1) Wird im Fall des $\S 58$ e zugleich mit der Kapitalherabsetzung eine Erhöhung des Stammkapitals beschlossen, so kann auch die Kapitalerhöhung in dem Jahresabschluss als vollzogen berücksichtigt werden. Die Beschlussfassung ist nur zulässig, wenn die neuen Stammeinlagen übernommen, keine Sacheinlagen festgesetzt sind und wenn auf jede neue Stammeinlage die Einzahlung geleistet ist, die nach $§ 56$ a zur Zeit der Anmeldung der Kapitalerhöhung bewirkt sein muss. Die Übernahme und die Einzahlung sind dem Notar nachzuweisen, der den Beschluss über die Erhöhung des Stammkapitals beurkundet.

(2) Sämtliche Beschlüsse sind nichtig, wenn die Beschlüsse über die Kapitalherabsetzung und die Kapitalerhöhung nicht binnen drei Monaten nach der Beschlussfassung in das Handelsregister eingetragen worden sind. Der Lauf der Frist ist gehemmt, solange eine Anfechtungs- oder Nichtigkeitsklage rechtshängig ist oder eine zur Kapitalherabsetzung oder Kapitalerhöhung beantragte staatliche Genehmigung noch nicht erteilt worden ist. Die Beschlüsse sollen nur zusammen in das Handelsregister eingetragen werden.

(3) Der Jahresabschluss darf nach $\S 325$ des Handelsgesetzbuchs erst offengelegt werden, nachdem die Beschlüsse über die Kapitalherabsetzung und Kapitalerhöhung eingetragen worden sind.

\section{§ 60 Auflösungsgründe}

(1) Die Gesellschaft mit beschränkter Haftung wird aufgelöst:

1. durch Ablauf der im Gesellschaftsvertrag bestimmten Zeit;

2. durch Beschluss der Gesellschafter; derselbe bedarf, sofern im Gesellschaftsvertrag nicht ein anderes bestimmt ist, einer Mehrheit von drei Vierteilen der abgegebenen Stimmen;

3. durch gerichtliches Urteil oder durch Entscheidung des Verwaltungsgerichts oder der Verwaltungsbehörde in den Fällen der $\S \S 61$ und 62;

4. durch die Eröffnung des Insolvenzverfahrens; wird das Verfahren auf Antrag des Schuldners eingestellt oder nach der Bestätigung eines Insolvenzplans, der den Fortbestand der Gesellschaft vorsieht, aufgehoben, so können die Gesellschafter die Fortsetzung der Gesellschaft beschließen;
(5) Neben den $\$ \S 53$ und 54 über die Abänderung des Gesellschaftsvertrags gelten die $\S \S 58 \mathrm{~b}$ bis $58 \mathrm{f}$.

\section{§ 58 f Kapitalherabsetzung bei gleichzeitiger Erhö- hung des Stammkapitals}

(1) Wird im Fall des $\S 58 \mathrm{e}$ zugleich mit der Kapitalherabsetzung eine Erhöhung des Stammkapitals beschlossen, so kann auch die Kapitalerhöhung in dem Jahresabschluss als vollzogen berücksichtigt werden. Die Beschlussfassung ist nur zulässig, wenn die neuen Geschäftsanteile übernommen, keine Sacheinlagen festgesetzt sind und wenn auf jeden neuen Geschäftsanteil die Einzahlung geleistet ist, die nach § 56a zur Zeit der Anmeldung der Kapitalerhöhung bewirkt sein muss. Die Übernahme und die Einzahlung sind dem Notar nachzuweisen, der den Beschluss über die Erhöhung des Stammkapitals beurkundet.

(2) Sämtliche Beschlüsse sind nichtig, wenn die Beschlüsse über die Kapitalherabsetzung und die Kapitalerhöhung nicht binnen drei Monaten nach der Beschlussfassung in das Handelsregister eingetragen worden sind. Der Lauf der Frist ist gehemmt, solange eine Anfechtungs- oder Nichtigkeitsklage rechtshängig ist oder eine zur Kapitalherabsetzung oder Kapitalerhöhung beantragte staatliche Genehmigung noch nicht erteilt worden ist. Die Beschlüsse sollen nur zusammen in das Handelsregister eingetragen werden.

(3) Der Jahresabschluss darf nach $\S 325$ des Handelsgesetzbuchs erst offengelegt werden, nachdem die Beschlüsse über die Kapitalherabsetzung und Kapitalerhöhung eingetragen worden sind.

\section{§60 Auflösungsgrüinde}

(1) Die Gesellschaft mit beschränkter Haftung wird aufgelöst:

1. durch Ablauf der im Gesellschaftsvertrag bestimmten Zeit;

2. durch Beschluss der Gesellschafter; derselbe bedarf, sofern im Gesellschaftsvertrag nicht ein anderes bestimmt ist, einer Mehrheit von drei Vierteilen der abgegebenen Stimmen;

3. durch gerichtliches Urteil oder durch Entscheidung des Verwaltungsgerichts oder der Verwaltungsbehörde in den Fällen der $\S \S 61$ und 62;

4. durch die Eröffnung des Insolvenzverfahrens; wird das Verfahren auf Antrag des Schuldners eingestellt oder nach der Bestätigung eines Insolvenzplans, der den Fortbestand der Gesellschaft vorsieht, aufgehoben, so können die Gesellschafter die Fortsetzung der Gesellschaft beschließen; 
5. mit der Rechtskraft des Beschlusses, durch den die Eröffnung des Insolvenzverfahrens mangels Masse abgelehnt worden ist;

6. mit der Rechtskraft einer Verfügung des Registergerichts, durch welche nach den $\S \S 144 a, 144 b$ des Gesetzes über die Angelegenheiten der freiwilligen Gerichtsbarkeit ein Mangel des Gesellschaftsvertrags oder die Nichteinhaltung der Verpflichtungen nach § 19 Abs. 4 dieses Gesetzes festgestellt worden ist;

7. durch die Löschung der Gesellschaft wegen Vermögenslosigkeit nach $\S 141$ a des Gesetzes über die Angelegenheiten der freiwilligen Gerichtsbarkeit.

(2) Im Gesellschaftsvertrag können weitere Auflösungsgründe festgesetzt werden.

\section{§ 64 Insolvenzantragspflicht}

(1) Wird die Gesellschaft zahlungsunfähig, so haben die Geschäftsführer ohne schuldhaftes Zögern, spätestens aber drei Wochen nach Eintritt der Zahlungsunfähigkeit, die Eröffnung des Insolvenzverfahrens zu beantragen. Dies gilt sinngemäß, wenn sich eine Überschuldung der Gesellschaft ergibt.

(2) Die Geschäftsführer sind der Gesellschaft zum Ersatz von Zahlungen verpflichtet, die nach Eintritt der Zahlungsunfähigkeit der Gesellschaft oder nach Feststellung ihrer Überschuldung geleistet werden. Dies gilt nicht von Zahlungen, die auch nach diesem Zeitpunkt mit der Sorgfalt eines ordentlichen Geschäftsmanns vereinbar sind. Auf den Ersatzanspruch finden die Bestimmungen in $\S 43$ Abs. 3 und 4 entsprechende Anwendung.

\section{§ 65 Anmeldung der Auflösung}

(1) Die Auflösung der Gesellschaft ist zur Eintragung in das Handelsregister anzumelden. Dies gilt nicht in den Fällen der Eröffnung oder der Ablehnung der Eröffnung des Insolvenzverfahrens und der gerichtlichen Feststellung eines Mangels des Gesellschaftsvertrags oder der Nichteinhaltung der Verpflichtungen nach $\S 19$ Abs. 4. In diesen Fällen hat das Gericht die Auflösung und ihren Grund von Amts wegen einzutragen. Im Falle der Löschung der Gesellschaft ( $\$ 60$ Abs. 1 Nr. 7) entfällt die Eintragung der Auflösung.

(2) Die Auflösung ist von den Liquidatoren $\mathrm{zu}$ drei verschiedenen Malen in den Gesellschaftsblättern bekanntzumachen. Durch die Bekanntmachung sind zugleich die Gläubiger der Gesellschaft aufzufordern, sich bei derselben zu melden.
5. mit der Rechtskraft des Beschlusses, durch den die Eröffnung des Insolvenzverfahrens mangels Masse abgelehnt worden ist;

6. mit der Rechtskraft einer Verfügung des Registergerichts, durch welche nach $\S 144$ a des Gesetzes über die Angelegenheiten der freiwilligen Gerichtsbarkeit ein Mangel des Gesellschaftsvertrags festgestellt worden ist;

7. durch die Löschung der Gesellschaft wegen Vermögenslosigkeit nach $\S 141$ a des Gesetzes über die Angelegenheiten der freiwilligen Gerichtsbarkeit.

(2) Im Gesellschaftsvertrag können weitere Auflösungsgründe festgesetzt werden.

\section{§ 64 Insolvenzantragspflicht}

(1) [weggefallen]

Die Geschäftsführer sind der Gesellschaft zum Ersatz von Zahlungen verpflichtet, die nach Eintritt der Zahlungsunfähigkeit der Gesellschaft oder nach Feststellung ihrer Überschuldung geleistet werden. Dies gilt nicht von Zahlungen, die auch nach diesem Zeitpunkt mit der Sorgfalt eines ordentlichen Geschäftsmanns vereinbar sind. Die gleiche Verpflichtung trifft die Geschäftsführer für Zahlungen an Gesellschafter, soweit diese zur Zahlungsunfähigkeit der Gesellschaft führen mussten, es sei denn, dies war auch bei Beachtung der in Satz 2 bezeichneten Sorgfalt nicht erkennbar. Auf den Ersatzanspruch finden die Bestimmungen in $\S 43$ Abs. 3 und 4 entsprechende Anwendung.

\section{§ 65 Anmeldung der Auflösung}

(1) Die Auflösung der Gesellschaft ist zur Eintragung in das Handelsregister anzumelden. Dies gilt nicht in den Fällen der Eröffnung oder der Ablehnung der Eröffnung des Insolvenzverfahrens und der gerichtlichen Feststellung eines Mangels des Gesellschaftsvertrags [...]. In diesen Fällen hat das Gericht die Auflösung und ihren Grund von Amts wegen einzutragen. Im Falle der Löschung der Gesellschaft (\$ 60 Abs. 1 Nr. 7) entfällt die Eintragung der Auflösung.

(2) Die Auflösung ist von den Liquidatoren $\mathrm{zu}$ drei verschiedenen Malen in den Gesellschaftsblättern bekanntzumachen. Durch die Bekanntmachung sind zugleich die Gläubiger der Gesellschaft aufzufordern, sich bei derselben zu melden. 


\section{§ 66 Liquidatoren}

(1) In den Fällen der Auflösung außer dem Fall des Insolvenzverfahrens erfolgt die Liquidation durch die Geschäftsführer, wenn nicht dieselbe durch den Gesellschaftsvertrag oder durch Beschluss der Gesellschafter anderen Personen übertragen wird.

(2) Auf Antrag von Gesellschaftern, deren Geschäftsanteile zusammen mindestens dem zehnten Teil des Stammkapitals entsprechen, kann aus wichtigen Gründen die Bestellung von Liquidatoren durch das Gericht (§ 7 Abs. 1) erfolgen.

(3) Die Abberufung von Liquidatoren kann durch das Gericht unter derselben Voraussetzung wie die Bestellung stattfinden. Liquidatoren, welche nicht vom Gericht ernannt sind, können auch durch Beschluss der Gesellschafter vor Ablauf des Zeitraums, für welchen sie bestellt sind, abberufen werden.

(4) Für die Auswahl der Liquidatoren findet $\S 6$ Abs. 2 Satz 3 und 4 entsprechende Anwendung.

(5) Ist die Gesellschaft durch Löschung wegen Vermögenslosigkeit aufgelöst, so findet eine Liquidation nur statt, wenn sich nach der Löschung herausstellt, dass Vermögen vorhanden ist, das der Verteilung unterliegt. Die Liquidatoren sind auf Antrag eines Beteiligten durch das Gericht zu ernennen.

\section{§ 71 Bilanz; Rechte und Pflichten}

(1) Die Liquidatoren haben für den Beginn der Liquidation eine Bilanz (Eröffnungsbilanz) und einen die Eröffnungsbilanz erläuternden Bericht sowie für den Schluss eines jeden Jahres einen Jahresabschluss und einen Lagebericht aufzustellen.

(2) Die Gesellschafter beschließen über die Feststellung der Eröffnungsbilanz und des Jahresabschlusses sowie über die Entlastung der Liquidatoren. Auf die Eröffnungsbilanz und den erläuternden Bericht sind die Vorschriften über den Jahresabschluss entsprechend anzuwenden. Vermögensgegenstände des Anlagevermögens sind jedoch wie Umlaufvermögen $\mathrm{zu}$ bewerten, soweit ihre Veräußerung innerhalb eines übersehbaren Zeitraums beabsichtigt ist oder diese Vermögensgegenstände nicht mehr dem Geschäftsbetrieb dienen; dies gilt auch für den Jahresabschluss.

(3) Das Gericht kann von der Prüfung des Jahresabschlusses und des Lageberichts durch einen Abschlussprüfer befreien, wenn die Verhältnisse der Gesellschaft so überschaubar sind, dass eine Prüfung im Interesse der Gläubiger und der Gesellschafter nicht geboten erscheint. Gegen die Entscheidung ist die sofortige Beschwerde zulässig.

\section{§ 66 Liquidatoren}

(1) In den Fällen der Auflösung außer dem Fall des Insolvenzverfahrens erfolgt die Liquidation durch die Geschäftsführer, wenn nicht dieselbe durch den $\mathrm{Ge}-$ sellschaftsvertrag oder durch Beschluss der Gesellschafter anderen Personen übertragen wird.

(2) Auf Antrag von Gesellschaftern, deren Geschäftsanteile zusammen mindestens dem zehnten Teil des Stammkapitals entsprechen, kann aus wichtigen Gründen die Bestellung von Liquidatoren durch das Gericht (§ 7 Abs. 1) erfolgen.

(3) Die Abberufung von Liquidatoren kann durch das Gericht unter derselben Voraussetzung wie die Bestellung stattfinden. Liquidatoren, welche nicht vom Gericht ernannt sind, können auch durch Beschluss der Gesellschafter vor Ablauf des Zeitraums, für welchen sie bestellt sind, abberufen werden.

(4) Für die Auswahl der Liquidatoren findet $\S 6$ Abs. 2 Satz 2 und 3 entsprechende Anwendung.

(5) Ist die Gesellschaft durch Löschung wegen Vermögenslosigkeit aufgelöst, so findet eine Liquidation nur statt, wenn sich nach der Löschung herausstellt, dass Vermögen vorhanden ist, das der Verteilung unterliegt. Die Liquidatoren sind auf Antrag eines Beteiligten durch das Gericht zu ernennen.

\section{§ 71 Bilanz; Rechte und Pflichten}

(1) Die Liquidatoren haben für den Beginn der Liquidation eine Bilanz (Eröffnungsbilanz) und einen die Eröffnungsbilanz erläuternden Bericht sowie für den Schluss eines jeden Jahres einen Jahresabschluss und einen Lagebericht aufzustellen.

(2) Die Gesellschafter beschließen über die Feststellung der Eröffnungsbilanz und des Jahresabschlusses sowie über die Entlastung der Liquidatoren. Auf die Eröffnungsbilanz und den erläuternden Bericht sind die Vorschriften über den Jahresabschluss entsprechend anzuwenden. Vermögensgegenstände des Anlagevermögens sind jedoch wie Umlaufvermögen $\mathrm{zu}$ bewerten, soweit ihre Veräußerung innerhalb eines übersehbaren Zeitraums beabsichtigt ist oder diese Vermögensgegenstände nicht mehr dem Geschäftsbetrieb dienen; dies gilt auch für den Jahresabschluss.

(3) Das Gericht kann von der Prüfung des Jahresabschlusses und des Lageberichts durch einen Abschlussprüfer befreien, wenn die Verhältnisse der Gesellschaft so überschaubar sind, dass eine Prüfung im Interesse der Gläubiger und der Gesellschafter nicht geboten erscheint. Gegen die Entscheidung ist die sofortige Beschwerde zulässig. 
(4) Im übrigen haben sie die aus $\S \S 36,37,41$ Abs. 1, $\S 43$ Abs. 1, 2 und 4, $\$ 49$ Abs. 1 und 2, § 64 sich ergebenden Rechte und Pflichten der Geschäftsführer.

(5) Auf allen Geschäftsbriefen, die an einen bestimmten Empfänger gerichtet werden, müssen die Rechtsform und der Sitz der Gesellschaft, die Tatsache, dass die Gesellschaft sich in Liquidation befindet, das Registergericht des Sitzes der Gesellschaft und die Nummer, unter der die Gesellschaft in das Handelsregister eingetragen ist, sowie alle Liquidatoren und, sofern die Gesellschaft einen Aufsichtsrat gebildet und dieser einen Vorsitzenden hat, der Vorsitzende des Aufsichtsrats mit dem Familiennamen und mindestens einem ausgeschriebenen Vornamen angegeben werden. Werden Angaben über das Kapital der Gesellschaft gemacht, so müssen in jedem Falle das Stammkapital sowie, wenn nicht alle in Geld zu leistenden Einlagen eingezahlt sind, der Gesamtbetrag der ausstehenden Einlagen angegeben werden. Der Angaben nach Satz 1 bedarf es nicht bei Mitteilungen oder Berichten, die im Rahmen einer bestehenden Geschäftsverbindung ergehen und für die üblicherweise Vordrucke verwendet werden, in denen lediglich die im Einzelfall erforderlichen besonderen Angaben eingefügt $\mathrm{zu}$ werden brauchen. Bestellscheine gelten als Geschäftsbriefe im Sinne des Satzes 1; Satz 3 ist auf sie nicht anzuwenden.

\section{§ 82 Falsche Angaben}

(1) Mit Freiheitsstrafe bis zu drei Jahren oder mit Geldstrafe wird bestraft, wer

1. als Gesellschafter oder als Geschäftsführer zum Zweck der Eintragung der Gesellschaft über die Übernahme der Stammeinlagen, die Leistung der Einlagen, die Verwendung eingezahlter Beträge, über Sondervorteile, Gründungsaufwand, Sacheinlagen und Sicherungen für nicht voll eingezahlte Geldeinlagen,

\section{2. als Gesellschafter im Sachgründungsbericht,}

3. als Geschäftsführer zum Zweck der Eintragung einer Erhöhung des Stammkapitals über die Zeichnung oder Einbringung des neuen Kapitals oder über Sacheinlagen,

4. als Geschäftsführer in der in $\S 57 \mathrm{i}$ Abs. 1 Satz 2 vorgeschriebenen Erklärung oder

5. als Geschäftsführer in der nach $\S 8$ Abs. 3 Satz 1 oder $\S 39$ Abs. 3 Satz 1 abzugebenden Versicherung oder als Liquidator in der nach $\S 67$ Abs. 3 Satz 1 abzugebenden Versicherung falsche Angaben macht.

(2) Ebenso wird bestraft, wer

1. als Geschäftsführer zum Zweck der Herabsetzung
(4) Im übrigen haben sie die aus $\S \S 37,41,43$ Abs. 1, 2 und 4, § 49 Abs. 1 und 2, § 64 sich ergebenden Rechte und Pflichten der Geschäftsführer.

(5) Auf den Geschäftsbriefen ist anzugeben, dass sich die Gesellschaft in Liquidation befindet; im Übrigen gilt $§ 35$ a entsprechend.

\section{§ 82 Falsche Angaben}

(1) Mit Freiheitsstrafe bis $\mathrm{zu}$ drei Jahren oder mit Geldstrafe wird bestraft, wer

1. als Gesellschafter oder als Geschäftsführer zum Zweck der Eintragung der Gesellschaft über die Übernahme der Geschäftsanteile, die Leistung der Einlagen, die Verwendung eingezahlter Beträge, über Sondervorteile, Gründungsaufwand und Sacheinlagen,

2. als Gesellschafter im Sachgründungsbericht,

3. als Geschäftsführer zum Zweck der Eintragung einer Erhöhung des Stammkapitals über die Zeichnung oder Einbringung des neuen Kapitals oder über Sacheinlagen,

4. als Geschäftsführer in der in $\S 57 \mathrm{i}$ Abs. 1 Satz 2 vorgeschriebenen Erklärung oder

5. als Geschäftsleiter einer inländischen oder ausländischen juristischen Person in der nach $\S 8$ Abs. 3 Satz 1 oder $§ 39$ Abs. 3 Satz 1 abzugebenden Versicherung oder als Liquidator in der nach $\S 67$ Abs. 3 Satz 1 abzugebenden Versicherung falsche Angaben macht.

(2) Ebenso wird bestraft, wer

1. als Geschäftsführer zum Zweck der Herabsetzung des Stammkapitals über die Befriedigung oder Sicher- 
des Stammkapitals über die Befriedigung oder Sicherstellung der Gläubiger eine unwahre Versicherung abgibt oder

2. als Geschäftsführer, Liquidator, Mitglied eines Aufsichtsrats oder ähnlichen Organs in einer öffentlichen Mitteilung die Vermögenslage der Gesellschaft unwahr darstellt oder verschleiert, wenn die Tat nicht in $\S 331$ Nr. 1 oder Nr. 1a des

Handelsgesetzbuchs mit Strafe bedroht ist.

\section{§ 84 Pflichtverletzung bei Verlust, Zahlungsunfä-} higkeit oder Überschuldung

(1) Mit Freiheitsstrafe bis $\mathrm{zu}$ drei Jahren oder mit Geldstrafe wird bestraft, wer es

1. als Geschäftsführer unterlässt, den Gesellschaftern einen Verlust in Höhe der Hälfte des Stammkapitals anzuzeigen,

oder

2. als Geschäftsführer entgegen $\S 64$ Abs. 1 oder als Liquidator entgegen $\S 71$ Abs. 4 unterlässt, bei Zahlungsunfähigkeit oder Überschuldung die Eröffnung des Insolvenzverfahrens zu beantragen.

(2) Handelt der Täter fahrlässig, so ist die Strafe Freiheitsstrafe bis zu einem Jahr oder Geldstrafe.

\section{§ 86 Umstellung auf Euro}

(1) Gesellschaften, die vor dem 1. Januar 1999 in das Handelsregister eingetragen worden sind, dürfen ihr auf Deutsche Mark lautendes Stammkapital beibehalten; entsprechendes gilt für Gesellschaften, die vor dem 1. Januar 1999 zur Eintragung in das Handelsregister angemeldet, aber erst danach bis zum 31 . Dezember 2001 eingetragen werden. Für Mindestbetrag und Teilbarkeit von Kapital, Einlagen und Geschäftsanteilen sowie für den Umfang des Stimmrechts bleiben bis zu einer Kapitaländerung nach Satz 4 die bis dahin gültigen Beträge weiter maßgeblich. Dies gilt auch, wenn die Gesellschaft ihr Kapital auf Euro umgestellt hat; das Verhältnis der mit den Geschäftsanteilen verbundenen Rechte zueinander wird durch Umrechnung zwischen Deutscher Mark und Euro nicht berührt. Eine Änderung des Stammkapitals darf nach dem 31. Dezember 2001 nur eingetragen werden, wenn das Kapital auf Euro umgestellt und die in Euro berechneten Nennbeträge der Geschäftsanteile auf einen durch zehn teilbaren Betrag, mindestens jedoch auf fünfzig Euro gestellt werden.

(2) Bei Gesellschaften, die zwischen dem 1. Januar 1999 und dem 31. Dezember 2001 zum Handelsregister angemeldet und in das Register eingetragen werden, dürfen Stammkapital und Stammeinlagen auch auf Deutsche Mark lauten. Für Mindestbetrag und stellung der Gläubiger eine unwahre Versicherung abgibt oder

2. als Geschäftsführer, Liquidator, Mitglied eines Aufsichtsrats oder ähnlichen Organs in einer öffentlichen Mitteilung die Vermögenslage der Gesellschaft unwahr darstellt oder verschleiert, wenn die Tat nicht in $\S 331$ Nr. 1 oder Nr. 1a des

Handelsgesetzbuchs mit Strafe bedroht ist.

\section{§ 84 Pflichtverletzung bei Verlust, Zahlungsunfä-} higkeit oder Überschuldung

(1) Mit Freiheitsstrafe bis $\mathrm{zu}$ drei Jahren oder mit Geldstrafe wird bestraft, wer es als Geschäftsführer unterlässt, den Gesellschaftern einen Verlust in Höhe der Hälfte des Stammkapitals anzuzeigen.

(2) Handelt der Täter fahrlässig, so ist die Strafe Freiheitsstrafe bis zu einem Jahr oder Geldstrafe.

\section{§ 86 Umstellung auf Euro}

[weggefallen]. 
Teilbarkeit von Kapital, Einlagen und Geschäftsanteilen sowie für den Umfang des Stimmrechts gelten die zu dem vom Rat der Europäischen Union gemäß Artikel 1091 Abs. 4 Satz 1 des EG-Vertrages unwiderruflich festgelegten Umrechnungskurs in Deutsche Mark umzurechnenden Beträge des Gesetzes in der ab dem 1. Januar 1999 geltenden Fassung.

(3) Die Umstellung des Stammkapitals und der Geschäftsanteile sowie weiterer satzungsmäßiger Betragsangaben auf Euro zu dem gemäß Artikel 1091 Abs. 4 Satz 1 des EGVertrages unwiderruflich festgelegten Umrechnungskurs erfolgt durch Beschluß der Gesellschafter mit einfacher Stimmenmehrheit nach $\S$ 47; § 53 Abs. 2 Satz 1 findet keine Anwendung. Auf die Anmeldung und Eintragung der Umstellung in das Handelsregister ist $\S 54$ Abs. 1 Satz 2 nicht anzuwenden. Werden mit der Umstellung weitere Maßnahmen verbunden, insbesondere das Kapital verändert, bleiben die hierfür geltenden Vorschriften unberührt; auf eine Herabsetzung des Stammkapitals, mit der die Nennbeträge der Geschäftsanteile auf einen Betrag nach Absatz 1 Satz 4 gestellt werden, findet jedoch $\S$ 58 Abs. 1 keine Anwendung, wenn zugleich eine Erhöhung des Stammkapitals gegen Bareinlagen beschlossen und diese in voller Höhe vor der Anmeldung zum Handelsregister geleistet werden.

\section{§ 87 Übergangsvorschriften zum Transparenz- und} Publizitätsgesetz

$\S 42 \mathrm{a}$ Abs. 4 in der Fassung des Artikels 3 Abs. 3 des Transparenz- und Publizitätsgesetzes vom 19. Juli 2002 (BGBl. I S. 2681) ist erstmals auf den Konzernabschluss und den Konzernlagebericht für das nach dem 31. Dezember 2001 beginnende Geschäftsjahr anzuwenden.
§ 87 Übergangsvorschriften zum Transparenz- und Publizitätsgesetz

[weggefallen] 


\section{§ 2 Synopse zum Niederländischen BV-Recht}

\begin{tabular}{|l|l|}
\hline Bisherige Fassung (Stand: bis 31. Mai 2007) & Geplante Fassung (Stand: 31. Mai 2007) \\
\hline \multicolumn{2}{|c|}{\begin{tabular}{c} 
Titel 1 \\
\hline \multicolumn{2}{|c|}{ Algemene bepalingen }
\end{tabular}} \\
\hline $\begin{array}{l}\text { Artikel 24d } \\
\text { houders stemmen, aanwezig of vertegenwoordigd zijn, } \\
\text { of in hoeverre het aandelenkapitaal verschaft wordt of } \\
\text { vertegenwoordigd is, wordt geen rekening gehouden } \\
\text { met lidmaatschappen of aandelen waarvan de wet } \\
\text { bepaalt dat daarvoor geen stem kan worden uit- } \\
\text { gebracht. }\end{array}$ & $\begin{array}{l}\text { Artikel 24d } \\
\text { houders stemmen, aanwezig of vertegenwoordigd zijn, } \\
\text { of in hoeverre het aandelenkapitaal verschaft wordt of } \\
\text { vertegenwoordigd is, wordt geen rekening gehouden } \\
\text { met lidmaatschappen of aandelen waarvan de wet of } \\
\text { de statuten bepalen dat daarvoor geen stem kan wor- } \\
\text { den uitgebracht. }\end{array}$ \\
\hline
\end{tabular}

Titel 3

Coöperaties en onderlinge waarborgmaatschappijen

Afdeling 2

De raad van commissarissen bij de grote coöperatie en bij de grote onderlinge waarborgmaatschappij

\section{Artikel 63a}

In deze afdeling wordt onder een afhankelijke maatschappij verstaan:

A/ Een rechtspersoon waaraan de coöperatie of onderlinge waarborgmaatschappij of een of meer afhankelijke maatschappijen alleen of samen voor eigen rekening ten minste de helft van het geplaatste kapitaal verschaffen.

B/ Een vennootschap waarvan een onderneming in het handelsregister is ingeschreven en waarvoor de coöperatie of onderlinge waarborgmaatschappij als vennote jegens derden volledig aansprakelijk is voor alle schulden.

\section{Art. 63a}

In deze afdeling wordt onder een afhankelijke maatschappij verstaan:

A/ Een rechtspersoon waaraan de coöperatie of onderlinge waarborgmaatschappij of een of meer afhankelijke maatschappijen alleen of samen voor eigen rekening ten minste de helft van het geplaatste kapitaal verschaffen.

$\mathrm{B} /$ Een vennootschap waarvan een onderneming in het handelsregister is ingeschreven en waarvoor de coöperatie of onderlinge waarborgmaatschappij als vennote jegens derden volledig aansprakelijk is voor alle schulden.

In afwijking van artikel $24 d$ wordt bij de toepassing van onderdeel a ten aanzien van een besloten vennootschap met beperkte aansprakelijkheid tevens rekening gehouden met aandelen waarvan de statuten bepalen dat daarvoor geen stem kan worden uitgebracht.

Titel 4

Naamloze vennootschappen

Afdeling 6

De raad van commissarissen bij de grote naamloze vennootschap

\section{Artikel 152}

Artikel 152

In deze afdeling wordt onder een afhankelijke maat- 
schappij verstaan:

A/ Een rechtspersoon waaraan de naamloze vennootschap of een of meer afhankelijke maatschappijen alleen of samen voor eigen rekening ten minste de helft van het geplaatste kapitaal verschaffen,

B/ Een vennootschap waarvan een onderneming in het handelsregister is ingeschreven en waarvoor de naamloze vennootschap of een afhankelijke maatschappij als vennote jegens derden volledig aansprakelijk is voor alle schulden. schappij verstaan:

A/ Een rechtspersoon waaraan de naamloze vennootschap of een of meer afhankelijke maatschappijen alleen of samen voor eigen rekening ten minste de helft van het geplaatste kapitaal verschaffen,

$\mathrm{B} /$ Een vennootschap waarvan een onderneming in het handelsregister is ingeschreven en waarvoor de naamloze vennootschap of een afhankelijke maatschappij als vennote jegens derden volledig aansprakelijk is voor alle schulden.

In afwijking van artikel $24 d$ wordt bij de toepassing van onderdeel a ten aanzien van een besloten vennootschap met beperkte aansprakelijkheid tevens rekening gehouden met aandelen waarvan de statuten bepalen dat daarvoor geen stem kan worden uitgebracht

Titel 5

Besloten vennootschappen met beperkte aansprakelijkheid

\author{
Afdeling 1 \\ Algemene bepalingen
}

\begin{abstract}
Artikel 175
1/ De besloten vennootschap met beperkte aansprakelijkheid is een rechtspersoon met een in aandelen verdeeld maatschappelijk kapitaal. Aandeelbewijzen worden niet uitgegeven; de aandelen zijn niet vrij overdraagbaar. Een aandeelhouder is niet persoonlijk aansprakelijk voor hetgeen in naam van de vennootschap wordt verricht en is niet gehouden boven het bedrag dat op zijn aandelen behoort te worden gestort in de verliezen van de vennootschap bij te dragen.
\end{abstract}

2/ De vennootschap wordt door een of meer personen opgericht bij notariële akte. Voor oprichting is vereist een verklaring van Onze Minister van Justitie dat hem van geen bezwaren is gebleken. De akte wordt getekend door iedere oprichter en door ieder die blijkens deze akte een of meer aandelen neemt.

3/ De akte van oprichting moet binnen drie maanden na de dagtekening van de verklaring van geen bezwaar zijn verleden, op straffe van verval van de verklaring. Onze Minister kan op verzoek van belanghebbenden op grond van gewichtige redenen deze termijn met ten hoogste drie maanden verlengen.

\section{Artikel 178}

1/ De statuten vermelden het bedrag van het maatschappelijk kapitaal en het aantal en het bedrag van de aandelen in euro tot ten hoogste twee cijfers achter de komma. Zijn er verschillende soorten aandelen, dan

\section{Artikel 175}

1/ De besloten vennootschap met beperkte aansprakelijkheid is een rechtspersoon met een in overdraagbare aandelen verdeeld kapitaal. De aandelen zijn op naam gesteld. Een aandeelhouder is niet persoonlijk aansprakelijk voor hetgeen in naam van de vennootschap wordt verricht en is niet gehouden boven het bedrag dat op zijn aandelen behoort te worden gestort in de verliezen van de vennootschap bij te dragen. Ten minste één aandeel met stemrecht wordt gehouden door een ander dan de vennootschap of een van haar dochtermaatschappijen.

2/ De vennootschap wordt door een of meer personen opgericht bij notariële akte. Voor oprichting is vereist een verklaring van Onze Minister van Justitie dat hem van geen bezwaren is gebleken. De akte wordt getekend door iedere oprichter en door ieder die blijkens deze akte een of meer aandelen neemt.

3/ De akte van oprichting moet binnen drie maanden na de dagtekening van de verklaring van geen bezwaar zijn verleden, op straffe van verval van de verklaring. Onze Minister kan op verzoek van belanghebbenden op grond van gewichtige redenen deze termijn met ten hoogste drie maanden verlengen.

\section{Artikel 178}

1/ De statuten vermelden het nominale bedrag van de aandelen. Zijn er aandelen van verschillende soort, dan vermelden de statuten het nominale bedrag van elke soort. Indien de statuten bepalen dat er een maat- 
vermelden de statuten het aantal en het bedrag van elke soort. De akte van oprichting vermeldt het bedrag van het geplaatste kapitaal en van het gestorte deel daarvan. Zijn er verschillende soorten aandelen dan worden de bedragen van het geplaatste en van het gestorte kapitaal uitgesplitst per soort. De akte vermeldt voorts van ieder die bij de oprichting aandelen neemt de in artikel 196 lid 2 onder b en c bedoelde gegevens met het aantal en de soort van de door hem genomen aandelen en het daarop gestorte bedrag.

2/ Het maatschappelijke en het geplaatste kapitaal en het gestorte deel daarvan moeten bij de oprichting ten minste het minimumkapitaal bedragen[Red: Bij Stb. 2000/322 is dit bedrag m.i.v. 1 september 2000 vastgesteld op 18000 euro.] dat bij koninklijk besluit is vastgesteld. Het minimumkapitaal wordt ten hoogste eenmaal in de twee jaren verhoogd of verlaagd, evenredig aan de ontwikkeling sedert 1 januari 1985 van een bij algemene maatregel van bestuur aan te wijzen prijsindexcijfer; het wordt daarbij afgerond op het naaste veelvoud van tweeduizendvijfhonderd euro. Het minimumkapitaal wordt niet opnieuw vastgesteld zo lang als het minder dan tweeduizend euro afwijkt van het onafgeronde bedrag.

3/ Is de som van het gestorte en opgevraagde deel van het kapitaal en de reserves die krachtens een andere wetsbepaling of de statuten moeten worden aangehouden, geringer dan het laatst vastgestelde minimumkapitaal, dan moet de vennootschap een reserve aanhouden ter grootte van het verschil.

4/ Van het maatschappelijke kapitaal moet ten minste een vijfde gedeelte zijn geplaatst.

5/ Een besloten vennootschap die is ontstaan voor 1 januari 2002 kan het bedrag van het maatschappelijk kapitaal en het bedrag van de aandelen in gulden vermelden tot ten hoogste twee cijfers achter de komma.

\section{Artikel 180}

1/ De bestuurders zijn verplicht de vennootschap te doen inschrijven in het handelsregister en een authentiek afschrift van de akte van oprichting en van de daaraan ingevolge de artikelen 203a, 204 en 204a gehechte stukken neer te leggen ten kantore van het handelsregister. Tegelijkertijd moeten zij opgave doen van het totaal van de vastgestelde en geraamde kosten die met de oprichting verband houden en ten laste van de vennootschap komen.

2/ De bestuurders zijn naast de vennootschap hoofdelijk aansprakelijk voor elke tijdens hun bestuur verrichte rechtshandeling waardoor de vennootschap wordt verbonden in het tijdvak voordat:

A/ De opgave ter eerste inschrijving in het handelsregister, vergezeld van de neer te leggen afschriften, is schappelijk kapitaal is, dan wordt het bedrag daarvan vermeld. De akte van oprichting vermeldt het bedrag van het geplaatste kapitaal en het gestorte deel daarvan. Zijn er aandelen van verschillende soort, dan worden de bedragen van het geplaatste en het gestorte kapitaal uitgesplitst per soort. De akte vermeldt voorts van ieder die bij de oprichting aandelen neemt de in artikel 196 lid 2 onder $b$ en $c$ bedoelde gegevens met het aantal en de soort van de door hem genomen aandelen en het daarop gestorte bedrag.

2/ Het bedrag van het maatschappelijke en het geplaatste kapitaal en het gestorte deel daarvan, alsmede het nominale bedrag van de aandelen kunnen luiden in ander geld dan euro. Een besloten vennootschap die is ontstaan voor 1 januari 2002 kan het bedrag van het maatschappelijke kapitaal en het nominale bedrag van de aandelen in gulden vermelden tot ten hoogste twee cijfers achter de komma.

\section{Artikel 180}

1/ De bestuurders zijn verplicht de vennootschap te doen inschrijven in het handelsregister en een authentiek afschrift van de akte van oprichting en van de daaraan ingevolge artikel 204 gehechte stukken neer te leggen ten kantore van het handelsregister.

2/ De bestuurders zijn naast de vennootschap hoofdelijk aansprakelijk voor elke tijdens hun bestuur verrichte rechtshandeling waardoor de vennootschap wordt verbonden in het tijdvak voordat de opgave ter eerste inschrijving in het handelsregister, vergezeld van de neer te leggen afschriften, is geschied. 
geschied,

B/ Het gestorte deel van het kapitaal ten minste het bij de oprichting voorgeschreven minimumkapitaal bedraagt, en

C/ Op het bij de oprichting geplaatste kapitaal ten minste een vierde van het nominale bedrag is gestort.

\section{Artikel 181}

1/ Wanneer de besloten vennootschap zich krachtens artikel 18 omzet in een vereniging, coöperatie of onderlinge waarborgmaatschappij, wordt iedere aandeelhouder lid, tenzij hij de schadeloosstelling heeft gevraagd, bedoeld in lid 2 .

2/ Op het besluit tot omzetting is artikel 209 van toepassing, tenzij de vennootschap zich omzet in een naamloze vennootschap. Na zulk een besluit kan iedere aandeelhouder die niet met het besluit heeft ingestemd, de vennootschap schadeloosstelling vragen voor het verlies van zijn aandelen. Het verzoek tot schadeloosstelling moet schriftelijk aan de vennootschap worden gedaan binnen één maand nadat zij aan de aandeelhouder heeft meegedeeld dat hij deze schadeloosstelling kan vragen. De mededeling geschiedt op de zelfde wijze als de oproeping tot een algemene vergadering.

3/ Bij gebreke van overeenstemming wordt de schadeloosstelling bepaald door een of meer onafhankelijke deskundigen, ten verzoeke van de meest gerede partij te benoemen door de rechtbank bij de machtiging tot omzetting of door de voorzieningenrechter van de rechtbank. De artikelen 351 en 352 zijn van toepassing.

\section{Artikel 182}

[Vervallen per 01-01-1992]

\section{Artikel 181}

1/ Wanneer de besloten vennootschap zich krachtens artikel 18 omzet in een vereniging, coöperatie of onderlinge waarborgmaatschappij, wordt iedere aandeelhouder lid, tenzij hij de schadeloosstelling heeft gevraagd, bedoeld in lid 2 .

2/ $\mathrm{Na}$ een besluit tot omzetting kan iedere aandeelhouder die niet met het besluit heeft ingestemd, de vennootschap schadeloosstelling vragen voor het verlies van zijn aandelen, tenzij de vennootschap zich omzet in een naamloze vennootschap. Na zulk een besluit kan iedere aandeelhouder die niet met het besluit heeft ingestemd, de vennootschap schadeloosstelling vragen voor het verlies van zijn aandelen. Het verzoek tot schadeloosstelling moet schriftelijk aan de vennootschap worden gedaan binnen één maand nadat zij aan de aandeelhouder heeft meegedeeld dat hij deze schadeloosstelling kan vragen. De mededeling geschiedt op de zelfde wijze als de oproeping tot een algemene vergadering.

3/ Bij gebreke van overeenstemming wordt de schadeloosstelling bepaald door een of meer onafhankelijke deskundigen, ten verzoeke van de meest gerede partij te benoemen door de rechtbank bij de machtiging tot omzetting of door de voorzieningenrechter van de rechtbank. De artikelen 351 en 352 zijn van toepassing.

\section{Artikel 182}

1/ De vennootschap legt het besluit tot omzetting in een vereniging, coöperatie of onderlinge waarborgmaatschappij neer ten kantore van het handelsregister en kondigt de nederlegging aan in een landelijk verspreid dagblad.

2/ De vennootschap moet, op straffe van gegrondverklaring van een verzet als bedoeld in lid 3 , voor iedere schuldeiser die dit verlangt zekerheid stellen of hem een andere waarborg geven voor de voldoening van zijn vordering. Dit geldt niet, indien de schuldeiser voldoende waarborgen heeft of de vermogenstoestand van de vennootschap voldoende zekerheid biedt dat de vordering zal worden voldaan.

3/ Binnen twee maanden na de in lid 1 vermelde aankondiging kan iedere schuldeiser door een verzoekschrift aan de rechtbank tegen een besluit tot omzetting als bedoeld in lid 1 in verzet komen met 


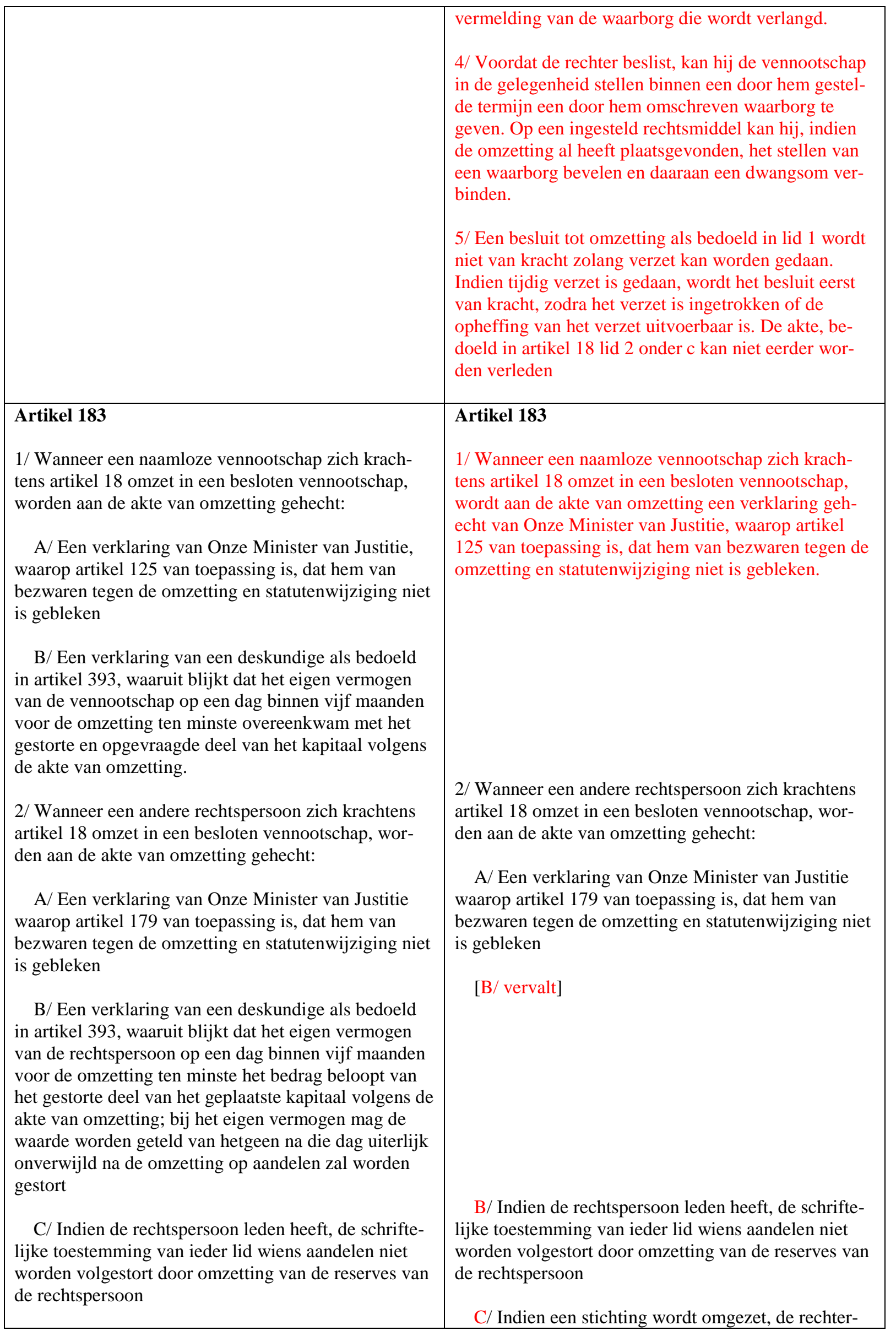




\begin{abstract}
D/ Indien een stichting wordt omgezet, de rechterlijke machtiging daartoe.

3/ Wanneer een vereniging, coöperatie of onderlinge waarborgmaatschappij zich krachtens artikel 18 omzet in een besloten vennootschap, wordt ieder lid aandeelhouder. De omzetting kan niet geschieden, zolang een lid nog kan opzeggen op grond van artikel 36 lid 4.

4/ Na de omzetting kunnen een aandeelhouder, een vruchtgebruiker en een pandhouder de aan een aandeel verbonden rechten niet uitoefenen, zolang zij niet in het in artikel 194 bedoelde register zijn ingeschreven. Voor zover aandeelbewijzen zijn uitgegeven, vindt geen inschrijving plaats dan tegen afgifte van de aandeelbewijzen aan de vennootschap.
\end{abstract}

\section{Artikel 185}

1/ Op verzoek van het openbaar ministerie ontbindt de rechtbank de vennootschap, wanneer deze haar doel, door een gebrek aan baten, niet kan bereiken, en kan de rechtbank de vennootschap ontbinden, wanneer deze haar werkzaamheden tot verwezenlijking van haar doel heeft gestaakt. Het openbaar ministerie deelt de Kamer van Koophandel en Fabrieken, in wier handelsregister de vennootschap is ingeschreven, mee dat het voornemens is een verzoek tot ontbinding in te stellen.

2/ Op verzoek van het openbaar ministerie wordt een vennootschap waarvan het eigen vermogen geringer is dan het laatst vastgestelde minimumkapitaal door de rechtbank ontbonden, indien:

$\mathrm{A} / \mathrm{Zij}$ in strijd met de wet winst of reserves heeft uitgekeerd,

B/ Zij in strijd met de wet haar kapitaal heeft verminderd,

$\mathrm{C} / \mathrm{Zij}$ of een dochtermaatschappij aandelen in haar kapitaal of certificaten daarvan in strijd met de wet heeft verkregen, of

D/ Het eigen vermogen nooit ten minste het bij de oprichting vereiste minimumkapitaal heeft geëvenaard.

3/ Alvorens de ontbinding uit te spreken kan de rechter de vennootschap in de gelegenheid stellen binnen een door hem te bepalen termijn het verzuim te herstellen.

\section{Artikel 189a}

Voor de toepassing van de artikelen 195, 206, 210 lid 6 en 239 wordt onder orgaan van de vennootschap verstaan de algemene vergadering van aandeelhouders, de vergadering van houders van aandelen van lijke machtiging daartoe.

3/ Wanneer een vereniging, coöperatie of onderlinge waarborgmaatschappij zich krachtens artikel 18 omzet in een besloten vennootschap, wordt ieder lid aandeelhouder. De omzetting kan niet geschieden, zolang een lid nog kan opzeggen op grond van artikel 36 lid 4.

4/ Na de omzetting kunnen een aandeelhouder, een vruchtgebruiker en een pandhouder de aan een aandeel verbonden rechten niet uitoefenen, zolang zij niet in het in artikel 194 bedoelde register zijn ingeschreven. Voor zover aandeelbewijzen zijn uitgegeven, vindt geen inschrijving plaats dan tegen afgifte van de aandeelbewijzen aan de vennootschap

\section{Artikel 185}

1/ Op verzoek van het openbaar ministerie ontbindt de rechtbank de vennootschap, wanneer deze haar doel, door een gebrek aan baten, niet kan bereiken, en kan de rechtbank de vennootschap ontbinden, wanneer deze haar werkzaamheden tot verwezenlijking van haar doel heeft gestaakt. Het openbaar ministerie deelt de Kamer van Koophandel en Fabrieken, in wier handelsregister de vennootschap is ingeschreven, mee dat het voornemens is een verzoek tot ontbinding in te stellen.

[2/ vervalt]

2/ Alvorens de ontbinding uit te spreken kan de rechter de vennootschap in de gelegenheid stellen binnen een door hem te bepalen termijn het verzuim te herstellen.

\section{Artikel 189a}

Voor de toepassing van de artikelen 192, 195a, 195b, 206, 210 lid 6, 216 lid 1, 227 lid 2, 239 en 244 wordt onder orgaan van de vennootschap verstaan de algemene vergadering, de vergadering van houders van 
een bijzonder soort, het bestuur, de raad van commissarissen en de gemeenschappelijke vergadering van het bestuur en de raad van commissarissen. aandelen van een bepaalde soort of aanduiding, het bestuur, de raad van commissarissen en de gemeenschappelijke vergadering van het bestuur en de raad van commissarissen

\section{Afdeling 2 De aandelen}

Artikel 190
Aandelen zijn de gedeelten, waarin het maatschappe-
lijk kapitaal bij de statuten is verdeeld.

Artikel 191

1/ Bij het nemen van het aandeel moet daarop het nominale bedrag worden gestort. Bedongen kan worden dat een deel, ten hoogste drie vierden, van het nominale bedrag eerst behoeft te worden gestort nadat de vennootschap het zal hebben opgevraagd.

2/ Een aandeelhouder kan niet geheel of gedeeltelijk worden ontheven van de verplichting tot storting, behoudens het bepaalde in artikel 208 .

3/ De aandeelhouder en, in het geval van artikel 199, de voormalige aandeelhouder zijn niet bevoegd tot verrekening van hun schuld uit hoofde van dit artikel.

\section{Artikel 191a}

1/ Storting op een aandeel moet in geld geschieden voor zover niet een andere inbreng is overeengekomen.

2/ Voor of bij de oprichting kan storting in vreemd geld slechts geschieden, indien de akte van oprichting vermeldt dat storting in vreemd geld is toegestaan; na de oprichting kan dit slechts geschieden met toestemming van de vennootschap. Storting in een valuta die een eenheid is van de euro krachtens artikel 109L, vierde lid van het Verdrag betreffende de Europese Unie wordt niet beschouwd als storting in vreemd geld.

3/ Met storting in vreemd geld wordt aan de stortingsplicht voldaan voor het bedrag waartegen het gestorte bedrag vrijelijk in Nederlands geld kan worden gewisseld. Bepalend is de wisselkoers op de dag van de storting dan wel, indien vroeger dan een maand voor de oprichting is gestort, op de dag van de oprichting.

\section{Artikel 190}

Rechten die stemrecht noch aanspraak op uitkering van winst of reserves omvatten, worden niet als aandeel aangemerkt.

\section{Artikel 191}

1/ Bij het nemen van het aandeel moet daarop het nominale bedrag worden gestort. Bedongen kan worden dat het nominale bedrag of een deel daarvan eerst behoeft te worden gestort na verloop van een bepaalde tijd of nadat de vennootschap het zal hebben opgevraagd.

2/ Een aandeelhouder kan niet geheel of gedeeltelijk worden ontheven van de verplichting tot storting, behoudens het bepaalde in artikel 208 .

3/ De aandeelhouder en, in het geval van artikel 199, de voormalige aandeelhouder zijn niet bevoegd tot verrekening van hun schuld uit hoofde van dit artikel.

\section{Artikel 191a}

1/ Storting op een aandeel moet in geld geschieden voor zover niet een andere inbreng is overeengekomen.

2/ Voor of bij de oprichting kan storting in ander geld dan dat waarin het nominale bedrag van de aandelen luidt slechts geschieden, indien de akte van oprichting vermeldt dat storting in ander geld is toegestaan. $\mathrm{Na}$ de oprichting kan dit slechts geschieden met toestemming van de vennootschap, tenzij de statuten anders bepalen.

3/ Met storting in ander geld dan dat waarin de nominale waarde luidt wordt aan de stortingsplicht voldaan voor het bedrag waartegen het gestorte bedrag vrijelijk kan worden gewisseld in het geld waarin de nominale waarde luidt. Bepalend is de wisselkoers op de dag van de storting dan wel, indien vroeger dan een maand voor de oprichting is gestort, op de dag van de oprichting. 


\begin{tabular}{|c|c|}
\hline Artikel 192 & Artikel 192 \\
\hline $\begin{array}{l}\text { Aan een aandeelhouder kan niet, zelfs niet door wijzi- } \\
\text { ging van de statuten, tegen zijn wil enige verplichting } \\
\text { boven de storting tot het nominale bedrag van het } \\
\text { aandeel worden opgelegd. }\end{array}$ & 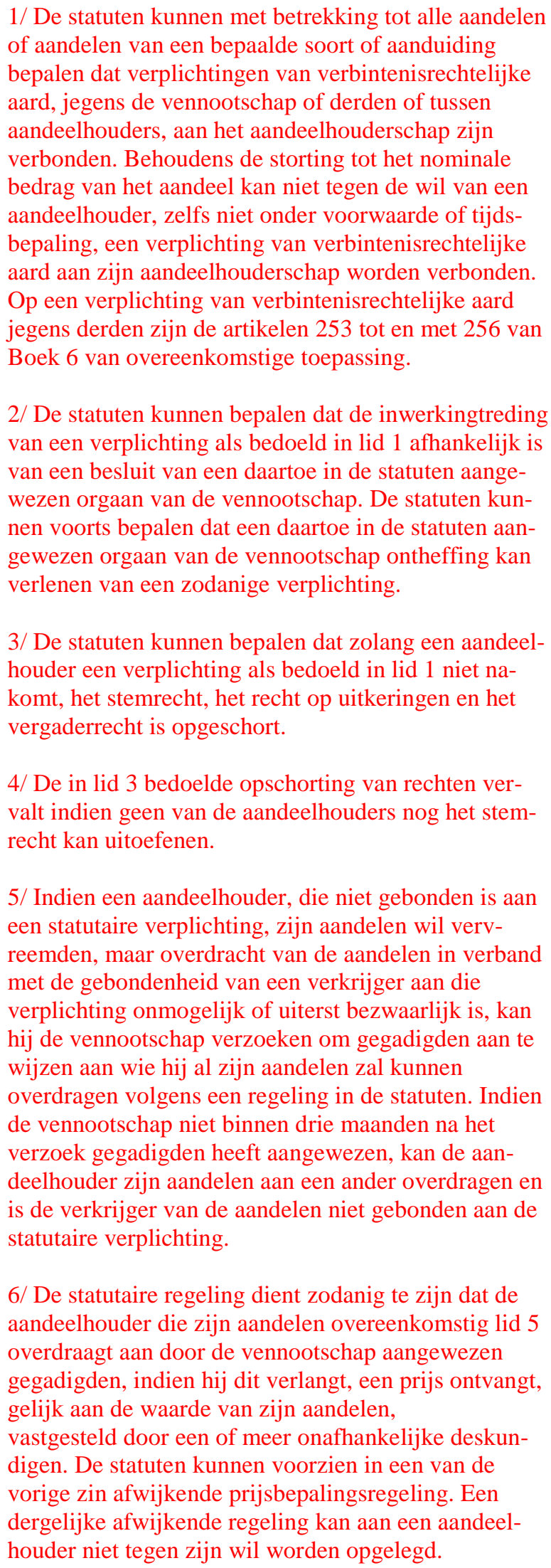 \\
\hline Artikel 193 & Artikel 193 \\
\hline
\end{tabular}


De vereffenaar van een vennootschap en, in geval van faillissement, de curator, zijn bevoegd tot uitschrijving en inning van alle nog niet gedane stortingen op de aandelen, onverschillig hetgeen bij de statuten daaromtrent is bepaald.
De vereffenaar van een vennootschap en, in geval van faillissement, de curator, zijn bevoegd tot uitschrijving en inning van alle nog niet gedane stortingen op de aandelen. Deze bevoegdheid geldt onverschillig hetgeen bij de statuten daaromtrent is bepaald of op grond van artikel 191 lid 1 is bedongen, met dien verstande dat indien bedongen is dat een storting plaatsvindt op een tijdstip na de dag van de faillietverklaring, volstaan kan worden met voldoening van de contante waarde daarvan op de dag van de faillietverklaring.

\section{Artikel 194}

1/ Het bestuur van de vennootschap houdt een register waarin de namen en de adressen van alle aandeelhouders zijn opgenomen, met vermelding van de datum waarop zij de aandelen hebben verkregen, de datum van de erkenning of betekening, alsmede van het op ieder aandeel gestorte bedrag. Daarin worden tevens opgenomen de namen en adressen van hen die een recht van vruchtgebruik of pandrecht op aandelen hebben, met vermelding van de datum waarop zij het recht hebben verkregen, de datum van erkenning of betekening, alsmede met vermelding welke aan de aandelen verbonden rechten hun overeenkomstig de leden 2 en 4 van de artikelen 197 en 198 van dit boek toekomen.

2/ Het register wordt regelmatig bijgehouden; daarin wordt mede aangetekend elk verleend ontslag van aansprakelijkheid voor nog niet gedane stortingen.

3/ Het bestuur verstrekt desgevraagd aan een aandeelhouder, een vruchtgebruiker en een pandhouder om niet een uittreksel uit het register met betrekking tot zijn recht op een aandeel. Rust op het aandeel een recht van vruchtgebruik of een pandrecht, dan vermeldt het uittreksel aan wie de in de leden 2 en 4 van de artikelen 197 en 198 van dit Boek bedoelde rechten toekomen.

4/ Het bestuur legt het register ten kantore van de vennootschap ter inzage van de aandeelhouders, alsmede van de vruchtgebruikers en pandhouders aan

\section{Artikel 194}

1/ Het bestuur van de vennootschap houdt een register waarin de namen en adressen van alle aandeelhouders zijn opgenomen, met vermelding van de datum waarop zij de aandelen hebben verkregen, de datum van de erkenning of betekening, alsmede van het op ieder aandeel gestorte bedrag. Indien aan aandelen ingevolge een statutaire regeling op grond van artikel 228 lid 5 geen stemrecht toekomt, worden de aandelen als stemrechtloos vermeld. In het register worden opgenomen de namen en adressen van hen die een recht van vruchtgebruik of pandrecht op aandelen hebben, met vermelding van de datum waarop zij het recht hebben verkregen, de datum van erkenning of betekening, alsmede met vermelding welke aan de aandelen verbonden rechten hun toekomen. In het register worden opgenomen de namen en adressen van de houders van certificaten van aandelen waaraan vergaderrecht is verbonden, met vermelding van de datum waarop zij het certificaat hebben verkregen en de datum van erkenning of betekening. Indien aan een certificaat van een aandeel vergaderrecht is verbonden, wordt dat vermeld.

2/ Het register wordt regelmatig bijgehouden; daarin wordt mede aangetekend elk verleend ontslag van aansprakelijkheid voor nog niet gedane stortingen.

3/ Aandeelhouders en anderen van wie gegevens ingevolge lid 1 in het register moeten worden opgenomen, verschaffen aan het bestuur tijdig de nodige gegevens.

4/ Het bestuur verstrekt desgevraagd aan een aandeelhouder, een vruchtgebruiker, een pandhouder en een houder van een certificaat van een aandeel waaraan bij de statuten vergaderrecht is verbonden om niet een uittreksel uit het register met betrekking tot zijn recht op een aandeel of certificaat van een aandeel. Rust op het aandeel een recht van vruchtgebruik of een pandrecht, dan vermeldt het uittreksel aan wie de in de leden 2 en 4 van de artikelen 197 en 198 van dit Boek bedoelde rechten toekomen.

5/ Het bestuur legt het register ten kantore van de vennootschap ter inzage van de aandeelhouders, alsmede van de vruchtgebruikers en pandhouders aan 
wie de in lid 4 van de artikelen 197 en 198 van dit Boek bedoelde rechten toekomen. De gegevens van het register omtrent niet-volgestorte aandelen zijn ter inzage van een ieder; afschrift of uittreksel van deze gegevens wordt ten hoogste tegen kostprijs verstrekt. wie de in lid 4 van de artikelen 197 en 198 van dit Boek bedoelde rechten toekomen. De gegevens van het register omtrent niet-volgestorte aandelen zijn ter inzage van een ieder; afschrift of uittreksel van deze gegevens wordt ten hoogste tegen kostprijs verstrekt.

\section{Artikel 195}

1/ Een aandeelhouder kan, voor zover de statuten deze bevoegdheid niet beperken of uitsluiten, een of meer van zijn aandelen vrijelijk overdragen aan zijn echtgenoot of geregistreerde partner, aan zijn bloed- en aanverwanten, in de rechte lijn onbeperkt en in de zijlijn in de tweede graad, aan een mede-aandeelhouder en aan de vennootschap. De kring van personen aan wie de aandeelhouder een of meer van zijn aandelen vrijelijk kan overdragen, kan bij de statuten worden uitgebreid tot zijn bloed- en aanverwanten in de zijlijn, of sommigen van hen, in de derde en vierde graad.

2/ Voor iedere andere overdracht dan die welke ingevolge het vorige lid vrijelijk kan geschieden, dienen de statuten een blokkeringsregeling te bevatten.

3/ De overdracht krachtens legaat geldt voor de toepassing van de blokkeringsregeling als een overdracht door de erflater.

4/ Deze blokkeringsregeling dient zodanig te zijn dat de aandeelhouder voor de overdracht, wil zij geldig zijn, de goedkeuring behoeft van een bij de statuten daartoe aangewezen orgaan der vennootschap. De overdracht moet plaatsvinden binnen drie maanden nadat de goedkeuring is verleend. De goedkeuring wordt geacht te zijn verleend indien het orgaan der vennootschap dat met de beslissing is belast niet gelijktijdig met de weigering van de goedkeuring aan de verzoeker opgave doet van een of meer gegadigden die bereid zijn al de aandelen waarop het verzoek om goedkeuring betrekking heeft tegen contante betaling te kopen.

5/ Het vierde lid vindt geen toepassing, voor zover de statuten een blokkeringsregeling bevatten, volgens welke de aandeelhouder die een of meer aandelen wil vervreemden, deze eerst moet aanbieden aan zijn mede-aandeelhouders. Deze regeling kan voorts inhouden dat, zo de mede-aandeelhouders het aanbod niet aanvaarden, het aanbod moet geschieden aan andere gegadigden, aangewezen door een bij de statuten daarmede belast orgaan der vennootschap. De aanbieder blijft bevoegd zijn aanbod in te trekken, mits dit geschiedt binnen een maand nadat hem be-

\section{Artikel 195}

1/ Tenzij de statuten anders bepalen is voor een geldige overdracht van aandelen vereist dat de aandeelhouder die een of meer aandelen wil vervreemden, deze eerst aanbiedt aan zijn mede-aandeelhouders naar evenredigheid van het aantal aandelen dat ten tijde van de aanbieding door ieder van hen wordt gehouden. De aandeelhouder ontvangt, indien hij dit verlangt, van de mede-aandeelhouders een prijs, gelijk aan de waarde van zijn aandeel of aandelen, vastgesteld door een of meer onafhankelijke deskundigen. Indien vaststaat dat niet al de aandelen waarop het aanbod betrekking heeft tegen contante betaling worden gekocht, zal de aanbieder de aandelen binnen drie maanden na die vaststelling vrijelijk mogen overdragen.

2/ De overdracht kr achtens legaat geldt voor de toepassing van lid 1 als een overdracht door de erflater.

3/ De overdraagbaarheid van aandelen kan bij de statuten voor een bepaalde termijn worden uitgesloten. Een overdracht in strijd met een statutaire uitsluiting is ongeldig. Een tot uitsluiting van de overdraagbaarheid strekkend besluit tot statutenwijziging wordt genomen met algemene stemmen in een vergadering waarin het gehele geplaatste kapitaal vertegenwoordigd is.

4/ De overdraagbaarheid van aandelen kan bij de statuten ook op andere wijze dan overeenkomstig lid 1 of lid 3 worden beperkt. Een overdracht in strijd met een statutaire beperking is ongeldig. Een dergelijke statutaire regeling dient zodanig te zijn dat een aandeelhouder die zijn aandelen wil overdragen, indien hij dit verlangt, een prijs ontvangt, gelijk aan de waarde van zijn aandeel of aandelen, vastgesteld door een of meer onafhankelijke deskundigen. De statuten kunnen voorzien in een van de vorige zin afwijkende prijsbepalingsregeling. Een dergelijke afwijkende regeling kan aan een aandeelhouder niet tegen zijn wil worden opgelegd.

5/ Bepalingen in de statuten omtrent de overdraagbaarheid van aandelen vinden geen toepassing, indien de overdracht door die bepalingen onmogelijk of uiterst bezwaarlijk wordt gemaakt, tenzij de onmogelijkheid het gevolg is van een statutaire uitsluiting als bedoeld in lid 3 of een statutaire prijsbepalingsregeling als bedoeld in lid 4. Hetzelfde geldt voor toedeling van aandelen uit een gemeenschap. 
kend is aan welke gegadigden hij al de aandelen waarop het aanbod betrekking heeft kan verkopen en tegen welke prijs. Indien vaststaat dat niet al de aandelen waarop het aanbod betrekking heeft tegen contante betaling worden gekocht, zal de aanbieder de aandelen binnen drie maanden na die vaststelling vrijelijk mogen overdragen.

6/ De blokkeringsregeling dient zodanig te zijn dat de aandeelhouder, indien hij dit verlangt, van degenen die als gegadigden in de zin van het vierde lid worden opgegeven of aan wie ingevolge de blokkeringsregeling als bedoeld in het vijfde lid moet worden aangeboden een prijs ontvangt, gelijk aan de waarde van zijn aandeel of aandelen, vastgesteld door een of meer onafhankelijke deskundigen.

7/ De vennootschap zelf kan slechts met de instemming van de aandeelhouder ingevolge het vierde of het vijfde lid gegadigde zijn.

8/ Beperking van de overdraagbaarheid van de aandelen kan niet zodanig geschieden, dat die overdracht onmogelijk of uiterst bezwaarlijk wordt gemaakt. Hetzelfde geldt voor toedeling van aandelen uit een gemeenschap.

9/ Bepalingen in de statuten omtrent overdraagbaarheid van aandelen gelden niet, indien de houder krachtens de wet tot overdracht van zijn aandeel aan een eerdere houder verplicht is.
6/ Indien de aandeelhouder krachtens de wet tot overdracht van zijn aandeel aan een eerdere houder verplicht is, vindt lid 1, alsmede bepalingen in de statuten omtrent overdraagbaarheid, geen toepassing.

7/ Ingeval van executoriaal beslag, faillissement, een schuldsaneringsregeling natuurlijke personen, afgifte van een legaat, toedeling uit een gemeenschap of een pandrecht kan de rechter lid 1, alsmede bepalingen in de statuten omtrent overdraagbaarheid, geheel of gedeeltelijk buiten toepassing verklaren. Het verzoek daartoe kan worden gedaan door onderscheidenlijk de executant, de curator, de bewindvoerder, een belanghebbende bij de afgifte van het legaat of de toedeling of de pandhouder. De rechter wijst het verzoek, zonodig in afwijking van artikel $474 \mathrm{~g}$, vierde lid, van het Wetboek van Burgerlijke Rechtsvordering, slechts toe indien de belangen van de verzoeker dat bepaaldelijk vorderen en de belangen van anderen daardoor niet onevenredig worden geschaad. De rechter kan bepalen dat de vennootschap aan de executant of de curator inzage moet geven in het register, bedoeld in artikel 194.

\section{Artikel 195a}

1/ De statuten kunnen bepalen dat in gevallen, in de statuten omschreven, de aandeelhouder gehouden is zijn aandelen aan te bieden en over te dragen. De statuten kunnen daarbij bepalen dat zolang de aandeelhouder zijn verplichtingen tot aanbieding of overdracht niet nakomt, zijn stemrecht, zijn recht op deelname aan de algemene vergadering en zijn recht op uitkeringen is opgeschort.

\section{Artikel 195a}

1/ De statuten kunnen bepalen dat in gevallen, in de statuten omschreven, de aandeelhouder gehouden is zijn aandelen of een deel daarvan aan te bieden en over te dragen. De statuten kunnen bepalen dat een orgaan van de vennootschap ontheffing van de verplichting tot aanbieding en overdracht kan verlenen. De regeling dient zodanig te zijn dat de aandeelhouder die dit verlangt een prijs ontvangt, gelijk aan 
2/ De statuten kunnen bepalen dat indien een aandeelhouder niet binnen een bepaalde redelijke termijn zijn statutaire verplichtingen tot aanbieding en overdracht van zijn aandelen is nagekomen, de vennootschap onherroepelijk gevolmachtigd is de aandelen aan te bieden en over te dragen. Wanneer er geen gegadigden zijn aan wie de aandeelhouder al zijn aandelen zal kunnen overdragen volgens een regeling in de statuten, ontbreekt de volmacht en is de aandeelhouder onherroepelijk van het bepaalde in lid 1 ontheven.

3/ De regeling dient zodanig te zijn dat de aandeelhouder die dit verlangt een prijs ontvangt, gelijk aan de waarde van zijn aandeel of aandelen, vastgesteld door een of meer onafhankelijke deskundigen. de waarde van zijn aandeel of aandelen, vastgesteld door een of meer onafhankelijke deskundigen. De statuten kunnen voorzien in een van de vorige zin afwijkende prijsbepalingsregeling. Een dergelijke afwijkende regeling kan aan een aandeelhouder niet tegen zijn wil worden opgelegd.

2/ De statuten kunnen bepalen dat zolang de aandeelhouder zijn verplichting tot aanbieding en overdracht niet nakomt, het aan de aandelen verbonden stemrecht, recht op uitkeringen en vergaderrecht is opgeschort.

3/ De statuten kunnen bepalen dat indien een aandeelhouder niet binnen een bepaalde redelijke termijn zijn statutaire verplichtingen tot aanbieding en overdracht is nagekomen, de vennootschap onherroepelijk gevolmachtigd is de aandelen aan te bieden en over te dragen. Wanneer er geen gegadigden zijn aan wie de aandeelhouder zijn ingevolge lid 1 aangeboden aandelen zal kunnen overdragen, ontbreekt de volmacht en is de aandeelhouder onherroepelijk van het bepaalde in lid 1 en lid 2 ontheven.

4/ Op een verplichting tot aanbieding en overdracht als bedoeld in dit artikel is artikel 192 niet van toepassing.

\section{Artikel 195b}

1/ De statuten kunnen bepalen dat van de aandeelhouder die niet of niet langer aan in de statuten gestelde eisen voldoet het stemrecht, het recht op deelname aan de algemene vergadering en het recht op uitkeringen is opgeschort.

2/ Indien de aandeelhouder een of meer van de in lid 1 genoemde rechten niet kan uitoefenen en de aandeelhouder niet gehouden is zijn aandelen aan te bieden en over te dragen, is hij onherroepelijk van de in de statuten gestelde eisen ontheven wanneer de vennootschap niet binnen drie maanden na een verzoek daartoe van de aandeelhouder gegadigden heeft aangewezen aan wie hij al zijn aandelen zal kunnen overdragen volgens een regeling in de statuten.

3/ De regeling dient zodanig te zijn dat de aandeelhouder die dit verlangt een prijs ontvangt, gelijk aan de waarde van zijn aandeel of aandelen, vastgesteld door een of meer onafhankelijke deskundigen.
1/ De statuten kunnen bepalen dat van de aandeelhouder die niet of niet langer aan in de statuten gestelde eisen aan het aandeelhouderschap voldoet het stemrecht, het vergaderrecht en het recht op uitkeringen is opgeschort. De statuten kunnen bepalen dat een orgaan van de vennootschap ontheffing van de gestelde eisen kan verlenen.

2/ De in lid 1 bedoelde opschorting van rechten vervalt zodra geen van de aandeelhouders nog het stemrecht kan uitoefenen.

3/ Indien de aandeelhouder op grond van lid 1 een of meer van de daar genoemde rechten niet kan uitoefenen en de aandeelhouder niet gehouden is zijn aandelen aan te bieden en over te dragen, is hij onherroepelijk van de in de statuten gestelde eisen ontheven en eindigt de opschorting van de in lid 1 genoemde rechten wanneer de vennootschap niet binnen drie maan- 


\begin{tabular}{|c|c|}
\hline & $\begin{array}{l}\text { den na een verzoek daartoe van de aandeelhouder } \\
\text { gegadigden heeft aangewezen aan wie hij al zijn aan- } \\
\text { delen zal kunnen overdragen volgens een regeling in } \\
\text { de statuten. Indien de aandeelhouder gehouden is zijn } \\
\text { aandelen aan te bieden en over te dragen en er geen } \\
\text { gegadigden zijn aan wie hij zijn aandelen overeen- } \\
\text { komstig artikel 195a zal kunnen overdragen, is hij } \\
\text { onherroepelijk van de in de statuten gestelde eisen } \\
\text { ontheven. } \\
\text { 4/ Een aandeelhouder die zijn aandelen wil vervreem- } \\
\text { den maar dat voornemen niet ten uitvoer kan leggen in } \\
\text { verband met een statutaire eis aan het aandeelhouder- } \\
\text { schap die de overdracht onmogelijk of uiterst } \\
\text { bezwaarlijk maakt, kan de vennootschap verzoeken } \\
\text { om gegadigden aan te wijzen aan wie hij al zijn aande- } \\
\text { len zal kunnen overdragen volgens een regeling in de } \\
\text { statuten. Indien de vennootschap niet binnen drie } \\
\text { maanden na het verzoek gegadigden heeft aangewe- } \\
\text { zen, kan de aandeelhouder zijn aandelen aan een ander } \\
\text { overdragen en is de verkrijger van de aandelen niet } \\
\text { gebonden aan de statutaire eis aan het aandeelhouder- } \\
\text { schap. } \\
\text { 5/ De statutaire regeling dient zodanig te zijn dat de } \\
\text { aandeelhouder die zijn aandelen overeenkomstig lid } 3 \\
\text { of lid } 4 \text { overdraagt aan door de vennootschap aange- } \\
\text { wezen gegadigden, indien hij dit verlangt, een prijs } \\
\text { ontvangt, gelijk aan de waarde van zijn aandelen, } \\
\text { vastgesteld door een of meer onafhankelijke deskun- } \\
\text { digen. De statuten kunnen } \\
\text { voorzien in een van de vorige zin afwijkende prijsbe- } \\
\text { palingsregeling. Een dergelijke afwijkende regeling } \\
\text { kan aan een aandeelhouder niet tegen zijn wil worden } \\
\text { opgelegd. }\end{array}$ \\
\hline Artikel 196c & $\begin{array}{l}\text { Artikel 196c } \\
\text { De artikelen 196a en 196b zijn van overeenkomstige } \\
\text { toepassing met betrekking tot de levering van een } \\
\text { certificaat van een aandeel waaraan vergaderrecht is } \\
\text { verbonden, met dien verstande dat de in artikel 196b } \\
\text { bedoelde overlegging of betekening geschiedt van een } \\
\text { afschrift van de akte van levering. }\end{array}$ \\
\hline Artikel 197 & Artikel 197 \\
\hline $\begin{array}{l}\text { 1/ De bevoegdheid tot het vestigen van vruchtgebruik } \\
\text { op een aandeel kan bij de statuten niet worden beperkt } \\
\text { of uitgesloten. }\end{array}$ & $\begin{array}{l}\text { 1/ De bevoegdheid tot het vestigen van vruchtgebruik } \\
\text { op een aandeel kan bij de statuten niet worden beperkt } \\
\text { of uitgesloten. }\end{array}$ \\
\hline $\begin{array}{l}\text { 2/ De aandeelhouder heeft het stemrecht op de aande- } \\
\text { len waarop een vruchtgebruik is gevestigd. }\end{array}$ & $\begin{array}{l}\text { 2/ De aandeelhouder heeft het stemrecht op de aande- } \\
\text { len waarop een vruchtgebruik is gevestigd. }\end{array}$ \\
\hline $\begin{array}{l}\text { 3/ In afwijking van het voorgaande lid komt het stem- } \\
\text { recht toe aan de vruchtgebruiker, indien zulks bij de } \\
\text { vestiging van het vruchtgebruik is bepaald en de } \\
\text { vruchtgebruiker een persoon is, aan wie de aandelen } \\
\text { overeenkomstig artikel } 195 \text { lid } 1 \text { van dit Boek vrijelijk } \\
\text { kunnen worden overgedragen. Indien de vruchtgebru- }\end{array}$ & $\begin{array}{l}\text { 3/ In afwijking van het voorgaande lid komt het stem- } \\
\text { recht toe aan de vruchtgebruiker, indien dit bij de } \\
\text { vestiging van het vruchtgebruik is bepaald of nadien } \\
\text { schriftelijk tussen de aandeelhouder en de vrucht- } \\
\text { gebruiker is overeengekomen en de vruchtgebruiker } \\
\text { een persoon is aan wie de aandelen vrijelijk kunnen }\end{array}$ \\
\hline
\end{tabular}


iker niet zulk een persoon is, komt hem het stemrecht uitsluitend toe, indien dit bij de vestiging van het vruchtgebruik is bepaald en de statuten dit niet verbieden, mits zowel deze bepaling als - bij overdracht van het vruchtgebruik - de overgang van het stemrecht is goedgekeurd door het vennootschapsorgaan dat bij de statuten is aangewezen om goedkeuring te verlenen tot een voorgenomen overdracht van aandelen, dan wel bij ontbreken van zodanige aanwijzing - door de algemene vergadering van aandeelhouders. Bij een vruchtgebruik als bedoeld in de artikelen 19 en 21 van Boek 4 komt het stemrecht eveneens aan de vruchtgebruiker toe, tenzij bij de vestiging van het vruchtgebruik door partijen of door de kantonrechter op de voet van artikel 23 lid 4 van Boek 4 anders wordt bepaald.

4/ De aandeelhouder die geen stemrecht heeft en de vruchtgebruiker die stemrecht heeft, hebben de rechten, die door de wet zijn toegekend aan de houders van met medewerking ener vennootschap uitgegeven certificaten van aandelen. De vruchtgebruiker die geen stemrecht heeft, heeft deze rechten, indien de statuten dit bepalen en bij de vestiging of overdracht van het vruchtgebruik niet anders is bepaald.

5/ Uit het aandeel voortspruitende rechten, strekkende tot het verkrijgen van aandelen, komen aan de aandeelhouder toe met dien verstande dat hij de waarde daarvan moet vergoeden aan de vruchtgebruiker, voor zover deze krachtens zijn recht van vruchtgebruik daarop aanspraak heeft.

\section{Artikel 198}

1/ Op aandelen kan pandrecht worden gevestigd, indien de statuten niet anders bepalen.

2/ De aandeelhouder heeft het stemrecht op de verpande aandelen.

3/ In afwijking van het voorgaande lid komt het stemrecht toe aan de pandhouder, indien zulks bij de vestiging van het pandrecht is bepaald en de pandhouder een persoon is, aan wie de aandelen overeenkomstig artikel 195 lid 1 van dit Boek vrijelijk kunnen worden overgedragen. Indien de pandhouder niet zulk een persoon is, komt hem het stemrecht uitsluitend toe indien dit bij de vestiging van het pandrecht is bepaald en de vestiging van het pandrecht is goedgekeurd door het vennootschapsorgaan dat bij de statuten is aangewezen om goedkeuring te verlenen tot een voorgenomen overdracht van aandelen, dan wel - bij ontbreken van zodanige aanwijzing - door de algemene vergade- worden overgedragen. Indien de vruchtgebruiker een persoon is aan wie de aandelen niet vrijelijk kunnen worden overgedragen, komt hem het stemrecht uitsluitend toe, indien dit bij de vestiging van het vruchtgebruik is bepaald of nadien schriftelijk tussen de aandeelhouder en de vruchtgebruiker is overeengekomen, mits zowel deze bepaling als - bij overdracht van het vruchtgebruik - de overgang van het stemrecht is goedgekeurd door een daartoe in de statuten aangewezen orgaan, dan wel - bij ontbreken van zodanige aanwijzing - door de algemene vergadering. Van het bepaalde in de vorige zin kan in de statuten worden afgeweken. Bij een vruchtgebruik als bedoeld in de artikelen 19 en 21 van Boek 4 komt het stemrecht eveneens aan de vruchtgebruiker toe, tenzij bij de vestiging van het vruchtgebruik door partijen of door de kantonrechter op de voet van artikel 23 lid 4 van Boek 4 anders wordt bepaald. Op de in de eerste en tweede zin bedoelde schriftelijke overeenkomst zijn artikel 196a en artikel 196b van overeenkomstige toepassing.

[4/ vervalt]

4/ Uit het aandeel voortspruitende rechten, strekkende tot het verkrijgen van aandelen, komen aan de aandeelhouder toe met dien verstande dat hij de waarde daarvan moet vergoeden aan de vruchtgebruiker, voor zover deze krachtens zijn recht van vruchtgebruik daarop aanspraak heeft.

\section{Artikel 198}

1/ Op aandelen kan pandrecht worden gevestigd, indien de statuten niet anders bepalen.

2/ De aandeelhouder heeft het stemrecht op de verpande aandelen.

3/ In afwijking van het voorgaande lid komt het stemrecht toe aan de pandhouder, indien dit, al dan niet onder opschortende voorwaarde, bij de vestiging van het pandrecht is bepaald of nadien schriftelijk tussen de aandeelhouder en de pandhouder is overeengekomen en de pandhouder een persoon is, aan wie de aandelen vrijelijk kunnen worden overgedragen. Indien de pandhouder een persoon is aan wie de aandelen niet vrijelijk kunnen worden overgedragen, komt hem het stemrecht uitsluitend toe, indien dit, al dan niet onder opschortende voorwaarde, bij de vestiging van het pandrecht is bepaald of nadien schriftelijk tussen de aandeelhouder en de pandhouder is ove- 
ring van aandeelhouders. Treedt een ander in de rechten van de pandhouder, dan komt hem het stemrecht slechts toe, indien het in de vorige zin bedoelde orgaan dan wel, bij gebreke daarvan, de algemene vergadering de overgang van het stemrecht goedkeurt. De bevoegdheid tot toekenning van het stemrecht aan de pandhouder kan in de statuten worden uitgesloten.

4/ De aandeelhouder die geen stemrecht heeft en de pandhouder die stemrecht heeft, hebben de rechten, die door de wet zijn toegekend aan de houders van met medewerking ener vennootschap uitgegeven certificaten van aandelen. De pandhouder die geen stemrecht heeft, heeft deze rechten indien de statuten dit bepalen en bij de vestiging of overgang van het pandrecht niet anders is bepaald.

5/ Artikel 195 van dit Boek en de statutaire bepalingen ten aanzien van de vervreemding en overdracht van aandelen zijn van toepassing op de vervreemding en overdracht van de aandelen door de pandhouder of de verblijving van de aandelen aan de pandhouder, met dien verstande dat de pandhouder alle ten aanzien van de vervreemding en overdracht aan de aandeelhouder toekomende rechten uitoefent en diens verplichtingen ter zake nakomt. reengekomen, mits zowel deze bepaling als - indien een ander in de rechten van de pandhouder treedt - de overgang van het stemrecht is goedgekeurd door een daartoe in de statuten aangewezen orgaan, dan wel bij ontbreken van zodanige aanwijzing - door de algemene vergadering. Van het bepaalde in de voorgaande twee zinnen kan in de statuten worden afgeweken. Op de in de eerste en tweede zin bedoelde schriftelijke overeenkomst zijn artikel 196a en artikel 196 b van overeenkomstige toepassing.

4/ Bij de vestiging van het pandrecht kan worden bepaald dat artikel 196a lid 2 buiten toepassing blijft. Alsdan zijn de leden 3 en 4 van artikel 239 lid 3 van Boek 3 van overeenkomstige toepassing, waarbij erkenning door of betekening aan de vennootschap in de plaats treedt van de in die bepaling bedoelde mededeling.

5/ Een statutaire regeling ten aanzien van de vervreemding en de overdracht van aandelen is van toepassing op de vervreemding en overdracht van de aandelen door de pandhouder of de verblijving van de aandelen aan de pandhouder, met dien verstande dat de pandhouder alle ten aanzien van vervreemding en overdracht aan de aandeelhouder toekomende rechten uitoefent en diens verplichtingen ter zake nakomt.

\section{Afdeling 3 \\ Het vermogen van de vennootschap}

\begin{abstract}
Artikel 203
1/ Uit rechtshandelingen, verricht namens een op te richten besloten vennootschap met beperkte aansprakelijkheid, ontstaan slechts rechten en verplichtingen voor de vennootschap wanneer zij die rechtshandelingen na haar oprichting uitdrukkelijk of stilzwijgend bekrachtigt of ingevolge lid 4 wordt verbonden.
\end{abstract}

2/ Degenen die een rechtshandeling verrichten namens een op te richten besloten vennootschap met beperkte aansprakelijkheid zijn, tenzij met betrekking tot die rechtshandeling uitdrukkelijk anders is bedongen, daardoor hoofdelijk verbonden, totdat de vennootschap na haar oprichting de rechtshandeling heeft bekrachtigd.

3/ Indien de vennootschap haar verplichtingen uit de bekrachtigde rechtshandeling niet nakomt, zijn degenen die namens de op te richten vennootschap handelden hoofdelijk aansprakelijk voor de schade die de derde dientengevolge lijdt, indien zij wisten of redelijkerwijs konden weten dat de vennootschap haar verplichtingen niet zou kunnen nakomen, onverminderd de aansprakelijkheid terzake van de bestuurders wegens de bekrachtiging. De wetenschap dat de vennootschap haar verplichtingen niet zou kunnen nako-

\section{Artikel 203}

1/ Uit rechtshandelingen, verricht namens een op te richten besloten vennootschap met beperkte aansprakelijkheid, ontstaan slechts rechten en verplichtingen voor de vennootschap wanneer zij die rechtshandelingen na haar oprichting uitdrukkelijk of stilzwijgend bekrachtigt of ingevolge lid 4 wordt verbonden.

2/ Degenen die een rechtshandeling verrichten namens een op te richten besloten vennootschap met beperkte aansprakelijkheid zijn, tenzij met betrekking tot die rechtshandeling uitdrukkelijk anders is bedongen, daardoor hoofdelijk verbonden, totdat de vennootschap na haar oprichting de rechtshandeling heeft bekrachtigd.

3/ Indien de vennootschap haar verplichtingen uit de bekrachtigde rechtshandeling niet nakomt, zijn degenen die namens de op te richten vennootschap handelden hoofdelijk aansprakelijk voor de schade die de derde dientengevolge lijdt, indien zij wisten of redelijkerwijs konden weten dat de vennootschap haar verplichtingen niet zou kunnen nakomen, onverminderd de aansprakelijkheid terzake van de bestuurders wegens de bekrachtiging. De wetenschap dat de vennootschap haar verplichtingen niet zou kunnen nako- 
men, wordt vermoed aanwezig te zijn, wanneer de vennootschap binnen een jaar na de oprichting in staat van faillissement wordt verklaard.

4/ De oprichters kunnen de vennootschap in de akte van oprichting slechts verbinden door het uitgeven van aandelen, het aanvaarden van stortingen daarop, het aanstellen van bestuurders, het benoemen van commissarissen en het verrichten van rechtshandelingen als bedoeld in artikel 204 lid 1. Indien een oprichter hierbij onvoldoende zorgvuldigheid heeft betracht, zijn de artikelen 9 en 248 van overeenkomstige toepassing. men, wordt vermoed aanwezig te zijn, wanneer de vennootschap binnen een jaar na de oprichting in staat van faillissement wordt verklaard.

4/ De oprichters kunnen de vennootschap in de akte van oprichting slechts verbinden door het uitgeven van aandelen, het aanvaarden van stortingen daarop, het aanstellen van bestuurders, het benoemen van commissarissen, het verrichten van rechtshandelingen als bedoeld in artikel 204 lid 1 en het betalen van kosten die met de oprichting verband houden. Indien een oprichter hierbij onvoldoende zorgvuldigheid heeft betracht, zijn de artikelen 9 en 248 van overeenkomstige toepassing.

Artikel 203a
1/ Indien voor of bij de oprichting op aandelen wordt
gestort in geld, moeten aan de akte van oprichting een
of meer verklaringen worden gehecht, inhoudende dat
de bedragen die op de bij de oprichting te plaatsen
aandelen moeten worden gestort:

A/ Hetzij terstond na de oprichting ter beschikking zullen staan van de vennootschap

B/ Hetzij alle op een zelfde tijdstip, ten vroegste vijf maanden voor de oprichting, op een afzonderlijke rekening stonden welke na de oprichting uitsluitend ter beschikking van de vennootschap zal staan, mits de vennootschap de stortingen in de akte aanvaardt.

2/ Indien vreemd geld is gestort, moet uit de verklaring blijken tegen hoeveel geld het vrijelijk kon worden gewisseld op een dag waarop daarmee krachtens artikel 191a lid 3 kon worden voldaan aan de stortingsplicht.

3/ Zulk een verklaring kan slechts worden afgelegd door een bankier, die een kredietinstelling is als bedoeld in artikel 1 , eerste lid, onderdeel a, onder $1^{\circ}$, van de Wet toezicht kredietwezen 1992 en die hetzij als kredietinstelling is geregistreerd ingevolge artikel 52 van de Wet toezicht kredietwezen 1992, hetzij in een lidstaat van de Europese Gemeenschappen of in een andere staat die partij is bij de Overeenkomst betreffende de Europese Economische Ruimte is onderworpen aan bedrijfseconomisch toezicht van overheidswege. Zij kan slechts worden afgegeven aan een notaris.

4/ Worden voor de oprichting aan de rekening, bedoeld in onderdeel b van lid 1, bedragen onttrokken, dan zijn de oprichters hoofdelijk jegens de vennootschap verbonden tot vergoeding van die bedragen, totdat de vennootschap de onttrekkingen uitdrukkelijk heeft bekrachtigd.

5/ De notaris moet de bankiers wier verklaring hij heeft ontvangen terstond verwittigen van de oprich-

\section{Artikel 203a}

[vervalt] 
ting. Indien de oprichting niet doorgaat, moet hij hun de verklaring terugzenden.

6/ Indien na de oprichting in vreemd geld is gestort, legt de vennootschap binnen twee weken na de storting een verklaring, als bedoeld in lid 2 , van een in het derde lid bedoelde bankier neer ten kantore van het handelsregister.

\section{Artikel 204a}

1/ Indien bij de oprichting inbreng op aandelen anders dan in geld wordt overeengekomen, maken de oprichters een beschrijving op van hetgeen wordt ingebracht, met vermelding van de daaraan toegekende waarde en van de toegepaste waarderingsmethoden. Deze methoden moeten voldoen aan normen die in het maatschappelijke verkeer als aanvaardbaar worden beschouwd. De beschrijving heeft betrekking op de toestand van hetgeen wordt ingebracht op een dag die niet eerder ligt dan hetzij vijf maanden voor de oprichting hetzij een maand voordat de ministeriële verklaring van geen bezwaar is aangevraagd voor een oprichting die uiterlijk een maand na de verklaring van geen bezwaar geschiedt. De beschrijving wordt door alle oprichters ondertekend. De vennootschap legt deze te haren kantore ter inzage van de houders van haar aandelen of van certificaten daarvan die met haar medewerking zijn uitgegeven.

2/ Over de beschrijving van hetgeen wordt ingebracht moet een registeraccountant, of een accountantadministratieconsulent een verklaring afleggen. Indien wordt ingebracht in een vennootschap waarvan de jaarrekening moet worden onderzocht, mag slechts hij die bevoegd is tot het verplichte onderzoek van de jaarrekening, de verklaring over de beschrijving afleggen. Hetzelfde geldt, indien de waarde van alle in te brengen activa, zonder aftrek van passiva, ten minste EUR 3600000 bedraagt. De verklaring houdt in dat de waarde van hetgeen wordt ingebracht, bij toepassing van in het maatschappelijke verkeer als aanvaardbaar beschouwde waarderingsmethoden, ten minste beloopt het in de verklaring genoemde bedrag van de stortingsplicht, in geld uitgedrukt, waaraan met de inbreng moet worden voldaan. De verklaring moet aan de akte van oprichting worden gehecht. Indien bekend is dat de waarde na de beschrijving aanzienlijk is gedaald, is een tweede verklaring vereist.

3/ De beschrijving en accountantsverklaring zijn niet vereist, indien alle oprichters hiervan hebben afgezien en een rechtspersoon die aandelen heeft genomen of waarvan een groepsmaatschappij aandelen heeft genomen, de volgende vereisten vervult:

A/ De rechtspersoon heeft bij het handelsregister waar de vennootschap is ingeschreven een verklaring neergelegd dat hij zich hoofdelijk aansprakelijk stelt voor de uit rechtshandelingen van de vennootschap

\section{Artikel 204a}

1/ Indien bij de oprichting inbreng op aandelen anders dan in geld wordt overeengekomen, maken de oprichters een beschrijving op van hetgeen wordt ingebracht, met vermelding van de daaraan toegekende waarde en van de toegepaste waarderingsmethoden. Deze methoden moeten voldoen aan normen die in het maatschappelijke verkeer als aanvaardbaar worden beschouwd. De beschrijving heeft betrekking op de toestand van hetgeen wordt ingebracht op een dag die niet eerder ligt dan hetzij zes maanden voor de oprichting hetzij een maand voordat de ministeriële verklaring van geen bezwaar is aangevraagd voor een oprichting die uiterlijk een maand na de verklaring van geen bezwaar geschiedt. De beschrijving wordt door alle oprichters ondertekend. De vennootschap legt deze te haren kantore ter inzage van de houders van haar aandelen en anderen aan wie vergaderrecht toekomt.

2/ Indien voor de inbreng bekend is dat de waarde na de in lid 1, derde zin, bedoelde dag aanzienlijk is gedaald, is een tweede beschrijving vereist.

3/ De beschrijving is niet vereist, indien alle oprichters hiervan hebben afgezien en een rechtspersoon die aandelen heeft genomen of waarvan een groepsmaatschappij aandelen heeft genomen, de volgende vereisten vervult:

A/ De rechtspersoon heeft bij het handelsregister waar de vennootschap is ingeschreven een verklaring neergelegd dat hij zich hoofdelijk aansprakelijk stelt voor de uit rechtshandelingen van de vennootschap 
voortvloeiende schulden

$\mathrm{B} / \mathrm{Zijn}$ laatste vastgestelde balans met toelichting is krachtens de toepasselijke wet vastgesteld en onderzocht in overeenstemming met de vierde richtlijn van de Europese Gemeenschappen inzake het vennootschapsrecht; een in het Nederlands, Frans, Duits of Engels gesteld exemplaar daarvan en van de accountantsverklaring daarover overeenkomstig die wet is neergelegd ten kantore van het handelsregister en sedert de balansdatum zijn nog geen achttien maanden verlopen

$\mathrm{C} /$ Blijkens de onder b bedoelde balans overtreft het eigen vermogen van de rechtspersoon het nominaal gestorte bedrag van de aandelen waarop na de balansdatum wordt ingebracht met toepassing van dit lid in vennootschappen waarvoor de rechtspersoon een verklaring heeft afgelegd als bedoeld onder a.

4/ Artikel 404 is van overeenkomstige toepassing met dien verstande, dat de verklaring niet kan worden ingetrokken binnen twee jaren na de inbreng.

\section{Artikel 204b}

1/ Indien na de oprichting inbreng op aandelen anders dan in geld wordt overeengekomen, maakt de vennootschap overeenkomstig artikel 204a lid 1 een beschrijving op van hetgeen wordt ingebracht. De beschrijving heeft betrekking op de toestand op een dag die niet eerder dan vijf maanden ligt voor de dag waarop de aandelen worden genomen dan wel waartegen een bijstorting is uitgeschreven of waarop zij is overeengekomen. De bestuurders ondertekenen de beschrijving; ontbreekt de handtekening van een of meer hunner, dan wordt daarvan onder opgave van reden melding gemaakt.

2/ Artikel 204a lid 2 is van overeenkomstige toepassing.

3/ De leden 3 en 4 van artikel 204a zijn van toepassing, met dien verstande dat niet de oprichters maar alle aandeelhouders moeten hebben afgezien van het opstellen van de beschrijving en de accountantsverklaring.

4/ De vennootschap legt, binnen acht dagen na de dag waarop de aandelen zijn genomen dan wel waarop de bijstorting opeisbaar werd, de accountantsverklaring bij de inbreng of een afschrift daarvan neer ten kantore van het handelsregister met opgave van de namen van de inbrengers en van het bedrag van het aldus gestorte deel van het geplaatste kapitaal. voortvloeiende schulden

$\mathrm{B} / \mathrm{Zijn}$ laatste vastgestelde balans met toelichting is krachtens de toepasselijke wet vastgesteld en onderzocht in overeenstemming met de vierde richtlijn van de Europese Gemeenschappen inzake het vennootschapsrecht; een in het Nederlands, Frans, Duits of Engels gesteld exemplaar daarvan en van de accountantsverklaring daarover overeenkomstig die wet is neergelegd ten kantore van het handelsregister en sedert de balansdatum zijn nog geen achttien maanden verlopen

$\mathrm{C} / \mathrm{Blijkens}$ de onder $\mathrm{b}$ bedoelde balans overtreft het eigen vermogen van de rechtspersoon het nominaal gestorte bedrag van de aandelen waarop na de balansdatum wordt ingebracht met toepassing van dit lid in vennootschappen waarvoor de rechtspersoon een verklaring heeft afgelegd als bedoeld onder a.

4/ Artikel 404 is van overeenkomstige toepassing met dien verstande, dat de verklaring niet kan worden ingetrokken binnen twee jaren na de inbreng.

\section{Artikel 204b}

1/ Indien na de oprichting inbreng op aandelen anders dan in geld wordt overeengekomen, maakt de vennootschap overeenkomstig artikel 204a lid 1 een beschrijving op van hetgeen wordt ingebracht. De beschrijving heeft betrekking op de toestand op een dag die niet eerder dan zes maanden ligt voor de dag waarop de aandelen worden genomen dan wel waartegen een bijstorting is uitgeschreven of waarop zij is overeengekomen. De bestuurders ondertekenen de beschrijving; ontbreekt de handtekening van een of meer hunner, dan wordt daarvan onder opgave van reden melding gemaakt. De vennootschap legt de beschrijving te haren kantore ter inzage van de houders van haar aandelen en anderen aan wie vergaderrecht toekomt.

2/ Artikel 204a lid 2 is van overeenkomstige toepassing.

3/ De leden 3 en 4 van artikel 204a zijn van toepassing, met dien verstande dat niet de oprichters maar alle aandeelhouders moeten hebben afgezien van het opstellen van de beschrijving [...].

$[4 /$ vervalt $]$

4/ Dit artikel is niet van toepassing voor zover de 
inbreng bestaat uit aandelen, certificaten van aandelen, daarin converteerbare rechten of winstbewijzen van een andere rechtspersoon, waarop de vennootschap een openbaar bod heeft uitgebracht, mits deze effecten of een deel daarvan zijn opgenomen in de prijscourant van een effectenbeurs of geregeld op de incourante markt worden verhandeld.

\section{Artikel 204c}

1/ Een rechtshandeling die de vennootschap heeft verricht zonder goedkeuring van de algemene vergadering van aandeelhouders of zonder de verklaring, bedoeld in lid 3, kan ten behoeve van de vennootschap worden vernietigd, indien de rechtshandeling:

A/ Strekt tot het verkrijgen van goederen, met inbegrip van vorderingen die worden verrekend, die een jaar voor de oprichting of nadien toebehoorden aan een oprichter of aandeelhouder, en

$\mathrm{B}$ / Is verricht voordat twee jaren zijn verstreken na de inschrijving van de vennootschap in het handelsregister.

2/ Indien de goedkeuring wordt gevraagd, maakt de vennootschap een beschrijving op van de te verkrijgen goederen en van de tegenprestatie. De beschrijving heeft betrekking op de toestand van het beschrevene op een dag die niet voor de oprichting ligt. In de beschrijving worden de waarden vermeld die aan de goederen en tegenprestatie worden toegekend alsmede de toegepaste waarderingsmethoden. Deze methoden moeten voldoen aan normen die in het maatschappelijke verkeer als aanvaardbaar worden beschouwd. De bestuurders ondertekenen de beschrijving; ontbreekt de handtekening van een of meer hunner, dan wordt daarvan onder opgave van reden melding gemaakt.

3/ Artikel 204a lid 2 is van overeenkomstige toepassing, met dien verstande dat de verklaring moet inhouden dat de waarde van de te verkrijgen goederen, bij toepassing van in het maatschappelijke verkeer als aanvaardbaar beschouwde waarderingsmethoden, overeenkomt met ten minste de waarde van de tegenprestatie.

4/ Op het ter inzage leggen en in afschrift ter beschikking stellen van de in de vorige leden bedoelde stukken is artikel 212 van overeenkomstige toepassing.

5/ De vennootschap legt binnen acht dagen na de rechtshandeling of na de goedkeuring, indien achteraf verleend, de in het derde lid bedoelde verklaring of een afschrift daarvan neer ten kantore van het handelsregister.

6/ Voor de toepassing van dit artikel blijven buiten beschouwing: inbreng bestaat uit aandelen, certificaten van aandelen, daarin converteerbare rechten of winstbewijzen van een andere rechtspersoon, waarop de vennootschap een openbaar bod heeft uitgebracht, mits deze effecten of een deel daarvan zijn opgenomen in de prijscourant van een effectenbeurs of geregeld op de incourante markt worden verhandeld.

\section{Artikel 204c}

[vervalt] 


\begin{abstract}
A/ Verkrijgingen op een openbare veiling of ter beurze,

B/ Verkrijgingen die onder de bedongen voorwaarden tot de gewone bedrijfsuitoefening van de vennootschap behoren,

C/ Verkrijgingen waarvoor een accountantsverklaring als bedoeld in artikel 204a is afgelegd, en

D/ Verkrijgingen ten gevolge van fusie of splitsing.

7/ De leden 3 en 4 van artikel 204a zijn van overeenkomstige toepassing, met dien verstande dat niet de oprichters maar alle aandeelhouders moeten hebben afgezien van het opstellen van de beschrijving en de accountantsverklaring en dat de waarde van alle tegenprestaties waarbij dat is geschied, wordt overtroffen door het eigen vermogen van de medeaansprakelijke rechtspersoon.
\end{abstract}

\section{Artikel 206a}

1/ Voor zover de statuten niet anders bepalen, heeft iedere aandeelhouder bij uitgifte van aandelen een voorkeursrecht naar evenredigheid van het gezamenlijke bedrag van zijn aandelen, behoudens de beide volgende leden. Hij heeft geen voorkeursrecht op aandelen die worden uitgegeven aan werknemers van de vennootschap of van een groepsmaatschappij. Het voorkeursrecht kan, telkens voor een enkele uitgifte, worden beperkt of uitgesloten bij besluit van de algemene vergadering van aandeelhouders, voor zover de statuten niet anders bepalen.

2/ Voor zover de statuten niet anders bepalen, hebben houders van aandelen die

A/ Niet boven een bepaald percentage van het nominale bedrag of slechts in beperkte mate daarboven delen in de winst, of

B/ Niet boven het nominale bedrag of slechts in beperkte mate daarboven delen in een overschot na vereffening,

geen voorkeursrecht op uit te geven aandelen.

3/ Voor zover de statuten niet anders bepalen, hebben de aandeelhouders geen voorkeursrecht op uit te geven aandelen in een van de in het vorige lid onder a en b omschreven soorten.

4/ De vennootschap kondigt de uitgifte met voorkeursrecht en het tijdvak waarin dat kan worden uitgeoefend, aan in een schriftelijke mededeling aan alle

\section{Artikel 206a}

1/ Voor zover de statuten niet anders bepalen, heeft iedere aandeelhouder bij uitgifte van aandelen een voorkeursrecht naar evenredigheid van het gezamenlijke bedrag van zijn aandelen, behoudens de beide volgende leden. Hij heeft geen voorkeursrecht op aandelen die worden uitgegeven aan werknemers van de vennootschap of van een groepsmaatschappij. Het voorkeursrecht kan, telkens voor een enkele uitgifte, worden beperkt of uitgesloten bij besluit van de algemene vergadering van aandeelhouders, voor zover de statuten niet anders bepalen.

2/ Voor zover de statuten niet anders bepalen, hebben houders van aandelen

$\mathrm{A} /$ die niet boven een bepaald percentage van het nominale bedrag of slechts in beperkte mate daarboven delen in de winst, of

$\mathrm{B} /$ die niet boven het nominale bedrag of slechts in beperkte mate daarboven delen in een overschot na vereffening, of

$\mathrm{C} /$ waaraan ingevolge een statutaire regeling op grond van artikel 228 lid 5 geen stemrecht is verbonden,

geen voorkeursrecht op uit te geven aandelen.

3/ Voor zover de statuten niet anders bepalen, hebben de aandeelhouders geen voorkeursrecht op uit te geven aandelen in een van de in lid 2 onder $a, b$ en $c$ omschreven soorten.

4/ De vennootschap kondigt de uitgifte met voorkeursrecht en het tijdvak waarin dat kan worden uitgeoefend, aan in een schriftelijke mededeling aan alle 
aandeelhouders aan het door hen opgegeven adres.

5/ Het voorkeursrecht kan worden uitgeoefend gedurende ten minste vier weken na de dag van de verzending van de aankondiging.

6/ Voor zover de statuten niet anders bepalen, hebben de aandeelhouders een voorkeursrecht bij het verlenen van rechten tot het nemen van andere aandelen dan de in lid 2 onder a en b omschreven soorten; de vorige leden zijn van overeenkomstige toepassing. Aandeelhouders hebben geen voorkeursrecht op aandelen die worden uitgegeven aan iemand die een voordien reeds verkregen recht tot het nemen van aandelen uitoefent.

\section{Artikel 207}

1/ Verkrijging door de vennootschap van niet volgestorte aandelen in haar kapitaal is nietig.

2/ Volgestorte eigen aandelen mag de vennootschap slechts verkrijgen om niet of indien:

A/ Het eigen vermogen, verminderd met de verkrijgingsprijs, niet kleiner is dan het gestorte en opgevraagde deel van het kapitaal vermeerderd met de reserves die krachtens de wet of de statuten moeten worden aangehouden,

$\mathrm{B} / \mathrm{Het}$ nominale bedrag van de te verkrijgen en de reeds door de vennootschap en haar dochtermaatschappijen tezamen gehouden aandelen in haar kapitaal niet meer dan de helft van het geplaatste kapitaal bedraagt,

$\mathrm{C} / \mathrm{De}$ statuten de verkrijging toestaan, en

$\mathrm{D} /$ Machtiging tot de verkrijging is verleend door de algemene vergadering van aandeelhouders of door een ander vennootschapsorgaan dat daartoe bij de statuten of door de algemene vergadering van aandeelhouders is aangewezen.

3/ Voor de geldigheid van de verkrijging is bepalend de grootte van het eigen vermogen volgens de laatst vastgestelde balans, verminderd met de verkrijgingsprijs voor aandelen in het kapitaal van de vennootschap en uitkeringen uit winst of reserves aan anderen, die zij en haar dochtermaatschappijen na de balansdatum verschuldigd werden. Is een boekjaar meer dan zes maanden verstreken zonder dat de jaarrekening is vastgesteld, dan is verkrijging overeenkomstig lid 2 niet toegestaan. aandeelhouders aan het door hen opgegeven adres.

5/ Het voorkeursrecht kan worden uitgeoefend gedurende ten minste vier weken na de dag van de verzending van de aankondiging.

6/ Voor zover de statuten niet anders bepalen, hebben de aandeelhouders een voorkeursrecht bij het verlenen van rechten tot het nemen van andere aandelen dan de in lid 2 onder a, b en c omschreven soorten; de vorige leden zijn van overeenkomstige toepassing. Aandeelhouders hebben geen voorkeursrecht op aandelen die worden uitgegeven aan iemand die een voordien reeds verkregen recht tot het nemen van aandelen uitoefent.

\section{Artikel 207}

1/ Het bestuur beslist over de verkrijging van aandelen in het kapitaal van de vennootschap.

2/ De vennootschap mag, behalve om niet, geen eigen aandelen verkrijgen ten laste van de reserves die krachtens de wet of de statuten moeten worden aangehouden of indien het bestuur weet of redelijkerwijs behoort te voorzien dat de vennootschap na de verkrijging niet zal kunnen blijven voortgaan met het betalen van haar opeisbare schulden.

3/ Indien de vennootschap na een verkrijging anders dan om niet niet kan voortgaan met het betalen van haar opeisbare schulden, zijn de bestuurders die dat ten tijde van de verkrijging wisten of redelijkerwijs behoorden te voorzien, jegens de vennootschap hoofdelijk verbonden tot vergoeding van de verkrijgingsprijs met de wettelijke rente vanaf de verkrijging. Niet verbonden is de bestuurder die bewijst dat het niet aan hem te wijten is dat de vennootschap de aandelen heeft verkregen en dat hij niet nalatig is geweest in het treffen van maatregelen om de gevolgen daarvan af te wenden. Artikel 216 lid 4 is van overeenkomstige toepassing. Indien de vennootschap binnen een jaar na een verkrijging in staat van faillissement wordt verklaard, is de vervreemder van de aandelen die wist of redelijkerwijs behoorde te voorzien dat de vennootschap na de verkrijging niet zou kunnen blij- 
4/ De vorige leden gelden niet voor aandelen die de vennootschap onder algemene titel verkrijgt.

5/ Onder het begrip aandelen in dit artikel zijn certificaten daarvan begrepen.

\section{Artikel 207a}

1/ Verkrijging van aandelen in strijd met het tweede lid van het vorige artikel is nietig. De bestuurders zijn hoofdelijk aansprakelijk jegens de vervreemder te goeder trouw die door de nietigheid schade lijdt.

2/ De vennootschap mag niet langer dan gedurende drie jaren nadat zij eigen aandelen om niet of onder algemene titel heeft verkregen, samen met haar dochtermaatschappijen meer aandelen in haar kapitaal houden dan de helft van het geplaatste kapitaal. De bestuurders zijn hoofdelijk aansprakelijk voor de vergoeding aan de vennootschap van de waarde van de aandelen die zij te veel houdt of doet houden op het einde van de laatste dag van die drie jaren, met de wettelijke rente van dat tijdstip af. Betaling van de vergoeding geschiedt tegen overdracht van de aandelen.

3/ Lid 2 is van overeenkomstige toepassing op elk niet volgestort aandeel dat de vennootschap onder algemene titel heeft verkregen en niet binnen drie jaren daarna heeft vervreemd of ingetrokken.

4/ Onder het begrip aandelen in dit artikel zijn certificaten daarvan begrepen. ven voortgaan met het betalen van haar opeisbare schulden jegens de vennootschap gehouden tot terugbetaling van de verkrijgingsprijs met de wettelijke rente vanaf de verkrijging. Indien de bestuurders de vordering uit hoofde van de eerste zin hebben voldaan, geschiedt de in de vorige zin bedoelde terugbetaling aan de bestuurders, naar evenredigheid van het gedeelte dat door ieder der bestuurders is voldaan. De bestuurders en de vervreemder zijn niet bevoegd tot verrekening van hun schuld uit hoofde van dit artikel.

4/ De statuten kunnen de verkrijging door de vennootschap van eigen aandelen uitsluiten of beperken.

5/ De vorige leden gelden niet voor aandelen die de vennootschap onder algemene titel verkrijgt.

6/ Onder het begrip aandelen in dit artikel zijn certificaten daarvan begrepen.

\section{Artikel 207a}

$1 /$ Verkrijging van aandelen ten laste van de in artikel 207 lid 2 bedoelde reserves of in strijd met een uitsluiting of beperking als bedoeld in artikel 207 lid 4 is nietig. De bestuurders zijn hoofdelijk aansprakelijk jegens de vervreemder te goeder trouw die door de nietigheid schade lijdt.

2/ Indien de vennootschap eigen aandelen onder algemene titel heeft verkregen en deze verkrijging tot gevolg zou hebben dat de vennootschap, samen met haar dochtermaatschappijen alle aandelen in haar kapitaal houdt, gaat het laagst genummerde aandeel met stemrecht op het tijdstip van de verkrijging van rechtswege over op de gezamenlijke bestuurders. Ontbreekt een nummering, dan wordt een aandeel met stemrecht door loting aangewezen. Iedere bestuurder is hoofdelijk verbonden voor de vergoeding aan de vennootschap van de waarde van het aandeel ten tijde van de verkrijging met de wettelijke rente van dat tijdstip af.

3/ Onder het begrip aandelen in dit artikel zijn certificaten daarvan begrepen

\section{Artikel 207c}

1/ De vennootschap mag niet, met het oog op het nemen of verkrijgen door anderen van aandelen in haar kapitaal of van certificaten daarvan, zekerheid
Artikel 207c

[vervalt] 
stellen, een koersgarantie geven, zich op andere wijze sterk maken of zich hoofdelijk of anderszins naast of voor anderen verbinden. Dit verbod geldt ook voor haar dochtermaatschappijen.

2/ Leningen met het oog op het nemen of verkrijgen van aandelen in haar kapitaal of van certificaten daarvan, mag de vennootschap slechts verstrekken tot ten hoogste het bedrag van de uitkeerbare reserves en voor zover de statuten dit toestaan.

3/ De vennootschap houdt een niet uitkeerbare reserve aan tot het uitstaande bedrag van de in het vorige lid genoemde leningen.

\section{Artikel 207d}

1/ Een dochtermaatschappij mag voor eigen rekening geen aandelen nemen of doen nemen in het kapitaal van de vennootschap. Zulke aandelen mogen dochtermaatschappijen voor eigen rekening onder bijzondere titel slechts verkrijgen of doen verkrijgen, voor zover de vennootschap zelf ingevolge de leden 1-3 van artikel 207 eigen aandelen mag verkrijgen.

$2 /$ Indien is gehandeld in strijd met het vorige lid, zijn de bestuurders van de vennootschap hoofdelijk aansprakelijk tot vergoeding aan de dochtermaatschappij van de verkrijgingsprijs met de wettelijke rente daarover van het tijdstip af waarop de aandelen zijn genomen of verkregen. Betaling van de vergoeding geschiedt tegen overdracht van deze aandelen. Een bestuurder behoeft de verkrijgingsprijs niet te vergoeden, indien hij bewijst dat het nemen of verkrijgen niet aan de vennootschap is te wijten.

3/ Een dochtermaatschappij mag, nadat zij dochtermaatschappij is geworden of nadat zij als dochtermaatschappij aandelen in het kapitaal van de vennootschap om niet of onder algemene titel heeft verkregen, niet langer dan gedurende drie jaren samen met de vennootschap en haar andere dochtermaatschappijen meer van deze aandelen voor eigen rekening houden of doen houden dan de helft van het geplaatste kapitaal. De bestuurders van de vennootschap zijn hoofde-

\section{Artikel 207d}

1/ Een dochtermaatschappij mag voor eigen rekening geen aandelen nemen of doen nemen in het kapitaal van de vennootschap. Zulke aandelen mogen dochtermaatschappijen voor eigen rekening onder bijzondere titel slechts verkrijgen of doen verkrijgen, indien het bestuur van de vennootschap heeft ingestemd met de verkrijging. Een verkrijging onder bijzondere titel in strijd met de vorige zin is nietig. Op het besluit tot instemming is artikel 207 lid 2 van overeenkomstige toepassing. Artikel 207 lid 3 is van overeenkomstige toepassing met dien verstande dat de hoofdelijke verbondenheid van de bestuurders geldt jegens de dochtermaatschappij.

2/ Indien een rechtspersoon, nadat hij dochtermaatschappij is geworden of nadat hij als dochtermaatschappij aandelen in het kapitaal van de vennootschap onder algemene titel heeft verkregen, samen met de vennootschap en haar andere dochtermaatschappijen alle aandelen in het kapitaal van de vennootschap voor eigen rekening houdt of doet houden, gaat één aandeel met stemrecht op het tijdstip waarop hij dochtermaatschappij is geworden of op het tijdstip waarop de aandelen zijn verkregen van rechtswege over op de gezamenlijke bestuurders van de vennootschap. Iedere bestuurder is hoofdelijk verbonden voor de vergoeding aan de dochtermaatschappij van de waarde van het aandeel of de aandelen op het tijdstip waarop de dochtermaatschappij dochtermaatschappij is geworden of op het tijdstip waarop het aandeel of de aandelen zijn verkregen met de wettelijke rente van dat tijdstip af. 
lijk aansprakelijk voor de vergoeding aan de dochtermaatschappij van de waarde van de aandelen die zij te veel houdt of doet houden op het einde van de laatste dag van die drie jaren, met de wettelijke rente van dat tijdstip af. Betaling van de vergoeding geschiedt tegen overdracht van de aandelen. Een bestuurder behoeft de vergoeding niet te betalen, indien hij bewijst dat het niet aan de vennootschap is te wijten dat de aandelen nog worden gehouden.

4/ Onder het begrip aandelen in dit artikel zijn certificaten daarvan begrepen.

\section{Artikel 208}

1/ De algemene vergadering van aandeelhouders kan besluiten tot vermindering van het geplaatste kapitaal door intrekking van aandelen of door het bedrag van aandelen bij statutenwijziging te verminderen. In dit besluit moeten de aandelen waarop het besluit betrekking heeft, worden aangewezen en moet de uitvoering van het besluit zijn geregeld. Het gestorte en opgevraagde deel van het kapitaal mag niet kleiner worden dan het ten tijde van het besluit voorgeschreven minimumkapitaal.

2/ Een besluit tot intrekking kan slechts betreffen aandelen die de vennootschap zelf houdt of waarvan zij de certificaten houdt, dan wel alle aandelen van een soort waarvan alle aandeelhouders instemmen of waarvan voor de uitgifte in de statuten is bepaald dat zij kunnen worden ingetrokken met terugbetaling, of wel de uitgelote aandelen van een soort waarvan voor de uitgifte in de statuten is bepaald dat zij kunnen worden uitgeloot met terugbetaling.

3/ Vermindering van het bedrag van aandelen zonder terugbetaling en zonder ontheffing van de verplichting tot storting moet naar evenredigheid op alle aandelen van een zelfde soort geschieden. Van het vereiste van evenredigheid mag worden afgeweken met instemming van alle betrokken aandeelhouders.

4/ Gedeeltelijke terugbetaling op aandelen of ontheffing van de verplichting tot storting is slechts mogelijk ter uitvoering van een besluit tot vermindering van het bedrag van de aandelen. Zulk een terugbetaling of ontheffing moet naar evenredigheid op alle aandelen geschieden, tenzij voor de uitgifte van een bepaalde soort aandelen in de statuten is bepaald dat terugbetaling of ontheffing kan geschieden uitsluitend op die aandelen; voor die aandelen geldt de eis van evenredigheid. Van het vereiste van evenredigheid mag worden afgeweken met instemming van alle betrokken aandeelhouders.

5/ De oproeping tot een vergadering waarin een in dit
3/ Onder het begrip aandelen in dit artikel zijn certificaten daarvan begrepen.

\section{Artikel 208}

1/ De algemene vergadering [...] kan besluiten tot vermindering van het geplaatste kapitaal door intrekking van aandelen of door het bedrag van aandelen bij statutenwijziging te verminderen. In dit besluit moeten de aandelen waarop het besluit betrekking heeft, worden aangewezen en moet de uitvoering van het besluit zijn geregeld. Een besluit als bedoeld in de eerste zin mag niet leiden tot terugbetalingen ten laste van de reserves die krachten de wet of de statuten moeten worden aangehouden.

2/ Een besluit tot intrekking kan slechts betreffen aandelen die de vennootschap zelf houdt of waarvan zij de certificaten houdt, dan wel alle aandelen van een soort waarvan voor de uitgifte in de statuten is bepaald dat zij kunnen worden ingetrokken met terugbetaling, of wel de uitgelote aandelen van een soort waarvan voor de uitgifte in de statuten is bepaald dat zij kunnen worden uitgeloot met terugbetaling. In andere gevallen kan slechts tot intrekking worden besloten met instemming van alle houders van aandelen van de desbetreffende soort.

3/ Vermindering van het nominale bedrag van aandelen zonder terugbetaling en zonder ontheffing van de verplichting tot storting moet naar evenredigheid op alle aandelen van een zelfde soort geschieden. Van het vereiste van evenredigheid mag worden afgeweken met instemming van alle betrokken aandeelhouders.

4/ Gedeeltelijke terugbetaling op aandelen of ontheffing van de verplichting tot storting is slechts mogelijk ter uitvoering van een besluit tot vermindering van het bedrag van de aandelen. Zulk een terugbetaling of ontheffing moet naar evenredigheid op alle aandelen geschieden, tenzij voor de uitgifte van aandelen van een bepaalde soort in de statuten is bepaald dat terugbetaling of ontheffing kan geschieden uitsluitend op die aandelen; voor die aandelen geldt de eis van evenredigheid. Van het vereiste van evenredigheid mag worden afgeweken met instemming van alle betrokken aandeelhouders.

5/ De oproeping tot een vergadering waarin een in dit 


\begin{abstract}
artikel genoemd besluit wordt genomen, vermeldt het doel van de kapitaalvermindering en de wijze van uitvoering. Het tweede, derde en vierde lid van artikel 233 zijn van overeenkomstige toepassing.
\end{abstract}

artikel genoemd besluit wordt genomen, vermeldt het doel van de kapitaalvermindering en de wijze van uitvoering. Het tweede, derde en vierde lid van artikel 233 zijn van overeenkomstige toepassing.

6/ Op een besluit tot vermindering van het geplaatste kapitaal met terugbetaling op aandelen zijn de leden 2 tot en met 4 van artikel 216 van overeenkomstige toepassing

\section{Artikel 209}

[vervalt]
1/ De vennootschap legt de in het vorige artikel bedoelde besluiten neer ten kantore van het handelsregister en kondigt de nederlegging aan in een landelijk verspreid dagblad.

2/ De vennootschap moet, op straffe van gegrondverklaring van een verzet als bedoeld in het volgende lid, voor iedere schuldeiser die dit verlangt zekerheid stellen of hem een andere waarborg geven voor de voldoening van zijn vordering. Dit geldt niet, indien de schuldeiser voldoende waarborgen heeft of de vermogenstoestand van de vennootschap voldoende zekerheid biedt dat de vordering zal worden voldaan.

3/ Binnen twee maanden na de in het eerste lid vermelde aankondiging kan iedere schuldeiser door een verzoekschrift aan de rechtbank tegen het besluit tot kapitaalvermindering in verzet komen met vermelding van de waarborg die wordt verlangd.

4/ Voordat de rechter beslist, kan hij de vennootschap in de gelegenheid stellen binnen een door hem gestelde termijn een door hem omschreven waarborg te geven. Op een ingesteld rechtsmiddel kan hij, indien het kapitaal al is verminderd, het stellen van een waarborg bevelen en daaraan een dwangsom verbinden.

5/ Een besluit tot vermindering van het geplaatste kapitaal wordt niet van kracht zolang verzet kan worden gedaan. Indien tijdig verzet is gedaan, wordt het besluit eerst van kracht, zodra het verzet is ingetrokken of de opheffing van het verzet uitvoerbaar is. Een voor de vermindering van het kapitaal vereiste akte van statutenwijziging kan niet eerder worden verleden.

6/ Indien de vennootschap haar kapitaal wegens geleden verliezen vermindert tot een bedrag dat niet lager is dan dat van haar eigen vermogen, behoeft zij geen waarborg te geven en wordt het besluit onmiddellijk van kracht.

\section{Artikel 216}

1/ Voor zover bij de statuten niet anders is bepaald, komt de winst de aandeelhouders ten goede.

\section{Artikel 216}

1/ De algemene vergadering is bevoegd tot bestemming van de winst die door de vaststelling van de jaarrekening is bepaald en tot vaststelling van uitke- 
2/ De vennootschap kan aan de aandeelhouders en andere gerechtigden tot de voor uitkering vatbare winst slechts uitkeringen doen voor zover het eigen vermogen groter is dan het gestorte en opgevraagde deel van het kapitaal vermeerderd met de reserves die krachtens de wet of de statuten moeten worden aangehouden.

3/ Uitkering van winst geschiedt na de vaststelling van de jaarrekening waaruit blijkt dat zij geoorloofd is.

4/ De vennootschap mag tussentijds slechts uitkeringen doen, indien de statuten dit toelaten en aan het vereiste van het tweede lid is voldaan.

5/ Bij de berekening van de winstverdeling tellen de aandelen die de vennootschap in haar kapitaal houdt, mede, tenzij bij de statuten anders is bepaald.

6/ Bij de berekening van het winstbedrag, dat op ieder aandeel zal worden uitgekeerd, komt slechts het bedrag van de verplichte stortingen op het nominale bedrag van de aandelen in aanmerking, tenzij bij de statuten anders is bepaald.

7/ De statuten kunnen bepalen dat de vordering van ringen, voor zover het eigen vermogen groter is dan de reserves die krachtens de wet of de statuten moeten worden aangehouden. De statuten kunnen de bevoegdheden, bedoeld in de eerste zin, beperken of toekennen aan een ander orgaan.

2/ Een besluit dat strekt tot uitkering heeft geen gevolgen zolang het bestuur geen instemming heeft verleend. Het bestuur weigert de instemming indien het weet of redelijkerwijs behoort te voorzien dat de vennootschap na de uitkering niet zal kunnen blijven voortgaan met het betalen van haar opeisbare schulden.

3/ Indien de vennootschap na een uitkering niet kan voortgaan met het betalen van haar opeisbare schulden, zijn de bestuurders die dat ten tijde van de uitkering wisten of redelijkerwijs behoorden te voorzien jegens de vennootschap hoofdelijk verbonden voor het bedrag of de waarde van die uitkering met de wettelijke rente vanaf de uitkering. Niet verbonden is de bestuurder die bewijst dat het niet aan hem te wijten is dat de vennootschap de uitkering heeft gedaan en dat hij niet nalatig is geweest in het treffen van maatregelen om de gevolgen daarvan af te wenden. Indien de vennootschap binnen een jaar na het doen van een uitkering in staat van faillissement wordt verklaard, is degene die de uitkering ontving terwijl hij wist of redelijkerwijs behoorde te voorzien dat de vennootschap na de verkrijging niet zou kunnen blijven voortgaan met het betalen van haar opeisbare schulden, gehouden tot terugbetaling aan de vennootschap van het bedrag of de waarde van de uitkering met de wettelijke rente vanaf de uitkering. Indien de bestuurders de vordering uit hoofde van de eerste zin hebben voldaan, geschiedt de in de derde zin bedoelde terugbetaling aan de bestuurders, naar evenredigheid van het gedeelte dat door ieder der bestuurders is voldaan. Ten aanzien van een schuld uit hoofde van de eerste of de derde zin is de schuldenaar niet bevoegd tot verrekening.

4/ Met een bestuurder wordt voor de toepassing van lid 3 gelijkgesteld degene die het beleid van de vennootschap heeft bepaald of mede heeft bepaald, als ware hij bestuurder. De vordering kan niet worden ingesteld tegen de door de rechter benoemde bewindvoerder.

5/ Bij de berekening van iedere uitkering tellen de aandelen die de vennootschap in haar kapitaal houdt, niet mede, tenzij bij de statuten anders is bepaald.

6/ Bij de berekening van het bedrag, dat op ieder aandeel zal worden uitgekeerd, komt slechts het bedrag van de verplichte stortingen op het nominale bedrag van de aandelen in aanmerking, tenzij bij de statuten anders is bepaald.

7/ Bij de statuten kan worden bepaald dat aandelen 
een aandeelhouder niet door verloop van vijf jaren verjaart, doch eerst na een langere termijn vervalt. Een zodanige bepaling is alsdan van overeenkomstige toepassing op de vordering van de houder van een certificaat van een aandeel op de aandeelhouder.

8/ Geen van de aandeelhouders kan geheel worden uitgesloten van het delen in de winst.

9/ De statuten kunnen bepalen dat de winst waartoe houders van aandelen van een bepaalde soort gerechtigd zijn, geheel of gedeeltelijk te hunnen behoeve wordt gereserveerd. van een bijzondere soort of aanduiding geen of slechts beperkt recht geven tot deling in de winst of reserves van de vennootschap.

8/ Voor een statutaire regeling als bedoeld in lid 6 of lid 7 is de instemming vereist van alle houders van aandelen waaraan de statutenwijziging afbreuk doet.

9/ De statuten kunnen bepalen dat de vordering van een aandeelhouder niet door verloop van vijf jaren verjaart, doch eerst na een langere termijn vervalt. Een zodanige bepaling is alsdan van overeenkomstige toepassing op de vordering van de houder van een certificaat van een aandeel op de aandeelhouder.

10/ De statuten kunnen bepalen dat de winst waartoe houders van aandelen van een bepaalde soort gerechtigd zijn, geheel of gedeeltelijk te hunnen behoeve wordt gereserveerd.

$11 /$ Lid 3 is niet van toepassing op uitkeringen in de vorm van aandelen in het kapitaal van de vennootschap of bijschrijvingen op niet volgestorte aandelen.

Afdeling 4 De algemene vergadering

\section{Afdeling 4 De algemene vergadering van aandeel- houders}

\section{Artikel 217}

1/ Aan de algemene vergadering van aandeelhouders behoort, binnen de door de wet en de statuten gestelde grenzen, alle bevoegdheid, die niet aan het bestuur of aan anderen is toegekend.

2/ Het bestuur en de raad van commissarissen verschaffen haar alle verlangde inlichtingen, tenzij een zwaarwichtig belang der vennootschap zich daartegen verzet.

\section{Artikel 218}

1/ Jaarlijks wordt ten minste één algemene vergadering gehouden.

2/ Wanneer bij de statuten niet een kortere termijn is gesteld, wordt de jaarvergadering gehouden binnen zes maanden na afloop van het boekjaar der vennootschap.

\section{Artikel 220}

1/ Een of meer houders van aandelen die gezamenlijk ten minste een tiende gedeelte van het geplaatste kapitaal vertegenwoordigen, of een zoveel geringer bedrag als bij de statuten is bepaald, kunnen door de voorzieningenrechter van de rechtbank op hun verzoek worden gemachtigd tot de bijeenroeping van een algemene vergadering. De voorzieningenrechter wijst dit

\section{Artikel 217}

1/ Aan de algemene vergadering [...] behoort, binnen de door de wet en de statuten gestelde grenzen, alle bevoegdheid, die niet aan het bestuur of aan anderen is toegekend.

2/ Het bestuur en de raad van commissarissen verschaffen haar alle verlangde inlichtingen, tenzij een zwaarwichtig belang der vennootschap zich daartegen verzet.

\section{Artikel 218}

Tijdens ieder boekjaar wordt ten minste één algemene vergadering gehouden of ten minste eenmaal overeenkomstig artikel 238 lid 1 of lid 3 besloten.

\section{Artikel 220}

1/ Een of meer houders van aandelen die alleen of gezamenlijk ten minste een honderdste gedeelte van het geplaatste kapitaal vertegenwoordigen, kunnen aan het bestuur en aan de raad van commissarissen schriftelijk en onder nauwkeurige opgave van de te behandelen onderwerpen het verzoek richten een algemene vergadering bijeen te roepen. Het bestuur en de raad 
verzoek af, indien hem niet is gebleken, dat verzoekers voordien aan het bestuur en aan de raad van commissarissen, schriftelijk en onder nauwkeurige opgave van de te behandelen onderwerpen het verzoek hebben gericht een algemene vergadering bijeen te roepen, en dat noch het bestuur noch de raad van commissarissen - daartoe in dit geval gelijkelijk bevoegd - de nodige maatregelen hebben getroffen, opdat de algemene vergadering binnen zes weken na het verzoek kon worden gehouden.

2/ Voor de toepassing van dit artikel worden met houders van aandelen gelijkgesteld de houders van de certificaten op naam van aandelen, welke met medewerking van de vennootschap zijn uitgegeven. van commissarissen - daartoe in dit geval gelijkelijk bevoegd - treffen de nodige maatregelen, opdat de algemene vergadering binnen vier weken na het verzoek kan worden gehouden, tenzij een zwaarwichtig belang van de vennootschap zich daartegen verzet. In de statuten kan het vereiste gedeelte van het kapitaal lager worden gesteld en de termijn waarbinnen de algemene vergadering moet worden gehouden, worden verkort. Indien het bestuur en de raad van commissarissen geen uitvoering geven aan het verzoek, kunnen de in de eerste zin bedoelde aandeelhouders op hun verzoek door de voorzieningenrechter van de rechtbank worden gemachtigd tot de bijeenroeping van de algemene vergadering.

2/ Voor de toepassing van dit artikel worden met houders van aandelen gelijkgesteld anderen aan wie vergaderrecht toekomt.

3/ In afwijking van artikel 24d wordt bij de toepassing van lid 1 tevens rekening gehouden met aandelen waarvan de statuten bepalen dat daarvoor geen stem kan worden uitgebracht.

\section{Artikel 221}

1/ De voorzieningenrechter van de rechtbank verleent, na verhoor of oproeping van de vennootschap, de verzochte machtiging, indien de verzoekers summierlijk hebben doen blijken, dat de in het vorige artikel gestelde voorwaarden zijn vervuld, en dat zij een redelijk belang hebben bij het houden van de vergadering. De voorzieningenrechter van de rechtbank wijst het verzoek af, indien een zwaarwichtig belang van de vennootschap zich tegen het houden van een algemene vergadering verzet. Indien de voorzieningenrechter van de rechtbank de verzochte machtiging verleent, stelt hij de vorm en de termijnen voor de oproeping tot de algemene vergadering vast. Hij kan tevens iemand aanwijzen, die met de leiding van de algemene vergadering zal zijn belast.

2/ Bij de oproeping ingevolge het eerste lid wordt vermeld dat zij krachtens rechterlijke machtiging geschiedt. De op deze wijze gedane oproeping is rechtsgeldig, ook indien mocht blijken dat de machtiging ten onrechte was verleend.

3/ Tegen de beschikking van de voorzieningenrechter is generlei voorziening toegelaten, behoudens cassatie in het belang der wet.
3/ Tegen de beschikking van de voorzieningenrechter is generlei voorziening toegelaten, behoudens cassatie in het belang der wet.

\section{Artikel 223}

De oproeping tot een algemene vergadering geschiedt door middel van oproepingsbrieven gericht aan de adressen van de aandeelhouders en overige vergader-
1/ De oproeping tot een algemene vergadering van aandeelhouders geschiedt door middel van oproepingsbrieven gericht aan de adressen der aandeelhou- 
ders, zoals deze zijn vermeld in het register van aandeelhouders.

2/ Zijn er met medewerking van de vennootschap certificaten op naam van haar aandelen uitgegeven, dan worden de houders daarvan opgeroepen door aankondiging in een landelijk verspreid dagblad. De statuten kunnen deze oproeping anders regelen.

\section{Artikel 224}

1/ De oproepingsbrieven vermelden de te behandelen onderwerpen. Bij de oproeping in een dag- of nieuwsblad worden de te behandelen onderwerpen vermeld of wordt meegedeeld dat de houders van met medewerking van de vennootschap uitgegeven certificaten van haar aandelen er ten kantore van de vennootschap kennis van kunnen nemen.

2/ Omtrent onderwerpen waarvan de behandeling niet bij de oproeping of op de zelfde wijze is aangekondigd met inachtneming van de voor oproeping gestelde termijn, kan niet wettig worden besloten, tenzij het besluit met algemene stemmen wordt genomen in een vergadering waarin het gehele geplaatste kapitaal vertegenwoordigd is.

3/ Mededelingen welke krachtens de wet of de statuten aan de algemene vergadering moeten worden gericht, kunnen geschieden door opneming in de oproepingsbrieven alsmede, in voorkomend geval, hetzij in de aankondiging in een dag- of nieuwsblad, hetzij in het stuk dat ter kennisneming ten kantore van de vennootschap is neergelegd, mits daarvan in de aankondiging melding wordt gemaakt.

\section{Artikel 224a}

1/ Een onderwerp, waarvan de behandeling schriftelijk is verzocht door een of meer houders van aandelen die alleen of gezamenlijk ten minste een honderdste gedeelte van het geplaatste kapitaal vertegenwoordigen, wordt opgenomen in de oproeping of op dezelfde wijze aangekondigd indien de vennootschap het verzoek niet later dan op de dertigste dag voor die van de vergadering heeft ontvangen en mits geen zwaarwichtig belang van de vennootschap zich daartegen verzet. In de statuten kan het vereiste gedeelte van het kapitaal lager worden gesteld en de termijn voor indiening van het verzoek worden verkort.

2/ Voor de toepassing van dit artikel worden met de houders van aandelen gelijkgesteld de houders van de certificaten van aandelen die met medewerking van de vennootschap zijn uitgegeven. gerechtigden, zoals deze zijn vermeld in het register, bedoeld in artikel 194.
2/ Omtrent onderwerpen waarvan de behandeling niet bij de oproeping is aangekondigd met inachtneming van de voor oproeping gestelde termijn, kan niet wettig worden besloten, tenzij alle vergadergerechtigden ermee hebben ingestemd dat de besluitvorming over die onderwerpen plaatsvindt en de bestuurders en de commissarissen voorafgaand aan de besluitvorming in de gelegenheid zijn gesteld om advies uit te brengen.

\section{Artikel 224a}

1/ Een onderwerp, waarvan de behandeling schriftelijk is verzocht door een of meer houders van aandelen die alleen of gezamenlijk ten minste een honderdste gedeelte van het geplaatste kapitaal vertegenwoordigen, wordt opgenomen in de oproeping of op dezelfde wijze aangekondigd indien de vennootschap het verzoek niet later dan op de dertigste dag voor die van de vergadering heeft ontvangen en mits geen zwaarwichtig belang van de vennootschap zich daartegen verzet. In de statuten kan het vereiste gedeelte van het kapitaal lager worden gesteld en de termijn voor indiening van het verzoek worden verkort.

2/ Voor de toepassing van dit artikel worden met de houders van aandelen gelijkgesteld anderen aan wie vergaderrecht toekomt.

3/ In afwijking van artikel 24d wordt bij de toepassing van lid 1 tevens rekening gehouden met aandelen waarvan de statuten bepalen dat daarvoor geen stem 
3/ Tenzij de statuten anders bepalen, wordt aan de eis van schriftelijkheid van het verzoek als bedoeld in lid 1 voldaan indien dit verzoek elektronisch is vastgelegd. kan worden uitgebracht.

4/ Tenzij de statuten anders bepalen, wordt aan de eis van schriftelijkheid van het verzoek als bedoeld in lid 1 voldaan indien dit verzoek elektronisch is vastgelegd.

\section{Artikel 225}

Behoudens het bepaalde bij de tweede zin van het eerste lid van artikel 221 geschiedt de oproeping niet later dan op de vijftiende dag vóór die der vergadering. Was die termijn korter of heeft de oproeping niet plaats gehad, dan kunnen geen wettige besluiten worden genomen, tenzij met algemene stemmen in een vergadering, waarin het gehele geplaatste kapitaal vertegenwoordigd is.

\section{Artikel 226}

De algemene vergaderingen worden gehouden in Nederland ter plaatse bij de statuten vermeld, of anders in de gemeente waar de vennootschap haar woonplaats heeft. In een algemene vergadering, gehouden elders dan behoort, kunnen wettige besluiten slechts worden genomen, indien het gehele geplaatste kapitaal vertegenwoordigd is.

\section{Artikel 227}

1/ Iedere aandeelhouder is bevoegd, in persoon of bij schriftelijk gevolmachtigde, de algemene vergadering van aandeelhouders bij te wonen, daarin het woord te voeren en het stemrecht uit te oefenen. Bij de statuten kan de bevoegdheid van aandeelhouders zich te doen vertegenwoordigen, worden beperkt. De bevoegdheid van aandeelhouders zich te doen vertegenwoordigen door een advocaat, notaris, kandidaat-notaris, registeraccountant of accountant-administratieconsulent kan niet worden uitgesloten.

\section{Artikel 225}

Onverminderd het bepaalde in de derde zin van lid 1 van artikel 221 geschiedt de oproeping niet later dan op de achtste dag vóór die van de vergadering. Was die termijn korter of heeft de oproeping niet plaats gehad, dan kunnen geen wettige besluiten worden genomen, tenzij alle vergadergerechtigden ermee hebben ingestemd dat de besluitvorming plaatsvindt en de bestuurders en de commissarissen voorafgaand aan de besluitvorming in de gelegenheid zijn gesteld om advies uit te brengen.

\section{Artikel 226}

$1 /$ De algemene vergadering wordt gehouden ter plaatse bij de statuten vermeld of anders in de gemeente waar de vennootschap haar woonplaats heeft. De in de statuten vermelde plaats kan een plaats buiten Nederland zijn.

2/ Wordt na de oprichting een plaats buiten Nederland aangewezen, dan kan het daartoe strekkende besluit tot wijziging van de statuten slechts worden genomen met algemene stemmen in een vergadering waarin het gehele geplaatste kapitaal is vertegenwoordigd en voor zover alle vergadergerechtigden met de statutenwijziging hebben ingestemd.

3/ Een algemene vergadering kan elders dan behoort worden gehouden, mits alle vergadergerechtigden hebben ingestemd met de plaats van de vergadering en de bestuurders en de commissarissen voorafgaand aan de besluitvorming in de gelegenheid zijn gesteld om advies uit te brengen.

\section{Artikel 227}

1/ Onder vergaderrecht wordt in deze titel verstaan het recht om, in persoon of bij schriftelijk gevolmachtigde, de algemene vergadering bij te wonen en daar het woord te voeren. 
2/ Iedere houder van een met medewerking van de vennootschap uitgegeven certificaat op naam van een aandeel is bevoegd, in persoon of bij schriftelijk gevolmachtigde, de algemene vergadering bij te wonen en daarin het woord te voeren. De laatste zin van lid 1 is van overeenkomstige toepassing.

3/ De statuten kunnen bepalen dat een aandeelhouder niet gerechtigd is tot deelname aan de algemene vergadering zolang hij in gebreke is te voldoen aan een wettelijke of statutaire verplichting. De statuten kunnen bepalen, dat voor bijwoning van de aandeelhoudersvergadering vereist is, dat de aandeelhouder van zijn voornemen hiertoe kennis geeft aan het bestuur van de vennootschap. Bij de oproeping van de vergadering wordt alsdan vermeld de dag waarop de kennisgeving uiterlijk moet geschieden. Deze dag kan niet vroeger worden gesteld dan op de derde dag voor die der vergadering. Indien de statuten een voorschrift overeenkomstig de voorgaande bepalingen van dit lid voor de aandeelhouders bevatten, geldt dat mede voor de houders van de certificaten op naam van aandelen, die met medewerking van de vennootschap zijn uitgegeven.

4/ De bestuurders en de commissarissen hebben als zodanig in de algemene vergaderingen een raadgevende stem.

5/ Aan de eis van schriftelijkheid van de volmacht wordt voldaan indien de volmacht elektronisch is vastgelegd.
2/ Het vergaderrecht komt toe aan aandeelhouders, aan houders van certificaten waaraan bij de statuten vergaderrecht is verbonden, aan aandeelhouders die vanwege een vruchtgebruik of pandrecht geen stemrecht hebben en aan vruchtgebruikers en pandhouders die stemrecht hebben. Vruchtgebruikers en pandhouders die geen stemrecht hebben, hebben vergaderrecht, indien de statuten dit bepalen en bij de vestiging of overdracht van het vruchtgebruik of pandrecht niet anders is bepaald. De statuten kunnen bepalen dat het verbinden en ontnemen van vergaderrecht aan certificaten van aandelen geschiedt door een daartoe in de statuten aangewezen orgaan.

3 / Iedere aandeelhouder is bevoegd, in persoon of bij schriftelijk gevolmachtigde, het hem toekomende stemrecht uit te oefenen in de algemene vergadering.

4/ Een besluit tot wijziging van de statuten dat tot gevolg heeft dat het vergaderrecht aan een of meer certificaten wordt ontnomen, kan slechts worden genomen met instemming van de betrokken certificaathouders.

5/ Bij de statuten kan de bevoegdheid van vergadergerechtigden zich te doen vertegenwoordigen worden beperkt. De bevoegdheid van vergadergerechtigden zich te doen vertegenwoordigen door een advocaat, notaris, registeraccountant of accountant-

administratieconsulent kan niet worden uitgesloten.

6/ De statuten kunnen bepalen dat het vergaderrecht is opgeschort zolang een vergadergerechtigde in gebreke is te voldoen aan een wettelijke of statutaire verplichting. De statuten kunnen bepalen, dat voor bijwoning van de algemene vergadering vereist is, dat de vergadergerechtigde van zijn voornemen hiertoe kennis geeft aan het bestuur van de vennootschap. Bij de oproeping van de vergadering wordt alsdan vermeld de dag waarop de kennisgeving uiterlijk moet geschieden. Deze dag kan niet vroeger worden gesteld dan op de derde dag voor die van de vergadering.

7/ De bestuurders en de commissarissen hebben als zodanig in de algemene vergadering een raadgevende 


\begin{tabular}{|c|c|}
\hline & $\begin{array}{l}\text { stem. } \\
\text { 8/ Aan de eis van schriftelijkheid van de volmacht } \\
\text { wordt voldaan indien de volmacht elektronisch is } \\
\text { vastgelegd. }\end{array}$ \\
\hline Artikel 228 & Artikel 228 \\
\hline $\begin{array}{l}\text { 1/ Slechts aandeelhouders hebben stemrecht. Iedere } \\
\text { aandeelhouder heeft ten minste één stem. De statuten } \\
\text { kunnen bepalen dat een aandeelhouder niet gerechtigd } \\
\text { is tot uitoefening van het stemrecht zolang hij in } \\
\text { gebreke is te voldoen aan een wettelijke of statutaire } \\
\text { verplichting. }\end{array}$ & $\begin{array}{l}\text { 1/ Slechts aandeelhouders hebben stemrecht. Iedere } \\
\text { aandeelhouder heeft ten minste één stem. De statuten } \\
\text { kunnen bepalen dat een aandeelhouder niet gerechtigd } \\
\text { is tot uitoefening van het stemrecht zolang hij in } \\
\text { gebreke is te voldoen aan een wettelijke of statutaire } \\
\text { verplichting. }\end{array}$ \\
\hline $\begin{array}{l}\text { 2/ Indien het maatschappelijk kapitaal in aandelen van } \\
\text { een zelfde bedrag is verdeeld, brengt iedere aandeel- } \\
\text { houder zoveel stemmen uit als hij aandelen heeft. }\end{array}$ & $\begin{array}{l}\text { 2/ Indien het }[\ldots] \text { kapitaal in aandelen van een zelfde } \\
\text { bedrag is verdeeld, brengt iedere aandeelhouder zo- } \\
\text { veel stemmen uit als hij aandelen heeft. }\end{array}$ \\
\hline $\begin{array}{l}\text { 3/ Indien het maatschappelijk kapitaal in aandelen van } \\
\text { verschillend bedrag is verdeeld, is het aantal stemmen } \\
\text { van iedere aandeelhouder gelijk aan het aantal malen, } \\
\text { dat het bedrag van het kleinste aandeel is begrepen in } \\
\text { het gezamenlijk bedrag van zijn aandelen; gedeelten } \\
\text { van stemmen worden verwaarloosd. }\end{array}$ & $\begin{array}{l}\text { 3/ Indien het }[\ldots] \text { kapitaal in aandelen van verschil- } \\
\text { lend bedrag is verdeeld, is het aantal stemmen van } \\
\text { iedere aandeelhouder gelijk aan het aantal malen, dat } \\
\text { het bedrag van het kleinste aandeel is begrepen in het } \\
\text { gezamenlijk bedrag van zijn aandelen; gedeelten van } \\
\text { stemmen worden verwaarloosd. }\end{array}$ \\
\hline $\begin{array}{l}\text { 4/ Echter kan het door een zelfde aandeelhouder uit te } \\
\text { brengen aantal stemmen bij de statuten worden be- } \\
\text { perkt, mits aandeelhouders wier bedrag aan aandelen } \\
\text { gelijk is, hetzelfde aantal stemmen uitbrengen en de } \\
\text { beperking voor de houders van een groter bedrag aan } \\
\text { aandelen niet gunstiger is geregeld dan voor de hou- } \\
\text { ders van een kleiner bedrag aan aandelen. }\end{array}$ & $\begin{array}{l}\text { 4/ Van de leden } 2 \text { en } 3 \text { kan bij de statuten worden } \\
\text { afgeweken. Een besluit tot statutenwijziging dat een } \\
\text { wijziging in het stemrecht betreft, kan slechts worden } \\
\text { genomen met algemene stemmen in een vergadering } \\
\text { waarin het gehele geplaatste kapitaal is vertegenwoor- } \\
\text { digd. }\end{array}$ \\
\hline $\begin{array}{l}\text { 5/ Van het bepaalde bij het tweede en het derde lid } \\
\text { kan bij de statuten ook op andere wijze worden afge- } \\
\text { weken, mits aan eenzelfde aandeelhouder niet meer } \\
\text { dan zes stemmen worden toegekend indien het maat- } \\
\text { schappelijk kapitaal is verdeeld in honderd of meer } \\
\text { aandelen, en niet meer dan drie stemmen indien het } \\
\text { kapitaal in minder dan honderd aandelen is verdeeld. }\end{array}$ & $\begin{array}{l}\text { 5/ In afwijking van de leden } 1 \text { tot en met } 4 \text { kunnen de } \\
\text { statuten bepalen dat aan aandelen geen stemrecht is } \\
\text { verbonden. Een dergelijke regeling kan slechts wor- } \\
\text { den getroffen ten aanzien van alle aandelen van een } \\
\text { bepaalde soort of aanduiding waarvan alle aandeel- } \\
\text { houders instemmen of waarvan voor de uitgifte in de } \\
\text { statuten is bepaald dat } \\
\text { daaraan geen stemrecht is verbonden. De aandelen } \\
\text { worden in de statuten als stemrechtloos aangeduid. } \\
\text { Een besluit tot wijziging van de statuten waarmee } \\
\text { nadeel wordt toegebracht aan de rechten van houders } \\
\text { van stemrechtloze aandelen kan niet zonder hun } \\
\text { instemming worden genomen. Artikel } 216 \text { lid } 7 \text { is niet } \\
\text { van toepassing op stemrechtloze aandelen. }\end{array}$ \\
\hline $\begin{array}{l}\text { 6/ Voor een aandeel dat toebehoort aan de vennoot- } \\
\text { schap of aan een dochtermaatschappij daarvan kan in } \\
\text { de algemene vergadering geen stem worden uit- } \\
\text { gebracht; evenmin voor een aandeel waarvan een } \\
\text { hunner de certificaten houdt. Vruchtgebruikers en } \\
\text { pandhouders van aandelen die aan de vennootschap en } \\
\text { haar dochtermaatschappijen toebehoren, zijn evenwel } \\
\text { niet van hun stemrecht uitgesloten, indien het vrucht- } \\
\text { gebruik of pandrecht was gevestigd voordat het aan- } \\
\text { deel aan de vennootschap of een dochtermaatschappij } \\
\text { daarvan toebehoorde. De vennootschap of een doch- }\end{array}$ & $\begin{array}{l}\text { 6/ Voor een aandeel dat toebehoort aan de vennoot- } \\
\text { schap of aan een dochtermaatschappij daarvan kan in } \\
\text { de algemene vergadering geen stem worden uit- } \\
\text { gebracht; evenmin voor een aandeel waarvan een } \\
\text { hunner de certificaten houdt. Vruchtgebruikers en } \\
\text { pandhouders van aandelen die aan de vennootschap en } \\
\text { haar dochtermaatschappijen toebehoren, zijn evenwel } \\
\text { niet van hun stemrecht uitgesloten, indien het vrucht- } \\
\text { gebruik of pandrecht was gevestigd voordat het aan- } \\
\text { deel aan de vennootschap of een dochtermaatschappij } \\
\text { daarvan toebehoorde. De vennootschap of een doch- }\end{array}$ \\
\hline
\end{tabular}


termaatschappij daarvan kan geen stem uitbrengen voor een aandeel waarop zij een recht van vruchtgebruik of een pandrecht heeft. termaatschappij daarvan kan geen stem uitbrengen voor een aandeel waarop zij een recht van vruchtgebruik of een pandrecht heeft. Indien de toepassing van dit lid in verband met een statutaire regeling als bedoeld in lid 4 tot gevolg heeft dat voor geen van de aandelen een stem kan worden uitgebracht, blijft die statutaire regeling buiten toepassing.

\section{Artikel 230}

1/ Alle besluiten waaromtrent bij de statuten geen grotere meerderheid is voorgeschreven, worden genomen bij volstrekte meerderheid van de uitgebrachte stemmen. Staken de stemmen bij verkiezing van personen, dan beslist het lot, staken de stemmen bij een andere stemming, dan is het voorstel verworpen; een en ander voor zover in de statuten niet een andere oplossing is aangegeven. Deze oplossing kan bestaan in het opdragen van de beslissing aan een derde.

2/ Tenzij bij de statuten anders is bepaald, is de geldigheid van besluiten niet afhankelijk van het ter vergadering vertegenwoordigd gedeelte van het kapitaal.

3/ Indien in de statuten is bepaald dat de geldigheid van een besluit afhankelijk is van het ter vergadering vertegenwoordigd gedeelte van het kapitaal en dit gedeelte ter vergadering niet vertegenwoordigd was, kan, tenzij de statuten anders bepalen, een nieuwe vergadering worden bijeengeroepen waarin het besluit kan worden genomen, onafhankelijk van het op deze vergadering vertegenwoordigd gedeelte van het kapitaal. Bij de oproeping tot de nieuwe vergadering moet worden vermeld dat en waarom een besluit kan worden genomen, onafhankelijk van het ter vergadering vertegenwoordigd gedeelte van het kapitaal. vertegenwoordigd gedeelte van het kapitaal.

4/ Het bestuur van de vennootschap houdt van de genomen besluiten aantekening. De aantekeningen liggen ten kantore van de vennootschap ter inzage van de aandeelhouders en de houders van de met medewerking van de vennootschap uitgegeven certificaten van haar aandelen. Aan ieder van dezen wordt desgevraagd afschrift of uittreksel van deze aantekeningen verstrekt tegen ten hoogste de kostprijs.

\section{Artikel 238}

1/ De statuten kunnen bepalen dat besluitvorming van aandeelhouders op andere wijze dan in een vergadering kan geschieden, tenzij met medewerking van de vennootschap certificaten op naam van aandelen zijn uitgegeven. Indien de statuten een zodanige regeling bevatten, is zulk een besluitvorming slechts mogelijk met algemene stemmen van de stemgerechtigde aandeelhouders. De stemmen worden schriftelijk uitgebracht.

\section{Artikel 230}

1/ Alle besluiten waaromtrent bij de wet of de statuten geen grotere meerderheid is voorgeschreven, worden genomen bij volstrekte meerderheid van de uitgebrachte stemmen. Staken de stemmen bij verkiezing van personen, dan beslist het lot, staken de stemmen bij een andere stemming, dan is het voorstel verworpen; een en ander voorzover in de statuten niet een andere oplossing is aangegeven. Deze oplossing kan bestaan in het opdragen van de beslissing aan een derde.

2/ Tenzij bij de wet of de statuten anders is bepaald, is de geldigheid van een besluit niet afhankelijk van het ter vergadering vertegenwoordigde gedeelte van het kapitaal.

3 / Indien in de statuten is bepaald dat de geldigheid van een besluit afhankelijk is van het ter vergadering vertegenwoordigd gedeelte van het kapitaal en dit gedeelte ter vergadering niet vertegenwoordigd was, kan, tenzij de statuten anders bepalen, een nieuwe vergadering worden bijeengeroepen waarin het besluit kan worden genomen, onafhankelijk van het op deze vergadering vertegenwoordigd gedeelte van het kapitaal. Bij de oproeping tot de nieuwe vergadering moet worden vermeld dat en waarom een besluit kan worden genomen, onafhankelijk van het ter vergadering vertegenwoordigd gedeelte van het kapitaal. vertegenwoordigd gedeelte van het kapitaal.

4/ Het bestuur van de vennootschap houdt van de genomen besluiten aantekening. De aantekeningen liggen ten kantore van de vennootschap ter inzage van de aandeelhouders en de houders van de met medewerking van de vennootschap uitgegeven certificaten van haar aandelen. Aan ieder van dezen wordt desgevraagd afschrift of uittreksel van deze aantekeningen verstrekt tegen ten hoogste de kostprijs.

\section{Artikel 238}

1/ Besluitvorming van aandeelhouders kan op andere wijze dan in een vergadering geschieden, mits alle vergadergerechtigden met deze wijze van besluitvorming hebben ingestemd. De stemmen worden schriftelijk uitgebracht. De bestuurders en de commissarissen worden voorafgaand aan de besluitvorming in de gelegenheid gesteld om advies uit te brengen. 
2/ Tenzij de statuten anders bepalen kunnen de stemmen ook langs elektronische weg worden uitgebracht.
2/ Tenzij de statuten anders bepalen kunnen de stemmen ook langs elektronische weg worden uitgebracht en kan de instemming met de wijze van besluitvorming langs elektronische weg plaatsvinden.

3/ Indien alle aandeelhouders tevens bestuurder van de vennootschap zijn, geldt ondertekening van de jaarrekening door alle bestuurders en commissarissen tevens als vaststelling in de zin van artikel 210 lid 3, mits alle vergadergerechtigden in de gelegenheid zijn gesteld om kennis te nemen van de opgemaakte jaarrekening en met deze wijze van vaststelling hebben ingestemd. De statuten kunnen de in de vorige zin bedoelde wijze van vaststelling van de jaarrekening uitsluiten.

\section{Afdeling 5 \\ Het bestuur van de vennootschap en het toezicht op het bestuur}

\section{Artikel 239}

$1 /$ Behoudens beperkingen volgens de statuten is het bestuur belast met het besturen van de vennootschap.

2/ De statuten kunnen bepalen dat een met name of in functie aangeduide bestuurder meer dan één stem wordt toegekend. Een bestuurder kan niet meer stemmen uitbrengen dan de andere bestuurders tezamen.

3/ Besluiten van het bestuur kunnen bij of krachtens de statuten slechts worden onderworpen aan de goedkeuring van een ander orgaan van de vennootschap.

4/ De statuten kunnen bepalen dat het bestuur zich dient te gedragen naar de aanwijzingen van een orgaan van de vennootschap die de algemene lijnen van het te voeren beleid op nader in de statuten aangegeven terreinen betreffen.

\section{Artikel 242}

1/ De benoeming van bestuurders geschiedt voor de eerste maal bij de akte van oprichting en later door de algemene vergadering van aandeelhouders, tenzij zij overeenkomstig artikel 272 van dit Boek door de raad van commissarissen geschiedt.

2/ De statuten kunnen de kring van benoembare personen beperken door eisen te stellen waaraan de bestuurders moeten voldoen. De eisen kunnen terzijde

\section{Artikel 239}

$1 /$ Behoudens beperkingen volgens de statuten is het bestuur belast met het besturen van de vennootschap.

2/ De statuten kunnen bepalen dat een met name of in functie aangeduide bestuurder meer dan één stem wordt toegekend. Een bestuurder kan niet meer stemmen uitbrengen dan de andere bestuurders tezamen.

3/ Besluiten van het bestuur kunnen bij of krachtens de statuten slechts worden onderworpen aan de goedkeuring van een ander orgaan van de vennootschap.

4/ De statuten kunnen bepalen dat het bestuur zich dient te gedragen naar de aanwijzingen van een ander orgaan van de vennootschap [...]. Het bestuur is gehouden de aanwijzingen op te volgen, tenzij deze in strijd zijn met het belang van de vennootschap en de met haar verbonden onderneming.

\section{Artikel 242}

1/ De benoeming van bestuurders geschiedt voor de eerste maal bij de akte van oprichting en later door de algemene vergadering of, indien de statuten zulks bepalen, door een vergadering van houders van aandelen van een bepaalde soort of aanduiding, mits iedere aandeelhouder met stemrecht kan deelnemen aan de besluitvorming inzake de benoeming van ten minste één bestuurder. Op een statutaire regeling als bedoeld in de vorige zin is artikel 228 lid 4, tweede volzin, en lid 6 van overeenkomstige toepassing. De eerste zin geldt niet indien de benoeming overeenkomstig artikel 272 door de raad van commissarissen geschiedt.

2/ De statuten kunnen de kring van benoembare personen beperken door eisen te stellen aan de bestuurders. De eisen kunnen terzijde worden gesteld door 
worden gesteld door een besluit van de algemene vergadering genomen met twee derden van de uitgebrachte stemmen die meer dan de helft van het geplaatste kapitaal vertegenwoordigen. een besluit van de algemene vergadering, genomen overeenkomstig de ingevolge de artikelen 230 en 231 geldende besluitvormingsregels.

\section{Artikel 243}

1/ Bij de statuten kan worden bepaald, dat de benoeming door de algemene vergadering zal geschieden uit een voordracht, die ten minste twee personen voor iedere te vervullen plaats bevat.

2/ De algemene vergadering kan echter aan zodanige voordracht steeds het bindend karakter ontnemen bij een besluit genomen met twee derden van de uitgebrachte stemmen, die meer dan de helft van het geplaatste kapitaal vertegenwoordigen.
3/ De vorige leden zijn niet van toepassing, indien de benoeming geschiedt door de raad van commissarissen.

\section{Artikel 244}

1/ Iedere bestuurder kan te allen tijde worden geschorst en ontslagen door degene die bevoegd is tot benoeming.

$2 /$ Indien in de statuten is bepaald dat het besluit tot schorsing of ontslag slechts mag worden genomen met een versterkte meerderheid in een algemene vergadering, waarin een bepaald gedeelte van het kapitaal is vertegenwoordigd, mag deze versterkte meerderheid twee derden der uitgebrachte stemmen, vertegenwoordigende meer dan de helft van het kapitaal, niet te boven gaan.

3/ Een veroordeling tot herstel van de arbeidsovereenkomst tussen vennootschap en bestuurder kan door de rechter niet worden uitgesproken.

4/ De statuten moeten voorschriften bevatten omtrent de wijze, waarop in het bestuur van de vennootschap voorlopig wordt voorzien in geval van ontstentenis of

\section{Artikel 243}

1/ Bij de statuten kan worden bepaald dat de benoeming door de algemene vergadering geschiedt uit een voordracht.

2/ De algemene vergadering kan echter aan zodanige voordracht steeds het bindend karakter ontnemen bij een besluit genomen met ten minste twee derden van de uitgebrachte stemmen, welke twee derden meer dan de helft van het geplaatste kapitaal vertegenwoordigen. Indien het bindend karakter aan de voordracht is ontnomen, kan de algemene vergadering een nieuwe voordracht vragen aan degene aan wie het voordrachtsrecht toekomt en een kandidaat voor de nieuwe voordracht aanbevelen.

3/ Indien de voordracht één kandidaat voor een te vervullen plaats bevat, heeft een besluit over de voordracht tot gevolg dat de kandidaat is benoemd, tenzij het bindend karakter aan de voordracht wordt ontnomen en mits aan de vereisten voor een besluit tot benoeming is voldaan.

4/ De leden 1, 2 en 3 zijn niet van toepassing, indien de benoeming geschiedt door de raad van commissarissen.

\section{Artikel 244}

1/ Iedere bestuurder kan te allen tijde worden geschorst en ontslagen door het orgaan dat bevoegd is tot benoeming. De statuten kunnen bepalen dat een bestuurder eveneens kan worden ontslagen door een ander orgaan, tenzij de benoeming overeenkomstig artikel 272 door de raad van commissarissen geschiedt.

2/ Indien in de statuten is bepaald dat het besluit tot schorsing of ontslag slechts mag worden genomen met een versterkte meerderheid in een algemene vergadering, waarin een bepaald gedeelte van het kapitaal is vertegenwoordigd, mag deze versterkte meerderheid twee derden der uitgebrachte stemmen, vertegenwoordigende meer dan de helft van het kapitaal, niet te boven gaan.

3/ Een veroordeling tot herstel van de arbeidsovereenkomst tussen vennootschap en bestuurder kan door de rechter niet worden uitgesproken.

4/ De statuten moeten voorschriften bevatten omtrent de wijze waarop in het bestuur van de vennootschap voorlopig wordt voorzien in geval van ontstentenis of 


\begin{tabular}{|c|}
\hline belet van bestuurders. \\
\hline Artikel 252 \\
\hline $\begin{array}{l}\text { 1/ De commissarissen die niet reeds bij de akte van } \\
\text { oprichting zijn aangewezen, worden benoemd door de } \\
\text { algemene vergadering van aandeelhouders. De statu- } \\
\text { ten kunnen de kring van benoembare personen beper- } \\
\text { ken door eisen te stellen waaraan de commissarissen } \\
\text { moeten voldoen. De eisen kunnen terzijde worden } \\
\text { gesteld door een besluit van de algemene vergadering } \\
\text { genomen met twee derden van de uitgebrachte stem- } \\
\text { men die meer dan de helft van het geplaatste kapitaal } \\
\text { vertegenwoordigen. }\end{array}$ \\
\hline
\end{tabular}

2/ De eerste twee leden van artikel 243 van dit Boek zijn van overeenkomstige toepassing, indien de benoeming door de algemene vergadering van aandeelhouders geschiedt.

3/ Bij een aanbeveling of voordracht tot benoeming van een commissaris worden van de kandidaat medegedeeld zijn leeftijd, zijn beroep, het bedrag aan door hem gehouden aandelen in het kapitaal der vennootschap en de betrekkingen die hij bekleedt of die hij heeft bekleed voor zover die van belang zijn in verband met de vervulling van de taak van een commissaris. Tevens wordt vermeld aan welke rechtspersonen hij reeds als commissaris is verbonden; indien zich daaronder rechtspersonen bevinden, die tot een zelfde groep behoren, kan met de aanduiding van die groep worden volstaan. De aanbeveling en de voordracht tot benoeming of herbenoeming worden gemotiveerd. Bij herbenoeming wordt rekening gehouden met de wijze waarop de kandidaat zijn taak als commissaris heeft vervuld. belet van een of meer bestuurders. De statuten kunnen nader bepalen wanneer er sprake is van belet.

\section{Artikel 252}

1/ De commissarissen die niet reeds bij de akte van oprichting zijn aangewezen, worden benoemd door de algemene vergadering of, indien de statuten zulks bepalen, door een

vergadering van houders van aandelen van een bepaalde soort of aanduiding, mits iedere aandeelhouder met stemrecht kan deelnemen aan de besluitvorming inzake de benoeming van ten minste één commissaris. Op een statutaire regeling als bedoeld in de vorige zin is artikel 228 lid 4, tweede volzin, en lid 6 van overeenkomstige toepassing. De eerste zin geldt niet indien de benoeming overeenkomstig artikel 268 geschiedt. De statuten kunnen de kring van benoembare personen beperken door eisen te stellen waaraan de commissarissen moeten voldoen. De eisen kunnen terzijde worden gesteld door een besluit van de algemene vergadering, genomen overeenkomstig de regels die gelden voor de totstandkoming van een besluit tot statutenwijziging.

2. De eerste drie leden van artikel 243 van dit Boek zijn van overeenkomstige toepassing, indien de benoeming door de algemene vergadering [...] geschiedt.

3/ Bij een aanbeveling of voordracht tot benoeming van een commissaris worden van de kandidaat medegedeeld zijn leeftijd, zijn beroep, het bedrag aan door hem gehouden aandelen in het kapitaal der vennootschap en de betrekkingen die hij bekleedt of die hij heeft bekleed voor zover die van belang zijn in verband met de vervulling van de taak van een commissaris. Tevens wordt vermeld aan welke rechtspersonen hij reeds als commissaris is verbonden; indien zich daaronder rechtspersonen bevinden, die tot een zelfde groep behoren, kan met de aanduiding van die groep worden volstaan. De aanbeveling en de voordracht tot benoeming of herbenoeming worden gemotiveerd. Bij herbenoeming wordt rekening gehouden met de wijze waarop de kandidaat zijn taak als commissaris heeft vervuld.

4/ De statuten moeten voorschriften bevatten omtrent de wijze waarop in de toezichthoudende taak voorlopig wordt voorzien in geval van ontstentenis of belet van commissarissen. De statuten kunnen nader bepalen wanneer er sprake is van belet.

\section{Artikel 253}

Bij de statuten kan worden bepaald dat een of meer commissarissen, doch ten hoogste een derde van het gehele aantal, worden benoemd door anderen dan de algemene vergadering of een vergadering van houders van aandelen van een bepaalde soort of aanduiding, 


\begin{tabular}{|l|l}
\hline $\begin{array}{l}268 \text { en } 269 \text { van dit Boek, dan vindt de vorige zin geen } \\
\text { toepassing. }\end{array}$ & $\begin{array}{l}\text { mits iedere aandeelhouder kan deelnemen aan de } \\
\text { besluitvorming inzake de benoeming van ten minste } \\
\text { één commissaris. Op een statutaire regeling als be- } \\
\text { doeld in de vorige zin is artikel } 228 \text { lid } 4 \text {, tweede } \\
\text { volzin, en lid } 6 \text { van overeenkomstige toepassing. Is de } \\
\text { benoeming van commissarissen geregeld overeen- } \\
\text { komstig de artikelen } 268 \text { en } 269 \text {, dan vindt de eerste } \\
\text { zin geen toepassing. }\end{array}$ \\
\end{tabular}

\section{Artikel 254}

1/ Een commissaris kan worden geschorst en ontslagen door degene die bevoegd is tot benoeming, tenzij artikel 271 leden 2 en 3 of artikel 271a van dit Boek van toepassing is..

2/ Het tweede en het derde lid van artikel 244 van dit Boek zijn van overeenkomstige toepassing.

\section{Artikel 254}

1/ Een commissaris kan worden geschorst en ontslagen door degene die bevoegd is tot benoeming [...]. De statuten kunnen bepalen dat een commissaris eveneens kan worden ontslagen door de algemene vergadering. Het voorgaande is niet van toepassing indien artikel 271 lid 2 en lid 3, of artikel 271a van toepassing is.

2/ Het tweede en het derde lid van artikel 244 van dit Boek zijn van overeenkomstige toepassing.

\section{Artikel 257}

1/ Tenzij bij de statuten anders is bepaald, is de raad van commissarissen bevoegd iedere bestuurder te allen tijde te schorsen.

2/ De schorsing kan te allen tijde worden opgeheven door de vergadering van aandeelhouders die bevoegd is tot benoeming. ing worden opgeheven, tenzij de bevoegdh tot benoeming van de bestuurders bij de raad van commissarissen berust.

Afdeling 6

De raad van commissarissen bij de grote besloten vennootschap met beperkte aansprakelijkheid

\section{Artikel 262}

In deze afdeling wordt onder een afhankelijke maatschappij verstaan:

A/ Een rechtspersoon waaraan de vennootschap of een of meer afhankelijke maatschappijen alleen of samen voor eigen rekening ten minste de helft van het geplaatste kapitaal verschaffen,

$\mathrm{B} / \mathrm{E}$ en vennootschap waarvan een onderneming in het handelsregister is ingeschreven en waarvoor de vennootschap of een afhankelijke maatschappij als vennote jegens derden volledig aansprakelijk is voor alle schulden.

\section{Artikel 262}

In deze afdeling wordt onder een afhankelijke maatschappij verstaan:

A/ Een rechtspersoon waaraan de vennootschap of een of meer afhankelijke maatschappijen alleen of samen voor eigen rekening ten minste de helft van het geplaatste kapitaal verschaffen,

$\mathrm{B} / \mathrm{E}$ en vennootschap waarvan een onderneming in het handelsregister is ingeschreven en waarvoor de vennootschap of een afhankelijke maatschappij als vennote jegens derden volledig aansprakelijk is voor alle schulden.

In afwijking van artikel 24d wordt bij de toepassing van onderdeel a ten aanzien van een besloten vennootschap met beperkte aansprakelijkheid tevens rekening gehouden met aandelen waarvan de statuten bepalen dat daarvoor geen stem kan worden uitgebracht; 
FUSIE EN SPLITSING

\author{
Afdeling 3 \\ Bijzondere bepalingen voor fusies van naamloze en besloten vennootschappen
}

\begin{abstract}
Artikel 325
1/ Indien aandelen of certificaten van aandelen in het kapitaal van een te fuseren vennootschap zijn toegelaten tot de handel op een markt in financiële instrumenten als bedoeld in artikel 1:1 van de Wet op het financieel toezicht, kan de ruilverhouding afhankelijk zijn van de prijs van die aandelen onderscheidenlijk certificaten op die markt op een of meer in het voorstel tot fusie te bepalen tijdstippen, gelegen voor de dag waarop de fusie van kracht wordt.
\end{abstract}

2/ Indien krachtens de ruilverhouding van de aandelen recht bestaat op geld of schuldvorderingen, mag het gezamenlijke bedrag daarvan een tiende van het nominale bedrag van de toegekende aandelen niet te boven gaan.

3/ Bij de akte van fusie kan de verkrijgende vennootschap aandelen in haar kapitaal die zij zelf of een andere fuserende vennootschap houdt, intrekken tot ten hoogste het bedrag van de aandelen die zij toekent aan haar nieuwe aandeelhouders. De artikelen 99, 100, 208 en 209 gelden niet voor dit geval..

4/ Aandelen in het kapitaal van de verdwijnende vennootschappen die worden gehouden door of voor rekening van de fuserende vennootschappen, vervallen.

\section{Artikel 325}

$1 /$ Indien aandelen of certificaten van aandelen in het kapitaal van een te fuseren vennootschap zijn toegelaten tot de handel op een markt in financiële instrumenten als bedoeld in artikel 1:1 van de Wet op het financieel toezicht, kan de ruilverhouding afhankelijk zijn van de prijs van die aandelen onderscheidenlijk certificaten op die markt op een of meer in het voorstel tot fusie te bepalen tijdstippen, gelegen voor de dag waarop de fusie van kracht wordt.

2/ Indien krachtens de ruilverhouding van de aandelen recht bestaat op geld of schuldvorderingen, mag het gezamenlijke bedrag daarvan een tiende van het nominale bedrag van de toegekende aandelen niet te boven gaan.

3/ Bij de akte van fusie kan de verkrijgende vennootschap aandelen in haar kapitaal die zij zelf of een andere fuserende vennootschap houdt, intrekken tot ten hoogste het bedrag van de aandelen die zij toekent aan haar nieuwe aandeelhouders. De artikelen 99, 100, 208 en 216 gelden niet voor dit geval.

4/ Aandelen in het kapitaal van de verdwijnende vennootschappen die worden gehouden door of voor rekening van de fuserende vennootschappen, vervallen.

\title{
Afdeling 5 \\ BIJZONDERE BEPALINGEN VOOR SPLITSINGEN WAARBIJ EEN NAAMLOZE OF BESLOTEN VENNOOTSCHAP WORDT GESPLITST OF WORDT OPGERICHT
}

\begin{abstract}
Artikel 334x
1/ Indien aandelen of certificaten van aandelen in het kapitaal van een splitsende vennootschap zijn toegelaten tot de handel op een markt in financiële instrumenten als bedoeld in artikel 1:1 van de Wet op het financieel toezicht, kan de ruilverhouding afhankelijk zijn van de prijs van die aandelen onderscheidenlijk certificaten op die beurs op een of meer in het voorstel tot splitsing te bepalen tijdstippen, gelegen voor de dag waarop de splitsing van kracht wordt.
\end{abstract}

2/ Indien krachtens de ruilverhouding van de aandelen recht bestaat op geld of schuldvorderingen, mag het

\section{Artikel 334x}

1/ Indien aandelen of certificaten van aandelen in het kapitaal van een splitsende vennootschap zijn toegelaten tot de handel op een markt in financiële instrumenten als bedoeld in artikel 1:1 van de Wet op het financieel toezicht, kan de ruilverhouding afhankelijk zijn van de prijs van die aandelen onderscheidenlijk certificaten op die beurs op een of meer in het voorstel tot splitsing te bepalen tijdstippen, gelegen voor de dag waarop de splitsing van kracht wordt.

2/ Indien krachtens de ruilverhouding van de aandelen recht bestaat op geld of schuldvorderingen, mag het 
gezamenlijke bedrag daarvan een tiende van het nominale bedrag van de door de betrokken vennootschap toegekende aandelen niet te boven gaan.

3/ Bij de akte van splitsing kan een verkrijgende vennootschap aandelen in haar kapitaal die zij zelf houdt of krachtens de akte van splitsing verkrijgt, intrekken tot ten hoogste het bedrag van de aandelen die zij toekent aan haar nieuwe aandeelhouders. De artikelen 99, 100, 208 en 209 gelden niet voor dit geval.

4/ Aandelen in het kapitaal van de splitsende vennootschap die worden gehouden door of voor rekening van een verkrijgende rechtspersoon of door of voor rekening van de splitsende vennootschap vervallen, indien de splitsende vennootschap bij de splitsing ophoudt te bestaan. gezamenlijke bedrag daarvan een tiende van het nominale bedrag van de door de betrokken vennootschap toegekende aandelen niet te boven gaan.

3/ Bij de akte van splitsing kan een verkrijgende vennootschap aandelen in haar kapitaal die zij zelf houdt of krachtens de akte van splitsing verkrijgt, intrekken tot ten hoogste het bedrag van de aandelen die zij toekent aan haar nieuwe aandeelhouders. De artikelen 99, 100, 208 en 216 gelden niet voor dit geval.

4/ Aandelen in het kapitaal van de splitsende vennootschap die worden gehouden door of voor rekening van een verkrijgende rechtspersoon of door of voor rekening van de splitsende vennootschap vervallen, indien de splitsende vennootschap bij de splitsing ophoudt te bestaan.

\section{Artikel 334bb}

1/ Ten aanzien van de door een verkrijgende naamloze vennootschap toegekende aandelen zijn de artikelen 94a en 94b van overeenkomstige toepassing [...] Een ingevolge artikel $94 \mathrm{a}[\ldots]$ vereiste verklaring van een accountant behoeft echter niet aan de akte van oprichting te worden gehecht. nootschap toegekende aandelen de artikelen 204a en 204b. Een ingevolge de artikelen 94a of 204a vereiste verklaring van een accountant behoeft echter niet aan de akte van oprichting te worden gehecht.

2/ Op een ingevolge lid 1 vereiste verklaring van een accountant is artikel $334 \mathrm{~h}$ van overeenkomstige toepassing.
2/ Op een ingevolge lid 1 vereiste verklaring van een accountant is artikel $334 \mathrm{~h}$ van overeenkomstige toepassing.

Titel 8

Geschillenregeling en het recht van enquête

Afdeling 1

Geschillenregeling

\section{Artikel 336}

1/ Een of meer houders van aandelen die alleen of gezamenlijk ten minste een derde van het geplaatste kapitaal verschaffen, kunnen van een aandeelhouder die door zijn gedragingen het belang van de vennootschap zodanig schaadt, dat het voortduren van zijn aandeelhouderschap in redelijkheid niet kan worden geduld, in rechte vorderen dat hij zijn aandelen overeenkomstig artikel 341 overdraagt.

2/ De vordering kan niet worden ingesteld door de vennootschap of een dochtermaatschappij van de vennootschap. De houder van aandelen waarvan de vennootschap of een dochtermaatschappij certificaten houdt, kan de vordering slechts instellen indien en voor zover certificaten door anderen worden gehouden. Een aandeelhouder ten titel van beheer kan de vordering slechts voor door hem beheerde aandelen

\section{Artikel 336}

1/ Een of meer houders van aandelen die alleen of gezamenlijk ten minste een derde van het geplaatste kapitaal verschaffen, kunnen van een aandeelhouder die door zijn gedragingen het belang van de vennootschap zodanig schaadt, dat het voortduren van zijn aandeelhouderschap in redelijkheid niet kan worden geduld, in rechte vorderen dat hij zijn aandelen overeenkomstig artikel 341 overdraagt.

2/ De vordering kan niet worden ingesteld door de vennootschap of een dochtermaatschappij van de vennootschap. De houder van aandelen waarvan de vennootschap of een dochtermaatschappij certificaten houdt, kan de vordering slechts instellen indien en voor zover certificaten door anderen worden gehouden. Een aandeelhouder ten titel van beheer kan de vordering slechts voor door hem beheerde aandelen 
instellen indien de desbetreffende certificaathouders daarmee tevoren hebben ingestemd.

3/ Tot de kennisneming van de vordering is in eerste aanleg bevoegd de rechtbank van de woonplaats van de vennootschap. Hoger beroep kan uitsluitend worden ingesteld bij de ondernemingskamer van het gerechtshof te Amsterdam. Artikel 344 van het Wetboek van Burgerlijke Rechtsvordering is van toepassing met dien verstande dat voor "een meervoudige kamer" wordt gelezen: de ondernemingskamer.

4/ De rechter kan zijn beslissing omtrent de vordering voor een door hem te bepalen termijn aanhouden, indien ten processe blijkt dat de vennootschap of één of meer aandeelhouders op zich nemen maatregelen te treffen waardoor het nadeel dat de vennootschap lijdt zoveel mogelijk wordt ongedaan gemaakt of beperkt. instellen indien de desbetreffende certificaathouders daarmee tevoren hebben ingestemd.

3/ Tot de kennisneming van de vordering is in eerste aanleg uitsluitend bevoegd de rechtbank van de woonplaats van de vennootschap. Hoger beroep kan uitsluitend worden ingesteld bij de ondernemingskamer van het gerechtshof te Amsterdam. Artikel 344 van het Wetboek van Burgerlijke Rechtsvordering is van toepassing met dien verstande dat voor "een meervoudige kamer" wordt gelezen: de ondernemingskamer.

4/ De rechter kan zijn beslissing omtrent de vordering voor een door hem te bepalen termijn aanhouden, indien ten processe blijkt dat de vennootschap of één of meer aandeelhouders op zich nemen maatregelen te treffen waardoor het nadeel dat de vennootschap lijdt zoveel mogelijk wordt ongedaan gemaakt of beperkt.

5/ De in lid 3, eerste en tweede zin, bedoelde rechter is eveneens bevoegd kennis te nemen van met de in lid 1 bedoelde gedragingen samenhangende vorderingen tussen dezelfde partijen of tussen een der partijen en de vennootschap.

\section{Artikel 337}

1/ Indien de statuten of een overeenkomst een regeling bevatten voor de oplossing van geschillen als in deze afdeling bedoeld, kan op een daarin opgenomen afwijking van deze afdeling geen beroep worden gedaan voorzover deze de overdracht van aandelen onmogelijk of uiterst bezwaarlijk maakt.

2/ In de statuten of een overeenkomst kan worden bepaald dat geschillen als in deze afdeling bedoeld, dadelijk ter kennis worden gebracht van de ondernemingskamer van het gerechtshof te Amsterdam of aan arbitrage worden onderworpen, dan wel anderszins wordt afgeweken van de rechterlijke bevoegdheid als geregeld in artikel 336 leden 3 en

\section{Artikel 338}

1/ Nadat de dagvaarding aan hem is betekend en tot de dag waarop het vonnis onherroepelijk is geworden, kan de gedaagde zijn aandelen niet vervreemden, verpanden of daarop een vruchtgebruik vestigen, tenzij de eisers daarvoor toestemming verlenen. Indien de eisers de toestemming weigeren, kan de rechter voor wie het geschil aanhangig is op vordering van gedaagde de toestemming verlenen, indien gedaagde bij de rechtshandeling een redelijk belang heeft. Tegen de beslissing van de rechter staat geen hogere voorziening open.

2/ Nadat de vordering is toegewezen, kan de gedaagde de aandelen slechts overdragen met inachtneming van de artikelen 339 tot en met 341.
2/ Nadat het vonnis waarbij de vordering is toegewezen onherroepelijk is geworden, kan de gedaagde de aandelen slechts overdragen met inachtneming van de 
bepalingen van artikel 339 tot en met 341.

3/ Een voorlopige voorziening als bedoeld in artikel 223 van het Wetboek van Burgerlijke Rechtsvordering kan worden getroffen met werking tot het tijdstip dat de aandelen worden overgedragen. Een vordering tot het treffen van een voorlopige voorziening wordt met de meeste spoed behandeld.

\section{Artikel 339}

$1 /$ Indien de vordering wordt toegewezen benoemt de rechter een of drie deskundigen die over de prijs van de aandelen schriftelijk bericht moeten uitbrengen. De artikelen 194 tot en met 200 van het Wetboek van Burgerlijke Rechtsvordering zijn voor het overige van toepassing. De deskundigen vangen hun werkzaamheden pas aan, nadat het vonnis onherroepelijk is geworden. Tegen de deskundigenbenoeming staat geen hogere voorziening open.

2/ Indien de eisers zulks gevorderd hebben, kan de rechter bij het vonnis waarbij de vordering wordt toegewezen, de gedaagde verbieden het stemrecht nog uit te oefenen. Dit verbod kan uitvoerbaar bij voorraad worden verklaard.

3/ De deskundigen stellen hun bericht op met inachtneming van hetgeen omtrent de vaststelling van de waarde van de aandelen in de blokkeringsregeling is bepaald. De artikelen 351 en 352 zijn van overeenkomstige toepassing.

\section{Artikel 339}

$1 /$ Indien de vordering wordt toegewezen benoemt de rechter een of meer deskundigen die over de prijs schriftelijk bericht moeten uitbrengen. De artikelen 194 tot en met 199 van het Wetboek van Burgerlijke Rechtsvordering zijn voor het overige van toepassing. De artikelen 351 en 352 zijn van overeenkomstige toepassing. Van het vonnis waarbij de vordering wordt toegewezen kan hoger beroep slechts worden ingesteld tegelijk met dat van het vonnis, bedoeld in artikel 340 lid 1, tenzij de rechter anders heeft bepaald. Tegen de deskundigenbenoeming staat geen hogere voorziening open.

2/ Indien tussen partijen op grond van de statuten of een overeenkomst in de zin van artikel 337 lid 1 bepalingen omtrent de vaststelling van de waarde van de aandelen gelden, stellen de deskundigen hun bericht op met inachtneming daarvan.

3/ De rechter kan in afwijking van lid 1 de benoeming van deskundigen achterwege laten, indien tussen partijen overeenstemming bestaat over de waardering van de aandelen, alsmede indien de statuten of een overeenkomst in de zin van artikel 337 lid 1 een duidelijke maatstaf voor de bepaling van de waarde van de aandelen bevatten en de rechter aan de hand daarvan de prijs zonder meer kan vaststellen.

\section{Artikel 340}

1/ Zijn deskundigen benoemd, dan bepaalt de rechter de prijs van de aandelen nadat de deskundigen hun bericht hebben uitgebracht. Bij hetzelfde vonnis bepaalt hij tevens wie

van de partijen de kosten van het deskundigenbericht moet dragen. Hij kan ook bepalen dat de vennootschap de kosten moet dragen na deze ter zake te hebben gehoord. Hij kan de kosten verdelen tussen partijen onderling of tussen partijen of een van hen en de vennootschap.

2/ Vindt geen benoeming van deskundigen plaats, dan bepaalt de rechter de prijs van de aandelen in het vonnis waarbij de vordering wordt toegewezen.

3/ Met bepalingen in de statuten of een overeenkomst omtrent de vaststelling van de waarde van de aandelen houdt de rechter geen rekening voorzover dat tot een kennelijk onredelijke prijs zou leiden. 


\begin{abstract}
2/ Het vonnis houdt tevens een veroordeling in van de eisers tot contante betaling van de hun zo nodig na toepassing van artikel 341 lid 5 over te dragen aandelen. Indien artikel 341 lid 6 van toepassing is, omvat die veroordeling mede de certificaathouders die met het instellen van de vordering hebben ingestemd.
\end{abstract}

4/ Het vonnis houdt tevens een veroordeling in van de eisers tot contante betaling van de hun zo nodig na toepassing van artikel 341 lid 5 over te dragen aandelen. Indien artikel 341 lid 6 van toepassing is, omvat die veroordeling mede de certificaathouders die met het instellen van de vordering hebben ingestemd.

\section{Artikel 341}

1/ De gedaagde is verplicht binnen twee weken nadat hem een afschrift van het onherroepelijk geworden vonnis als bedoeld in artikel 340 lid 1 is betekend, zijn aandelen aan de eisers te leveren en de eisers zijn verplicht de aandelen tegen gelijktijdige betaling van de vastgestelde prijs te aanvaarden, behoudens het bepaalde in lid 2. De aanvaarding geschiedt zoveel mogelijk naar evenredigheid van ieders aandelenbezit, tenzij anders wordt overeengekomen. Met eisers worden gelijkgesteld de aandeelhouders die zich in het rechtsgeding aan de zijde van de eisers hebben gevoegd en daarbij de wens te kennen hebben gegeven in dezelfde positie als de eisers te worden geplaatst.

$2 /$ Indien in de statutaire blokkeringsregeling is bepaald dat de aandeelhouder die een of meer aandelen wil vervreemden, deze moet aanbieden aan zijn medeaandeelhouders of anderen, biedt de vennootschap de aandelen onverwijld nadat een afschrift van het onherroepelijk geworden vonnis aan haar is betekend, schriftelijk namens de gedaagde aan de aandeelhouders of anderen aan, zoveel mogelijk met overeenkomstige toepassing van de statutaire regeling en deelt hun daarbij tevens de vastgestelde prijs mee. Zij kunnen het aanbod binnen een maand na verzending van de mededeling aanvaarden door schriftelijke kennisgeving aan de vennootschap. De vennootschap kan slechts met instemming van de gedaagde aandelen aanvaarden. Binnen een week na het verstrijken van deze termijn deelt de vennootschap aan de gedaagde en de eisers mee of en zo ja hoeveel aandelen zijn aanvaard en aan wie deze zijn toegewezen. De gedaagde is verplicht onverwijld na ontvangst van deze mededeling zijn aandelen aan de medeaandeelhouders of de anderen te leveren tegen gelijktijdige betaling.

3/ Indien in het geval van lid 2 geen aandelen zijn aanvaard of minder aandelen zijn aanvaard dan zijn aangeboden, of de vastgestelde prijs niet binnen twee weken na ontvangst van de mededeling van de vennootschap omtrent de toewijzing van de aandelen aan de gedaagde die tot gelijktijdige levering wilde overgaan wordt voldaan, vindt lid 1 toepassing ten aanzien van de aandelen, de overgebleven aandelen of de aandelen waarvoor niet tijdig betaling is ontvangen.

\section{Artikel 341}

1/ De gedaagde is verplicht binnen twee weken nadat hem een afschrift van het [...] vonnis als bedoeld in artikel 340 lid 1 is betekend, zijn aandelen aan de eisers te leveren en de eisers zijn verplicht de aandelen tegen gelijktijdige betaling van de vastgestelde prijs te aanvaarden, behoudens het bepaalde in lid 2. Was het vonnis niet uitvoerbaar bij voorraad verklaard, dan heeft betekening daarvan slechts het in de eerste zin bedoelde gevolg als zij geschiedt nadat het vonnis alsnog uitvoerbaar bij voorraad is verklaard of onherroepelijk is geworden. De aanvaarding geschiedt zoveel mogelijk naar evenredigheid van ieders aandelenbezit, tenzij anders wordt overeengekomen. Met eisers worden gelijkgesteld de aandeelhouders die zich in het rechtsgeding aan de zijde van de eisers hebben gevoegd en daarbij de wens te kennen hebben gegeven in dezelfde positie als de eisers te worden geplaatst.

2/ Indien de aandeelhouder die een of meer aandelen wil vervreemden, deze ingevolge artikel 195 of een regeling in de statuten moet aanbieden aan zijn medeaandeelhouders of anderen, biedt de vennootschap de aandelen onverwijld nadat een afschrift van het vonnis aan haar is betekend, schriftelijk namens de gedaagde aan de aandeelhouders of anderen aan, zoveel mogelijk met overeenkomstige toepassing van de wettelijke of statutaire regeling en deelt hun daarbij tevens de vastgestelde prijs mee. Zij kunnen het aanbod binnen een maand na verzending van de mededeling aanvaarden door schriftelijke kennisgeving aan de vennootschap. [...] Binnen een week na het verstrijken van deze termijn deelt de vennootschap aan de gedaagde en de eisers mee of en zo ja hoeveel aandelen zijn aanvaard en aan wie deze zijn toegewezen. De gedaagde is verplicht onverwijld na ontvangst van deze mededeling zijn aandelen aan de mede-

aandeelhouders of de anderen te leveren tegen gelijktijdige betaling. Lid 1, tweede zin, is van overeenkomstige toepassing.

3/ Indien in het geval van lid 2 geen aandelen zijn aanvaard of minder aandelen zijn aanvaard dan zijn aangeboden, of de vastgestelde prijs niet binnen twee weken na ontvangst van de mededeling van de vennootschap omtrent de toewijzing van de aandelen aan de gedaagde die tot gelijktijdige levering wilde overgaan wordt voldaan, vindt lid 1 toepassing ten aanzien van de aandelen, de overgebleven aandelen of de aandelen waarvoor niet tijdig betaling is ontvangen. 
4/ Blijft de gedaagde in gebreke met de levering van zijn aandelen, dan levert de vennootschap namens hem de aandelen tegen gelijktijdige betaling.

5/ Blijven een of meer eisers in gebreke met de aanvaarding van de aandelen tegen gelijktijdige betaling van de vastgestelde prijs, dan zijn de overige eisers verplicht om binnen twee weken nadat dit is komen vast te staan die aandelen tegen gelijktijdige betaling te aanvaarden, ieder zoveel mogelijk naar evenredigheid van zijn aandelenbezit.

6/ Is een eiser aandeelhouder ten titel van beheer, dan zijn naast hem de certificaathouders die met het instellen van de vordering hebben ingestemd, aansprakelijk voor het krachtens dit artikel verschuldigde, ieder zoveel mogelijk naar evenredigheid van zijn bezit aan certificaten. Blijven een of meer van deze certificaathouders in gebreke, dan zijn de overige certificaathouders die met het instellen van de vordering hebben ingestemd verplicht dat deel te voldoen, ieder zoveel mogelijk naar evenredigheid van zijn bezit aan certificaten.

7/ Op verzoek van de meest gerede partij beslist de rechter die de vordering in eerste instantie of in hoger beroep heeft toegewezen over geschillen betreffende de uitvoering van de regeling. Tegen deze beslissing staat geen hogere voorziening open.
4/ Blijft de gedaagde in gebreke met de levering van zijn aandelen, dan levert de vennootschap namens hem de aandelen tegen gelijktijdige betaling.

5/ Blijven een of meer eisers in gebreke met de aanvaarding van de aandelen tegen gelijktijdige betaling van de vastgestelde prijs, dan zijn de overige eisers verplicht om binnen twee weken nadat dit is komen vast te staan die aandelen tegen gelijktijdige betaling te aanvaarden, ieder zoveel mogelijk naar evenredigheid van zijn aandelenbezit.

6/ Is een eiser aandeelhouder ten titel van beheer, dan zijn naast hem de certificaathouders die met het instellen van de vordering hebben ingestemd, aansprakelijk voor het krachtens dit artikel verschuldigde, ieder zoveel mogelijk naar evenredigheid van zijn bezit aan certificaten. Blijven een of meer van deze certificaathouders in gebreke, dan zijn de overige certificaathouders die met het instellen van de vordering hebben ingestemd verplicht dat deel te voldoen, ieder zoveel mogelijk naar evenredigheid van zijn bezit aan certificaten.

7/ Op verzoek van een partij beslist de rechter die de vordering in eerste instantie of in hoger beroep heeft toegewezen over geschillen betreffende de uitvoering van de regeling. Tegen deze beslissing staat geen hogere voorziening open.

\section{Artikel 341a}

1/ Wordt een vonnis als bedoeld in artikel 340 lid 1 na het instellen van een rechtsmiddel vernietigd, dan blijft de rechtsgrond voor op grond van dat vonnis verrichte handelingen in stand, maar ontstaat voor partijen een verbintenis tot ongedaanmaking van de reeds ingetreden gevolgen.

2/ Indien de reeds ingetreden gevolgen bezwaarlijk ongedaan kunnen worden gemaakt of de billijkheid zulks anderszins vordert, kan de rechter desgevraagd de verplichting tot ongedaanmaking beperken of uitsluiten. Hij kan aan een partij die daardoor onbillijk wordt bevoordeeld, de verplichting opleggen tot een uitkering in geld aan de partij die benadeeld wordt.

\section{Artikel 342}

1/ Een of meer houders van aandelen die alleen of gezamenlijk ten minste een derde van het geplaatste kapitaal verschaffen, kunnen van een stemgerechtigde vruchtgebruiker of pandhouder van een aandeel in rechte vorderen dat het stemrecht op het aandeel overgaat op de houder van het aandeel, indien die vruchtgebruiker of pandhouder door zijn gedragingen het belang van de vennootschap zodanig schaadt dat in redelijkheid niet kan worden geduld dat hij het stemrecht blijft uitoefenen. 
2/ Een afschrift van het exploit van dagvaarding moet onverwijld door eisers aan de houder van het aandeel, die niet zelf tevens eiser is, worden betekend. Artikel 336, leden 2, 3 en 4 en artikel 339 lid 2 zijn van toepassing en de artikelen 337 en 338 lid 1 zijn van overeenkomstige toepassing, in dier voege dat in het geval van artikel 338 lid 1 de vruchtgebruiker of pandhouder het vruchtgebruik of het pandrecht niet op een ander kan doen overgaan.

3/ Indien de vordering tot overgang van het stemrecht is toegewezen, vindt de overgang plaats door het in kracht van gewijsde gaan van het vonnis.
2/ Een afschrift van het exploit van dagvaarding moet onverwijld door eisers aan de houder van het aandeel, die niet zelf tevens eiser is, worden betekend. Artikel 336, leden 2, 3 en 4 en artikel 339 lid 2 zijn van toepassing en de artikelen 337 en artikel 338 leden 1 en 3 , tweede volzin zijn van overeenkomstige toepassing, in dier voege dat in het geval van artikel 338 leden 1 en 3, tweede volzin de vruchtgebruiker of pandhouder het vruchtgebruik of het pandrecht niet op een ander kan doen overgaan.

3/ Indien de vordering tot overgang van het stemrecht is toegewezen, vindt de overgang plaats door het in kracht van gewijsde gaan van het vonnis.

\section{Artikel 343}

1/ De aandeelhouder die door gedragingen van een of meer mede-aandeelhouders zodanig in zijn rechten of belangen wordt geschaad dat het voortduren van zijn aandeelhouderschap in redelijkheid niet meer van hem kan worden gevergd, kan van die mede-

aandeelhouders in rechte vorderen dat zijn aandelen overeenkomstig de leden 3, 4 en 5 van dit artikel worden overgenomen. De artikelen 336 leden 3 en 4, 337, 338 lid 1, 339 leden 1 en 3, en 340 lid 1 zijn van toepassing. Het vonnis houdt tevens in een veroordeling van de eisers tot levering aan gedaagden van de hun, zo nodig na toepassing van het zevende lid, over te dragen aandelen.

2/ De aandeelhouder tegen wie een vordering is ingesteld kan een andere aandeelhouder in het geding oproepen, indien hij van oordeel is dat de vordering ook of uitsluitend tegen die aandeelhouder had behoren te worden ingesteld.

De artikelen 210 tot en met 216 van het Wetboek van Burgerlijke Rechtsvordering zijn van overeenkomstige toepassing.

3/ Binnen twee weken nadat hem een afschrift van het onherroepelijk geworden vonnis als bedoeld in artikel 340 lid 1 is betekend, is ieder van de gedaagden verplicht het door de rechter vastgestelde aantal aandelen tegen gelijktijdige betaling van de vastgestelde prijs over te nemen, behoudens het bepaalde in lid 4 en is de eiser verplicht zijn aandelen aan de gedaagden te leveren. Met gedaagden worden gelijkgesteld de aandeelhouders die zich in het rechtsgeding aan de

\section{Artikel 343}

1/ De aandeelhouder die door gedragingen van één of meer mede-aandeelhouders zodanig in zijn rechten of belangen is geschaad dat het voortduren van zijn aandeelhouderschap in redelijkheid niet meer van hem kan worden gevergd, kan tegen die mede-

aandeelhouders een vordering tot uittreding instellen, inhoudende dat zijn aandelen overeenkomstig de leden 1, 2 en 3 van artikel 343a worden overgenomen. Een vordering tot uittreding kan ook worden ingesteld tegen de vennootschap op grond van gedragingen van één of meer mede-aandeelhouders of van de vennootschap zelf. Een vordering tegen de vennootschap kan evenwel niet worden toegewezen, voorzover artikel 98 of 207 aan verkrijging van de aandelen door de vennootschap in de weg staat, met dien verstande evenwel dat geen rekening wordt gehouden met artikel 207 lid 2 , het vereiste van een machtiging als bedoeld in artikel 98 lid 4 of een daarmee vergelijkbaar statutair voorschrift dan wel een na het tijdstip van instellen van de vordering ten nadele van eiser tot stand gebrachte wijziging van de statuten. Bij toewijzing van de vordering is artikel 207 lid 3 niet van toepassing.

2/ De artikelen 336 leden 3, 4 en 5, 337, 338 leden 1 en 3, 339 en 340, leden 1, 2 en 3 zijn van toepassing of van overeenkomstige toepassing.

3 / Is de vordering tegen een aandeelhouder ingesteld, dan kan deze een andere aandeelhouder in het geding oproepen, indien hij van oordeel is dat de vordering ook of uitsluitend tegen die aandeelhouder had behoren te worden ingesteld. De oproeping geschiedt uiterlijk tegen de voor het nemen van de conclusie van antwoord bepaalde dag. 
zijde van de gedaagden hebben gevoegd en daarbij de wens te kennen hebben gegeven in dezelfde positie als de gedaagden te worden geplaatst.

4/ Indien in de statutaire blokkeringsregeling is bepaald dat de aandeelhouder die een of meer aandelen wil vervreemden deze moet aanbieden aan zijn medeaandeelhouders of anderen, biedt de vennootschap de aandelen onverwijld nadat een afschrift van het onherroepelijk geworden vonnis aan haar is betekend, schriftelijk namens de eiser aan de aandeelhouders of anderen aan, zoveel mogelijk met overeenkomstige toepassing van de statutaire regeling en deelt hun daarbij tevens de vastgestelde prijs mee. Zij kunnen het aanbod binnen een maand na verzending van de mededeling aanvaarden door schriftelijke kennisgeving aan de vennootschap. De vennootschap kan slechts met instemming van de eiser aandelen aanvaarden. Binnen een week na het verstrijken van deze termijn deelt de vennootschap aan de eiser en de gedaagden mee of en zo ja hoeveel aandelen zijn aanvaard en aan wie deze zijn toegewezen. De eiser is verplicht onverwijld na ontvangst van deze mededeling zijn aandelen aan de mede-aandeelhouders of de anderen te leveren tegen gelijktijdige betaling.

5/ Indien in het geval van lid 4 geen aandelen zijn aanvaard of minder aandelen zijn aanvaard dan zijn aangeboden, of de vastgestelde prijs niet binnen twee weken na ontvangst van de mededeling van de vennootschap omtrent de toewijzing van de aandelen aan de eiser die tot gelijktijdige levering wilde overgaan wordt voldaan, vindt ten aanzien van de aandelen, de overgebleven aandelen of de aandelen waarvoor niet tijdig betaling is ontvangen lid 3 toepassing, met dien verstande dat de aanvaarding van de niet afgenomen aandelen door de gedaagden zoveel mogelijk geschiedt naar evenredigheid van het voor ieder overeenkomstig lid 3 vastgestelde aantal aandelen.

6/ Blijft de eiser in gebreke met de levering van zijn aandelen, dan levert de vennootschap namens hem de aandelen, tegen gelijktijdige betaling.

7/ Blijven een of meer gedaagden in gebreke met de aanvaarding van de aandelen tegen gelijktijdige betaling van de vastgestelde prijs, dan zijn de overige gedaagden verplicht om binnen twee weken nadat dit is komen vast te staan die aandelen tegen gelijktijdige betaling te aanvaarden, zoveel mogelijk naar evenredigheid van het voor ieder overeenkomstig lid 3 vastgestelde aantal aandelen.

8/ Is een gedaagde aandeelhouder ten titel van beheer, dan zijn naast hem de certificaathouders aansprakelijk voor het krachtens dit artikel verschuldigde, ieder zoveel mogelijk naar evenredigheid van zijn bezit aan certificaten. Blijven een of meer certificaathouders in gebreke, dan zijn de overige certificaathouders verplicht dat deel te voldoen, ieder zoveel mogelijk
4/ Bij het bepalen van de prijs van de aandelen kan de rechter desgevorderd een billijke verhoging toepassen in verband met gedragingen van de gedaagde, of van anderen dan de gedaagde, indien aannemelijk is dat die gedragingen hebben geleid tot een vermindering van de waarde van de over te dragen aandelen en deze vermindering niet, of niet volledig, voor rekening van eiser behoort te blijven.

5/ Bij toewijzing van de vordering tot uittreding bevat het vonnis tevens een veroordeling van de eiser tot levering aan gedaagden van de hun, zo nodig na toepassing van artikel 343 a lid 5, over te dragen aandelen. 


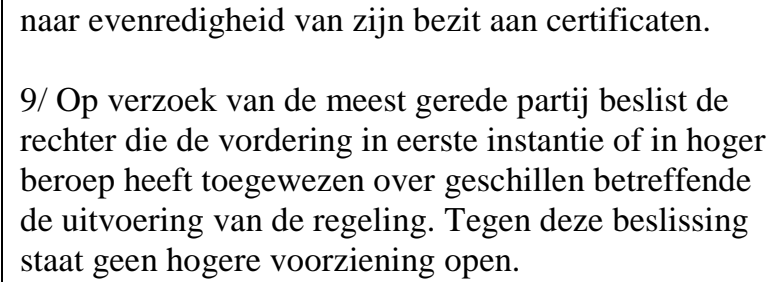

\section{Artikel 343a}

1/ Binnen twee weken nadat hem een afschrift is betekend van het vonnis waarbij de prijs van de aandelen is bepaald, is ieder van de gedaagden verplicht het door de rechter vastgestelde aantal aandelen tegen gelijktijdige betaling van de vastgestelde prijs over te nemen, behoudens lid 2, en is de eiser verplicht zijn aandelen aan de gedaagden te leveren. Was het vonnis niet uitvoerbaar bij voorraad verklaard, dan heeft betekening daarvan slechts het in de eerste zin bedoelde gevolg als zij geschiedt nadat het vonnis alsnog uitvoerbaar bij voorraad is verklaard of onherroepelijk is geworden. Met gedaagden worden gelijkgesteld de aandeelhouders die zich in het rechtsgeding aan de zijde van de gedaagden hebben gevoegd en daarbij de wens te kennen hebben gegeven in dezelfde positie als de gedaagden te worden geplaatst.

2/ Indien de aandeelhouder die een of meer aandelen wil vervreemden deze ingevolge artikel 195 of een regeling in de statuten moet aanbieden aan zijn medeaandeelhouders of anderen, biedt de vennootschap de aandelen onverwijld nadat een afschrift van het vonnis aan haar is betekend, schriftelijk namens de eiser aan de aandeelhouders of anderen aan, zoveel mogelijk met overeenkomstige toepassing van de wettelijke of statutaire regeling en deelt hun daarbij tevens de vastgestelde prijs mee. Zij kunnen het aanbod binnen een maand na verzending van de mededeling aanvaarden door schriftelijke kennisgeving aan de vennootschap. Binnen een week na het verstrijken van deze termijn deelt de vennootschap aan de eiser en de gedaagden mee of en zo ja hoeveel aandelen zijn aanvaard en aan wie deze zijn toegewezen. De eiser is verplicht onverwijld na ontvangst van deze mededeling zijn aandelen aan de mede-aandeelhouders of de anderen te leveren tegen gelijktijdige betaling. Lid 1, tweede zin, is van overeenkomstige toepassing.

3/ Indien in het geval van lid 2 geen aandelen zijn aanvaard of minder aandelen zijn aanvaard dan zijn aangeboden, of de vastgestelde prijs niet binnen twee weken na ontvangst van de mededeling van de vennootschap omtrent de toewijzing van de aandelen aan de eiser die tot gelijktijdige levering wilde overgaan wordt voldaan, vindt ten aanzien van de aandelen, de overgebleven aandelen of de aandelen waarvoor niet tijdig betaling is ontvangen lid 1 toepassing, met dien verstande dat de aanvaarding van de niet afgenomen aandelen door de gedaagden zoveel mogelijk geschiedt naar evenredigheid van het voor ieder ove- 


\begin{tabular}{|c|c|}
\hline & $\begin{array}{l}\text { reenkomstig lid } 1 \text { vastgestelde aantal aandelen. } \\
\text { 4/ Blijft de eiser in gebreke met de levering van zijn } \\
\text { aandelen, dan levert de vennootschap namens hem de } \\
\text { aandelen, tegen gelijktijdige betaling. } \\
\text { 5/ Blijven een of meer gedaagden in gebreke met de } \\
\text { aanvaarding van de aandelen tegen gelijktijdige beta- } \\
\text { ling van de vastgestelde prijs, dan zijn de overige } \\
\text { gedaagden verplicht om binnen twee weken nadat dit } \\
\text { is komen vast te staan die aandelen tegen gelijktijdige } \\
\text { betaling te aanvaarden, zoveel mogelijk naar evenre- } \\
\text { digheid van het voor ieder overeenkomstig lid } 1 \\
\text { vastgestelde aantal aandelen. } \\
\text { 6/ Is een gedaagde aandeelhouder ten titel van beheer, } \\
\text { dan zijn naast hem de certificaathouders aansprakelijk } \\
\text { voor het krachtens dit artikel verschuldigde, ieder } \\
\text { zoveel mogelijk naar evenredigheid van zijn bezit aan } \\
\text { certificaten. Blijven een of meer certificaathouders in } \\
\text { gebreke, dan zijn de overige certificaathouders } \\
\text { verplicht dat deel te voldoen, ieder zoveel mogelijk } \\
\text { naar evenredigheid van zijn bezit aan certificaten. De } \\
\text { eerste en tweede zin vinden slechts toepassing op } \\
\text { certificaathouders die door de eiser tijdig in het geding } \\
\text { zijn opgeroepen. Zo nodig verstrekt de gedaagde aan } \\
\text { eiser de daartoe benodigde gegevens. } \\
\text { 7/ Op verzoek van een partij beslist de rechter die de } \\
\text { vordering in eerste instantie of in hoger beroep heeft } \\
\text { toegewezen over geschillen betreffende de uitvoering } \\
\text { van de regeling. Tegen deze beslissing staat geen } \\
\text { hogere voorziening open. }\end{array}$ \\
\hline $\begin{array}{l}\text { Artikel 343b } \\
{[\ldots]}\end{array}$ & $\begin{array}{l}\text { Artikel 343b } \\
\text { In het geval van vernietiging van het vonnis als be- } \\
\text { doeld in artikel } 343 \text { a lid } 1 \text { is artikel } 341 \text { a van overeen- } \\
\text { komstige toepassing. }\end{array}$ \\
\hline $\begin{array}{l}\text { Artikel 343c } \\
{[\ldots]}\end{array}$ & $\begin{array}{l}\text { Artikel 343c } \\
\text { 1/ Bestaat tussen een aandeelhouder en een of meer } \\
\text { van zijn mede-aandeelhouders of de vennootschap } \\
\text { overeenstemming dat de aandeelhouder zijn aandelen } \\
\text { zal overdragen tegen gelijktijdige betaling van een } \\
\text { nader vast te stellen prijs, dan kunnen zij zich bij ge- } \\
\text { zamenlijk verzoekschrift wenden tot de rechter, be- } \\
\text { doeld in artikel } 336 \text { lid 3, teneinde de prijs van de } \\
\text { aandelen te doen vaststellen. Het verzoek kan ook } \\
\text { worden gedaan door één der partijen, mits de andere } \\
\text { partij in zijn verweerschrift verklaart zich daartegen } \\
\text { niet te verzetten. } \\
\text { 2/ Partijen kunnen de rechter verzoeken bij de benoe- } \\
\text { ming van de deskundige of deskundigen bepaalde } \\
\text { aanwijzingen te geven over de in acht te nemen waar- } \\
\text { deringsmaatstaf, de datum waartegen gewaardeerd } \\
\text { moet worden en andere omstandigheden waarmee bij } \\
\text { de waardering rekening moet worden gehouden. }\end{array}$ \\
\hline
\end{tabular}




\begin{tabular}{|c|c|}
\hline & $\begin{array}{l}\text { Voorzover partijen niet eenstemmig zijn, beslist de } \\
\text { rechter naar billijkheid. } \\
\text { 3/ De procedure wordt gevoerd als verzoekschriftpro- } \\
\text { cedure, waarbij de artikelen } 343 \text { lid } 2 \text { en 343a zoveel } \\
\text { mogelijk van overeenkomstige toepassing zijn. } \\
\text { 4/ Indien partijen in het verzoekschrift dan wel ove- } \\
\text { reenkomstig lid 1, tweede zin, verklaren dat zij } \\
\text { omtrent de prijs van de aandelen een bericht van } \\
\text { deskundigen wensen dat tussen hen de werking van } \\
\text { een vaststellingsovereenkomst zal hebben, zijn de } \\
\text { wettelijke bepalingen betreffende het voorlopig } \\
\text { deskundigenbericht voorzoveel nodig van overeen- } \\
\text { komstige toepassing. Een partij kan op artikel } 904 \text { lid } \\
1 \text { van Boek } 7 \text { slechts een beroep doen gedurende vier } \\
\text { weken vanaf de verzending aan die partij door de } \\
\text { griffier op de voet van artikel } 198 \text { lid } 4 \text { in verband met } \\
\text { artikel } 205 \text { lid } 1 \text { van het Wetboek van Burgerlijke } \\
\text { Rechtsvordering. Bij toepassing van artikel } 904 \text { lid } 2 \\
\text { van Boek } 7 \text { is de in artikel } 336 \text { lid } 3 \text { bedoelde rechter } \\
\text { bevoegd. Diezelfde rechter beslist op verzoek van een } \\
\text { partij over geschillen betreffende de uitvoering van de } \\
\text { overdracht. } \\
\text { 5/ Tegen beslissingen van de rechter als bedoeld in dit } \\
\text { artikel staat geen hogere voorziening open. }\end{array}$ \\
\hline \multicolumn{2}{|c|}{$\begin{array}{c}\text { Afdeling } 2 \\
\text { Het recht van enquête }\end{array}$} \\
\hline Artikel 346 & Artikel 346 \\
\hline $\begin{array}{l}\text { Tot het indienen van een verzoek als bedoeld in artikel } \\
345 \text { zijn bevoegd }\end{array}$ & $\begin{array}{l}\text { Tot het indienen van een verzoek als bedoeld in artikel } \\
345 \text { zijn bevoegd }\end{array}$ \\
\hline $\begin{array}{l}\text { A/ Indien het betreft een vereniging, een coöperatie of } \\
\text { een onderlinge waarborgmaatschappij: de leden van } \\
\text { de rechtspersoon ten getale van ten minste } 300 \text {, of } \\
\text { zoveel leden als ten minste een tiende gedeelte van het } \\
\text { ledental uitmaken, of zoveel leden als tezamen be- } \\
\text { voegd zijn tot het uitbrengen van ten minste een tiende } \\
\text { gedeelte der stemmen in de algemene vergadering; }\end{array}$ & $\begin{array}{l}\text { A/ Indien het betreft een vereniging, een coöperatie of } \\
\text { een onderlinge waarborgmaatschappij: de leden van } \\
\text { de rechtspersoon ten getale van ten minste 300, of } \\
\text { zoveel leden als ten minste een tiende gedeelte van het } \\
\text { ledental uitmaken, of zoveel leden als tezamen be- } \\
\text { voegd zijn tot het uitbrengen van ten minste een tiende } \\
\text { gedeelte der stemmen in de algemene vergadering; }\end{array}$ \\
\hline $\begin{array}{l}\text { B/ I ndien het betreft een naamloze vennootschap of } \\
\text { een besloten vennootschap met beperkte aansprake- } \\
\text { lijkheid: een of meer houders van aandelen of van } \\
\text { certificaten van aandelen, die alleen of gezamenlijk } \\
\text { ten minste een tiende gedeelte van het geplaatste kapi- } \\
\text { taal vertegenwoordigen of rechthebbenden zijn op een } \\
\text { bedrag van aandelen of certificaten daarvan tot een } \\
\text { nominale waarde van } € 225000 \text { of zoveel minder als } \\
\text { de statuten bepalen; }\end{array}$ & $\begin{array}{l}\text { B/ I ndien het betreft een naamloze vennootschap of } \\
\text { een besloten vennootschap met beperkte aansprake- } \\
\text { lijkheid: een of meer houders van aandelen of van } \\
\text { certificaten van aandelen, die alleen of gezamenlijk } \\
\text { ten minste een tiende gedeelte van het geplaatste kapi- } \\
\text { taal vertegenwoordigen of rechthebbenden zijn op een } \\
\text { bedrag van aandelen of certificaten daarvan tot een } \\
\text { nominale waarde van } € 225000 \text { of zoveel minder als } \\
\text { de statuten bepalen; }\end{array}$ \\
\hline $\begin{array}{l}\mathrm{C} / \text { Degenen, aan wie daartoe bij de statuten of bij } \\
\text { overeenkomst met de rechtspersoon de bevoegdheid is } \\
\text { toegekend. }\end{array}$ & $\begin{array}{l}\text { C/ Degenen, aan wie daartoe bij de statuten of bij } \\
\text { overeenkomst met de rechtspersoon de bevoegdheid is } \\
\text { toegekend. }\end{array}$ \\
\hline
\end{tabular}




\begin{tabular}{|c|c|}
\hline & $\begin{array}{l}\text { In afwijking van artikel 24d wordt bij de toepassing } \\
\text { van de eerste zin ten aanzien van een besloten ven- } \\
\text { nootschap met beperkte aansprakelijkheid tevens } \\
\text { rekening gehouden met aandelen waarvan de statuten } \\
\text { bepalen dat daarvoor geen stem kan worden uit- } \\
\text { gebracht. }\end{array}$ \\
\hline \multicolumn{2}{|c|}{$\begin{array}{c}\text { Titel } 9 \\
\text { De jaarrekening en het jaarverslag } \\
\text { Afdeling } 3 \\
\text { fften omtrent de balans en de toelichting daarop }\end{array}$} \\
\hline Artikel 373 & Artikel 373 \\
\hline $\begin{array}{l}\text { 1/ Onder het eigen vermogen worden afzonderlijk } \\
\text { opgenomen: }\end{array}$ & $\begin{array}{l}\text { 1/ Onder het eigen vermogen worden afzonderlijk } \\
\text { opgenomen: }\end{array}$ \\
\hline A/ Het geplaatste kapitaal & A/ Het geplaatste kapitaal \\
\hline B/ Agio & B/ Agio \\
\hline $\mathrm{C} /$ Herwaarderingsreserves & $\mathrm{C} /$ Herwaarderingsreserves \\
\hline $\begin{array}{l}\text { D/ Andere wettelijke reserves, onderscheiden naar } \\
\text { hun aard }\end{array}$ & $\begin{array}{l}\text { D/ Andere wettelijke reserves, onderscheiden naar } \\
\text { hun aard }\end{array}$ \\
\hline E/ Statutaire reserves & E/ Statutaire reserves \\
\hline $\mathrm{F} /$ Overige reserves & $\mathrm{F} /$ Overige reserves \\
\hline $\begin{array}{l}\text { G/ Niet verdeelde winsten, met afzonderlijke ver- } \\
\text { melding van het resultaat na belastingen van het boek- } \\
\text { jaar, voor zover de bestemming daarvan niet in de } \\
\text { balans is verwerkt. }\end{array}$ & $\begin{array}{l}\text { G/ Niet verdeelde winsten, met afzonderlijke ver- } \\
\text { melding van het resultaat na belastingen van het boek- } \\
\text { jaar, voor zover de bestemming daarvan niet in de } \\
\text { balans is verwerkt. }\end{array}$ \\
\hline $\begin{array}{l}\text { 2/ Is het geplaatste kapitaal niet volgestort, dan wordt } \\
\text { in plaats daarvan het gestorte kapitaal vermeld of, } \\
\text { indien stortingen zijn uitgeschreven, het gestorte en } \\
\text { opgevraagde kapitaal. Het geplaatste kapitaal wordt in } \\
\text { deze gevallen vermeld. }\end{array}$ & $\begin{array}{l}2 \text { / Is het geplaatste kapitaal niet volgestort, dan wordt } \\
\text { in plaats daarvan het gestorte kapitaal vermeld of, } \\
\text { indien stortingen zijn uitgeschreven, het gestorte en } \\
\text { opgevraagde kapitaal. Het geplaatste kapitaal wordt in } \\
\text { deze gevallen vermeld. }\end{array}$ \\
\hline $\begin{array}{l}\text { 3/ Het kapitaal wordt niet verminderd met het bedrag } \\
\text { van eigen aandelen of certificaten daarvan die de } \\
\text { rechtspersoon of een dochtermaatschappij houdt. }\end{array}$ & $\begin{array}{l}\text { 3/ Het kapitaal wordt niet verminderd met het bedrag } \\
\text { van eigen aandelen of certificaten daarvan die de } \\
\text { rechtspersoon of een dochtermaatschappij houdt. }\end{array}$ \\
\hline $\begin{array}{l}\text { 4/ Wettelijke reserves zijn de reserves die moeten } \\
\text { worden aangehouden ingevolge de artikelen 67a lid 2, } \\
\text { 67a lid 3, 94a lid } 3 \text { onderdeel f., } 178 \text { lid 3, 178a lid 2, } \\
\text { 178a lid 3, 207c lid 3, } 365 \text { lid 2, 389, leden } 6 \text { en } 8 \text {, } \\
\text { 390, } 401 \text { lid 2, en } 423 \text { lid } 4 \text {. }\end{array}$ & $\begin{array}{l}\text { 4/ Wettelijke reserves zijn de reserves die moeten } \\
\text { worden aangehouden ingevolge de artikelen 67a lid 2, } \\
\text { 67a lid 3, 94a lid } 3 \text { onder f, 178a lid 2, 178a lid 3, } 365 \\
\text { lid 2, } 389 \text { lid 6, en } 390 \text {. }\end{array}$ \\
\hline $\begin{array}{l}\text { 5/ In een jaarrekening die in een vreemde geldeenheid } \\
\text { wordt opgesteld, wordt de in lid } 1 \text { onderdeel } a \text { bedoel- } \\
\text { de post opgenomen in die geldeenheid, naar de koers } \\
\text { op de balansdatum. Tevens worden dan deze koers en } \\
\text { het bedrag in Nederlands geld vermeld. Voor de toe- } \\
\text { passing van artikel } 178 \text { lid } 3 \text { wordt naar de zelfde } \\
\text { koers gerekend. }\end{array}$ & $\begin{array}{l}\text { 5/ In een jaarrekening die in een vreemde geldeenheid } \\
\text { wordt opgesteld, wordt de in lid } 1 \text { onderdeel } a \text { bedoel- } \\
\text { de post opgenomen in die geldeenheid, naar de koers } \\
\text { op de balansdatum. Tevens worden dan deze koers en } \\
\text { het bedrag in Nederlands geld vermeld. Voor de toe- } \\
\text { passing van artikel } 178 \text { lid } 3 \text { wordt naar de zelfde } \\
\text { koers gerekend. }\end{array}$ \\
\hline
\end{tabular}




\title{
$\S 3$ Vorschriften des Code de Commerce betreffend die S.à.r.l. ${ }^{1273}$
}

\author{
CODE DE COMMERCE \\ (Partie Législative) \\ Chapitre III : Des sociétés à responsabilité limitée
}

\author{
Article L223-1 \\ (Loi $n^{\circ}$ 2005-882 du 2 août 2005 art. 33 Journal Officiel du 3 août 2005)
}

La société à responsabilité limitée est instituée par une ou plusieurs personnes qui ne supportent les pertes qu'à concurrence de leurs apports.

Lorsque la société ne comporte qu'une seule personne, celle-ci est dénommée « associé unique ». L'associé unique exerce les pouvoirs dévolus à l'assemblée des associés par les dispositions du présent chapitre. Un décret approuve un modèle de statuts types qui peuvent être utilisés pour la société à responsabilité limitée dont l'associé unique assume personnellement la gérance.

La société est désignée par une dénomination sociale, à laquelle peut être incorporé le nom d'un ou plusieurs associés, et qui doit être précédée ou suivie immédiatement des mots «société à responsabilité limitée » ou des initiales «SARL » et de l'énonciation du capital social.

Les sociétés d'assurance, de capitalisation et d'épargne ne peuvent adopter la forme de société à responsabilité limitée.

\section{Article L223-2}

(Ordonnance $n^{\circ}$ 2000-916 du 19 septembre 2000 art. 4 et annexe II Journal Officiel du 22 septembre 2000 en vigueur le ler janvier 2002)

(Loi $n^{o}$ 2003-721 du 1 août 2003 art. 1 I Journal Officiel du 5 août 2003)

Le montant du capital de la société est fixé par les statuts. Il est divisé en parts sociales égales.

\section{Article L223-3}

(Ordonnance $n^{\circ}$ 2004-274 du 25 mars 2004 art. 11 Journal Officiel du 27 mars 2004)

Le nombre des associés d'une société à responsabilité limitée ne peut être supérieur à cent. Si la société vient à comprendre plus de cent associés, elle est dissoute au terme d'un délai d'un an à moins que, pendant ce délai, le nombre des associés soit devenu égal ou inférieur à cent ou que la société ait fait l'objet d'une transformation.

\section{Article L223-4}

En cas de réunion en une seule main de toutes les parts d'une société à responsabilité limitée, les dispositions de l'article 1844-5 du code civil relatives à la dissolution judiciaire ne sont pas applicables.

\section{Article L223-5}

Une société à responsabilité limitée ne peut avoir pour associé unique une autre société à responsabilité limitée composée d'une seule personne.

En cas de violation des dispositions de l'alinéa précédent, tout intéressé peut demander la dissolution des sociétés irrégulièrement constituées. Lorsque l'irrégularité résulte de la réunion en une seule main de toutes les parts

1273 Code de Commerce in der Fassung vom 24. Juli 1996. Die vorangestellten Buchstaben „L“ bzw. „D“ bezeichnen die Rechtsquelle, nämlich entweder eine Gesetz im eigentlichen Sinne (Loi) oder aber eine Rechtsverordnung (Décret). Der Code de Commerce besteht aus einem Gesetzesteil (partie législative) und einem Verordnungsteil (partie réglementaire). Demenstprechend bezihen sich die Artikelangaben bei vorangestelltem „L“ bzw. „D“ entweder auf den Gesetzes- oder Verordnungsteil. 
d'une société ayant plus d'un associé, la demande de dissolution ne peut être faite moins d'un an après la réunion des parts. Dans tous les cas, le tribunal peut accorder un délai maximal de six mois pour régulariser la situation et ne peut prononcer la dissolution si, au jour où il statue sur le fond, la régularisation a eu lieu.

\section{Article L223-6}

Tous les associés doivent intervenir à l'acte constitutif de la société, en personne ou par mandataire justifiant d'un pouvoir spécial.

\section{Article L223-7}

(Loi $n^{\circ}$ 2001-420 du 15 mai 2001 art. 124 I Journal Officiel du 16 mai 2001)

Les parts sociales doivent être souscrites en totalité par les associés. Elles doivent être intégralement libérées lorsqu'elles représentent des apports en nature. Les parts représentant des apports en numéraire doivent être libérées d'au moins un cinquième de leur montant. La libération du surplus intervient en une ou plusieurs fois sur décision du gérant, dans un délai qui ne peut excéder cinq ans à compter de l'immatriculation de la société au registre du commerce et des sociétés. Toutefois, le capital social doit être intégralement libéré avant toute souscription de nouvelles parts sociales à libérer en numéraire, à peine de nullité de l'opération.

Le cas échéant, les statuts déterminent les modalités selon lesquelles peuvent être souscrites des parts sociales en industrie.

La répartition des parts sociales est mentionnée dans les statuts.

Les fonds provenant de la libération des parts sociales sont déposés dans les conditions et délais déterminés par décret en Conseil d'Etat.

\section{Article L223-8}

(Ordonnance $n^{\circ}$ 2004-274 du 25 mars 2004 art. 15 Journal Officiel du 27 mars 2004)

Le retrait des fonds provenant de la libération des parts sociales ne peut être effectué par le mandataire de la société, avant l'immatriculation de celle-ci au registre du commerce et des sociétés.

Si la société n'est pas constituée dans le délai de six mois à compter du premier dépôt de fonds, ou si elle n'est pas immatriculée au registre du commerce et des sociétés dans le même délai, les apporteurs peuvent individuellement demander en justice l'autorisation de retirer le montant de leurs apports. Dans les mêmes cas, un mandataire, dès lors qu'il représente tous les apporteurs, peut demander directement au dépositaire le retrait des fonds.

Si les apporteurs décident ultérieurement de constituer la société, il doit être procédé à nouveau au dépôt des fonds.

\section{Article L223-9 \\ (Ordonnance $n^{\circ} 2000-916$ du 19 septembre 2000 art. 4 et annexe II Journal Officiel du 22 septembre 2000 en vigueur le ler janvier 2002)}

Les statuts doivent contenir l'évaluation de chaque apport en nature. Il y est procédé au vu d'un rapport annexé aux statuts et établi sous sa responsabilité par un commissaire aux apports désigné à l'unanimité des futurs associés ou à défaut par une décision de justice à la demande du futur associé le plus diligent.

Toutefois, les futurs associés peuvent décider à l'unanimité que le recours à un commissaire aux apports ne sera pas obligatoire, lorsque la valeur d'aucun apport en nature n'excède 7500 euros et si la valeur totale de l'ensemble des apports en nature non soumis à l'évaluation d'un commissaire aux apports n'excède pas la moitié du capital.

Lorsque la société est constituée par une seule personne, le commissaire aux apports est désigné par l'associé unique. Toutefois le recours à un commissaire aux apports n'est pas obligatoire si les conditions prévues à l'alinéa précédent sont réunies.

Lorsqu'il n'y a pas eu de commissaire aux apports ou lorsque la valeur retenue est différente de celle proposée par le commissaire aux apports, les associés sont solidairement responsables pendant cinq ans, à l'égard des tiers, de la valeur attribuée aux apports en nature lors de la constitution de la société.

\section{Article L223-10}


Les premiers gérants et les associés auxquels la nullité de la société est imputable sont solidairement responsables, envers les autres associés et les tiers, du dommage résultant de l'annulation. L'action se prescrit par le délai prévu au premier alinéa de l'article L. 235-13.

\section{Article L223-11}

(Ordonnance $n^{\circ}$ 2004-274 du 25 mars 2004 art. 12 Journal Officiel du 27 mars 2004)

(Loi $n^{\circ}$ 2004-1343 du 9 décembre 2004 art. 78 XV Journal Officiel du 10 décembre 2004)

Une société à responsabilité limitée, tenue en vertu de l'article L. 223-35 de désigner un commissaire aux comptes et dont les comptes des trois derniers exercices de douze mois ont été régulièrement approuvés par les associés, peut, sans faire appel public à l'épargne, émettre des obligations nominatives.

L'émission d'obligations est décidée par l'assemblée des associés conformément aux dispositions applicables aux assemblées générales d'actionnaires. Ces titres sont soumis aux dispositions applicables aux obligations émises par les sociétés par actions, à l'exclusion de celles prévues par les articles L. 228-39 à L. 228-43 et L. 228-51.

Lors de chaque émission d'obligations par une société remplissant les conditions de l'alinéa 1er, la société doit mettre à la disposition des souscripteurs une notice relative aux conditions de l'émission et un document d'information selon les modalités fixées par décret en Conseil d'Etat.

A peine de nullité de la garantie, il est interdit à une société à responsabilité limitée de garantir une émission de valeurs mobilières, sauf si l'émission est faite par une société de développement régional ou s'il s'agit d'une émission d'obligations bénéficiant de la garantie subsidiaire de l'Etat.

\section{Article L223-12}

Les parts sociales ne peuvent être représentées par des titres négociables.

\section{Article L223-13}

(Ordonnance $n^{\circ}$ 2004-274 du 25 mars 2004 art. 13 Journal Officiel du 27 mars 2004)

(Loi no 2004-1343 du 9 décembre 2004 art. 78 XV Journal Officiel du 10 décembre 2004)

Les parts sociales sont librement transmissibles par voie de succession ou en cas de liquidation de communauté de biens entre époux et librement cessibles entre conjoints et entre ascendants et descendants.

Toutefois, les statuts peuvent stipuler que le conjoint, un héritier, un ascendant ou un descendant ne peut devenir associé qu'après avoir été agréé dans les conditions prévues à l'article L. 223-14. A peine de nullité de la clause, les délais accordés à la société pour statuer sur l'agrément ne peuvent être plus longs que ceux prévus à l'article L. 223-14, et la majorité exigée ne peut être plus forte que celle prévue audit article. En cas de refus d'agrément, il est fait application des dispositions des troisième et quatrième alinéas de l'article L. 223-14. Si aucune des solutions prévues à ces alinéas n'intervient dans les délais impartis, l'agrément est réputé acquis.

Les statuts peuvent stipuler qu'en cas de décès de l'un des associés la société continuera avec son héritier ou seulement avec les associés survivants. Lorsque la société continue avec les seuls associés survivants, ou lorsque l'agrément a été refusé à l'héritier, celui-ci a droit à la valeur des droits sociaux de son auteur.

Il peut aussi être stipulé que la société continuera, soit avec le conjoint survivant, soit avec un ou plusieurs des héritiers, soit avec toute autre personne désignée par les statuts ou, si ceux-ci l'autorisent, par dispositions testamentaires.

Dans les cas prévus au présent article, la valeur des droits sociaux est déterminée au jour du décès conformément à l'article 1843-4 du code civil.

\section{Article L223-14}

(Loi $n^{\circ}$ 2003-721 du 1 août 2003 art. 1 III Journal Officiel du 5 août 2003)

(Ordonnance $n^{o}$ 2004-274 du 25 mars 2004 art. 14 Journal Officiel du 27 mars 2004)

Les parts sociales ne peuvent être cédées à des tiers étrangers à la société qu'avec le consentement de la majorité des associés représentant au moins la moitié des parts sociales, à moins que les statuts prévoient une majorité plus forte. 
Lorsque la société comporte plus d'un associé, le projet de cession est notifié à la société et à chacun des associés. Si la société n'a pas fait connaître sa décision dans le délai de trois mois à compter de la dernière des notifications prévues au présent alinéa, le consentement à la cession est réputé acquis.

Si la société a refusé de consentir à la cession, les associés sont tenus, dans le délai de trois mois à compter de ce refus, d'acquérir ou de faire acquérir les parts à un prix fixé dans les conditions prévues à l'article 1843-4 du code civil, sauf si le cédant renonce à la cession de ses parts. Les frais d'expertise sont à la charge de la société. A la demande du gérant, ce délai peut être prolongé par décision de justice, sans que cette prolongation puisse excéder six mois.

La société peut également, avec le consentement de l'associé cédant, décider, dans le même délai, de réduire son capital du montant de la valeur nominale des parts de cet associé et de racheter ces parts au prix déterminé dans les conditions prévues ci-dessus. Un délai de paiement qui ne saurait excéder deux ans peut, sur justification, être accordé à la société par décision de justice. Les sommes dues portent intérêt au taux légal en matière commerciale.

Si, à l'expiration du délai imparti, aucune des solutions prévues aux troisième et quatrième alinéas ci-dessus n'est intervenue, l'associé peut réaliser la cession initialement prévue.

Sauf en cas de succession, de liquidation de communauté de biens entre époux, ou de donation au profit d'un conjoint, ascendant ou descendant, l'associé cédant ne peut se prévaloir des dispositions des troisième et cinquième alinéas ci-dessus s'il ne détient ses parts depuis au moins deux ans.

Toute clause contraire aux dispositions du présent article est réputée non écrite.

\title{
Article L223-15
}

Si la société a donné son consentement à un projet de nantissement de parts sociales dans les conditions prévues aux premier et deuxième alinéas de l'article L. 223-14, ce consentement emportera agrément du cessionnaire en cas de réalisation forcée des parts sociales nanties selon les dispositions du premier alinéa de l'article 2078 du code civil, à moins que la société ne préfère, après la cession, racheter sans délai les parts, en vue de réduire son capital.

\section{Article L223-16}

Les parts sont librement cessibles entre les associés.

Si les statuts contiennent une clause limitant la cessibilité, les dispositions de l'article L. 223-14 sont applicables. Toutefois, les statuts peuvent, dans ce cas, réduire la majorité ou abréger les délais prévus audit article.

\section{Article L223-17}

La cession des parts sociales est soumise aux dispositions de l'article L. 221-14.

\author{
Article L223-18 \\ (Ordonnance $n^{\circ}$ 2004-274 du 25 mars 2004 art. 16 Journal Officiel du 27 mars 2004)
}

(Loi no 2005-882 du 2 août 2005 art. 26 II Journal Officiel du 3 août 2005)

La société à responsabilité limitée est gérée par une ou plusieurs personnes physiques.

Les gérants peuvent être choisis en dehors des associés. Ils sont nommés par les associés, dans les statuts ou par un acte postérieur, dans les conditions prévues à l'article L. 223-29. Dans les mêmes conditions, la mention du nom d'un gérant dans les statuts peut, en cas de cessation des fonctions de ce gérant pour quelque cause que ce soit, être supprimée par décision des associés.

En l'absence de dispositions statutaires, ils sont nommés pour la durée de la société.

Dans les rapports entre associés, les pouvoirs des gérants sont déterminés par les statuts, et dans le silence de ceux-ci, par l'article L. 221-4.

Dans les rapports avec les tiers, le gérant est investi des pouvoirs les plus étendus pour agir en toute circonstance au nom de la société, sous réserve des pouvoirs que la loi attribue expressément aux associés. La société est engagée même par les actes du gérant qui ne relèvent pas de l'objet social, à moins qu'elle ne prouve que le tiers savait que l'acte dépassait cet objet ou qu'il ne pouvait l'ignorer compte tenu des circonstances, étant exclu que la seule publication des statuts suffise à constituer cette preuve.

Les clauses statutaires limitant les pouvoirs des gérants qui résultent du présent article sont inopposables aux tiers. 
En cas de pluralité de gérants, ceux-ci détiennent séparément les pouvoirs prévus au présent article. L'opposition formée par un gérant aux actes d'un autre gérant est sans effet à l'égard des tiers, à moins qu'il ne soit établi qu'ils en ont eu connaissance.

Le déplacement du siège social dans le même département ou dans un département limitrophe peut être décidé par le ou les gérants, sous réserve de ratification de cette décision par les associés dans les conditions prévues au deuxième alinéa de l'article L. 223-30.

Dans les mêmes conditions, le gérant peut mettre les statuts en harmonie avec les dispositions impératives de la loi et des règlements.

Lorsque des parts sociales ont fait l'objet d'un contrat de bail en application de l'article L. 239-1, le gérant peut inscrire dans les statuts la mention du bail et du nom du locataire à côté du nom de l'associé concerné, sous réserve de la ratification de cette décision par les associés dans les conditions prévues à l'article L. 223-29. Il peut, dans les mêmes conditions, supprimer cette mention en cas de non-renouvellement ou de résiliation du bail.

\section{Article L223-19}

Le gérant ou, s'il en existe un, le commissaire aux comptes, présente à l'assemblée ou joint aux documents communiqués aux associés en cas de consultation écrite, un rapport sur les conventions intervenues directement ou par personnes interposées entre la société et l'un de ses gérants ou associés. L'assemblée statue sur ce rapport. Le gérant ou l'associé intéressé ne peut prendre part au vote et ses parts ne sont pas prises en compte pour le calcul du quorum et de la majorité.

Toutefois, s'il n'existe pas de commissaire aux comptes, les conventions conclues par un gérant non associé sont soumises à l'approbation préalable de l'assemblée.

Par dérogation aux dispositions du premier alinéa, lorsque la société ne comprend qu'un seul associé et que la convention est conclue avec celui-ci, il en est seulement fait mention au registre des décisions.

Les conventions non approuvées produisent néanmoins leurs effets, à charge pour le gérant, et, s'il y a lieu, pour l'associé contractant, de supporter individuellement ou solidairement, selon les cas, les conséquences du contrat préjudiciables à la société.

Les dispositions du présent article s'étendent aux conventions passées avec une société dont un associé indéfiniment responsable, gérant, administrateur, directeur général, membre du directoire ou membre du conseil de surveillance, est simultanément gérant ou associé de la société à responsabilité limitée.

\section{Article L223-20}

Les dispositions de l'article L. 223-19 ne sont pas applicables aux conventions portant sur des opérations courantes et conclues à des conditions normales.

\section{Article L223-21}

A peine de nullité du contrat, il est interdit aux gérants ou associés autres que les personnes morales de contracter, sous quelque forme que ce soit, des emprunts auprès de la société, de se faire consentir par elle un découvert, en compte courant ou autrement, ainsi que de faire cautionner ou avaliser par elle leurs engagements envers les tiers. Cette interdiction s'applique aux représentants légaux des personnes morales associées.

L'interdiction s'applique également aux conjoint, ascendants et descendants des personnes visées à l'alinéa précédent ainsi qu'à toute personne interposée.

Toutefois, si la société exploite un établissement financier, cette interdiction ne s'applique pas aux opérations courantes de ce commerce conclues à des conditions normales.

\section{Article L223-22}

Les gérants sont responsables, individuellement ou solidairement, selon le cas, envers la société ou envers les tiers, soit des infractions aux dispositions législatives ou réglementaires applicables aux sociétés à responsabilité limitée, soit des violations des statuts, soit des fautes commises dans leur gestion.

Si plusieurs gérants ont coopéré aux mêmes faits, le tribunal détermine la part contributive de chacun dans la réparation du dommage.

Outre l'action en réparation du préjudice subi personnellement, les associés peuvent, soit individuellement, soit en se groupant dans les conditions fixées par décret en Conseil d'Etat, intenter l'action sociale en responsabilité contre les gérants. Les demandeurs sont habilités à poursuivre la réparation de l'entier préjudice subi par la société à laquelle, le cas échéant, les dommages-intérêts sont alloués. 
Est réputée non écrite toute clause des statuts ayant pour effet de subordonner l'exercice de l'action sociale à l'avis préalable ou à l'autorisation de l'assemblée, ou qui comporterait par avance renonciation à l'exercice de cette action.

Aucune décision de l'assemblée ne peut avoir pour effet d'éteindre une action en responsabilité contre les gérants pour faute commise dans l'accomplissement de leur mandat.

\section{Article L223-23}

Les actions en responsabilité prévues aux articles L. 223-19 et L. 223-22 se prescrivent par trois ans à compter du fait dommageable ou, s'il a été dissimulé, de sa révélation. Toutefois, lorsque le fait est qualifié crime, l'action se prescrit par dix ans.

\section{Article L223-24}

En cas d'ouverture d'une procédure de redressement ou de liquidation judiciaire en application des dispositions du livre VI, titre II, les personnes visées par ces dispositions peuvent être rendues responsables du passif social et sont soumises aux interdictions et déchéances, dans les conditions prévues par lesdites dispositions.

\section{Article L223-25}

(Ordonnance $n^{\circ}$ 2004-274 du 25 mars 2004 art. 17 Journal Officiel du 27 mars 2004)

Le gérant peut être révoqué par décision des associés dans les conditions de l'article L. 223-29, à moins que les statuts prévoient une majorité plus forte. Si la révocation est décidée sans juste motif, elle peut donner lieu à des dommages et intérêts.

En outre, le gérant est révocable par les tribunaux pour cause légitime, à la demande de tout associé.

Par dérogation au premier alinéa, le gérant d'une société à responsabilité limitée exploitant une entreprise de presse au sens de l'article 2 de la loi no 86-897 du 1er août 1986 portant réforme du régime juridique de la presse n'est révocable que par une décision des associés représentant au moins les trois quarts du capital social.

\section{Article L223-26}

(Ordonnance $n^{\circ}$ 2004-1382 du 20 décembre 2004 art. 5 Journal Officiel du 22 décembre 2004)

Le rapport de gestion, l'inventaire et les comptes annuels établis par les gérants, sont soumis à l'approbation des associés réunis en assemblée, dans le délai de six mois à compter de la clôture de l'exercice.

A cette fin, les documents visés à l'alinéa précédent, le texte des résolutions proposées ainsi que le cas échéant, le rapport des commissaires aux comptes, les comptes consolidés et le rapport sur la gestion du groupe sont communiqués aux associés dans les conditions et délais déterminés par décret en Conseil d'Etat. Toute délibération, prise en violation des dispositions du présent alinéa et du décret pris pour son application, peut être annulée.

A compter de la communication prévue à l'alinéa précédent, tout associé a la faculté de poser par écrit des questions auxquelles le gérant est tenu de répondre au cours de l'assemblée.

L'associé peut, en outre, et à toute époque, obtenir communication, dans les conditions fixées par décret en Conseil d'Etat, des documents sociaux déterminés par ledit décret et concernant les trois derniers exercices.

Toute clause contraire aux dispositions du présent article et du décret pris pour son application, est réputée non écrite.

Les troisième à sixième alinéas de l'article L. 225-100 et l'article L. 225-100-1 s'appliquent au rapport de gestion. Le cas échéant, l'article L. 225-100-2 s'applique au rapport consolidé de gestion.

Nota : Ordonnance 2004-1382 2004-12-20 art. 12 : Les dispositions de la présente ordonnance s'appliquent à partir du premier exercice ouvert à compter du 1er janvier 2005.

\section{Article L223-27}

(Loi no 2003-7 du 3 janvier 2003 art. 50 II Journal Officiel du 4 janvier 2003)

(Ordonnance $n^{o}$ 2004-274 du 25 mars 2004 art. 18 Journal Officiel du 27 mars 2004)

Les décisions sont prises en assemblée. Toutefois, les statuts peuvent stipuler qu'à l'exception de celles prévues 
au premier alinéa de l'article L. 223-26 toutes les décisions ou certaines d'entre elles peuvent être prises par consultation écrite des associés ou pourront résulter du consentement de tous les associés exprimé dans un acte.

Les associés sont convoqués aux assemblées dans les formes et délais prévus par décret en Conseil d'Etat. La convocation est faite par le gérant ou, à défaut, par le commissaire aux comptes, s'il en existe un. L'assemblée ne peut se tenir avant l'expiration du délai de communication des documents mentionnés à l'article L. 223-26.

Un ou plusieurs associés détenant la moitié des parts sociales ou détenant, s'ils représentent au moins le quart des associés, le quart des parts sociales, peuvent demander la réunion d'une assemblée. Toute clause contraire est réputée non écrite.

Tout associé peut demander en justice la désignation d'un mandataire chargé de convoquer l'assemblée et de fixer son ordre du jour.

En cas de décès du gérant unique, le commissaire aux comptes ou tout associé convoque l'assemblée des associés à seule fin de procéder au remplacement du gérant. Cette convocation a lieu dans les formes et délais prévus par décret en Conseil d'Etat.

Toute assemblée irrégulièrement convoquée peut être annulée. Toutefois, l'action en nullité n'est pas recevable lorsque tous les associés étaient présents ou représentés.

\section{Article L223-28}

Chaque associé a droit de participer aux décisions et dispose d'un nombre de voix égal à celui des parts sociales qu'il possède.

Un associé peut se faire représenter par son conjoint à moins que la société ne comprenne que les deux époux. Sauf si les associés sont au nombre de deux, un associé peut se faire représenter par un autre associé.

Il ne peut se faire représenter par une autre personne que si les statuts le permettent.

Un associé ne peut constituer un mandataire pour voter du chef d'une partie de ses parts et voter en personne du chef de l'autre partie.

Toute clause contraire aux dispositions des premier, deuxième et quatrième alinéas ci-dessus est réputée non écrite.

\section{Article L223-29}

Dans les assemblées ou lors des consultations écrites, les décisions sont adoptées par un ou plusieurs associés représentant plus de la moitié des parts sociales.

Si cette majorité n'est pas obtenue et sauf stipulation contraire des statuts, les associés sont, selon les cas, convoqués ou consultés une seconde fois, et les décisions sont prises à la majorité des votes émis, quel que soit le nombre des votants.

\section{Article L223-30}

(Loi $n^{\circ}$ 2005-882 du 2 août 2005 art. 35 Journal Officiel du 3 août 2005)

Les associés ne peuvent, si ce n'est à l'unanimité, changer la nationalité de la société.

Toutes autres modifications des statuts sont décidées par les associés représentant au moins les trois quarts des parts sociales. Toute clause exigeant une majorité plus élevée est réputée non écrite.

Toutefois, pour les modifications statutaires des sociétés à responsabilité limitée constituées après la publication de la loi $\mathrm{n}^{\circ}$ 2005-882 du 2 août 2005 en faveur des petites et moyennes entreprises, l'assemblée ne délibère valablement que si les associés présents ou représentés possèdent au moins, sur première convocation, le quart des parts et, sur deuxième convocation, le cinquième de celles-ci. A défaut de ce quorum, la deuxième assemblée peut être prorogée à une date postérieure de deux mois au plus à celle à laquelle elle avait été convoquée. Dans l'un ou l'autre de ces deux cas, les modifications sont décidées à la majorité des deux tiers des parts détenues par les associés présents ou représentés. Les statuts peuvent prévoir des quorums ou une majorité plus élevés, sans pouvoir, pour cette dernière, exiger l'unanimité des associés.

Les sociétés constituées antérieurement à la publication de la loi no 2005-882 du 2 août 2005 précitée peuvent, sur décision prise à l'unanimité des associés, être régies par les dispositions du troisième alinéa.

La majorité ne peut en aucun cas obliger un associé à augmenter son engagement social.

Par dérogation aux dispositions des deuxième et troisième alinéas, la décision d'augmenter le capital par incorporation de bénéfices ou de réserves est prise par les associés représentant au moins la moitié des parts sociales. 
Les trois premiers alinéas de l'article L. 223-26 et les articles L. 223-27 à L. 223-30 ne sont pas applicables aux sociétés ne comprenant qu'un seul associé.

Dans ce cas, le rapport de gestion, l'inventaire et les comptes annuels sont établis par le gérant. L'associé unique approuve les comptes, le cas échéant après rapport des commissaires aux comptes, dans le délai de six mois à compter de la clôture de l'exercice. Lorsque l'associé unique est seul gérant de la société, le dépôt au registre du commerce et des sociétés, dans le même délai, du rapport de gestion, de l'inventaire et des comptes annuels, dûment signés, vaut approbation des comptes.

L'associé unique ne peut déléguer ses pouvoirs. Ses décisions, prises au lieu et place de l'assemblée, sont répertoriées dans un registre.

Les décisions prises en violation des dispositions du présent article peuvent être annulées à la demande de tout intéressé.

\section{Article L223-32}

En cas d'augmentation de capital par souscription de parts sociales en numéraire, les dispositions du dernier alinéa de l'article L. 223-7 sont applicables.

Le retrait des fonds provenant de souscriptions peut être effectué par un mandataire de la société après l'établissement du certificat du dépositaire.

Si l'augmentation du capital n'est pas réalisée dans le délai de six mois à compter du premier dépôt de fonds, il peut être fait application des dispositions du deuxième alinéa de l'article L. 223-8.

\section{Article L223-33 \\ (Loi no 2003-7 du 3 janvier 2003 art. 50 II Journal Officiel du 4 janvier 2003)}

Si l'augmentation du capital est réalisée, soit en totalité, soit en partie par des apports en nature, les dispositions du premier alinéa de l'article L. 223-9 sont applicables. Toutefois, le commissaire aux apports est nommé par décision de justice à la demande d'un gérant.

Lorsqu'il n'y a pas eu de commissaire aux apports ou lorsque la valeur retenue est différente de celle proposée par le commissaire aux apports, les gérants de la société et les personnes ayant souscrit à l'augmentation du capital sont solidairement responsables pendant cinq ans, à l'égard des tiers, de la valeur attribuée auxdits apports.

\section{Article L223-34}

La réduction du capital est autorisée par l'assemblée des associés statuant dans les conditions exigées pour la modification des statuts. En aucun cas, elle ne peut porter atteinte à l'égalité des associés.

S'il existe des commissaires aux comptes, le projet de réduction du capital leur est communiqué dans le délai fixé par décret en Conseil d'Etat. Ils font connaître à l'assemblée leur appréciation sur les causes et conditions de la réduction.

Lorsque l'assemblée approuve un projet de réduction du capital non motivée par des pertes, les créanciers dont la créance est antérieure à la date de dépôt au greffe du procès-verbal de délibération peuvent former opposition à la réduction dans le délai fixé par décret en Conseil d'Etat. Une décision de justice rejette l'opposition ou ordonne, soit le remboursement des créances, soit la constitution de garanties, si la société en offre et si elles sont jugées suffisantes. Les opérations de réduction du capital ne peuvent commencer pendant le délai d'opposition.

L'achat de ses propres parts par une société est interdit. Toutefois, l'assemblée qui a décidé une réduction du capital non motivée par des pertes peut autoriser le gérant à acheter un nombre déterminé de parts sociales pour les annuler.

\section{Article L223-35}

Les associés peuvent nommer un ou plusieurs commissaires aux comptes dans les conditions prévues à l'article L. 223-29.

Sont tenues de désigner un commissaire aux comptes au moins les sociétés à responsabilité limitée qui dépassent à la clôture d'un exercice social des chiffres fixés par décret en Conseil d'Etat pour deux des critères suivants : le total de leur bilan, le montant hors taxes de leur chiffre d'affaires ou le nombre moyen de leurs salariés au cours d'un exercice.

Même si ces seuils ne sont pas atteints, la nomination d'un commissaire aux comptes peut être demandée en justice par un ou plusieurs associés représentant au moins le dixième du capital. 


\title{
Article L223-36
}

Tout associé non gérant peut, deux fois par exercice, poser par écrit des questions au gérant sur tout fait de nature à compromettre la continuité de l'exploitation. La réponse du gérant est communiquée au commissaire aux comptes.

\section{Article L223-37}

Un ou plusieurs associés représentant au moins le dixième du capital social peuvent, soit individuellement, soit en se groupant sous quelque forme que ce soit, demander en justice la désignation d'un ou plusieurs experts chargés de présenter un rapport sur une ou plusieurs opérations de gestion.

Le ministère public et le comité d'entreprise sont habilités à agir aux mêmes fins.

S'il est fait droit à la demande, la décision de justice détermine l'étendue de la mission et des pouvoirs des experts. Elle peut mettre les honoraires à la charge de la société.

Le rapport est adressé au demandeur, au ministère public, au comité d'entreprise, au commissaire aux comptes ainsi qu'au gérant. Ce rapport doit, en outre, être annexé à celui établi par le commissaire aux comptes en vue de la prochaine assemblée générale et recevoir la même publicité.

\author{
Article L223-39 \\ (Loi $n^{o}$ 2003-706 du 1 août 2003 art. 116 Journal Officiel du 2 août 2003)
}

(Ordonnance $n^{o}$ 2005-1126 du 8 septembre 2005 art. 20 III Journal Officiel du 9 septembre 2005)

Les commissaires aux comptes sont avisés, au plus tard en même temps que les associés, des assemblées ou consultations. Ils ont accès aux assemblées.

Les documents visés au premier alinéa de l'article L. 223-26 sont mis à la disposition des commissaires aux comptes dans les conditions déterminées par décret en Conseil d'Etat.

\section{Article L223-40}

La répétition des dividendes ne correspondant pas à des bénéfices réellement acquis peut être exigée des associés qui les ont reçus.

L'action en répétition se prescrit par le délai de trois ans à compter de la mise en distribution des dividendes.

\section{Article L223-41}

La société à responsabilité limitée n'est pas dissoute lorsqu'un jugement de liquidation judiciaire, la faillite personnelle, l'interdiction de gérer prévue par l'article L. 625-8 ou une mesure d'incapacité est prononcé à l'égard de l'un des associés.

Elle n'est pas non plus dissoute par le décès d'un associé, sauf stipulation contraire des statuts.

\section{Article L223-42 \\ (Loi no 2003-721 du 1 août 2003 art. 1 IV Journal Officiel du 5 août 2003)}

$\mathrm{Si}$, du fait de pertes constatées dans les documents comptables, les capitaux propres de la société deviennent inférieurs à la moitié du capital social, les associés décident, dans les quatre mois qui suivent l'approbation des comptes ayant fait apparaître cette perte s'il y a lieu à dissolution anticipée de la société.

Si la dissolution n'est pas prononcée à la majorité exigée pour la modification des statuts, la société est tenue, au plus tard à la clôture du deuxième exercice suivant celui au cours duquel la constatation des pertes est intervenue, de réduire son capital d'un montant au moins égal à celui des pertes qui n'ont pu être imputées sur les réserves, si, dans ce délai, les capitaux propres n'ont pas été reconstitués à concurrence d'une valeur au moins égale à la moitié du capital social.

Dans les deux cas, la résolution adoptée par les associés est publiée selon les modalités fixées par décret en Conseil d'Etat.

A défaut par le gérant ou le commissaire aux comptes de provoquer une décision ou si les associés n'ont pu délibérer valablement, tout intéressé peut demander en justice la dissolution de la société. Il en est de même si les dispositions du deuxième alinéa ci-dessus n'ont pas été appliquées. Dans tous les cas, le tribunal peut accorder à 
la société un délai maximal de six mois pour régulariser sa situation. Il ne peut prononcer la dissolution, si, au jour où il statue sur le fond, cette régularisation a eu lieu.

Les dispositions du présent article ne sont pas applicables aux sociétés en procédure de sauvegarde ou de redressement judiciaire ou qui bénéficient d'un plan de sauvegarde ou de redressement judiciaire.

\title{
Article L223-43
}

(Ordonnance $n^{\circ}$ 2000-916 du 19 septembre 2000 art. 4 et annexe II Journal Officiel du 22 septembre 2000 en vigueur le ler janvier 2002)

La transformation d'une société à responsabilité limitée en société en nom collectif, en commandite simple ou en commandite par actions, exige l'accord unanime des associés.

La transformation en société anonyme est décidée à la majorité requise pour la modification des statuts. Toutefois, elle peut être décidée par des associés représentant la majorité des parts sociales si les capitaux propres figurant au dernier bilan excèdent 750000 euros.

La décision est précédée du rapport d'un commissaire aux comptes inscrit, sur la situation de la société.

Toute transformation, effectuée en violation des règles du présent article, est nulle.

\section{CODE DE COMMERCE \\ (Partie Législative)}

\section{Chapitre Ier : Des infractions concernant les sociétés à responsabilité limitée}

\author{
Article L241-1 \\ (Ordonnance $n^{\circ}$ 2000-916 du 19 septembre 2000 art. 3 Journal Officiel du 22 septembre 2000 en vigueur le ler \\ janvier 2002)
}

(Loi no 2003-721 du 1 août 2003 art. $91^{\circ}$ Journal Officiel du 5 août 2003)

Est puni d'un emprisonnement de six mois et d'une amende de 9000 euros le fait, pour les associés d'une société à responsabilité limitée, d'omettre, dans l'acte de société, la déclaration concernant la répartition des parts sociales entre tous les associés, la libération des parts ou le dépôt des fonds.

Les dispositions du présent article sont applicables en cas d'augmentation du capital.

\author{
Article L241-2 \\ (Ordonnance $n^{\circ} 2000-916$ du 19 septembre 2000 art. 3 Journal Officiel du 22 septembre 2000 en vigueur le ler \\ janvier 2002)
}

(Ordonnance $n^{\circ}$ 2004-274 du 25 mars 2004 art. 19 Journal Officiel du 27 mars 2004)

Est puni d'un emprisonnement de six mois et d'une amende de 9000 euros le fait, pour des gérants, d'émettre, directement ou par personne interposée, pour le compte de la société des valeurs mobilières quelconques à l'exception des obligations émises dans les conditions déterminées par l'article L. 223-11.

\section{Article L241-3}

(Ordonnance $n^{\circ}$ 2000-916 du 19 septembre 2000 art. 3 Journal Officiel du 22 septembre 2000 en vigueur le ler janvier 2002)

Est puni d'un emprisonnement de cinq ans et d'une amende de 375000 euros :

$1^{\circ}$ Le fait, pour toute personne, de faire attribuer frauduleusement à un apport en nature une évaluation supérieure à sa valeur réelle ;

$2^{\circ}$ Le fait, pour les gérants, d'opérer entre les associés la répartition de dividendes fictifs, en l'absence d'inventaire ou au moyen d'inventaires frauduleux ;

$3^{\circ}$ Le fait, pour les gérants, même en l'absence de toute distribution de dividendes, de présenter aux associés des comptes annuels ne donnant pas, pour chaque exercice, une image fidèle du résultat des opérations de l'exercice, de la situation financière et du patrimoine à l'expiration de cette période en vue de dissimuler la véritable situation de la société ; 
$4^{\circ}$ Le fait, pour les gérants, de faire, de mauvaise foi, des biens ou du crédit de la société, un usage qu'ils savent contraire à l'intérêt de celle-ci, à des fins personnelles ou pour favoriser une autre société ou entreprise dans laquelle ils sont intéressés directement ou indirectement;

$5^{\circ}$ Le fait, pour les gérants, de faire, de mauvaise foi, des pouvoirs qu'ils possèdent ou des voix dont ils disposent, en cette qualité, un usage qu'ils savent contraire aux intérêts de la société, à des fins personnelles ou pour favoriser une autre société ou une autre entreprise dans laquelle ils sont intéressés directement ou indirectement.

\section{Article L241-4}

(Loi $n^{\circ}$ 2001-420 du 15 mai 2001 art. $1222^{\circ}$ Journal Officiel du 16 mai 2001)

(Ordonnance no 2000-916 du 19 septembre 2000 art. 3 Journal Officiel du 22 septembre 2000 en vigueur le 1er janvier 2002)

Est puni d'une amende de 9000 euros :

$1^{\circ}$ Le fait, pour les gérants, de ne pas, pour chaque exercice, dresser l'inventaire, établir les comptes annuels et un rapport de gestion;

$2^{\circ}$ et $3^{\circ}$ (supprimés).

\section{Article L241-5}

(Ordonnance $n^{\circ}$ 2000-916 du 19 septembre 2000 art. 3 Journal Officiel du 22 septembre 2000 en vigueur le 1er janvier 2002)

Est puni d'un emprisonnement de six mois et d'une amende de 9000 euros le fait, pour les gérants, de ne pas procéder à la réunion de l'assemblée des associés dans les six mois de la clôture de l'exercice ou, en cas de prolongation, dans le délai fixé par décision de justice, ou de ne pas soumettre à l'approbation de ladite assemblée ou de l'associé unique les documents prévus au $1^{\circ}$ de l'article L. 241-4.

\section{Article L241-6}

(Ordonnance n $n^{o}$ 2000-916 du 19 septembre 2000 art. 3 Journal Officiel du 22 septembre 2000 en vigueur le ler janvier 2002)

Est puni d'un emprisonnement de six mois et d'une amende de 4500 euros le fait, pour les gérants, lorsque les capitaux propres de la société, du fait de pertes constatées dans les documents comptables, deviennent inférieurs à la moitié du capital social :

$1^{\circ}$ De ne pas dans les quatre mois qui suivent l'approbation des comptes ayant fait apparaître ces pertes, consulter les associés afin de décider s'il y a lieu à dissolution anticipée de la société ;

$2^{\circ}$ De ne pas déposer au greffe du tribunal de commerce, inscrire au registre du commerce et des sociétés et publier dans un journal d'annonces légales, la décision adoptée par les associés.

\section{Article L241-9}

(Loi no 2003-721 du 1 août 2003 art. $95^{\circ}$ Journal Officiel du 5 août 2003)

Les dispositions des articles L. 241-2 à L. 241-6 sont applicables à toute personne qui, directement ou par personne interposée, aura, en fait, exercé la gestion d'une société à responsabilité limitée sous le couvert ou au lieu et place de son gérant légal.

\section{CODE DE COMMERCE \\ (Partie Réglementaire)}

\section{Chapitre III : Des sociétés à responsabilité limitée}

\section{Article R223-1}

Si les statuts sont établis par acte sous seing privé, il est dressé autant d'originaux qu'il est nécessaire pour le dépôt d'un exemplaire au siège social et l'exécution des diverses formalités requises.

En outre, un exemplaire des statuts établi sur papier libre est remis à chaque associé. 


\section{Article D223-2}

Un modèle de statuts types de la société à responsabilité limitée dont l'associé unique assume personnellement la gérance figure en annexe 2-1 au présent livre.

Le recours à ce modèle revêt un caractère facultatif. Ce modèle peut être complété en tant que de besoin.

Le centre de formalités des entreprises propose ce modèle de statuts types au fondateur de la société.

\section{Article R223-3}

Dans les huit jours de leur réception, les fonds provenant de la libération des parts sociales sont déposés pour le compte de la société en formation et par les personnes qui les ont reçus à la Caisse des dépôts et consignations, chez un notaire ou dans un établissement de crédit.

Mention de la libération des parts et du dépôt des fonds est portée dans les statuts.

\section{Article R223-4}

Le retrait des fonds est accompli par le mandataire de la société sur présentation du certificat du greffier attestant l'immatriculation de la société au registre du commerce et des sociétés.

\section{Article R223-5}

Pour l'application du deuxième alinéa de l'article L. 223-8 :

$1^{\circ}$ L'autorisation de retirer les fonds individuellement est donnée par le président du tribunal de commerce du lieu du siège social, statuant sur requête ;

$2^{\circ}$ Le mandataire justifie, en vue du retrait collectif des fonds, de l'autorisation écrite de tous les apporteurs.

\section{Article R223-6}

Le commissaire aux apports est choisi parmi les commissaires aux comptes inscrits sur la liste prévue à l'article L. 822-1 ou parmi les experts inscrits sur l'une des listes établies par les cours et tribunaux.

Il est désigné, le cas échéant, par ordonnance du président du tribunal de commerce statuant sur requête, notamment dans le cas prévu à l'article L. 223-33.

\section{Article R223-7}

Le document d'information mentionné à l'article L. 223-11 est établi préalablement à toute souscription. Il est remis ou envoyé à toute personne dont la souscription est sollicitée.

Il comprend toutes les mentions utiles à l'information des souscripteurs et au moins les renseignements suivants :

$1^{\circ}$ La dénomination sociale, précédée ou suivie immédiatement, conformément au deuxième alinéa de l'article L. 223-1, des mots « société à responsabilité limitée » ou des initiales «SARL » et suivie, le cas échéant, de son sigle, l'adresse du siège social, le montant du capital social ainsi que les mentions prévues aux $1^{\circ}$ et $2^{\circ}$ de l'article R. 123-237;

$2^{\circ}$ L'objet social, indiqué sommairement ;

$3^{\circ}$ La date d'expiration normale de la société ;

$4^{\circ}$ La description de son activité et de ses perspectives d'évolution ;

$5^{\circ}$ Le nom du ou des gérants ;

$6^{\circ}$ Le nom des commissaires aux comptes et de leurs suppléants ainsi que la date de leur nomination ;

$7^{\circ}$ Le montant des capitaux propres, le montant total et la ventilation par échéance des engagements autres que ceux résultant de l'émission et, le cas échéant, les sûretés constituées pour garantir le remboursement des titres précédemment émis ;

$8^{\circ}$ Les faits significatifs, notamment les affaires contentieuses, pouvant avoir une incidence sur l'activité ou la situation financière de la société.

\section{Article R223-8}

Sont annexés au document d'information mentionné à l'article R. 223-7 :

$1^{\circ}$ Une copie du dernier bilan approuvé par l'assemblée générale des associés, certifiée par le gérant ;

$2^{\circ} \mathrm{Si}$ ce bilan a été arrêté à une date antérieure de plus de dix mois à celle du début de l'émission, un état de la situation active et passive de la société datant de dix mois au plus et établi sous la responsabilité du gérant ; 
$3^{\circ}$ Des renseignements sur la marche des affaires sociales depuis le début de l'exercice en cours ainsi que sur le précédent exercice si l'assemblée appelée à statuer sur celui-ci n'a pas encore été réunie.

\section{Article R223-9}

La notice mentionnée à l'article L. 223-11 est établie préalablement à toute souscription. Elle est remise ou envoyée à toute personne dont la souscription est sollicitée.

Elle comprend les renseignements suivants :

$1^{\circ}$ Le but de l'émission;

$2^{\circ}$ Le montant de l'émission ;

$3^{\circ}$ Le nombre d'obligations émises et leur valeur nominale, le produit brut et l'estimation du produit net de l'émission ;

$4^{\circ}$ Les conditions de l'émission, le taux, le mode de calcul et les modalités de paiement des intérêts, l'époque et les conditions de remboursement ;

$5^{\circ}$ Le cas échéant, les sûretés constituées pour garantir le remboursement des titres ainsi que les renseignements permettant d'identifier les garants et d'apprécier leur solvabilité ;

$6^{\circ}$ Les modalités de cession ainsi que, le cas échéant, de rachat des titres ;

$7^{\circ}$ L'existence et l'organisation de la masse des titulaires de titres ;

$8^{\circ}$ Le montant non amorti, au moment de l'émission, des obligations antérieurement émises ;

$9^{\circ}$ Le montant, au moment de l'émission, des emprunts obligataires garantis par la société et, le cas échéant, la fraction garantie de ces emprunts.

\section{Article R223-10}

L'article R. 228-60, sauf en tant qu'il détermine les conditions d'application du deuxième alinéa de l'article L. 228-51, et les articles R. 228-61 à R. 228-64 sont applicables aux représentants de la masse des obligataires. Les articles R. 228-65 à R. 228-69 et R. 228-72 à R. 228-80 sont applicables aux assemblées d'obligataires. Les articles R. 228-81 à R. 228-83 sont applicables aux sûretés constituées pour garantir le remboursement des obligations.

Les articles R. 228-84 à R. 228-86 sont applicables en cas de procédure de sauvegarde ou de redressement ou liquidation judiciaire.

\section{Article R223-11}

La notification du projet de cession ou de nantissement de parts sociales, prévue au deuxième alinéa de l'article L. 223-14 et à l'article L. 223-15, est faite par acte extrajudiciaire ou par lettre recommandée avec demande d'avis de réception.

La désignation de l'expert prévue à l'article 1843-4 du code civil est faite par le président du tribunal de commerce ; celui-ci statue par ordonnance sur requête dans le cas prévu au troisième alinéa de l'article L. 223-14 et par ordonnance de référé dans le cas prévu au quatrième alinéa du même article. Ces ordonnances ne sont pas susceptibles de recours.

\section{Article R223-12}

Dans le délai de huit jours à compter de la notification qui lui a été faite en application de l'article R. 223-11, le gérant convoque l'assemblée des associés pour qu'elle délibère sur le projet de cession des parts sociales ou, si les statuts le permettent, consulte les associés par écrit sur ce projet.

La décision de la société est notifiée au cédant par lettre recommandée avec demande d'avis de réception.

\section{Article R223-13}

La cession de parts sociales est soumise aux formalités de publicité prévue par l'article R. 221-9.

\section{Article R223-14}

Tout associé a le droit, à toute époque, d'obtenir, au siège social, la délivrance d'une copie certifiée conforme des statuts en vigueur au jour de la demande.

La société annexe à ce document la liste des gérants et, le cas échéant, des commissaires aux comptes en exercice et ne peut, pour cette délivrance, exiger le paiement d'une somme supérieure à 0,30 Euros. 


\section{Article R223-15}

Tout associé a le droit, à toute époque, de prendre par lui-même connaissance des documents suivants au siège social : bilans, comptes de résultats, annexes, inventaires, rapports soumis aux assemblées et procès-verbaux de ces assemblées concernant les trois derniers exercices. Sauf en ce qui concerne l'inventaire, le droit de prendre connaissance emporte celui de prendre copie.

A cette fin, il peut se faire assister d'un expert inscrit sur une des listes établies par les cours et tribunaux.

\section{Article R223-16}

Le gérant avise le commissaire aux comptes, s'il en existe un, des conventions mentionnées à l'article L. 22319, dans le délai d'un mois à compter de la conclusion de ces conventions.

Lorsque l'exécution de conventions conclues au cours d'exercices antérieurs a été poursuivie au cours du dernier exercice, le commissaire aux comptes est informé de cette situation dans le délai d'un mois à compter de la clôture de l'exercice.

\section{Article R223-17}

Le rapport prévu au premier alinéa de l'article L. 223-19 contient :

$1^{\text {o }}$ L'énumération des conventions soumises à l'approbation de l'assemblée des associés ;

$2^{\circ}$ Le nom des gérants ou associés intéressés ;

$3^{\circ}$ La nature et l'objet de ces conventions ;

$4^{\circ}$ Les modalités essentielles de ces conventions, notamment l'indication des prix ou tarifs pratiqués, des ristournes et commissions consenties, des délais de paiement accordés, des intérêts stipulés, des sûretés conférées et, le cas échéant, de toutes autres indications permettant aux associés d'apprécier l'intérêt qui s'attachait à la conclusion des conventions analysées ;

$5^{\circ}$ L'importance des fournitures livrées ou des prestations de service fournies ainsi que le montant des sommes versées ou reçues au cours de l'exercice en exécution des conventions mentionnées au deuxième alinéa de l'article R. 223-16.

\section{Article R223-18}

Les comptes annuels, le rapport de gestion, le texte des résolutions proposées, ainsi que, le cas échéant, les comptes consolidés, le rapport sur la gestion du groupe et les rapports du commissaire aux comptes sur les comptes annuels et les comptes consolidés sont adressés aux associés quinze jours au moins avant la date de l'assemblée prévue par l'article L. 223-26.

Pendant le délai de quinze jours qui précède l'assemblée, l'inventaire est tenu, au siège social, à la disposition des associés, qui ne peuvent en prendre copie.

\section{Article R223-19}

En cas de convocation d'une assemblée autre que celle prévue au premier alinéa de l'article L. 223-26, le texte des résolutions proposées, le rapport des gérants ainsi que, le cas échéant, celui des commissaires aux comptes sont adressés aux associés quinze jours au moins avant la date de l'assemblée.

En outre, pendant le délai de quinze jours qui précède l'assemblée les mêmes documents sont tenus, au siège social, à la disposition des associés, qui peuvent en prendre connaissance ou copie.

\section{Article R223-20}

Les associés sont convoqués, quinze jours au moins avant la réunion de l'assemblée, par lettre recommandée. Celle-ci indique l'ordre du jour. Toutefois, lorsque l'assemblée est convoquée, en raison du décès du gérant unique, par le commissaire aux comptes ou un associé, conformément aux dispositions du cinquième alinéa de l'article L. 223-27, le délai est réduit à huit jours.

Sous réserve des questions diverses, qui ne doivent présenter qu'une minime importance, les questions inscrites à l'ordre du jour sont libellées de telle sorte que leur contenu et leur portée apparaissent clairement, sans qu'il y ait lieu de se reporter à d'autres documents.

Le mandataire chargé de convoquer l'assemblée dans le cas prévu par le quatrième alinéa de l'article L. 223-27 est désigné par ordonnance du président du tribunal de commerce statuant en référé. 


\section{Article R223-21}

Le mandat de représentation d'un associé est donné pour une seule assemblée. Il peut cependant être donné pour deux assemblées tenues le même jour ou dans un délai de sept jours.

Le mandat donné pour une assemblée vaut pour les assemblées successives convoquées avec le même ordre du jour.

\section{Article R223-22}

En cas de consultation écrite, le texte des résolutions proposées ainsi que les documents nécessaires à l'information des associés sont adressés à chacun de ceux-ci par lettre recommandée.

Les associés disposent d'un délai minimal de quinze jours, à compter de la date de réception des projets de résolution, pour émettre leur vote par écrit.

\section{Article R223-23}

L'assemblée des associés est présidée par le gérant ou par l'un des gérants. Si aucun des gérants n'est associé ou en cas de décès de l'associé-gérant unique, elle est présidée par l'associé présent et acceptant qui possède ou représente le plus grand nombre de parts sociales.

Si deux associés qui possèdent ou représentent le même nombre de parts sont acceptants, la présidence de l'assemblée est assurée par le plus âgé.

\section{Article R223-24}

Toute délibération de l'assemblée des associés est constatée par un procès-verbal qui indique la date et le lieu de réunion, les nom, prénoms et qualité du président, les nom et prénoms des associés présents ou représentés avec l'indication du nombre de parts sociales détenues par chacun, les documents et rapports soumis à l'assemblée, un résumé des débats, le texte des résolutions mises au voix et le résultat des votes.

En cas de consultation écrite, il en est fait mention dans le procès-verbal, auquel est annexée la réponse de chaque associé.

Les procès-verbaux sont établis et signés par les gérants et, le cas échéant, par le président de séance. Les dispositions des articles R. 221-3 et R. 221-4 leur sont applicables.

\section{Article R223-25}

Dans les sociétés qui comportent une seule personne et dont l'associé unique n'est pas le seul gérant, et en ce qui concerne les décisions d'approbation des comptes prises par l'associé unique en lieu et place de l'assemblée, le rapport de gestion, les comptes et, le cas échéant, le rapport des commissaires aux comptes sont adressés par le gérant à l'associé unique un mois au moins avant l'expiration du délai prévu au deuxième alinéa de l'article L. 223-31. Pendant ce délai, l'inventaire est tenu au siège social à la disposition de l'associé unique.

\section{Article R223-26}

Chaque décision prise par l'associé unique en lieu et place de l'assemblée est consignée par lui sur le registre prévu au troisième alinéa de l'article L. 223-31. Le registre est tenu au siège social. Il est coté et paraphé, soit par un juge du tribunal de commerce, soit par un juge du tribunal d'instance, soit par le maire de la commune du siège social ou un adjoint du maire, dans la forme ordinaire et sans frais. La certification des copies ou extraits du registre est faite conformément aux dispositions de l'article R. 221-4.

Les conventions mentionnées à l'article L. 223-19 sont portées au registre dans les mêmes conditions.

Pour l'application du deuxième alinéa de l'article L. 223-31, lorsque l'associé unique est seul gérant, il porte au registre, dans les mêmes conditions, le récépissé du dépôt au registre du commerce et des sociétés du rapport de gestion, de l'inventaire et des comptes annuels.

\section{Article R223-27}

Les dispositions de l'article R. 221-5 sont applicables à la désignation ou à la nomination d'un commissaire aux comptes dans les sociétés à responsabilité limitée.

\section{Article R223-28}


Les comptes annuels, le rapport de gestion et, le cas échéant, les comptes consolidés et le rapport sur la gestion du groupe sont tenus, au siège social, à la disposition des commissaires aux comptes un mois au moins avant, selon le cas :

$1^{\circ}$ La convocation de l'assemblée prévue à l'article L. 223-26 ;

$2^{\circ}$ La date limite prévue pour leur envoi à l'associé unique par l'article R. 223-25 ;

$3^{\circ}$ Le dépôt au registre du commerce et des sociétés, par l'associé unique seul gérant de la société, des documents mentionnés au deuxième alinéa de l'article L. 223-31.

\section{Article R223-29}

Le gérant répond par écrit dans le délai d'un mois aux questions qui lui sont posées en application de l'article L. 223-36. Dans le même délai, il transmet copie de la question et de sa réponse au commissaire aux comptes.

\section{Article R223-30}

L'expert chargé de présenter un rapport sur une ou plusieurs opérations de gestion dans les conditions prévues au premier alinéa de l'article L. 223-37 est désigné par le président du tribunal de commerce statuant en la forme des référés, après que le greffier a convoqué le gérant à l'audience par lettre recommandée avec demande d'avis de réception.

La demande d'expertise du procureur de la République est présentée par requête. Le greffier informe le procureur de la République de la date de l'audience.

Le rapport d'expertise est déposé au greffe. Le greffier en assure la communication.

\section{Article R223-31}

S'ils représentent au moins le dixième du capital social, des associés peuvent, dans un intérêt commun, charger à leurs frais un ou plusieurs d'entre eux de les représenter pour soutenir, tant en demande qu'en défense, l'action sociale contre les gérants.

Le retrait en cours d'instance d'un ou plusieurs des associés mentionnés à l'alinéa précédent, soit qu'ils aient perdu la qualité d'associé, soit qu'ils se soient volontairement désistés, est sans effet sur la poursuite de l'instance.

\section{Article R223-32}

Lorsque l'action sociale est intentée par un ou plusieurs associés, agissant soit individuellement, soit dans les conditions prévues à l'article R. 223-31, le tribunal ne peut statuer que si la société a été régulièrement mise en cause par l'intermédiaire de ses représentants légaux.

Le tribunal peut désigner un mandataire ad hoc pour représenter la société dans l'instance, lorsqu'il existe un conflit d'intérêt entre celle-ci et ses représentants légaux.

\section{Article R223-33}

Le projet de réduction du capital est communiqué aux commissaires aux comptes, s'il en existe, quarante-cinq jours au moins avant la date de réunion de l'assemblée des associés appelée à statuer sur ce projet.

\section{Article R223-34}

Lorsque la réduction du capital a été décidée dans les conditions prévues au quatrième alinéa de l'article L. 223-34, l'achat des parts sociales est réalisé dans le délai de trois mois à compter de l'expiration du délai d'opposition prévu à l'article R. 223-35. Cet achat emporte l'annulation des parts.

\section{Article R223-35}

Le délai d'opposition des créanciers à la réduction du capital est d'un mois à compter de la date du dépôt, au greffe du tribunal de commerce, du procès-verbal de la délibération qui a décidé la réduction.

L'opposition est signifiée à la société par acte extrajudiciaire et portée devant le tribunal de commerce.

\section{Article R223-36}

Dans le cas où, du fait de pertes constatées dans les documents comptables, les capitaux propres de la société deviennent inférieurs à la moitié du capital social, la décision des associés prévue à l'article L. 223-42 est publiée 
dans un journal habilité à recevoir les annonces légales dans le département du siège social, déposée au greffe du tribunal de commerce du lieu de ce siège et inscrite au registre du commerce et des sociétés. 


\section{Verzeichnis der Abkürzungen}

\section{einschließlich einzelner juristischer Werke}

Allgemein werden die gebräuchlichen Abkürzungen verwendet; dazu Kirchner/Butz, Abkürzungsverzeichnis der Rechtssprache, 5. A. 2003.

Aufl.

a. A.

a. a. O.

ABl

AB1. EG

Abs.

abw

abwM

a. E.

AG

AktG

AktGE

AnfG

Anm

Asser-Maeijer 2-III

Assink 2006

Assink/Olden
Auflage

anderer Ansicht

am angegebenen Ort

Amtsblatt

Amtsblatt der Europäischen Gemeinschaften

Absatz

abweichend

abweichende Meinung

am Ende

Aktiengesellschaft; Die Aktiengesellschaft (Zeitschrift)

Aktiengesetz

Entwurf eines Aktiengesetzes

Anfechtungsgesetz

Anmerkung

J. M. M. Maeijer, Mr. C. Asser's Handleiding tot de beoefening van het Nederlands Burgerlijk recht. 2. De naamloze en de besloten vennootschap. Deel III. Vertegenwoordiging en rechtsperoon, Deventer: W. E. J. Tjeenk-Willink, 2000

B.F. Assink, Over vrijheid van ondernemingsbeleid en het enquêterecht - Divergentie en convergentie van bestuurlijke gedragsnormen en rechterlijke toetsingsnormen nader bezien, Ondernemingsrecht 2006, S. 307-316

B.F. Assink/P.D: Olden, Over bestuurdersaansprakelijkheid - De 
Baumbach/Hopt/Bearbeiter

Baumbach/Hueck/Bearbeiter

BB

$\mathrm{Bd}$

BDI

BDI / Hengeler Müller

Bearb

Begr.

Behrens, Die GmbH

Behrens, Gesellschaftsrecht

Beil

Beschl.

BGB

BGB1

$\mathrm{BGH}$

BGHZ

BMJ

BNotO reikwijdte van de maatstaf ,ernstig verwijt“, vrijtekening en vrijwaring nader bezien, Ondernemingsrecht 2006, S. 9-16

Baumbach/Hopt/Merkt, Handelsgesetzbuch mit GmbH \& Co., Handelsklauseln, Bank- und Börsenrecht, Transportrecht (ohne Seerecht), 31. A. 2003, siehe auch Hopt

Kommentar zum GmbH-Gesetz, begründet von Adolf Baumbach, fortgeführt von Alfred Hueck, bearbeitet von Lorenz Fastrich, Götz Hueck, Joachim Schulze-Osterloh, Wolfgang Zöllner, 18. Auflage 2006

Betriebs-Berater

Band

Bundesverband der Deutschen Industrie e.V.

BDI / Hengeler Müller(Hrsg.) Die GmbH im Wettbewerb der Rechtsformen - Modernisierungsbedarf im Recht der GmbH (Redaktion: Scheel/Wulfetange/Heidenhain/Hasselmann/Böhm), Studie 2006

Bearbeitung

Begründung

Behrens, Peter, Die GmbH im europäischen und internationalen Recht, Berlin, 2. Auflage 1997

Behrens, Peter, Gesellschaftsrecht, in Manfred A. Dauses (Hrsg.), Handbuch des EU-Wirtschaftsrechts, Stand 5/2004

Beilage

Beschluß

Bürgerliches Gesetzbuch

Bundesgesetzblatt

Bundesgerichtshof

Entscheidungen des BGH in Zivilsachen

Bundesminister(ium) der Justiz

Bundesnotarordnung 
BODACC

Borrius 2004

Boschma

Boschma/Lennarts 1994

Boschma/ Schutte-Veenstra 2007
Bulletin officiel des annonces civiles et commerciales

Borrius Y., Kronek bestuurdersaansprakelijkheid, in G. van Solinge/M. Holtzer (Hrsg.), Geschriften vanwege de vereniging corporate litigation 2003-2004,Deventer: Kluwer 2004, S. 7-34

H.E. Boschma De eenpersoons-BV, Deventer: Kluwer 1997

H.E. Boschma/M.L. Lennarts, Het voortzetten van verliesgevende activiteiten in rechtsvergelijkend perspectief, Tijdschrift voor Insolventierecht 1994, S. 285-290

H.E. Boschma/ J.N. Schutte-Veenstra, De bv in de steigers Opknapbeurt of grondige verbouwing?, Rechtsgeleerd Magazijn THEMIS 2007, 197

Boschma/Lennarts/Schutte-Veenstra H.E. Boschma/M.L. Lennarts/J.N. Schutte-Veenstra, Alternatieve rapport 2005 systemene voor kapitaalbeschermin, 18 augustus 2005. Zie in dit verband eveneens: H.E. Boschma/M.L. Lennarts/J.N. SchutteVeenstra, Alternative system for capital protection, Deventer: Kluwer 2005

Boyle \& Birds’ Company Law

Bras

BRDA

BR-Drucks

Brenninkmeijer 1973

BT

BT-Drucks.

Buchst

Bull.

Bull. civ.

Bull. CNCC
Boyle \& Birds' Company Law, herausgegeben von John Birds, A. J. Boyle, Lain MacNeil, Gerard McCormack, Christian Twigg-Flesner, Charlotte Villiers, 5. Auflage 2004

M. Bras, Verslag vergadering Vereniging Corporate Litigation over "Verantwoordelijkheid van aandelhouders ten opzichte van de vennootschap”, Ondernemingsrecht 2006, S. 480-483

Bulletin rapide de droit des affaires

Drucksache des Bundesrats

A.M. Brenninkmeijer, Stemovereenkomsten vann aandeelhouders, Vennootschaps- en rechtspersonenrecht, Serie Monografieen vanwege het Van der Heijden-Instituut, Deventer: Kluwer 1973

Bundestag

Drucksache des Deutschen Bundestags

Buchstabe

Bulletin

Bulletin des arrêts des chambres civiles de la Cour de cassation

Bulletin du Conseil National des Commissaires aux Comptes, édité 
BV

bzw.

CA

Cass. Com.

C.com

Chaussade-Klein

CNCC

Cozian/Viandier/Deboissy

D. aff.

DB

DNotZ

Dortmond 2000 II

Dr. sociétés

DStR

DWiR, DZWir

EG

EGV

EHUG

Einl

$\operatorname{ErgBd}$ par la Commission Nationale des Commissaires aux Comptes

besloten vennootschap

beziehungsweise

Cour d'Appel

Cour de Cassation, chambre commerciale

Code de Commerce

Chaussade-Klein, Bernadette, Gesellschaftsrecht in Frankreich,

2. Auflage 1998

Compagnie nationale des commissaires aux comptes

Cozian,Maurice/Viandier, Alain/ Deboissy, Florence, Droit des sociétés, 21eme édition, Litec Paris, 25 août 2008

Bulletin rapide de droit des affaires

Der Betrieb

Deutsche Notar-Zeitschrift

P.J. Dortmond Stemovereenkomsten rondom de eeuwwisseling (oratie Leiden), Deventer: Kluwer 2000

Droit des sociétés

Deutsches Steuerrecht

Deutsche Zeitschrift für Wirtschafts- und Insolvenzrecht

Europäische Gemeinschaften

Vertrag zur Gründung der Europäischen Gemeinschaft

Gesetz über das elektronische Handels- und Unternehmensregister

Einleitung

Ergänzungsband 
EU

$\mathrm{EuGH}$

EuZW

EWG

EWiR

EWIV-AusführungsG

EWR

f., ff.

Fn.

FS

G

Gaz. Pal.

GB1

GbR

Ges

GesR

GesRZ

GG

gg.

$\mathrm{GmbH}$

GmbHG

GmbHGE

GmbHR

GO
Europäische Union

Europäischer Gerichtshof

Europäische Zeitschrift für Wirtschaftsrecht

Europäische Wirtschaftsgemeinschaft

Entscheidungen zum Wirtschaftsrecht

Gesetz zur Ausführung der EWG-Verordnung über die Europäische wirtschaftliche Interessenvereinigung vom 14. 4. 1988 (BGB1 I, 514)

Europäischer Wirtschaftsraum

folgend(e)

Fußnote

Festschrift

Gesetz (in Zusammensetzungen)

Gazette du palais

Gesetzblatt

Gesellschaft bürgerlichen Rechts

Gesellschaft

Gesellschaftsrecht

Der Gesellschafter (Zeitschrift)

Grundgesetz

gegen

Gesellschaft mit beschränkter Haftung

Gesetz betreffend die Gesellschaften mit beschränkter Haftung

Entwurf eines Gesetzes betreffend die Gesellschaften mit beschränkter Haftung

GmbH-Rundschau

Geschäftsordnung 
Goette

Gotzen

Gotzen, Die GmbH

Grds

grds

de Groot 2003

GroßKommAktG/Bearbeiter

GroßkommGmbHG/Bearbeiter

Grunewald

Guyon, Les sociétés

Haarhuis

Habersack

Hachenburg/Bearbeiter

Halbs

J.J.A. Hamers/L.P.W. van Vliet

Hansmann \& Kraakman 2004 I

Hansmann \& Kraakman 2004 II
Goette, Die GmbH nach der BGH-Rechtsprechung, 2. A. 2002

Gotzen, Paul, Niederländisches Handels- und Wirtschaftsrecht,

\section{Auflage 2000}

Die Gesellschaft mit beschränkter Haftung in den Niederlanden, 1975

Grundsatz

grundsätzlich

H. de Groot,Bestuurdersaansprakelijkheid, Deventer: Kluwer 2003

Hopt/Wiedemann (Hrsg.), Aktiengesetz. Großkommentar, 4. A. 1992 ff.

Großkommentar zum GmbH-Gesetz, herausgegeben von Peter Ulmer, Mathias Habersack und Martin Winter, Band 1 Ausführlichen

$\begin{array}{lllll}\text { Einleitung, } & \S \S & 1 & \text { bis } & 28\end{array}$

2005; $\quad$ Band $\quad 2 \quad$ § $\quad 29 \quad$ bis $\quad 52$

2006

Barbara Grunewald, Gesellschaftsrecht, 6. Auflage Köln, Tübingen 2005

Yves Guyon, Les sociétés. Aménagements statutaires et conventions entre associés, $5^{\circ}$ éd., LGDJ, 2002

Haarhuis, Koen J., Gesellschaftsrecht in den Niederlanden, 1995

Habersack, Matthias, Europäisches Gesellschaftsrecht,

3. Auflage 2006

Hachenburg, Gesetz betreffend die Gesellschaften mit beschränkter Haftung (GmbHG), Großkommentar, 8. A. 1992 ff.

Halbsatz

J.J.A. Hamers/L.P.W. van Vliet, Inleiding personenvennootschaapen 3. A. 2007

H. Hansmann \& R. Kraakman „What is Corporate Law?“ in R. Kraakman u.a.,The Anatomy of Corporate Law, Oxford: Oxford University Press 2004, S. 1-19

H. Hansmann \& R. Kraakman „The basic governance structure“ in 
Haratsch/Koenig/Pechstein

Heckschen/Heidinger

Hendriks-Jansen 1982

Herdegen

HGB

HGrG

Hirte/Bücker/Bearbeiter

HK-HGB

h. L.

h. M.

HR

HRV

HRN

Hrsg.

Huizink 1989

IHK

Van den Ingh 1991

Van den Ingh 2002 I
R. Kraakman u.a.,The Anatomy of Corporate Law, Oxford: Oxford University Press 2004, S. 33-70

Europarecht, 5. Auflage 2006

Heribert Heckschen/Andreas Heidinger, Die GmbH in der Gestaltungspraxis, Köln - Berlin - München 2005

Th.C.M. Hendriks-Jansen, Stemovereenkomsten, De Naamloze Vennotschap 1982, S. 6-13

Europarecht, 2. Auflage 1999

Handelsgesetzbuch

Gesetz über die Grundsätze des Haushaltsrechts des Bundes und der Länder (Haushaltsgrundsätzegesetz)

Hirte, Heribert/Bücker, Thomas (Hrsg.), Grenzüberschreitende Gesellschaften - Praxishandbuch für ausländische Kapitalgesellschaften mit Sitz im Inland -,

Köln - Berlin - München 2005

Glanegger/Güroff/Kusterer/Niedner/Peuker/Ruß/Selder/Stuhlfelner, Heidelberger Kommentar zum Handelsgesetzbuch, 5. A. 1999

herrschende Lehre

herrschende Meinung

Handelsregister

Handelsregisterverordnung

Hoge Raad der Nederlanden

Herausgeber

J.B. Huizink Bestuurders van rechtspersonen, Deventer: Kluwer 1989

Industrie- und Handelskammer

F.J.P. van den Ingh, Certificering en certificaat van aandeel bij de besloten vennootschap, Deventer : Kluwer 1991

F.J.P. van den Ingh, De bevelstructuur in de vennootschap, in L. Timmermann u.a., Concernverhoudingen, Deventer : Kluwer 2002, S. 
Van den Ingh 2002 II

InsO

InsOE

IPR

iZw.

JA

JCP

jew.

JO AN

J. soc.:

$\mathrm{JuS}$

JZ

Keidel/Krafka/Willer

KG

$\mathrm{KO}$

Komm

Kortmann/Faber 1996

krit.

Kroeze 2005
F.J.P. van den Ingh, Bestuurdersaansprakelijkheid bij wanpresterende vennootschappen, in F.J.P. van den Ingh u.a. (Hrsg.), Met en zekere stijl. Gedenkboek ter ere van mr. Justus Voûte, Den Haag:Boom Juridische uitgevers 2002, S. 99-111

Insolvenzordnung vom 5. 10. 1994 (BGB1 I, 2866)

Entwurf einer Insolvenzordnung

Internationales Privatrecht

im Zweifel

Juristische Arbeitsblätter

Semaine juridique (JurisClasseur périodique : générale, entreprises, commerce et industrie, sociale,...)

jeweils

Journal Officiel - compte rendu des débats de l'Assemblée Nationale Juri Social

Juristische Schulung

Juristenzeitung

Keidel, Theodor / Krafka, Alexander / Willer, Heinz

Registerrecht, 6. Auflage 2003

Kommanditgesellschaft; Kammergericht

Konkursordnung

Kommentar

S.C.J.J. Kortmann/N.E.D. Faber, Bestuurdersaansprakelijkheid en faillisement. Einige beschouwingen omtrent het rechtskarakter van de art. 2:138 en 2:248 BW, WPNR 1996, S. 899-906

Kritisch

M.J. Kroeze, Bange bestuurders (oratie Rotterdam), Deventer: Klu- 
wer 2005

Langenfeld

Lefebvre

lfd

LG

Libchaber, La société, contrat spécial Remy Libchaber, La société, contrat spécial, in Prospectives de droit

LIE

Lit.

lit.

LM

LS

Lutter/Hommelhoff

Lutter Kapital in Europa

Lutter Europ. UR économique. Dialogues avec Michel Jeantin, Dalloz, 1999

Langenfeld, G., GmbH-Vertragspraxis, Dr. Otto Schmidt Verlag, 5. Aufl. Köln 2006

Charvériat/Couret/Janin/Mercadal, Memento pratique Editions Francis Lefebvre, Sociétés commerciales 2008

laufend

Landgericht

loi pour l'initiative économique

litera

Nachschlagewerk des Bundesgerichtshofs, herausgegeben von Lindenmaier, Möhring ua

Leitsatz

Bayer/Hommelhoff/Kleindiek/Lutter, GmbH-Gesetz, Kommentar, 16. A. 2004

Lutter, Marcus (Hrsg.) Arbeitskreis Kapital in Europa, 2006

Lutter, Marcus, Europäisches Unternehmensrecht, 4. Auflage 1996
Literatur

Lutter/Scheffler/Schneider/Bearbeiter Lutter, Marcus/Scheffler, Eberhard/ Schneider, Uwe H.

Handbuch der Konzernfinanzierung, 1998

van Maanen

Mehring, Gesellschaftsrecht
M.H.J. van Maanen, Positiebepaling van de Hoge Raad bij het ontwikkelen van maatstaven voor bestuurdersaansprakelijkheid, Vennootschap \& Onderneming 2004, S. 118-122

Mehring, Eckhard W. in: Hohloch, EU-Handbuch Gesellschaftsrecht, (Hohloch Hrsg.), 1997 
Mehring, GmbH-Rechte

MDR

Mellert/Verführt

Mendel 1997

Merle

Michalski/Bearbeiter

MitbestG

MoMiG

MontanMitbestG

MünchAnwHdbGmbHR/Bearbeiter

MünchenerHdbGesR

MünchKommBGB

MünchKommHGB

m. w. N.

Nachw.

NBG

n. F.
Die $\mathrm{GmbH}$ in den Niederlanden, in: Centrale für $\mathrm{GmbH}$ Dr. Otto Schmidt (Hrsg.), Die GmbH-Rechte in den EG-Staaten, 1993, S. 205

Monatsschrift für Deutsches Recht

Mellert, Christofer Rudolf/Verführt, Ludger C. Wettbewerb der Gesellschaftsformen - Ausländische Kapitalgesellschaften als Alternative zu AG und GmbH -, Berlin 2005

M.M. Mendel Stemrecht, minderheidsaandeelhouders en ongelijkheidscompensatie, in L. Betten u.a. (Hrsg.) Ongelijkheidscompensatie als roode draad in het recht. Liber Amicorum voor prof. Mr. M.G. Rood, Deventer : Kluwer1007, S. 207-215

Merle, Philippe, Droit commercial - Sociétés commerciales, 9. Auflage 2003

Michalski (Hrsg.), Kommentar zum Gesetz betreffend die Gesellschaften mit beschränkter Haftung, 2002

Mitbestimmungsgesetz

Gesetz zur Modernisierung des GmbH-Rechts und zur Bekämpfung von Missbräuchen"

Montanmitbestimmungsgesetz

Münchener Anwalts-Handbuch GmbH-Recht, Volker Römermann (Hrsg.), München 2002

Münchener Handbuch des Gesellschaftsrechts, Band 3: GmbH, 2. Auflage 2003

Münchener Kommentar zum Bürgerlichen Gesetzbuch, 4. A. 2000 ff

Münchener Kommentar zum Handelsgesetzbuch, Band 1: Erstes Buch. Handelsstand (§§ 1-104), 2. Auflage 2005

mit weiteren Nachweisen

Nachweise

niederländisches Bürgerliches Gesetzbuch, Burgerlijk Wetboek neue Fassung

Nederlandse Jurisprudentie (uitspraken in burgerlijke en strafza- 
ken)

NJB

NJW

NJW-RR

$\mathrm{Nr}$.

NV

NZG

NZI

$\mathrm{O} \& \mathrm{~F}$

obs.

OHG

Olaerts

OLG

p.

Pélissier/Supiot/Jeammaud

Pitlo/Raaijmakers

RL

Raiser

Ranke

rechtl
Nederlands Juristenblad

Neue Juristische Wochenschrift

NJW-Rechtsprechungs-Report Zivilrecht

Nummer

Naamloze vennootschappen

Neue Zeitschrift für Gesellschaftsrecht

Neue Zeitschrift für das Recht der Insolvenz und Sanierung

Onderneming \& Financiering

Observations (=Beobachtungen/Anmerkungen)

offene Handelsgesellschaft

Olaerts, Mieke, Vennootschappelijke beleidsbepaling in geval van financiele moeilijkheden;de positie van bestuurders en aandeelhouders, Diss. 2007, Ius Commune Europaeum, Volume 69, 2007

Oberlandesgericht bzw Die Rechtsprechung der OLG auf dem Gebiete des Zivilrechts (bis 1928)

page $(=$ Seite $)$

Pélissier/Supiot/Jeammaud, Droit du travail, Paris 2002

M.J.G.C. Raaijmakers, Pitlo. Het Nederlands burgerlijk recht Deel 2. Ondernemingsrecht, Deventer: Kluwer 2006

Richtlinie

Raiser Thomas, Recht der Kapitalgesellschaften, 3. A. 2001

Ranke, Fritz, Arbeitsrecht in Frankreich 1. Auflage 1995

rechtlich 


\section{RefE \\ RegBegr \\ RegE}

Rensen 2005

Rép.

Rép. Min.

Rev. sociétés

RIW

RJC

RJDA

$\mathrm{Rn}$.

Roth/Altmeppen/Bearbeiter

Rowedder/Schmidt- Leithoff

Rspr.

S.

S.

S.à.r.l.

van Schilfgaarde/Winter

Schwanna

Schwarz, C.A.
Referentenentwurf

Regierungsbegründung

Regierungsentwurf, ohne Zusatz: Entwurf eines Gesetzes über Gesellschaften mit beschränkter Haftung (BT-Drucks 7/253)

G.J.C. Rensen Extra-verpflichtingen van leden en aandeelhouders, Serie vanwege het Van der Heijden Instituut, Deventer: Kluweer 2005

Réponse

réponse du Ministère de la Justice

Revue des Sociétés

Recht der internationalen Wirtschaft (Außenwirtschaftsdienst des Betriebs-Beraters)

Revue de Jurisprudence Commerciale

Revue de Jurisprudence de Droit des Affaires

Randnote, Randnummer

Roth/Altmeppen, GmbHG, Kommentar, 4. A. 2003

Rowedder/Schmidt-Leithoff, Gesetz betreffend die Gesellschaften mit beschränkter Haftung (GmbHG), 4. A. 2002

Rechtsprechung

Satz; Seite

siehe

société à responsabilité limitée

Schilfgaarde van, P., Van de BV en de NV, bearbeitet von J. Winter, Deventer: Kluwer 2006

Schwanna, André, Die Gründung von Gesellschaften in Deutschland, Frankreich und Großbritannien, 2002

Schwarz, C.A., Blokkering van aandelen, 1987 
Schwarz, C.A. 2004

Schwarz, C.A., Aandelen

Schwarz

K. Schmidt GesR

Scholz/Bearbeiter

Slagter 2004

Slagter 2005

Sog.

Sonnenberger

Sp.

Staudinger/Bearbeiter

str.

st. Rspr

Süß/Wachter/Bearbeiter

teilw.

Üb., Übers.

umstr.
Schwarz, C.A., Certificering als beschermingsconstructie; bruikbaarheid in een veranderend tijdsgewricht, Tijdschrift voor Ondernemingsbestuur 2004, S. 220-225

Schwarz, C.A., Aandelen zonder stemrecht

Schwarz, Günter Christian, Europäisches Gesellschaftsrecht 2000

Karsten Schmidt, Gesellschaftsrecht, 4. A. 2002

Scholz, Kommentar zum GmbH-Gesetz, 9. und 10. A. 2002/2007/2008

W.J. Slagter „De lidmaatschapsverhouding als Grondslag van het rechtspersonenrecht" Ondernemingsrecht 2004, S. 424-428

W.J. Slagter Compendium Ondernemingsrecht, Deventer: Kluwer 2005

sogenannt

Sonnenberger, Hans Jürgen, Französisches Handels- und Wirtschaftsrecht, 2. Auflage 1991

Spalte(n)

Staudinger, Kommentar zum Bürgerlichen Gesetzbuch mit Einführungsgesetz und Nebengesetzen, 13. Bearb. 1993 ff und Neubearbeitungen $2000 \mathrm{ff}$ (zitiert nach Erscheinungsjahr)

streitig

ständige Rechtsprechung

Süß, Rembert / Wachter Thomas, Handbuch des internationalen GmbH-Rechts, Angelbachtal 2006

teilweise

Übersicht

umstritten 
van der Heijden/van der Grinten E.J.J. van der Heijden/W.C.L. van der Grinten, Handboek voor de 1992 Naamloze en de Besloten Vennootschap, Zwolle: W.E.J. Tjeenl Willink 1992

vgl. vergleiche

Vorb.

Vorbemerkung

WFR

Weekblad voor fiscaalrecht

WM

Wertpapier-Mitteilungen

WODC

Wetenschappelijk Onderzoek- en Documentatiecentrum

WODC Eindrapport

J.M. Fernández/M. van Olffen, Eindrapport Beschrijving rechtsvorm en gebruik LLP's WODC, Onderzoekcentrum Onderneming en Recht, Faculteit der Rechtgeleerdheid, Nijmegen, 2007

WP Wirtschaftsprüfer

WPNR

Weekblad voor Privaatrecht, Notariaat en Registratie

ZGR

Zeitschrift für Unternehmens- und Gesellschaftsrecht

ZHR

Zeitschrift für das gesamte Handelsrecht und Wirtschaftsrecht

Ziff.

Ziffer

ZIP

Zeitschrift für Wirtschaftsrecht

zit.

zitiert

ZPO

Zivilprozeßordnung

ZRP

Zeitschrift für Rechtspolitik 


\section{Schrifttumsverzeichnis}

Albicher, H. M. A./

Mierlo van, J. J. M.

Altmeppen, Holger

ders.

Ammelung, Ulrich/

Kaeser, Christian

Arbeitsgruppe Europäisches

Gesellschaftsrecht

Bachmann, Gregor

Bahans, J.-M.

Banerjea, Nirmal Robert
Eerste Tranche ambtelijk voorontwerp

nieuw BV-recht: inventarisatie naar aanleiding van de consultatieronde

Tijdschrift voor Ondernemingsbestuur 2005, 122

Schutz vor „europäischen“ Kapitalgesellschaften

NJW 2004, 97

Parteifähigkeit, Sitztheorie und „Centros“

- Besprechung des BGH-Beschlusses vom 30.3.2000, VII ZR 370/98, DStR 2000, 1064 -

DStR 2000, 1061

Cash-Management-Systeme in Konzernen

DStR 2003, 655

Zur Entwicklung des Europäischen

Gesellschaftsrechts: Stellungnahme der Group of German Experts on Corporate Law zum Report of the High Level Group of Company Law Experts on a Modern Regulatory Framework for Company Law in Europe

ZIP 2003, 863

ECLR - Grundtendenzen der Reform geschlossener Gesellschaften in Europa

ZGR 2001, 351

La libération du capirtal des SARL à capital variable, RJC 1999, p. 310

Die Gesellschafterklage im GmbH- und Aktienrecht: Überlegungen zum deutschen und europäischen Recht vor dem Hintergrund der schweizeri- 
schen Verantwortlichkeitsklage und der USamerikanischen Derivative Suit

Köln/Berlin/Bonn/München 2000

Barta, Sebastian

Bauer, Markus

Bayer, Walter

ders.

ders.

ders.

ders.

Bayer, Walter / Graff Simone
Das Kapitalsystem von GmbH und AG - Inhalt und Zweck der Regelungen über Stamm- bzw. Grundkapital

Zugleich Anmerkungen zum Referentenentwurf eines „Gesetzes zur Neuregelung des Mindestkapitals der GmbH (MindestKapG)“

GmbHR 2005, 657

Gläubigerschutz durch eine formelle Nennkapitalziffer - Kapitalgesellschaftsrechtliche Notwendigkeit oder überholtes Konzept? 1995

Aktuelle Entwicklungen im Europäischen Gesellschaftsrecht

BB 2004, 1

Die EuGH-Entscheidung Inspire Art und die deutsche GmbH im Wettbewerb der europäischen Rechtsordnungen

BB 2003, 2357

Zulässige und unzulässige Einschränkungen der europäischen Grundfreiheiten im Gesellschaftsrecht,

BB 2002, 2289

Moderner Kapitalschutz

ZGR 2007, 220

Zentrale Konzernfinanzierung, Cash Management und Kapitalerhaltung, FS für Marcus Lutter, 2000, S. $1011-1032$

Das neue Eigenkapitalersatzrecht nach dem Mo$\mathrm{MiG}$ 
DStR 2006, 1654

Bayer, Walter /

Hoffmann, Thomas / Schmidt, Jessica

Bechtel, Wolfram

Becker, Patricia

dies.

dies.

Beckmann, $H$.

Behrens, Peter

ders.
Satzungskomplexität und Mustersatzung |

GmbHR 2007, 953

Parteifähigkeit trotz Verlegung des Gesellschaftssitzes nach Deutschland - Kommentar zu BGH, NZG 2000, 1025 und OLG Frankfurt, RIW 1999, 783

NZG 2001, 21

Becker, Baldiges Gründungsverfahren in Frankreich: Die französische „Blitz-S.A.R.L.“

GmbHR 2003, 706

Verabschiedung des Gesetzes über die französische Blitz-S.A.R.L.

GmbHR 2003, 1120

Die zivilrechtliche Haftung des französischen Geschäftsführers einer S.A.R.L. gegenüber der Gesellschaft GmbHR 2003, 162

Mimimumkapitaal, aansprakelijkheid en publiciteit: wat moet de crediteur hiermee?

Ondernemingsrecht 2004, 22

Formerfordernisse bei der Anteilsübertragung aus rechtsvergleichender Sicht

in: Die GmbH-Reform in der Diskussion, Sondertagung der Gesellschaftsrechtlichen Vereinigung (VGR), herausgegeben in der Schriftenreihe der Gesellschaftsrechtlichen Vereinigung, Köln 2006

Die grenzüberschreitende Sitzverlegung von Gesellschaften in der EWG

IPRax 1989, 354 
ders.

ders.

ders.

ders.

Bellinghausen, Rupert

ten Berg, J. A. M.

Bervoets, Cécile /

Lembeck, Eva Désirée

Bier, Barbara

dies.
Das Internationale Gesellschaftsrecht nach dem Centros-Urteil des EuGH

IPRax 1999, 323

EuGH entscheidet über Sitzverlegung von Gesellschaften

EuZW 2000, 385

Reaktionen mitgliedstaatlicher Gerichte auf das Centros-Urteil des EuGH

IPRax 2000, 384

Gemeinschaftliche Grenzen der Anwendung inländischen Gesellschaftsrechts auf Auslandsgesellschaften nach Inspire Art - zu EuGH, 30.9.2003 Rs. C-167/01 - Kramer van Koophandel en Fabrieken voor Amsterdam/Inspire Art Ltd., IPRax 2004, S.46

IPRax 2004, 20

Der Missbrauch von Minderheitsrechten in Kapitalgesellschaften nach französischem Recht

RIW 1997, 101

Aandelen in de bv-nieuwe stijl: stemrecht en stortingsplicht

Ondernemingsrecht 2007, 341

Die „GmbH Light“ - ein Trend in Europa, SWI 2004, 355

Kapitalbescherming: overbodig of nodig?

Ondernemingsrecht 2004, 10

Vereenvoudiging en flexisbilisering van het BVrecht

Ondernemingsrecht 2006, 350 
Binz, Mark K./Mayer, Gerd

Bitter, Georg

ders.

Blaurock, Uwe

ders.

Böcker, Philipp

Poertzgen, Christoph

Böttcher, Roland /

Ries, Peter

Böttcher, Lars

Blasche, Sebastian

Bohlscheid, Markus

Bohrer, Michael
Die ausländische Kapitalgesellschaft \& Co. KG im Aufwind

GmbHR 2003, 249

Flurschäden im Gläubigerschutzrecht durch Centros \& Co.? - Eine Zwischenbilanz

WM 2004, 2190

Rechtsperson und Kapitalerhaltung

ZHR 186 (2004), 302

Recht der Unternehmen in Europa

1993

Mindestkapital und Haftung bei der $\mathrm{GmbH}$, in: Festschrift für Thomas Raiser zum 70. Geburtstag, 2005: S. 3-22

Kausalität und Verschulden beim künftigen $§ 64$

Satz 3 GmbHG

WM 2007, 1203

Formularpraxis des Handelsregisterrechts

(2003)

Gutgläubiger Erwerb von Geschäftsanteilen entsprechend der in der Gesellschafterliste eingetragenen Stückelung nach dem MoMiG

NZG 2007, 565

Ausländer als Gesellschafter und Geschäftsführer einer deutschen GmbH RNotZ 2005, 505

Fehlerquellen und gutgläubiger Erwerb im Geschäftsanteilsverkehr - Das Vertrauensschutzkonzept im Regierungsentwurf des MoMiG

DStR 2007, 995 
ders.

Borges, Georg

Bork, Reinhard

Bormann, Michael

ders.

ders.

Brandner, Hans Erich

Bredthauer, Jürgen

Breitenstein, Jürgen / Meyding, Bernhard
Notarielle Form, Beurkundung und elektronischer

Rechtsverkehr

DNotZ 2008, 39

Gläubigerschutz bei ausländischen Gesellschaften mit inländischem Sitz

ZIP 2004, 733

Abschaffung des Eigenkapitalersatzrechts zugunsten des Insolvenzrechts?

ZGR 2007, 250

Der Entwurf des „MoMiG“ und die Auswirkungen auf die Kapitalaufbringung

GmbHR 2006, 1021

Kapitalerhaltung bei Aktiengesellschaft und GmbH nach dem Referentenentwurf zum MoMiG DB 2006, 2616

Die Kapitalaufbringung nach dem Regierungsentwurf des MoMiG

GmbHR 2007, 897

Verdeckte Sacheinlage - eine Aufgabe für den Gesetzgeber? | Verantwortung und Gestaltung 1996, 37-46 (Festschrift für Karlheinz Boujong zum 65. Geburtstag)

Zur Wirksamkeit gesellschaftsrechtlicher Beurkundungen im Kanton Zürich

BB 1986, 1864

GmbH-Reform: Die „neue“ GmbH als wettbewerbsfähige Alternative oder nur als „GmbH light"?

BB 2006, 1457 
dies.

Büchel, Helmut

Bungert, Hartwin

Burg, Michael

Westerheide, Stefan

Büttner von Gieseking, Hermann

Cahn, Andreas

Centrale für GmbH Dr. Otto Schmidt

Cozian, Maurice

Viandier, Alain

Deboissy, Florence

Dautzenberg, $N$.

Deininger, Rainer
Der Regierungsentwurf zum MoMiG: Die Deregulierung des GmbH-Rechts schreitet voran

BB 2007, 1457

De l'utilité de constituer une SARL ?

Rev. Sociétés 2004, p. 825.

Kapitalaufbringung, insbesondere Regelung der verdeckten Sacheinlage nach dem Regierungsentwurf des MoMiG

GmbHR 2007, 1065

Konsequenzen der Centros-Entscheidung des EuGH für die Sitzanknüpfung des deutschen internationalen Gesellschaftsrechts

DB 1999, 1841

Praktische Auswirkungen des MoMiG auf die Finanzierung von Konzernen

BB 2008, 62

Identität und Kontinuität bei der Gründung juristischer Personen

1967

Kapitalaufbringung im Cash Pool

ZHR 166 (2002), 278 ff.

Die GmbH-Rechte in den EG-Staaten Köln 1993

Droit des sociétés

21eme édition

Litec Paris, 25 août 2008

Verwerfung der Sitztheorie

FR 1999, 451

Körperschaftsteuerrechtliche Auswirkungen der Überseering-Entscheidung des EuGH 
IStR 2003, 214

Dierksmeier, Jochen

Scharbert, Markus

Drygala, Tim

ders.

ders.

Drygala, Tim

Kremer, Thomas

Duuren van, T. P.

Ebenroth/Eyles

Ebers, Martin

Ebke, Werner F.
$\mathrm{GmbH}$ und englische Ltd. im Wettlauf der

Reformen 2006

BB 2006, 1517

Für eine alternative Rechtform neben einer reformierten $\mathrm{GmbH}$ - Leipziger Entwurf einer Kommanditgesellschaft mit beschränkter Haftung $(\mathrm{KmbH})$

ZIP 2006, 1797

Zur Neuregelung der Tätigkeitsverbote für Geschäftsleiter von Kapitalgesellschaften

ZIP 2005, 423

Zweifelsfragen im Regierungsentwurf zum Mo$\mathrm{MiG}$

NZG 2007, 561

Alles neu macht der Mai - Zur Neuregelung der Kapitalerhaltungsvorschriften im Regierungsentwurf zum MoMiG

ZIP 2007, 1289

De positie van de Nederlands BV ten opzichte van haar buitenlandse equivalenten en de Europese BV Ondernemingsrecht 2004, 4

DB 1989, 363

Company Law in Member States against the Background of Legal Harmonisation and Competition between Legal Systems

ERPL 2003, 509

Überseering: Die wahre Liberalität ist Anerkennung, 
JZ 2003, 927

ders.

ders.

Efferink, Harm van /

Ebert, Sabine /

Levedag, Christian

Ehinger, Nicolaus Johannes

ders.

Eidenmüller, Horst

ders.
Das Centros-Urteil des EuGH und seine Relevanz für das deutsche Internationale Gesellschaftsrecht

- Das Schicksal der Sitztheorie nach dem CentrosUrteil des EuGH

JZ 1999, 656

The European Conflict-of-Corporate-Laws Revolution: Überseering, Inspire Art and Beyond,

EBLR 2005, 9

Die zugezogene niederländische B.V. als

Rechtsformalternative zur deutschen

$\mathrm{GmbH}$ für in- und ausländische Investoren in

Deutschland

GmbHR 2004, 880

Referentenentwurf des MoMiG: Optimierung der Regelungstechnik wünschenswert

BB Special 2006 Nr. 7, S. 24

Auswirkungen des MoMiG auf die Praxis der $\mathrm{GmbH} \& \mathrm{Co} . \mathrm{KG}$

BB 2006, 2701

Europäisches und deutsches Gesellschaftsrecht im europäischen Wettbewerb der Gesellschaftsrechte, in: S. Lorenz/A. Trunk/H. Eidenmüller/Ch. Wendehorst/J. Adolff (Hrsg.), Festschrift für Andreas Heldrich zum 70. Geburtstag (München: C. H. Beck, 2005) S. 581 - 595.

Geschäftsleiter- und Gesellschafterhaftung bei europäischen Auslandsgesellschaften mit tatsächlichem Inlandssitz

NJW 2005, 1618 
ders.

ders.

ders.

Eidenmüller, Horst

Rehberg, Markus

Eidenmüller, Horst /

Rehm; Gebhard M.

Eidenmüller, Horst

Engert, Andreas

Elsing, Andre

ders.

Engert, Andreas
Wettbewerb der Gesellschaftsrechte in Europa -

Zugleich Besprechung des Urteils des Europäischen Gerichtshofs vom 5-11-2002 in der Rechtssache C-208/00 (Überseering BV gegen Nordic Construction Company Baumanagement $\mathrm{GmbH}$ )

ZIP 2002, 2233

Die GmbH im Wettbewerb der Rechtsformen ZGR 2007, 168

in: Eidenmüller (Hrsg.) Ausländische Kapitalgesellschaften im deutschen Recht 2004

Umgehung von Gewerbeverboten mittels

Auslandsgesellschaften

NJW 2008, 28

Niederlassungsfreiheit versus Schutz des

inländischen Rechtsverkehrs: Konturen eines Europäischen Internationalen Gesellschaftsrechts

ZGR 2004, 159

Rechtsökonomik des Mindestkapitals im

GmbH-Recht

GmbHR 2005, 433

Gesellschafterliste und Anzeigen von Gesellschaftsanteilsabtretungen mit Blick auf das Mo$\mathrm{MiG}$

ZNotP 2007, 332

Entfallen der Beurkundungspflicht

ZNotP 2007, 377

Die Wirksamkeit des Gläubigerschutzes durch Nennkapital - Überprüfung anhand von Daten der Creditreform Rating AG und weiteren Rechtstatsachen

GmbHR 2007, 337 
Fastrich, Lorenz

Flaßhoff, Carsten /

Krömker, Michael

Fleming, $J$.

Fleischer, Holger

ders.

ders.

Flesner, Patrick

Flitsch, Michael

Flume, Werner
Optimierung des Gläubigerschutzes bei der $\mathrm{GmbH}$

- Praktikabilität und Effizienz, DStR 2006, 656

Europäische Nachbarn machen Druck auf die $\mathrm{GmbH}$ - Ist die Wettbewerbsfähigkeit der Rechtsform noch zu retten? - Durchgreifende Reformen sind nötig Börsenzeitung v. 7.9.2005, S. 2

Verslag van het viftiende congres van het Instituut voor Ondernemingsrecht: de vereenvoudiging van het BV-recht

Ondernemingsrecht 2004, 537

Gläubigerschutz in der kleinen Kapitalgesellschaft: Deutsche $\mathrm{GmbH}$ versus englische private limited company, DStR 2000, 1015

Erweiterte Außenhaftung der Organmitglieder im Europäischen Gesellschafts- und Kapitalmarktrecht ZGR 2004, 437

Bestellungshindernisse und Tätigkeitsverbote von Geschäftsleitern im Aktien-, Bank- und Kapitalmarktrecht WM 2004, 157

Die GmbH-Reform aus Sicht der Akquisitionsund Restrukturierungspraxis

NZG 2006, 641

Das Eigenkapitalersatzrecht vor dem Aus?

Die geplanten Änderungen durch das Gesetz zur Modernisierung des GmbH-Rechts und zur Bekämpfung von Missbräuchen (MoMiG)

DZWiR 2006, 397

Allg. Teil des Bürgerlichen Rechts Band I, Teil 2, Die juristische Person

Berlin, Heidelberg, New York 1983 
Forsthoff, Ulrich

ders.

Freitag, Robert

ders.

Freitag, Robert

Riemenschneider, Markus

Fuchs, Rainer /

Hinkelbein, Gerhard /

Schabe, Torsten

Geerts, P.G.F.A.

Gehb, Jürgen / Drange, Günter /

Heckelmann, Martin
EuGH fördert Vielfalt im Gesellschaftsrecht Traditionelle deutsche Sitztheorie verstößt gegen Niederlassungsfreiheit

DB 2002, 2471

Rechts- und Parteifähigkeit ausländischer Gesellschaften mit Verwaltungssitz in Deutschland? Die Sitztheorie vor dem EuGH - Anmerkung zu dem Vorlagebeschluss des BGH vom 30.03.2000 VII ZR 370/98

DB 2002, 2471

Der Wettbewerb der Rechtsordnungen im Internationalen Gesellschaftsrecht

EuZW 1999, 267

Finanzverfassung und Finanzierung von $\mathrm{GmbH}$ und AG nach dem Regierungsentwurf des MoMiG WM 2007, 1681

Die Unternehmergesellschaft - "GmbH light" als Konkurrenz für die Limited?

ZIP 2007, 1485

„Leitfaden zur Gründung eines

Unternehmens in Frankreich“, Heidelberg

(1992) (BB Sonderveröffentlichung)

Enkele formele aspecten van het enqêterecht Groningen 2004

Gesellschaftsrechtlicher Typenzwang als Zwang zu neuem Gesellschaftstyp - Gemeinschaftsrecht fordert deutsche UGG

NZG 2006, 88 
Gernoth, Jan P.

Gesell, Harald

Gesmann-Nuissl, Dagmar

Geyrhalter, Volker /

Gänßler, Peggy

dies.

Görk, Stefan

Goette, Wulf

ders.

ders.

ders.
Pseudo Foreign Companies - Who Art Thou?

Englische Briefkastengesellschaften in Deutschland und ihre Behandlung nach englischem und deutschem Recht, Baden-Baden 2005

Verdeckte Sacheinlage \& Co. im Lichte des Mo$\mathrm{MiG}$

BB 2007, 2241

Quo vadis GmbH? - zum Entwurf des Gesetzes zur Modernisierung des GmbH-Rechts und zur Bekämpfung von Missbräuchen (MoMiG) WM 2006, 1756

Perspektiven nach „Überseering“ - wie geht es weiter?

NZG 2003, 409

Inspire Art - Briefkastengesellschaften on the Move

DStR 2003, 2167

Zur Vereinbarkeit der Sitztheorie mit dem Gemeinschaftsrecht

MittBayNot 1999, 300

Krisenvermeidung und Krisenbewältigung in der $\mathrm{GmbH}$ - ein Überblick

ZGR 2006, 261

Wo steht der BGH nach Centros und Inspire Art?

DStR 2005, 197

Auslandsbeurkundungen im Kapitalgesellschaftsrecht

MittRhNotK 1997, 1

Das neue GmbH-Recht nach dem MoMiG 
DRiZ 2007, 313

Göttsche, Max

Götze, Cornelius /

Bressler, Stefan

Gravenstein, Viky

Französisches Gesellschaftsrecht

Greulich, Sven

Bunnemann, Jan

Grinten, v. d.

Grobys, Marcel / Glanz, Peter

Groenewald, Th.

Großerichter, Helge
Das Centros-Urteil des EuGH und seine Auswirkungen - Eine Bestandsaufnahme aus gesellschafts-, handels- und steuerrechtlicher Sicht

DStR 1999, 1403

Praxisfragen der Gesellschafterliste und des gutgläubigen Erwerbs von Geschäftsanteilen nach dem MoMiG

NZG 2007, 894

Französisches Gesellschaftsrecht, das Gesetz vom 24.7.1966,

3. Auflage 1988

Geschäftsführerhaftung für zur

Zahlungsunfähigkeit führende Zahlungen an die Gesellschafter nach $\S 64$ Abs. 2 Satz 3 GmbHGRefE - Solvenztest im deutschen Recht?

NZG 2006, 681

in v. d. Heijden

Handboek voor de Naamloze en de Besloten Vennootschap, Zwolle 1989

Kopplungsklauseln in Geschäftsführerverträgen

NJW-Spezial 2007, 129

De doelloze BV

Ondernemingsrecht 2004, 25

Ausländische Kapitalgesellschaften im deutschen Rechtsraum - Das deutsche Internationale Gesellschaftsrecht und seine Perspektiven nach der Entscheidung Überseering

DStR 2003, 159 
Grunewald, Barbara

dies.

dies.

Grunewald, Barbara /

Noack, Ulrich

Grunewald, Barbara /

Gehling, Christian / Rodewig, Desiree

Guyon, Yves

ders.

Haas, Ulrich

ders.

ders.
Rechtsfolgen verdeckter Sacheinlagen, in: Festschrift für Heinz Rowedder zum 75. Geburtstag 1994, 111-118

Cash-Pooling und Sacheinlagen: Was bringt das MoMiG, was könnte es bringen?

WM 2006, 2333

Der gutgläubige Erwerb von GmbH-Anteilen: Eine neue Option

Der Konzern 2007, 13

Zur Zukunft des Kapitalsystems der

$\mathrm{GmbH}$ - Die Ein-Euro-GmbH in

Deutschland

GmbHR 2005, 189

Gutgläubiger Erwerb von GmbH-Anteilen ZIP 2006, 685

Droit des affaires, Band 1,

12. Auflage 2003

Les sociétés. Aménagements statutaires et conventions entre associés, $5^{\circ}$ éd., LGDJ, 2002

Mindestkapital und Gläubigerschutz in der $\mathrm{GmbH}$

DStR 2006, 993

Reform des gesellschaftsrechtlichen Gläubigerschutzes

Gutachten E zum 66. Deutschen Juristentag Stuttgart 2006

Die Disziplinierung des GmbH-Geschäftsführers im Interesse der Gesellschaftsgläubiger,

WM 2006, 1369 (Teil I)

und 1417 (Teil II) 
ders.

ders.

ders.

ders.

Europäische Privatgesellschaft

Habersack, Matthias

ders.

Hägele, Matthias

Hadding, Walter

Halbhuber, Harald
Kapitalerhaltung, Insolvenzanfechtung, Schadensersatz und Existenzvernichtung - wann wächst zusammen, was zusammen gehört?

ZIP 2006, 1373

Der Entwurf des „MoMiG“ und weitergehende Vorschläge zur Bekämpfung des Missbrauchs der GmbH, GmbHR 2006, 729

Das neue Kapitalersatzrecht nach dem RegEMoMiG

ZInsO 2007, 617

in: Hommelhoff, / Helms, (Hrsg.)

Wege in die Europäische Privatgesellschaft, 2001, S. 155

Das Aktiengesetz und das Europäische Recht ZIP 2006, 445

Gesellschafterdarlehen nach dem MoMiG - Anwendungsbereich, Tatbestand und Rechtsfolgen der Neuregelung

ZIP 2007, 2145

Mitteilungspflichten bei Beteiligungserwerb wann sind sie wirklich entbehrlich? Das Verhältnis des $§ 16$ GmbHG zu 21 AktG unter Berücksichtigung des „MoMiG“,

GmbHR 2007, 258

Zum gesetzlich notwendigen Umfang der notariellen Beurkundung der "Vereinbarung", einen GmbH-Geschäftsanteil zu übertragen ZIP 2003, 2133;

Das Ende der Sitztheorie als Kompetenztheorie ZEuP 2003, 418 
von Halen, Curt Christian

Hamann, Hanjo

Hamers, J.J.A.

Happ, Wilhelm

Happ, Wilhelm / Holler, Lorenz

Harbarth Stephan

Heckschen, Heribert

ders.

Heidenhain, Martin
Das internationale Gesellschaftsrecht nach dem Überseering-Urteil des EuGH

WM 2003, 571

GmbH-Anteilserwerb vom Nichtberechtigten Die Mischung verschiedener Gutglaubenstatbestände im MoMiG-Regierungsentwurf

NZG 2007, 492

Hamers, J.J.A., Verpanding van aandelen en de beslotenheid van kapitaalvennootschappen, 1996

Deregulierung der $\mathrm{GmbH}$ im Wettbewerb der Rechtsformen

Entformalisierung des Rechts der Gesellschafter ZHR 169 (2005), 6

Limited statt $\mathrm{GmbH}$ ?

DStR 2004, 730

Gutgläubiger Erwerb von GmbHGeschäftsanteilen nach dem MoMiG-RegE ZIP 2008, 57

Die GmbH-Reform - Wege und Irrwege

DStR 2007, 1442

MoMiG - Ein Überblick über den aktuellen Diskussionsstand

NotBZ 2006, 381

Aufgabe des Beurkundungserfordernisses beim Verkauf und der Abtretung von GmbHGeschäftsanteilen

ZIP 2001, 721 
ders.

Nochmals: Der Zweck der Beurkundungspflicht

für Veräußerungsverträge über $\mathrm{GmbH}$ -

Geschäftsanteile

ZIP 2001, 2113.

ders.

Katastrophale Rechtsfolgen verdeckter Sacheinlagen

GmbHR 2006, 455

ders.

Ausländische Kapitalgesellschaften mit Verwaltungssitz in Deutschland

NZG 2002, 1141

Heidinger, Andreas

Der Kapitalschutz der GmbH auf dem Prüfstand

DNotZ 2005, 97

ders.

Die wirtschaftliche Neugründung

ZGR 2005, 101

Heneweer, Rainer

Das Erfordernis öffentlicher Beglaubigung im Handelsregisterverkehr ( $\$ 12$ HGB)

FGPRax 2004, 259

Hirsch, Alexander /

Artfully Inspired - Werden deutsche

Britain, Richard

Gesellschaften englisch?

NZG 2003, 1100

Hirte, Heribert

Die organisierte Bestattung von Kapitalgesellschaften: Gesetzgeberischer Handlungsbedarf im Gesellschafts- und Insolvenzrecht

ZInSO 2003, 833

Hölzle, Gerrit

Gesellschafterfremdfinanzierung und Kapitalerhaltung im Regierungsentwurf des MoMiG

GmbHR 2007, 729

Hoffmann, Jochen

Neue Möglichkeiten zur identitätswahrenden Sitzverlegung in Europa? - Richtlinienvorentwurf zur 
Verlegung des Gesellschaftssitzes innerhalb der EU

ZHR 164 (2000) 43

Hofmeister, Jörg

Horn, Norbert

Hommelhoff, Peter

ders.

Huber, Ulrich

Habersack, Mathias

Jacob, Thomas

Jäger, Axel

Jaeger, Gerold
Grundlagen und Entwicklungen des Internationalen Gesellschaftsrechts

WM 2007, 868

Deutsches und europäisches Gesellschaftsrecht und die EuGH-Rechtsprechung zur Niederlassungsfreiheit - Inspire Art

NJW 2004, 893

Für eine minimalinvasive und dennoch höchst effektive Reform des Eigenkapitalersatzrechts in: Die GmbH-Reform in der Diskussion, Sondertagung der Gesellschaftsrechtlichen Vereinigung (VGR), herausgegeben in der Schriftenreihe der Gesellschaftsrechtlichen Vereinigung, Köln 2006

Die „Societe fermee europeenne“

WM 1997, 2101

GmbH-Reform: Zwölf Thesen zu einer möglichen Reform des Rechts der kapitalersetzenden Gesellschafterdarlehen

BB 2006, 1

Konzeption der Existenzvernichtungshaftung vor dem Hintergrund des MoMiG-Entwurfs

GmbHR 2007, 796

Kapitalaufbringung und Haftungsrisiken in CashManagement-Systemen von GmbH-Konzernen DStR 2000, 1653

Kapitalgesellschaften in der EU - dauerhaft Niederlassungsberechtigte zweiter Klasse? - Kommentar zu den Vorlagebeschlüssen des BGH vom 
30-3- 2000 und des AG Heidelberg vom 3-3-2000 sowie zur Rechtsprechung in den Niederlanden und Österreich als Antwort auf die CentrosEntscheidung des EuGH vom 9-3-1999

NZG 2000, 918

Jansen, H. G. T. J.

Jeep, Jens /

Wiedemann, Klaus

John, Uwe

ders.

Joost, Detlev

Jungmann, Carsten

Just, Clemens

Kallmeyer, Harald

ders.
GmbH-International -

Haftungssituationen in der niederländischen B V

GmbHR 1995, 286

Die Praxis der elektronischen Registeranmeldung - die Umsetzung des EHUG aus notarieller und richterlicher Sicht

NJW 2007, 2439

Die Gründung der Einmann-GmbH, 1986

Die doppelstöckige Einmann-GmbH-Gründung BB 1985, 626

Der Eigenkapitalschutz vor neuen Herausforderungen - Cash-Pool-Systeme, International Financial Reporting Standards, Solvency Test

in: Die GmbH-Reform in der Diskussion, Sondertagung der Gesellschaftsrechtlichen Vereinigung (VGR), herausgegeben in der Schriftenreihe der Gesellschaftsrechtlichen Vereinigung, Köln 2006

Solvenztest- versus Kapitalschutzregeln ZGR 2006, 638

Die englische Limited in der Praxis 2005

Vor- und Nachteile der englischen Limited im Vergleich zur GmbH oder GmbH\&Co.KG

DB 2004, 636

Bereinigung der Finanzverfassung der $\mathrm{GmbH}$ 
GmbHR 2004, 377

ders.

ders.

\section{Kammeter, Roland}

Geißelmeier, Werner

Kanzleiter, Rainer

ders.

Karsten, Frederik

ders.

Kersting, Christian

Kersting, Christian /

Schindler, Clemens Philipp
Kapitalaufbringung und Kapitalerhaltung nach dem MoMiG: Änderungen für die GmbHBeratungspraxis

DB 2007, 2755

Tragweite des Überseering-Urteils des EuGH vom 5.11.2002 zur grenzüberschreitenden Sitzverlagerung

DB 2002, 2521

Der Rangrücktritt - Bestandsaufnahme und Auswirkungen des MoMiG im Handelsbilanz- und Steuerrecht

NZI 2007, 214

Der Zweck der Beurkundungspflicht für Veräußerungsverträge über $\mathrm{GmbH}-\mathrm{Geschäftsanteile}$ ZIP 2001, 2105

„Inspire Art“ - die Konsequenzen

DNotZ 2003, 885

Deregulierung der GmbH-Gründung

GmbHR 2006, 57

Kann man eine $\mathrm{GmbH}$ auf einem Bierdeckel gründen?

GmbHR 2007, 958

Rechtswahlfreiheit im Europäischen Gesellschaftsrecht nach Überseering - Ein Richtlinienvorschlag NZG 2003, 9

Die EuGH-Entscheidung „Inspire Art“ und ihre Auswirkungen auf die Praxis

RdW 2003, 621 
Aktuelle Entwicklungen des Wettbewerbs der Gesellschaftsrechte in: Ökonomische Analyse der europäischen Zivilrechtsentwicklung - Beiträge zum X. Travemünder Symposium zur ökonomischen Analyse des Rechts (29. März bis 1. April 2006) Hrsg. v. Thomas Eger u. Hans-Bernd Schäfer

dies.

ECLR Niederlassungsfreiheit als Rechtswahlfreiheit - Besprechung der Entscheidung EuGH EuZW 1999, 216 - Centros Ltd. ./. Erhvervs- og Selskabsstyrelsen

ZGR 1999, 724

Kindler, Peter

ders.

ders.

ders.

ders.

Kleberger, Franz Friedrich
GmbH-Reform und internationales Gesellschaftsrecht

AG 2007, 721

Niederlassungsfreiheit für Scheinauslandsgesellschaften? - Die „Centros“-Entscheidung des EuGH und das internationale Privatrecht NJW 1999, 1993

Auf dem Weg zur Europäischen Briefkastengesellschaft? - Die "Überseering"-Entscheidung des EuGH und das internationale Privatrecht NJW 2003, 1073

„Inspire Art“ - Aus Luxemburg nichts Neues zum internationalen Gesellschaftsrecht

NZG 2003, 1086

Internationales Gesellschaftsrecht am Scheideweg RIW 2000, 649

Die rechtliche Behandlung von Sicherungen bei der Gründung der Einmann-GmbH, 1986 
Kleindiek, Detlef

ders.

ders.

Kleinert, Jens /

Probst, Peter

dies.

Knof, Béla

ders.

Knof, Béla

Mock, Sebastian

Koch, Ulrich
Auf dem Weg zur Reform des GmbH-Rechts Die Initiative zur Neuregelung des Mindestkapitals der GmbH (MindestkapG)

DStR 2005, 1366

Krisenvermeidung in der $\mathrm{GmbH}$ : Gesetzliches Mindestkapital, Kapitalschutz und Eigenkapitalersatz

ZGR 2006, 335

Ordnungswidrige Liquidation durch organisierte „Firmenbestattung“

ZGR 2007, 276

Endgültiges Aus für Sonderanknüpfungen bei (Schein-)Auslandsgesellschaften - Anmerkung zu dem EuGH-Urteil vom 30.9.2003 - Rs. C-167/01 Inspire Art, DB 2003, S. 2219

DB 2003, 2217

Schein-Auslandsgesellschaften - Erneute Betonung der Niederlassungsfreiheit durch den EuGH

MDR 2003, 1265

Die neue Insolvenzverursachungshaftung nach $\S$ 64 Satz 3 RegE-GmbHG (Teil I)

DStR 2007, 1536

Die neue Insolvenzverursachungshaftung nach $\S$ 64 Satz 3 RegE-GmbHG (Teil II)

DStR 2007, 1580

Das MoMiG und die Auslandsinsolvenz haftungsbeschränkter Gesellschaften

GmbHR 2007, 852

Die Beteiligung einer Gesellschaft bürgerlichen Rechts an der GmbH-Gründung

ZHR 146 (1982), 118 
Koegel, Steffen

Kornblum, Udo

ders.

Krafka, Alexander

Krause, Nils

Krause, Rüdiger

Kreuzer, Karl

Krieger, Gerd

Kröll, Stefan
Formalien der GmbH-Gründung - ein Musterbeispiel für zuviel Staat

GmbHR 2003, 1225

Bundesweite Rechtstatsachen zum Unternehmensund Gesellschaftsrecht, Stand 1. 1. 2004

GmbHR 2006, 28

Bundesweite Rechtstatsachen zum Unternehmensund Gesellschaftsrecht, Stand 1. 1. 2007

GmbHR 2008, 19

Das neue Handels- und Unternehmensregister Übersicht über das Registerrecht in der Fassung des Referentenentwurfs $\mathrm{zu}$ einem Gesetz über elektronische Handelsregister und Genossenschaftsregister sowie das Unternehmensregister (EHUG-RefE) - MittBayNot 2005, 290

Auswirkungen des Allgemeinen Gleichbehandlungsgesetzes auf die Organbesetzung

AG 2007, 392

Die Stellung von KMU im europäischen Gesellschaftsrecht

EuZW 2003, 747

Die allgemeinen Gläubigerschutzbestimmungen der GmbH-Novelle

ZIP 1980, 597

Zur Heilung verdeckter Sacheinlagen in der $\mathrm{GmbH}$ ZGR 1996, 674

Beurkundung gesellschaftsrechtlicher Vorgänge durch einen ausländischen Notar

ZGR 2000, 111 
Krolop, Kaspar

Krüger, Markus E.

Kuiper/Ruypers/Slangen

Lange, Knut Werner

Lanzius, Tim

Leemrijse, J. J. C. A.

Leible, Stefan

Leible, Stefan

Hoffmann, Jochen

dies.
Die deliktische Haftung der Gesellschafter wegen Gläubigerschädigung bei der $\mathrm{GmbH}$ und der in Deutschland aktiven Limited im Lichte des MoMiG und der Aufgabe des bisherigen Konzepts der Existenzvernichtungshaftung

NotBZ 2007, 265

Mindestkapital und Gläubigerschutz, 2005

Kuiper/Ruypers/Slangen, Burgerlijk Recht Geschetst - Rechtspersonenrecht geschetst, 1993

Zur Niederlassungsfreiheit im Zusammenhang mit der Eintragung einer inländischen Zweigniederlassung einer ausländischen Gesellschaft

DNotZ 1999, 599

Die Directors Disqualification des englischen Rechts - ein Baustein zum Schutz des deutschen Rechtsverkehrs vor Scheinauslandsgesellschaften ZInsO 2004, 296

De Eerste Tranche van het vereenvoudigd BVRecht

Tijdschrift vor Ondernemingsbestuur 2005, 39

Niederlassungsfreiheit und Verweigerung der Eintragung einer Zweigniederlassung

NZG 1999, 300

Überseering und das (vermeintliche) Ende der Sitztheorie - Anmerkung zu EuGH, Urteil vom 5.11.2002 - Rs.C-208/00, RIW 2002, 945 - Überseering

RIW 2002, 925

Wie inspiriert ist Inspire Art?

EuZW 2003, 677 
Lennarts, M. L.

dies.

WPNR 2007, 966

Lennarts M. L. /Timmermann L.

Leuering, Dieter

Leuering, Dieter

Rubner, Daniel

Leuering, Dieter / Simon, Stefan

Libchaber, Remy

Lutter, Marcus

ders.

ders.

ders.
Crediteurenbescherming bij de lichte BV

Ondernemingsrecht 2004, 16

De vorgestelde regeling van uitkeringen aan aandeelhouders van een bv nader beschouwd

Überschuldung, een zinnig idee voor het Nederlandse recht?

De NV 1997, 308

Die Unternehmergesellschaft als Alternative zur Limited

NJW-Spezial 2007, 315

Neues Konzept der Existenzvernichtungshaftung

NJW-Spezial 2007, 363

Der Referentenentwurf zur GmbH-Reform

NJW-Spezial 2006, Heft 7, 315

La société, contrat spécial, in Prospectives de droit économique. Dialogues avec Michel Jeantin, Dalloz, 1999, p. 281

Zur Entwicklung der GmbH in Europa und in der Welt

GmbHR 2005, 1

Überseering und die Folgen

BB 2003, 7

Für eine Unternehmer-Gesellschaft (UG) - Zur notwendigen Erweiterung der geplanten $\mathrm{GmbH}-$ Reform, in:

BB 2006, BB-Special 7, S. 2 - 4

Perspektiven einer GmbH-Reform 
ders.

Maier-Bridou, Arno

Maul, Silja /

Eggenhofer, Erich /

Lanfermann, Georg

Maul, Silja /

Schmidt, Claudia

McCahery, J. A./

Vermeulen, E. P. M.

Mehring, Eckhard W.

Meilicke, Wienand

ders.

ders. in: Die GmbH-Reform in der Diskussion, Sondertagung der Gesellschaftsrechtlichen Vereinigung (VGR), herausgegeben in der Schriftenreihe der Gesellschaftsrechtlichen Vereinigung, Köln 2006

Gesetzliches Garantiekapital als Probleme europäischer und deutscher Rechtspolitik AG 1998, 375

Maier-Bridou, Die GmbH in Frankreich, in: Centrale für GmbH Dr. Otto Schmidt (Hrsg.), Die GmbH-Rechte in den EG-Staaten, 1993, S. 77

Deregulierung der EU-Regelungen zur

Kapitalaufbringung und -erhaltung

BB-Special 2004, Nr 6, 5-8

Inspire Art - Quo vadis Sitztheorie?

BB 2003, 2297

De behoefte aan een Nederlands „personenvennootschap met beperkte aansprakelijkheid"

Ondernemingsrecht 2005, 382

Die GmbH in niederländischen Recht, GmbHR 1991, 297

Das Eigenkapitalersatzrecht - eine deutsche Fehlentwicklung

GmbHR 2007, 225

Die Niederlassungsfreiheit nach Überseering GmbHR 2003, 793

Niederlassungsrecht von Zweigniederlassungen unter Umgehung des nationalen Rechts

DB 1999, 625 
ders.

Meinema, $M$.

Meijers, V. A. E. M.

Mellert, Christofer Rudolf

Meyer, Justus / Ludwig, Sören

Meyer, Justus / Hermes, Judith

Meyer, Justus

Micheler, Eva

Mincke, Wolfgang

Mülbert, Peter $O$.

ders.

Empfiehlt es sich, im Interesse des Anlegerschutzes und zur Förderung des Finanzplatzes Deutsch-

Sitztheorie versus Niederlassungsfreiheit? - Besprechung des Vorlagebeschlusses des BGH vom 30-3-2000 - VII ZR 370/98

GmbHR 2000, 693

Artikel 2:25 BW en de afstand van (vennootschap)recht

Ondernemingsrecht 2004, 36

Handboek Handelsregister Deventer: Kluwer 2005.

Das MindestkapG - Hoffentlich aufgehoben und nicht aufgeschoben,

BB 2005, 1809

Französische GmbH-Reform 2003/2004: Gründungserleichterungen und weitere „Vereinfachung des Rechts“

GmbHR 2005, 459

Das GmbH-Schutzschild in der Insolvenz GmbHR 2005, 807

Die Insolvenzanfälligkeit der $\mathrm{GmbH}$ als rechtspolitisches Problem

GmbHR 2004, 1417

Gläubigerschutz im englischen Gesellschaftsrecht ZGR 2004, 324

Mincke, Einführung in das niederländische Recht, 2002

Zukunft der Kapitalaufbringung/Kapitalerhaltung

Der Konzern 2004, 151 
land das Kapitalmarkt- und Börsenrecht neu zu regeln?

JZ 2002, 826

Müller, Klaus J.

Müller-Bonanni, Thomas

Niemeier, Wilhelm

Noack, Ulrich

ders.

ders.

ders.

Oelkers, Janine

Paefgen, Walter G.
Der Entwurf des "MoMiG" und die Auswirkungen auf den Unternehmens- und Beteiligungskauf

GmbHR 2006, 953

Unternehmensmitbestimmung nach Überseering und Inspire Art

GmbHR 2003, 1235

Die „Mini-GmbH“ (UG) trotz Marktwende bei der Limited?

ZIP 2007, 1794

Reform des deutschen Kapitalgesellschaftsrechts: Das Gesetz zur Modernisierung des GmbH-Rechts und zur Bekämpfung von Missbräuchen,

DB 2006, 1475

Überlegungen zu Grundlinien eines Gesetzes über Elektronische Handelsregister und Unternehmensregister notar 2005, 14

Gesellschaftervereinbarungen bei Kapitalgesellschaften

1994

Der Regierungsentwurf des MoMiG - Die Reform des GmbH-Rechts geht in die Endrunde DB 2007, 1395

Mindestkapital und Nennkapital - Leistungskraft für den Gläubigerschutz, GesRZ 06/2004, 360-371 (1.Teil) und 01/2005, 27-33 (2.Teil)

Wider die gesellschaftsrechtliche Ausländerphobie ZIP 2004, 2253 
ders.

Peters, Andrea

Peters, Andrea/Dechow, Angela

Poertzgen, Christoph

ders.

ders.

Portengen, H. J.

Preuß, Nicola
Auslandsgesellschaften und Durchsetzung deutscher Schutzinteressen nach Überseering

DB 2003, 487

Gezeitenwechsel im Gesellschaftskollisionsrecht Anmerkung zu EuGH, Urteil vom 5.11.2002- Rs. C-208/00 = WM 2002, 2372 Überseering WM 2003, 561

Regressfallen in der notariellen Beratungspraxis im Zusammenhang mit dem Kleinbeteiligungsprivileg des § 32a Abs 3 Satz 2 GmbHG

ZNotP 2004, 418

Sonderprüfungsrecht für $\quad \mathrm{GmbH}-$ Minderheitsgesellschafter, Aufnahme eines Sonderprüfungsrechts in das MoMiG und in die GmbH-Satzung, GmbHR 2007, 236

Neues zur Insolvenzverschleppungshaftung - der Regierungsentwurf des MoMiG

NZI 2008, 9

Die künftige Insolvenzverschleppungshaftung nach dem MoMiG

GmbHR 2007, 1258

Die rechtsformneutrale Insolvenzantragspflicht (§ 15a InsO)

ZInsO 2007, 574

Interne verhoudingen - flex bv

WPNR 2007, 940

Die Wahl des Satzungssitzes im geltenden Gesellschaftsrecht und nach dem MoMiG-Entwurf

GmbHR 2007, 57 
Priester, Hans-Joachim

ders.

ders.

ders.

ders.

ders.

ders.

Puszkajler, Karl Peter

Recq, /Hoffmann,

Reichel, Marc
Aktuelle Tendenzen und Entwicklungen im Gesellschaftsrecht

NotRV 2004, 106

Kapitalaufbringung beim Cash Pool - Kurswechsel durch das MoMiG?

ZIP 2006, 1557

Unternehmensgründergesellschaft statt „ $\mathrm{GmbH}$ light“"!

ZIP 2006, 161

„GmbH light“ - ein Holzweg ZIP 2005, 921

Die deutsche GmbH nach „Inspire Art“ - brauchen wir eine neue?

DB 2005, 1315

Mindestkapital und Sacheinlageregeln in: Die GmbH-Reform in der Diskussion, Sondertagung der Gesellschaftsrechtlichen Vereinigung (VGR), herausgegeben in der Schriftenreihe der Gesellschaftsrechtlichen Vereinigung, Köln 2006

Kapitalaufbringung nach Gutdünken - Ein Zwischenruf zum MoMiG

ZIP 2008, 55

Luxemburg locuta, causa non finita?, IPRax 2000, 79

Die französische S.A.R.L. als GmbH-Ersatz GmbHR 2004, 1070

In einer Liga mit Ruanda und Nigeria - Notwendigkeit einer Reform des Firmeneintragungsverfahrens

ZRP 2004, 184 
Riegger, Bodo

Risse, Jörg

Roest, J.

Römermann, Volker

ders.

Roth, Günter H.

ders.

Roth, Wulf-Henning
Centros - Überseering - Inspire Art: Folgen für die

Praxis

ZGR 2004, 510

Brauchen wir die Unternehmergesellschaft und den Verzicht auf die notarielle Beurkundung des Gesellschaftsvertrages?

NotBZ 2007, 244

Zum Eintrag einer Zweigniederlassung einer ausländischen Gesellschaft ohne Geschäftstätigkeit im Gründungsstaat

MDR 1999, 752

Geschillenregeling

WPNR 2007, 959

Der Entwurf des „MoMiG“ - die deutsche Antwort auf die Limited,

GmbHR 2006, 673

Die Limited in Deutschland - eine Alternative zur $\mathrm{GmbH}$ ?

NJW 2006, 2065

Gläubigerschutz bei der $\mathrm{GmbH}$ : Was ist unverzichtbar?, in Festschrift Peter Doralt zum 65. Geburtstag (2004), S. 479

$\S 10$ IPRG und die europäische Niederlassungsfreiheit

RdW 1999, 381

Internationales Gesellschaftsrecht nach Überseering - zu EuGH, 5.11.2002 - Rs.208/00 - Überseering BV / Nordic Construction Company Baumanagement GmbH (NCC), IPRax 2003, 65

IPRax 2003, 117 
ders.

Sack, Rolf

Saenger, Ingo

Scheuch, Alexander

Salomons, F. R.

Sandrock, Otto

Sandrock, Otto /

Austmann, Andreas

Sandrock, Otto /

Wetzler, Christop F. (Hrsg.)

Sangen van der, G. J. H.

Sangen van der, G. J. H./

Raaijmakers, M. J. G. C.
Die Sitzverlegung vor dem EuGH - Anmerkungen zu den Vorlagen des AG Heidelberg vom 3 März 2000 - HRB 831, ZIP 2000, 1617 und des BGH vom 30 März 2000 - VII ZR 370/98, ZIP 2000, 967

ZIP 2000, 1597

Auswirkungen der Art 52, 58 EWGV auf das internationale Gesellschaftsrecht - EuGH, NJW 1989, 2186

JuS 1990, 352

Auslandsbeurkundung bei der $\mathrm{GmbH}$ -

Konsequenzen aus MoMiG und Reform des Schweizer Obligationenrechts

BB 2008, 65

De flexibele BV en de personenvennotschap

Ondernemingsrecht 2006, 509

Centros: ein Etappensieg für die Überlagerungstheorie

BB 1999, 1337

Das Internationale Gesellschaftsrecht nach der Daily Mail-Entscheidung des Europäischen Gerichtshofs - Quo vadis?

RIW 1989, 249

Deutsches Gesellschaftsrecht im

Wettbewerb der Rechtsordnungen (2004)

Civiel Recht - Een selectie (januari 2004 - juli 2004)

Tijdschrift voor Ondernemingsbestuur 2004, 211

Modernisering van het BV-recht en crediteurenbescherming 
Tijdschrift voor Ondernemingsbestuur 2004, 247

Schäfer, Carsten

ders.

Schärtl, Christoph

Schall, Alexander /

Westhoff, André

dies.

Schall, Alexander

Schanze, Erich /

Jüttner, Andreas

dies.

Schemmann, Till
Probleme des Cash-Poolings bei Kapitalaufbringung und -erhaltung - Welche Lösung bringt das MoMiG?

BB 2006 BB Special Nr. 7, 5

Reform des GmbHR durch das MoMiG - viel Lärm um nichts?

DStR 2006, 2085

Die Doppelfunktion des Stammkapitals als Schlüssel für ein wettbewerbsfähiges $\mathrm{GmbH}-\mathrm{Recht}$ in Deutschland?

GmbHR 2007, 344

Warum Deutschland eine neue

Kapitalgesellschaftsform braucht

GmbHR 2004, R 381

Die Neuwahlen zum Deutschen Bundestag liegen hinter uns -- kommt jetzt die „UGG“?

GmbHR 2005, R 357

Englischer Gläubigerschutz bei der Limited in Deutschland

ZIP 2005, 965

Anerkennung und Kontrolle ausländischer

Gesellschaften

AG 2003, 30

Die Entscheidung für Pluralität: Kollisionsrecht und Gesellschaftsrecht nach der EuGHEntscheidung „Inspire Art“

AG 2003, 661

Die Neufassung der ersten gesellschaftsrechtlichen Richtlinie 
GPR 2004, 92

Schiffer, K. Jan

Schmahl, Hermannjosef

Schmidt, Karsten

ders.

ders.

ders.

ders.
Alea jacta est? Praxisanmerkungen zur vorgesehenen Deregulierung des Eigenkapitalersatzrechts

BB 2006, BB Special Nr. 7, 14

Subsidiäres Insolvenzantragsrecht bei führungslosen juristischen Personen nach dem Regierungsentwurf des MoMiG - Versuch einer rechtzeitigen begrifflichen und sachlichen Klärung NZI 2008, 6

Verlust der Mitte durch „Inspire Art“? - Verwerfungen im Unternehmensrecht durch Schreckreaktionen der Literatur -ZHR 168 (2004), 493

GmbH-Reform, Solvenzgewährleistung und Insolvenzpraxis, - Gedanken zum MoMiG-Entwurf GmbHR 2007, 1

Brüderchen und Schwesterchen für die $\mathrm{GmbH}$ ?

Eine Kritik der Vorschläge zur Vermehrung der Rechtsformen

DB 2006, 1096

... ut aliquid fiat - Von der GmbH-Reform 2005 zum Referentenentwurf eines Mindestkapitalgesetzes

DB 2005, 1095

Verantwortlichkeit der Geschäftsführer - Ausweitung des Ausschlusses bestimmter Personen von der Geschäftsführung - Haftung im Vorfeld der Krise

in: Die GmbH-Reform in der Diskussion, Sondertagung der Gesellschaftsrechtlichen Vereinigung (VGR), herausgegeben in der Schriftenreihe der Gesellschaftsrechtlichen Vereinigung, Köln 2006 
ders.

Schmidt-Gerdts, Matthias

Schön, Wolfgang

Schöpflin, Martin

Scholz, Oliver

Schröder, Oliver

Cannivé, Klaus

Schröder, Henning /

Schneider, Vera Maria

Schwarz, C.A.

Schwarz, G. Chr.

Sedemund, Jochim /

Hausmann, Friedrich

Seibert, Ulrich
Reform der Kapitalsicherung und Haftung in der

Krise nach dem Regierungsentwurf des MoMiG

GmbHR 2007, 1072

Was bringt 2008...und was sollte es bringen?! -

Das EU-Unternehmensrecht im Scharnierjahr 2008

Status:Recht 01/2008, S. 13

Die Zukunft der Kapitalaufbringung/-erhaltung

Der Konzern 2004, 162

Die Lehre von der verdeckten Sacheinlage - eine gelungene Rechtsfortbildung? GmbHR 2003, 57

Die Einführung elektronischer Handelsregister im Europarecht

EuZW 2004, 172

Der Unternehmensgegenstand der $\mathrm{GmbH}$ vor und nach dem MoMiG

NZG 2008, 1

Geschäftsführerhaftung bei einer Private

Limited Company mit Verwaltungssitz in Deutschland

GmbHR 2005, 1288

De BV zonder wettelijk verplichte blokkering

Ondernemingsrecht 2004, 30

Europäisches Gesellschaftsrecht 2000

Niederlassungsfreiheit contra Sitztheorie -

Abschied von. Daily-Mail?

BB 1999, 809

GmbH-Reform: Der Referentenentwurf eines Gesetzes zur Modernisierung des GmbH-Rechts 
ders.

und zur Bekämpfung von Missbräuchen - Mo-

$\mathrm{MiG}$,

ZIP 2006, 1157

ders.

$\mathrm{GmbH}-\mathrm{Reform}$ und alternative Konzepte

GmbHR 2006, R 241

ders.

Der Regierungsentwurf des MoMiG und die haftungsbeschränkte Unternehmergesellschaft

GmbHR 2007, 673

Sieger, Jürgen J. /

Cash-Pool - Fehlgeschlagene

Wirtz, Johannes

Kapitalmaßnahmen und Heilung im Recht der $\mathrm{GmbH}$

ZIP 2005, 2277

Sikora, Markus

Das EHUG in der notariellen Praxis

Schwab, Martin T.

MittBayNot 2007, 1

Sonnenberger, Hans Jürgen /

Autexier, Christian

Sonnenberger, /Autexier,

Einführung in das französische Recht, 2000

Sonnenberger, Hans Jürgen /

Großerichter, Helge

Konfliktlinien zwischen internationalem

Gesellschaftsrecht und Niederlassungsfreiheit - Im

Blickpunkt - Die Centros-Entscheidung des EuGH als gesetzgeberische Herausforderung

RIW 1999, 721

Sontheimer, Jürgen

Die neuen Verjährungsfristen für die StB- und RA-

Haftung und im Gesellschaftsrecht

DStR 2005, 834

Spahlinger, Andreas /

Internationales Gesellschaftsrecht in der

Wegen, Gerhard

Praxis, 2005 
Spindler, Gerald

Spindler, Gerald/

Berner, Olaf

Steffek, Felix

ders.

Stein, Ursula

Steinberger, Christian

Steindorff, Ernst

Teichmann, Christoph

Theisen, Manuel René
Der Gläubigerschutz zwischen Gesellschafts- und Insolvenzrecht

JZ 2006, 839

Inspire Art - Der europäische Wettbewerb um das Gesellschaftsrecht ist endgültig eröffnet

RIW 2003, 949

Präventionsdefizite im InsolvenzanfechtungsrechtZugleich ein Plädoyer für die Einführung einer Geschäftsleiter-Disqualifizierung nach englischem Vorbild

ZRP 2007, 228

Zustellungen und Zugang von Willenserklärungen nach dem Regierungsentwurf zum MoMiG - Inhalt und Bedeutung der Änderungen für GmbHs, AGs und ausländische Kapitalgesellschaften

BB 2007, 2077

$\S 6$ Abs 2 Satz 2 GmbHG, § 76 Abs 3 Satz 2 AktG - Verfassungswidrige Berufsverbote?

AG 1987, 165

Die Europäische Privatgesellschaft - Schaffung einer europaweiten Gesellschaftsform für kleine und mittlere Unternehmen im Binnenmarkt

BB 2006, 27

Centros und das Recht auf die günstigste Rechtsordnung

JZ 1999, 1140

Reform des Gläubigerschutzes im Kapitalgesellschaftsrecht

NJW 2006, 2444

Der Konzern, 2. Aufl. 2000, S. 452 ff. 
Thiessen, Jan

ders.

Thole, Christoph

Thoma, $J$

Tillmanns, Wolfhard

Timme, Michael /

Hülk, Fabian

Timmermann, L.

ders.

ders.

Triebel, Volker
Eigenkapitalersatz ohne Analogieverbot - eine Alternativlösung zum MoMiG-Entwurf

ZIP 2007, 253

Insolvenzeröffnungskapital statt Mindestkapital ein Vorschlag zur GmbH-Reform

ZIP 2006, 1892

Die Us-amerikanische Neuschöpfung des „Tort of Deepening Insovency“ - ein Vorbild für den deutschen Gläubigerschutz?

ZIP 2007, 1590

The Überseering ruling: a tale of serendipity ERPL 2003, 545

Das französische GmbH-Recht, IWB Fach 5 Frankreich Gruppe 3, S. 547

Das Ende der Sitztheorie im Internationalen Gesellschaftsrecht? - EuGH, EuZW 1999, 216 JuS 1999, 1055

Van digitaal naar analoog vennootschapsrecht en de gevolgen daarvan voor de concurrentie tussen vennootschapssystemen

Ondernemingsrecht 2003, 42

Een BV zonder bestuur en zonder aandelhoudersvergadering

Ondernemingsrecht 2004, 27

Kroniek van het vennootschaapsrecht

NJB 2004, 1629

BB 2003, Heft 36 Die erste Seite 
Triebel, Volker / Otte, Sabine

dies.

Triebel, Volker /

von Hase, Karl

Triebel, Volker

Otte, Sabine

Kimpel, Bert

Trölitzsch, Thomas

Ulmer, Peter

ders.

20 Vorschläge für eine GmbH-Reform: Welche

Lektion kann der deutsche Gesetzgeber vom englischen

lernen?

ZIP 2006, 311

Reform des GmbH-Rechts: MoMiG - ein vernünftiger Schritt zur Stärkung der GmbH im Wettbewerb oder Kompromiss auf halber Strecke?

ZIP 2006, 1321

Wegzug und grenzüberschreitende Umwandlungen deutscher Gesellschaften nach Überseering und Inspire Art

BB 2003, 2409

Die englische Limited Liability

Partnership in Deutschland: eine attraktive

Rechtsform für deutsche Beratungsgesellschaften?

BB 2005, 1233

Differenzhaftung für Sacheinlagen in Kapitalgesellschaften

1998

Gläubigerschutz bei Scheinauslandsgesellschaften - Zum Verhältnis zwischen gläubigerschützendem nationalem Gesellschafts-, Delikts- und Insolvenzrecht und der EG-Niederlassungsfreiheit

NJW 2004, 1201

Der „Federstrich des Gesetzgebers“ und die Anforderungen der Rechtsdogmatik - Kritische Anmerkungen aus rechtssystematischer Sicht zur Ausgestaltung bestimmter Deregulierungsvorschläge im RegE MoMiG

ZIP 2008, 45 
van Veen, W. J. M.

Veil, Rüdiger

ders.

Verbrugh, Maarten

Verkerk, $B$.

Vetter, Jochen

ders.

Vossius, Oliver

ders.

Vossius, Oliver /

Wachter, Thomas
Statutaire verbintenissen, verplichtingen tot uittreden en het ontnemen van aan aandelen verbonden rechten volgens het ontwerp inzake de Flex-BV

WPNR 2007, 950

Die Unternehmergesellschaft nach dem Regierungsentwurf des MoMiG

GmbHR 2007, 1080

Die Reform des Rechts der Kapitalaufbringung durch den RegE MoMiG

ZIP 2007, 1241

Verslag van de vergadering van de Vereeniging Handelsrecht over „De vereenvoudigde BV“

Ondernemingsrecht 2006, 617

Aansprakelijkheid in verband met uuitkeringen in het vereenvoudigde BV-Recht

O \& F 2008, 43

Grundlinien der GmbH-Gesellschafterhaftung ZGR 2005, 788

Reform des gesellschaftsrechtlichen Gläubigerschutzes, in: Verhandlungen des 66. Deutschen Juristentages, Band II/1, 2006, P 75

Zum Entwurf eines ganzheitlichen GmbHReformgesetzes aus der Praxis

GmbHR 2005, R 373

Gutgläubiger Erwerb von GmbH-Anteilen nach MoMiG

DB 2007, 2299

BB-Forum: Entwurf eines GmbH-

Reformgesetzes

BB 2005, 2539 
Wachter, Thomas

ders.

ders.

ders.

ders.

ders.

Wagner, Magnus

Walz, Robert /

Fembacher, Tobias
Der Entwurf des „MoMiG“ und die Auswirkungen auf inländische Zweigniederlassungen von Auslandsgesellschaften,

GmbHR 2006, 793

Verschlankung des Registerverfahrens bei der GmbH-Gründung

Zwölf Vorschläge aus der Praxis

in: Die GmbH-Reform in der Diskussion, Sondertagung der Gesellschaftsrechtlichen Vereinigung (VGR), herausgegeben in der Schriftenreihe der Gesellschaftsrechtlichen Vereinigung, Köln 2006

Wettbewerb des GmbH-Rechts in Europa

Vergleich der Rechtslage in ausgewählten Ländern GmbHR 2005, 717

Frankreich: die „Ein-Euro-GmbH“

ab 2004

GmbHR 2003, R 377

Existenz- und Vertretungsnachweise bei der englischen Private Limited Company

DB 2004, 2795

Errichtung, Publizität, Haftung und Insolvenz von Zweigniederlassungen ausländischer Kapitalgesellschaften nach Inspire Art - Rechtspraktische Anleitung und Wegweisung

GmbHR 2003, 1254

Neues Verjährungsrecht in der zivilrechtlichen Beratungspraxis

ZIP 2005, 558

Zweck und Umfang der

Beurkundung nach $\S 15 \mathrm{GmbHG}$

NZG 2003, 1134 
WeissSusanne /

Wöhlert, Helge-Torsten

Weller, Marc-Philippe

ders.

ders.

Wessels, Peter

Westermann, Harm Peter

Wetzel, Nathalie

Wetzel, Michael

Weyand, Raimund

Wicke, Hartmut
Die Sevic-Entscheidung des EuGH - sudden death für Societas Europaea und Richtlinie zur grenzüberschreitenden Verschmelzung und Wegbereiter für grenzüberschreitende Spaltungen?

WM 2007, 580

Die Existenzvernichtungshaftung im modernisierten GmbH-Recht - eine Außenhaftung für für Forderungsvereitelung ( $\$ 826$ BGB)

DStR 2007, 1166

Solvenztest und Existenzvernichtungshaftung Zwei grundverschiedene Gläubigerschutzfiguren DStR 2007, 116

Inspire Art - Weitgehende Freiheiten beim Einsatz ausländischer Briefkastengesellschaften

DStR 2003, 1800

Cash-Pooling und Upstream-Sicherheiten - Gestaltungspraxis im Lichte aktueller BGHRechtsprechung und anstehender GmbH-Novelle ZIP 2006, 1701

Die $\mathrm{GmbH}$ in der nationalen und internationalen Konkurrenz der Rechtsformen

GmbHR 2005, 4

Die niederländische GmbH, IWB Fach 5,

Gruppe 3, 189 (1997)

Gesetzlicher Ausschluss vom Geschäftsführeramt ZInsO 2007, 754

Die Bedeutung der öffentlichen Beurkundung im GmbH-Recht

ZIP 2006, 977 
Wiesner, Peter M.

ders.

Wilhelmi, Rüdiger

Winter, Michael

de Wulf, Hans

Wulfetange, Jan

Zaman, D. F. M. M.

van der Zanden, $P . M$
Corporate Governance und kein Ende

ZIP 2003, 977

Verbot der Zahlung, aber Strafdrohung bei Nichtzahlung gegen den Geschäftsführer einer insolvenzreifen $\mathrm{GmbH}$

ZIP 2007, 1781

Unternehmergesellschaft (haftungsbeschränkt) Der neue $\S 5$ a GmbHG in dem RegE zum MoMiG DB 2007, 1510

Das Mindestkapital als Mindestschutz - eine Apologie im Hinblick auf die Diskussion um eine Reform der $\mathrm{GmbH}$ angesichts der englischen Limited GmbHR, 2006, 13

Upstream-Finanzierung nach dem MoMiGRegierungsentwurf - Rückkehr zum bilanziellen Denken

DStR 2007, 1484

Centros: vrijheid van vestiging zonder race to the bottom

Ondernemingsrecht 1999, 318

Die Reform des GmbH-Rechts: Schneller und einfacher gründen, wettbewerbsfähiger in Europa werden!

BB 2006, 19

Vereenvoudiging en flexibilisering van het BVrecht

Tijdschrift voor Ondernemingsbestuur 2004, 115

Een economisch en accountancy perspectief op het nieuwe BV-recht, meer in het bijzonder de kapitalbescherming

WPNR 2007, 975 
Ziemons, Hildegard

dies.

Zimmer, Daniel

ders.

ders.

Zöllner, Wolfgang

Zöllner, Wolfgang /

Noack, Ulrich

Zuidgeest, R.N.F.
Mehr Transaktionssicherheit durch das MoMiG

BB-Special 2006, Nr 7, 9-14

Freie Bahn für den Umzug von Gesellschaften nach Inspire Art?! - Zugleich Besprechung EuGH, Urt v 30-9-2003 - Rs C- 167/01, ZIP 2003, 1885 Inspire Art

ZIP 2003, 1913

Wie es Euch gefällt? Offene Fragen nach dem Überseering-Urteil des EuGH

BB 2003, 1

Internationales Gesellschaftsrecht und Niederlassungsfreiheit - Das Rätsel vor der Lösung?

BB 2000, 1361

Nach „Inspire Art“ - Grenzenlose Gestaltungsfreiheit für deutsche Unternehmen?

NJW 2003, 3585

Übertragung von GmbH-Anteilen - Zwei rechtspolitische Grundsatzfragen

in: Die GmbH-Reform in der Diskussion, Sondertagung der Gesellschaftsrechtlichen Vereinigung (VGR), herausgegeben in der Schriftenreihe der Gesellschaftsrechtlichen Vereinigung, Köln 2006

Geltendmachung von Beschlußmängeln

im GmbH-Recht

ZGR 1989, 525

Flexibel bv-recht en ,verbondenheit“ in het belastingrecht: buigen of barsten?

WFR 2007, 1162 